\title{
MODELO TEÓRICO PARA CONTROLE DA CAPACIDADE DE CARGA À TRAÇÃO DE ESTACAS METÁLICAS HELICOIDAIS EM SOLO ARENOSO
}

Cristina de Hollanda Cavalcanti Tsuha

Tese apresentada à Escola de Engenharia de São Carlos, da Universidade de São Paulo, como parte dos requisitos para a obtenção do título de doutor em Geotecnia.

ORIENTADOR: Prof. Dr. Nelson Aoki

EESC, Universidade de São Paulo

São Carlos 2007 
Candidata: Engenheira CRISTINA DE HOLLANDA CAVALCANTI TSUHA

Tese defendida e julgada em 26/11/2007 perante a Comissão Julgadora:

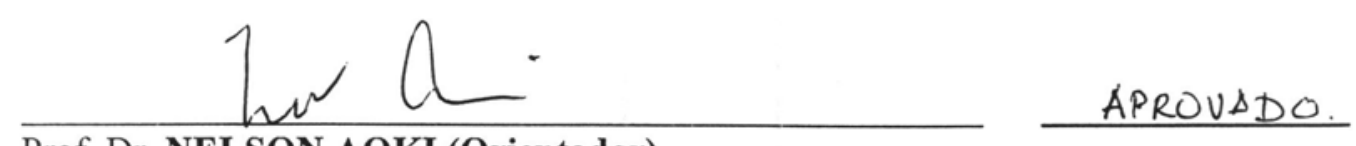

Prof. Dr. NELSON AOKI (Orientador)

(Escola de Engenharia de São Carlos/USP)

Licincin Lis

Prof Titular JOSÉ/HENRIQUE ALBIERO

(Escola de Engenharia de São Carlos/USP)

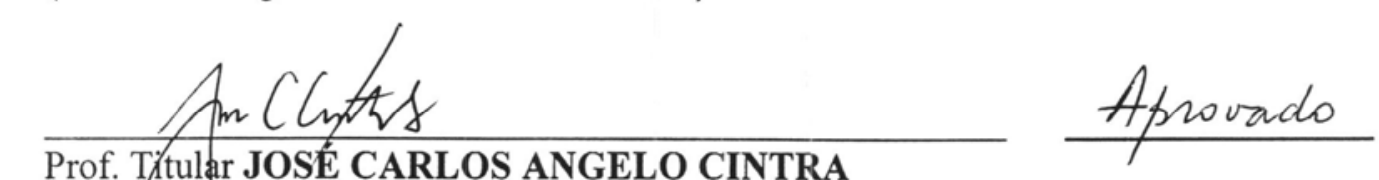

(Escola de)Engenharia de São Carlos/USP)



(Universidade Federal do Rio de Janeiro/UFRJ)

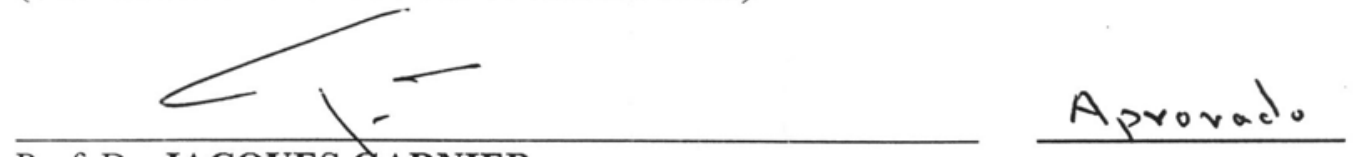

Prof. Dr. JACQUES GARNIER

(Laboratoire Central des Pants et Chaussées/LQPC-França)



\section{AGRADECIMENTOS}

Ao Prof. Nelson Aoki, pela sua preciosa orientação, amizade, dedicação e apoio durante todas as fases deste trabalho.

Ao Prof. José Carlos A. Cintra por ter sido o intermediador fundamental para a realização do estágio de doutorado concretizado nesta tese no Laboratoire Central de Ponts et Chaussés (LCPC)/ França.

À CAPES pela concessão das bolsas de estudo.

À Vértice Engenharia pela contribuição financeira cedida aos experimentos realizados no LCPC.

Ao Prof. Jacques Garnier pelos ensaios realizados no LCPC, pelas suas importantes sugestões relativas a este trabalho e pela amizade com que me recebeu.

Ao Eng. Gérard Rault, por sua ampla contribuição nos ensaios em centrífuga, pelos ensinamentos transmitidos, e principalmente por sua amizade que tornou este trabalho muito agradável de ser realizado.

Ao Eng. Luc Thorel, responsável pela centrífuga do LCPC, por ter sido sempre prestativo e afável.

Aos técnicos de laboratório do LCPC: Claude Favraud, Patrick Gaudicheau, Philippe Audrain e Alain Neel. Todos eles se dedicaram com grande capacidade e empenho na realização dos ensaios executados no LCPC. Em especial gostaria a agradecer ao Claude, uma pessoa extremamente habilidosa nas montagens mecânicas dos ensaios executados. Esta habilidade possibilitou a solução de problemas mecânicos ocorridos nesta investigação. 
Ao técnico Oscar dos Santos Neto do Departamento de Geotecnia da USP/ São Carlos pelo auxílio dado nos ensaios realizados no laboratório de Mecânica dos Solos.

Aos funcionários do Departamento de Geotecnia Maristela, Neiva, Álvaro e Herivelto por serem sempre prestativos e amigos.

A todos os colegas do Departamento de Geotecnia, especialmente à Luciene e ao Gilmar que colaboraram nos ensaios realizados no Campo Experimental de Fundações da EESC.

Aos meus pais e ao meu marido Gustavo que sempre me apoiaram e incentivaram durante estes anos de doutorado. 


\section{SUMÁRIO}

LISTA DE FIGURAS $\quad$ i

LISTA DE TABELAS ix

LISTA DE SÍMBOLOS - xi

RESUMO Xiii

ABSTRACT Xiv

1. INTRODUÇÃO 1

1.1. Objetivos

1.2. Escopo e organização do trabalho 2

2. REVISÃO BIBLIOGRÁFICA 4

2.1. Introdução 4

2.2. Estacas metálicas helicoidais 10

$\begin{array}{ll}\text { 2.2.1. Definição } & 10\end{array}$

$\begin{array}{ll}\text { 2.2.2. Vantagens } & 15\end{array}$

2.2.3. Método de execução 19

2.2.4. Métodos de previsão de capacidade de carga à tração 22

2.2.4.1. Método da ruptura cilíndrica para areia 24

2.2.4.2. Método das capacidades de carga individuais para areia 35

$\begin{array}{lll}\text { 2.2.4.3. } & \text { Método empírico } & 37\end{array}$

2.2.5. Torque de instalação x capacidade de carga à tração em areia 40

2.2.5.1. Método de Ghaly et al. (1991b) 41 
2.2.5.2. Método de Ghaly e Hanna (1991)

2.2.5.3. Método de Perko (2000) 63

2.2.6. Provas de carga à tração 66

$\begin{array}{lr}\text { 2.3. Modelagem física } & 69\end{array}$

2.3.1. Considerações gerais $\quad 69$

2.3.2. Modelagem física de ancoragem helicoidal em centrífuga 71

3. MODELO TEÓRICO 73

3.1. Premissas básicas do modelo 73

$\begin{array}{lll}\text { 3.1.1. Fase de instalação } & 73\end{array}$

$\begin{array}{lll}\text { 3.1.2. Fase de carregamento } & 75\end{array}$

3.2. Relação teórica entre o torque de instalação e a capacidade de carga à tração $\quad 78$

$\begin{array}{ll}\text { 3.2.1. Relação física entre } \mathrm{Q}_{\mathrm{s}} \text { e } \mathrm{T}_{\mathrm{s}} & 78\end{array}$

3.2.2. Relação física entre $\mathrm{Q}_{\mathrm{h}}$ e $\mathrm{T}_{\mathrm{h}} \quad 80$

3.2.3. Relação física entre $\mathrm{Q}_{\mathrm{u}}$ e $\mathrm{T} \quad 89$

4. MATERIAIS E MÉTODOS 91

$\begin{array}{ll}\text { 4.1. Ensaios de campo } & 91\end{array}$

$\begin{array}{ll}\text { 4.1.1. Provas de carga em Contagem } & 91\end{array}$

4.1.2. Provas de carga no Campo Experimental de Fundações -EESC 96

4.2. Ensaios de laboratório 100

$\begin{array}{ll}\text { 4.2.1. Ensaios em centrífuga } & 100\end{array}$

4.2.1.1. $\quad$ Ensaios de caracterização da areia 102

4.2.1.2. Preparo dos maciços para ensaio em centrífuga 104 
4.2.1.4. Ensaios de estacas metálicas helicoidais em centrífuga 108

4.2.1.5. Ensaios de arrancamento a 1G 119

$\begin{array}{ll}\text { 4.2.2. Ensaios de cisalhamento direto na interface } & 121\end{array}$

4.2.2.1. Interface areia e aço da hélice do modelo ensaiado em centrífuga 122

4.2.2.2. Interface areia e aço da chapa da hélice comercialmente utilizada 125

$\begin{array}{lll}\text { 4.2.2.3. } & \text { Ensaio de rugosidade das interfaces } & 128\end{array}$

$\begin{array}{ll}\text { 4.2.3. Ensaios de torção do tubo da estaca } & 128\end{array}$

5. RESULTADOS 132

5.1. Provas de carga realizadas em campo 132

$\begin{array}{ll}\text { 5.1.1. Contagem } & 132\end{array}$

5.1.2. Campo Experimental EESC 136

$\begin{array}{ll}\text { 5.1.3. Capacidade de carga } & 139\end{array}$

$\begin{array}{ll}\text { 5.2. Modelagem física } & 140\end{array}$

$\begin{array}{ll}\text { 5.2.1. Ensaios na centrífuga } & 145\end{array}$

$\begin{array}{ll}\text { 5.2.2. Ensaios de arrancamento a } 1 G & 165\end{array}$

$\begin{array}{ll}\text { 5.3. Ensaios de cisalhamento direto } & 167\end{array}$

5.3.1. Interface areia e aço da hélice do modelo ensaiado na centrífuga 167

5.3.2. Interface areia e aço da chapa da hélice comercialmente utilizada 174

5.4. Ensaios de Torção 192

6. ANÁLISE DOS RESULTADOS 196

6.1. Verificação do modelo teórico proposto 196 
$\begin{array}{ll}\text { 6.1.2. } & \text { Ensaios de campo } \\ \end{array}$

6.2. Estudo da capacidade de carga à tração 203

6.2.1. Previsão da capacidade de carga à tração 203

6.2.1.1. Método das capacidades de carga individuais 204

6.2.1.2. Método da ruptura cilíndrica 210

$\begin{array}{ll}\text { 6.2.2. Fator de capacidade de carga à tração } & 217\end{array}$

6.3. Efeito do número de hélices em $\mathrm{T}_{\mathrm{h}}$ e $\mathrm{Q}_{\mathrm{h}} \quad 220$

6.4. Efeito da dimensão da hélice no torque de instalação 228

7. CONCLUSÕES 232

7.1. Considerações iniciais 232

7.2. Modelo teórico proposto 232

7.3. Métodos de cálculo de capacidade de carga à tração 234

7.4. Efeito do número de hélices 236

7.5. Resistência ao cisalhamento do fuste da estaca durante a instalação 237

8. SUGESTÕES PARA FUTURAS PESQUISAS 239

9. REFERÊNCIAS BIBLIOGRÁFICAS 240

$\begin{array}{ll}\text { ANEXO A } & 246\end{array}$

$\begin{array}{ll}\text { ANEXO B } & 248\end{array}$ 


\section{LISTA DE FIGURAS}

FIGURA 2.1 - Farol com fundação em estaca helicoidal (A. B. Chance Co., 4 1994)

FIGURA $2.2 \quad$ - Modelo de estaca metálica helicoidal (Wilson, 1950) 5

FIGURA 2.3 - Fundação de cais no Golfo de Izmit (Turquia) em estaca 6

FIGURA 2.4 - Estacas helicoidais instaladas em terreno mole para fundação de 7 quebra-mar na Escócia (Morgan, 1944 apud Little, 1961)

FIGURA 2.5 - Fundação de cais em estaca helicoidal realizada em 1941, Calcutá 8 (Du-Plat-Taylor, 1949)

FIGURA 2.6 - Tipos básicos de ancoragens (Kulhawy, 1985) 11

FIGURA $2.7 \quad-\quad$ Estacas metálicas helicoidais simples e multi-hélices (Kulhawy, 12 1985)

FIGURA 2.8 - Instalação de estaca metálica helicoidal (A. B. Chance Co., 2006) 13

FIGURA $2.9 \quad-\quad$ Estaca metálica helicoidal (A. B. Chance Co., 2004) 14

FIGURA 2.10 - Emenda de tubos de uma estaca metálica helicoidal (A. B. 14 Chance Co., 2004)

FIGURA 2.11 - Estaca helicoidal multi-hélices típica nos Estados Unidos (Das, 15 1990)

FIGURA 2.12 - Caminhão adaptado para a instalação de estacas metálicas 20 helicoidais (A. B. Chance Co., 2004)

FIGURA 2.13 - Instalação de estaca metálica helicoidal inclinada (A. B. Chance 21 Co., 2004)

FIGURA 2.14 - Torquímetro (A. B. Chance Co., 2004) 21

FIGURA 2.15 - Superfícies de ruptura de estacas helicoidais (Clemence et 24 al.,1994)

FIGURA 2.16 - Estaca multi-hélice instalada em areia e sujeita à tração (Das, 25 1990)

FIGURA 2.17 - Superfície de ruptura típica em areia de uma ancoragem rasa 26 solicitada à tração (Das, 1990)

FIGURA 2.18 - Superfície de ruptura típica em areia de uma estaca multi-hélices 27 em condição de ancoragem profunda (Das, 1990)

FIGURA 2.19 - Variação de $\left(\mathrm{H}_{1} / \mathrm{D}_{1}\right)_{\text {cr }}$ com o ângulo de atrito do solo (Das, 1990) 28

FIGURA 2.20 - Superfície de ruptura adotada em areias para condição de 29 ancoragem rasa: $\mathrm{H}_{1} / \mathrm{D}_{1} \leq\left(\mathrm{H}_{1} / \mathrm{D}_{1}\right)_{\mathrm{cr}}$, (Das, 1990) 
FIGURA 2.21 - Valores recomendados de coeficiente de empuxo à tração $\left(\mathrm{K}_{\mathrm{u}}\right) \quad 3$ para fundações em estacas helicoidais solicitadas à tração (Mitsch e Clemence, 1985)

FIGURA 2.22 - Superfície de ruptura adotada em areias para condição de ancoragem profunda (Das, 1990)

FIGURA 2.23 - Fator de capacidade de carga à tração $\left(\mathrm{N}_{\mathrm{qu}}\right)$ versus razão $\mathrm{H} / \mathrm{D}$ para estacas helicoidais em areia (Mitsch e Clemence, 1985)

FIGURA 2.24 - Fator de capacidade de carga para solos sem coesão (A. B. Chance Co., 1994)

FIGURA 2.25 - Torque de instalação x valor $\mathrm{N}_{\mathrm{SPT}}$ de estaca instalada na areia (A. 39 B. Chance Co., 1994)

FIGURA 2.26 - (a) Ancoragem helicoidal com um passo, passo pequeno. (b) Ancoragem helicoidal com um passo, passo médio. (c) Ancoragem helicoidal com um passo, passo largo. (d) Ancoragem helicoidal multi-passos, passos iguais e hélices assimétricas. (e) Ancoragem helicoidal multi-passos, passos variáveis e hélices paralelas. Dimensões em milímetros (Ghaly et al., 1991b)

FIGURA 2.27 - Forças atuantes nas superfícies de ruptura assumidas para ancoragens rasas e profundas (Ghaly et al., 1991b)

FIGURA 2.28 - Forças atuantes na hélice desenvolvida (Ghaly et al., 1991b)

FIGURA 2.29 - Comparação entre os resultados teóricos e experimentais dos ensaios em ancoragens de passo simples instaladas em areia compacta (Ghaly et al., 1991b)

FIGURA 2.30 - Comparação entre os resultados teóricos e experimentais para ancoragens de passo simples e médio (Ghaly et al., 1991b)

FIGURA 2.31 - Forças atuantes em uma estaca helicoidal com hélice de um passo durante a instalação (Ghaly e Hanna, 1991)

FIGURA 2.32 - Comparação entre resultados teóricos e experimentais para modelos de estacas com hélices um passo de diferentes medidas de passo (p), instaladas em areia compacta $\left(\phi=42^{\circ}\right)$, median. compacta $\left(\phi=36^{\circ}\right)$ e fofa $\left(\phi=31^{\circ}\right)$ (Ghaly e Hanna, 1991)

FIGURA 2.33 - Relação entre fator de capacidade de carga e fator de torque (Ghaly e Hanna, 1991)

FIGURA 2.34 - Comparação entre resultados teóricos de torque e resultados de ensaios de campo reportados na literatura (Ghaly e Hanna, 1991)

FIGURA 2.35 - Modelo de hélice utilizada nos ensaios (dimensões em milímetros) (Ghaly, 1995)

FIGURA 2.36 - Relação torque de instalação x capacidade de carga à tração (Ghaly, 1995)

FIGURA 2.37 - Relação entre fator de capacidade de carga e fator de torque (Ghaly, 1995) 
FIGURA 2.38 - Relação entre fator de capacidade de carga e fator de torque

(Ghaly, 1995)

FIGURA 2.39 - Relação entre fator de capacidade de carga e fator de torque (Prasad, 1996)

FIGURA 2.40 - Propriedades da instalação da estaca helicoidal (Perko, 2000)

FIGURA 2.41 - Comparação entre valores medidos e previstos pelo modelo (Perko, 2000)

FIGURA 3.1 - Diagrama dos momentos resistentes originados em uma estaca metálica helicoidal durante a instalação

FIGURA 3.2 - Diagrama de forças resistentes ao arrancamento de uma estaca metálica helicoidal

FIGURA 3.3 - Forças que compensam as forças resistentes à penetração da estaca no solo por rotação

FIGURA $3.4 \quad$ - Analogia entre um exemplo de parafuso de força e uma estaca metálica helicoidal

FIGURA 3.5 - Forças em um corpo movendo-se para cima em um plano inclinado (Faires, 1943)

FIGURA 3.6 - Triângulo de forças correspondente à Figura 3.5 (b) 84

FIGURA 3.7 - Adaptação da Figura. 3.5 para o caso de uma estaca metálica 86

FIGURA 3.8 - Triângulo de forças correspondente à Figura 3.7 (b) 86

FIGURA 4.1 - Estacas utilizadas nos ensaios em Contagem 92

FIGURA 4.2 - Perfil geotécnico do maciço de instalação das estacas 1C, 2C, 3C 93 e $4 \mathrm{C}$

FIGURA 4.3 - Instalação de estaca metálica helicoidal em Contagem 94

FIGURA 4.4 - Procedimento de emenda da estaca (Contagem) 95

FIGURA 4.5 - Torquímetro utilizado em Contagem 95

FIGURA 4.6 - Prova de carga realizada em Contagem 95

FIGURA 4.7 - Relógios comparadores 96

FIGURA 4.8 - Perfil geotécnico do maciço de instalação das estacas 5C e 6C 98

FIGURA 4.9 - Retirada de amostras com trado no Campo Experimental da 98 EESC

FIGURA 4.10 - Torquímetro digital utilizado no Campo Experimental da EESC 99

FIGURA 4.11 - Prova de carga realizada no Campo Experimental da EESC $\quad 100$

FIGURA 4.12 - Preparo da amostra por chuva de areia 103

FIGURA 4.13 - Ensaio de cisalhamento direto da areia 104

FIGURA 4.14 - Preparo dos containeres por chuva automática de areia 105 
FIGURA 4.15 - Controle do peso específico do maciço após o ensaio em 106 centrífuga

FIGURA 4.16 - Penetrômetro do LCPC 107

FIGURA 4.17 - Centrífuga do LCPC 108

FIGURA 4.18 - Fotografia dos modelos de estacas metálicas helicoidais (Grupo I) 110

FIGURA 4.19 - Fotografia dos modelos de estacas sem hélices (Grupo II) 111

FIGURA 4.20 - Modelos típicos das estacas ensaiadas 111

FIGURA 4.21 - Sistema servo controlador para ensaios em centrífuga 113

FIGURA 4.22 - Sistema servo controlador instalado na centrífuga 114

FIGURA 4.23 - Torquímetro acoplado ao sistema servo controlador $\quad 114$

FIGURA 4.24 - Sistema de aquisição de dados embarcado na swinging basket 115

FIGURA 4.25 - Estacas danificadas após a penetração por rotação de $280 \mathrm{~mm} \quad 116$ dentro do maciço de areia $(\mathrm{Dr}=85 \%)$ a $22 \mathrm{~g}$

FIGURA 4.26 - Profundidade das estacas no momento anterior ao carregamento 117

FIGURA 4.27 - Locação das estacas modelo dentro do container $2 \quad 118$ $\left(\gamma=16,30 \mathrm{kN} / \mathrm{m}^{3}\right)$

FIGURA 4.28 - Fixação das estacas no container com linhas de nylon 119

FIGURA 4.29 - Nivelamento do maciço e aplicação da camada de areia colorida 120

FIGURA 4.30 - Ensaio de arrancamento das estacas a 1g 120

FIGURA 4.31 - Saturação do maciço de areia por capilaridade após ensaio de $\quad 121$ tração nas estacas

FIGURA 4.32 - Fotografia das superfícies das hélices da estaca modelo No9 123

FIGURA 4.33 - Meia-caixa inferior com as interfaces ensaiadas: de solda 123 (esquerda) e de aço (direita)

FIGURA 4.34 - Preparo da amostra de areia na meia-caixa superior $\quad 124$

FIGURA 4.35 - Ensaio de cisalhamento na interface 125

FIGURA 4.36 - Interface de aço ensaiada instalada na meia-caixa inferior $\quad 126$

FIGURA 4.37 - Caixa com a amostra pronta para o ensaio 127

FIGURA 4.38 - Encaixe da caixa no equipamento de ensaio e realização do $\quad 127$

FIGURA 4.39 - Aparelho SURTRONIC 3+ para medir rugosidade de superfícies 128 (Catálogo da Taylor Hobson Precision, 2007)

FIGURA 4.40 - Esquema do ensaio de torção no tubo 131

FIGURA $5.1 \quad-$ Curva torque de instalação x profundidade da ponta das estacas 133 $1 \mathrm{C}, 2 \mathrm{C}, 3 \mathrm{C}$ e $4 \mathrm{C}$

FIGURA 5.2 - Curva carga de tração x deslocamento da estaca 1C 134

FIGURA 5.3 - Curva carga de tração x deslocamento da estaca 2C 134 
FIGURA 5.4 - Curva carga de tração x deslocamento da estaca 3C 135

FIGURA 5.5 - Curva carga de tração x deslocamento da estaca 4C 135

FIGURA 5.6 - Curva torque de instalação x profundidade da ponta das estacas 137 $5 \mathrm{C}$ e $6 \mathrm{C}$

FIGURA 5.7 - Curva carga de tração x deslocamento da estaca 5C 138

FIGURA 5.8 - Curva carga de tração x deslocamento da estaca 6C 138

FIGURA 5.9 - Curva granulométrica da areia de Fontainebleau 140

FIGURA 5.10 - Curvas força cisalhante x deslocamento relativo 142 $\left(\operatorname{amostra} \gamma=15,46 \mathrm{kN} / \mathrm{m}^{3}\right)$

FIGURA 5.11 - Curvas força cisalhante $\mathrm{x}$ deslocamento relativo 142 $\left(\operatorname{amostra} \gamma=16,30 \mathrm{kN} / \mathrm{m}^{3}\right)$

FIGURA 5.12 - Perfil penetrométrico realizado dentro do container 1 143

FIGURA 5.13 - Perfis penetrométricos realizados dentro do container $2 \quad 144$ $\left(\gamma=16,30 \mathrm{kN} / \mathrm{m}^{3}\right)$

FIGURA 5.14 - Instalação e ensaio de arrancamento da estaca modelo $\mathrm{N}^{\mathrm{o}} 3$ no $\quad 146$ container 2 (areia de $\mathrm{D}_{\mathrm{r}}=85 \%$ )

FIGURA 5.15 - Curva torque de instalação x profundidade da ponta dos modelos de estacas com haste de diâmetro igual 3,0 mm instaladas no container 1

FIGURA 5.16 - Curva torque de instalação x profundidade da ponta dos modelos de estacas com haste de diâmetro igual 4,5 $\mathrm{mm}$ instaladas no container 1

FIGURA 5.17 - Curva torque de instalação x profundidade da ponta dos modelos de estacas com haste de diâmetro igual $6,0 \mathrm{~mm}$ instaladas no container 1

FIGURA 5.18 - Curva torque de instalação x profundidade da ponta dos modelos de estacas com haste de diâmetro igual 3,0 $\mathrm{mm}$ instaladas no container 2

FIGURA 5.19 - Curva torque de instalação x profundidade da ponta dos modelos de estacas com haste de diâmetro igual 4,5 mm instaladas no container 2

FIGURA 5.20 - Curva torque de instalação x profundidade da ponta dos modelos de estacas com haste de diâmetro igual $6,0 \mathrm{~mm}$ instaladas no container 2

FIGURA 5.21 - Curva carga de tração x deslocamento vertical da estaca $\mathrm{N}^{\circ} 1 \mathrm{~L}$ no container 1 (convertida para o protótipo)

FIGURA 5.22 - Curva carga de tração x deslocamento vertical da estaca $N^{\circ}$ 2L no 154 container 1 (convertida para o protótipo)

FIGURA 5.23 - Curva carga de tração x deslocamento vertical da estaca No $3 \mathrm{~L}$ no 154 container 1 (convertida para o protótipo) 
FIGURA 5.24 - Curva carga de tração x deslocamento vertical da estaca $\mathrm{N}^{\circ}$ 4L no 155 container 1 (convertida para o protótipo)

FIGURA 5.25 - Curva carga de tração x deslocamento vertical da estaca $\mathrm{N}^{\circ}$ 5L no 155 container 1 (convertida para o protótipo)

FIGURA 5.26 - Curva carga de tração x deslocamento vertical da estaca $\mathrm{N}^{\circ} 6 \mathrm{~L}$ no 155 container 1 (convertida para o protótipo)

FIGURA 5.27 - Curva carga de tração x deslocamento vertical da estaca No 7L e 156 $\mathrm{N}^{\mathrm{o}} 12 \mathrm{~L}$ no container 1 (convertida para o protótipo)

FIGURA 5.28 - Curva carga de tração x deslocamento vertical da estaca $\mathrm{N}^{\circ} 8 \mathrm{~L}$ e $\mathrm{N}^{\mathrm{o}} 12 \mathrm{~L}$ no container 1 (convertida para o protótipo)

FIGURA 5.29 - Curva carga de tração x deslocamento vertical da estaca $\mathrm{N}^{\circ}$ 9L e $\mathrm{N}^{\circ} 12 \mathrm{~L}$ no container 1 (convertida para o protótipo)

FIGURA 5.30 - Curva carga de tração x deslocamento vertical da estaca $N^{\circ} 1 \mathrm{~L}$ e $\mathrm{N}^{\mathrm{o}} 10 \mathrm{~L}$ no container 2 (convertida para o protótipo)

FIGURA 5.31 - Curva carga de tração x deslocamento vertical da estaca $\mathrm{N}^{\circ} 2 \mathrm{~L}$ e $\mathrm{N}^{\mathrm{o}} 10 \mathrm{~L}$ no container 2 (convertida para o protótipo)

FIGURA 5.32 - Curva carga de tração x deslocamento vertical da estaca $N^{\circ} 3 \mathrm{~L}$ e $\mathrm{N}^{\mathrm{o}} 10 \mathrm{~L}$ no container 2 (convertida para o protótipo)

FIGURA 5.33 - Curva carga de tração x deslocamento vertical da estaca $\mathrm{N}^{\circ} 4 \mathrm{~L}$ e $\mathrm{N}^{\mathrm{o}} 11 \mathrm{~L}$ no container 2 (convertida para o protótipo)

FIGURA 5.34 - Curva carga de tração x deslocamento vertical da estaca $\mathrm{N}^{0} 5 \mathrm{~L}$ e $\mathrm{N}^{\mathrm{o}} 11 \mathrm{~L}$ no container 2 (convertida para o protótipo)

FIGURA 5.35 - Curva carga de tração x deslocamento vertical da estaca $\mathrm{N}^{\circ} 6 \mathrm{~L}$ e $\mathrm{N}^{\mathrm{o}} 11 \mathrm{~L}$ no container 2 (convertida para o protótipo)

FIGURA 5.36 - Curva carga de tração x deslocamento vertical da estaca $\mathrm{N}^{0} 7 \mathrm{~L}$ e $\mathrm{N}^{\mathrm{o}} 12 \mathrm{~L}$ no container 2 (convertida para o protótipo)

FIGURA 5.37 - Curva carga de tração x deslocamento vertical da estaca $\mathrm{N}^{\circ} 8 \mathrm{~L}$ e $\mathrm{N}^{\mathrm{o}} 12 \mathrm{~L}$ no container 2 (convertida para o protótipo)

FIGURA 5.38 - Curva carga de tração x deslocamento vertical da estaca No $9 \mathrm{~L}$ e $\mathrm{N}^{\mathrm{o}} 12 \mathrm{~L}$ no container 2 (convertida para o protótipo)

FIGURA 5.39 - Fotografia do corte do maciço sobre a hélice 166

FIGURA 5.40 - Fotografia do corte do maciço entre as hélices da estaca modelo 167

FIGURA 5.41 - Curvas força cisalhante $\mathrm{x}$ deslocamento relativo da interface entre 168 aço e areia (amostra $\gamma=15,46 \mathrm{kN} / \mathrm{m}^{3}$ )

FIGURA 5.42 - Curvas força cisalhante $\mathrm{x}$ deslocamento relativo da interface entre 168 chapa soldada e areia $\left(\operatorname{amostra} \gamma=15,46 \mathrm{kN} / \mathrm{m}^{3}\right.$ )

FIGURA 5.43 - Curvas força cisalhante $\mathrm{x}$ deslocamento relativo da interface entre aço e areia (amostra $\gamma=16,30 \mathrm{kN} / \mathrm{m}^{3}$ )

FIGURA 5.44 - Curvas força cisalhante x deslocamento relativo da interface entre 170 chapa soldada e areia $\left(\operatorname{amostra} \gamma=16,30 \mathrm{kN} / \mathrm{m}^{3}\right)$ 
FIGURA 5.45 - Tensão cisalhante residual $\mathrm{x}$ tensão normal da interface entre aço e areia (amostra $\left.\gamma=15,46 \mathrm{kN} / \mathrm{m}^{3}\right)$

FIGURA 5.46 - Tensão cisalhante residual x tensão normal da interface entre chapa soldada e areia (amostra $\gamma=15,46 \mathrm{kN} / \mathrm{m}^{3}$ )

FIGURA 5.47 - Tensão cisalhante residual $\mathrm{x}$ tensão normal da interface entre aço e areia (amostra $\gamma=16,30 \mathrm{kN} / \mathrm{m}^{3}$ )

FIGURA 5.48 - Tensão cisalhante residual $\mathrm{x}$ tensão normal da interface entre chapa soldada e areia $\left(\operatorname{amostra} \gamma=16,30 \mathrm{kN} / \mathrm{m}^{3}\right)$

FIGURA 5.49 - Fotografia microscópica dos grãos da areia de Fontainebleau utilizada nos ensaios de cisalhamento direto de interface e em centrífuga

FIGURA 5.50 - Curva granulométrica da Areia $1 \quad 175$

FIGURA 5.51 - Curva granulométrica da Areia 2 176

FIGURA 5.52 - Curva granulométrica da Areia $3 \quad 176$

FIGURA 5.53 - Curvas tensão cisalhante x deslocamento horizontal relativo da 178 interface entre o aço e a Areia $1\left(\mathrm{D}_{\mathrm{r}}=25 \%\right)$

FIGURA 5.54 - Curvas tensão cisalhante $\mathrm{x}$ deslocamento horizontal relativo da interface entre o aço e a Areia $1\left(D_{r}=55 \%\right)$

FIGURA 5.55 - Curvas tensão cisalhante $\mathrm{x}$ deslocamento horizontal relativo da interface entre o aço e a Areia $1\left(\mathrm{D}_{\mathrm{r}}=85 \%\right)$

FIGURA 5.56 - Curvas tensão cisalhante $\mathrm{x}$ deslocamento horizontal relativo da interface entre o aço e a Areia $2\left(D_{r}=25 \%\right)$

FIGURA 5.57 - Curvas tensão cisalhante $\mathrm{x}$ deslocamento horizontal relativo da interface entre o aço e a Areia $2\left(D_{\mathrm{r}}=55 \%\right)$

FIGURA 5.58 - Curvas tensão cisalhante $\mathrm{x}$ deslocamento horizontal relativo da interface entre o aço e a Areia $2\left(D_{\mathrm{r}}=85 \%\right)$

FIGURA 5.59 - Curvas tensão cisalhante $\mathrm{x}$ deslocamento horizontal relativo da interface entre o aço e a Areia $3\left(\mathrm{D}_{\mathrm{r}}=25 \%\right)$

FIGURA 5.60 - Curvas tensão cisalhante $\mathrm{x}$ deslocamento horizontal relativo da interface entre o aço e a Areia $3\left(D_{r}=55 \%\right)$

FIGURA 5.61 - Curvas tensão cisalhante $\mathrm{x}$ deslocamento horizontal relativo da interface entre o aço e a Areia $3\left(\mathrm{D}_{\mathrm{r}}=85 \%\right)$

FIGURA 5.62 - Tensão cisalhante residual x tensão normal da interface entre o aço e a Areia $1\left(\mathrm{D}_{\mathrm{r}}=25 \%\right)$

FIGURA 5.63 - Tensão cisalhante residual $\mathrm{x}$ tensão normal da interface entre o aço e a Areia $1\left(D_{\mathrm{r}}=55 \%\right)$

FIGURA $5.64-$ Tensão cisalhante residual $\mathrm{x}$ tensão normal da interface entre o aço e a Areia $1\left(\mathrm{D}_{\mathrm{r}}=85 \%\right)$

FIGURA 5.65 - Tensão cisalhante residual x tensão normal da interface entre o aço e a Areia $2\left(D_{\mathrm{r}}=25 \%\right)$

178 
FIGURA 5.66 - Tensão cisalhante residual x tensão normal da interface entre o aço e a Areia $2\left(\mathrm{D}_{\mathrm{r}}=55 \%\right)$

FIGURA 5.67 - Tensão cisalhante residual x tensão normal da interface entre o aço e a Areia $2\left(\mathrm{D}_{\mathrm{r}}=85 \%\right)$

FIGURA 5.68 - Tensão cisalhante residual $\mathrm{x}$ tensão normal da interface entre $\mathrm{o}$ aço e a Areia $3\left(D_{\mathrm{r}}=25 \%\right)$

FIGURA 5.69 - Tensão cisalhante residual x tensão normal da interface entre o aço e a Areia $3\left(\mathrm{D}_{\mathrm{r}}=55 \%\right)$

FIGURA 5.70 - Tensão cisalhante residual x tensão normal da interface entre o aço e a Areia $3\left(\mathrm{D}_{\mathrm{r}}=85 \%\right)$

FIGURA 5.71 - Variação do ângulo de atrito residual na interface de uma superfície de aço com rugosidade de $10 \mu \mathrm{m}$ com o $\mathrm{D}_{50}$ da areia (Jardine et al., 1992 apud Jardine et al., 1998)

FIGURA 5.72 - Variação do ângulo de atrito residual na interface da superfície de aço estudada com o $\mathrm{D}_{50}$ da areia

FIGURA 5.73 - Fotografia dos grãos da Areia $1\left(\mathrm{D}_{50}=0,13 \mathrm{~mm}\right)$

FIGURA 5.74 - Fotografia dos grãos da Areia $2\left(\mathrm{D}_{50}=0,30 \mathrm{~mm}\right)$

FIGURA 5.75 - Fotografia dos grãos da Areia $3\left(\mathrm{D}_{50}=0,52 \mathrm{~mm}\right)$

FIGURA 5.76 - Variação do ângulo de atrito residual de interface com a densidade relativa da areia

FIGURA 5.77 - Curva de momento torçor x rotação do tubo de aço ensaiado com diâmetro externo igual a $73 \mathrm{~mm}$ e espessura igual a $5,16 \mathrm{~mm}$ (sem emenda)

FIGURA 5.78 - Curva de momento torçor x rotação do tubo de aço ensaiado com diâmetro externo igual a $73 \mathrm{~mm}$ e espessura igual a $5,16 \mathrm{~mm}$ (com emenda)

FIGURA 5.79 - Curva de momento torçor x rotação do tubo de aço ensaiado com diâmetro externo igual a $73 \mathrm{~mm}$ e espessura igual a 7,1 $\mathrm{mm}$ (sem emenda)

FIGURA 5.80 - Curva de momento torçor x rotação do tubo de aço ensaiado com diâmetro externo igual a $73 \mathrm{~mm}$ e espessura igual a $7,1 \mathrm{~mm}$ (com emenda)

FIGURA 6.1 - Comparação entre os resultados medidos e calculados da

$\begin{array}{ll} & \text { capacidade de carga à tração relativa às hélices }\left(\mathrm{Q}_{\mathrm{h}}\right) \\ \text { FIGURA 6.2 } & - \\ \text { Fator de capacidade de carga à tração }\left(\mathrm{N}_{\mathrm{qu}}\right) \text { obtidos nos ensaios }\end{array}$ em centrífuga versus diâmetro da hélice (D)

FIGURA $6.3 \quad$ - Modelos de estacas utilizados nos ensaios em centrífuga instalados na profundidade final

FIGURA 6.4 - Estacas N ${ }^{\circ} 5 \mathrm{C}$ e N ${ }^{\circ} 6 \mathrm{C}$ ensaiadas na EESC em São Carlos

FIGURA 6.5 - Relação entre os valores medidos de torque de instalação das estacas $\mathrm{N}^{\circ} 5 \mathrm{C}$ e $\mathrm{N}^{\circ} 6 \mathrm{C}$ (para a mesma profundidade) 


\section{LISTA DE TABELAS}

TABELA $2.1 \quad-\quad$ Valores de $\mathrm{Ku}$ para alguns ângulos de atrito de solo $\phi$ (Mitsch e Clemence, 1985)

TABELA 2.2 - Propriedades da areia testada (Ghaly et al., 1991b)

TABELA 2.3 - Etapas de carregamento da prova de carga (A. B. Chance, 1994) 68

TABELA 2.4 - Fatores de escala para ensaios em centrífuga (Fuglsang e Ovesen, 71 1988)

TABELA 4.1 - Dimensões das estacas ensaiadas em Contagem 93

TABELA 4.2 - Dimensões das estacas ensaiadas na EESC 97

TABELA 4.3 - Fatores de escala para modelagem física em centrífuga 102

TABELA 4.4 - Parâmetros das chuvas de areia dos maciços ensaiados 105

TABELA 4.5 - Características do penetrômetro do LCPC 107

TABELA 4.6 - Características da centrífuga do LCPC 109

TABELA 4.7 - Dimensões das estacas modelo 112

TABELA 4.8 - Profundidade final das estacas modelo 117

TABELA 5.1 - Profundidade da ponta da estaca x torque de instalação 132 (Contagem)

TABELA 5.2 - Profundidade da ponta das estacas x torque de instalação (EESC) 136

TABELA 5.3 - Valores de capacidade de carga à tração $\left(\mathrm{Q}_{\mathrm{u}}\right)$ das estacas $\quad 139$ ensaiadas em campo

TABELA 5.4 - Propriedades da areia utilizada na modelagem física 141

TABELA 5.5 - Valores do peso próprio do sistema de ensaio + estaca (protótipo) 153

TABELA 5.6 - Resultados de capacidade de carga a tração e de torque final de 161 instalação das estacas ensaiadas (convertidos para o protótipo)

TABELA $5.7 \quad-$ Resultados de deslocamento vertical na ruptura (convertidos para 163 o protótipo)

TABELA 5.8 - Valores medidos de $\mathrm{K}_{\mathrm{t}}{ }_{\mathrm{t}} \quad 164$

TABELA 5.9 - Ângulo de atrito residual nas interfaces entre o material das $\quad 172$ hélices e as amostras de areia $\left(\delta_{\mathrm{r}}\right)$

TABELA 5.10 - Rugosidade máxima das chapas ensaiadas 173

TABELA 5.11 - Propriedades das areias utilizadas nos ensaios 175

TABELA 5.12 - Características dos ensaios de cisalhamento direto em interface 177 aço/areia 
TABELA 5.13 - Ângulo de atrito residual nas interfaces entre o material da hélice comercialmente utilizada e as amostras de areia de diferentes $\mathrm{D}_{50}$

TABELA 5.14 - Comparação entre valores de momento torçor máximo medidos e calculados

TABELA 6.1 - Parcela de capacidade de carga à tração relativa às hélices $\left(\mathrm{Q}_{\mathrm{h}}\right)$ calculada

TABELA 6.2 - Comparação entre $Q_{h}$ calculada e $Q_{h}$ medida

TABELA 6.3 - Comparação entre os valores de torque final de instalação medidos e calculados

TABELA 6.4 - Valores de $\mathrm{Q}_{\mathrm{h}}$ calculados pelo Método de Capacidades de Carga Individuais para as estacas ensaiadas em centrífuga

TABELA 6.5 - Comparação entre os valores de $\mathrm{Q}_{\mathrm{h}}$ calculados pelo Método de Capacidades de Carga Individuais e medidos nos ensaios em centrífuga

TABELA 6.6 - Valores de $\mathrm{Q}_{\mathrm{h}}$ calculados pelo Método de Capacidades de Carga Individuais para as estacas ensaiadas em campo

TABELA 6.7 - Comparação entre os valores de $\mathrm{Q}_{\mathrm{h}}$ calculados pelo Método de Capacidades de Carga Individuais e medidos nos ensaios de campo

TABELA 6.8 - Valores de $\mathrm{Q}_{\mathrm{h}}$ calculados pelo Método da Ruptura Cilíndrica para as estacas ensaiadas em centrífuga

TABELA 6.9 - Comparação entre os valores de $\mathrm{Q}_{\mathrm{h}}$ calculados pelo Método da Ruptura Cilíndrica medidos nos ensaios em centrífuga

TABELA 6.10 - Comparação dos valores de $\mathrm{Q}_{\mathrm{h}}$ calculados pelo Método da Ruptura Cilíndrica e pelo Método das Capacidades de Carga Individuais com os valores medidos nos ensaios em centrífuga

TABELA 6.11 - Valores de $\mathrm{Q}_{\mathrm{u}}$ calculados pelo Método da Ruptura Cilíndrica para as estacas ensaiadas em campo

TABELA 6.12 - Comparação entre os valores de $\mathrm{Q}_{\mathrm{u}}$ calculados pelo Método de Ruptura Cilíndrica e medidos nos ensaios de campo

TABELA 6.13 - Valores do fator de capacidade de carga à tração $\left(\mathrm{N}_{\mathrm{qu}}\right)$ encontrados nos ensaios em centrífuga (estacas com a razão H/D igual a 13,5$)$

TABELA 6.14 - Parcelas de torque e de capacidade de carga relativas às hélices nas estacas com duas hélices ensaiadas em centrífuga

TABELA 6.15 - Parcelas de torque e de capacidade de carga relativas às hélices nas estacas com três hélices ensaiadas em centrífuga

TABELA 6.16 - Valores de torque final de instalação calculados pela Equação 3.16 


\section{LISTA DE SÍMBOLOS}

d

$\mathrm{d}_{\mathrm{c}}$

D

$\mathrm{D}_{\mathrm{r}}$

$\mathrm{D}_{50}$

g

$\mathrm{H}$

$\mathrm{K}_{\mathrm{t}}$

$\mathrm{K}^{\prime}{ }_{\mathrm{t}}$

L

$\mathrm{N}_{\mathrm{qu}}$

$\mathrm{N}$

$\mathrm{N}_{\mathrm{SPT}}$

$\mathrm{p}$

$\mathrm{Q}_{\mathrm{f}}$

$\mathrm{Q}_{\mathrm{h}}$

$\mathrm{Q}_{\mathrm{p}}$

$\mathrm{Q}_{\mathrm{s}}$

$\mathrm{Qu}_{\mathrm{u}}$

$\mathrm{R}_{\max }$

$\mathrm{T}$

$\mathrm{T}_{\mathrm{s}}$

$\mathrm{T}_{\mathrm{h}}$

$\mathrm{u}$

$\delta_{\mathrm{r}}$

$\phi$

$\gamma$

$\sigma$ diâmetro externo do tubo (ou haste) da estaca diâmetro do círculo correspondente a área da hélice diâmetro externo da hélice da estaca densidade relativa diâmetro médio do agregado aceleração da gravidade profundidade da hélice de topo da estaca fator empírico de torque razão entre $\mathrm{Q}_{\mathrm{h}}$ e $\mathrm{T}_{\mathrm{h}}$ espaçamento entre hélices comprimento da estaca fator de capacidade de carga à tração nível de aceleração resistência à penetração do ensaio SPT (Standard Penetration Test) passo da hélice da estaca capacidade de carga devido à resistência por atrito na superfície cilíndrica parcela da capacidade de carga à tração relativa às hélices capacidade de carga à tração relativa a hélice de topo resistência por atrito lateral do tubo capacidade de carga à tração rugosidade máxima torque de instalação momento resistente à instalação atuante na superfície do tubo (ou haste) momento resistente à instalação atuante nas hélices deslocamento da estaca na ruptura ângulo de atrito residual na interface ângulo de atrito do solo peso específico do solo tensão normal ângulo da hélice da estaca com a horizontal tensão cisalhante 
tensão cisalhante residual 


\section{RESUMO}

TSUHA, C. H. C. Modelo Teórico para Controle da Capacidade de Carga à Tração de Estacas Metálicas Helicoidais em Solo Arenoso. Tese (Doutorado) - Escola de Engenharia de São Carlos, Universidade de São Paulo, São Carlos, 2007, 245p.

O monitoramento em campo de fundações em estacas metálicas helicoidais é baseado em correlações empíricas entre a capacidade de carga à tração e o torque medido durante a instalação. Nesta pesquisa é proposto um modelo teórico da relação entre o torque de instalação e a capacidade de carga à tração deste tipo de estaca em areias para ser utilizado como procedimento de controle durante a execução deste tipo de fundação. Para validar esta relação teórica e para avaliar o desempenho desta fundação em solos arenosos, foi realizado um programa experimental dividido em dois grupos: ensaios de campo e ensaios de laboratório. Em campo foram realizadas provas de carga à tração na Escola de Engenharia de São Carlos (EESC) e em Contagem (Minas Gerais). Os ensaios de laboratório foram divididos em três grupos. O primeiro corresponde aos ensaios de modelagem física em centrífuga realizados no Laboratoire Central des Ponts et Chaussées (LCPC) em Nantes, França. O segundo engloba ensaios de cisalhamento direto de interface entre o aço da hélice da estaca e diferentes areias, parte executada no LCPC e parte na EESC. O terceiro grupo refere-se a ensaios de torção de tubos de estacas metálicas helicoidais efetuados na EESC. A partir dos resultados dos ensaios, o modelo teórico proposto nesta tese foi verificado e mostrou-se adequado para estacas metálicas helicoidais profundas com diferentes dimensões e número de hélices instaladas em solos arenosos. Os resultados das provas de carga realizadas em centrífuga e em campo foram examinados por meio dos métodos existentes na literatura para estimativa de capacidade de carga à tração desenvolvidos para este tipo de fundação. Por meio dos resultados obtidos nos ensaios em centrífuga, constatou-se que nas estacas multi-hélices a porcentagem de capacidade de carga relativa à hélice da ponta aumenta de acordo com o diâmetro da hélice e com a densidade da areia. Nos ensaios de torção de fustes de estacas helicoidais observou-se que, para tubos de mesmo diâmetro e espessura, a ruptura se inicia a partir do mesmo valor de momento torçor aplicado, independentemente de conter ou não emenda.

Palavras-chave: estaca metálica helicoidal, capacidade de carga à tração, fundações profundas, controle durante execução, areia, modelagem física em centrífuga. 


\section{ABSTRACT}

TSUHA, C. H. C. Theoretical Model to Control on Site the Uplift Capacity of Helical Screw Piles Embedded in Sandy Soil. Tese (Doutorado) - Escola de Engenharia de São Carlos, Universidade de São Paulo, São Carlos, 2007, 245p.

Empirical correlations between installation torque and uplift capacity of helical screw piles are routinely used as a procedure for quality control on site of this type of foundation. In this work, a theoretical model of the relationship between uplift capacity and installation torque of deep helical screw piles in sand was presented to be used as a quality control method for this type of foundation. An experimental program of laboratory and field investigations was carried out in order to validate this theoretical relationship. The field study included uplift tests of full-scale piles installed at the Escola de Engenharia de São Carlos (EESC) and in Contagem (Minas Gerais). The laboratory tests were performed in the Laboratoire Central des Ponts et Chaussées (LCPC/ Nantes) and at the EESC. In the LCPC a program of centrifuge and direct shear interface tests was completed. A set of torsion tests on pile shafts and of direct shear interface tests were carried out at the EESC. The results showed that the theoretical model presented is applicable to different pile dimensions, number of helices, and sand relative density. The methods existing in the literature for estimating uplift capacity of helical screw piles were used to verify the results of uplift capacities measured in field and in centrifuge studies. The results of centrifuge modelling tests demonstrated that the fraction of uplift capacity corresponding to the bottom helix increases with helix diameter and sand density. The torsion tests showed that the failure of the pile shaft begins at the same torque magnitude in experiments on shafts with and without connections.

Key words: helical screw pile, uplift capacity, deep foundations, quality control on site, sand, centrifuge physical modelling. 


\section{$1 \quad$ INTRODUÇÃO}

As fundações em estacas metálicas helicoidais começaram a ser utilizadas no Brasil, no final da década passada, para resistir esforços de tração em obras de torres de linhas de transmissão de energia elétrica e de telecomunicação. Contudo, este tipo de estaca tem sido empregado há mais de 60 anos em outros países.

Embora existam na literatura geotécnica pesquisas sobre este tipo de fundação, em nosso país ainda são raros os estudos sobre ancoragens helicoidais. Entretanto, as informações disponíveis na literatura internacional são em sua maioria dirigidas para o projeto e não para o controle de qualidade e para a verificação do desempenho da estaca. Os procedimentos de controle da capacidade de carga usados na prática são baseados em regras empíricas estabelecidas pela experiência de empresas executoras deste tipo de fundação. Por esta razão, a empresa Vértice Engenharia, fabricante e instaladora deste tipo de estaca no Brasil, procurou a Escola de Engenharia de São Carlos e se dispôs a apoiar financeiramente a pesquisa de um procedimento de controle de capacidade de carga de estacas helicoidais baseado em um modelo teórico.

Para a concretização deste trabalho foram realizados ensaios de tração de modelos reduzidos de estacas em centrífuga, ensaios de cisalhamento direto de interface entre aço e areia, ensaios de torção de fuste e provas de carga à tração realizadas em campo.

\subsection{Objetivos}

Os objetivos desta tese são os seguintes:

1) Homogeneizar o conjunto das resistências à tração de estacas metálicas helicoidais, instaladas em solos arenosos, que juntas formam a fundação de uma estrutura sujeita a 
carregamento de tração, por meio de um procedimento de controle durante a execução. Para este fim, foi desenvolvido nesta tese um modelo teórico da relação entre o torque de instalação deste tipo de estaca executada em areia e sua capacidade de carga à tração, apresentado no capítulo 3. Este modelo foi verificado experimentalmente por meio de ensaios de modelagem física em centrífuga e de provas de carga em campo;

2) Verificar os métodos de cálculo de capacidade de carga à tração, existentes na literatura para este tipo de fundação em solo arenoso, por meio dos resultados obtidos nas provas de carga executadas em centrífuga e em campo;

3) Examinar o efeito do número de hélices de uma estaca metálica helicoidal instalada em areia no torque de instalação e na capacidade de carga à tração, para constatar se este influencia o modelo teórico proposto nesta tese, e para orientar o projetista deste tipo de fundação na definição do número de hélices a ser adotado na fabricação da estaca.

4) Analisar o torque máximo que pode ser aplicado no fuste de uma estaca metálica helicoidal durante a instalação para esta não ser danificada. Para este fim foram realizados ensaios de torção em tubos deste tipo de estaca com e sem emenda;

5) Averiguar se com a aplicação do modelo teórico proposto nesta tese é possível prever o valor de torque medido em uma estaca metálica helicoidal, por meio de uma estaca com hélices de dimensões reduzidas (que permita penetrar maiores profundidades). Na prática, esta estaca com hélice de menor diâmetro, poderia ser utilizada como método de investigação de subsolo adequado para o projeto deste tipo de fundação em solo arenoso.

\subsection{Escopo e organização do trabalho}

No capítulo 2 é apresentada uma revisão bibliográfica que se inicia com a definição do tipo de fundação objeto desta pesquisa. Em seguida, com referência às estacas metálicas 
helicoidais, são descritos: os métodos para o cálculo de capacidade de carga à tração em areia, as relações entre torque de instalação e capacidade de carga à tração, e os procedimentos empregados em provas de carga. Para complementar esta revisão, foi feita uma descrição resumida sobre modelagem física em centrífuga e sua aplicação em ancoragens helicoidais.

O modelo teórico da relação entre o torque de instalação e a capacidade de carga à tração de uma estaca helicoidal em areia, desenvolvido nesta tese para o controle de capacidade de carga desta estaca durante a sua execução, é detalhado no capítulo 3.

O capítulo 4 mostra os materiais e métodos utilizados na parte experimental desta tese. No capítulo 5 são apresentados e comentados os resultados destes experimentos.

No capítulo 6 foi feita a verificação do modelo teórico proposto nesta pesquisa, e dos métodos de cálculo de capacidade de carga apropriados para este tipo de fundação, existentes na literatura. Além destas verificações, foi analisado neste capítulo o efeito do número de hélices na instalação e no desempenho de uma estaca metálica helicoidal, e a possibilidade da utilização de uma estaca de hélice de menor diâmetro como instrumento de investigação de subsolo para o dimensionamento deste tipo de estaca.

O capítulo 7 refere-se às conclusões provenientes deste trabalho. 


\subsection{Introdução}

De acordo com Little (1961), as estacas helicoidais foram inventadas por Alexandre Mitchell, e utilizadas pela primeira vez na fundação do Farol de Maplin Sands no Rio Tamisa em 1838. Neste farol as estacas utilizadas tinham o diâmetro igual a 127 milímetros e o comprimento em torno de oito metros. As hastes das primeiras estacas eram feitas em ferro ou em madeira, e as hélices em ferro somente.

Este fato deu início à construção de uma série de faróis (Figura 2.1) na Inglaterra sustentados por este tipo de fundação (Stephenson, 2002).

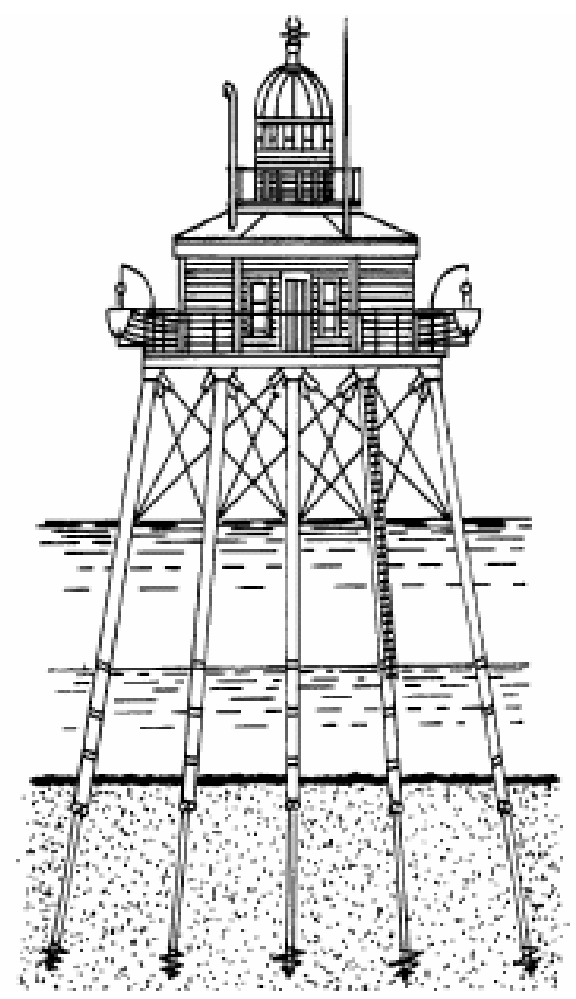

Figura 2.1 - Farol com fundação em estaca helicoidal (A. B. Chance Co., 1994) 
Segundo Rankine (1877), as estacas helicoidais são aparafusadas dentro do solo em que ela deverá permanecer como fundação.

Os primeiros modelos de estacas helicoidais (Figuras 2.2 e 2.3) eram diferentes dos modelos utilizados atualmente. As estacas eram feitas de madeira ou ferro e com a secção cilíndrica para facilitar a sua instalação no solo, no entanto em alguns casos apresentavam a secção octogonal. A ponta helicoidal era feita de ferro e fixada na extremidade da estaca, e raramente a hélice apresentava mais de uma volta. O diâmetro da hélice variava de duas a oito vezes o diâmetro do tubo da estaca, e o passo variava da metade a um quarto deste diâmetro. A instalação deste tipo de estaca era feita por aparafusamento utilizando-se força humana ou animal. Homens ou animais andavam sobre uma plataforma provisória para fazer a alavanca necessária para a instalação (Rankine, 1877).

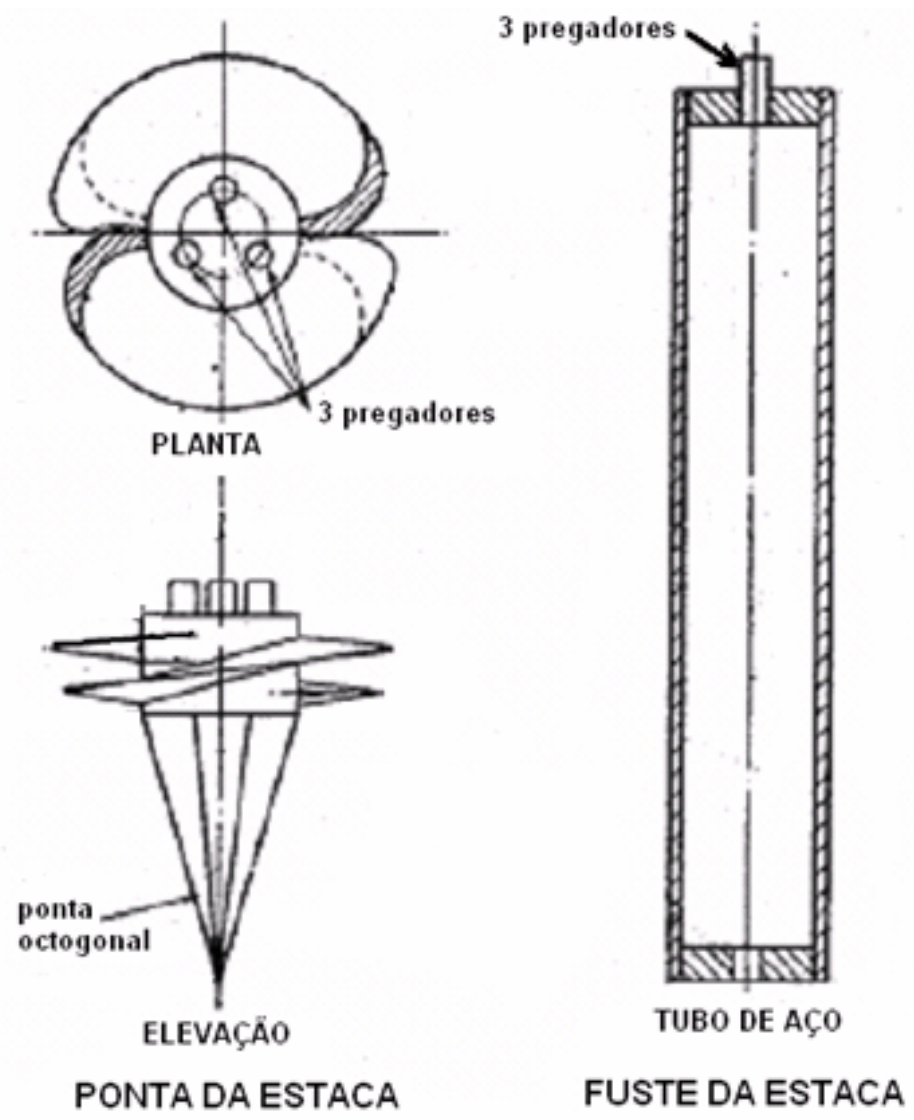

Figura 2.2 - Modelo de estaca metálica helicoidal (Wilson, 1950) 


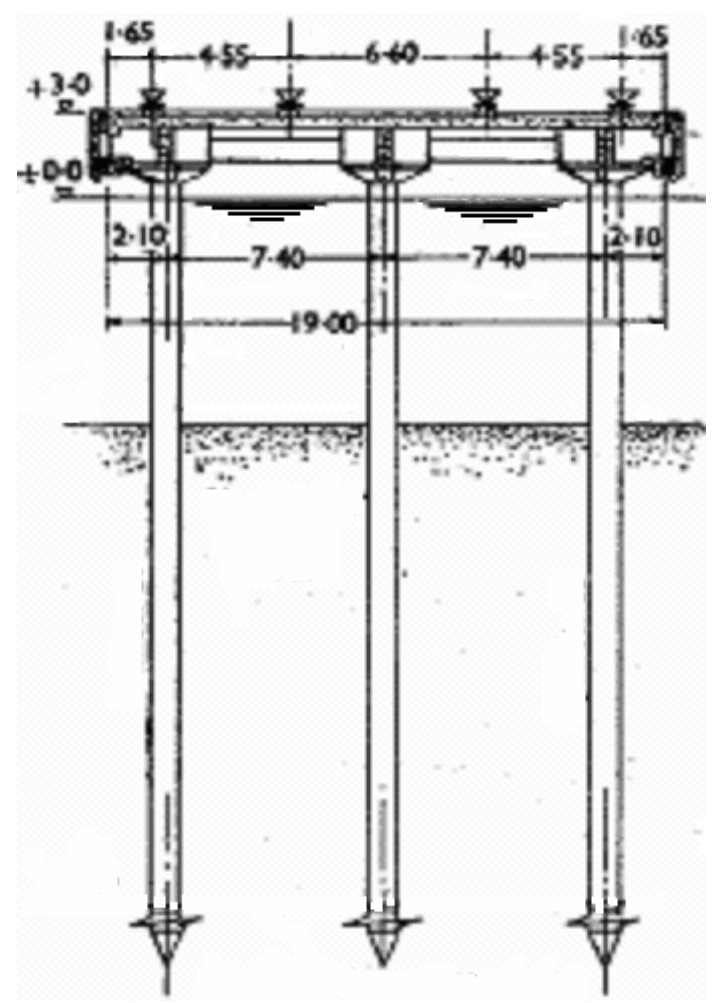

Figura 2.3 - Fundação de cais no Golfo de Izmit (Turquia) em estaca helicoidal realizada em 1945 (Wilson, 1950)

Little (1961) cita que as estacas helicoidais são formadas por um tubo de pequeno diâmetro com uma hélice de grande diâmetro na ponta, e esta hélice forma uma volta completa no tubo, com um passo grande o suficiente para que possa atravessar as pedras a serem encontradas. A penetração de estaca é mais fácil e eficiente em argilas moles e areias fofas. O aumento da área da hélice pode proporcionar um melhor comportamento deste tipo de estaca em relação a outras em solos de baixa resistência.

A Figura 2.4 apresenta a utilização de estacas helicoidais como fundação de um quebramar na Escócia em 1944. Nestas estacas, o diâmetro dos tubos é igual a $91,5 \mathrm{~cm}$ e o das hélices varia de 214 a $244 \mathrm{~cm}$. 


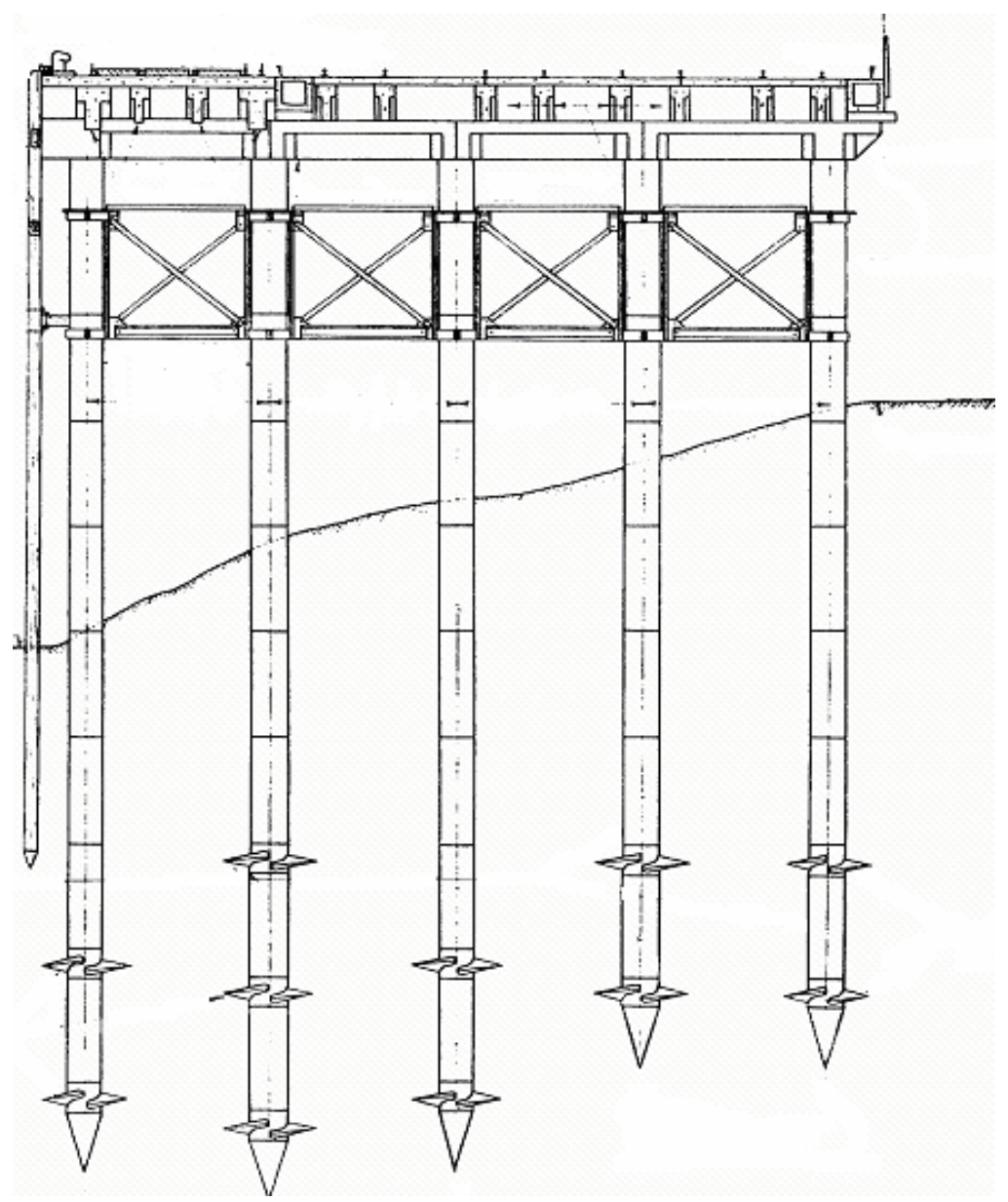

Figura 2.4 - Estacas helicoidais instaladas em terreno mole para fundação de quebra-mar na Escócia (Morgan, 1944 apud Little, 1961)

Segundo Frick (1905), não é conveniente instalar estacas com ponta helicoidal em terrenos arenosos e com cascalhos, porém, quando os terrenos são apropriados, a instalação é feita rapidamente, além de não provocar vibrações como as estacas cravadas. Anteriormente a 1905, este tipo de estaca foi utilizado como fundação de numerosas pontes nas estradas de ferro do sul da França.

Du-Plat-Taylor (1949) cita que as estacas helicoidais são muito utilizadas em fundações de obras portuárias. A Figura 2.5 apresenta um exemplo de projeto de fundações em estacas helicoidais de um cais em Calcutá executado em 1941. 


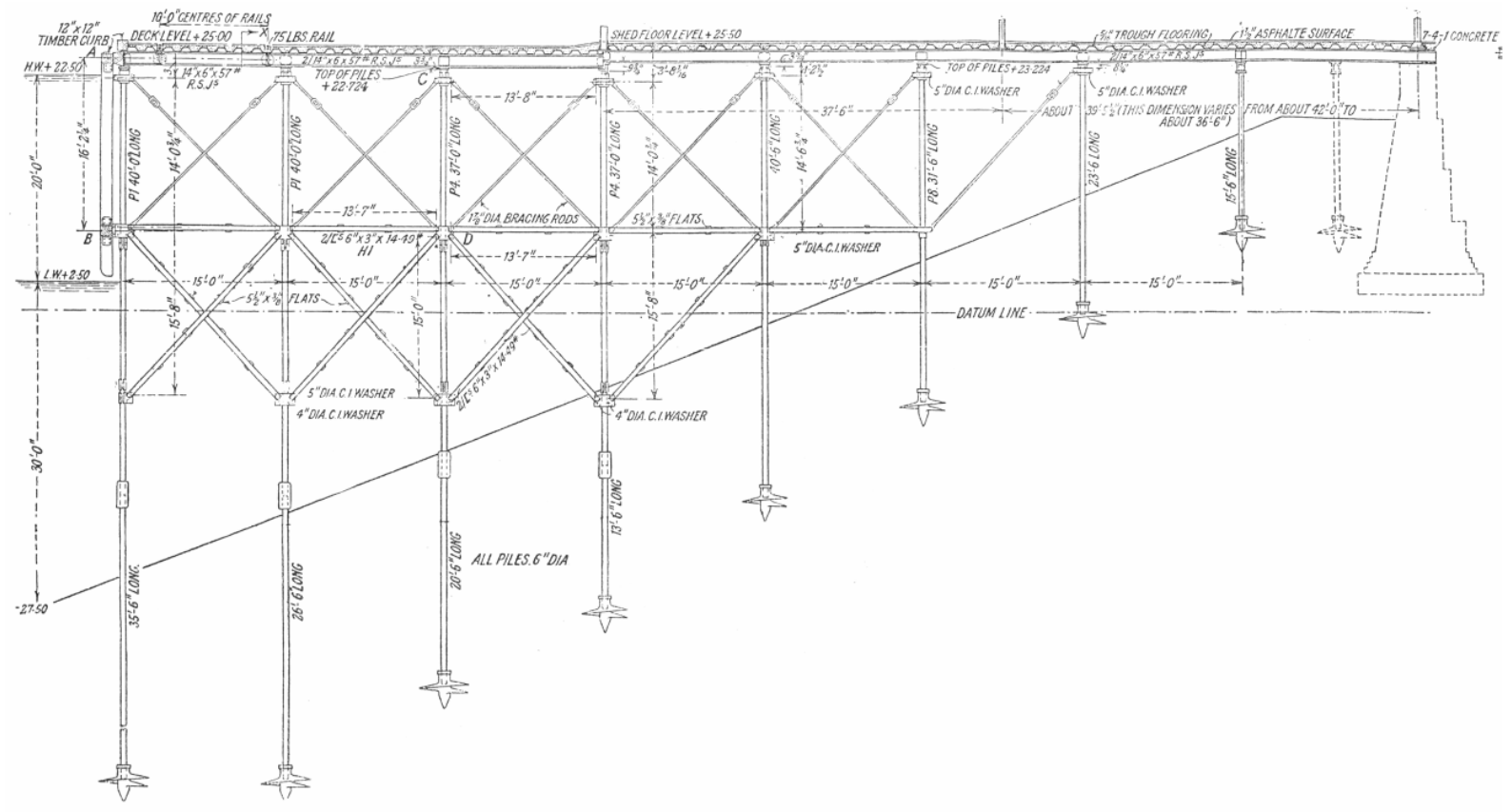

Figura 2.5 - Fundação de cais em estaca helicoidal realizada em 1941, Calcutá (Du-PlatTaylor, 1949)

Um amplo estudo da capacidade de carga deste tipo de fundação foi realizado por Wilson (1950). Este trabalho contém: provas de carga em protótipos de estacas helicoidais, observação dos deslocamentos, desenvolvimento de teoria e a verificação da relação entre o torque de instalação e a capacidade de carga.

Trofimekov e Mariupoiskii (1965) realizaram provas de carga em 200 estacas na antiga União Soviética, e a partir destes ensaios, desenvolveram método para calcular a capacidade de carga deste tipo de fundação. Segundo estes autores, as estacas helicoidais têm sido utilizadas com sucesso como fundação de torres em países como União Soviética e Canadá. Entre 1961 e 1964, foram executadas muitas torres de comunicação na União Soviética com este tipo de fundação. 
Em 1969, Robinson e Taylor relataram a relação entre capacidade de carga à tração e o torque de instalação deste tipo de fundação em testes realizados em duas linhas de transmissão de energia (Narasimha Rao et al., 1991).

Johnston e Ladanyi (1974) realizaram testes em estacas helicoidais, e os resultados indicaram que o comportamento quanto à resistência à tração deste tipo de fundação é semelhante ao comportamento de fundações em sapatas profundas na mesma dimensão da hélice (Narasimha Rao et al., 1991).

Segundo Narasimha Rao et al. (1991), Clemence e Pepe (1984) apresentaram estudo de estacas metálicas helicoidais instaladas em solos arenosos, e mais tarde foi desenvolvido método de projeto para a determinação da capacidade de carga à tração deste tipo de fundação em solos arenosos e argilosos à partir de um extenso número de testes em campo e em laboratório realizados por Bobbit e Clemence (1987).

Hoyt e Clemence (1989) citam que as fundações em estacas metálicas helicoidais têm sido utilizadas em vários tipos de construções, como em torres de transmissão de energia, obras de dutos e de contenções.

Numerosas torres de linhas de transmissão de energia dos Estados Unidos têm como fundação estacas metálicas helicoidais. Este tipo de estaca começou a ser executado em grande quantidade a partir de 1940 (Clemence et al., 1994).

Clemence (1985) relata que por volta de 1950, houve um desenvolvimento significante do modelo de estaca helicoidal, em relação às estacas helicoidais antigas. Este tipo de fundação começou a ser utilizada em torres de transmissão de energia, obra de dutos, residências, contenções, etc. No entanto, o uso desta estaca tem sido limitado, devido à falta de conhecimento do seu comportamento. Os projetos deste tipo de fundação costumam ser baseados em regras empíricas e recomendações dos fabricantes. 
Segundo Clemence (1985), existe a necessidade de conhecer-se mais detalhadamente o comportamento deste tipo de estaca quando solicitada à tração, por meio de experiências em laboratórios ou em campo.

Fundações em estacas metálicas helicoidais têm sido empregadas em diversas estruturas sujeitas a elevados esforços de tração (Narasimha Rao et al., 1991).

Conforme Stephenson (2002), este tipo de fundação vem crescendo rapidamente no mercado geotécnico.

De acordo com Pack (2003), enquanto existem informações para o projeto disponível na literatura geotécnica, faltam informações detalhadas sobre controle de qualidade, inspeção e monitoramento do comportamento de estacas metálicas helicoidais.

Existem fabricantes de estacas metálicas helicoidais em vários países do mundo, como: Estados Unidos, Japão, Inglaterra, Canadá e Austrália (Perko, 2000).

\subsection{Estacas metálicas helicoidais}

\subsubsection{Definição}

De acordo com Kulhawy (1985), as ancoragens são tipos de sistemas de fundações que são projetadas para resistir esforços de tração. As ancoragens podem ser classificadas em três categorias básicas: placas, injetadas e helicoidais. As ancoragens em placas (Figura 2.6a) podem ser de aço, concreto ou madeira, e as cargas são transmitidas á ancoragem por uma haste ou cabo de aço. Após a instalação, a placa é coberta por aterro compactado e de boa qualidade. As ancoragens injetadas (Figura 2.6c) consistem de um cabo ou barra de aço colocado dentro de um poço escavado, onde em seguida é injetada argamassa. As estacas helicoidais (Figura 2.6b) são compostas de tubos de aço onde são fixadas hélices. Esse tipo de 
ancoragem é instalado por aparafusamento da haste no solo. O passo e o espaçamento entre hélices são determinados, para que a perturbação no solo seja mínima. Esse tipo de ancoragem é instalado de modo a não ultrapassar o valor de torque máximo recomendado pelo fabricante.

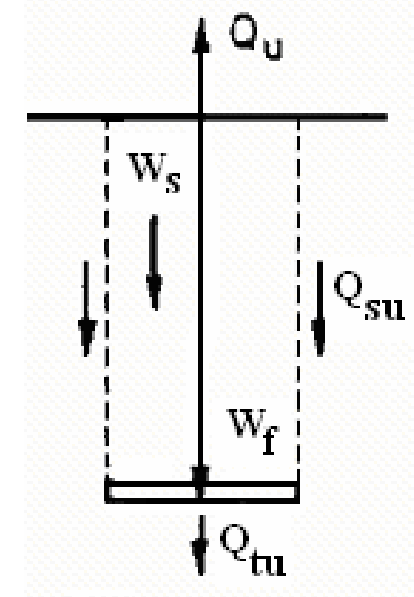

A) PLACAS



B) HELICOIDAIS



C) INJETADAS

Figura 2.6 - Tipos básicos de ancoragens (Kulhawy, 1985)

Segundo Mitsch e Clemence (1985), a estaca metálica helicoidal consiste de uma série de hélices de forma circular, feitas em chapa de aço soldadas a um tubo central com um determinado espaçamento entre elas.

Na Figura 2.7, tem-se a estaca simples e a multi-hélices. Estas estacas são instaladas no solo por aplicação de torque no tubo central. As chapas helicoidais penetram por rotação dentro do solo, com o auxílio de um motor hidráulico (Figura 2.8). A taxa de avanço é igual a um passo da hélice por revolução. De acordo com o avanço da estaca dentro do solo, são conectadas as extensões de tubo até encontrar-se a camada com resistência procurada. 


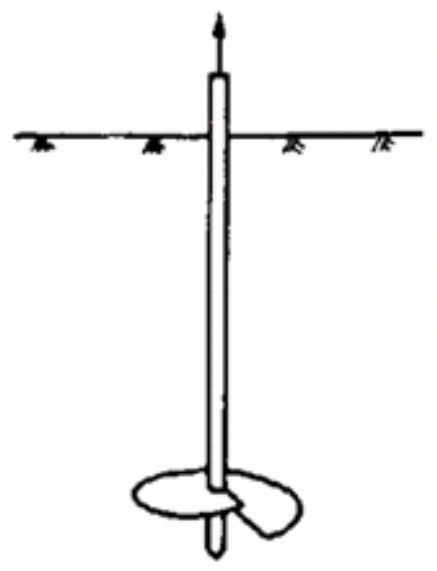

a) SIMPLES

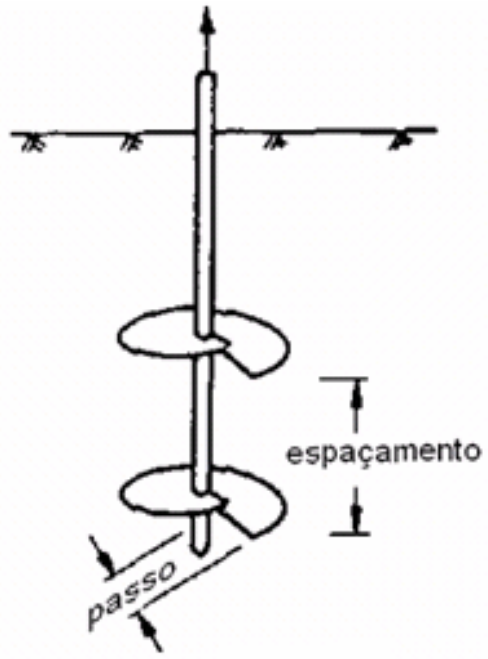

b) MULTI-HÉLICES

Figura 2.7 - Estacas metálicas helicoidais simples e multi-hélices (Kulhawy, 1985)

De acordo com Hoyt e Clemence (1989), a estaca metálica helicoidal consiste de uma ou mais hélices de forma circular afixadas a um tubo central.

Conforme Ghaly et al. (1991a), as estacas helicoidais podem ser encontradas em diferentes configurações. Elas podem ser de aço ou concreto, mas são geralmente fabricadas em aço.

Stephenson (2002) relata que as estacas helicoidais modernas são construídas em chapas circulares de aço soldadas em tubos. As chapas são dobradas como uma hélice com o passo controlado. As estacas podem ter mais que uma hélice com espaçamento apropriadamente determinado. O tubo central é usado para transmitir o torque durante a instalação e transferir cargas axiais às hélices.

Clemence et al. (1994) citam que as estacas metálicas helicoidais (Figura 2.9) são instaladas no solo por aplicação de torque. O torque é aplicado ao tubo central, e o avanço é igual ao passo da hélice para cada volta completa. Os tubos são emendados conforme a necessidade de se avançar dentro do solo. A instalação da estaca terminará quando atingir a camada com resistência apropriada. 
Segundo Flores et al. (2001), a primeira seção instalada no solo que contém as hélices é denominada seção guia, e o espaçamento entre as hélices é igual a três vezes o diâmetro da menor hélice. Se necessário, podem ser adicionadas seções de extensão à seção guia. As extensões podem ser instaladas imediatamente após a seção guia. A conexão entre a seção guia e as extensões são feitas por meio de parafusos (Figura 2.10), e os tubos de extensão apresentam a extremidade alargada para a emenda.



Figura 2.8 - Instalação de estaca metálica helicoidal (A. B. Chance Co., 2006) 


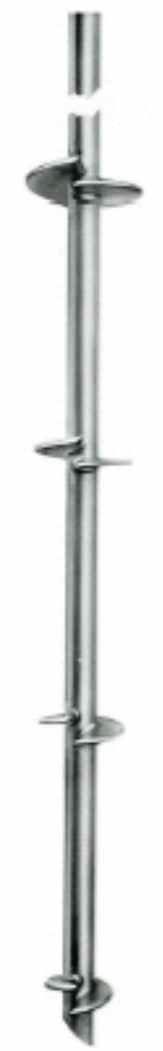

Figura 2.9 - Estaca metálica helicoidal (A. B. Chance Co., 2004)

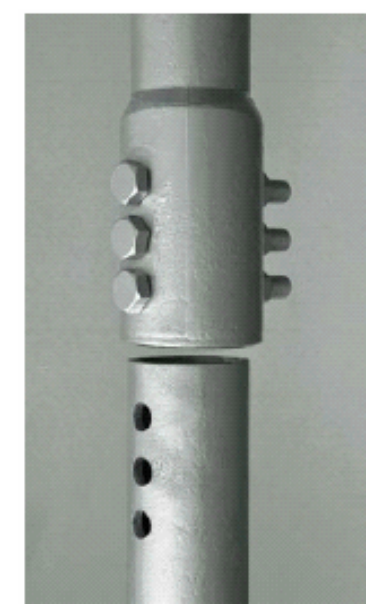

Figura 2.10 - Emenda de tubos de uma estaca metálica helicoidal (A. B. Chance Co., 2004)

A Figura 2.11 apresenta uma estaca metálica helicoidal multi-hélices, com dimensões tipicamente utilizadas nos Estados Unidos para construção de fundações de torres de linhas de transmissão de energia elétrica (Das, 1990). 


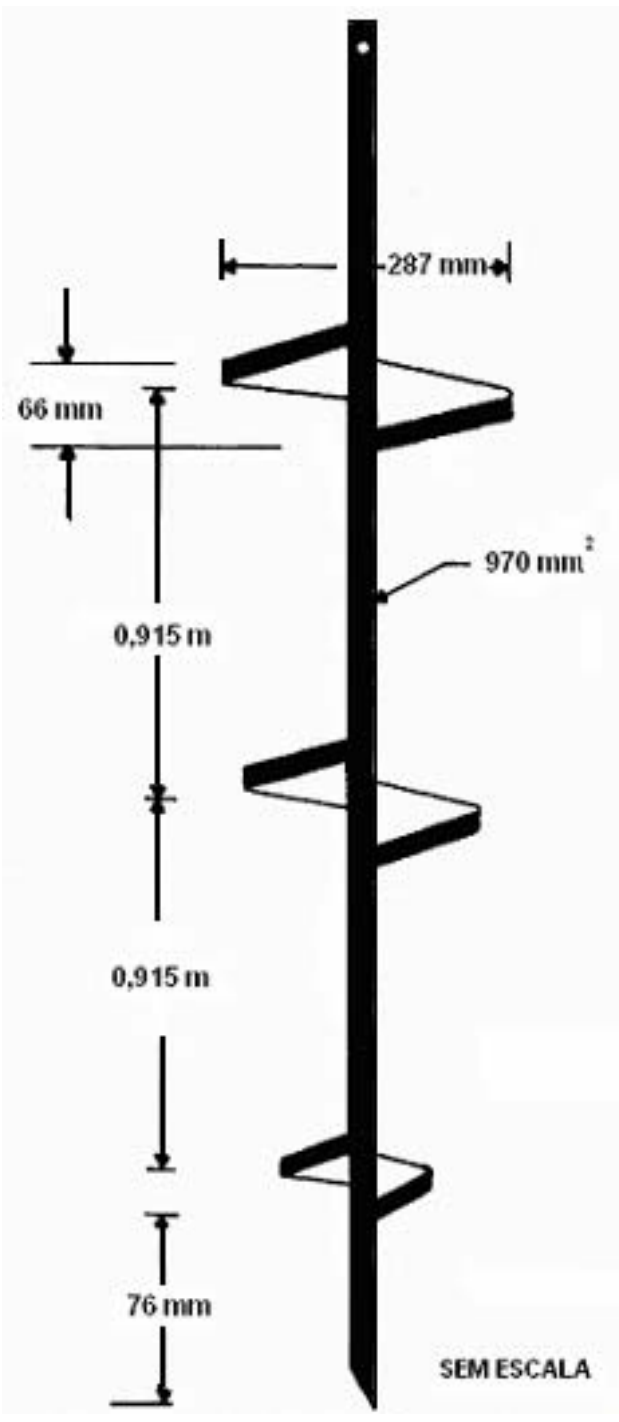

Figura 2.11 - Estaca helicoidal multi-hélices típica nos Estados Unidos (Das, 1990)

\subsubsection{Vantagens}

Segundo Frick (1905), dentro de terrenos convenientes, a instalação das estacas helicoidais é muito rápida, e apresenta também a vantagem de não perturbar o solo como as estacas comuns.

De acordo com Du-Plat-Taylor (1949) as vantagens das estacas helicoidais são as seguintes: 
- Imunidade à oxidação, pois elas podem ser revestidas com pintura especial para evitar corrosão;

- Equipamento de instalação mais leve do que equipamentos para instalação de estacas comuns;

- Em um solo mole, estacas helicoidais com comprimentos inferiores ao de estacas comuns conseguem atingir a mesma capacidade de carga que estas, devido à quantidade e tamanho de hélices;

- A instalação por aparafusamento causa menos vibração;

- Facilidade de transporte das estacas helicoidais, que por serem compostas de pedaços de tubos que são emendados por parafusos, são mais fáceis de serem deslocadas.

Wilson (1950) cita que no passado este tipo de fundação foi utilizado principalmente em obras de cais e pontes, por apresentar duas principais vantagens sobre outros tipos de estacas: capacidade de carga elevada e alta resistência aos momentos fletores. As investigações têm mostrado que este tipo de fundação apresenta capacidade de carga muito alta quando instalado em areias densas ou pedregulhos.

Para Ghaly et al. (1991a) as principais vantagens das estacas metálicas helicoidais são:

- Este tipo de fundação pode ser solicitado imediatamente após a instalação;

- Existem peças que facilitam a montagem das torres de transmissão de energia elétrica sobre este tipo de fundação;

- É uma fundação econômica quando o nível do lençol freático do terreno de instalação é elevado, pois deste modo não é necessário o gasto com o rebaixamento do lençol. 
Narasimha Rao et al. (1993) relatam que em solos pantanosos ou em terrenos em que o nível d'água é elevado é conveniente utilizar fundações em estacas metálicas helicoidais. As estacas metálicas helicoidais são tipicamente utilizadas como fundações de torres de transmissão de energia (autoportantes e estaiadas), contenção de escavações e sistemas de sustentação de túneis. As fundações em estacas helicoidais são ideais para estruturas offshore, devido à facilidade da instalação e ao fato de não haver necessidade concretagem ou de utilização de argamassa.

Segundo Ghaly (1995), acredita-se que a técnica de instalação das estacas metálicas helicoidais é a que causa menor alteração no solo existente.

Prasad e Rao (1994) citam que as estacas sujeitas a carregamento lateral cíclico apresentam redução da resistência ao arrancamento, e que nas estacas metálicas helicoidais esta redução é muito pequena, por isso elas são menos afetadas por este tipo de carregamento do que as outras estacas convencionais, comportando-se melhor neste tipo de situação.

De acordo com Perko et al. (2000), o aspecto mais conveniente deste tipo de fundação é que a sua capacidade de carga pode ser determinada pelo torque de instalação da estaca no solo. A relação entre a capacidade de carga e torque de instalação da estaca helicoidal é experimental e teoricamente estabelecida.

Para Perko et al. (2000) as principais vantagens das estacas metálicas helicoidais em relação aos outros tipos de fundações são as seguintes:

- Resistem ao solapamento em obras de pontes;

- Podem ser removidas em aplicações temporárias;

- São mais fáceis de serem transportadas aos lugares de difícil acesso, comparando-se ao concreto; 
- Pode se determinar a capacidade de carga da fundação por meio de correlações com o torque de instalação;

- Podem ser instaladas em terrenos com elevado nível d’água sem a necessidade de rebaixamento do lençol freático;

- Geralmente levam menos tempo para serem instaladas do que outro tipo de fundação profunda;

- Podem ser instaladas inclinadas para o aumento da resistência lateral;

- Podem ser instaladas com pequenos equipamentos em áreas inacessíveis;

- Durante a instalação o barulho e a vibração são mínimos;

- São galvanizadas para resistirem à corrosão;

- Elimina as visitas de retorno à obra para remover as formas do concreto;

- Não é necessário esperar tempo de cura, este tipo de estaca pode ser carregado imediatamente após a sua instalação;

- Não é retirado solo para bota-fora após a sua instalação.

Segundo Stephenson (2002), as principais vantagens das estacas metálicas helicoidais são:

- $\quad$ Rapidez na instalação;

- $\quad$ Capacidade de ser carregada imediatamente;

- Resistir aos esforços de tração e de compressão simultaneamente. 


\subsubsection{Método de execução}

Rankine (1877) cita que a execução deste tipo de fundação era feita no início por aparafusamento da estaca no solo, com o auxilio homens ou animais, que andavam sobre uma plataforma provisória para fazer a alavanca necessária para a instalação.

No entanto, o método de execução foi modernizado ao longo do tempo, com o desenvolvimento de motores que vieram substituir a força humana e de animais.

De acordo com Clemence et al. (1994), as estacas metálicas helicoidais são instaladas no solo pela aplicação de torque rotacional no sentido horário, aplicado na maioria dos casos por sistema de motor hidráulico de trados mecânicos (Figura 2.8). Aplica-se o torque no tubo que compõe a estaca, por meio de um dispositivo de acoplamento, e as hélices são rotacionadas dentro do terreno com a ajuda de uma pequena força para baixo que é empregada inicialmente para auxiliar a penetração da estaca no solo. A taxa de avanço é igual ao passo da hélice em cada revolução completa. O tubo é prolongado emendando-se extensões com a extremidade alargada para o encaixe e aparafusamento. A estaca é rotacionada no solo até encontrar a camada com a resistência procurada.

Segundo Ghaly e Hanna (1991), a técnica de instalação da estaca helicoidal no solo consiste da aplicação de torque no tubo da estaca, por trado motorizado, ou por outro meio apropriado. Deve-se aplicar inicialmente uma carga axial ao tubo da estaca para a garantia de um avanço constante no solo, igual a um passo de hélice por revolução. Devido à rotação da estaca quando se aplica o torque, forças são transmitidas às hélices, e a estaca penetra no solo e avança para baixo.

Stephenson (2002) relata que a instalação deste tipo de fundação pode ser instalada utilizando-se um caminhão com trado motorizado adaptado (Figura 2.12). A estaca é avançada no solo até o momento em que se encontra a camada apropriada e o valor de torque 
de instalação especificado é atingido. De acordo com a necessidade de penetração no terreno, as extensões são emendadas no tubo guia que contém as hélices.

O torque de instalação especificado em projeto é proporcional à capacidade de carga à tração e à compressão deste tipo de fundação (A. B. Chance Co., 1994).

De acordo com Hoyt e Clemence (1989), o torque de instalação especificado deverá ser o valor de torque médio aplicado para a penetração correspondente a três vezes o diâmetro da maior hélice.

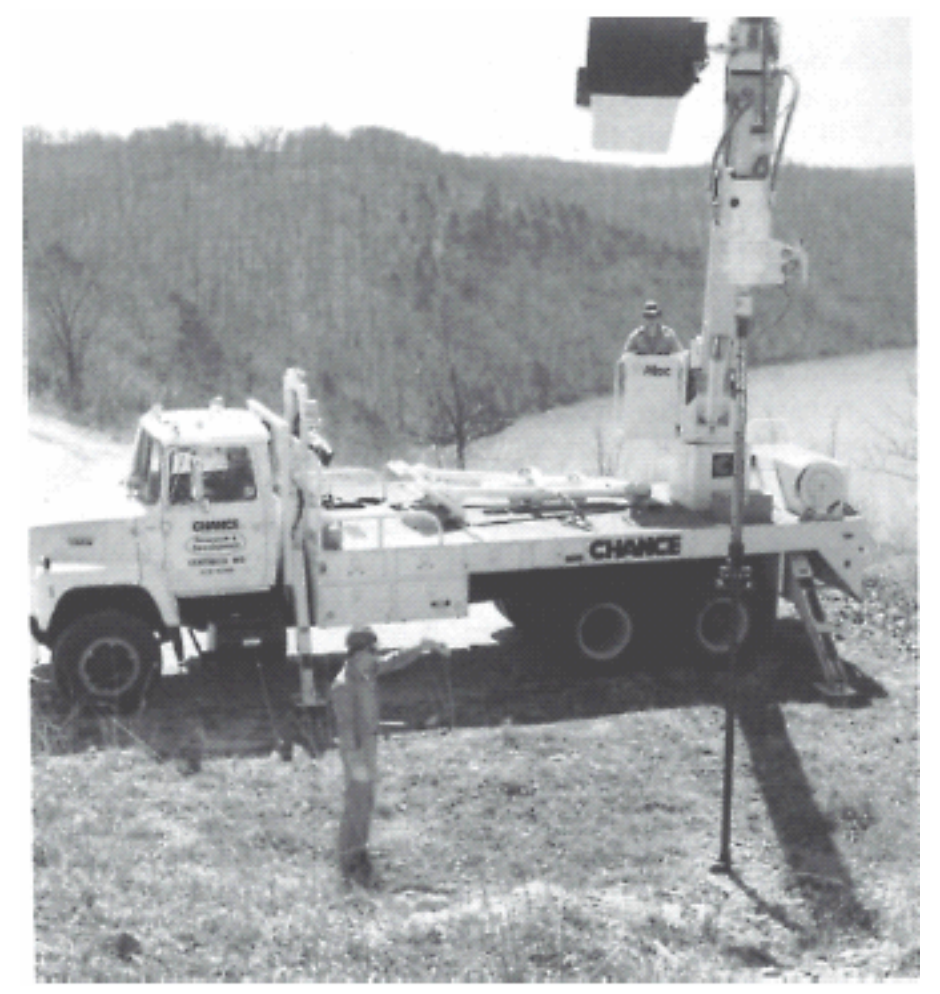

Figura 2.12 - Caminhão adaptado para a instalação de estacas metálicas helicoidais (A. B. Chance Co., 2004)

Conforme Flores et al. (2001), para se instalar este tipo de estaca no solo é necessário um equipamento com sistema hidráulico adequado para se atingir torques de até $12000 \mathrm{lbs} . \mathrm{ft}$ (16,3 kN.m) e rotação entre 13 e $20 \mathrm{rpm}$. De acordo com o manual da A. B. Chance Co. (2004), a estaca helicoidal deve ser instalada com velocidade de rotação constante entre 5 e 
$20 \mathrm{rpm}$. Como a capacidade de carga da fundação é diretamente proporcional ao torque de instalação, quando se atinge o torque requerido, a instalação é paralisada. A leitura do torque é feita por meio de um torquímetro (Figura 2.14). A Figura 2.13 apresenta um equipamento de instalação de estaca metálica helicoidal, com um torquímetro fixado no topo da haste.

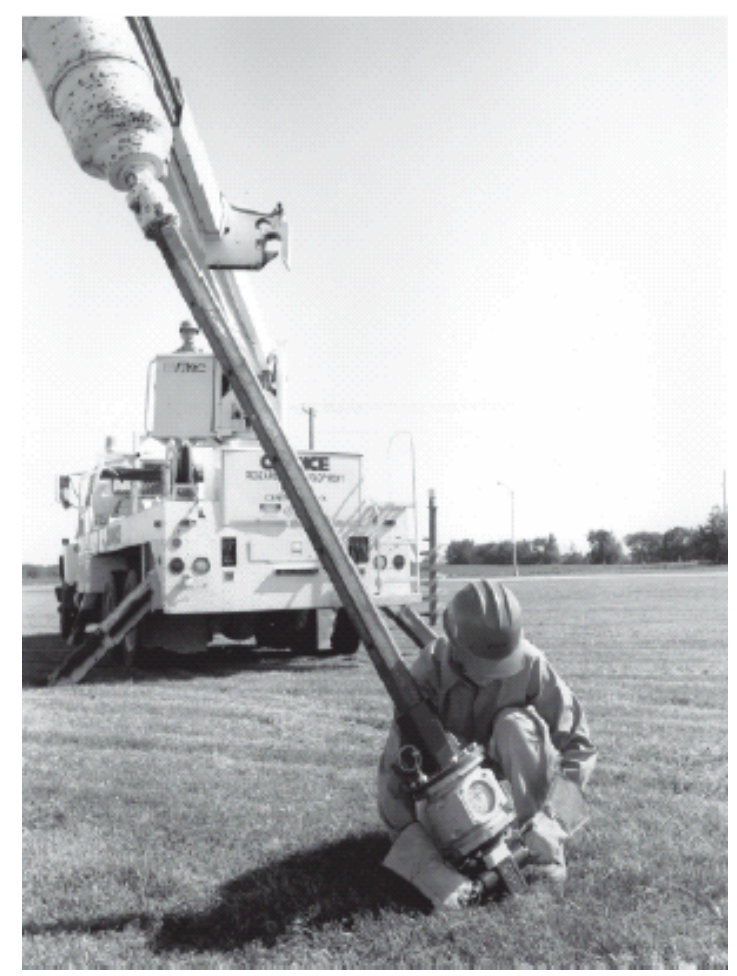

Figura 2.13 - Instalação de estaca metálica helicoidal inclinada (A. B. Chance Co., 2004)

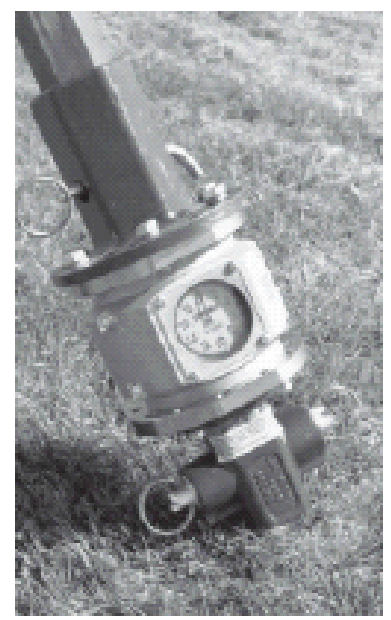

Figura 2.14 - Torquímetro (A. B. Chance Co., 2004) 
Segundo Perko (2000), As estaca metálicas helicoidais são instaladas no solo pela aplicação de torção utilizando-se um caminhão com um trado motorizado adaptado. Em área de acesso limitado, como por exemplo, dentro de edifícios existentes, a instalação pode ser feita utilizando-se um motor portátil para aplicação do torque.

\subsubsection{Métodos de previsão de capacidade de carga à tração}

Segundo Perko et al. (2000), existem três métodos para previsão da capacidade de carga de estacas helicoidais à tração e à compressão. Esses métodos são denominados como:

1) Método da ruptura cilíndrica

2) Método das capacidades de carga individuais

3) Torque de instalação

Perko et al. (2000) sugerem que quando possível, a decisão do engenheiro deve ser baseada nos resultados dos três métodos, considerando a confiabilidade dos parâmetros e dados fornecidos.

O método da ruptura cilíndrica assume que o volume inteiro de solo entre as hélices é mobilizado quando a estaca é solicitada. Deste modo, a capacidade de carga é a combinação da resistência ao cisalhamento do cilindro do solo formado entre as hélices e a capacidade de carga da hélice de topo. No método das capacidades de carga individuais (Figura 2.15), assume-se na ruptura o deslocamento de solo junto a cada hélice. No caso em que o espaçamento entre as hélices é aproximadamente igual a três diâmetros de hélice, os resultados dos dois métodos são aproximados (Perko et al., 2000). 
Conforme Perko et al. (2000), pelo método empírico baseado no torque de instalação, a capacidade de carga deste tipo de fundação é:

$$
Q=K . T
$$

onde:

$\mathrm{K}=$ coeficiente de torque (recomendado pelos fabricantes de estacas)

$\mathrm{T}=$ torque final de instalação

Usualmente para o cálculo de capacidade de carga de fundações rasas adota-se fator de segurança igual a três. No entanto, quando pelo procedimento de instalação é possível medirse indiretamente a capacidade de carga da fundação, permite-se utilizar um fator de segurança menor, como ocorre no caso de estacas cravadas. Como pelo torque de instalação das estacas metálicas helicoidais pode-se avaliar a resistência do solo na profundidade das hélices, é aceita a utilização de um fator de segurança menor para o cálculo de capacidade de carga à tração e à compressão. $\mathrm{O}$ fator de segurança tipicamente utilizado para este tipo de fundação é dois. No entanto, o engenheiro deve escolher o fator de segurança de acordo com o conhecimento das condições do subsolo, a precisão e acurácia do aparelho que mede o torque, a variação das solicitações aplicadas, e outros fatores (Perko et al., 2000).

De acordo com Hoyt e Clemence (1989), os métodos mais utilizados para previsão da capacidade de carga à tração de fundações em estacas metálicas helicoidais multi-hélices são:

1. Método da ruptura do cilindro formado entre as hélices (Figura 2.15). Neste método a resistência à tração da estaca depende da resistência de cisalhamento do cilindro formado entre as hélices de ponta e de topo, e da superfície acima da hélice de topo; 
2. Método das capacidades de carga individuais (Figura 2.15). Este método assume que as rupturas ocorrem acima de cada hélice particularmente, e a resistência à tração da estaca é a soma das capacidades individuais.

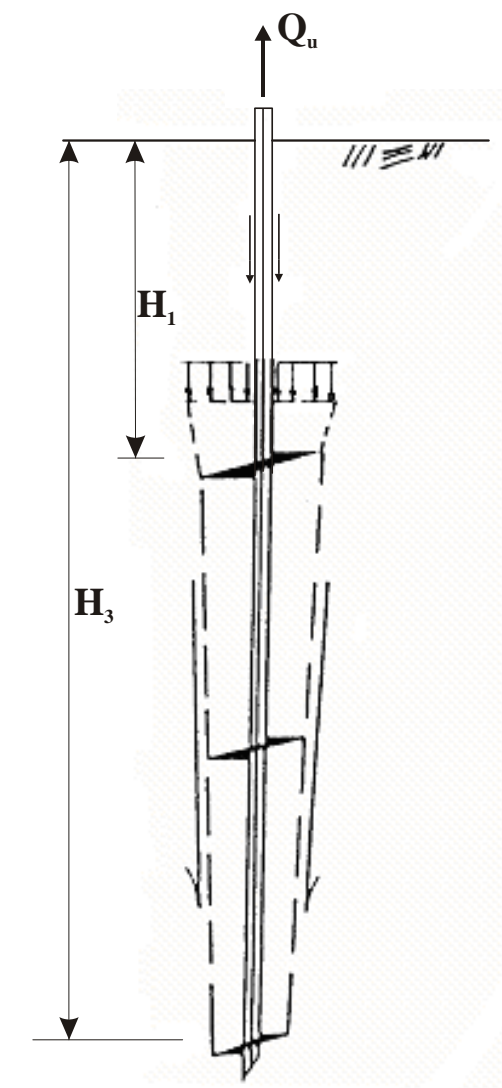

Ruptura do cilindro

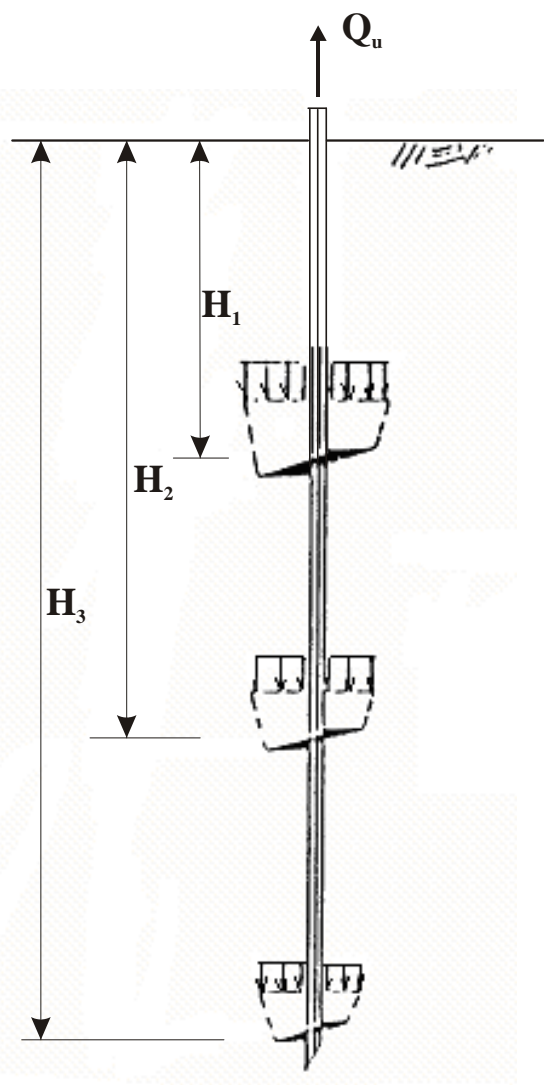

Ruptura das hélices individualmente

Figura 2.15 - Superfícies de ruptura de estacas helicoidais (Clemence et al.,1994)

\subsubsection{Método da ruptura cilíndrica para areia}

De acordo com Das (1990), a Figura 2.16 mostra uma estaca helicoidal multi-hélices instalada em solo arenoso e sujeita a esforço vertical de tração. O diâmetro da hélice de topo é $D_{1}$ e da hélice da ponta é $D_{n}$. A distância entre a superfície do terreno e a hélice do topo é $H_{1}$ e a distância entre a hélice da ponta e o nível do terreno é $H_{n}$. Simplificadamente, a capacidade de carga à tração desta fundação é: 


$$
Q_{u(g)}=Q_{u}+W_{a}
$$

onde:

$\mathrm{Q}_{\mathrm{u}(\mathrm{g})}=$ carga de ruptura

$\mathrm{Q}_{\mathrm{u}}=$ porção da capacidade de carga relativa ao solo

$\mathrm{W}_{\mathrm{a}}=$ peso próprio da estaca



Figura 2.16 - Estaca multi-hélices instalada em areia e sujeita à tração (Das, 1990)

Das (1990) cita que Mitsch e Clemence (1985) estudaram a superfície de ruptura do solo em torno de uma ancoragem helicoidal na carga última por meio de ensaios em modelos 
instalados em areia. A Figura 2.17 mostra o esquema da superfície de ruptura para uma condição em que a razão $\mathrm{H}_{1} / \mathrm{D}_{1}$ é relativamente pequena. Para este caso foi observado que:

- A superfície de ruptura acima da hélice de topo é um cone que encontra a superfície do terreno. O ângulo formado por este cone é proporcional ao ângulo de atrito do solo.

- Abaixo da hélice de topo, a superfície de ruptura do solo é aproximadamente cilíndrica. Isto significa que o solo entre as hélices se comporta de modo similar ao de uma estaca com o cisalhamento ocorrendo ao longo da superfície na interface.

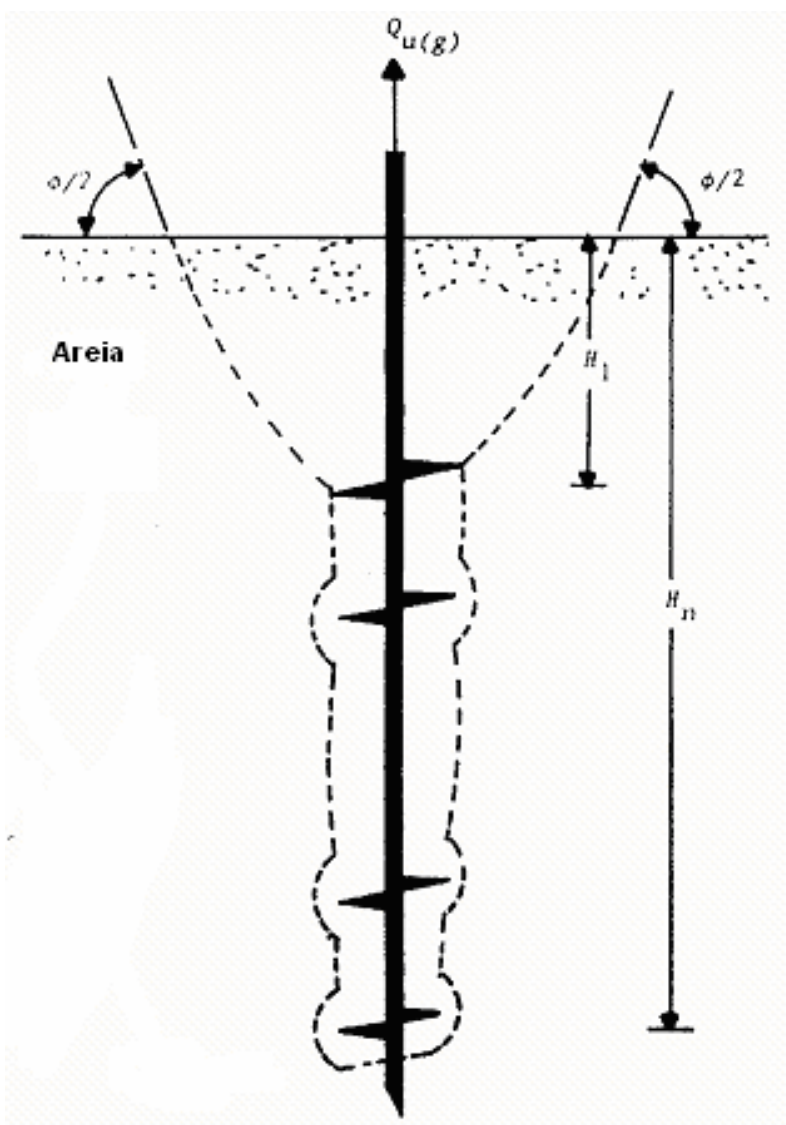

Figura 2.17 - Superfície de ruptura típica em areia de uma ancoragem rasa solicitada à tração (Das, 1990) 
Quando a superfície de ruptura cônica acima da hélice de topo atinge o nível do terreno, denomina-se esta condição de ancoragem rasa. No entanto, quando a razão $\mathrm{H}_{1} / \mathrm{D}_{1}$ apresenta um valor elevado, a superfície de ruptura acima da hélice de topo não irá atingir a superfície do terreno (Figura 2.18), e esta condição é chamada de ancoragem profunda (Das, 1990).

Das (1990) afirma que em solos granulares o valor limite da razão $H_{1} / D_{1}=\left(H_{1} / D_{1}\right)_{c r}$, mudança de condição de ancoragem rasa para ancoragem profunda, é similar ao sugerido por Meyerhof e Adams (1968). A Figura 2.19 apresenta a variação dos valores de $\left(\mathrm{H}_{1} / \mathrm{D}_{1}\right)_{\mathrm{cr}}$ com o ângulo de atrito do solo. De acordo com Mitsch e Clemence (1985), para areias com densidade relativa entre $44 \%$ e $90 \%$, as ancoragens helicoidais com a razão $H_{1} / D_{1}<5$ comportam-se como ancoragens rasas, e as ancoragens com a razão $\mathrm{H}_{1} / \mathrm{D}_{1}>5$ como profundas.

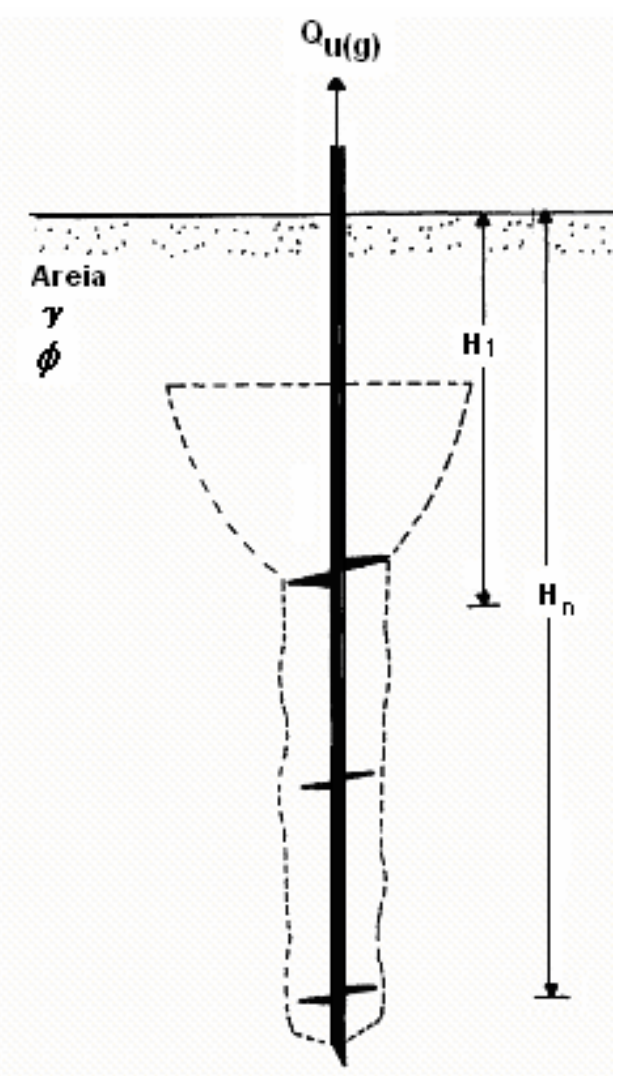

Figura 2.18 - Superfície de ruptura típica em areia de uma estaca multi-hélices em condição de ancoragem profunda (Das, 1990) 




\begin{tabular}{cc}
$\begin{array}{l}\text { Angulo de atrito } \\
\text { do solo } \mathbf{\text { (graus) }}\end{array}$ & $\begin{array}{c}\left(\mathbf{H} / \mathbf{D}_{1} \mathrm{cr}\right. \\
1\end{array}$ \\
\hline & \\
25 & 3 \\
30 & 4 \\
35 & 5 \\
40 & 7 \\
45 & 9 \\
48 & 11 \\
\hline
\end{tabular}

Figura 2.19 - Variação de $\left(\mathrm{H}_{1} / \mathrm{D}_{1}\right)_{\mathrm{cr}}$ com o ângulo de atrito do solo (Das, 1990)

\section{Ancoragens rasas}

De acordo com Das (1990), para condição de ancoragens rasas em areia, tem-se na Figura 2.20 a superfície de ruptura adotada. Deste modo, a porção da carga de ruptura da estaca à tração, relativa somente à ruptura do solo $\left(\mathrm{Q}_{\mathrm{u}}\right)$, estimada de acordo com Mitsch e Clemence (1985) é:

$$
Q_{u}=Q_{p}+Q_{f}
$$


onde:

$\mathrm{Q}_{\mathrm{p}}=$ resistência à ruptura acima da hélice de topo

$\mathrm{Q}_{\mathrm{f}}=$ resistência por atrito na superfície cilíndrica formada entre as hélices de ponta e de topo

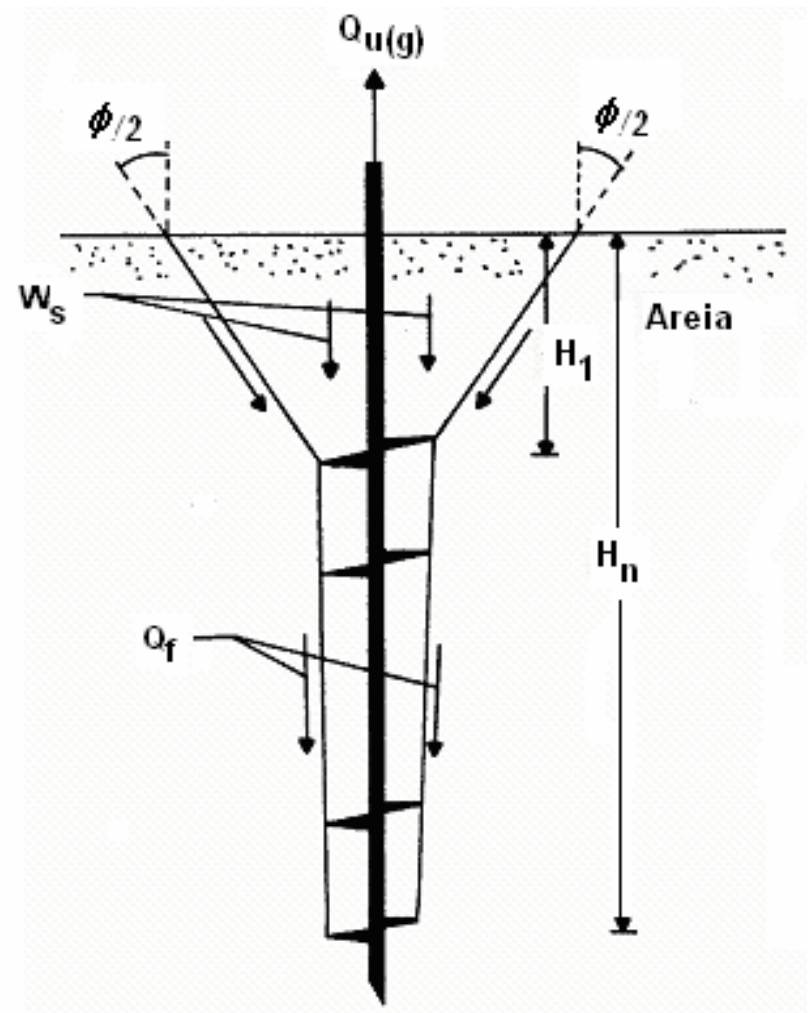

Figura 2.20 - Superfície de ruptura adotada em areias para condição de ancoragem rasa:

$$
\mathrm{H}_{1} / \mathrm{D}_{1} \leq\left(\mathrm{H}_{1} / \mathrm{D}_{1}\right)_{\mathrm{cr}},(\text { Das, } 1990)
$$

A magnitude de $\mathrm{Q}_{\mathrm{p}}$ é dada por:

$$
Q_{p}=\pi \gamma^{\prime} K_{u}(\tan \phi)\left[\cos ^{2}\left(\frac{\phi}{2}\right)\right]\left[\frac{D_{1} H_{1}^{2}}{2}+\frac{H_{1}^{3} \tan \left(\frac{\phi}{2}\right)}{3}\right]+W_{s}
$$

onde:

$\gamma^{\prime}=$ peso específico efetivo do solo 
$\phi=$ ângulo de atrito do solo

$\mathrm{K}_{\mathrm{u}}=$ coeficiente de empuxo à tração

$\mathrm{W}_{\mathrm{s}}=$ peso do solo dentro da superfície de ruptura

O peso do solo $\mathrm{W}_{\mathrm{s}}$ pode ser expresso por:

$$
W_{s}=\gamma^{\prime}\left\{\frac{\pi}{3} H_{1}\left[\left(D_{1}\right)^{2}+\left(D_{1}+2 H_{1} \tan \frac{\phi}{2}\right)^{2}+\left(D_{1}\right)\left(D_{1}+2 H_{1} \tan \frac{\phi}{2}\right)\right]\right\}
$$

A resistência por atrito ao longo da superfície cilíndrica formada entre as hélices de topo e de ponta é dada por:

$$
Q_{f}=\frac{\pi}{2} D_{a} \gamma^{\prime}\left(H_{n}{ }^{2}-H_{1}^{2}\right) K_{u} \tan \phi
$$

onde:

$\mathrm{D}_{\mathrm{a}}=$ diâmetro médio das hélices $=\left(D_{1}+D_{n}\right) / 2$

Deste modo, a carga de ruptura da estaca à tração pode ser dada pelas Equações 2.3, $2.4 \mathrm{e}$ 2.6:

$$
\mathrm{Q}_{\mathrm{u}}=\pi \gamma^{\prime} K_{u}(\tan \phi)\left[\cos ^{2}\left(\frac{\phi}{2}\right)\right]\left[\frac{D_{1} H_{1}^{2}}{2}+\frac{H_{1}^{3} \tan \left(\frac{\phi}{2}\right)}{3}\right]+W_{s}+\frac{\pi}{2} D_{a} \gamma^{\prime}\left(H_{n}{ }^{2}-H_{1}{ }^{2}\right) K_{u} \tan \phi
$$

Mitsch e Clemence (1985) recomendam os valores de $K_{u}$ mostrados na Tabela 2.1 e na Figura 2.21 para ancoragens helicoidais submetidas à tração. 
Tabela 2.1 - Valores de $\mathrm{K}_{\mathrm{u}}$ para alguns ângulos de atrito de solo $\phi$ (Mitsch e Clemence, 1985)

\begin{tabular}{cc}
\hline $\begin{array}{c}\text { Ângulo de atrito do solo } \phi \\
\text { (graus) }\end{array}$ & $\begin{array}{c}\text { Valores recomendados de } \mathrm{K}_{\mathrm{u}} \\
\text { para ancoragens helicoidais }\end{array}$ \\
\hline 25 & 0,70 \\
30 & 0,90 \\
35 & 1,50 \\
40 & 2,35 \\
45 & 3,20 \\
\hline
\end{tabular}

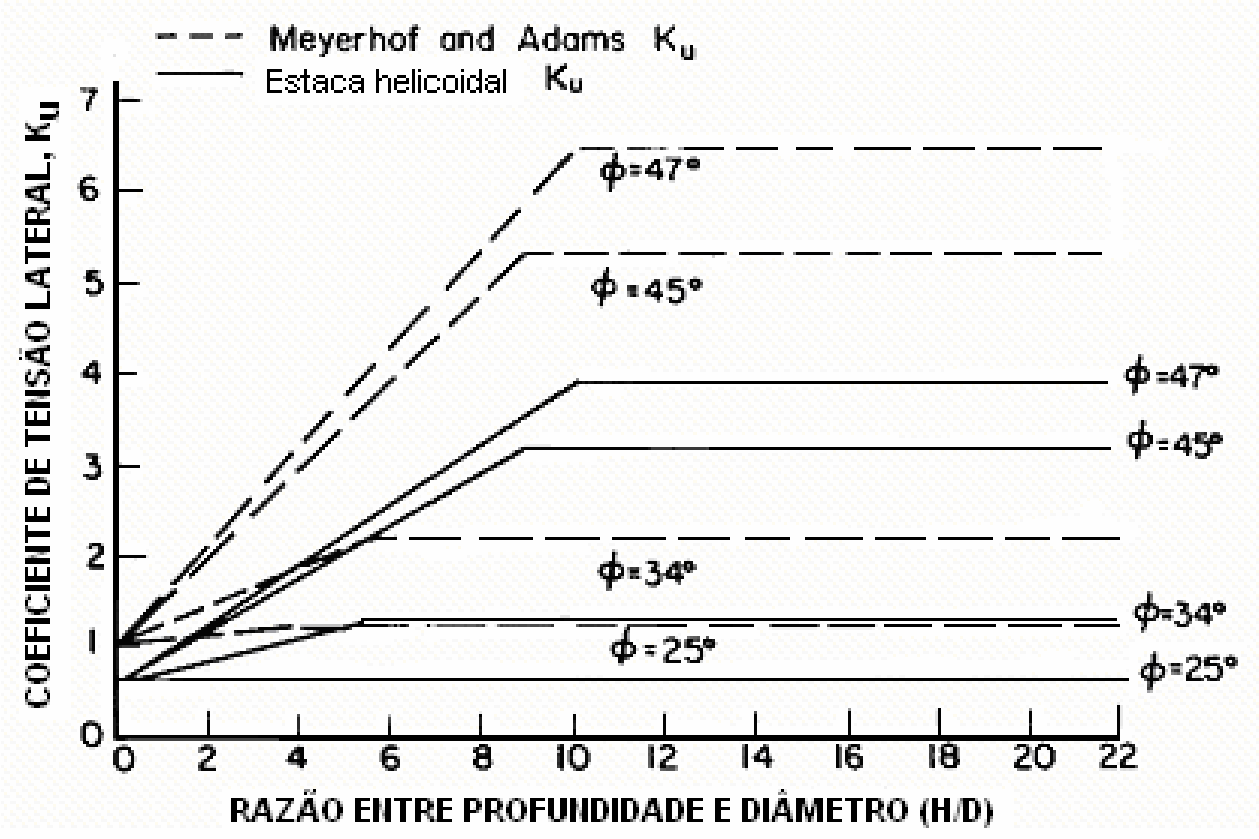

Figura 2.21 - Valores recomendados de coeficiente de empuxo à tração $\left(\mathrm{K}_{\mathrm{u}}\right)$ para fundações em estacas helicoidais solicitadas à tração (Mitsch e Clemence, 1985) 


\section{Ancoragens profundas}

Segundo Das (1990), a Figura 2.22 apresenta a superfície de ruptura idealizada em um solo em torno de uma ancoragem helicoidal profunda instalada na areia. Para esta condição, de acordo com Mitsch e Clemence (1985) a carga de ruptura à tração da ancoragem $\mathrm{Q}_{\mathrm{u}}$ será:

$$
Q_{u}=Q_{p}+Q_{f}+Q_{s}
$$

onde:

$\mathrm{Q}_{\mathrm{p}}=$ resistência à ruptura acima da hélice de topo

$\mathrm{Q}_{\mathrm{f}}=$ resistência por atrito na superfície cilíndrica formada entre as hélices de ponta e de topo $\mathrm{Q}_{\mathrm{s}}=$ resistência por atrito entre o tubo da ancoragem e o solo acima da hélice de topo

A resistência $Q_{p}$ acima da hélice de topo pode ser determinada em termos do fator $N_{q u}$ do seguinte modo:

$$
Q_{p}=\frac{\pi}{4} N_{q u} \gamma^{\prime} D_{1}^{2} H_{1}
$$

onde:

$\mathrm{N}_{\mathrm{qu}}=$ fator de capacidade de carga à tração

A Figura 2.23, citada em Mitsch e Clemence (1985), mostra valores do fator de capacidade de carga à tração $\mathrm{N}_{\mathrm{qu}}$ de Meyerhof e Adams (1968) e encontrados por outros pesquisadores na literatura. 


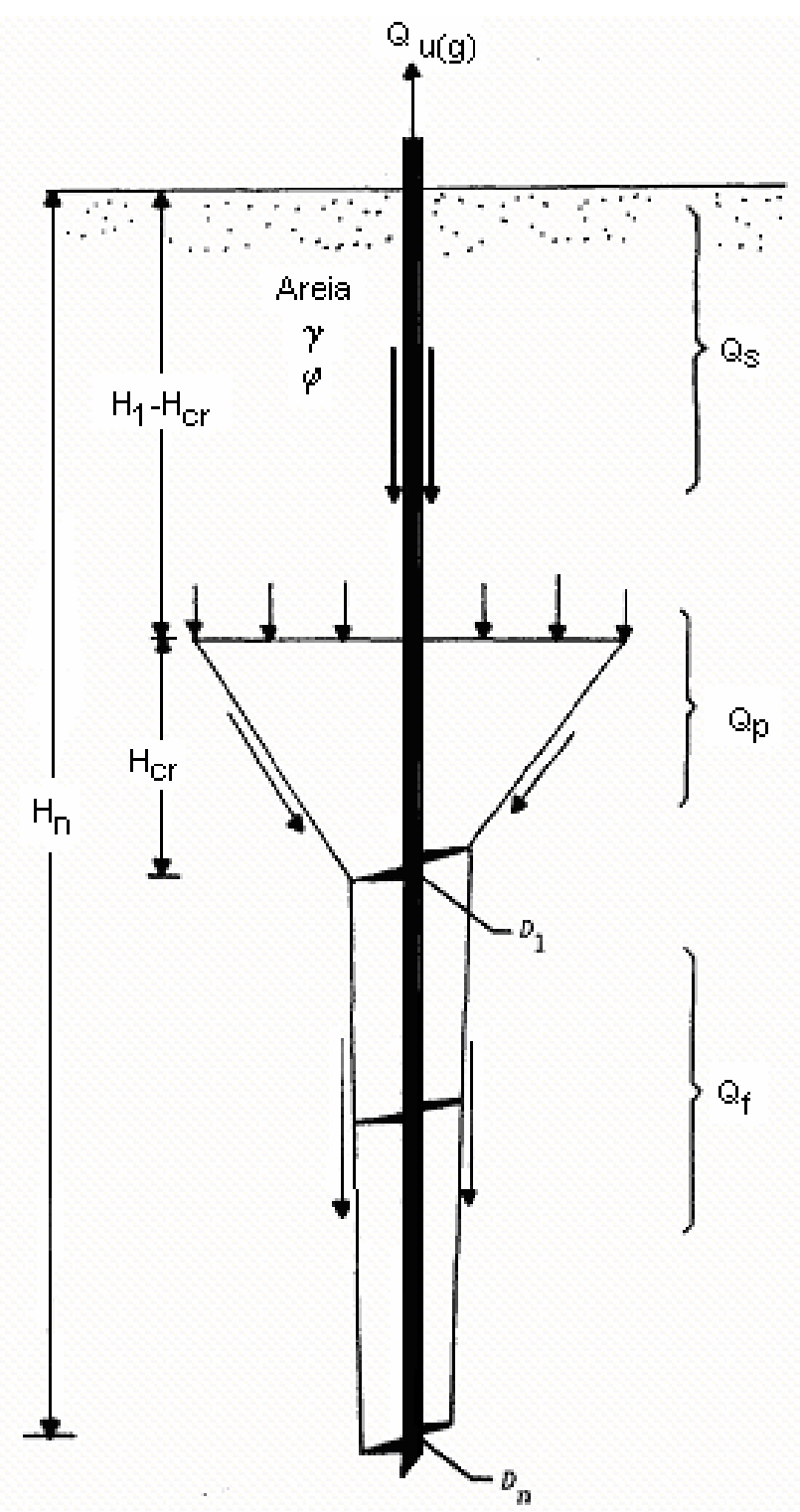

Figura 2.22 - Superfície de ruptura adotada em areias para condição de ancoragem profunda (Das, 1990)

A resistência de atrito ao longo da superfície cilíndrica formada entre as hélices de topo e de ponta, para ancoragens profundas é dada por:

$$
Q_{f}=\frac{\pi}{2} D_{a} \gamma^{\prime}\left(H_{n}^{2}-H_{1}^{2}\right) K_{u} \tan \phi
$$

onde:

$\mathrm{D}_{\mathrm{a}}=$ diâmetro médio das hélices $=\left(D_{1}+D_{n}\right) / 2$ 




Figura 2.23 - Fator de capacidade de carga à tração $\left(\mathrm{N}_{\mathrm{qu}}\right)$ versus razão H/D para estacas helicoidais em areia (Mitsch e Clemence, 1985)

A resistência de atrito entre o tubo da ancoragem e o solo acima da hélice de topo é dada por:

$$
Q_{s}=P_{s} H_{1}\left(\frac{\gamma^{\prime} H_{1}}{2}\right) K_{u} \tan \phi
$$

onde:

$\mathrm{P}_{\mathrm{s}}=$ perímetro do tubo da estaca

Deste modo, substituindo-se as Equações 2.9, 2.10 e 2.11 na Equação 2.8, tem-se que a carga de ruptura à tração de uma ancoragem profunda é: 


$$
Q_{u}=\frac{\pi}{4} N_{q u} \gamma^{\prime} D_{1}^{2} H_{1}+\frac{\pi}{2} D_{a} \gamma^{\prime}\left(H_{n}^{2}-H_{1}^{2}\right) K_{u} \tan \phi+P_{s} H_{1}\left(\frac{\gamma^{\prime} H_{1}}{2}\right) K_{u} \tan \phi
$$

\subsubsection{Método das capacidades de carga individuais para areia}

De acordo com Clemence et al. (1994), o método da A. B. Chance Company assume que a ruptura ocorre sobre cada hélice individualmente e a capacidade de carga total é dada pela soma das resistências individuais acima de cada hélice. A relação entre ângulo de atrito e o fator de capacidade de carga $\mathrm{N}_{\mathrm{q}}$ é utilizada para definir a resistência à tração. Deste modo, para cálculo de capacidade de carga de ancoragens profundas em areias, tem-se:

$$
Q_{u}=\sum_{n=1}^{n} A_{h} \bar{q} N_{q}
$$

onde:

$\mathrm{Q}_{\mathrm{u}}=$ capacidade de carga à tração

$\mathrm{A}_{\mathrm{h}}=$ área da hélice projetada

$\bar{q}=$ pressão efetiva do solo acima da hélice

$\mathrm{n}=$ número de hélices

$\mathrm{N}_{\mathrm{q}}=$ fator de capacidade de carga

No manual técnico da A. B. Chance Co. (1994) está citado que a carga última de uma fundação multi-hélice é igual à soma das capacidades individuais de cada hélice (Equação 2.14). No entanto, é sugerido neste manual que para estacas com hastes de diâmetro maior que $89 \mathrm{~mm}$ a resistência por atrito na haste deva ser considerada. Para que este método apresente resultados coerentes, é necessário que o espaçamento entre as hélices seja grande o suficiente para evitar sobreposição das zonas de tensão. A. B. Chance Company fabrica 
estacas com o espaçamento entre as hélices iguais a três diâmetros da mesma. De acordo com a experiência da A. B. Chance Company, esta distância entre hélices tem mostrado ser suficiente para prevenir a influência de uma hélice no comportamento de outra.

Para determinar a capacidade de carga individual de cada hélice, utiliza-se a Equação 2.15.

$$
Q_{t}=\sum Q_{h}
$$

onde:

$\mathrm{Q}_{\mathrm{t}}=$ capacidade de carga total da ancoragem multi-hélices

$\mathrm{Q}_{\mathrm{h}}=$ capacidade de carga individual de cada hélice

$$
Q_{h}=A_{h} \bar{q} N_{q} \leq Q_{s}
$$

onde:

$\mathrm{Q}_{\mathrm{h}}=$ capacidade de carga individual de cada hélice

$\mathrm{A}_{\mathrm{h}}=$ área projetada da hélice em um plano perpendicular ao eixo do tubo

$\bar{q}=$ pressão efetiva do solo acima da hélice

$\mathrm{N}_{\mathrm{q}}=$ fator de capacidade de carga (Figura 2.24)

$\mathrm{Q}_{\mathrm{s}}=$ limite superior determinado pela resistência da hélice 


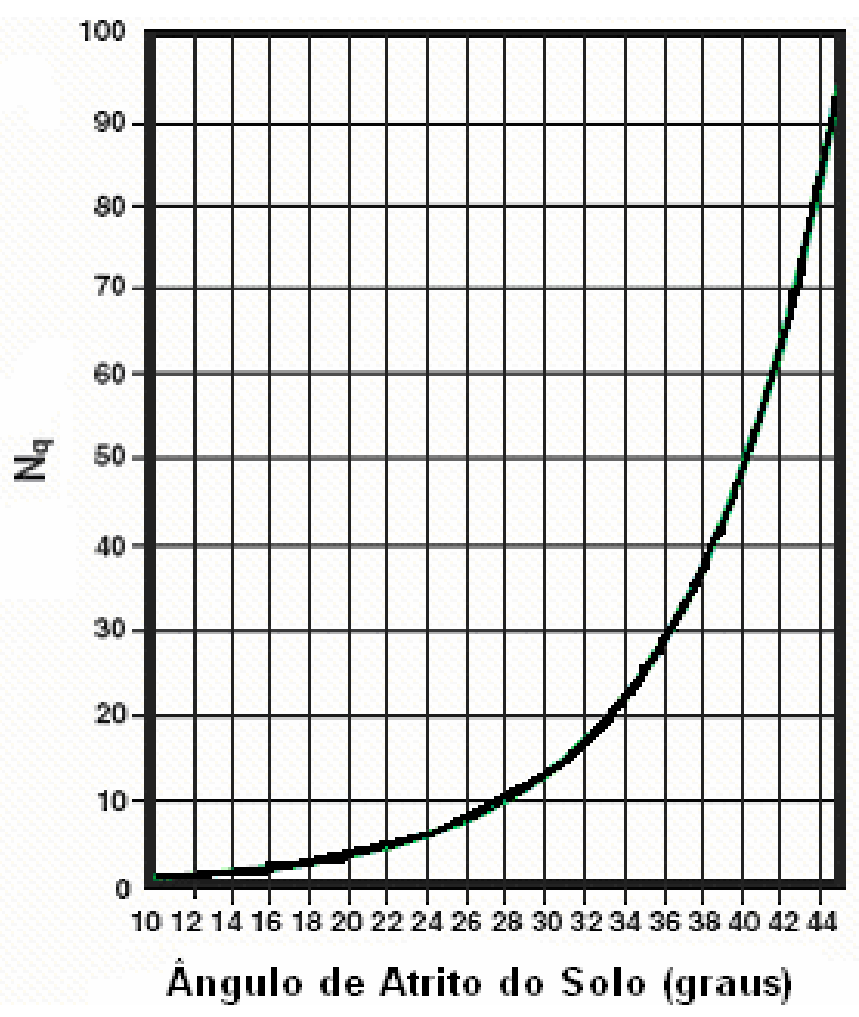

FIGURA 2.24 - Fator de capacidade de carga para areia

(A. B. Chance Co., 1994)

\subsubsection{Método empírico}

Wilson (1950) realizou um trabalho para verificar a relação entre o torque necessário para instalar uma estaca e sua capacidade de carga. Este autor observou que embora seja óbvio que exista uma relação entre o torque requerido para a instalação da estaca e sua capacidade de carga, esta relação é demasiadamente errática para ser utilizada em projetos de fundações. Esta conclusão foi formulada, após tentativas sem sucesso, para estimar-se a capacidade de carga de estacas instaladas por observação das características da instalação.

No entanto, a idéia de que o torque requerido para a instalação deste tipo de fundação é proporcional à capacidade de carga à tração e à compressão, tem sido difundida pela A. B. Chance Company (empresa fabricante e executora de estacas metálicas helicoidais). 
Clemence et al. (1994) relatam que um procedimento empírico têm sido desenvolvido pela A. B. Chance Company, no qual a capacidade de carga à tração pode ser estimada com base no valor médio do torque de instalação da estaca, correspondente à penetração final igual a três vezes o diâmetro da maior hélice da estaca.

No manual técnico da A. B. Chance Co. (1994), está citado que uma simples relação empírica tem sido utilizada por alguns anos. A Equação 2.16 apresenta a fórmula empírica que relaciona o torque de instalação com a capacidade de carga:

$$
Q_{u}=K_{t} \times T
$$

onde:

$\mathrm{Q}_{\mathrm{u}}=$ capacidade de carga à tração (em lb ou kN)

$\mathrm{K}_{\mathrm{t}}=$ fator empírico de torque $\left(\mathrm{em} \mathrm{ft}^{-1} \mathrm{ou} \mathrm{m}^{-1}\right)$

$\mathrm{T}=$ torque final de instalação

$\mathrm{O}$ valor de $\mathrm{K}_{\mathrm{t}}$ deve variar de 3 a $20 \mathrm{ft}^{-1}\left(10\right.$ a $\left.66 \mathrm{~m}^{-1}\right)$, dependendo das condições do solo e da geometria da estaca helicoidal (A. B. Chance Co., 1994).

Hoyt e Clemence (1989) citam que o fator empírico de torque $\mathrm{K}_{\mathrm{t}}$ é igual a: $10 \mathrm{ft}^{-1}\left(33 \mathrm{~m}^{-1}\right)$ para estacas com tubos de seção quadrada e circular de diâmetro menor que 3,5 in (89 mm), 7 $\mathrm{ft}^{-1}\left(23 \mathrm{~m}^{-1}\right)$ para estacas com tubos de seção circular de diâmetro igual a 3,5 in $(89 \mathrm{~mm})$, e 3 $\mathrm{ft}^{-1}\left(9,8 \mathrm{~m}^{-1}\right)$ para estacas com tubos de extensão (acima da hélice de topo) de seção circular de diâmetro igual a 8,63 in $(219 \mathrm{~mm})$.

$\mathrm{O}$ valor do fator empírico de torque $\mathrm{K}_{\mathrm{t}}$ da estaca helicoidal, para estacas com seção quadrada com dimensões menores que 2 in $(50,8 \mathrm{~mm})$, recomendado por Hoyt e Clemence, (1989) é igual a $10 \mathrm{ft}^{-1}\left(33 \mathrm{~m}^{-1}\right)$. Fabricantes de estacas helicoidais recomendam que os valores de $\mathrm{K}_{\mathrm{t}}$ devem ser utilizados para estacas com outras dimensões. A Ingal Precision Foundations 
Inc. recomenda valores de $\mathrm{K}_{\mathrm{t}}$ iguais a $9 \mathrm{ft}^{-1}$ e $7 \mathrm{ft}^{-1}$ para estacas com tubos de diâmetros $2^{1 / 2}$ in $(63,5 \mathrm{~mm})$ e 3 in $(76,2 \mathrm{~mm})$ respectivamente (Perko et al., 2000).

Perko et al. (2000) citam que pesquisas anteriores indicam que o fator $\mathrm{K}_{\mathrm{t}}$ deva depender da profundidade da estaca. Outros trabalhos mostram que o valor de $K_{t}$ independe do raio da hélice, e depende significantemente do diâmetro do tubo da estaca. Outras pesquisas apontam que o fator $\mathrm{K}_{\mathrm{t}}$ varia pouco com o número de hélices da estaca.

A Figura 2.25 apresenta o comportamento do torque de instalação de estacas helicoidais em areia com o aumento de $\mathrm{N}_{\mathrm{SPT}}$. De acordo com esta figura, o valor do torque para um dado valor de $\mathrm{N}_{\mathrm{SPT}}$ aumenta com a profundidade da estaca. A posição do nível d'água afeta diretamente o torque de instalação e a capacidade de carga da estaca por causar redução no peso unitário efetivo do solo abaixo deste nível. Em estacas abaixo do nível d'água ocorre diminuição do torque de instalação e da capacidade de carga da estaca.

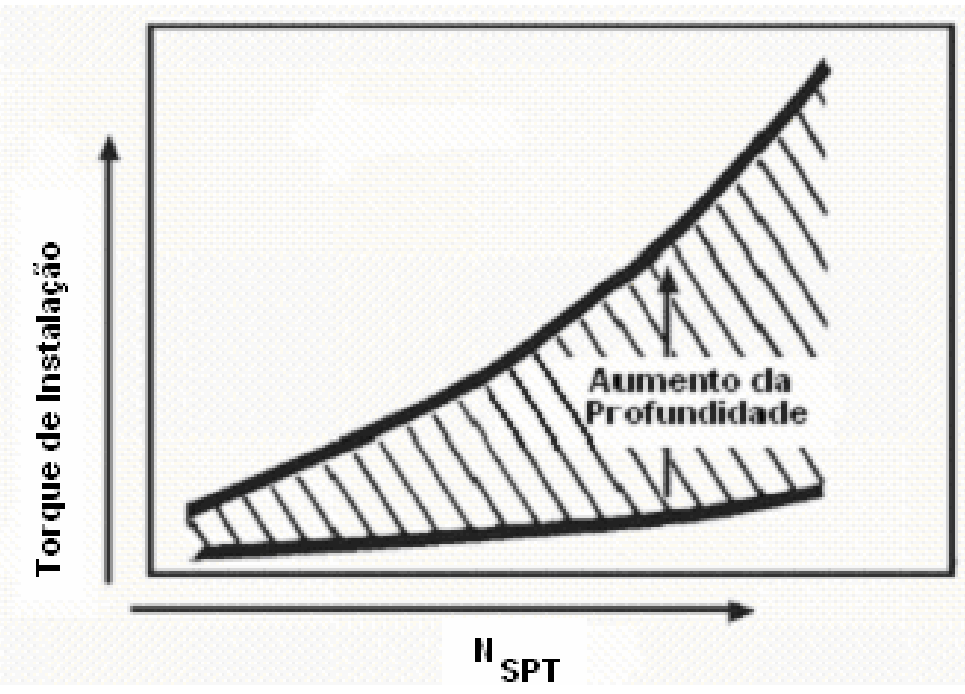

Figura 2.25 - Torque de instalação x valor $\mathrm{N}_{\mathrm{SPT}}$ de estaca instalada na areia

(A. B. Chance Co., 1994)

Além dos dois métodos teóricos (método da ruptura cilíndrica e método das capacidades de carga individuais), existe um terceiro método para o cálculo de capacidade de carga à 
tração de estacas helicoidais. Este terceiro método, que é freqüentemente utilizado para previsão da resistência á tração de uma estaca helicoidal, baseia-se na correlação entre o torque de instalação da estaca e sua capacidade de carga à tração, ou seja, na relação entre o esforço para se instalar uma estaca com a sua resistência ao arrancamento. Este método foi desenvolvido empiricamente, e atualmente existe a carência de seu esclarecimento baseado em conceitos da geotecnia tradicional. No entanto, esta regra empírica tem sido utilizada com sucesso na construção de milhares de ancoragens nos últimos 20 anos (Hoyt e Clemence, 1989).

\subsubsection{Torque de instalação $\mathrm{x}$ capacidade de carga à tração em areia}

Como visto anteriormente nesta revisão bibliográfica, a capacidade de carga de estacas helicoidais pode ser prevista por meio de correlações empíricas com o torque de instalação da estaca. Além dos métodos empíricos, existem diferentes correlações teóricas reportadas na literatura (Ghaly et al., 1991b; Ghaly e Hanna, 1991; Perko, 2000; e Narasimha Rao et al., 1989). Neste item são descritos apenas os métodos adequados para solos arenosos.

O primeiro método apresentado (item 2.2.5.1) é o de Ghaly et al.(1991b). A relação proposta por estes autores é um modelo simples para o controle em campo da capacidade de carga de estacas helicoidais com uma hélice instaladas em areia. No entanto, como esta relação não considera o atrito lateral na haste da estaca nas fases de instalação e de carregamento à tração, os resultados medidos para estacas mais profundas não apresentam boa concordância com os resultados calculados por este modelo (Figura 2.29).

O item 2.2.5.2 mostra a correlação de Ghaly e Hanna (1991) para estacas helicoidais instaladas em areia seca. Nas Figuras 2.33 e 2.34 têm-se as comparações entre resultados medidos e previstos por esta correlação. Por meio destas figuras observa-se que grande parte 
dos resultados obtidos experimentalmente não é explicada pela relação entre fator de capacidade de carga e fator de torque proposta por estes autores.

A relação proposta por Perko (2000) no item 2.2.5.3, baseada na equivalência entre as energias de carregamento e de penetração da estaca, é recomendada para qualquer tipo de solo e configuração de estaca helicoidal. Contudo, nota-se pela Figura 2.41, que esta relação não é válida para um grande número de resultados medidos na literatura.

\subsubsection{Método de Ghaly et al. (1991b)}

Ghaly et al. (1991b) apresentaram uma relação teórica entre o torque de instalação e a capacidade de carga à tração de uma ancoragem helicoidal com uma hélice instalada em areia. Para verificação deste método foram realizados ensaios em cinco diferentes modelos reduzidos de ancoragens helicoidais, com variadas as configurações dos passos das hélices (Figura 2.26). Neste trabalho as estacas foram instaladas em um tanque (seção de $1,00 \mathrm{~m} \mathrm{x}$ 0,70m e $1,25 \mathrm{~m}$ de altura) preenchido com areia seca (três diferentes densidades: compacta, medianamente compacta e fofa). Para obter os pesos específicos desejados, a areia foi compactada em camadas de $150 \mathrm{~mm}$. As características das areias utilizadas são apresentadas na Tabela 2.2.

Tabela 2.2 - Propriedades da areia testada (Ghaly et al., 1991b)

\begin{tabular}{lcc}
\hline & Propriedade & Valor \\
\hline Areia compacta & Peso específico & $16,7 \mathrm{kN} / \mathrm{m}^{3}$ \\
& Ângulo de atrito & $40^{\circ}$ \\
\hline Areia medianamente & Peso específico & $16,2 \mathrm{kN} / \mathrm{m}^{3}$ \\
compacta & Ângulo de atrito & $35^{\circ}$ \\
\hline Areia fofa & Peso específico & $15,7 \mathrm{kN} / \mathrm{m}^{3}$ \\
& Ângulo de atrito & $30^{\circ}$ \\
\hline
\end{tabular}



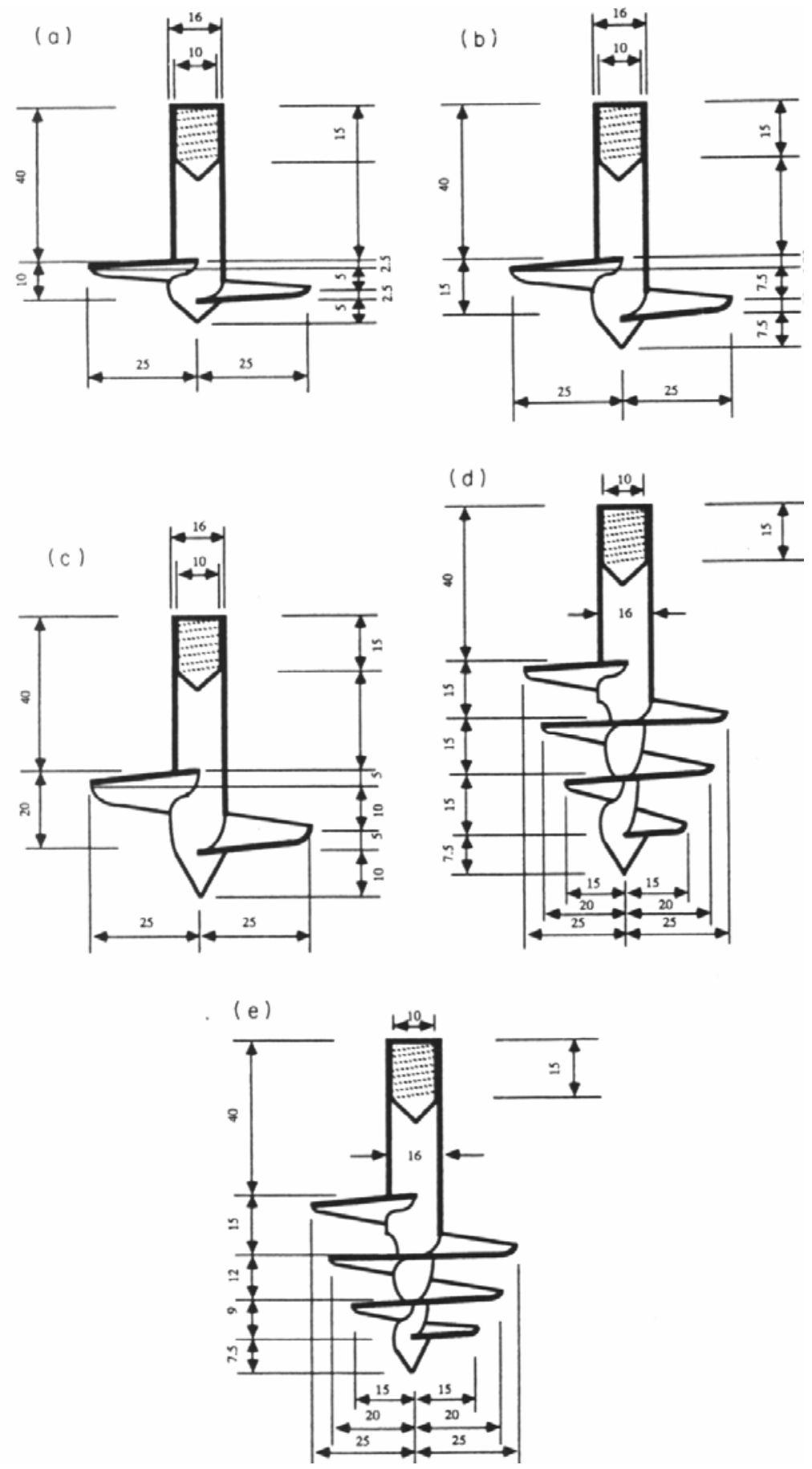

Figura 2.26 - (a) Ancoragem helicoidal com um passo, passo pequeno. (b) Ancoragem helicoidal com um passo, passo médio. (c) Ancoragem helicoidal com um passo, passo largo. (d) Ancoragem helicoidal multi-passos, passos iguais e hélices assimétricas. (e) Ancoragem helicoidal multi-passos, passos variáveis e hélices paralelas. Dimensões em milímetros (Ghaly et al., 1991b). 
As ancoragens foram instaladas em diferentes profundidades por meio de torque medido a cada $25 \mathrm{~mm}$ de penetração. Após a instalação as ancoragens foram tracionadas e os valores das cargas de ruptura foram medidos.

\section{Relação teórica entre torque de instalação e capacidade de carga}

De acordo com Ghaly et al. (1991b), o torque aplicado à estaca é resistido por um sistema de forças agindo na superfície superior da hélice. No caso de ancoragens rasas estas forças são o peso da areia dentro da superfície de ruptura e a componente vertical do empuxo de terra que age na superfície de ruptura. No caso de ancoragens profundas, estas forças são o peso da areia, a componente vertical do empuxo de terra que age na superfície de ruptura e a força resultante do confinamento da face superior da superfície de ruptura assumida.

Estes autores afirmam que este sistema de forças $(F)$ que se desenvolvem devido à penetração impedida da hélice é igual à capacidade de carga à tração de uma estaca helicoidal com uma hélice para uma mesma profundidade. A Figura 2.27 mostra as superfícies de ruptura da areia acima da hélice durante a instalação da estaca e na fase de carregamento à tração.

A Figura 2.28 mostra as forças que agem em um ponto (o) de uma hélice desenvolvida durante a aplicação do torque de instalação da ancoragem em areia. As forças desenvolvidas devido à rotação da ancoragem sem penetração são: força vertical $(F)$, força de atrito $(\mu N)$, e força normal ao plano inclinado $(\mathrm{N})$ para satisfazer as condições de equilíbrio estático. As forças desta figura estão em equilíbrio descrito pelas seguintes equações:

$$
\begin{aligned}
& R-N \cdot \operatorname{sen} \psi-\mu N \cdot \cos \psi=0 \\
& F+\mu N \cdot \operatorname{sen} \psi-N \cdot \cos \psi=0
\end{aligned}
$$


onde:

$\mathrm{N}=$ força normal ao plano inclinado da hélice desenvolvida

$\mathrm{R}=$ força aplicada para vencer a resistência por atrito atuante na hélice

$\psi=$ ângulo da hélice

A partir das Equações 2.17 e 2.18, considerando que $\mu=\tan \lambda$ (neste trabalho $\lambda$ é o ângulo de atrito na interface hélice/areia, e foi estimado como $0.6 \phi$, onde $\phi$ é o ângulo de atrito da areia) obteve-se a expressão abaixo:

$$
R=F \cdot \tan (\psi+\lambda)
$$

onde:

$\psi=\tan ^{-1}\left(p / \pi B_{r}\right) \quad($ Figura 2.28)

$\lambda=0.6 \phi(\mu=\tan \lambda)$

O diâmetro do círculo correspondente à superfície da hélice $\left(\mathrm{B}_{\mathrm{r}}\right)$, onde as forças se equilibram, é dado por:

$$
B_{r}=\frac{2}{3}\left[\frac{B^{3}-d^{3}}{B^{2}-d^{2}}\right]
$$

onde:

$\mathrm{B}=$ diâmetro externo da hélice

$\mathrm{d}=$ diâmetro interno da hélice 

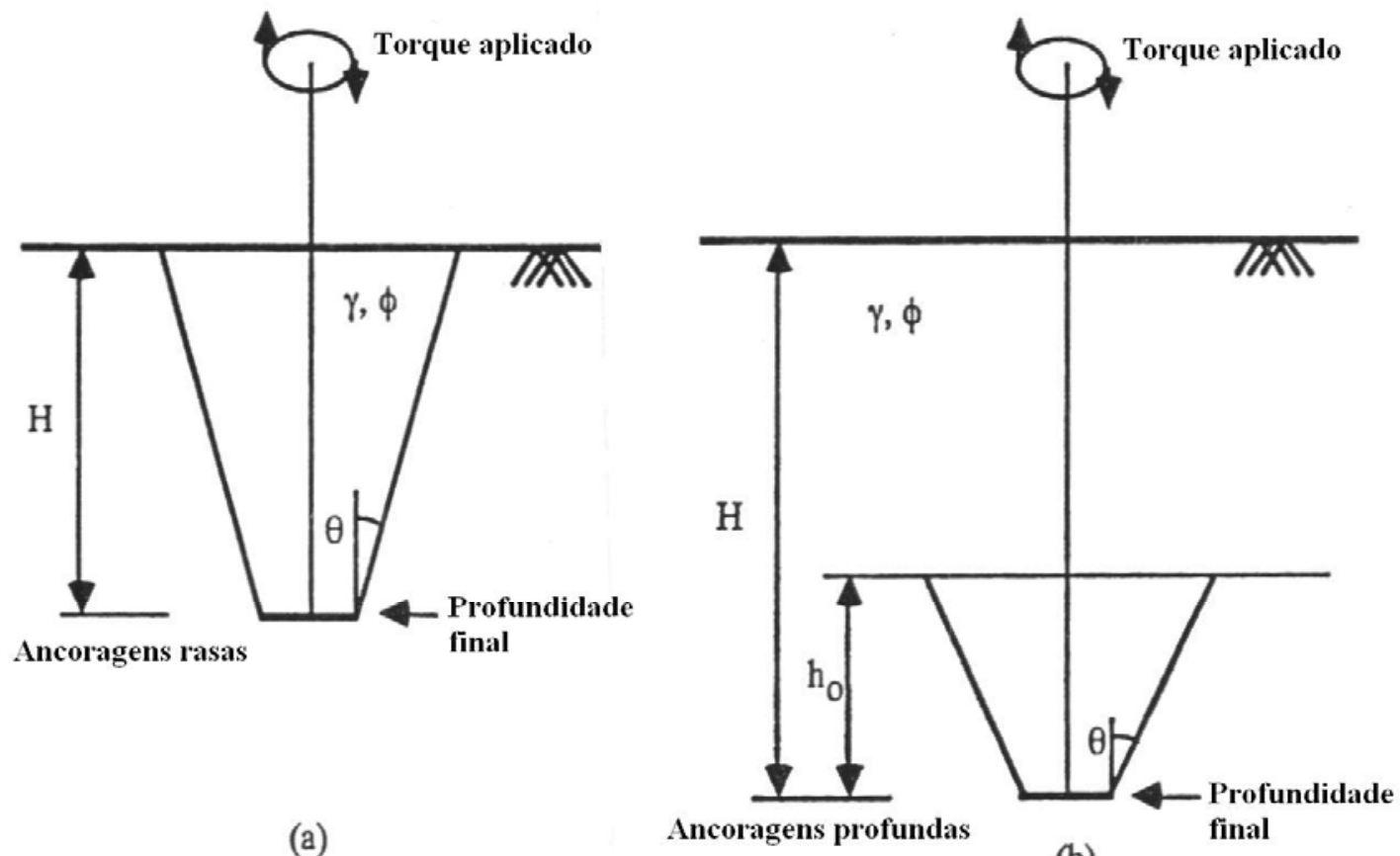

(a)
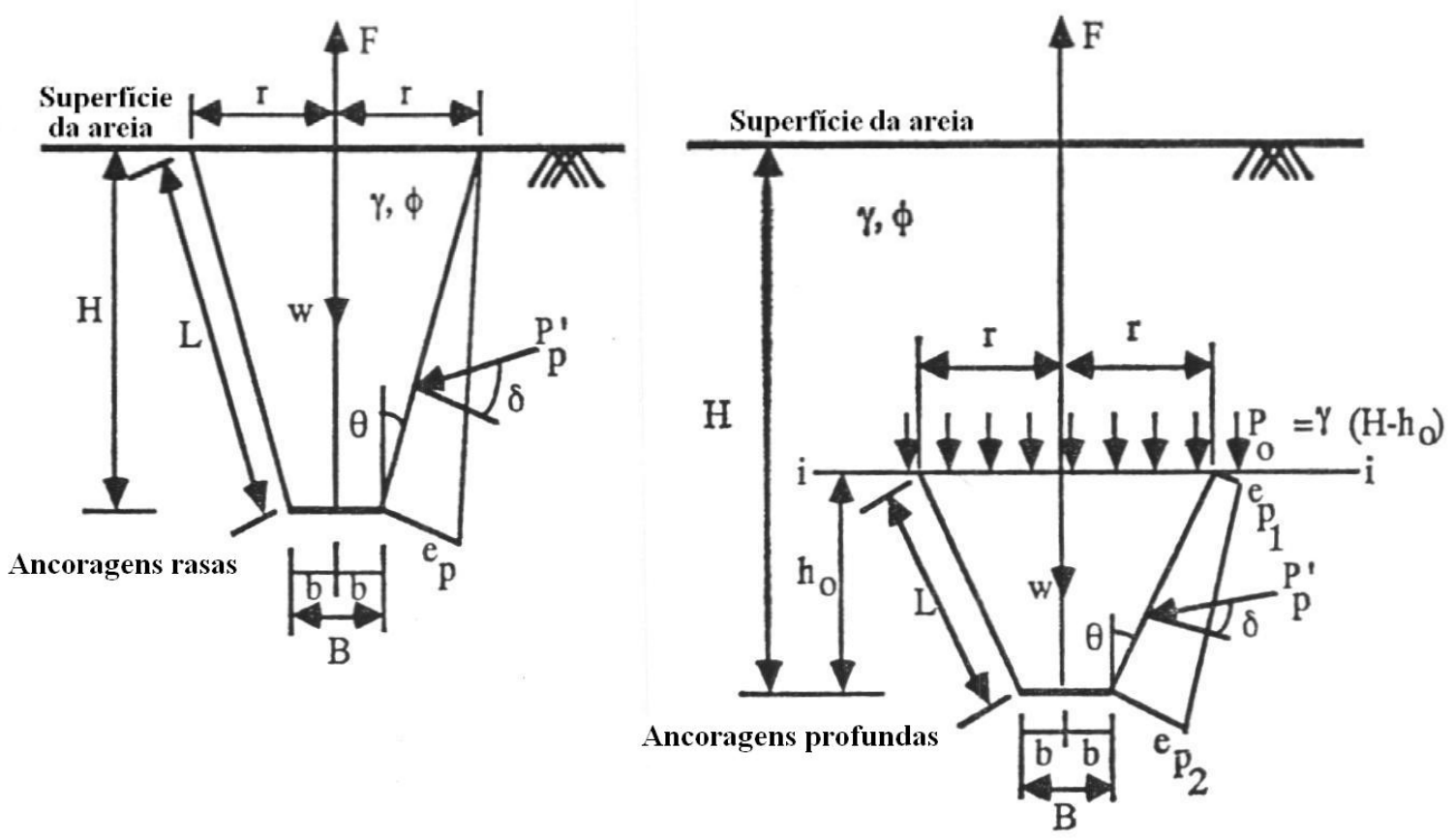

(c)

(d)

Figura 2.27 - Forças atuantes nas superfícies de ruptura assumidas para ancoragens rasas e profundas (Ghaly et al., 1991b)

O torque aplicado é dado pela seguinte equação: 


$$
T=R \cdot \frac{B_{r}}{2}
$$

Substituindo as Equações 2.19 e 2.20 na 2.21 tem-se a seguinte relação entre o torque de instalação $(\mathrm{T})$ e a capacidade de carga à tração $(\mathrm{F})$ :

$$
T=F \cdot \tan (\psi+\lambda)\left[\frac{B^{3}-d^{3}}{3\left(B^{2}-d^{2}\right)}\right]
$$

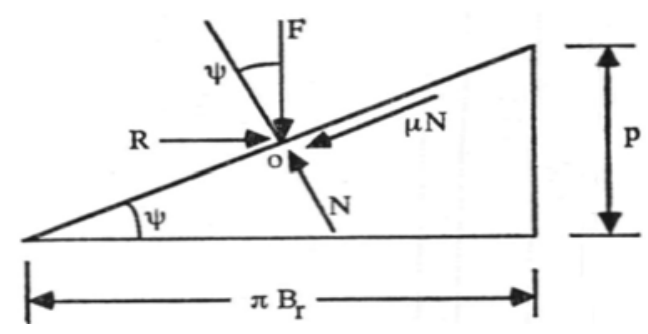

Figura 2.28 - Forças atuantes na hélice desenvolvida (Ghaly et al., 1991b)

\section{Comparação entre os resultados teóricos e experimentais}

A Figura 2.29 mostra a comparação entre os resultados de torque de instalação medidos e previstos pela Equação 2.22 para as estacas de passo simples (estacas a, b e c da Figura 2.26) instaladas em areia compacta. Nesta figura observa-se boa concordância entre os resultados medidos e calculados para as ancoragens rasas. No entanto existe uma discrepância maior para ancoragens profundas.

A Figura 2.30 apresenta a comparação entre os resultados de torque de instalação medidos e previstos para as estacas de passo simples médio (Figura $2.26 \mathrm{~b}$ ), instaladas em areia fofa, medianamente compacta e compacta. 


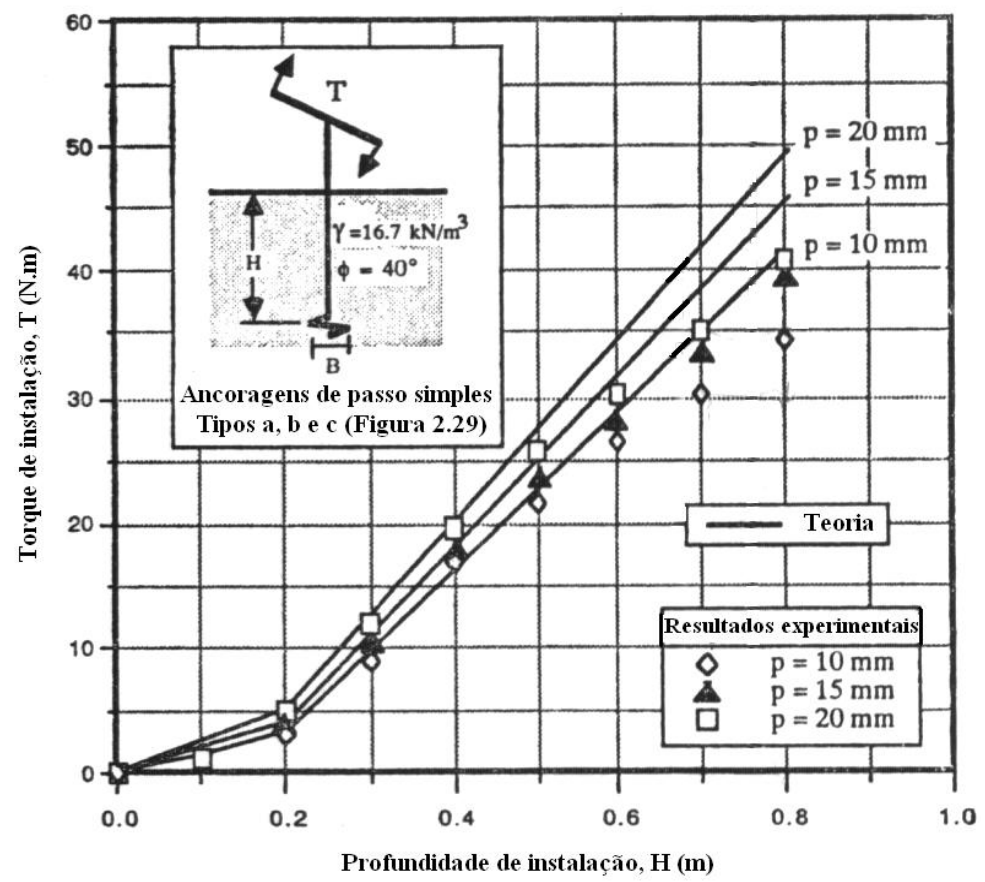

Figura 2.29 - Comparação entre os resultados teóricos e experimentais dos ensaios em ancoragens de passo simples instaladas em areia compacta (Ghaly et al., 1991b)



Figura 2.30 - Comparação entre os resultados teóricos e experimentais para ancoragens de passo simples e médio (Ghaly et al., 1991b) 
Para as ancoragens com hélices multi-passos (itens (d) e (e) da Figura 2.26), o caso é mais complexo, e os autores deste trabalho citado recomendam maior número de investigações para este tipo de ancoragem.

\subsubsection{Método de Ghaly e Hanna (1991)}

Ghaly e Hanna (1991) apresentaram um trabalho experimental e teórico sobre o torque de instalação de estacas metálicas helicoidais em areia. Os testes foram conduzidos em cinco modelos de estacas com as hélices apresentando diferentes geometrias (Figura 2.26), para ser analisado o efeito do formato da hélice no comportamento da estaca durante a instalação.

Para este experimento, os modelos de estaca foram instalados em areia compacta, medianamente compacta e fofa, preparadas em tanques de ensaios. Nos ensaios, foram medidos os deslocamentos na superfície, os valores de torque de instalação, as tensões desenvolvidas nas camadas de areia durante todas as fases dos testes (antes e durante a instalação, e durante o ensaio de tração da estaca). Neste mesmo programa de testes, foram realizados ensaios especiais em areais dispostas em camadas coloridas, para se examinar o efeito da instalação.

Com base nos resultados deste experimento, Ghaly e Hanna (1991) identificaram os fatores que afetam o valor do torque de instalação da estaca helicoidal. Neste estudo, os autores desenvolveram um modelo teórico para previsão do valor de torque de instalação deste tipo de estaca. Um fator de torque foi estabelecido com base nos parâmetros que afetam o valor do torque de instalação, e os autores deste trabalho propuseram uma correlação entre a resistência à tração da estaca e este fator de torque. Desta correlação, a capacidade de carga à tração de uma fundação em estaca metálica helicoidal, pode ser determinada pelo valor medido do torque requerido para a instalação da estaca. 
Ghaly e Hanna (1991) compararam neste trabalho os resultados experimentais e teóricos de capacidade de carga, e eles apresentaram-se aproximados.

A teoria proposta por esses autores também proporcionou resultados próximos aos de outras investigações experimentais.

Neste experimento foram colocados transdutores dentro do tanque de testes para medir o desenvolvimento das tensões na camada de areia durante a instalação do modelo de estaca. Eles foram locados em torno das estacas, no perímetro de círculos imaginários de $200 \mathrm{~mm}$ e de 400 mm de diâmetro. Nos ensaios, para aplicação de torque na instalação das estacas, foi utilizada uma broca elétrica. Os valores de torque aplicado foram medidos por torquímetros a cada $50 \mathrm{~mm}$ de penetração na profundidade.

Foi observado nesta pesquisa citada que para uma dada densidade de areia, o valor do torque aumenta com a razão passo/ diâmetro $(\mathrm{p} / \mathrm{B})$ e com o ângulo da hélice $\psi\left(\psi^{\mathrm{o}}=\tan ^{-1}\right.$ $\mathrm{p} / \pi \mathrm{B})$ da estaca helicoidal.

Os autores citam que Radhakrishna (1976), com base em ensaios de campo, observou que a configuração da hélice da estaca helicoidal exerce grande influência no valor do torque de instalação e conseqüentemente na capacidade de carga da estaca.

Segundo Ghaly e Hanna (1991), o desempenho da estaca helicoidal durante o processo de instalação é influenciado por diversos fatores que devem ser considerados. De acordo com os autores, os aspectos da estaca a serem considerados são os seguintes:

- Diâmetro da hélice superior;

- Passo da hélice;

- Ângulo da hélice;

- Diâmetro da haste (ou tubo) da estaca;

- Configuração geral da hélice; 
- Espessura da chapa da hélice;

- Forma da superfície de corte da hélice (plana, em forma de faca, etc.);

- Método utilizado na fabricação da estaca helicoidal (soldada, aparafusada, etc.);

- Material da estaca e rugosidade da superfície;

- Forma da ponta da estaca (cônica ou plana).

De acordo com Ghaly e Hanna (1991), a instalação da estaca helicoidal encontra resistência por atrito e de ponta exercida na chapa da hélice e na haste da estaca. O total de resistência de atrito que atua na superfície da hélice e na haste é devida a forças que geram momento contra o torque aplicado. Similarmente, o total de resistência de ponta que atua na chapa da hélice é composto por forças resistentes ao avanço (para baixo) da estaca no solo. Segundo os autores, uma força vertical V (sentido para baixo) deve ser aplicada na haste da estaca para superar as forças que atuam contra a instalação. Neste trabalho, foi desenvolvido um modelo teórico para o cálculo dos valores de torque requerido (T) e da força vertical (V).

A Figura 2.31 mostra os sistemas de forças atuantes na hélice e na haste de uma estaca helicoidal durante a aplicação do torque de instalação. As forças apresentadas nesta figura produzem resistência contra o movimento nas direções mostradas. As forças que atuam contra a rotação da estaca são as seguintes:

a) $\mathrm{O}$ empuxo lateral passivo exercido em todo comprimento enterrado da haste $\left(\mathrm{P}_{1}\right)$. Esta força tem duas componentes $\left(\mathrm{P}_{1 \mathrm{x}}\right.$ e $\left.\mathrm{P}_{1 \mathrm{y}}\right)$ de resistência de atrito: a primeira componente gera o momento que atua na haste resistindo à rotação $\left(\mathrm{T}_{1}\right)$ e a segunda gera o momento por atrito agindo na hélice da estaca $\left(\mathrm{T}_{2}\right)$.

b) A força $\left(\mathrm{P}_{2}\right)$ atua na coluna cilíndrica da areia no limite da hélice. Esta força é devida à compactação local que a instalação da estaca helicoidal causou na camada 
de areia. A força $\left(\mathrm{P}_{2}\right)$ tem duas componentes $\left(\mathrm{P}_{2 \mathrm{x}}\right.$ e $\left.\mathrm{P}_{2 \mathrm{y}}\right)$ : a primeira componente não produz resistência à torção, enquanto a segunda influencia na resistência como momento por atrito agindo na chapa da hélice $\left(\mathrm{T}_{3}\right)$.

c) Os empuxos passivos e ativos atuantes nas superfícies superiores e inferior da hélice devido ao avanço da estaca. Essas duas forças produzem as resistências por atrito $\left(\mathrm{T}_{4}\right.$ e $\left.\mathrm{T}_{5}\right)$ na superfície superior e inferior da hélice, resultando em momento que atua contra o torque de instalação.

d) A força (F) devida ao empuxo passivo atuante na superfície superior da hélice variando com sua inclinação (Figura 2.31 b). Esta força produz resistência contra a rotação, que é representada pela resistência torcional $\left(\mathrm{T}_{6}\right)$ contra o torque aplicado.

e) Força exercida no perímetro externo da hélice, devida à resistência por atrito entre a área correspondente à espessura da hélice e a areia em contato com esta área. Esta força produz o momento de resistência por atrito $\left(\mathrm{T}_{7}\right)$.

De acordo com o esquema de forças da Figura 2.31, o torque necessário para a instalação da estaca deve ser dado pela seguinte equação:

$$
\begin{gathered}
T=\sum_{i=1}^{n} T i \\
T=T_{1}+T_{2}+T_{3}+T_{4}+T_{5}+T_{6}+T_{7}
\end{gathered}
$$




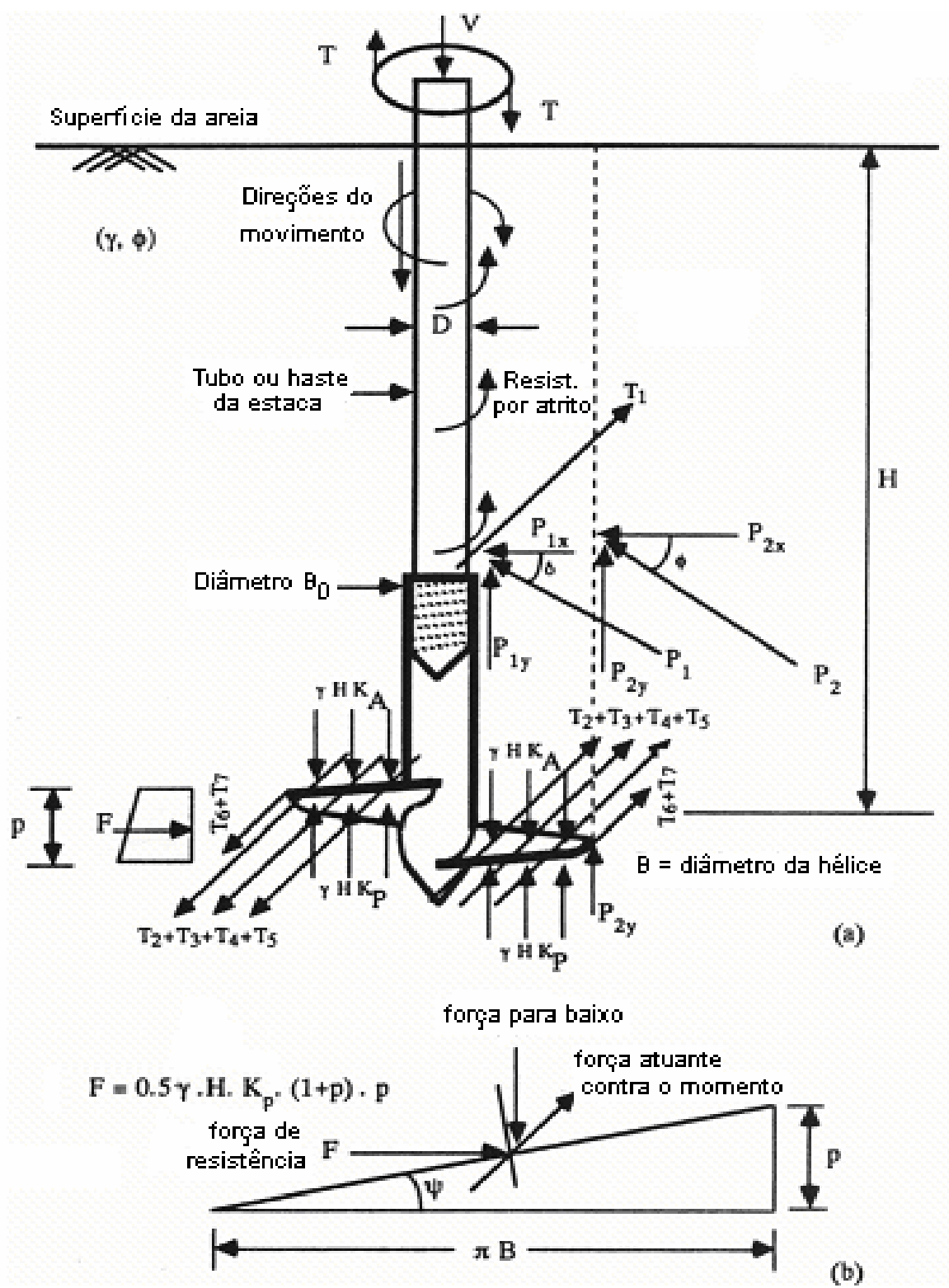

Figura 2.31 - Forças atuantes em uma estaca helicoidal com hélice de um passo durante a instalação (Ghaly e Hanna, 1991)

Os valores os termos da Equação 2.24 são dados pelas seguintes expressões:

$$
T_{1}=0,5 \cdot \gamma \cdot H^{2} \cdot \cos \delta \cdot K^{\prime}{ }_{p} \cdot K_{f} \cdot(\pi \cdot D) \cdot\left(\frac{D}{2}\right)
$$




$$
\begin{gathered}
T_{2}=0,5 \cdot \gamma \cdot H^{2} \cdot \operatorname{sen} \delta \cdot K^{\prime}{ }_{p} \cdot \tan (\delta+\psi) \cdot(\pi \cdot D) \cdot\left(\frac{D}{2}\right) \\
T_{3}=0,5 \cdot \gamma \cdot H^{2} \cdot \operatorname{sen} \phi \cdot K_{p}^{\prime} \cdot \tan (\delta+\psi) \cdot(\pi \cdot D) \cdot\left(\frac{B}{2}\right) \\
T_{4}=\gamma \cdot H \cdot K_{A} \cdot A_{t} \cdot \tan (\delta+\psi) \cdot\left[\frac{\left(B+B o_{o}\right)}{4}\right] \\
T_{5}=\gamma \cdot H \cdot K_{P} \cdot A_{b} \cdot \tan (\delta+\psi) \cdot\left[\frac{\left(B+B_{o}\right)}{4}\right] \\
T_{7}=\gamma \cdot H \cdot K_{P} \cdot K_{f} \cdot(\pi \cdot B) \cdot\left(\frac{B}{2}\right) \cdot t \\
T_{6}=F \cdot\left[\frac{(B-B)^{2}}{8}\right]
\end{gathered}
$$

onde:

$\mathrm{A}_{\mathrm{t}}=$ área da superfície superior da hélice

$A_{b}=$ área da superfície inferior da hélice

$\psi=$ ângulo da hélice

$\delta=$ ângulo de atrito entre o material da hélice e a areia em torno dela (considerado neste trabalho citado igual a $3 \phi / 4)$

$\phi=$ ângulo de atrito da areia

$\mathrm{B}=$ diâmetro externo da hélice 
$\mathrm{B}_{\mathrm{o}}=$ diâmetro interno da hélice

$\mathrm{D}=$ diâmetro do tubo da estaca

$\mathrm{H}=$ profundidade de instalação da hélice

$\mathrm{K}_{\mathrm{A}}=$ coeficiente de empuxo ativo $\left[K_{A}=\frac{(1-\operatorname{sen} \phi)}{(1+\operatorname{sen} \phi)}\right]$

$\mathrm{K}_{\mathrm{P}}=$ coeficiente de empuxo passivo $\left[K_{P}=\frac{(1+\operatorname{sen} \phi)}{(1-\operatorname{sen} \phi)}\right]$

$\mathrm{K}_{\mathrm{P}}^{\prime}=$ coeficiente de empuxo passivo modificado pelo processo de instalação da estaca (deduzido da presente investigação por meio dos transdutores como: $\mathrm{K}_{\mathrm{P}}{ }_{\mathrm{P}}=0,3 \mathrm{~K}_{\mathrm{P}}$ )

$\mathrm{K}_{\mathrm{f}}=$ coeficiente de atrito entre o material da hélice da estaca e o solo que a circunda $\left(\mathrm{K}_{\mathrm{f}}=\tan \delta\right)$

A magnitude da força vertical (V) necessária para superar as forças atuantes contra o movimento para baixo da estaca durante a instalação é dada pela seguinte equação:

$$
\begin{gathered}
V=\sum_{i=1}^{n} V i \\
V=V_{1}+V_{2}+V_{3}+V_{4}
\end{gathered}
$$

onde:

$\mathrm{V}_{1}=$ componente vertical $P_{1 y}$ da força $\mathrm{P}_{1}$

$\mathrm{V}_{2}=$ componente vertical $P_{2 y}$ da força $\mathrm{P}_{2}$

$\mathrm{V}_{3}=$ força resultante da resistência passiva atuante na superfície inferior da hélice

$\mathrm{V}_{4}=$ força de arrasto atuante na superfície superior da hélice devido à atuação ativa do empuxo

Os valores dos termos da Equação 2.33 são dados pelas seguintes expressões: 


$$
\begin{gathered}
V_{1}=0,5 \cdot \gamma \cdot H^{2} \cdot \operatorname{sen} \delta \cdot K_{p}^{\prime} \cdot(\pi \cdot D) \\
V_{2}=0,5 \cdot \gamma \cdot H^{2} \cdot \operatorname{sen} \phi \cdot K_{p}^{\prime} \cdot(\pi \cdot B) \\
V_{3}=\gamma \cdot H \cdot K_{P} \cdot A_{b} \cdot \cos \psi \\
V_{4}=\gamma \cdot H \cdot K_{A} \cdot A_{t} \cdot \cos \psi
\end{gathered}
$$

Ghaly e Hanna (1991) compararam os resultados obtidos pelo modelo teórico proposto por eles com os resultados experimentais de torque, e os valores apresentaram-se próximos. A Figura 2.32 mostra esta comparação feita para estacas helicoidais com hélices de um passo (Figura 2.26).

A teoria proposta por Ghaly e Hanna (1991) para determinação do torque de instalação da estaca helicoidal, juntamente com os resultados experimentais de capacidade de carga à tração das estacas, foi utilizada pelos autores para desenvolverem uma correlação para previsão da resistência à tração da estaca a partir do torque requerido para sua instalação. Um fator de torque $\left(\mathrm{F}_{\mathrm{t}}\right)$ similar ao conhecido fator de capacidade de carga $\left(\mathrm{N}_{\mathrm{qu}}\right)$ foi estabelecido para expressar o valor de torque de instalação de modo adimensional. Este fator inclui todos os termos que afetam a magnitude do torque de instalação, e é dado pela expressão:

$$
F_{t}=\frac{T}{\gamma A H p}
$$

onde:

$\mathrm{T}=$ torque de instalação

$\gamma=$ peso específico da areia 
$\mathrm{A}=$ área da superfície da hélice

$\mathrm{H}=$ profundidade de instalação

$\mathrm{p}=$ passo da hélice (parâmetro que controla o ângulo da hélice)

Neste estudo foram calculados os valores de $F_{t}$ para os ensaios dos modelos de estacas com a hélice de um passo, instaladas em areia compacta, medianamente compacta e fofa. Esses valores foram plotados na Figura 2.33 contra os valores correspondentes de $\mathrm{N}_{\mathrm{qu}}\left(\mathrm{N}_{\mathrm{qu}}=\right.$ $\left.\mathrm{Q}_{\mathrm{u}} / \gamma \mathrm{AH}\right)$. Para todos estes ensaios, com modelos instalados em diferentes profundidades e tipo de areia, foi apresentada uma relação única entre $N_{\text {qu }}$ e $F_{t}$ (Figura 2.33). Segundo os autores deste trabalho, este fato sugere que o fator de capacidade de carga $\left(\mathrm{N}_{\mathrm{qu}}\right)$ e o fator de torque $\left(\mathrm{F}_{\mathrm{t}}\right)$ são equivalentes, sujeitos a variarem quando suas componentes são alteradas. Esta relação é representada por uma curva logarítmica dada pela equação:

$$
\left[\frac{Q_{u}}{\gamma A H}\right]=2\left[\frac{T}{\gamma A H p}\right]^{(1.1)}
$$

De acordo com Ghaly e Hanna (1991), a correlação dada pela Equação 2.39 pode ser utilizada para uma determinação preliminar da capacidade de carga à tração da estaca helicoidal com base no torque de instalação medido.

Os autores deste trabalho citam que embora os dados plotados na Figura 2.33 sejam limitados para estacas helicoidais com hélices de um passo, a correlação dada pela Equação (2.39) pode ser estendida para outros tipos de hélices, com o fator de torque corrigido. 


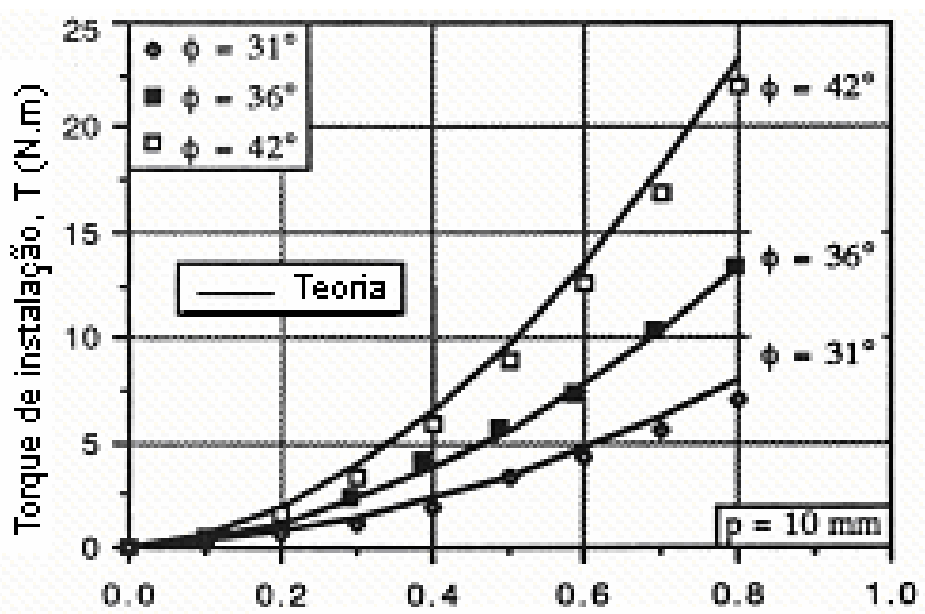

Profundidade de Instalaçẫo, H (m)
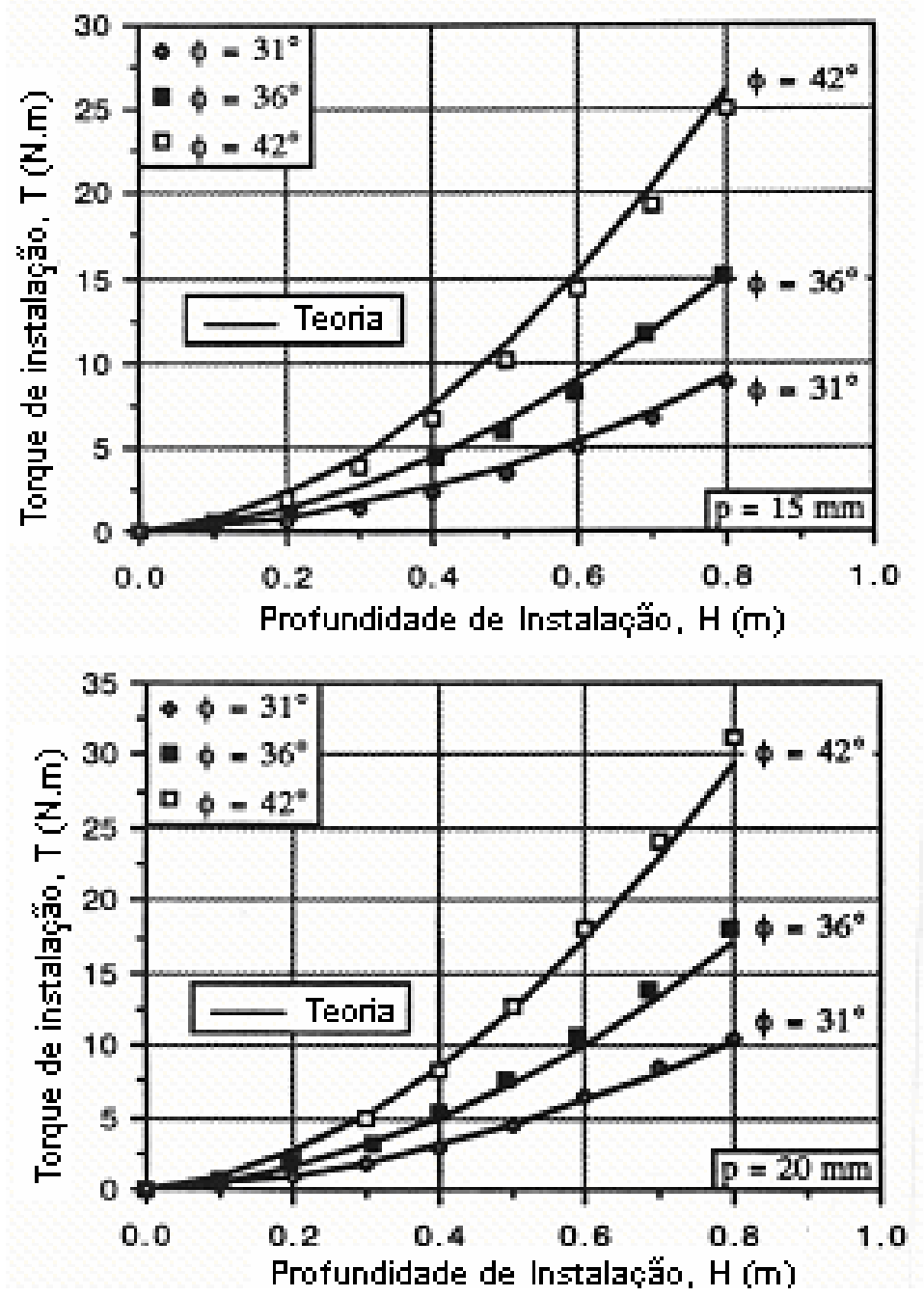

Figura 2.32 - Comparação entre resultados teóricos e experimentais para modelos de estacas com hélices um passo de diferentes medidas de passo (p), instaladas em areia compacta $\left(\phi=42^{\circ}\right)$, medianamente compacta $\left(\phi=36^{\circ}\right)$ e fofa $\left(\phi=31^{\circ}\right)($ Ghaly e Hanna, 1991$)$ 


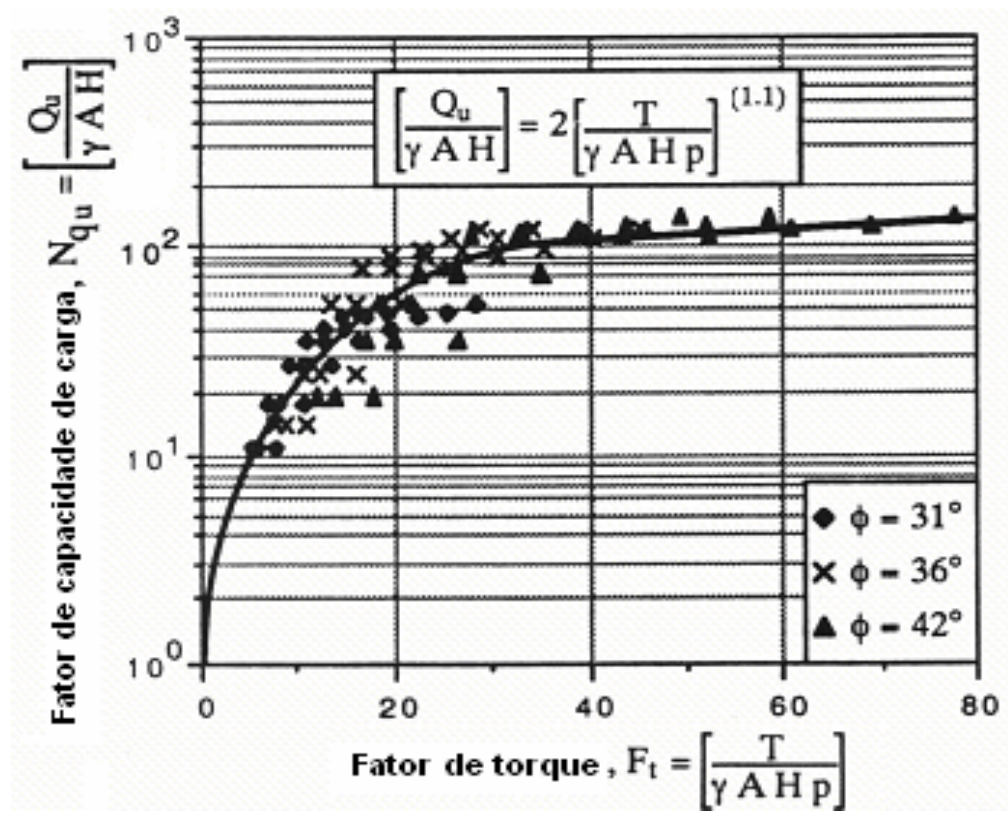

Figura 2.33 - Relação entre fator de capacidade de carga e fator de torque (Ghaly e Hanna, 1991)

Ghaly e Hanna (1991) coletaram resultados de torque de instalação de protótipos de estacas helicoidais ensaiados (em campo), encontrados na literatura. Estes resultados são de estacas com uma ou mais hélices instaladas em depósitos de areia. Os dados de campo são apresentados na Figura 2.34 por meio da relação entre fator de capacidade de carga $\left(\mathrm{N}_{\mathrm{qu}}\right)$ e fator de torque $\left(F_{t}\right)$ juntamente com a curva obtida por Ghaly e Hanna (1991) apresentada na Equação 2.39, a partir das investigações em estacas com hélice de um passo.

Foi observado pelos autores deste estudo, a partir da Figura 2.34, que os dados apresentados por Radhakrishna (1976) de estacas com hélice de um passo instaladas em areia siltosa, e os dados mostrados por Mitsch e Clemence (1985) de estacas com três hélices instaladas em areia pura, apresentaram-se próximos à curva da correlação proposta por eles.

Desta comparação, Ghaly e Hanna (1991) alegam que a relação entre $\mathrm{N}_{\mathrm{qu}}$ e $\mathrm{F}_{\mathrm{t}}$ é uma ferramenta eficaz para determinação da capacidade de carga à tração da estaca com base no torque de instalação medido, tanto para estacas com uma hélice como para estacas multihélices. 


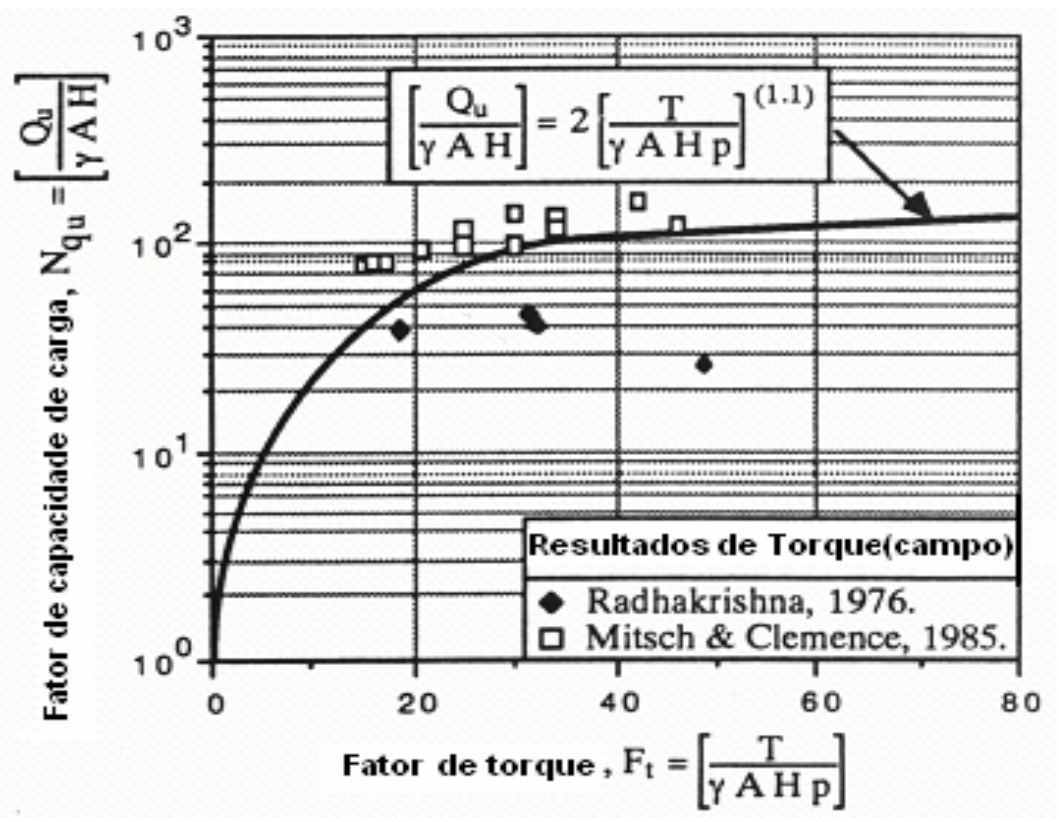

Figura 2.34 - Comparação entre resultados teóricos de torque e resultados de ensaios de campo reportados na literatura (Ghaly e Hanna, 1991)

Ghaly (1995) realizou um programa de ensaios para estudar o efeito da existência de água na areia no torque de instalação da estaca helicoidal. Neste estudo, o modelo de estaca helicoidal (Figura 2.35) foi instalado em areia compacta e submersa, com as condições de água variando de pressão hidrostática a um fluxo de percolação ascendente com diferentes velocidades. Com base nos resultados deste estudo, o autor deste trabalho mencionado concluiu que a presença de água na areia facilita o procedimento de instalação da estaca helicoidal, reduzindo o valor de torque requerido. Eles também observaram que a facilidade de instalação progride com o aumento da velocidade do fluxo de percolação de água (V) . 




Figura 2.35 - Modelo de hélice utilizada nos ensaios (dimensões em milímetros) (Ghaly, 1995)

Após o processo de instalação, os modelos foram tracionados e as cargas de ruptura $\left(\mathrm{Q}_{\mathrm{u}}\right)$ foram plotadas versus os valores de torque de instalação (T) na Figura 2.36. De acordo com Ghaly (1995), esta figura mostra que quanto maior é a resistência à instalação (maior torque requerido), maior é a capacidade de carga à tração da estaca helicoidal.

Com base nos resultados das investigações, Ghaly (1995) propôs a relação entre o fator de capacidade de carga $\left(\mathrm{N}_{\mathrm{qu}}\right)$ e o fator de torque $\left(\mathrm{F}_{\mathrm{t}}\right)$ representada graficamente na Figura 2.37:

$$
\left[\frac{Q_{u}}{\gamma A H}\right]=0,52\left[\frac{T}{\gamma A H p}\right]^{(1.2)}
$$

Na Equação 2.40 foi utilizado o peso efetivo da areia para o cálculo do fator de capacidade de carga $\left(\mathrm{N}_{\mathrm{qu}}\right)$ e do fator de torque $\left(\mathrm{F}_{\mathrm{t}}\right)$. 


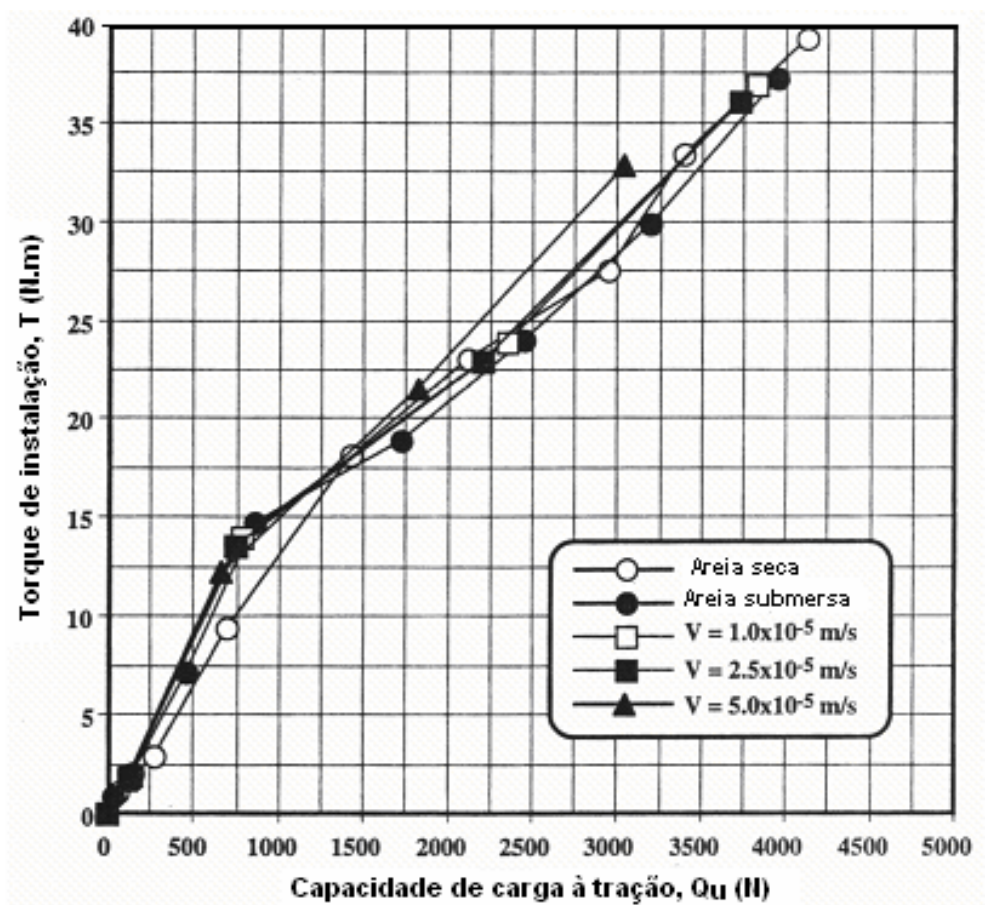

Figura 2.36 - Relação torque de instalação x capacidade de carga à tração (Ghaly, 1995)

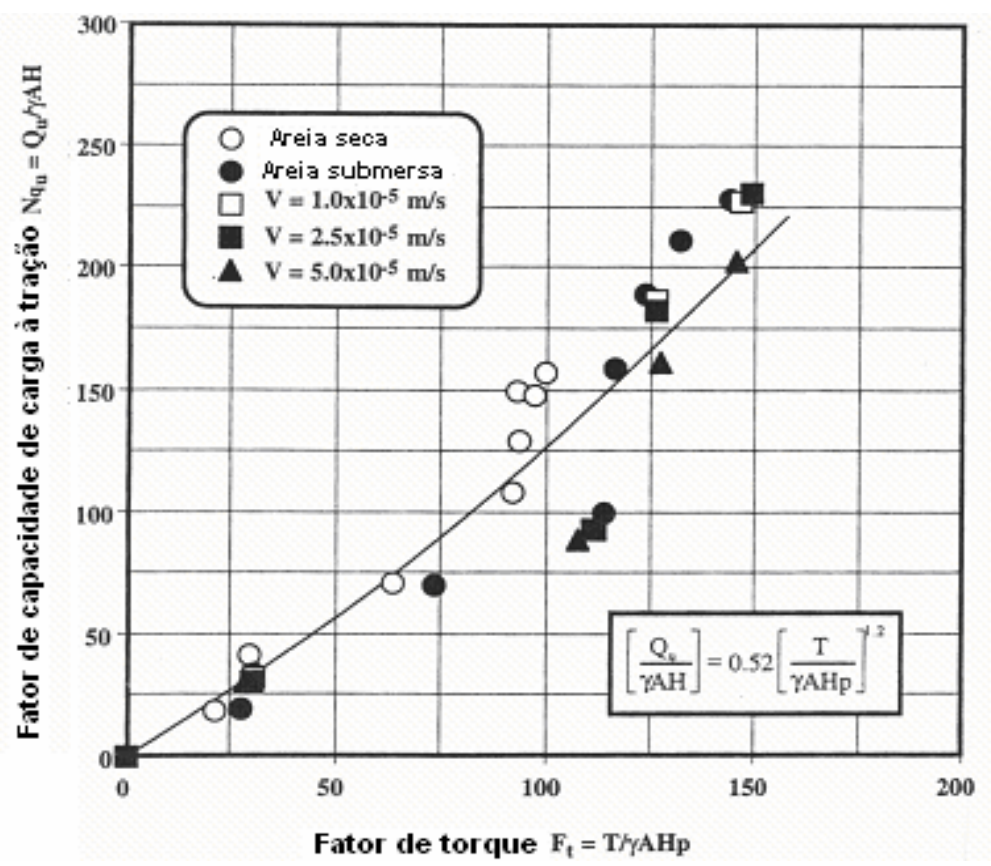

Figura 2.37 - Relação entre fator de capacidade de carga e fator de torque (Ghaly, 1995)

A Figura 2.38 apresenta as relações entre fator de capacidade de carga e fator de torque, obtida por Ghaly e Hanna (1991) por meio da Equação 2.39 (baseada em resultados de 72 
testes em modelos com hélices de diferentes passos instaladas em areia seca), e obtida por Ghaly (1995) por meio da Equação 2.40 (baseada em resultados de 28 testes em modelos de estacas instalados em areia seca, submersa e sujeita a fluxo de percolação ascendente).

Pela combinação dos resultados dos 100 testes, Ghaly (1995) apresentou a seguinte equação (representada na Figura 2.38):

$$
\left[\frac{Q_{u}}{\gamma A H}\right]=2,30\left[\frac{T}{\gamma A H p}\right]^{(0,96)}
$$

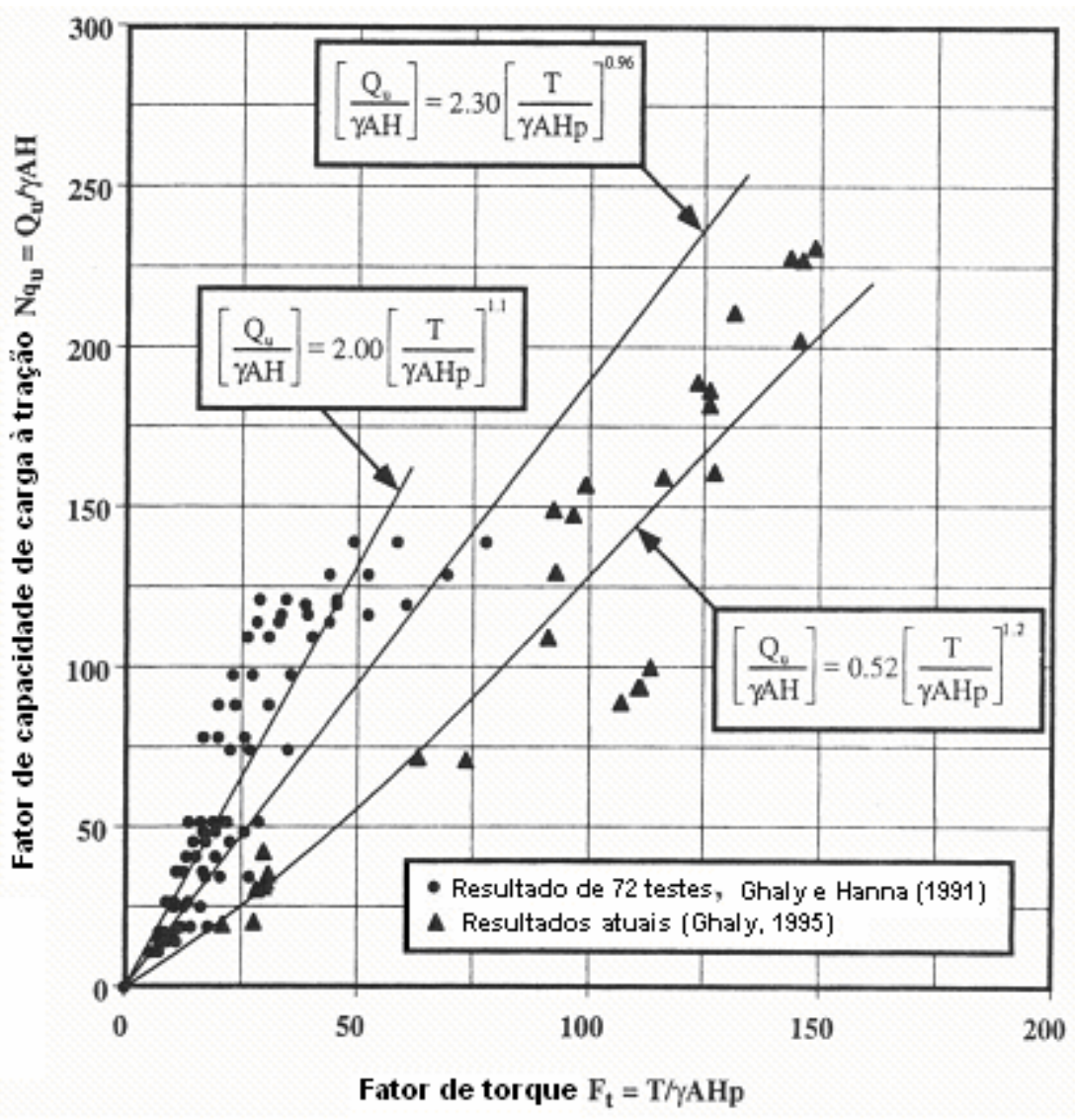

Figura 2.38 - Relação entre fator de capacidade de carga e fator de torque (Ghaly, 1995)

Prasad (1996) apresenta na Figura 2.39 a relação entre fator de capacidade de carga e fator de torque do trabalho de Ghaly (1995) juntamente com os resultados desta relação obtidos de 
análise dos ensaios em laboratório realizados por Mooney et al. (1985) de modelos de estacas helicoidais instalados em argila e em silte. Nesta figura, o autor citado apresenta separadamente esta relação para as estacas instaladas em areia em condição seca e submersa.

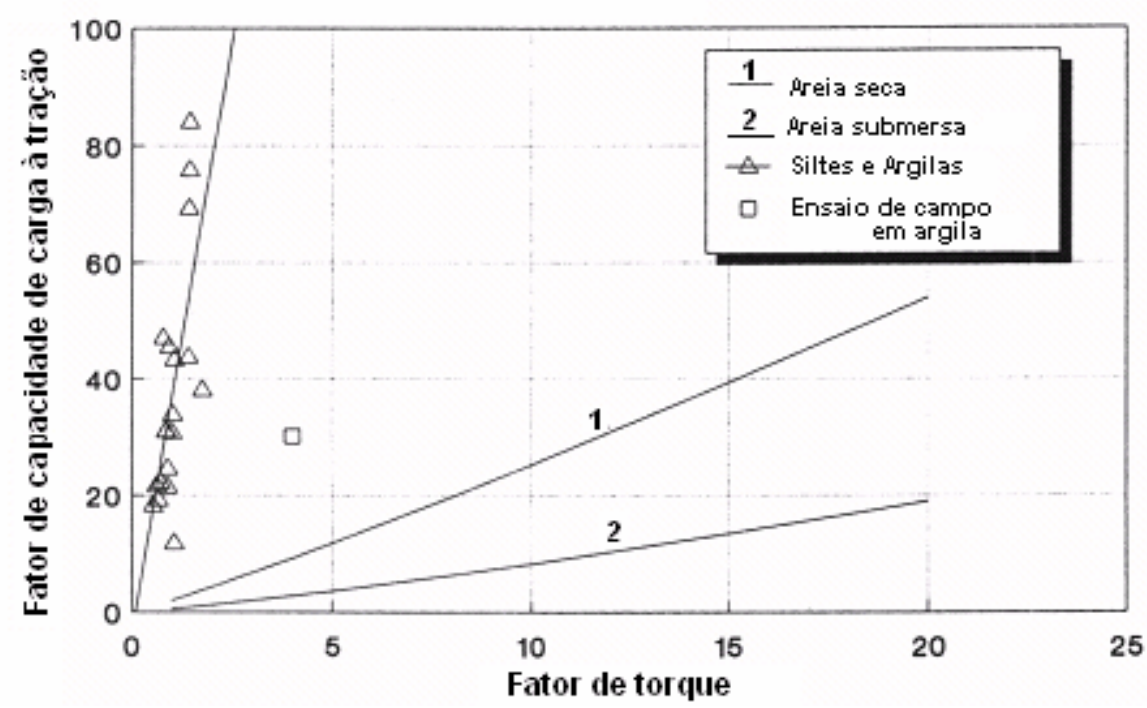

Figura 2.39 - Relação entre fator de capacidade de carga e fator de torque (Prasad, 1996)

\subsubsection{Método de Perko (2000)}

Perko (2000) desenvolveu um modelo teórico para esclarecer a relação empírica existente entre torque de instalação e capacidade de carga de fundações em estacas metálicas helicoidais. Este modelo é baseado na energia exercida durante a instalação e na energia necessária para deslocar a fundação helicoidal. Por meio dessa equivalência de energia, foi apresentado um modelo que relaciona a capacidade de carga à tração da estaca helicoidal diretamente com o torque de instalação.

Segundo Perko (2000), as medidas de torque obtidas durante a instalação da estaca helicoidal são indicadores da resistência de cisalhamento do solo na profundidade em que a hélice está passando. De acordo com este autor, é difícil relacionar as medidas de torque com 
o ângulo de atrito e a coesão do solo, devido à complexidade da interação entre as hélices e o solo. Por esta razão, o autor propôs um modelo que relaciona a capacidade de carga da estaca helicoidal com o torque de instalação baseado na equivalência de energia.

Este modelo considera a força (para baixo) aplicada durante a instalação, a geometria da hélice, o número de hélices, o passo da hélice e o raio da haste (ou tubo) da estaca.

O modelo de energia de Perko (2000), para previsão da relação entre capacidade de carga da estaca e torque de instalação, é baseado no postulado que diz que a energia de penetração é proporcional ao volume de solo deslocado multiplicado pela distância deslocada.

Neste modelo assume-se que a energia necessária para rotacionar um objeto é igual ao torque multiplicado pelo ângulo de rotação, e a energia exercida pela força (para baixo) é a força multiplicada pela distância em que a força atua. Para uma revolução, o volume de solo deslocado pela estaca helicoidal é igual à soma dos volumes deslocados de cada hélice mais o volume deslocado pelo movimento da haste (para baixo) multiplicado pela distância do passo, como mostra a Figura 2.40. Para a penetração da haste, a distância necessária para deslocar o solo é igual ao raio da haste. A energia perdida devido ao atrito é estimada pela conversão da resistência de cisalhamento do solo em torque e multiplicando pelo ângulo da torção.

Conforme Perko et al. (2000), o movimento das fundações na prática é limitado para pequenos deslocamentos. A capacidade da estaca para pequenos deslocamentos pode ser determinada pelo equilíbrio entre a energia exercida durante o carregamento e a energia de penetração correspondente para cada hélice da estaca. A energia perdida devida ao atrito ao longo da haste pode ser desprezada.

A Figura 2.41 apresenta uma comparação entre os valores medidos da razão capacidade carga/torque de instalação e os previstos pelo modelo de Perko (2000). Os dados desta comparação são de estacas helicoidais ensaiadas disponíveis na literatura, com diferentes geometrias e escalas. 


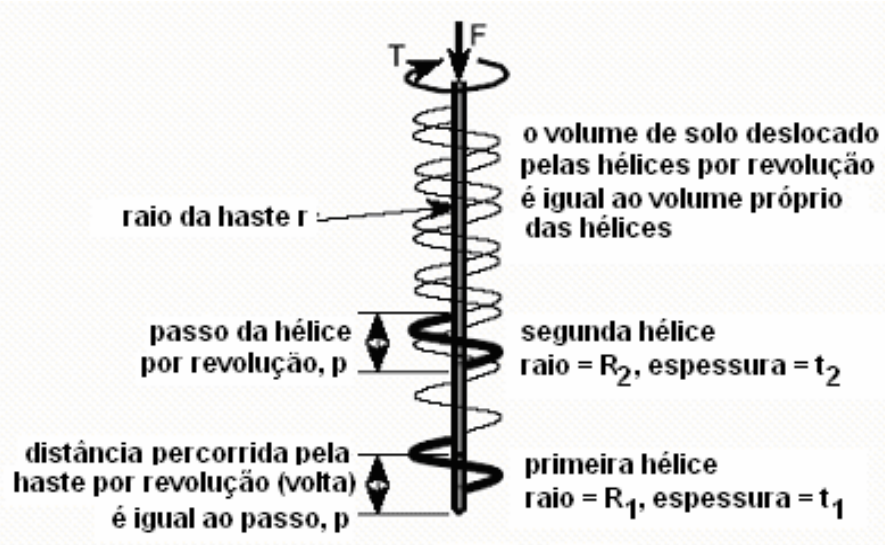

Figura 2.40 - Propriedades da instalação da estaca helicoidal (Perko, 2000)

Pela equivalência das energias de carregamento e de penetração da estaca, Perko (2000) obteve a seguinte expressão, que relaciona a capacidade de carga da estaca e o torque de instalação:

$$
Q=\frac{12 d(2 \pi T+F p)\left[r^{2}+\sum_{m}\left(R_{m}{ }^{2}-r^{2}\right)\right]}{3\left[2 r^{3} p+\sum_{n}\left(R_{n}{ }^{2}-r^{2}\right) t_{n}{ }^{2}\right]+16 \pi \alpha\left[3 r^{3} \lambda+\sum_{m}\left(R_{m}{ }^{3}-r^{3}\right) t_{m}\right]}
$$

onde:

$\mathrm{d}=$ deslocamento da estaca helicoidal (Perko et al. (2000) recomendam $\mathrm{d}=2,5 \mathrm{~cm}$ )

$\mathrm{T}=$ torque de instalação

$\mathrm{F}=$ força exercida no sentido da instalação (geralmente menor que $9 \mathrm{kN}$ )

$\mathrm{p}=$ passo da hélice

$\mathrm{r}=$ raio do tubo ou haste da hélice

$\mathrm{m}=$ número total de lâminas helicoidais da estaca

$\mathrm{n}=$ número de lâminas helicoidais que atravessam trajetórias independentes

$\mathrm{R}_{\mathrm{m}}=$ raio da lâmina $\mathrm{m}$

$\mathrm{R}_{\mathrm{n}}=$ raio da lâmina $\mathrm{n}$

$t_{m}=$ espessura da chapa da hélice $m$ 
$\mathrm{t}_{\mathrm{n}}=$ espessura da chapa da hélice $\mathrm{n}$

$\alpha=$ razão entre o cisalhamento lateral e a resistência à penetração

$\lambda=$ comprimento efetivo da haste da estaca



- Rupiper and Edwards (1969) tubo de seção quadrada

o Ghaly. Hanna, and Hanna (1991)

modelo (laboratório)

$\Delta$ Mitsch and Clemence (1985)

tubo de seçẫo quadrada

口Mitsch and Clemence (1985)

modelo (laboratório)

* Harorave and Thorsten (1982)

tubo de seçâo quadrada

+ Chance (1994):

tubo de seçấo quadrada

$\times$ Chance (1994)

tubo de seção circular

A Allas (1985)

tubo de seção quadrada

- Atlas (19e5)

tubo de seção circular

- Magnum Piering (2001)

tubo de seção circular

Figura 2.41 - Comparação entre valores medidos e previstos pelo modelo (Perko, 2000)

\subsubsection{Provas de carga à tração}

Segundo A. B. Chance Co. (2004), a resistência à tração de uma estaca helicoidal pode ser determinada somente pela aplicação de carregamento de tração em sua haste. De acordo com este manual técnico, as provas de carga nestas estacas devem obedecer às seguintes condições:

a) O carregamento deve ser aplicado na direção do eixo da haste da estaca;

b) Deve-se ser utilizada a mesma taxa de carregamento para cada configuração de estaca helicoidal; 
c) O aumento da carga deve ser feito em etapas, onde o carregamento será mantido constante por um intervalo de tempo determinado;

d) Nas etapas de carregamento não deve ser acrescentado mais do que $25 \%$ do valor da carga total;

e) Quanto menor for o acréscimo de carga nas etapas de carregamento, mais exata será a avaliação da capacidade da estaca;

f) As etapas de carregamento devem ser iguais (em acréscimo de carga e duração) para todas as estacas;

g) A ruptura da fundação é considerada quando, para uma determinada carga aplicada, o deslocamento por minuto da estaca ensaiada torna-se uniforme ou crescente. O teste é encerrado quando o deslocamento acumulado da haste da estaca ultrapassa o valor de quatro polegadas $(101,6 \mathrm{~mm})$.

h) Devem ser executadas múltiplas provas de carga para se conhecer o comportamento da estaca perante da variação do solo local.

De acordo com o manual técnico da A. B. Chance Co. (2003), o carregamento deverá ser aplicado até o momento em que não se conseguir manter a carga contínua requerida para o ensaio, ou quando a carga aplicada atingir o valor relativo a $200 \%$ da carga de projeto (DL), ou seja, o ensaio de carregamento é parado quando uma das duas situações ocorrer. O período de observação do último incremento de carga deverá ser de 10 minutos, e as leituras de deslocamento deverão ser feitas nos intervalos de 1, 2, 3, 4, 5 e 10 minutos (apenas durante o último incremento). Após o final do carregamento, o descarregamento deverá ser feito em quatro decrementos aproximadamente iguais, de acordo com a Tabela 2.3. O tempo de duração dos decrementos deve ser de 1 minuto, exceto para o último decremento, o qual deverá ser mantido por 5 minutos. 
Adams e Klym (1972) citam que no caso de estacas helicoidais que são utilizadas como fundação de torres de transmissão, a carga máxima de projeto é determinada por uma condição momentânea, de curta duração, que ocorre raramente durante a vida da estrutura. De acordo com esses autores, nos casos em que a natureza do carregamento proporciona deslocamentos consideráveis, a resistência em longo prazo deve ser consideravelmente menor do que em curto prazo, e este efeito deve ser ponderado nas análises de provas de carga que são feitas a curto prazo.

Tabela 2.3 - Etapas de carregamento da prova de carga (A. B. Chance Co., 2003)

\begin{tabular}{cc}
\hline Etapa de carregamento & Duração (minutos) \\
\hline AL & 2,5 \\
$0.20 \mathrm{DL}$ & 2,5 \\
$0.40 \mathrm{DL}$ & 2,5 \\
$0.50 \mathrm{DL}$ & 2,5 \\
$0.20 \mathrm{DL}$ & 1,0 \\
$\mathrm{AL}$ & 1,0 \\
$0.40 \mathrm{DL}$ & 1,0 \\
$0.60 \mathrm{DL}$ & 2,5 \\
$0.80 \mathrm{DL}$ & 2,5 \\
$1.0 \mathrm{DL}$ & 2,5 \\
$0.5 \mathrm{DL}$ & 1,0 \\
$0.2 \mathrm{DL}$ & 1,0 \\
AL & 1,0 \\
$0.5 \mathrm{DL}$ & 1,0 \\
$1.0 \mathrm{DL}$ & 1,0 \\
$1.2 \mathrm{DL}$ & 2,5 \\
$1.4 \mathrm{DL}$ & 2,5 \\
$1.6 \mathrm{DL}$ & 2,5 \\
$1.8 \mathrm{DL}$ & 2,5 \\
$2.0 \mathrm{DL}$ & 1,0 \\
$1.5 \mathrm{DL}$ & 1,0 \\
$1.0 \mathrm{DL}$ & 1,0 \\
$0.5 \mathrm{DL}$ & 1,0 \\
AL & 5,0 \\
AL $=$ carga de alinhamento; & carga de projeto \\
\hline &
\end{tabular}




\subsection{Modelagem física em centrífuga}

\subsubsection{Considerações gerais}

A modelagem em centrífuga tem sido utilizada extensivamente em estudos geotécnicos, e também é aplicada em muitas áreas de engenharia civil, como na mecânica das rochas, hidráulica e estruturas (Taylor, 1995).

Os ensaios em modelos reduzidos em centrífuga permitem reproduzir, a partir do mesmo material que o protótipo, o mesmo campo de forças de massa que ocorreria em uma obra em grandeza real. A regra de semelhança utilizada para este fim é a seguinte: a intensidade do campo gravitacional criado pela aceleração centrífuga aplicada ao modelo deve ser inversamente proporcional à escala de redução das dimensões da maquete (Corté, 1989).

A semelhança de comportamento entre o modelo e a obra em grandeza real implica na existência de fatores de escala $X^{*}\left(X^{*}=\mathrm{Xm} / \mathrm{Xp}\right)$ entre as variáveis $\mathrm{Xm}$ que representam o sistema Sm (modelo reduzido) e as variáveis Xp que descrevem os sistema Sp (protótipo). As condições de semelhança são expressas como relações entre os fatores de escala $X^{*}$ ou, de modo equivalente, pela existência de relações adimensionais que devem conservar os mesmos valores, sejam para as variáveis dos modelos ou para as variáveis dos protótipos (Garnier, 2001).

De acordo com Garnier (2001), todos os sistemas físicos devem satisfazer equações da mecânica, e a análise dimensional efetuada nas variáveis das relações físicas conduz às seguintes condições de semelhança conhecidas:

$$
\sigma^{*}=\rho^{*} g^{*} l^{*} \text { e } \xi^{*}=g^{*} t^{* 2}
$$


onde :

$\sigma^{*}=$ fator de escala das tensões

$\rho^{*}=$ fator de escala de massas específicas

$\mathrm{g}^{*}=$ fator de escala de forças de massa

$1^{*}=$ fator de escala de forças de dimensões lineares

$\xi=$ fator de escala de deslocamentos

$t^{*}=$ fator de escala dos tempos

Segundo Garnier (2001), as duas relações apresentadas nas Equações 2.43 e 2.44 podem ser reunidas da seguinte forma:

$$
\frac{\sigma^{*} t^{*^{2}}}{\rho^{*} l^{* 2}}=1 \text { ou } \frac{F^{*} t^{* 2}}{\rho^{*} l^{* 4}}=1
$$

O comportamento do solo e dos materiais granulares é função da história do nível de tensões ao qual ele foi submetido. Deste modo, é essencial reproduzir em modelos reduzidos os mesmos estados de tensão que regem as obras geotécnicas em grandeza real, o que conduz à imposição da seguinte condição suplementar (Garnier, 2001):

$$
\sigma^{*}=1
$$

Para todos os parâmetros são dados números adimensionais e as condições de semelhanças são expressas em termos de $\mathrm{N}$-valores. Supondo que a aceleração é escalada em $\mathrm{N}$, os comprimentos serão escalados em 1/N (Fuglsang e Ovesen, 1988).

A Tabela 2.4 mostra os fatores de escala estabelecidos para parâmetros de solo para ensaios em centrífuga. 
Tabela 2.4 - Fatores de escala para ensaios em centrífuga (Fuglsang e Ovesen, 1988)

\begin{tabular}{|c|c|c|c|c|}
\hline Parâmetro & Símbolo & $\begin{array}{c}\text { Números } \\
\text { adimensionais }\end{array}$ & Similaridade requerida & $\begin{array}{c}\text { Fator de } \\
\text { escala }\end{array}$ \\
\hline Aceleração & $\mathrm{a}$ & - & $\mathrm{N}_{\mathrm{a}}=$ & $\mathrm{N}$ \\
\hline Dimensão & B & - & $\mathrm{N}_{\mathrm{B}}=$ & $1 / \mathrm{N}$ \\
\hline Compacidade & $\rho$ & - & $\mathrm{N}_{\rho}=$ & 1 \\
\hline Tamanho do grão & d & $\mathrm{d} / \mathrm{B}$ & $\mathrm{N}_{\mathrm{d}}=$ & 1 \\
\hline Índice de vazios & e & $\mathrm{E}$ & $\mathrm{N}_{\mathrm{e}}=$ & 1 \\
\hline Saturação & $\mathrm{S}_{\mathrm{r}}$ & $\mathrm{S}_{\mathrm{r}}$ & $\mathrm{N}_{\mathrm{S}}=$ & 1 \\
\hline $\begin{array}{l}\text { Compacidade } \\
\text { líquida }\end{array}$ & $\rho_{1}$ & $\rho_{1} / \rho$ & $\mathrm{N}_{\rho l}=\mathrm{N}_{\rho}=$ & 1 \\
\hline Tensão superficial & $\sigma_{\mathrm{t}}$ & $\sigma_{t} / a d B \rho_{1}$ & $\mathrm{~N}_{\sigma \mathrm{t}}=\mathrm{N}_{\rho} \mathrm{N}_{\mathrm{a}} \mathrm{N}_{\mathrm{d}} \mathrm{N}_{\mathrm{B}}=$ & 1 \\
\hline Capilaridade & $\mathrm{h}_{\mathrm{c}}$ & $\mathrm{h}_{\mathrm{c}} \mathrm{ad} \rho_{\mathrm{l}} / \sigma_{\mathrm{t}}$ & $\mathrm{N}_{\mathrm{h}}=\mathrm{N}_{\sigma \mathrm{t}} \mathrm{N}_{\rho}^{-1} \mathrm{~N}_{\mathrm{a}}^{-1} \mathrm{~N}_{\mathrm{d}}^{-1}=$ & $1 / \mathrm{N}$ \\
\hline Viscosidade & $\eta$ & $\eta / d \rho_{1} \sqrt{a L}$ & $\mathrm{~N}_{\eta}=\mathrm{N}_{\rho} \mathrm{N}_{\mathrm{a}}^{1 / 2} \mathrm{~N}_{\mathrm{d}} \mathrm{N}_{\mathrm{B}}^{1 / 2}=$ & 1 \\
\hline Permeabilidade & $\mathrm{k}$ & $\mathrm{k} \eta / \operatorname{ad}^{2} \rho_{1}$ & $\mathrm{~N}_{\mathrm{k}}=\mathrm{N}_{\rho} \mathrm{N}_{\mathrm{a}} \mathrm{N}_{\mathrm{d}}^{2} \mathrm{~N}_{\eta}^{-1}=$ & $\mathrm{N}$ \\
\hline Ângulo de atrito & $\phi$ & $\phi$ & $\mathrm{N}_{\phi}=$ & 1 \\
\hline $\begin{array}{l}\text { Tensão } \\
\text { interpartículas }\end{array}$ & $\sigma_{\mathrm{c}}$ & $\sigma_{c} / a B \rho$ & $\mathrm{N}_{\sigma \mathrm{c}}=\mathrm{N}_{\rho} \mathrm{N}_{\mathrm{a}} \mathrm{N}_{\mathrm{B}}=$ & 1 \\
\hline Coesão & $\mathrm{c}$ & $\mathrm{c} / \mathrm{aB} \rho$ & $\mathrm{N}_{\mathrm{c}}=\mathrm{N}_{\rho} \mathrm{N}_{\mathrm{a}} \mathrm{N}_{\mathrm{B}}=$ & 1 \\
\hline Compressibilidade & $\mathrm{E}$ & $\mathrm{E} / \mathrm{aB} \rho$ & $\mathrm{N}_{\mathrm{E}}=\mathrm{N}_{\rho} \mathrm{N}_{\mathrm{a}} \mathrm{N}_{\mathrm{B}}^{=}$ & 1 \\
\hline
\end{tabular}

\subsubsection{Modelagem física de ancoragem helicoidal em centrífuga}

Levesque (2002) realizou o primeiro estudo reportado na literatura sobre modelagem física de ancoragens helicoidais em centrífuga. As modelagens físicas das pesquisas anteriores sobre este tipo de fundação foram realizadas por meio de modelos testados a 1g. Neste trabalho citado, foram executados ensaios de tração de ancoragens com 2 hélices instaladas em amostras de areia (compacta e fofa), e os resultados foram usados com sucesso para verificação do método da ruptura cilíndrica para estimar capacidade de carga à tração. Este 
autor citado recomendou em sua tese que em estudos futuros fossem medidos os valores de torque de instalação deste tipo de fundação em vôo (durante a centrifugação).

No trabalho de Levesque (2002) foi concluído a partir dos resultados experimentais que o método da ruptura cilíndrica é conservador para ancoragens helicoidais instaladas em areia compacta, porém superestima a capacidade de carga para ancoragens em areia fofa.

Esta pesquisa também estudou o efeito do procedimento de instalação da ancoragem no maciço. Foi verificado por meio de ensaio de cone em centrífuga, realizado em torno da estaca após a sua instalação, que o ângulo de atrito do maciço de areia fofa (neste trabalho não foi verificado este efeito em areia compacta) diminuiu em torno de $10 \%$ em relação ao valor do ângulo de atrito de pico medido em ensaios de cisalhamento direto. 


\section{MODELO TEÓRICO}

Este capítulo descreve o modelo teórico proposto nesta tese que relaciona fisicamente o torque de instalação e a capacidade de carga à tração de uma estaca metálica helicoidal em solo arenoso. Este modelo foi desenvolvido para estacas metálicas helicoidais profundas (razão $\mathrm{H} / \mathrm{D}>5$, onde $\mathrm{H}$ é a profundidade e $\mathrm{D}$ o diâmetro da hélice superior). Neste caso, considera-se a resistência por atrito lateral no tubo da estaca tanto na fase de instalação como na fase de carregamento.

Nota-se pela Figura 2.29, apresentada revisão bibliográfica desta tese, sobre a verificação da teoria que relaciona torque de instalação com resistência à tração de uma ancoragem helicoidal de uma hélice instalada em areia, proposta por Ghaly et al. (1991b), que para ancoragens mais profundas esta relação proposta não é adequada (maior é a discrepância entre valores medidos e calculados). Segundo o autor da presente tese, isto ocorre porque a relação proposta por Ghaly et al. (1991b) não considera a resistência por atrito nas hastes das ancoragens profundas nas fases de instalação e de carregamento. Quanto maior a profundidade da estaca, maior será a magnitude da resistência por atrito em ambas as fases. Por esta razão, o modelo apresentado nesta pesquisa considera o atrito atuante no tubo da estaca.

\subsection{Premissas básicas do modelo}

\subsubsection{Fase de instalação}

Nesta proposição, os momentos resistentes originados em uma estaca metálica helicoidal durante a instalação em um maciço de areia são apresentados na Figura 3.1. Esta figura 
exemplifica uma estaca com três hélices, no entanto, o diagrama apresentado pode ser adotado para estacas helicoidais com uma ou mais hélices.

O valor do torque demandado para a instalação de uma estaca metálica helicoidal em um maciço de solo, apresentado na Figura 3.1, é dado pelo seguinte equação:

$$
T=T_{h}+T_{s}
$$

onde:

$\mathrm{T}=$ torque de instalação

$\mathrm{T}_{\mathrm{h}}=$ momento resistente à instalação atuante nas hélices

$\mathrm{T}_{\mathrm{s}}=$ momento resistente à instalação atuante na superfície do tubo

O momento resistente à instalação atuante nas hélices $\left(T_{h}\right)$ é expresso por:

$$
T_{h}=\sum_{i=1}^{N} T_{h i}
$$

onde:

$\mathrm{T}_{\mathrm{hi}}=$ momento resistente à instalação atuante na hélice $\mathrm{i}$

$\mathrm{i}=$ índice de $1 \mathrm{a} \mathrm{N}$

$\mathrm{N}=$ número de hélices 

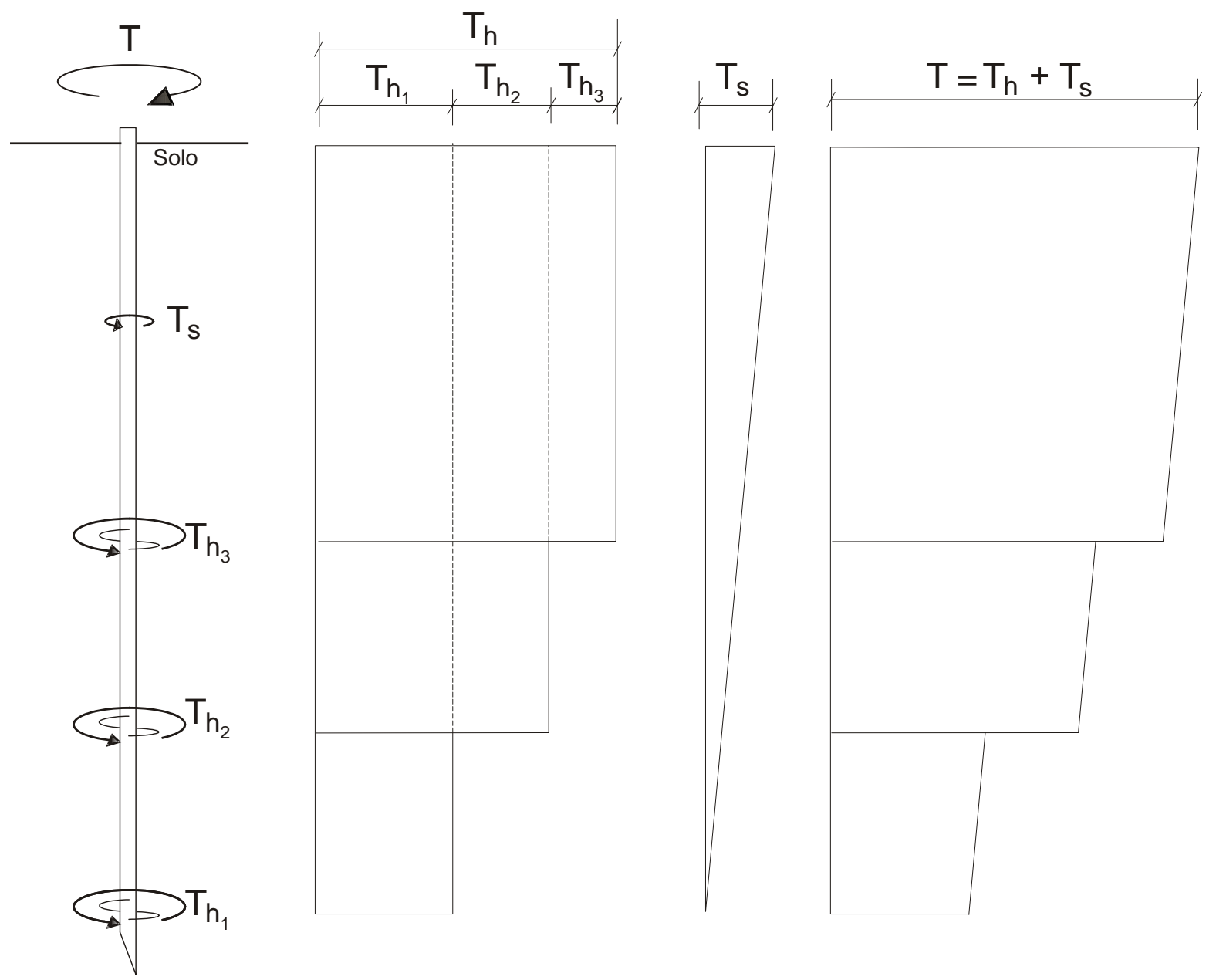

Figura 3.1 - Diagrama dos momentos resistentes originados em uma estaca metálica helicoidal durante a instalação

\subsubsection{Fase de carregamento}

No presente modelo, as forças resistentes ao arrancamento de uma estaca metálica helicoidal com três hélices são mostradas na Figura 3.2. O exemplo da Figura 3.2 apresenta uma estaca com três hélices, no entanto, o diagrama apresentado é proposto para estacas helicoidais com uma ou mais hélices. De acordo com esta figura, a capacidade de carga à tração da estaca é igual à soma da resistência por atrito lateral do tubo com as capacidades de carga relativa às hélices (Equação 3.3) 
Adams e Klym (1972) citaram que durante o arrancamento de uma estaca metálica helicoidal multi-hélices, cada hélice se comporta independentemente da outra se o espaçamento vertical entre elas for no mínimo igual a duas vezes o diâmetro da hélice inferior. O método de cálculo de capacidade de carga à tração da A.B. Chance Company, que assume que a ruptura ocorre individualmente acima de cada hélice, reportado na literatura por Clemence et al. (1994), é recomendado para estacas metálicas helicoidais fabricadas com o espaçamento entre hélices maiores ou iguais a três vezes o diâmetro da menor hélice.

Como as estacas metálicas helicoidais fabricadas no Brasil e as utilizadas nos experimentos deste trabalho foram fabricadas com espaçamento entre as hélices igual a três vezes o diâmetro da menor hélice, o modelo apresentado assume que a ruptura ocorre individualmente acima de cada hélice. Portanto, a teoria proposta é recomendada somente para estacas metálicas helicoidais fabricadas com o espaçamento entre hélices maiores ou iguais a três diâmetros da menor hélice.

A capacidade de carga à tração $\left(\mathrm{Q}_{u}\right)$, indicada na Figura 3.2, é calculada pela seguinte equação:

$$
Q_{u}=Q_{s}+Q_{h}
$$

onde:

$\mathrm{Q}_{\mathrm{u}}=$ capacidade de carga à tração

$\mathrm{Q}_{\mathrm{s}}=$ resistência por atrito lateral do tubo

$\mathrm{Q}_{\mathrm{h}}=$ parcela da capacidade de carga à tração relativa às hélices 

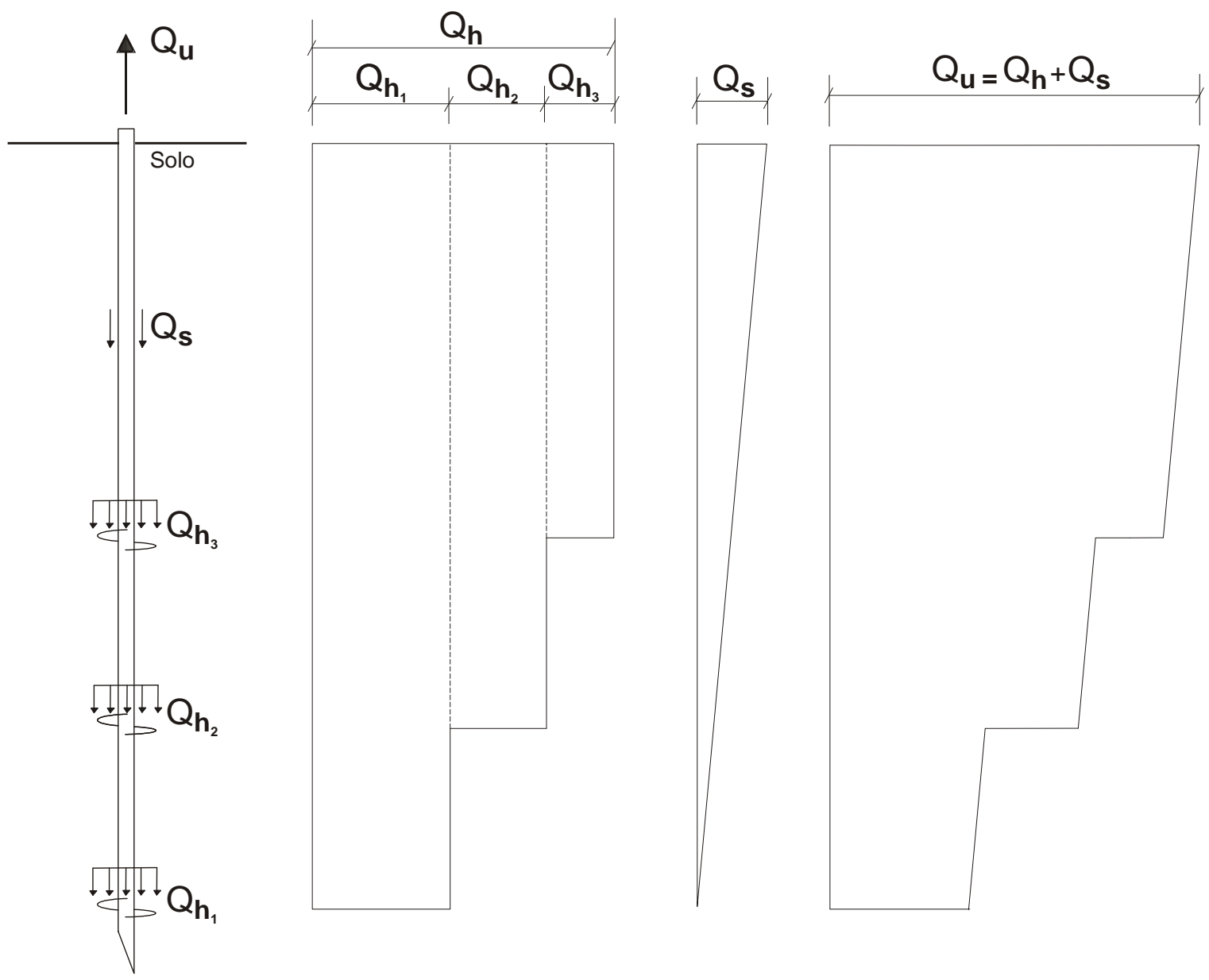

Figura 3.2 - Diagrama de forças resistentes ao arrancamento de uma estaca metálica helicoidal

A parcela de capacidade de carga à tração relativa às hélices $\left(\mathrm{Q}_{\mathrm{h}}\right)$ é expressa por:

$$
Q_{h}=\sum_{i=l}^{N} Q_{h i}
$$

onde:

$\mathrm{Q}_{\mathrm{hi}}=$ parcela de capacidade de carga relativa à hélice $\mathrm{i}$

$\mathrm{i}=$ índice de 1 a $\mathrm{N}$

$\mathrm{N}=$ número de hélices 


\subsection{Relação teórica entre o torque de instalação e a capacidade de carga à tração}

No modelo proposto, duas equações fundamentais são apresentadas. A primeira relaciona fisicamente a resistência por atrito lateral do tubo $\left(\mathrm{Q}_{\mathrm{s}}\right)$ e momento resistente à instalação gerado na superfície do tubo $\left(\mathrm{T}_{\mathrm{s}}\right)$. A segunda relaciona fisicamente a parcela de capacidade de carga à tração relativa às hélices $\left(\mathrm{Q}_{\mathrm{h}}\right)$ e momento resistente à instalação gerado nas hélices $\left(\mathrm{T}_{\mathrm{h}}\right)$. A partir da união destas equações tem-se a relação teórica proposta entre o torque de instalação e a capacidade de carga à tração de uma estaca metálica helicoidal

\subsubsection{Relação física entre $Q_{s} \mathbf{e} T_{s}$}

Esta relação apresentada considera que a resistência por atrito lateral do tubo de uma estaca metálica helicoidal submetida a um carregamento axial é representada pela resistência por atrito lateral do tubo derivada do carregamento torcional durante a instalação da estaca na areia. Deste modo, a equação que relaciona fisicamente a resistência por atrito lateral do tubo $\left(\mathrm{Q}_{\mathrm{s}}\right)$ e momento resistente à instalação gerado na superfície do tubo $\left(\mathrm{T}_{\mathrm{s}}\right)$ medido no final da instalação da estaca é a seguinte:

$$
Q_{s}=\frac{2 T_{s}}{d}
$$

onde:

d = diâmetro externo do tubo

Stoll (1972) desenvolveu um ensaio de campo para medir a resistência ao cisalhamento na interface tubo-solo por torção. De acordo com este autor, os valores de atrito lateral obtidos 
por ensaios de torque são conservadores quando extrapolados para estacas carregadas axialmente. Neste trabalho citado, os resultados de atrito lateral obtidos por medidas de torque foram comparados com resultados de atrito lateral obtidos por meio de cravação de estacas, e mostraram-se aproximados.

Segundo Kelley e Lutenegger (2004), a resistência por atrito lateral ao longo do comprimento de uma estaca é determinada multiplicando-se a área lateral total da estaca pelo atrito lateral unitário (resistência por atrito por unidade de área). Estes autores reportaram que o atrito lateral unitário obtido por sondagem à percussão com medida de torque, por ensaio de cone, e retrocalculado de provas de carga em estacas são equivalentes. Neste estudo mencionado, o atrito lateral unitário $\left(\mathrm{f}_{\mathrm{s}}\right)$ medido pelo ensaio SPT com medida de torque é expresso por:

$$
f_{s}=\frac{2 T}{\pi d^{2} L}
$$

onde:

$\mathrm{T}=$ torque medido

d = diâmetro externo do amostrador

$\mathrm{L}=$ comprimento penetrado

Zhang and Kong (2006) realizaram testes de modelos em centrífuga para investigar o comportamento referente à torção de uma estaca modelo instrumentada instalada em areia fofa e densa. Nesta pesquisa, a resistência média por atrito lateral obtido por torção da estaca na areia densa mostrou-se levemente maior do que a resistência média por atrito lateral obtida por carregamento axial, enquanto que na areia fofa ocorreu o oposto. Estes autores concluíram 
que estas diferenças insignificantes ocorreram porque na areia densa a tensão horizontal é maior do que a vertical, e na areia fofa a tensão horizontal é menor do que a vertical.

Baseando-se nestes estudos anteriores, e considerando-se que a diferença entre a resistência por atrito lateral de uma estaca submetida a carregamento torcional e a de uma estaca submetida a carregamento axial medida em Zhang e Kong (2006) é irrelevante, foi assumido no modelo proposto que a resistência por atrito lateral do tubo de uma estaca metálica helicoidal pode ser estimada pelo torque necessário para rotacionar o tubo na areia como mostra a Equação (3.5). Nesta hipótese, considera-se que o distúrbio causado no solo pelo movimento da hélice em uma camada de areia durante a instalação afeta igualmente a momento resistente à instalação atuante na superfície do tubo $\left(\mathrm{T}_{\mathrm{s}}\right)$ e a resistência por atrito lateral do tubo $\left(\mathrm{Q}_{\mathrm{s}}\right)$ quando carregado axialmente.

Para a aplicação da Equação (3.5) do modelo teórico apresentado, o momento resistente à instalação gerado na superfície do tubo $\left(\mathrm{T}_{\mathrm{s}}\right)$ pode ser estimado pela a resistência por atrito lateral do tubo $\left(\mathrm{Q}_{\mathrm{s}}\right)$ calculada pelo método de Mitsch e Clemence (1985) pela Equação 2.11 apresentada na revisão bibliográfica. No entanto, recomenda-se que seja calculada a resistência por atrito lateral ao longo de todo o comprimento do tubo (descontando-se somente a região relativa às hélices), e não somente acima da hélice superior como é considerado na Equação 2.11.

\subsubsection{Relação física entre $Q_{h}$ e $T_{h}$}

A relação física entre a parcela de capacidade de carga à tração relativa às hélices $\left(Q_{h}\right)$ e momento resistente à instalação gerado nas hélices $\left(T_{h}\right)$ é baseada em um mecanismo comumente utilizado em Elementos de Máquinas para projetar parafusos de força (também chamado de parafuso de acionamento ou parafuso de potência). Este tipo de parafuso converte 
o movimento de rotação em movimento linear e extrai sua força do fato de ser girado por uma alavanca. Como exemplos conhecidos deste tipo parafuso temos: a prensa, o torno de bancada, o macaco de rosca e o saca-rolhas (O’Brien, 1964).

De acordo com Ghaly et al. (1991b), o torque aplicado à estaca é resistido por um sistema de forças agindo na superfície superior da hélice. Estes autores afirmam que este sistema de forças que se desenvolvem devido à penetração impedida da hélice é igual à capacidade de carga à tração de uma estaca helicoidal (com uma hélice) para uma mesma profundidade. Weech (2002) cita que durante a instalação da estaca metálica helicoidal, a resistência à penetração do tubo da estaca no solo produz uma força (direcionada para cima) na estaca, que deve ser compensada pela resistência (direcionada para baixo) mobilizada ao longo da superfície superior das hélices, desde que não seja aplicada na estaca nenhuma força externa durante a instalação.

Os autores citados no parágrafo anterior relataram que durante a instalação da estaca helicoidal surgem forças agindo na superfície superior das hélices. No presente modelo, a soma destas forças é avaliada como a parcela de capacidade de carga à tração relativa às hélices $\left(\mathrm{Q}_{\mathrm{h}}\right)$ indicada na Figura 3.2.

A Figura 3.3 apresenta o esquema de forças que compensam as forças resistentes à penetração de estacas metálicas helicoidais (com uma ou mais hélices) no solo durante a instalação. Nesta fase, as hélices tendem a empurrar para cima o solo em contato na superfície superior e este esforço é contrabalançado pela parcela de capacidade de carga à tração relativa às hélices $\left(\mathrm{Q}_{\mathrm{h}}\right)$. Na Figura 3.3 a força $\mathrm{F}_{\mathrm{at}}$ representa a força de atrito que é mobilizada na superfície da hélice em contato com a areia durante a instalação, e o torque $T_{h}$ representa momento resistente à instalação gerado nas hélices (Figura 3.1). 



Figura 3.3 - Forças que compensam as forças resistentes à penetração da estaca no solo por rotação

Analogamente aos parafusos, a estaca metálica helicoidal é composta de uma haste central onde são soldadas hélices. O modelo físico apresentado é uma adaptação do modelo de cálculo utilizado em parafusos de força para o caso de estacas metálicas helicoidais instaladas em areia.

Neste modelo ajustado, apresentado na Figura 3.4, a hélice da estaca é equivalente à rosca do parafuso, a areia que envolve a estaca à porca, o ângulo de atrito residual entre a hélice e a areia envolvente $\left(\delta_{\mathrm{r}}\right)$ ao ângulo de atrito cinético entre o material da rosca do parafuso e o material da porca $(\beta)$, a carga a ser movimentada $(\mathrm{W})$ à parcela de capacidade de carga à tração relativa às hélices $\left(\mathrm{Q}_{\mathrm{h}}\right)$, e o torque aplicado ao parafuso $(\mathrm{T})$ ao momento resistente à instalação atuante nas hélices $\left(T_{h}\right)$. 


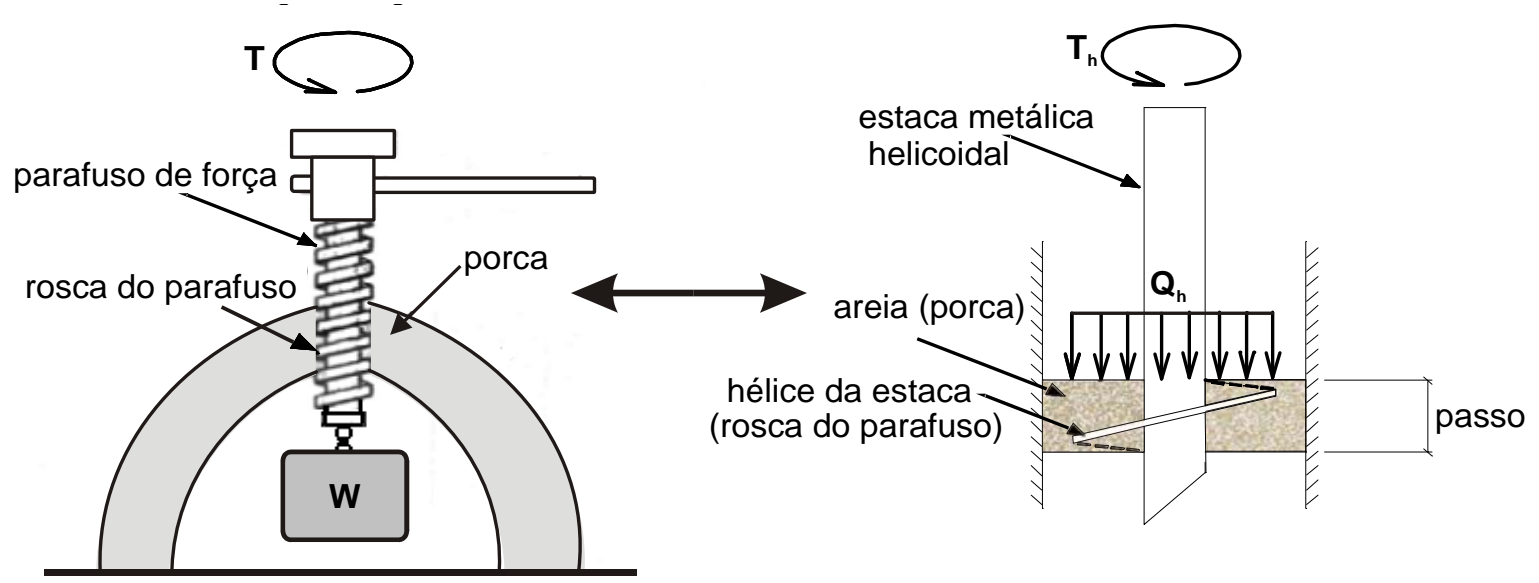

Figura 3.4 - Analogia entre um exemplo de parafuso de força e uma estaca metálica helicoidal

O procedimento de projeto de um parafuso de força foi descrito por Faires (1943). Segundo este autor, para obter-se a tensão torcional induzida pelo giro de um parafuso contra uma carga, deve-se derivar uma expressão do momento de torção necessário para movimentar a carga. Nesta descrição, a superfície da hélice é representada por um plano inclinado em torno de um cilindro. A Figura 3.5(b) mostra a hélice desenvolvida para simplificar a análise das forças. Nesta figura, a carga é representada por um bloco (com peso igual a W) posicionado sobre um plano inclinado, e a carga é movimentada a uma altura igual ao passo da hélice (correspondente a uma volta). As forças que agem no bloco (Figura 3.5) são o peso W (Figura 3.4), a força $Q$ que empurra o peso para cima ao longo do plano, a resistência por atrito $F_{t}$, e a reação normal $N$. A resistência por atrito $F_{t}$ e a reação normal $N$ combinadas resultam na reação total do plano R. A Figura. 3.6 mostra o triângulo de forças correspondente à Figura 3.5(b).

A Figura 3.5(b) é semelhante á Figura 2.28 da revisão bibliográfica desta pesquisa apresentada por Ghaly et al. (1991b). 


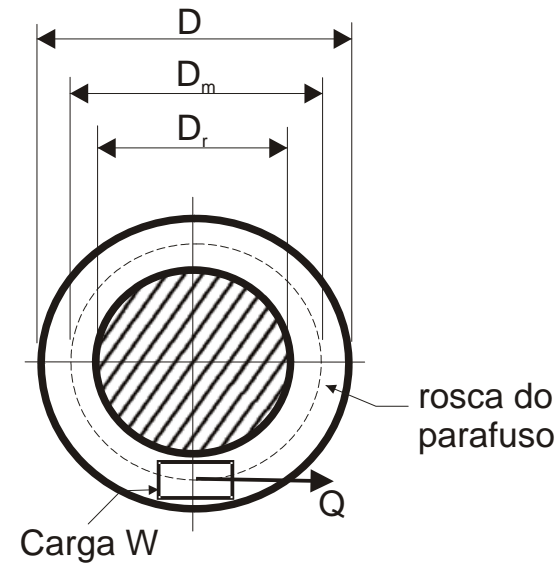

a) Vista superior da rosca do parafuso

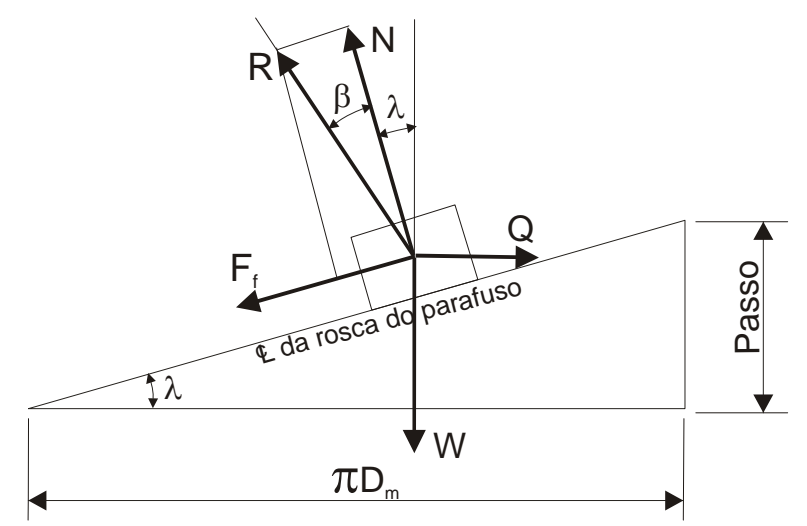

b) Linha central da rosca do parafuso desenvolvida

Figura 3.5 - Forças em um corpo movendo-se para cima em um plano inclinado (Faires, 1943)



Figura 3.6 - Triângulo de forças correspondente à Figura. 3.5 (b)

A equação mostrada abaixo foi obtida a partir da representação gráfica apresentada na Figura 3.6:

$$
W=\frac{Q}{\tan (\lambda+\beta)}
$$

onde:

$\mathrm{W}$ = carga total acima da hélice a ser movida para cima durante a penetração da hélice $\lambda=$ ângulo da linha central da rosca do parafuso em relação à horizontal 
$\beta=$ ângulo de atrito entre o material da rosca do parafuso e o material da porca $\mathrm{Q}=$ força necessária para mover a carga

O torque T necessário para rotacionar o parafuso contra a carga é dado por:

$$
T=Q \cdot \frac{D_{m}}{2}
$$

onde:

$\mathrm{D}_{\mathrm{m}}=$ diâmetro médio da rosca do parafuso

O diâmetro médio da rosca do parafuso $\left(\mathrm{D}_{\mathrm{m}}\right)$ é calculado pela seguinte equação:

$$
D_{m}=\frac{D+D_{r}}{2}
$$

onde:

$\mathrm{D}=$ diâmetro externo da rosca do parafuso

$\mathrm{D}_{\mathrm{r}}=$ diâmetro interno da rosca do parafuso

Substituindo-se a Equação (3.8) na Equação (3.7), a relação entre a carga a ser movida (W) e o torque necessário para rotacionar o parafuso contra a carga $(\mathrm{T})$, pode ser expresso pela seguinte equação:

$$
W=\frac{2 T}{D_{m} \cdot \tan (\lambda+\beta)}
$$


As Figuras 3.7 e 3.8 mostram a adaptação das Figuras 3.5 e 3.6 para o caso de estacas metálicas helicoidais, onde o maciço de areia funciona como porca e a estaca metálica helicoidal como um parafuso. Na Figura 3.7 a força $F_{\text {at }}$ representa a força de atrito que é mobilizada na superfície da hélice em contato com a areia durante a instalação. Neste ajuste do modelo utilizado em parafusos de força para o caso de estacas metálicas helicoidais instaladas em areia é analisado o equilíbrio de forças ativas na hélice da estaca durante a instalação. Neste modelo não são examinadas as forças reativas no maciço de solo envolvente.

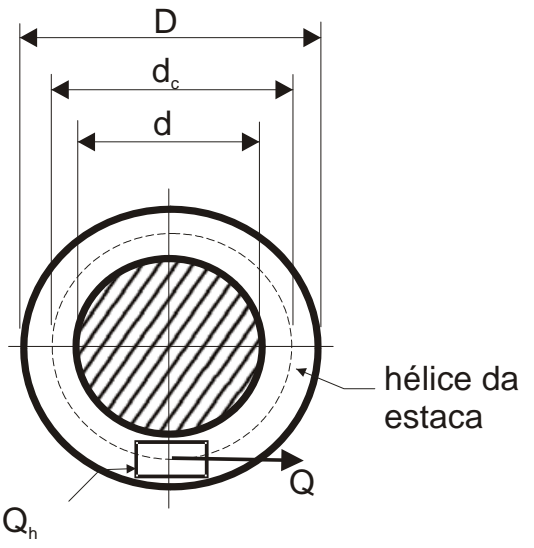

a) Vista superior da hélice da estaca

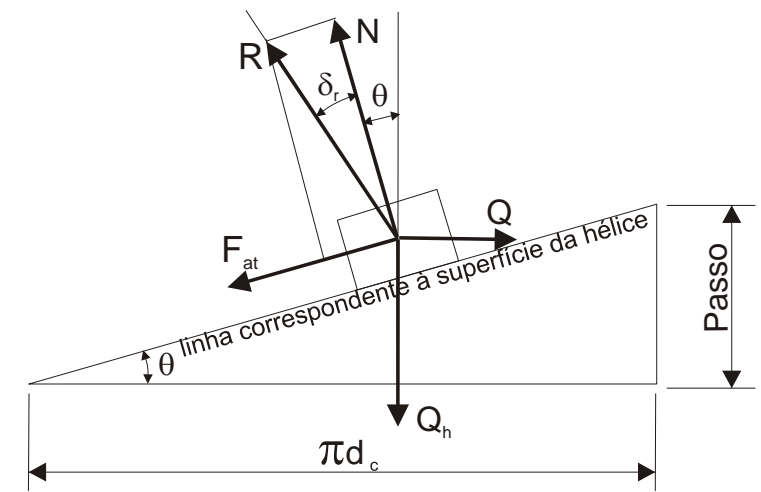

b) Linha correspondente à superfície da hélice desenvolvida (onde as forças resistentes se concentram durante a instalação da estaca)

Figura 3.7 - Adaptação da Figura. 3.5 para o caso de uma estaca metálica helicoidal instalada em areia

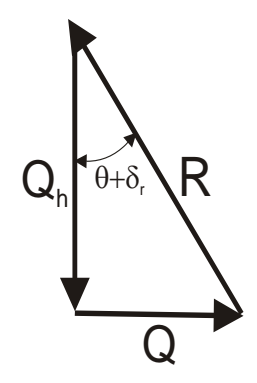

Figura 3.8 - Triângulo de forças correspondente à Figura 3.7 (b) 
A força F da Figura 2.28 (revisão bibliográfica) apresentada por Ghaly et al. (1991b) corresponde ao peso W da Figura 3.5 (Faires, 1943) e à parcela de capacidade de carga à tração relativa às hélices $\mathrm{Q}_{\mathrm{h}}$ do modelo proposto nesta tese (Figura 3.7).

O momento resistente à instalação atuante nas hélices $\left(\mathrm{T}_{\mathrm{h}}\right)$ é dado por:

$$
T_{h}=Q_{h} \cdot \frac{d_{c}}{2}
$$

onde:

$\mathrm{d}_{\mathrm{c}}=$ diâmetro do círculo correspondente a superfície da hélice (onde as forças resistentes são concentradas durante a instalação da estaca)

O diâmetro do círculo correspondente a superfície da hélice $\left(\mathrm{d}_{\mathrm{c}}\right)$ e o ângulo da linha correspondente a este círculo com a horizontal $(\theta)$ são dados pelas seguintes expressões:

$$
\begin{gathered}
d_{c}=\frac{2}{3}\left[\frac{D^{3}-d^{3}}{D^{2}-d^{2}}\right] \\
\theta=\tan ^{-1}\left(\frac{p}{\pi d_{c}}\right)
\end{gathered}
$$

onde:

$\mathrm{D}=$ diâmetro externo da hélice

d = diâmetro externo do tubo

$\mathrm{p}=$ passo da hélice na linha correspondente a superfície da hélice 
A partir das Figuras 3.7 e 3.8, a Equação (3.10) do parafuso de força adaptada para o caso de uma estaca metálica helicoidal instalada em areia é dada por:

$$
Q_{h}=\frac{2 T_{h}}{d_{c} \cdot \operatorname{tg}\left(\theta+\delta_{r}\right)}
$$

onde:

$\theta=$ ângulo da linha correspondente a superfície da hélice com a horizontal $\delta_{\mathrm{r}}=$ ângulo de atrito residual na interface entre a hélice e a areia envolvente

A Equação (3.12) é idêntica a equação publicada por Higdon e Stiles (1968) (divulgada igualmente por outros autores em livros de mecânica) para a determinação do raio de um círculo correspondente à superfície de um disco de embreagem, submetido a um momento necessário para vencer a resistência devida ao atrito, quando a pressão sobre o disco é assumida como uniformemente distribuída sobre a área de contato. Esta equação foi também utilizada por Conciani (1989) para determinar o raio de um círculo equivalente à superfície de uma placa helicoidal, onde as forças resistentes são concentradas durante a instalação da placa no terreno. Ghaly et al. (1991b) também utilizaram esta equação para determinar o diâmetro do círculo equivalente à superfície da hélice de uma ancoragem helicoidal, onde as forças resistentes são concentradas durante a sua instalação na areia.

A relação física entre a parcela de capacidade de carga à tração relativa às hélices $\left(\mathrm{Q}_{\mathrm{h}}\right)$ e o momento resistente à instalação atuante nas hélices $\left(T_{h}\right)$, demonstrada pela Equação (3.14), foi desenvolvida para controlar a capacidade de carga à tração de estacas metálicas helicoidais, com uma ou mais hélices de mesma dimensão e mesma areia envolvente, e com o espaçamento entre hélices maior que três vezes o diâmetro destas. Estas condições foram respeitadas nos experimentos realizados em centrífuga nesta tese. 


\subsubsection{Relação física entre $Q_{u}$ e $T$}

A equação que explana a relação física entre a capacidade de carga à tração $\left(Q_{u}\right)$ e as parcelas $T_{s}$ e $T_{h}$, componentes do torque final de instalação, foi desenvolvida substituindo-se as Equações (3.5) e (3.14) na Equação (3.3). Como resultado, o modelo teórico proposto nesta tese é expresso pela seguinte equação:

$$
Q_{u}=\frac{2 T_{s}}{d}+\frac{2 T_{h}}{d_{c} \cdot \operatorname{tg}\left(\theta+\delta_{r}\right)}
$$

O primeiro componente da Equação (3.15) é a resistência por atrito lateral do tubo $\left(\mathrm{Q}_{\mathrm{s}}\right)$ representada pela Equação (3.5) e o segundo componente é a capacidade de carga à tração relativa às hélices $\left(\mathrm{Q}_{\mathrm{h}}\right)$ representada pela Equação (3.14).

Como mencionado anteriormente, a capacidade de carga à tração da estaca metálica helicoidal é controlada pelo torque medido ao final da instalação. Por esta razão, este valor de torque deve ser estimado na fase de projeto, anteriormente à execução da estaca. Para este fim, substituindo-se as Equações (3.5) e (3.14) na Equação (3.1), a relação entre o valor do torque final de instalação $(\mathrm{T})$ e as parcelas $\mathrm{Q}_{\mathrm{s}}$ e $\mathrm{Q}_{\mathrm{h}}$, componentes da capacidade de carga à tração da estaca, é dada pela seguinte expressão:

$$
T=\frac{Q_{s} d}{2}+\frac{Q_{h} d_{c} \tan \left(\theta+\delta_{r}\right)}{2}
$$

O primeiro componente da Equação (3.16) é o momento resistente à instalação atuante na superfície do tubo $\left(\mathrm{T}_{\mathrm{s}}\right)$ representado pela Equação (3.5) e o segundo componente é o momento resistente à instalação atuante nas hélices $\left(\mathrm{T}_{\mathrm{h}}\right)$ representado pela Equação (3.14). 
Durante a fase de projeto, para estimar-se o valor de torque correspondente ao final da instalação de uma estaca metálica helicoidal, a magnitude das parcelas $\mathrm{Q}_{\mathrm{s}}$ e $\mathrm{Q}_{\mathrm{h}}$, componentes da capacidade de carga à tração, podem ser calculadas individualmente pelos métodos existentes para ancoragens helicoidais apresentados na revisão bibliográfica, e o ângulo de atrito residual na interface hélice-areia pode ser estimado de acordo com as propriedades da interface.

Para a aplicação deste método na prática de estacas metálicas helicoidais, foram realizados ensaios de cisalhamento direto de interface entre a chapa da hélice comercialmente utilizada na fabricação deste tipo de estaca e diferentes tipos de areia, com a finalidade de auxiliar o projetista deste tipo de fundação na estimativa do ângulo de atrito residual na interface héliceareia.

A Equação (3.16) proporciona um método simples para o cálculo do torque final necessário para a instalação de uma estaca metálica helicoidal. No entanto, como critério de finalização da instalação de uma estaca metálica helicoidal deve-se verificar duas ocorrências importantes. A primeira é o valor do torque final de instalação, que pode ser estimado por esta equação. A segunda é a profundidade mínima da estaca que corresponde aos valores mínimos de $\mathrm{Q}_{\mathrm{s}}$ e $\mathrm{Q}_{\mathrm{h}}$ calculados em projeto de acordo com as propriedades do solo e geometria da estaca. 
Neste capítulo é apresentada a descrição dos materiais e métodos utilizados nos ensaios realizados para esta pesquisa. Os experimentos desta tese foram divididos dois grupos: ensaios de campo e ensaios de laboratório.

Os ensaios de campo são constituídos de provas de carga à tração em estacas metálicas helicoidais realizadas em dois diferentes terrenos. Os ensaios executados em Contagem (Minas Gerais) fazem parte de um trabalho realizado pela empresa Vértice Engenharia, para verificar a configuração de estacas que seriam posteriormente utilizadas em uma obra. Os demais ensaios foram realizados no Campo Experimental da EESC.

Os ensaios de laboratório foram divididos em três grupos. O primeiro corresponde aos ensaios de modelagem física em centrífuga realizados no Laboratoire Central des Ponts et Chaussées (LCPC) em Nantes na França. O segundo grupo engloba os ensaios de cisalhamento direto de interface, sendo que uma parte foi realizada no laboratório de mecânica dos solos do Laboratoire Central des Ponts et Chaussées (LCPC) e outra parte no laboratório de mecânica dos solos da Escola de Engenharia de São Carlos (USP). O terceiro grupo de ensaios refere-se aos ensaios de torção de tubos de estacas metálicas helicoidais realizados no Departamento de Estruturas da Escola de Engenharia de São Carlos (USP).

\subsection{Ensaios de campo}

\subsubsection{Provas de Carga em Contagem}

Quatro provas de carga à tração foram realizadas em terreno localizado na Rua Pará de Minas, Contagem - MG. As estacas ensaiadas (Figura 4.1) foram fabricadas com tubos de 
diferentes diâmetros e espessuras, e também com diferente número de diâmetro de hélices de acordo com a Tabela 4.1.

A Figura 4.2 apresenta o resultado de uma sondagem à percussão realizada próxima ao local de instalação das estacas. O nível d'água não foi detectado nesta sondagem.

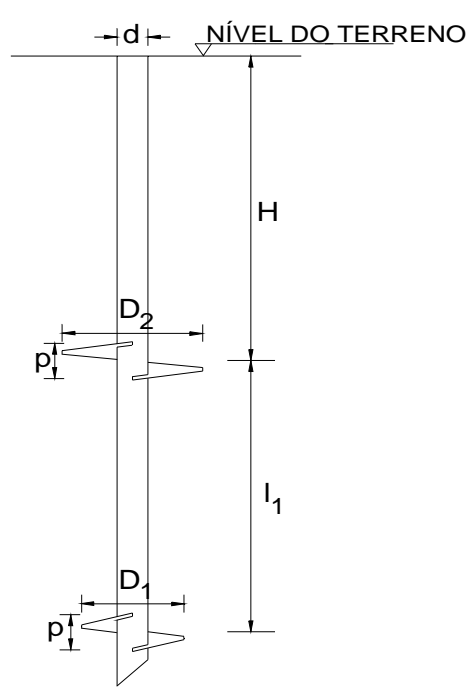
a) ESTACAS COM 2 HÉLICES
b) ESTACAS COM 3 HÉLICES

Figura 4.1 - Estacas utilizadas nos ensaios em Contagem

As estacas foram instaladas no terreno por meio de motor hidráulico adaptado a retroescavadeira (Figura 4.3). Em todas as estacas foram adicionadas seções de extensão às seções guia (que contém as hélices) para atingir as profundidades definidas anteriormente em projeto de acordo com o torque final de instalação medido. A conexão entre a seção guia e a extensão (Figura 4.4) foi feita por meio de parafusos (os tubos de extensão apresentam a extremidade alargada para a emenda). $\mathrm{O}$ valor do torque de instalação necessário para a 
penetração da estaca foi medido a cada metro por meio do torquímetro conectado ao topo da estaca (Figuras 4.3 e 4.5).

Tabela 4.1 - Dimensões das estacas ensaiadas em Contagem

\begin{tabular}{|c|c|c|c|c|c|c|c|c|c|c|}
\hline \multirow{2}{*}{ 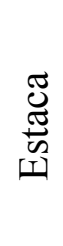 } & \multirow{2}{*}{ 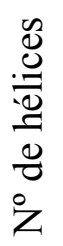 } & \multirow{2}{*}{ 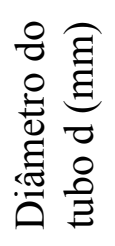 } & \multirow{2}{*}{ 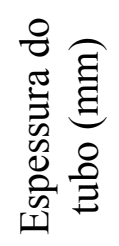 } & \multicolumn{3}{|c|}{$\begin{array}{l}\text { Diâmetro das hélices } \\
\qquad(\mathrm{mm})\end{array}$} & \multicolumn{2}{|c|}{$\begin{array}{l}\text { Espaçamento } \\
(\mathrm{mm})\end{array}$} & \multirow{2}{*}{ 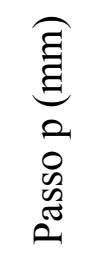 } & \multirow{2}{*}{ 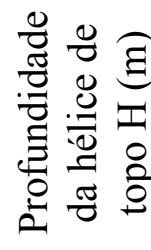 } \\
\hline & & & & $\mathrm{D}_{1}$ & $\mathrm{D}_{2}$ & $\mathrm{D}_{3}$ & $1_{1}$ & $1_{2}$ & & \\
\hline $1 \mathrm{C}$ & 2 & 73,0 & 7,01 & 304,8 & 355,6 & - & 914,4 & - & 97,0 & 4,64 \\
\hline $2 \mathrm{C}$ & 3 & 73,0 & 7,01 & 254,0 & 304,8 & 304,8 & 762,0 & 914,4 & 97,0 & 3,47 \\
\hline $3 C$ & 3 & 101,6 & 8,08 & 254,0 & 304,8 & 304,8 & 762,0 & 914,4 & 97,0 & 4,07 \\
\hline $4 C$ & 3 & 101,6 & 8,08 & 254,0 & 304,8 & 355,6 & 762,0 & 914,4 & 97,0 & 4,47 \\
\hline
\end{tabular}

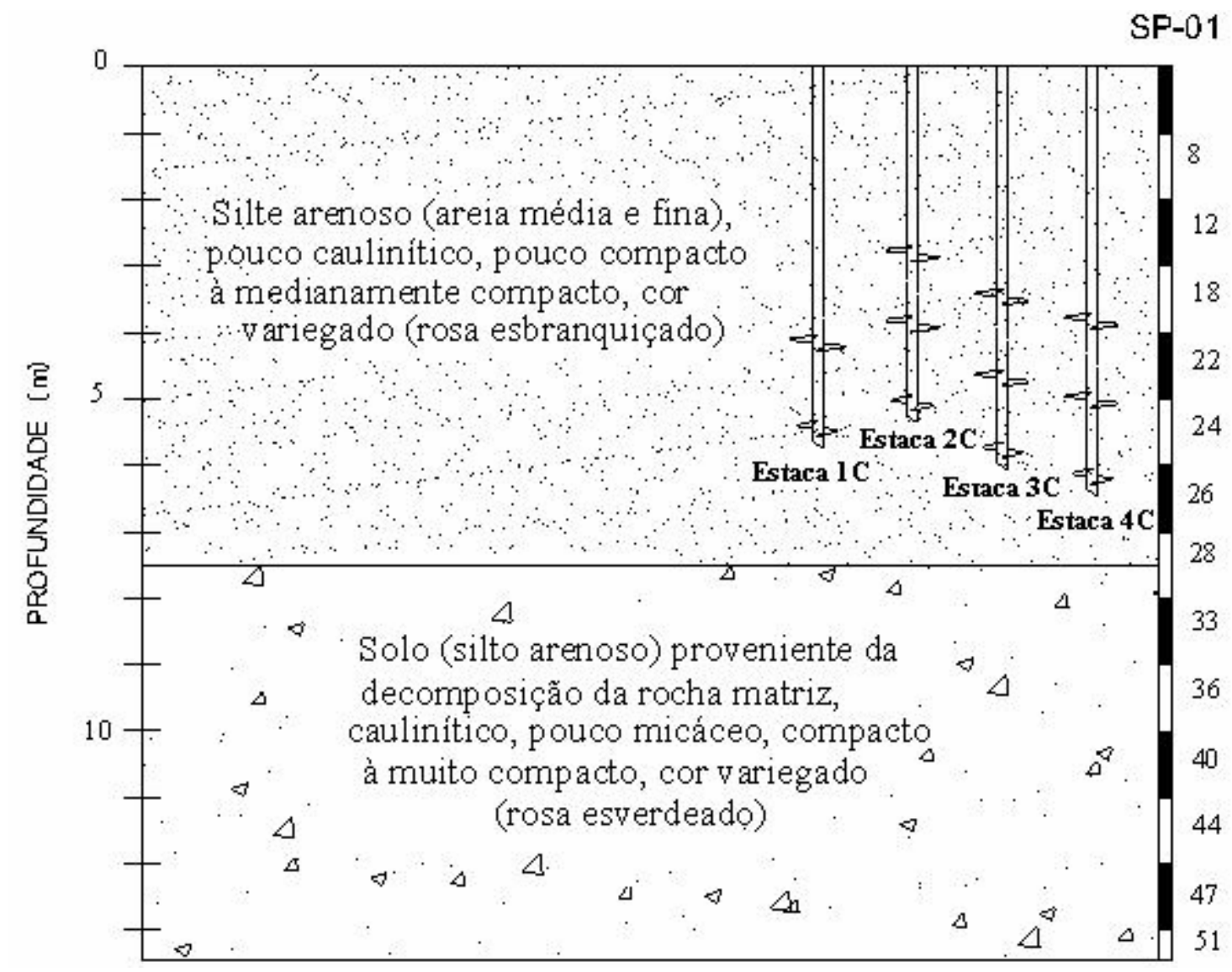

Figura 4.2 - Perfil geotécnico do maciço de instalação das estacas 1C, 2C, 3C e 4C 
A aplicação da carga nas provas de carga à tração foi feita por um cilindro hidráulico com capacidade de 60 toneladas, alimentado por bomba manual. A viga de reação utilizada foi projetada para suportar com segurança as cargas previstas nos ensaios. Sob a viga, dormentes foram dispostos no solo (Figura 4.6) para suportar a compressão durante o carregamento.

Durante os ensaios, as cargas aplicadas axialmente às estacas foram medidas por um manômetro instalado no sistema de alimentação do cilindro hidráulico. Os deslocamentos axiais no topo das estacas foram medidos simultaneamente por meio de dois relógios comparadores mecânicos (50 $\mathrm{mm}$ de curso e leituras a cada $0,01 \mathrm{~mm}$ ) instalados em um eixo ortogonal à viga de reação (Figura 4.7).

As provas de carga foram realizadas em três ciclos de carregamento e descarregamento. No primeiro ciclo o carregamento foi feito até a carga de trabalho da estaca, no segundo até a carga correspondente a 1,2 vezes a carga de trabalho, e no terceiro ciclo até a carga correspondente a duas vezes a carga de trabalho ou até o deslocamento de $5 \mathrm{~cm}$ da cabeça da estaca. $\mathrm{O}$ aumento da carga foi feito em etapas, onde o carregamento foi mantido constante por um intervalo de tempo de cinco minutos. Nos estágios de carregamento os incrementos foram de $10 \%$ da carga de trabalho, e nos estágios de descarregamento foram de $20 \%$.
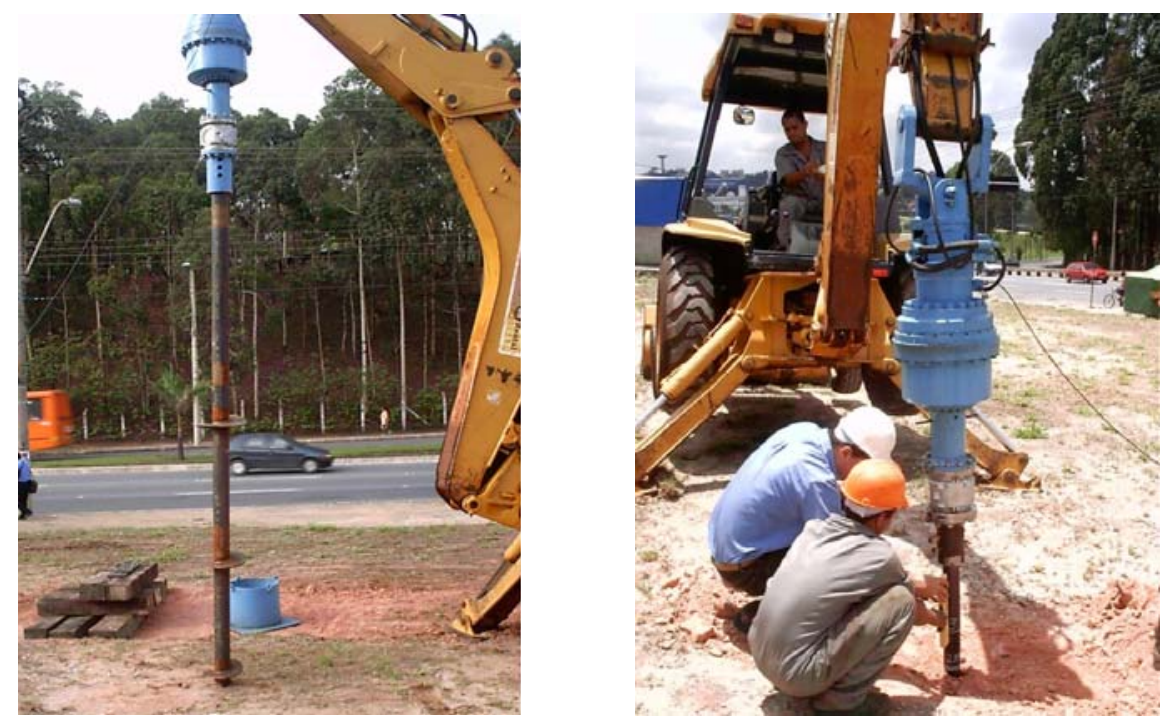

Figura 4.3 - Instalação de estaca metálica helicoidal em Contagem 


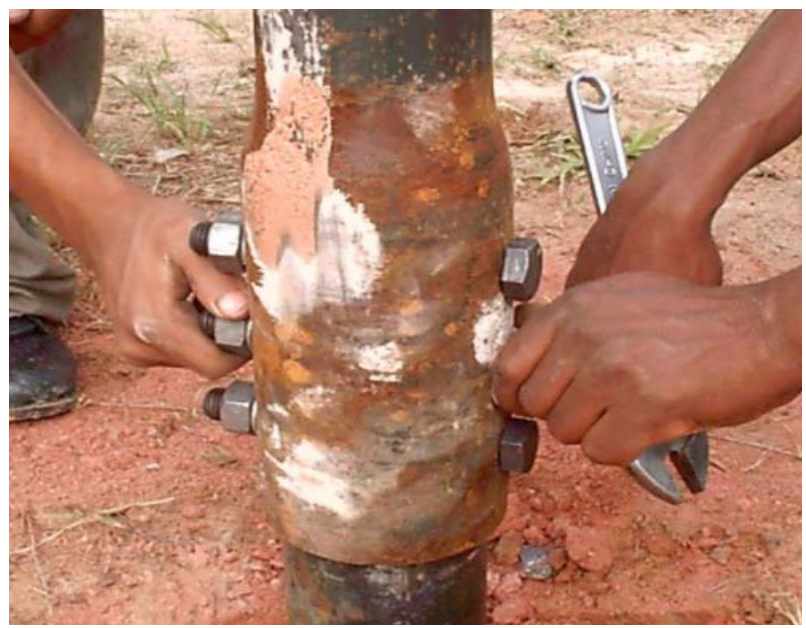

Figura 4.4 - Procedimento de emenda da estaca (Contagem)

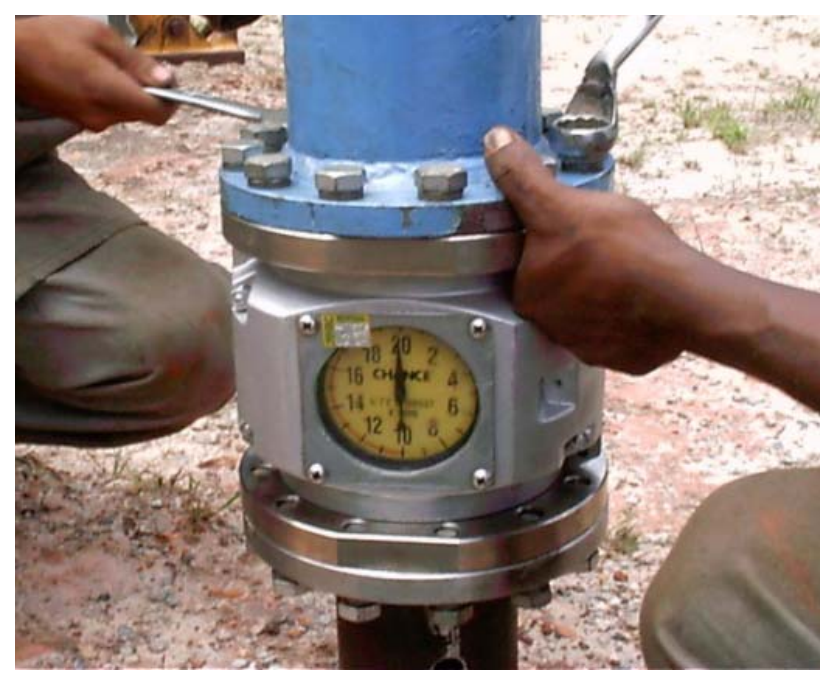

Figura 4.5 - Torquímetro utilizado em Contagem

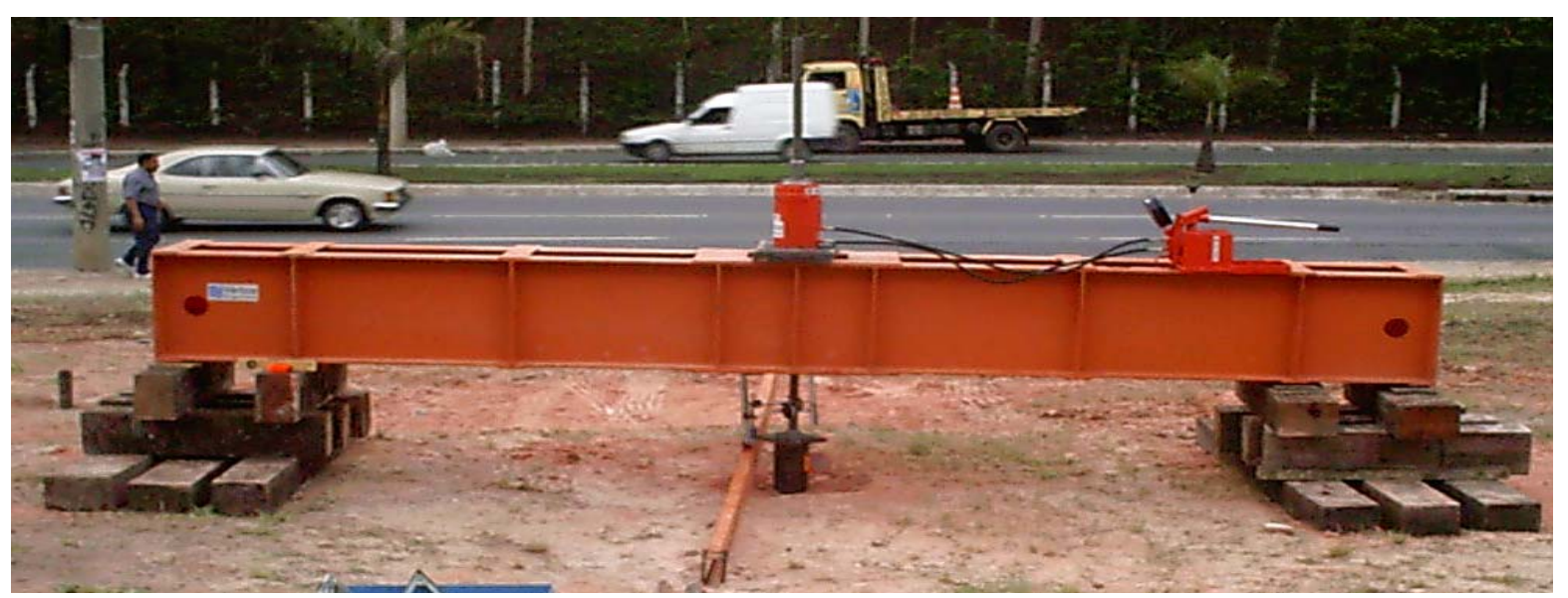

Figura 4.6 - Prova de carga realizada em Contagem 




Figura 4.7 - Relógios comparadores

\subsubsection{Provas de carga no Campo Experimental de Fundações -EESC}

No Campo Experimental de Fundações da Escola de Engenharia de São Carlos/USP foram realizadas duas provas de carga à tração em estacas metálicas helicoidais com duas hélices. As estacas ensaiadas são do tipo exibido na Figura 4.1(a) utilizado nos ensaios em Contagem (item 4.1.1). A Tabela 4.2 apresenta as dimensões das estacas de acordo com a Figura 4.1(a).

A estaca $\mathrm{n}^{\mathrm{o}}$ 6C da Tabela 4.2 foi fabricada com medidas fora de padrão. Esta estaca apresenta os diâmetros das hélices iguais à metade dos diâmetros das hélices da estaca $\mathrm{n}^{\mathrm{o}} 5 \mathrm{C}$. Os espaçamentos entre as hélices são iguais nas duas estacas e ambos foram instaladas à mesma profundidade. Esta configuração foi determinada para o estudo do efeito da dimensão das hélices durante a instalação da estaca, mostrado no capítulo 6 deste trabalho. 
Tabela 4.2 - Dimensões das estacas ensaiadas na EESC

\begin{tabular}{|c|c|c|c|c|c|c|c|c|}
\hline \multirow{2}{*}{ 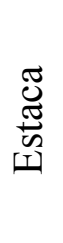 } & \multirow{2}{*}{$\begin{array}{l}\mathscr{y} \\
\dot{0} \\
: \frac{0}{0} \\
0 \\
0 \\
0 \\
0\end{array}$} & \multirow{2}{*}{ 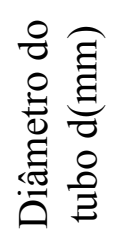 } & \multirow{2}{*}{  } & \multicolumn{2}{|c|}{$\begin{array}{l}\text { Diâmetro das } \\
\text { hélices (mm) }\end{array}$} & \multirow{2}{*}{ 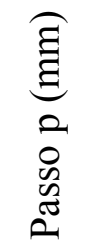 } & \multirow{2}{*}{ 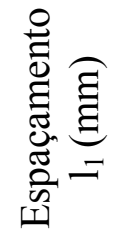 } & \multirow{2}{*}{ 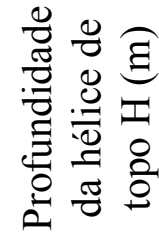 } \\
\hline & & & & $\mathrm{D}_{1}$ & $\mathrm{D}_{2}$ & & & \\
\hline $5 \mathrm{C}$ & 2 & 73 & 7,01 & 254,0 & 304,8 & 97,0 & 762,0 & 13,60 \\
\hline $6 \mathrm{C}$ & 2 & 73 & 7,01 & 127,0 & 152,4 & 57,0 & 762,0 & 13,60 \\
\hline
\end{tabular}

No Campo Experimental de Fundações da USP de São Carlos, a camada superficial de seis metros de espessura, comprovadamente colapsível, é composta por areia argilosa marrom escura (Sedimento Cenozóico) com valores de $\mathrm{N}_{\mathrm{SPT}}$ da ordem de 1 a 5 golpes. A partir dessa profundidade, separada por uma linha de seixos de aproximadamente 0,20 m de espessura, há uma camada formada por areia argilosa de cor variegada (Solo Residual do Grupo Bauru). O nível d'água se encontra variando de - 8,0 $\mathrm{m}$ a -10,0 m, em função da época de realização das sondagens.

A resistência à penetração da camada superficial de solo colapsível citada no parágrafo anterior varia de acordo com a sucção do solo no dia, que muda conforme o teor de umidade do terreno. Por esta razão, foram retirados com auxílio de um trado (Figura 4.9) amostras de solo no dia da instalação e das provas de carga das estacas. Por meio destas amostras foram determinados os teores de umidade do solo nas profundidades de -2,0 m e -5,0 m. Nestas profundidades deste terreno foi medida anteriormente a relação entre teor de umidade e sucção, conseqüentemente, por meio destas amostras os valores da sucção do terreno no dia dos ensaios foram identificados. Como resultado, na profundidade de $-2,0 \mathrm{~m}$ a sucção encontrada foi de $135 \mathrm{kPa}$ e na profundidade de $-5,0 \mathrm{~m}$ de $45 \mathrm{kPa}$.

A Figura 4.8 apresenta o perfil geotécnico médio do terreno e os resultados da sondagem à percussão realizada próxima as estacas ensaiadas (SPTT-2). 




Figura 4.8 - Perfil geotécnico do maciço de instalação das estacas 5C e 6C



Figura 4.9 - Retirada de amostras com trado no Campo Experimental da EESC 
O procedimento de instalação das estacas foi idêntico ao descrito no item anterior para a instalação das estacas ensaiadas em Contagem. A única diferença foi que na instalação das estacas em São Carlos foi utilizado um torquímetro digital (Figura 4.10).

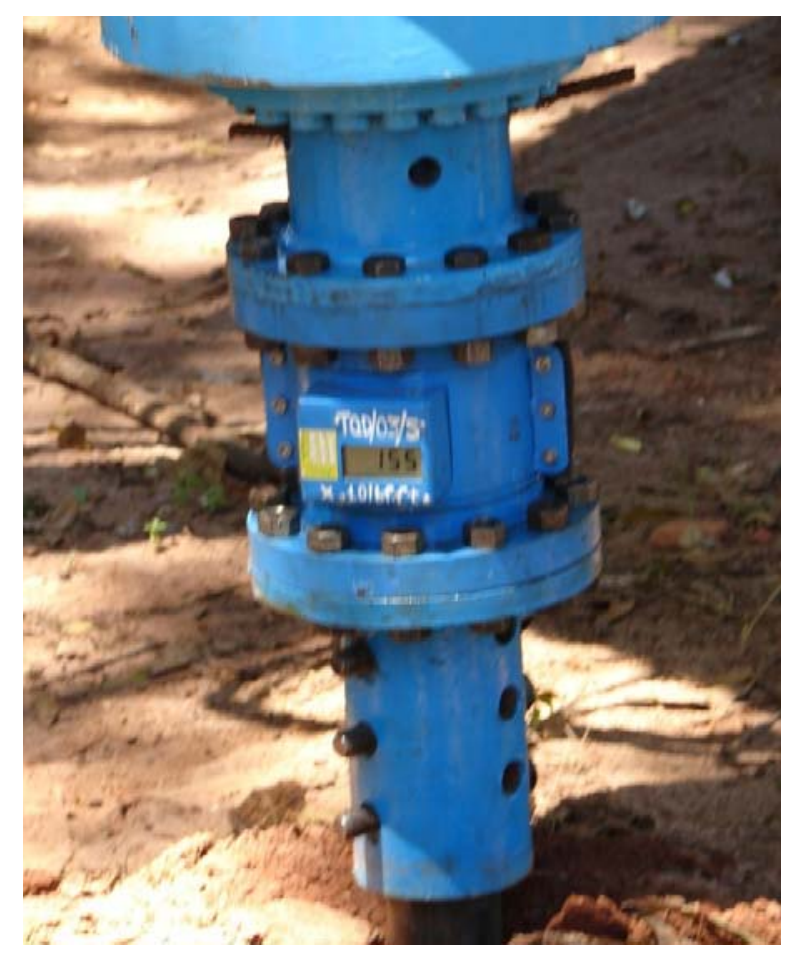

Figura 4.10 - Torquímetro digital utilizado no Campo Experimental da EESC

Os equipamentos utilizados nas provas de carga realizadas no Campo Experimental da EESC foram os mesmos utilizados em Contagem, descritos no item anterior.

Na prova de carga realizada na estaca 5C (Figura 4.11) foram feitos três ciclos de carregamento de acordo com o procedimento descrito pela A.B. Chance Co. (2003), mostrado na revisão bibliográfica desta tese. $\mathrm{Na}$ estaca $6 \mathrm{C}$, foi realizado um ciclo de carregamentos com incrementos de $10 \%$ da carga de trabalho, em estágios de 5 minutos, até o momento em que os valores da taxa de deslocamento/minuto da estaca tornaram-se crescentes. 




Figura 4.11 - Prova de carga realizada no Campo Experimental da EESC

\subsection{Ensaios de laboratório}

\subsubsection{Ensaios em centrífuga}

Os modelos ensaiados em centrífuga permitem reproduzir em laboratório a distribuição das tensões no maciço decorrentes do peso próprio do solo em uma obra real. Esta técnica apresenta as seguintes vantagens em relação aos ensaios em modelos em verdadeira grandeza: baixo custo, menor tempo de montagem e de execução, facilidade de repetição e a possibilidade da realização de um maior número de ensaios.

Os ensaios de modelagem física em centrífuga foram realizados no Laboratoire Central de Ponts et Chaussées em Nantes, França. Neste programa de ensaios, foram instaladas e ensaiadas à tração diferentes modelos de estacas metálicas helicoidais, em dois maciços de areia seca, o primeiro com densidade relativa igual a $56 \%$, e o segundo igual a $85 \%$.

O objetivo destes ensaios em centrífuga foi medir os valores de torque de instalação e de carga de ruptura à tração de diferentes modelos de estacas metálicas helicoidais, para verificar posteriormente a relação física mostrada na Equação 3.14 do modelo teórico proposto nesta 
tese. Além disso, estes ensaios foram programados para averiguar se o diâmetro e o número de hélices influenciavam esta equação.

Neste programa experimental em centrífuga foram realizados ensaios de caracterização das areias anteriormente e durante os ensaios. Além das provas de carga à tração em estacas executados em centrifugação à $22 \mathrm{~g}$, foram realizados ensaios de arrancamento de modelos de estacas a 1g, em maciço com camadas de areia colorida para verificação da superfície de ruptura.

Para extrapolar os resultados medidos em modelos ensaiados em centrífuga para a situação de uma estaca em grandeza real, deve-se submeter ao modelo uma aceleração gravitacional (N) igual ao inverso da escala de redução do modelo ( $1 / N$ ). As condições de semelhança são expressas como relações de $n\left(o\right.$ fator de escala $\left.x^{*}=1 / N\right)$.

Para submeter o modelo a uma aceleração gravitacional (N), uma das soluções consiste em submeter o modelo a aceleração centrífuga por meio de rotação a uma velocidade constante. A velocidade de rotação do modelo na escala $1 / \mathrm{N}$ é definida por:

$$
\omega=\sqrt{\frac{N g}{R}}
$$

onde $\mathrm{R}$ é o raio de rotação.

A Tabela 4.3 mostra alguns fatores de escala utilizados para a extrapolação dos resultados medidos em centrífuga. Para estimar os resultados que ocorreriam em grandeza real, basta dividir a grandeza medida na centrífuga pelo fator de escala apresentado nesta tabela. 
Tabela 4.3 - Fatores de escala para modelagem física em centrífuga

\begin{tabular}{cc}
\hline Parâmetro & Fator de escala \\
\hline Comprimento, deslocamento & $\ell^{*}=1 / \mathrm{N}$ \\
Massa específica & $\rho^{*=1}$ \\
Aceleração & $\mathrm{g}^{*=\mathrm{N}}$ \\
Tensão & $\sigma^{*}=1$ \\
Força & $\mathrm{F}^{*}=1 / \mathrm{N}^{2}$ \\
Área & $\mathrm{S}^{*}=1 / \mathrm{N}^{2}$ \\
Volume & $\mathrm{V}^{*}=1 / \mathrm{N}^{3}$ \\
Momento Fletor & $\mathrm{M}^{*}=1 / \mathrm{N}^{3}$ \\
\hline
\end{tabular}

Nos ensaios realizados nesta tese, o fator de escala utilizado foi igual a $1 / 22$. Sendo assim, os modelos foram construídos na escala $1 / 22$, e a aceleração aplicada na região da hélice inferior das estacas (mais profundas) foi igual a $22 \mathrm{~g}$. No entanto, como nesta investigação os modelos das estacas foram instalados em diferentes profundidades, para extrapolação das dimensões dos modelos para os valores de protótipos equivalentes foram considerados diferentes níveis de gravidade (de 21,44 a 22g)

Este fator de escala 1/22 foi escolhido de acordo com a profundidade do container disponível para o ensaio. Como o objetivo era de ensaiar estacas com profundidades em grandeza real variando de 3,0 a $6,0 \mathrm{~m}$, este fator de escala $1 / 22$ foi determinado para que as estacas atingissem estas profundidades, para ficar ao final da instalação com a ponta afastada em distâncias superiores a $8 \mathrm{~cm}$ do fundo do container.

\subsubsection{Ensaios de caracterização das areias}

Para os ensaios executados na centrífuga do LCPC foi utilizada a areia de Fontainebleau (França). Para a caracterização desta areia foram realizados ensaios de granulometria, de determinação dos índices de vazio máximo e mínimo e de massa específica dos sólidos. 
Além destes ensaios, foram realizados ensaios de cisalhamento direto para a obtenção dos valores dos ângulos de atrito interno dos maciços de areia utilizados nos ensaios em centrífuga, o primeiro com densidade relativa igual a $56 \%\left(\gamma=15,46 \mathrm{kN} / \mathrm{m}^{3}\right)$, e o segundo igual a $85 \%\left(\gamma=16,30 \mathrm{kN} / \mathrm{m}^{3}\right)$. Estes ensaios foram realizados em uma caixa de cisalhamento tipo Casagrande $(60 \times 60 \mathrm{~mm})$.

Os pesos específicos determinados para as amostras destes experimentos foram obtidos pela técnica de chuva de areia realizada por um mini pluviômetro (Figura 4.12). Por esta técnica o peso específico da areia desejado é obtido em função da altura de queda e da vazão de areia (esta varia de acordo com a abertura da peneira por onde passa a areia).
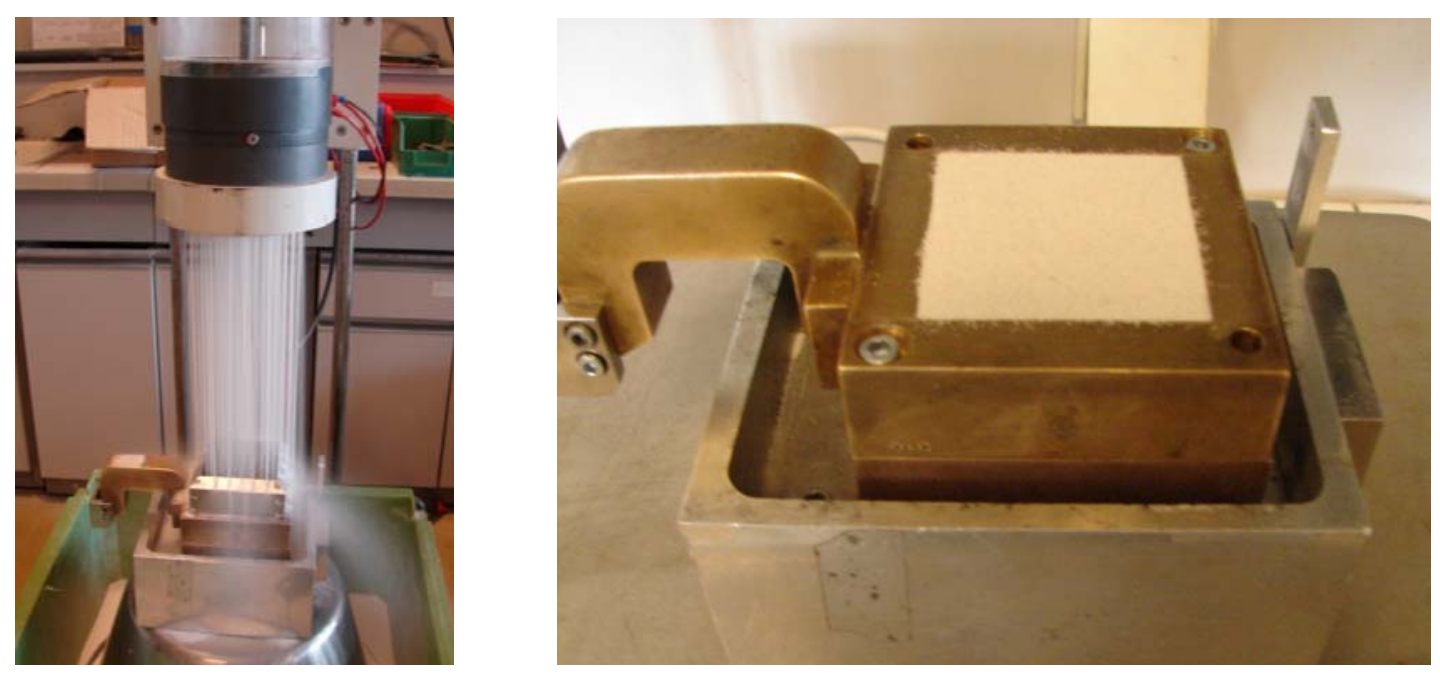

Figura 4.12 - Preparo da amostra por chuva de areia

Para cada amostra de areia $\left(D_{r}=56 \%\right.$ e $\left.85 \%\right)$ foram realizados três ensaios com diferentes níveis de tensão normal aplicada. Após a instalação da caixa no equipamento para ensaio de cisalhamento direto (Figura 4.13), a meia-caixa inferior era deslocada horizontalmente a uma velocidade constante igual a $0,11 \mathrm{~mm} /$ minuto. O ensaio era finalizado após a meia-caixa inferior atingir o deslocamento horizontal igual a $60 \mathrm{~mm}$. Nos ensaios foram medidos deslocamento horizontal e vertical e a força cisalhante. O equipamento era ligado a um 
sistema de aquisição de dados, com capacidade de leitura a cada 0,5 segundos, onde um software traçava os gráficos simultaneamente aos ensaios e transformava os resultados medidos em planilha do tipo Excel.

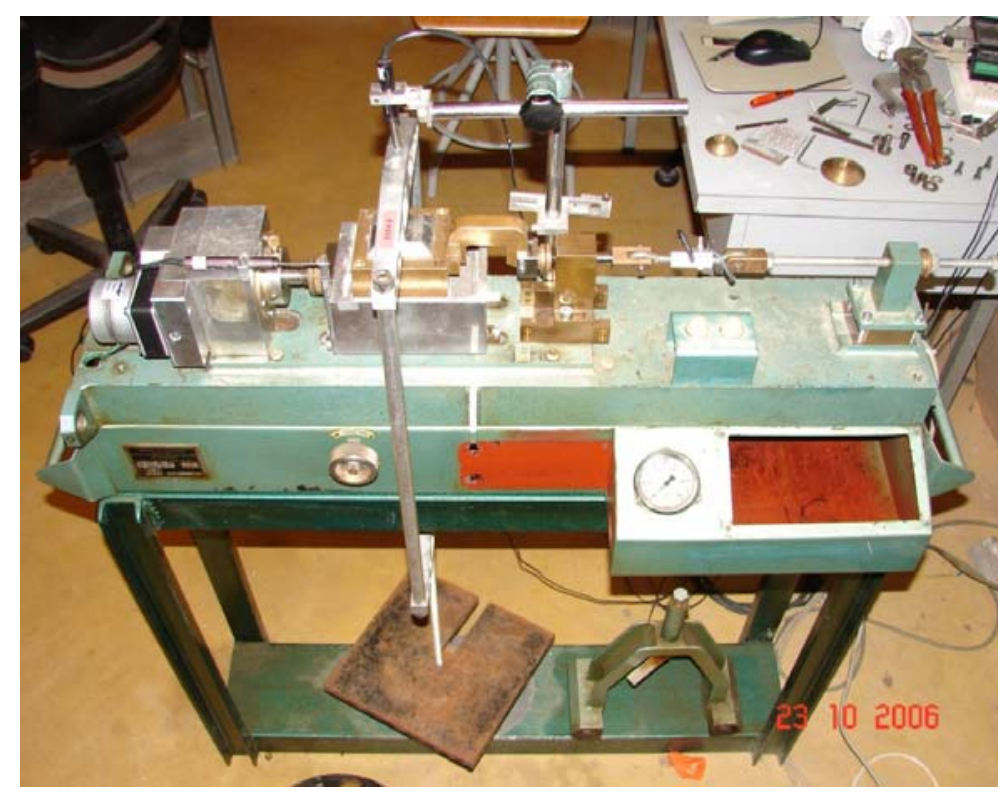

Figura 4.13 - Ensaio de cisalhamento direto da areia

\subsubsection{Preparo dos maciços para ensaio em centrífuga}

Os maciços onde foram instalados e ensaiados modelos de estacas metálica helicoidais na centrífuga foram preparados pela técnica de chuva de areia (Figura 4.14). Estes maciços foram reconstituídos em containeres com $1200 \mathrm{~mm}$ de comprimento, $800 \mathrm{~mm}$ de largura e $360 \mathrm{~mm}$ de altura. $\mathrm{O}$ equipamento de chuva de areia utilizado era automático, o que permitiu boa repetição do processo e conseqüentemente boa uniformidade dos maciços.

Dois containeres foram preparados, containeres 1 e 2 respectivamente. O primeiro foi preenchido de areia com peso específico igual a $15,46 \mathrm{kN} / \mathrm{m}^{3}$, e o segundo de areia com peso específico igual a $16,30 \mathrm{kN} / \mathrm{m}^{3}$. Para cada container foi utilizada uma combinação de parâmetros que proporcionasse maciços com os pesos específicos desejados. Os parâmetros 
essenciais para a reconstituição de um maciço de areia com uma determinada densidade são: altura de queda constante, largura da cortina de areia e velocidade horizontal da chuva de areia. Estes parâmetros utilizados nos dois maciços destes ensaios estão descritos na Tabela 4.4 .

Tabela 4.4 - Parâmetros das chuvas de areia dos maciços ensaiados

\begin{tabular}{|c|c|c|c|c|c|c|c|c|}
\hline  & 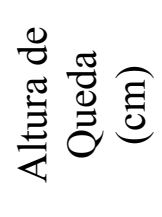 & 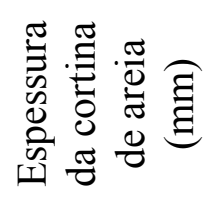 & 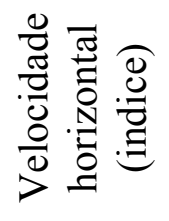 & $\begin{array}{l}\frac{\pi}{0} \\
\frac{\pi}{0} \\
0 \\
0 \\
0\end{array}$ &  & 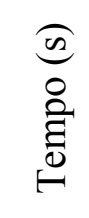 & 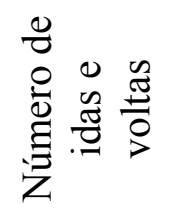 & 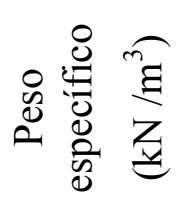 \\
\hline 1 & 60 & 4 & 3 & & 5 & 2,5 & 1 & 15,46 \\
\hline 2 & 80 & 3 & 3 & & 5 & 3 & 3 & 16,30 \\
\hline
\end{tabular}

Para controlar as densidades dos maciços foram posicionadas no fundo dos containeres quatro caixas cilíndricas calibradas (diâmetro $=80 \mathrm{~mm}$ ). Após a utilização dos containeres nos ensaios em centrífuga, a areia era aspirada e estas caixas recuperadas e pesadas para a determinação dos valores de peso específico areia (Figura 4.15).



Figura 4.14 - Preparo dos containeres por chuva automática de areia 

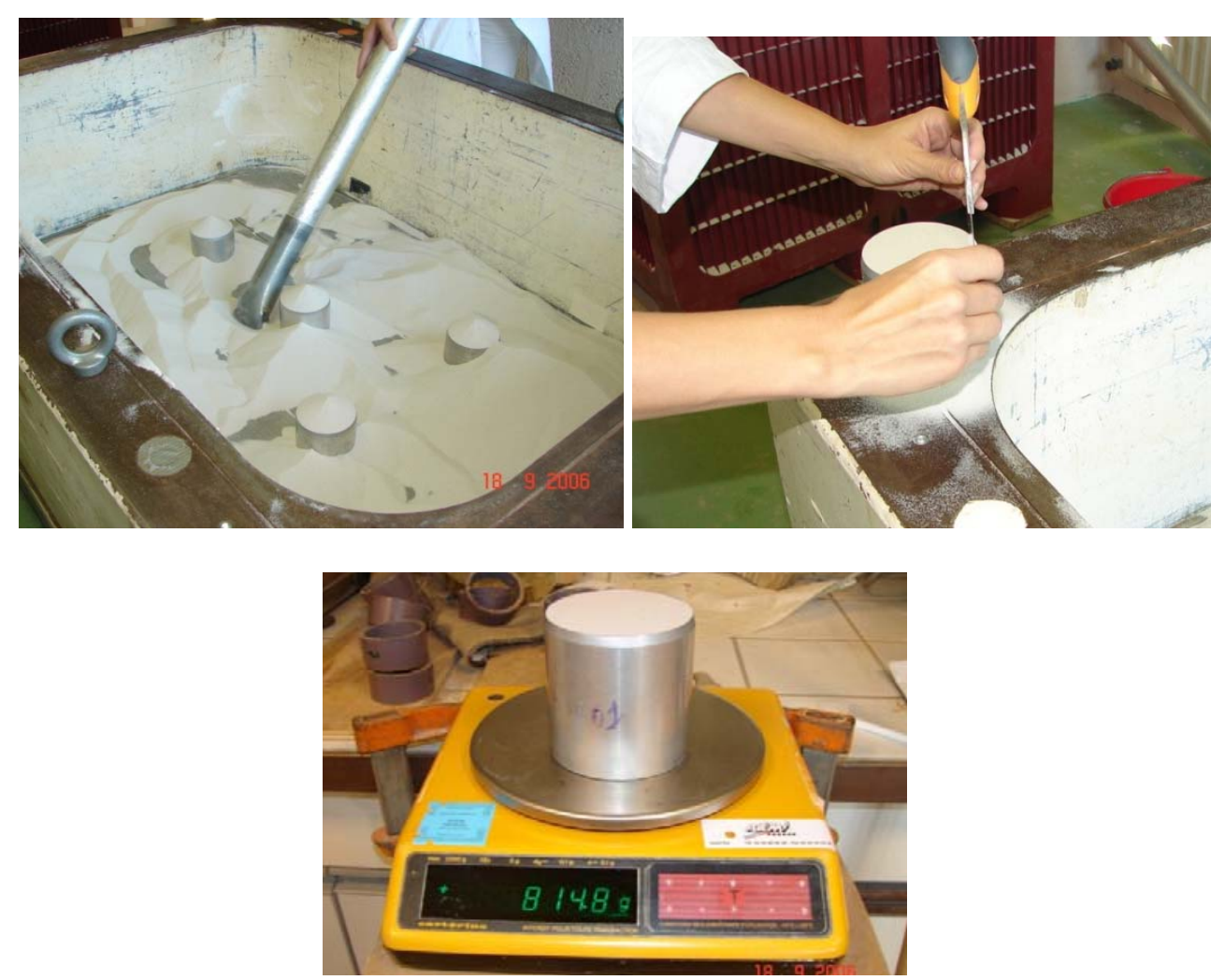

Figura 4.15 - Controle do peso específico do maciço após o ensaio em centrífuga

\subsubsection{Ensaios penetrométricos}

Durante os ensaios em centrífuga, foram realizados em vôo (a 22 g) ensaios penetrométricos nos containeres de areia para a caracterização da camada de solo ensaiado. Nestes ensaios foi medida a resistência contínua à penetração de uma ponta cônica padronizada dentro de cada maciço. Os resultados destes testes permitem estimar parâmetros da areia e verificar a uniformidade da densidade do maciço.

O aparelho utilizado foi um penetrômetro estático hidráulico do LCPC (Figura 4.16). Ele é constituído por uma haste munida na ponta por um transdutor de força em miniatura e por uma ponta cônica. A medida de penetração é feita por um cursor que emite um sinal elétrico. Este penetrômetro é montado sobre um dispositivo móvel que permite o seu deslocamento em vôo, sem a necessidade de parar a centrífuga. Sendo assim, muitos perfis podem ser 
executados durante a mesma campanha de ensaios. As características do penetrômetro do LCPC são apresentadas na Tabela 4.5.

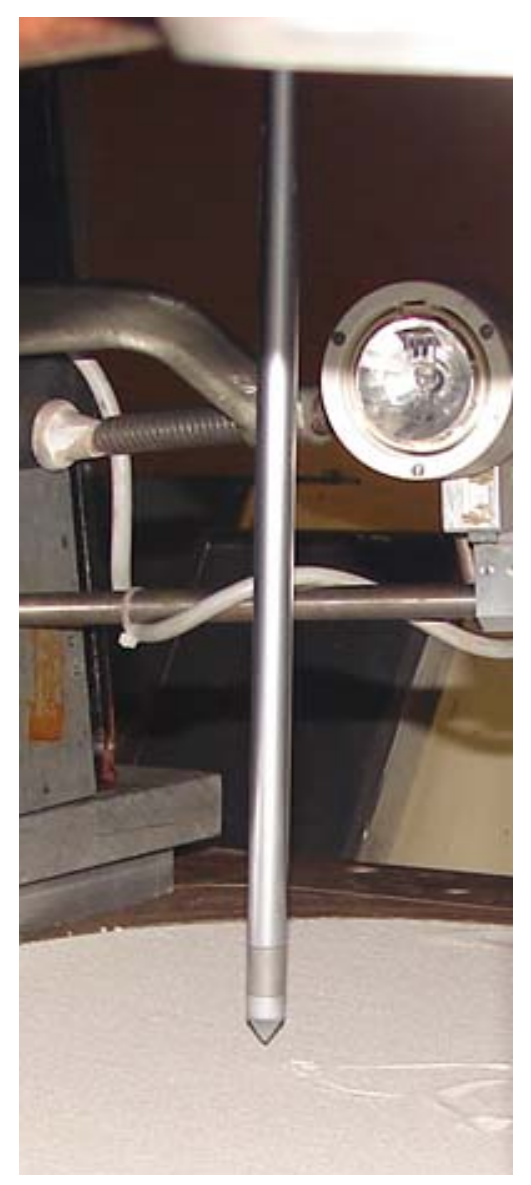

Figura 4.16 - Penetrômetro do LCPC

Tabela 4.5 - Características do penetrômetro do LCPC

\begin{tabular}{cc}
\hline Funcionamento em centrífuga & até 100 x g \\
Comprimento $(\mathrm{m})$ & 0,760 \\
Massa $(\mathrm{kg})$ & 4 \\
Pressão máxima (MPa) & 18 \\
Diâmetro da haste (m) & 0,012 \\
Curso (m) & 0.3 \\
Ângulo do cone (graus) & 60 \\
Transdutores de força (N) & 200 a 5000 \\
\hline
\end{tabular}




\subsubsection{Ensaios de estacas metálicas helicoidais em centrífuga}

\section{Centrífuga}

A centrífuga do LCPC (Figura 4.17) é um equipamento para estudos e pesquisas em macro gravidade. Ela permite a realização de estudos experimentais em modelos reduzidos dentro do domínio da engenharia civil. Nestes estudos, se as condições de semelhanças forem satisfeitas, os resultados podem ser extrapolados para uma obra em grandeza real. Esta centrífuga faz parte do grupo das maiores centrífugas geotécnicas do mundo, com um raio de 5,50 m e uma capacidade embarque de massa de 2 toneladas a $100 \mathrm{~g}$. As características da centrífuga do LCPC são apresentadas na Tabela 4.6.

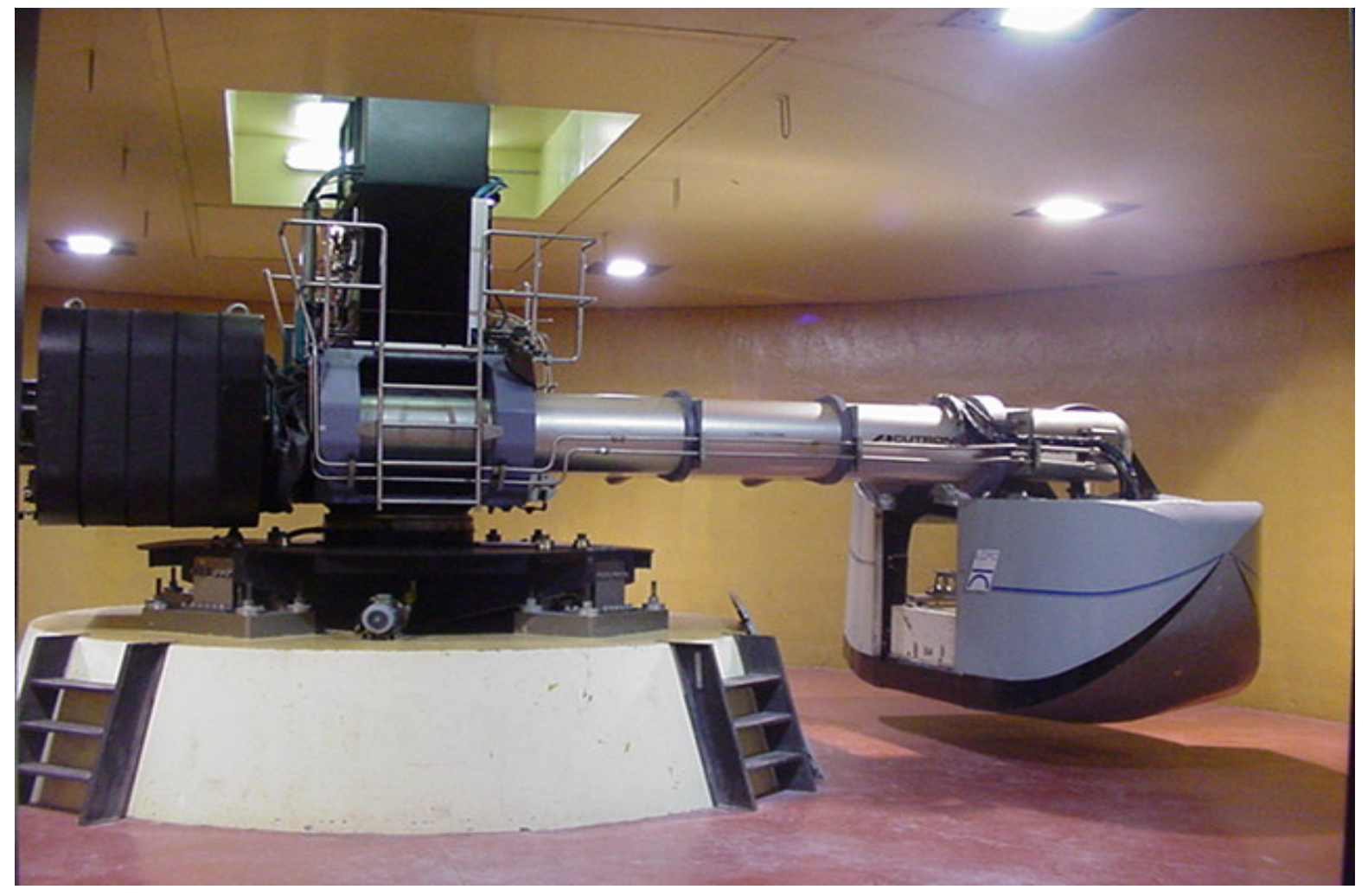

Figura 4.17 - Centrífuga do LCPC 
Tabela 4.6 - Características da centrífuga do LCPC

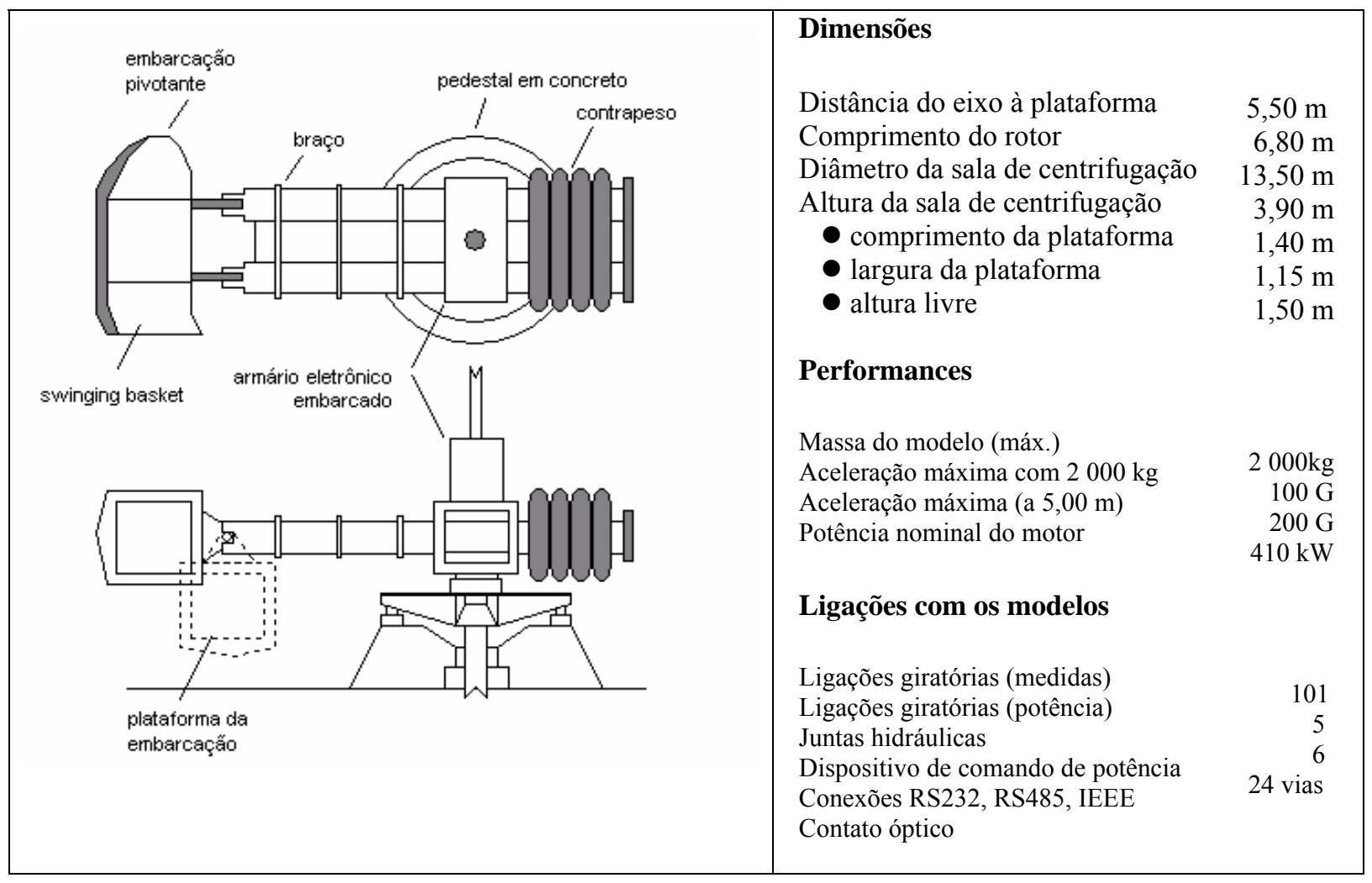

Uma das características importantes da centrífuga do LCPC é que os canais de aquisição de dados são embarcados dentro da swinging basket, e os sinais são obtidos antes de passar pelos contatos giratórios. Este fato elimina os problemas encontrados com a passagem dos sinais analógicos através dos contatos giratórios e também a passagem por longos cabos. $\mathrm{Na}$ época destes ensaios, uma ligação Ethernet em fibra ótica permitiu a transferência dos dados a $100 \mathrm{Mb} /$ segundo.

\section{Estacas modelos}

Dois diferentes grupos de modelos de estacas foram fabricados para a realização da modelagem física em centrífuga. O primeiro grupo (Figura 4.18) foi composto de nove diferentes modelos de estacas metálicas helicoidais, com hélices de 0,75 $\mathrm{mm}$ de espessura soldadas em hastes arredondadas de aço. O segundo grupo (Figura 4.19) foi composto de três 
modelos de estacas feitas de hastes arredondadas de aço, com diferentes diâmetros. O objetivo da fabricação de dois grupos distintos foi isolar as medidas das parcelas de torque de instalação e de capacidade de carga à tração relativas às hélices $\left(T_{h}\right.$ e $\left.Q_{h}\right)$ das medidas das parcelas de torque de instalação e capacidade de carga à tração correspondentes ao atrito no tubo da estaca $\left(\mathrm{T}_{\mathrm{s}}\right.$ e $\left.\mathrm{Q}_{\mathrm{s}}\right)$.

Os modelos de estacas de ambos os grupos foram fabricados com $355 \mathrm{~mm}$ de comprimento e diâmetro das hastes iguais a $3,0 \mathrm{~mm}, 4,5 \mathrm{~mm}$ e $6,0 \mathrm{~mm}$. Os modelos típicos das estacas fabricadas são apresentados na Figura 4.20. As dimensões das estacas modelos e dos correspondentes protótipos são dadas na Tabela 4.7.

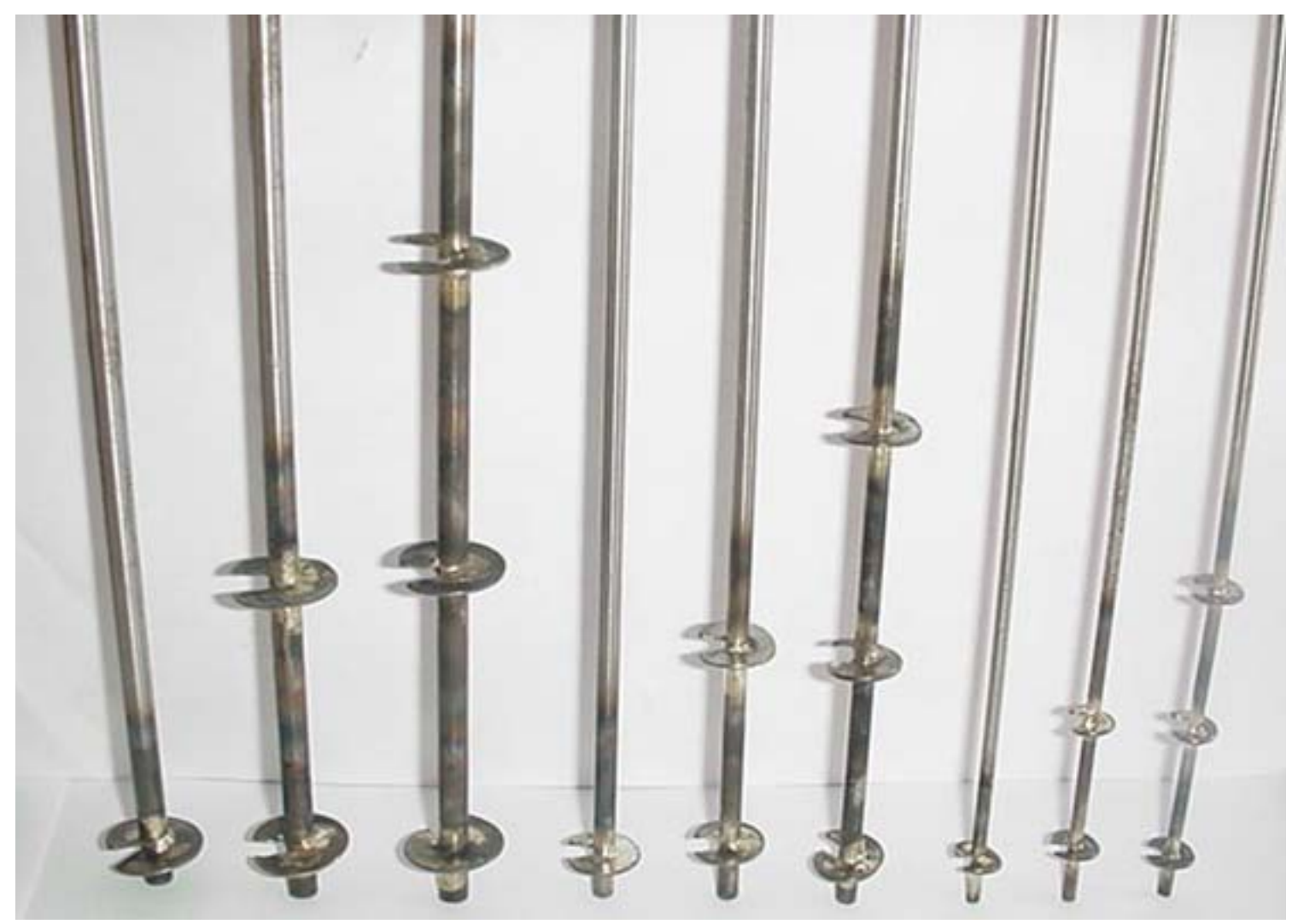

Figura 4.18 - Fotografia dos modelos de estacas metálicas helicoidais (Grupo I) 


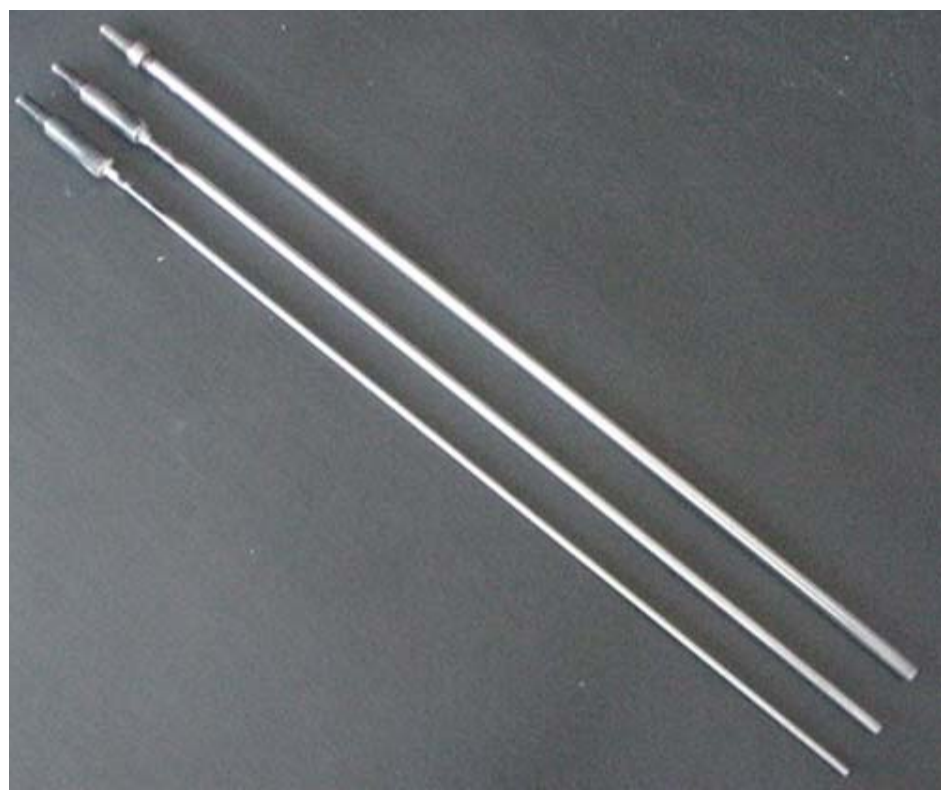

Figura 4.19 - Fotografia dos modelos de estacas sem hélices (Grupo II)
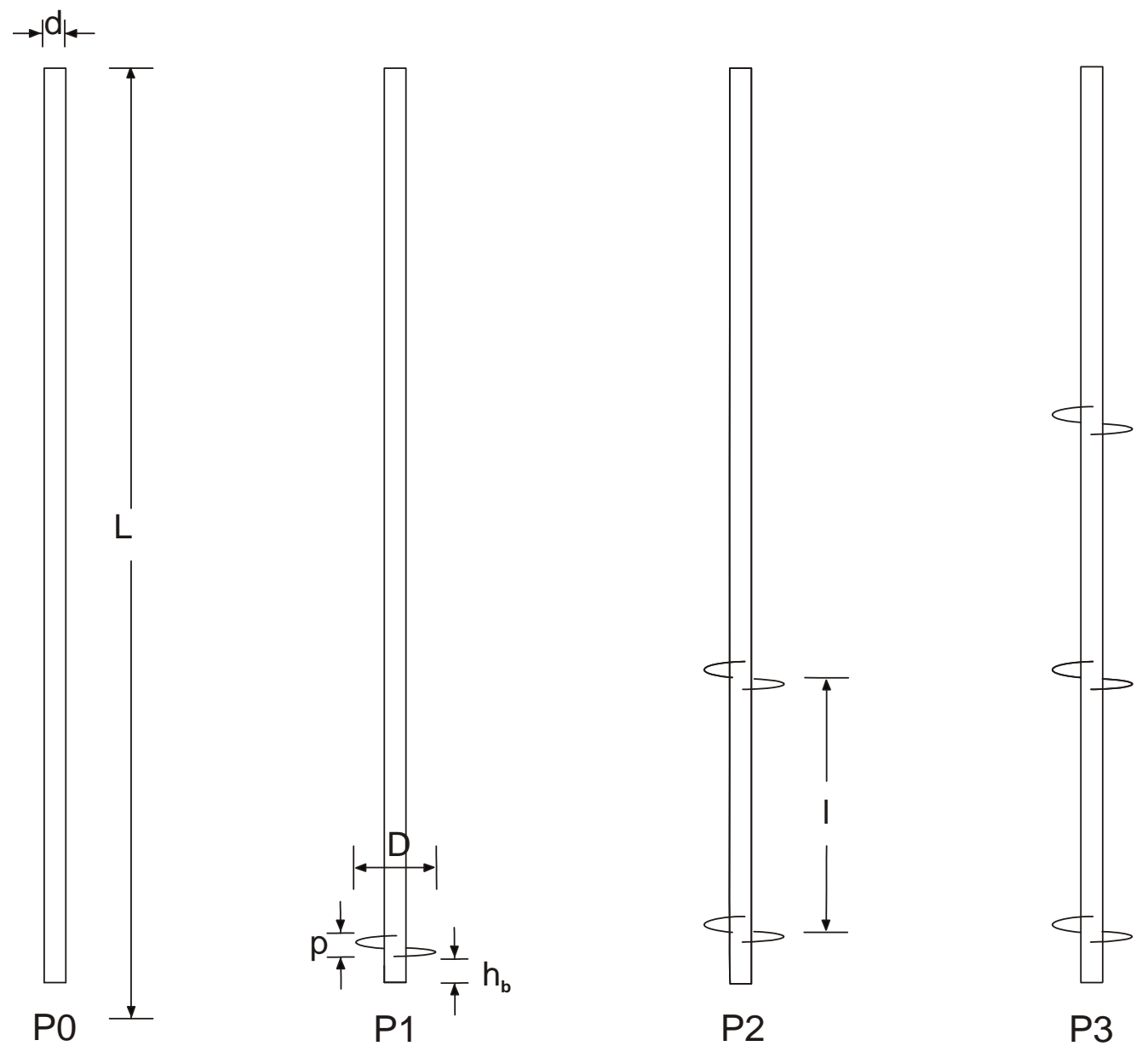

P3

Figura 4.20 - Modelos típicos das estacas ensaiadas 
Tabela 4.7 - Dimensões das estacas modelo

\begin{tabular}{|c|c|c|c|c|c|c|c|c|c|c|c|c|c|c|c|}
\hline \multirow[b]{2}{*}{ 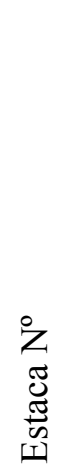 } & \multirow[b]{2}{*}{ 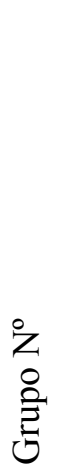 } & \multirow{2}{*}{  } & \multirow[b]{2}{*}{ 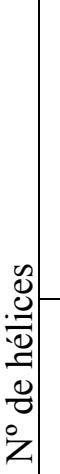 } & \multicolumn{2}{|c|}{ 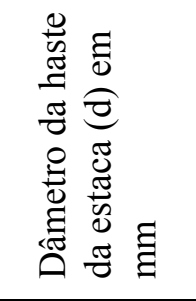 } & \multicolumn{2}{|c|}{ 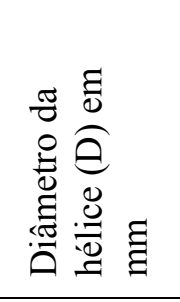 } & \multicolumn{2}{|c|}{ 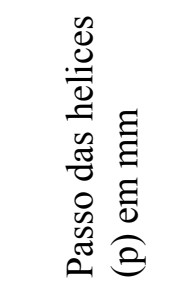 } & \multicolumn{2}{|c|}{ 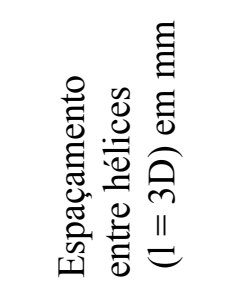 } & \multicolumn{2}{|c|}{ 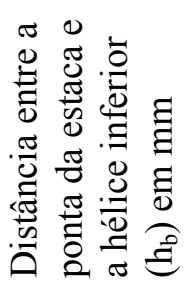 } & \multicolumn{2}{|c|}{ 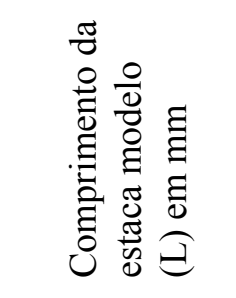 } \\
\hline & & & & $\frac{\frac{0}{0}}{\frac{8}{0}}$ &  & $\frac{\frac{0}{0}}{\frac{8}{2}}$ & $\begin{array}{l}\text { : } \\
.0 \\
0 \\
0 \\
0 \\
0\end{array}$ & $\frac{\frac{0}{0}}{\frac{0}{2}}$ & $\begin{array}{l}\text { 을 } \\
\text { : } \\
0 \\
0 \\
0\end{array}$ & $\begin{array}{l}\frac{0}{0} \\
\frac{0}{8} \\
\Sigma\end{array}$ & 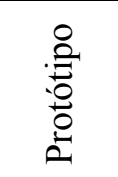 & $\begin{array}{l}\frac{0}{\frac{0}{0}} \\
\frac{0}{\Sigma}\end{array}$ & $\begin{array}{l}0 \\
.02 \\
0 \\
0 \\
0 \\
0\end{array}$ & $\frac{\frac{0}{0}}{\frac{0}{2}}$ & $\begin{array}{l}0 \\
: \\
0 \\
0 \\
0 \\
0 \\
0 \\
0\end{array}$ \\
\hline $1 \mathrm{~L}$ & I & $\mathrm{P} 1$ & 1 & 3,0 & 64,3 & 10 & 214,4 & 3,0 & 64,3 & 30,0 & 643,2 & 10 & 214,4 & 355,0 & 7611,2 \\
\hline $2 \mathrm{~L}$ & I & $\mathrm{P} 2$ & 2 & 3,0 & 64,3 & 10 & 214,4 & 3,0 & 64,3 & 30,0 & 643,2 & 10 & 214,4 & 355,0 & 7611,2 \\
\hline $3 \mathrm{~L}$ & I & P3 & 3 & 3,0 & 64,3 & 10 & 214,4 & 3,0 & 64,3 & 30,0 & 643,2 & 10 & 214,4 & 355,0 & 7611,2 \\
\hline $4 \mathrm{~L}$ & I & $\mathrm{P} 1$ & 1 & 4,5 & 97,7 & 15 & 325,7 & 3,2 & 69,5 & 45,0 & 977,0 & 10 & 217,1 & 355,0 & 7707,1 \\
\hline $5 \mathrm{~L}$ & I & $\mathrm{P} 2$ & 2 & 4,5 & 97,7 & 15 & 325,7 & 3,2 & 69,5 & 45,0 & 977,0 & 10 & 217,1 & 355,0 & 7707,1 \\
\hline $6 \mathrm{~L}$ & I & P3 & 3 & 4,5 & 97,7 & 15 & 325,7 & 3,2 & 69,5 & 45,0 & 977,0 & 10 & 217,1 & 355,0 & 7707,1 \\
\hline $7 \mathrm{~L}$ & I & $\mathrm{P} 1$ & 1 & 6,0 & 132,0 & 20 & 440,0 & 3,5 & 77,0 & 60,0 & 1320,0 & 10 & 220,0 & 355,0 & 7810,0 \\
\hline $8 \mathrm{~L}$ & I & $\mathrm{P} 2$ & 2 & 6,0 & 132,0 & 20 & 440,0 & 3,5 & 77,0 & 60,0 & 1320,0 & 10 & 220,0 & 355,0 & 7810,0 \\
\hline $9 \mathrm{~L}$ & I & $\mathrm{P} 3$ & 3 & 6,0 & 132,0 & 20 & 440,0 & 3,5 & 77,0 & 60,0 & 1320,0 & 10 & 220,0 & 355,0 & 7810,0 \\
\hline $10 \mathrm{~L}$ & I & $\mathrm{P} 0$ & - & 3,0 & 64,3 & - & - & - & - & - & - & - & - & 355,0 & 7611,2 \\
\hline $11 \mathrm{~L}$ & I & $\mathrm{P} 0$ & - & 4,5 & 97,7 & - & - & - & - & - & - & - & - & 355,0 & 7707,1 \\
\hline $12 \mathrm{~L}$ & I & $\mathrm{P} 0$ & - & 6,0 & 132,0 & - & - & - & - & - & - & - & - & 355,0 & 7810,0 \\
\hline \multicolumn{16}{|c|}{$\begin{array}{l}\text { Nota: Nesta investigação, os modelos das estacas foram instalados em diferentes profundidades, portanto, para extrapolação das } \\
\text { dimensões dos modelos para os valores de protótipos equivalentes, foram adotados os seguintes níveis de gravidade: }\end{array}$} \\
\hline
\end{tabular}

\section{Equipamentos de ensaio}

Um sistema servo controlador para ensaios em centrífuga (Figuras 4.21 e 4.22) foi utilizado para a instalação e para os ensaios de tração dos modelos de estacas nos containeres de areia, em vôo (durante a centrifugação). Neste sistema foi acoplado um torquímetro (Figura 4.23) para a obtenção dos valores de torque necessário para a instalação dos modelos de estacas no maciço. Este torquímetro utilizado tem capacidade de leitura de até 50 N.m e resolução de 0,05 N.m. A profundidade de penetração e a força axial medida na haste, nas fases de instalação e de carregamento, foram monitorados por transdutores de deslocamento 
(resolução de $0,15 \mathrm{~mm}$ ) e de força (resolução de $4 \mathrm{~N}$ ) acoplados ao sistema apresentado na Figura 4.21.

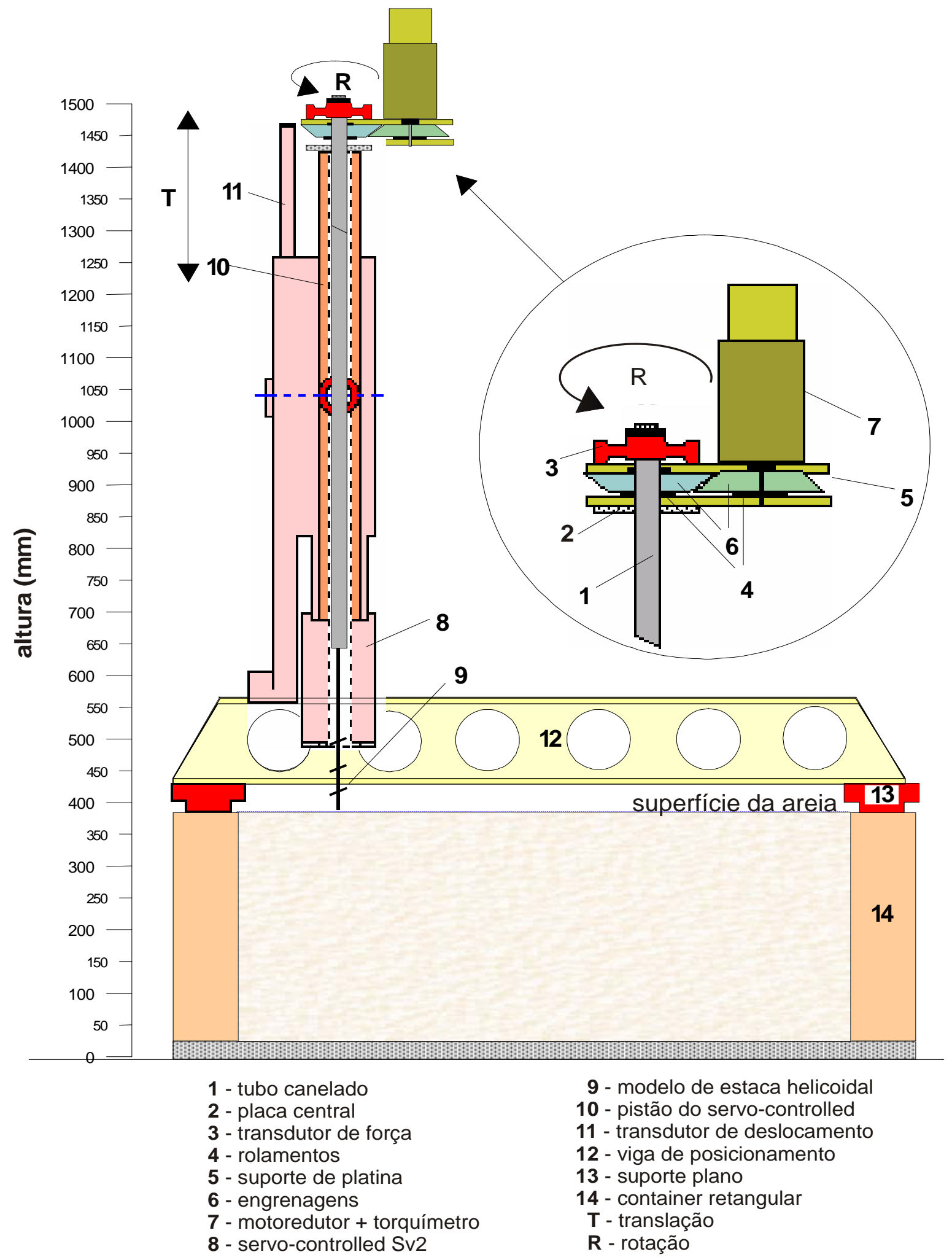

Figura 4.21 - Sistema servo controlador para ensaios em centrífuga 


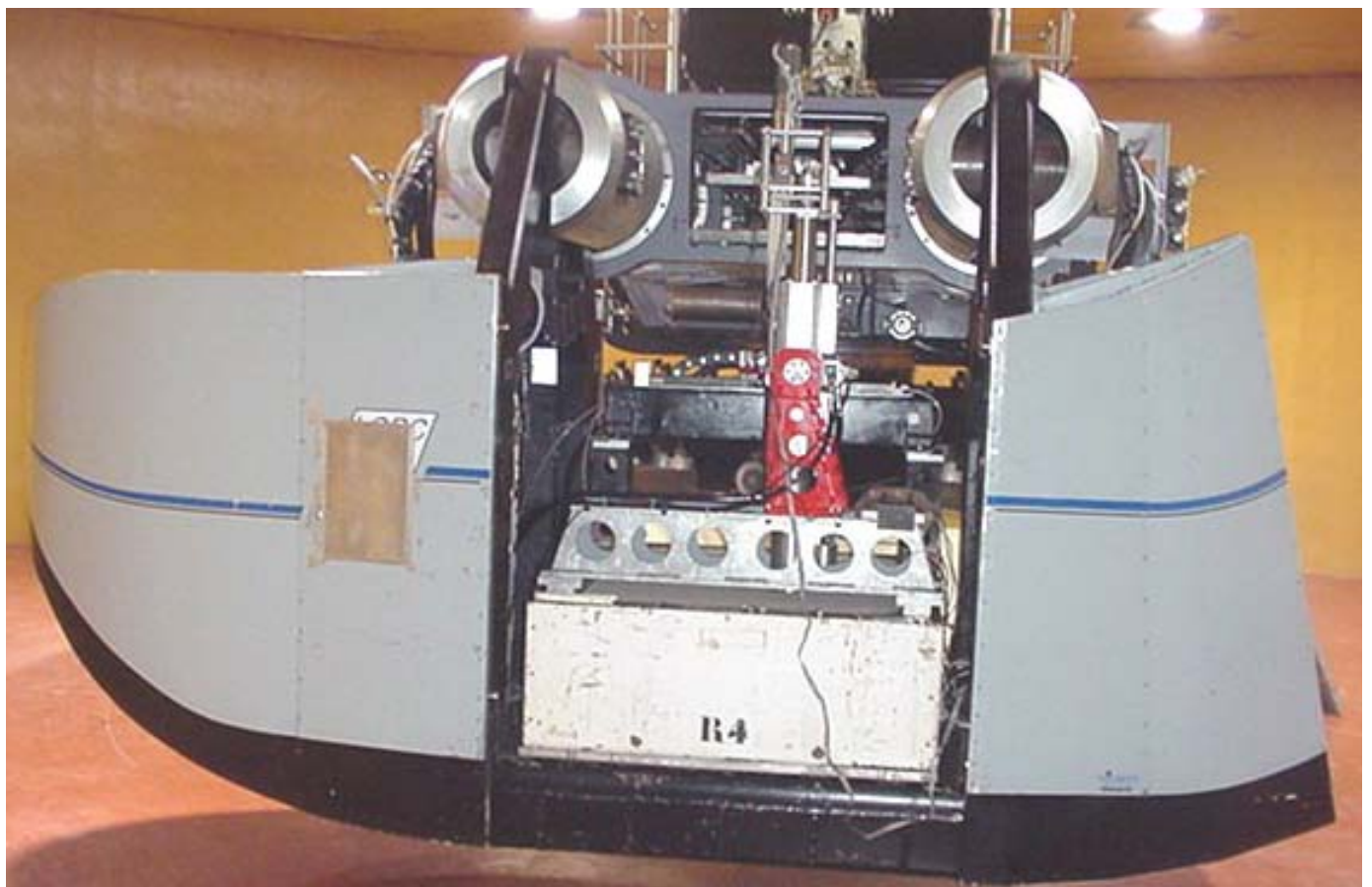

Figura 4.22 - Sistema servo controlador instalado na centrífuga
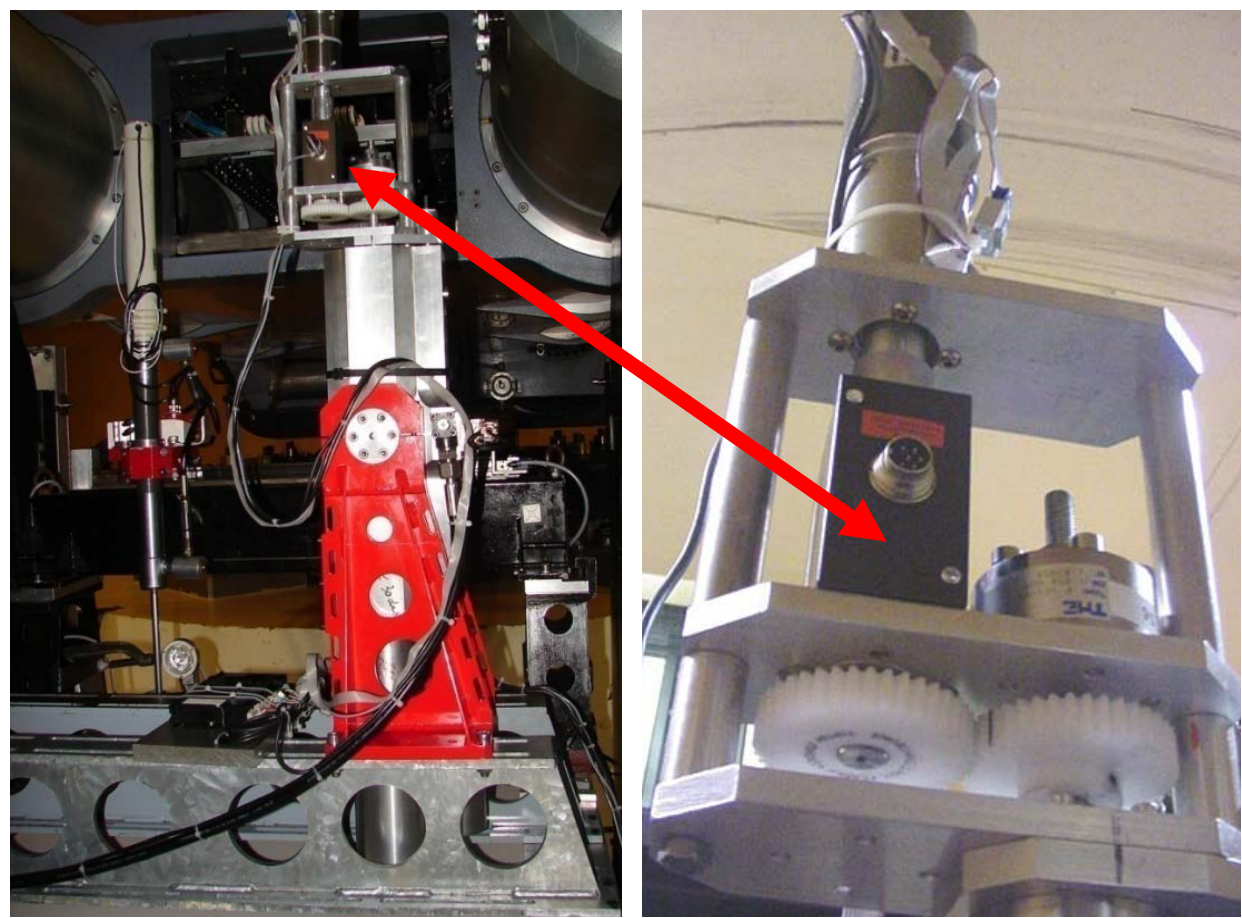

Figura 4.23 - Torquímetro acoplado ao sistema servo controlador

As medidas de torque, deslocamento e força, obtidas nas fases de instalação e carregamento das estacas, foram gravadas em um sistema de aquisição de dados automático 
embarcado dentro da swinging basket da centrífuga (Figura 4.24). Na fase de instalação das estacas modelos as leituras foram feitas a cada 0,6 segundos e na fase de carregamento a cada 0,2 segundos.

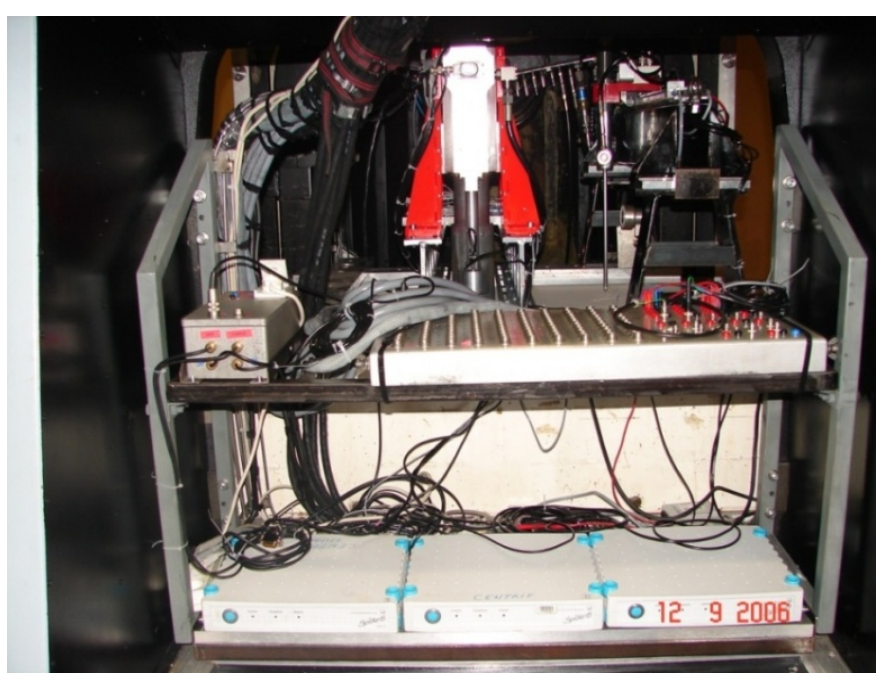

Figura 4.24 - Sistema de aquisição de dados embarcado na swinging basket

\section{Instalação e carregamento das estacas}

Antes da realização dos ensaios, foi preparado um container teste preenchido com o maciço de areia de densidade relativa maior $\left(D_{r}=85 \%\right)$. O objetivo deste teste foi verificar as operações de instalação e carregamento das estacas. Nestes ensaios, as estacas foram instaladas à profundidade de $280 \mathrm{~mm}$ com nível de gravidade igual a 22 g. No entanto, durante a instalação dos modelos de estacas foi registrada a flambagem das hélices (na estaca de maior diâmetro) e da haste (na estaca de menor diâmetro), como pode ser visto na Figura 4.25. Este problema foi resolvido dividindo-se a fase de instalação em dois estágios. No primeiro estágio as estacas foram instaladas a 1g. No segundo estágio, os últimos $60 \mathrm{~mm}$ de instalação das estacas foram realizados a 22 g. Este modificação no procedimento experimental não afetou o resultado de torque necessário para a verificação do modelo teórico 
proposto nesta tese, já que este modelo relaciona o torque final da instalação com a capacidade de carga à tração da estaca.



Figura 4.25 - Estacas danificadas após a penetração por rotação de $280 \mathrm{~mm}$ dentro do maciço

$$
\text { de areia }\left(D_{r}=85 \%\right) \text { a } 22 \mathrm{~g}
$$

Nos ensaios seguintes realizados, cada container preenchido com o maciço de areia (preparado de acordo com o item 4.2.1.2) instalado na swinging basket da centrífuga, foi submetido primeiramente a uma "consolidação" por meio de três ou cinco ciclos consecutivos de centrifugação a 22 g (aceleração aplicada na profundidade do maciço igual a $270 \mathrm{~mm}$ ) de acordo com a densidade de areia.

Uma vez que este procedimento era completado, o sistema servo controlador para ensaios era instalado na centrífuga (Figura 4.22). Depois que o equipamento para teste era posicionado, o modelo de estaca era instalado a $1 \mathrm{~g}$ no solo de um modo suave e contínuo com velocidade de rotação igual a 5,3 rpm (na prática de fundações em estacas metálicas helicoidais esta velocidade varia de 5 a $20 \mathrm{rpm}$, quanto menor velocidade, menor modificação nas propriedades do solo atravessado). Quando o primeiro estágio da instalação (a 1 g) era concluído, fechava-se a swinging basket e iniciava-se a centrifugação até atingir o nível de gravidade igual a 22g. Após atingir o nível de gravidade desejado, o segundo estágio da instalação (últimos $60 \mathrm{~mm}$ de penetração da estaca) era realizado na mesma velocidade de rotação do primeiro estágio até o momento em que a hélice inferior atingisse a profundidade 
igual a 13,5 vezes o diâmetro da hélice. As estacas do grupo II (sem hélices) foram instaladas na profundidade das estacas do grupo I de diâmetro de haste correspondente.

A Figura 4.26 mostra as estacas na profundidade final de instalação no momento anterior aos ensaios de carregamento. A Tabela 4.8 apresenta os valores das profundidades finais das estacas modelo. A locação das estacas dentro do container $2\left(\gamma=16,30 \mathrm{kN} / \mathrm{m}^{3}\right)$ é mostrada na Figura 4.27. Nos containeres 1 e 2 as estacas foram igualmente locadas.

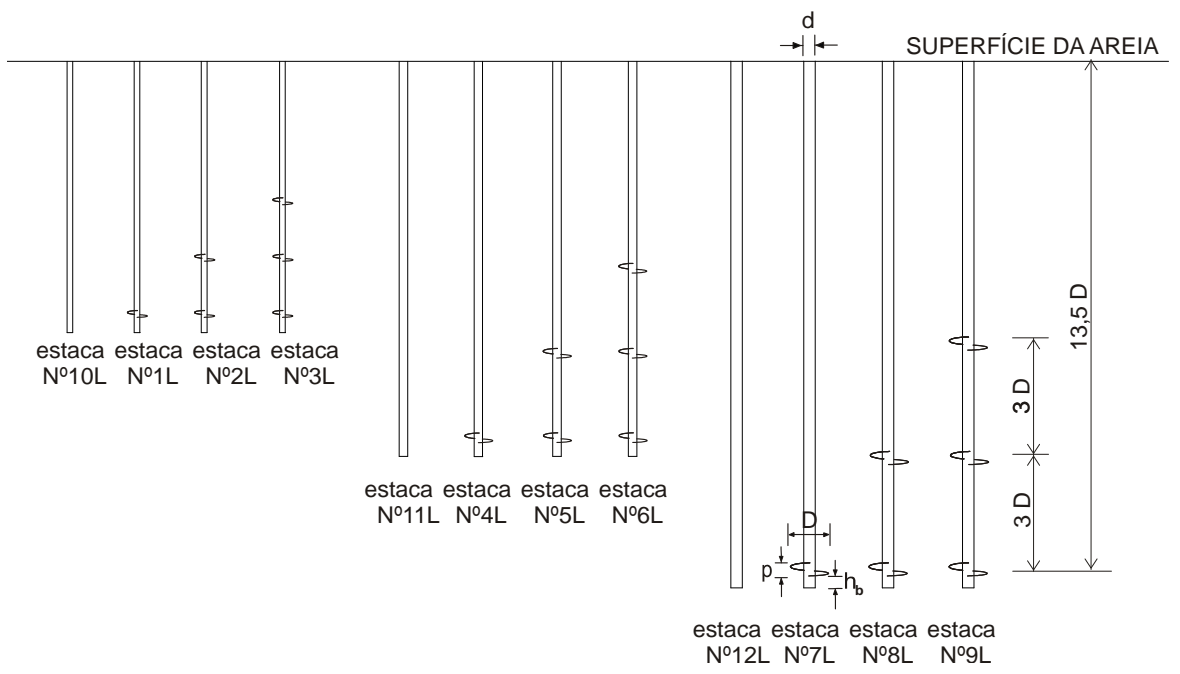

Figura 4.26 - Profundidade das estacas no momento anterior ao carregamento

Tabela 4.8 - Profundidade final das estacas modelo

\begin{tabular}{ccccc}
\hline $\begin{array}{c}\text { Estaca } \\
\mathrm{N}^{\mathbf{0}}\end{array}$ & $\begin{array}{c}\text { Grupo } \\
\mathrm{N}^{\mathbf{0}}\end{array}$ & $\begin{array}{c}\text { Diâmetro da } \\
\text { haste }(\mathrm{mm})\end{array}$ & $\begin{array}{c}\text { Profundidade } \\
\text { final }(\mathrm{mm})\end{array}$ & $\begin{array}{c}\text { Profundidade na escala } \\
\text { do protótipo }(\mathrm{m})\end{array}$ \\
\hline 1L & I & 3,0 & 145,0 & 3,109 \\
2L & I & 3,0 & 145,0 & 3,109 \\
3L & I & 3,0 & 145,0 & 3,109 \\
4L & I & 4,5 & 212,5 & 4,613 \\
5L & I & 4,5 & 212,5 & 4,613 \\
6L & I & 4,5 & 212,5 & 4,613 \\
$7 \mathrm{~L}$ & I & 6,0 & 280,0 & 6,160 \\
$8 \mathrm{~L}$ & I & 6,0 & 280,0 & 6,160 \\
9L & I & 6,0 & 280,0 & 6,160 \\
10L & II & 3,0 & 145,0 & 3,109 \\
11L & II & 4,5 & 212,5 & 4,613 \\
12L & II & 6,0 & 280,0 & 6,160 \\
\hline
\end{tabular}




\section{vista em planta}

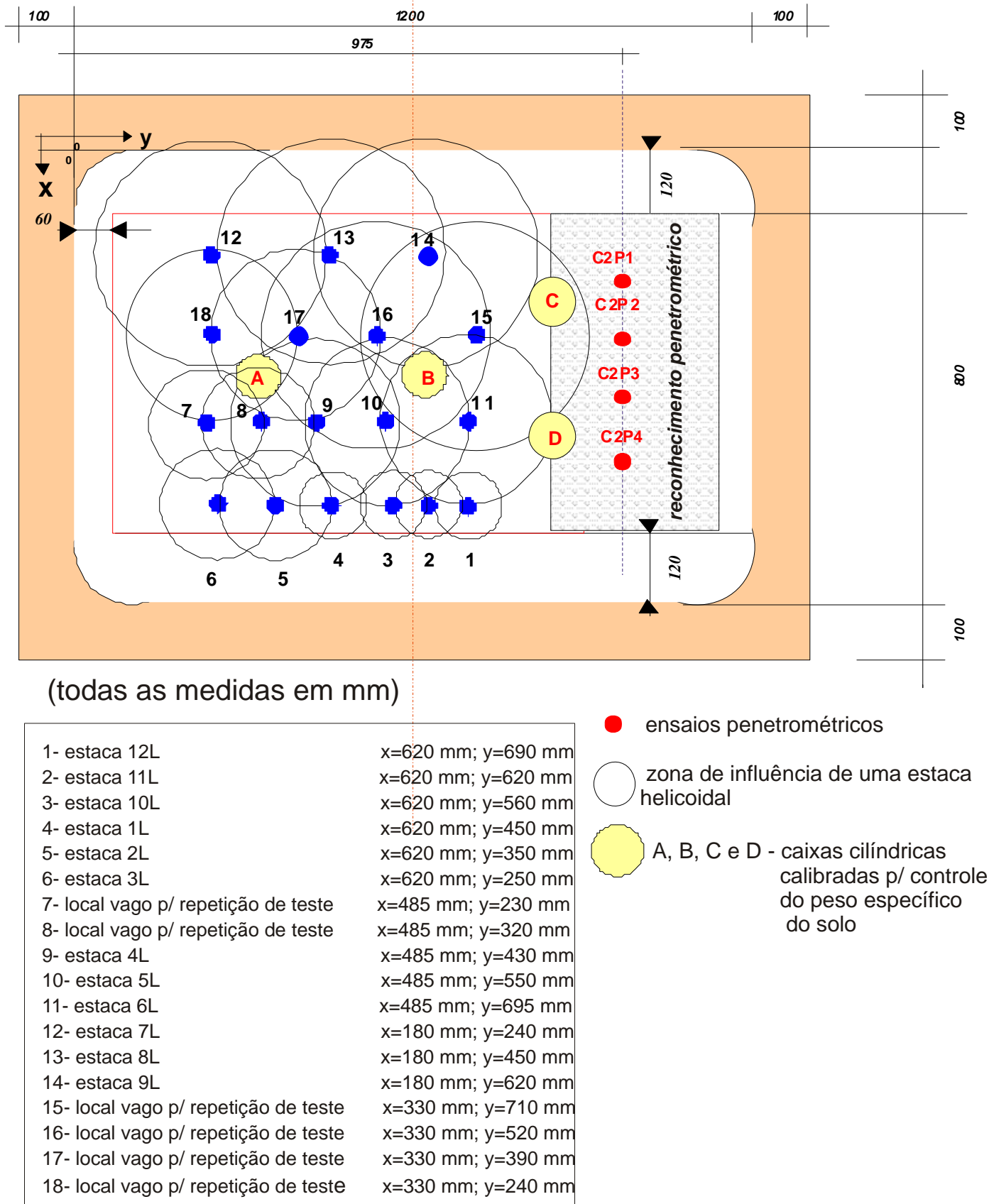

Figura 4.27 - Locação das estacas modelo dentro do container $2\left(\gamma=16,30 \mathrm{kN} / \mathrm{m}^{3}\right)$

Após a instalação de uma estaca na profundidade desejada, era aguardado um curto período de espera entre a fase de instalação e carregamento, sem parada da centrífuga. Em seguida, a estaca era extraída verticalmente com velocidade igual a $1 \mathrm{~mm} / \mathrm{segundo}$. Após cada 
ensaio de arrancamento, a centrífuga era parada para mudar a posição do sistema servo controlador, e em seguida era iniciada a instalação e ensaio em outra estaca.

Entre um ensaio e outro dentro do container 2, foram realizados ensaios penetrométricos na região indicada na Figura 4.27.

\subsubsection{Ensaios de arrancamento a 1G}

Para observar qualitativamente a superfície de ruptura de uma estaca metálica helicoidal dentro de um maciço de areia após o arrancamento, foi preparado um container de areia com camadas de areia colorida (mesma areia, porém com uma pigmentação azul) intercaladas regularmente entre camadas de areia branca de $20 \mathrm{~mm}$ de espessura.

Nestes ensaios foram utilizadas somente as estacas modelos fabricadas com hélices de maior diâmetro $(20 \mathrm{~mm})$ por assegurarem uma melhor sensibilidade do fenômeno observado.

Para a realização deste experimento, as estacas foram fixadas no container utilizando-se linhas de nylon (4.28). Em seguida foi realizado o preenchimento do container pela técnica de chuva de areia, interrompida a cada preenchimento de $20 \mathrm{~mm}$ de areia para o nivelamento do maciço e aplicação das camadas de areia colorida (4.29). A densidade relativa do maciço preparado foi de $85 \%$.



Figura 4.28 - Fixação das estacas no container com linhas de nylon 



Figura 4.29 - Nivelamento do maciço e aplicação da camada de areia colorida

Os ensaios de arrancamento foram feitos deslocando-se as estacas (fixadas em uma viga de aço) dez milímetros para cima (Figura 4.30). Após os ensaios, o container foi submetido à saturação pela base por capilaridade (Figura 4.31). Posteriormente à saturação completa, devido à umidade de areia foi possível cortá-la verticalmente sem desmoronamento. Pelo corte junto às estacas puderam ser vistas as camadas deformadas pelas rupturas locais.



Figura 4.30 - Ensaio de arrancamento das estacas a $1 \mathrm{~g}$ 


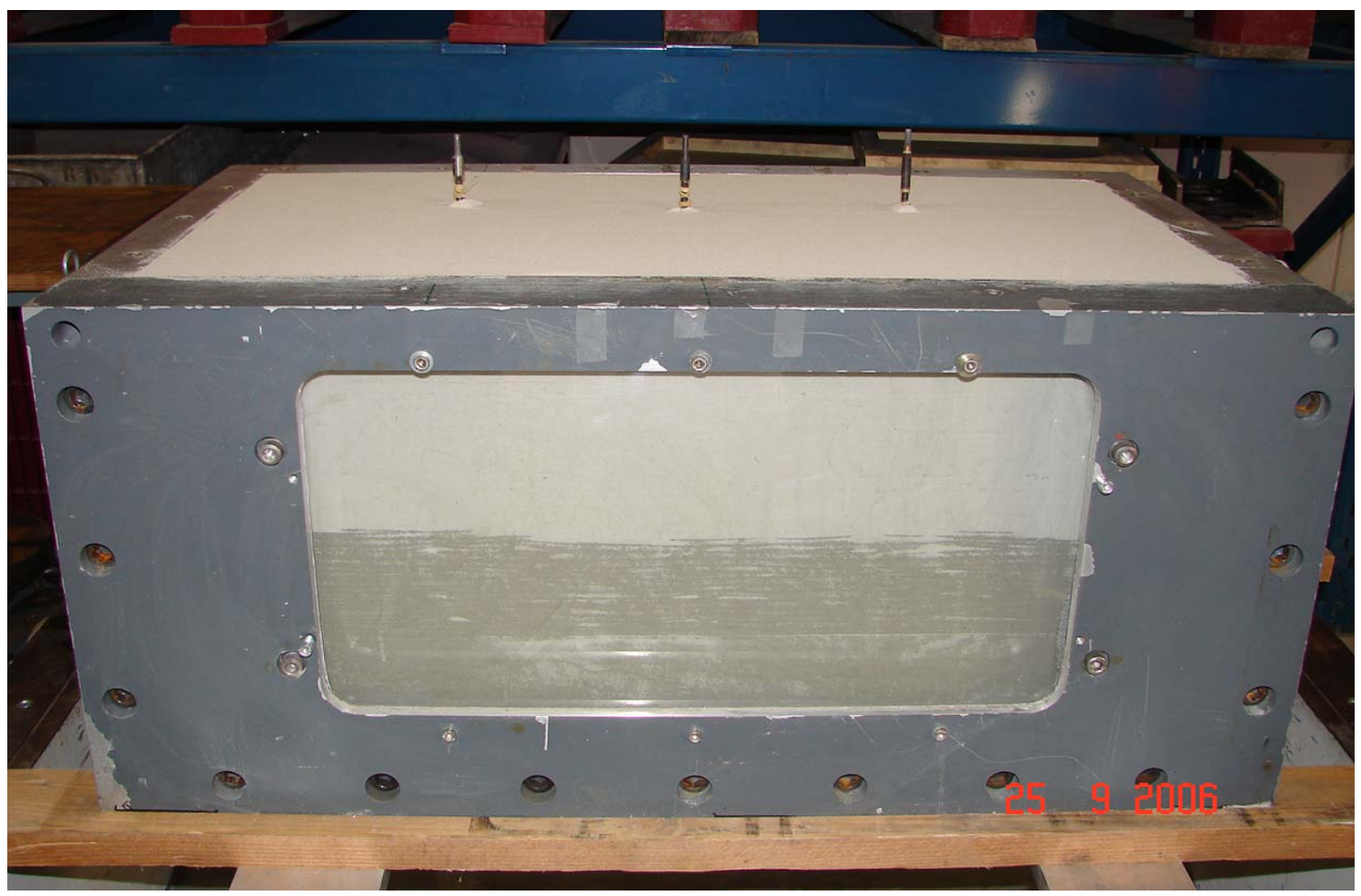

Figura 4.31 - Saturação do maciço de areia por capilaridade após ensaio de tração nas estacas

No entanto, em razão de um problema ocorrido no sistema de inundação do solo, a água penetrou no maciço anteriormente ao ensaio de arrancamento. Para solucionar o problema o container foi levado a uma estufa para secagem, porém devido à grande espessura da camada de areia, não foi secada completamente a água em maior profundidade dentro do maciço. Sendo assim, as estacas ensaiadas representaram a condição de um solo não saturado. Por este fato, é possível ver no corte do maciço o efeito da sucção nas hélices (capítulo 5).

\subsubsection{Ensaios de cisalhamento direto na interface}

O ângulo de atrito residual na interface entre a hélice da estaca metálica helicoidal e a areia envolvente $\left(\delta_{\mathrm{r}}\right)$ é um parâmetro fundamental do modelo teórico proposto nesta tese. Para a determinação deste parâmetro, foram realizados dois grupos de ensaios de cisalhamento direto na interface aço/areia. O primeiro grupo de ensaios foi executado no laboratório de mecânica 
dos solos do LCPC, com o objetivo de medir o ângulo de atrito residual na interface entre o material das hélices utilizadas nos modelos de estacas e a areia utilizada nos maciços ensaiados na centrífuga. O segundo grupo de ensaios foi realizado no laboratório de mecânica dos solos da Escola de Engenharia de São Carlos (USP), para a obtenção do ângulo de atrito residual na interface entre o material de hélices utilizadas em estacas metálicas helicoidais fabricadas comercialmente e diferentes tipos de areia. O objetivo destes ensaios foi determinar valores de $\delta_{r}$ para serem adotados no modelo proposto nesta tese (Equação 3.16), quando este for aplicado na prática deste tipo de fundação.

Uesugi e Kishida (1986) mostraram que a rugosidade do aço, o diâmetro médio da areia $\left(\mathrm{D}_{50}\right)$ e a forma do grão exercem grande influência no ângulo de atrito da interface entre aço e areia. Devido a este fato, foram feitas medidas de rugosidade do material das hélices utilizadas nos ensaios em centrífuga e em estacas metálicas helicoidais fabricadas comercialmente, e, nos ensaios de cisalhamento em interface realizados na Escola de Engenharia de São Carlos foram usadas na interface três tipos de areia com diferentes valores de $\mathrm{D}_{50}$.

\subsubsection{Interface areia e aço da hélice do modelo ensaiado em centrífuga}

Para validar a Equação 3.14 do modelo teórico desenvolvido nesta tese, utilizando-se os resultados dos ensaios em centrífuga, é essencial que se conheça o valor do ângulo de atrito entre o material utilizado na fabricação das hélices e a areia empregada para a reconstituição do maciço de solo utilizado nos ensaios em centrífuga.

Para este fim, foram realizados ensaios de cisalhamento direto em uma caixa de cisalhamento modelo Casagrande do laboratório de mecânica dos solos do LCPC. 
Como as hélices foram soldadas em torno de uma haste central, e os modelos de estacas foram fabricados em pequena dimensão, as superfícies das hélices em geral eram compostas de $50 \%$ de aço e $50 \%$ de material para solda (Figura 4.32). Considerando-se a heterogeneidade das superfícies das hélices, foram realizados ensaios de cisalhamento direto em duas diferentes interfaces feitas do aço de fabricação das hélices, uma coberta com solda e a outra sem solda. Essas interfaces foram construídas no diâmetro igual a $60 \mathrm{~mm}$ e fixadas na meia-caixa inferior do equipamento de cisalhamento direto (Figura 4.33).

Os resultados de ângulo de atrito residual na interface considerados para validação do modelo teórico proposto nesta tese foi o valor médio entre os resultados obtidos nos testes em interface com aço e em interface com solda.

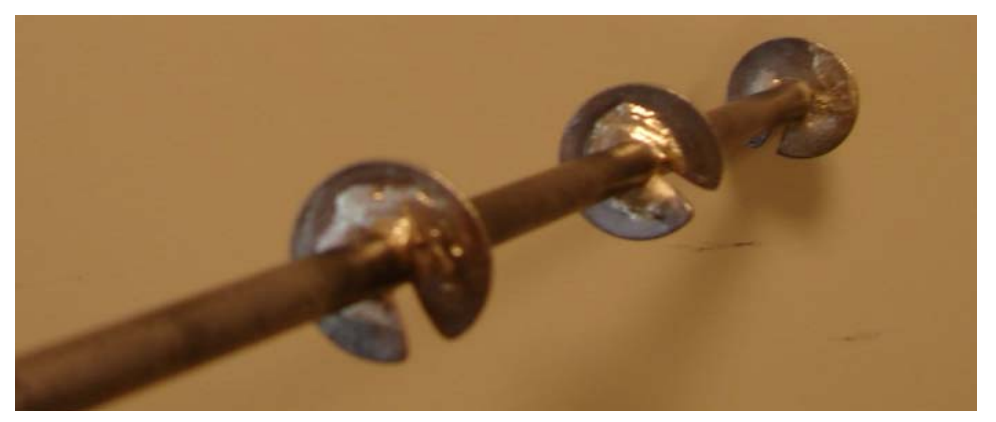

Figura 4.32 - Fotografia das superfícies das hélices da estaca modelo N9L
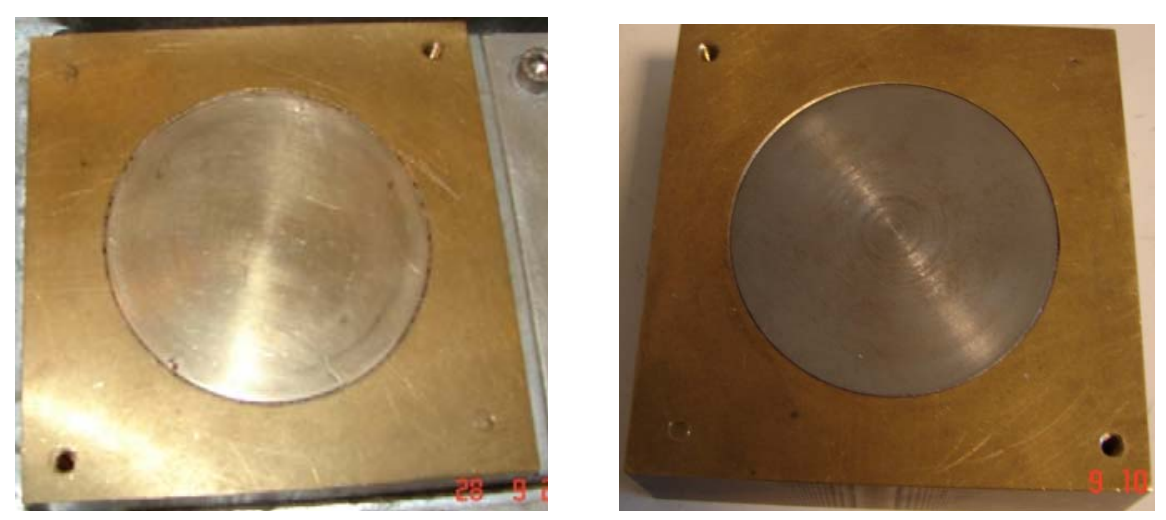

Figura 4.33 - Meia-caixa inferior com as interfaces ensaiadas: de solda (esquerda) e de aço (direita) 
Para cada tipo de interface foram executados 6 ensaios: 3 níveis de tensão normal para amostra de areia de densidade relativa $\left(D_{\mathrm{r}}\right)$ igual a $85 \%\left(\gamma=16,30 \mathrm{kN} / \mathrm{m}^{3}\right)$ e 3 níveis de tensão normal para amostra de areia de densidade relativa $\left(D_{r}\right)$ igual a $56 \%\left(\gamma=15,46 \mathrm{kN} / \mathrm{m}^{3}\right)$.

A amostra de areia era preparada na meia-caixa superior da caixa de Casagrande (Figura 4.34). Conhecendo-se o volume da caixa, era calculada e pesada a massa necessária para obter-se a densidade desejada. Após a instalação desta massa de areia na meia-caixa superior, a densidade relativa era controlada por meio de golpes sucessivos de um pequeno martelo. A meia-caixa superior foi dividida em 5 camadas (para 5 etapas de preenchimento com areia e golpes de martelo).
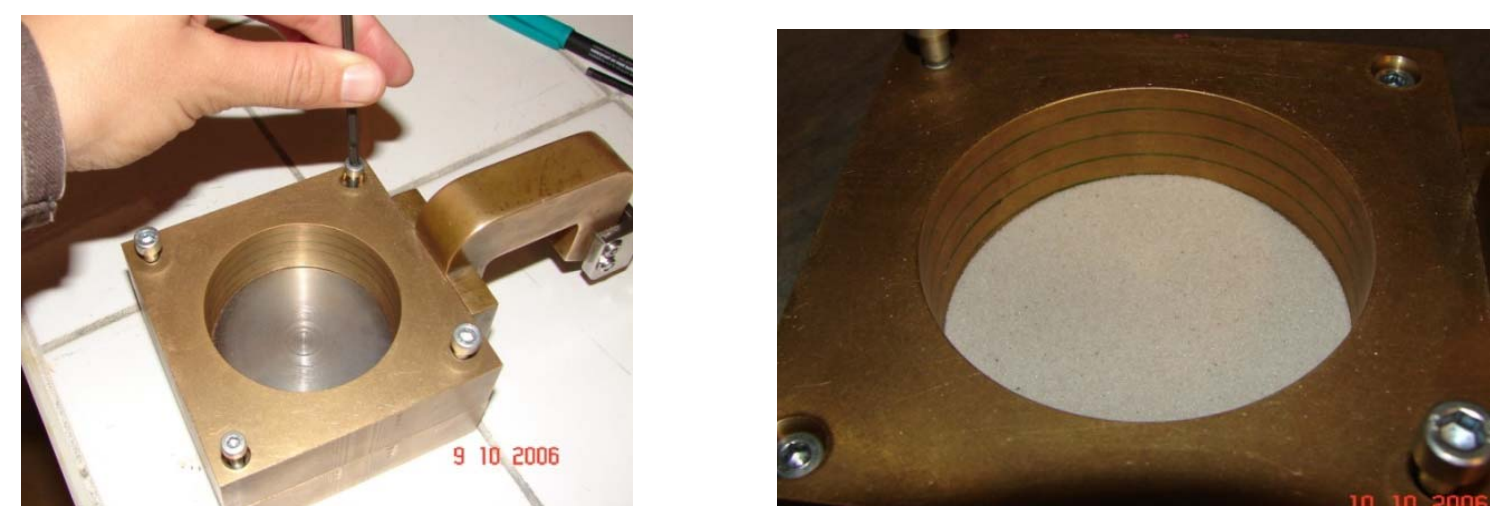

Figura 4.34 - Preparo da amostra de areia na meia-caixa superior

Após o preenchimento da meia-caixa superior com a amostra de areia, a caixa era instalada no equipamento para ensaios de cisalhamento direto, e a meia-caixa inferior (com a amostra de aço ou solda) era deslocada horizontalmente a uma velocidade constante igual a $0,11 \mathrm{~mm} /$ minuto (Figura 4.35 ) até atingir o deslocamento total igual a $30 \mathrm{~mm}$.

Nos ensaios foram medidos deslocamento horizontal e vertical e a força cisalhante. O equipamento era ligado a um sistema de aquisição de dados, com capacidade de leitura a cada 0,5 segundos, onde um software traçava os gráficos simultaneamente aos ensaios e transformava os resultados medidos em planilha do tipo Excel. 


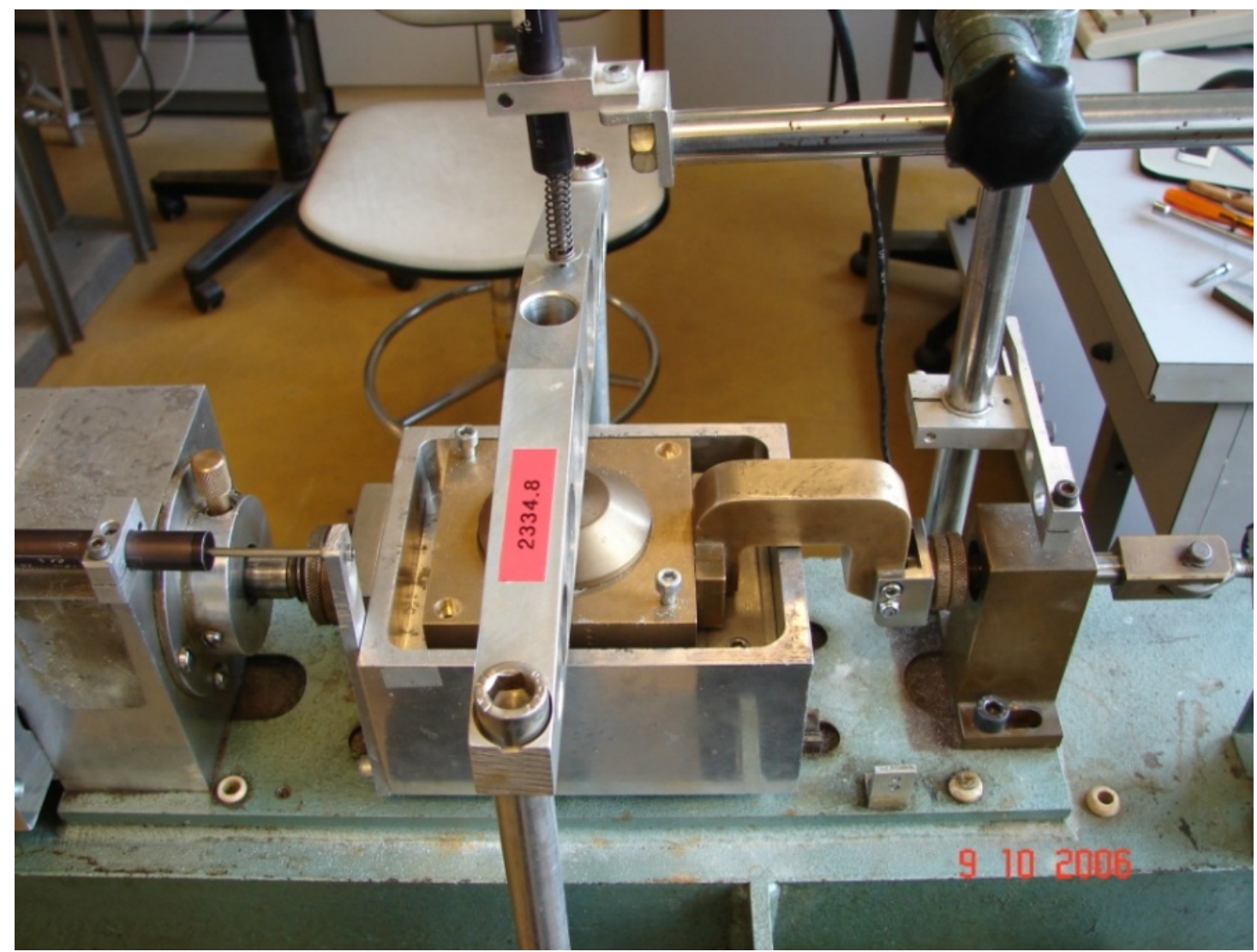

Figura 4.35- Ensaio de cisalhamento na interface

\subsubsection{Interface areia e aço da chapa da hélice comercialmente utilizada}

Para a aplicação do modelo teórico proposto nesta tese na prática de fundações em estacas metálicas helicoidais, é de grande importância o conhecimento do ângulo de atrito na interface hélice/areia correspondente a fase de instalação da estaca no terreno. Saibaba Reddy et al. (2000) citaram que o ângulo de atrito na interface não pode ser expresso como uma porcentagem constante do ângulo de atrito interno do solo, e que este ângulo é função das propriedades da interface. Por esta razão, foram realizados ensaios de cisalhamento em interfaces entre o material da chapa da hélice utilizada em estacas metálicas helicoidais fabricadas comercialmente (chapa grossa ASTM-A36) e diferente tipos de areia. 
Foram realizados 27 diferentes configurações de ensaio. A chapa de aço da hélice foi testada em interfaces com três tipos de areia de diferentes $\mathrm{D}_{50}$, sendo que para cada tipo foram ensaiadas três diferentes densidades relativas, e para cada densidade relativa foram testados três níveis de tensão normal.

As três areias utilizadas nos ensaios de cisalhamento na interface foram caracterizadas no laboratório de mecânica dos solos da Escola de Engenharia de São Carlos, por meio de ensaios de granulometria e de determinação dos índices de vazio máximo e mínimo. Além desses ensaios, foram feitas fotos com microscópio dos três tipos de areia ensaiados para a visualização do formato dos grãos, com o objetivo de verificar se o formato dos grãos interferiram nos resultados.

Nestes ensaios foi utilizada a caixa de cisalhamento composta por duas metades (inferior e superior) de dimensões internas de $100 \mathrm{~mm}$ x $100 \mathrm{~mm}$ x $25 \mathrm{~mm}$. Na meia-caixa inferior foi fixada a amostra da placa de aço ASTM-A36 (Figura 4.36).
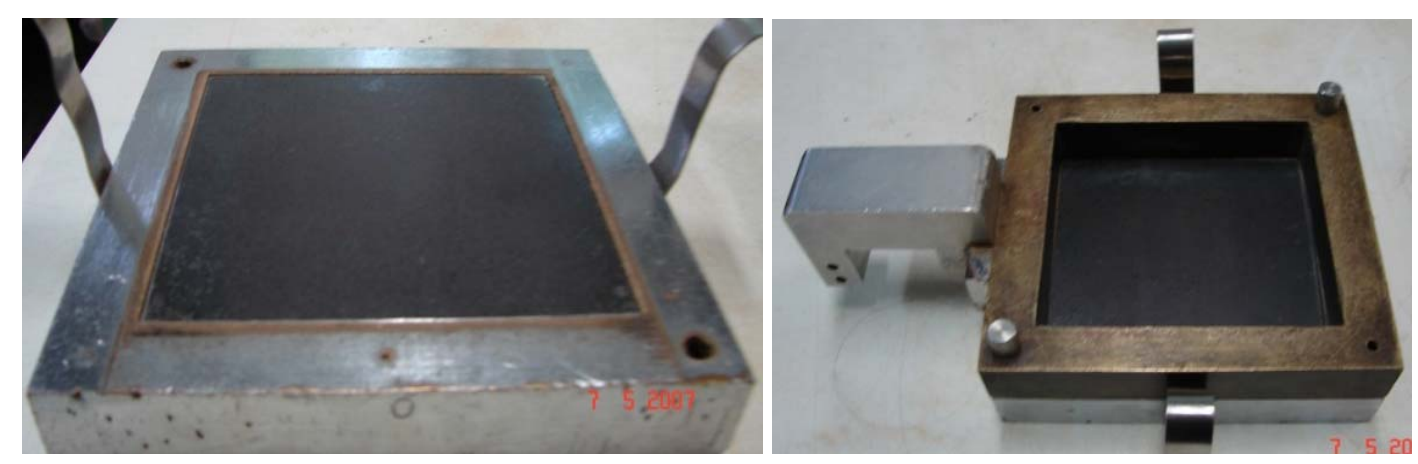

Figura 4.36 - Interface de aço ensaiada instalada na meia-caixa inferior

O procedimento de preparo da amostra de areia foi semelhante ao realizado nos ensaios de cisalhamento direto citados no item anterior. A densidade relativa das amostras de areia foi controlada por golpes de martelo. Após o preparo da amostra (Figura 4.37), a caixa era instalada no equipamento de cisalhamento direto, e a meia-caixa inferior (com a amostra de 
aço) era deslocada horizontalmente a uma velocidade constante igual a $0,10 \mathrm{~mm} /$ minuto (Figura 4.38).

Nos ensaios foram medidos os deslocamentos horizontais e verticais e as forças cisalhantes. As leituras foram feitas diretamente pela observação dos relógios comparadores, em intervalos correspondentes ao deslocamento horizontal igual a $0,025 \mathrm{~mm}$ no início (até o deslocamento inicial igual a $0,10 \mathrm{~mm}$ ), passando mais tarde a $0,05 \mathrm{~mm}$ (até o deslocamento de $0,60 \mathrm{~mm}$ ) e depois a cada $0,10 \mathrm{~mm}$ até o final do ensaio (correspondente ao deslocamento horizontal da meia-caixa inferior igual a $6 \mathrm{~mm}$ ).

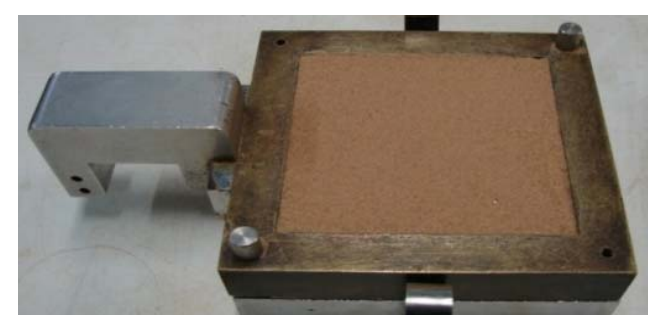

Figura 4.37 - Caixa com a amostra pronta para o ensaio
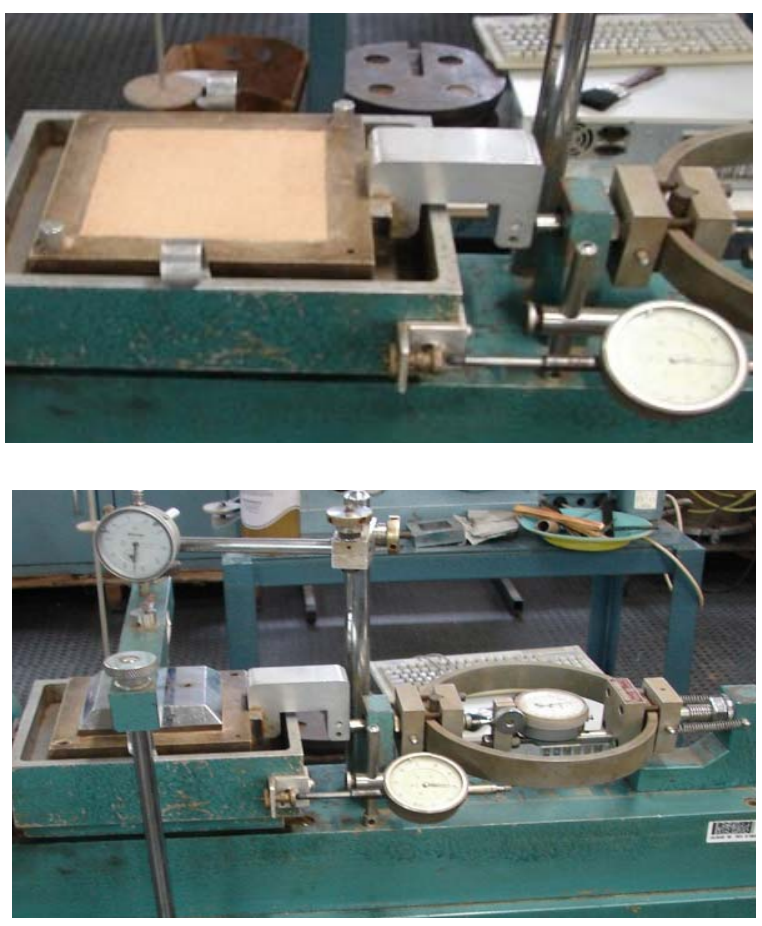

Figura 4.38 - Encaixe da caixa no equipamento de ensaio e realização do ensaio 


\subsubsection{Ensaio de rugosidade das interfaces}

Foram executados no laboratório de metrologia da Escola de Engenharia de São Carlos ensaios de rugosidade nas placas utilizadas nos ensaios de cisalhamento em interface realizados no LCPC e na EESC. As três seguintes placas foram ensaiadas:

- Placa de aço utilizada na fabricação das hélices dos modelos de estacas ensaiados em centrífuga;

- Placa de aço coberta com o material da solda utilizada nos modelos de estacas ensaiados em centrífuga;

- Placa de aço (chapa grossa ASTM-A36) utilizada na fabricação das estacas metálicas helicoidais utilizadas comercialmente.

O aparelho utilizado para as medidas de rugosidade foi o SURTRONIC 3+ (Figura 4.39).

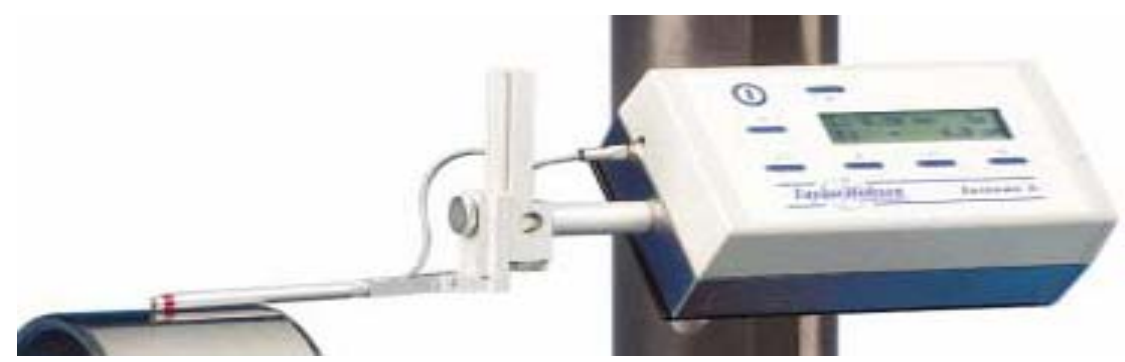

Figura 4.39 - Aparelho SURTRONIC 3+ para medir rugosidade de superfícies (Catálogo da Taylor Hobson Precision, 2007)

\subsubsection{Ensaios de torção do tubo da estaca}

Durante a instalação de uma estaca metálica helicoidal no terreno deve-se verificar se o torque de instalação não ultrapassa o valor do momento torçor máximo tolerável para a secção 
do tubo da estaca. Caso o torque ultrapasse este valor, o tubo da estaca sofrerá cisalhamento por torção e a estaca será danificada.

O cálculo do momento torçor admissível para tubos de aço é determinado pela seguinte fórmula (Queiroz, 1988):

$$
M_{t}=\frac{\tau_{\max } \cdot \pi \cdot\left(D^{4}-d^{4}\right)}{16 . D}
$$

onde:

$\tau_{\max }=$ tensão de cisalhamento admissível

$\mathrm{D}=$ diâmetro externo do tubo;

d = diâmetro interno do tubo.

Em uma obra realizada no Brasil, em que foram utilizadas estacas metálicas helicoidais, foram observados problemas de torção em tubos de estacas durante a instalação. O problema ocorreu devido ao fato de que o torquímetro que fazia as leituras de torque durante a instalação estava danificado, e os torques reais aplicados ao tubo eram na realidade maiores do que os valores lidos no torquímetro. Devido a este episódio, os tubos das estacas utilizados nesta obra foram verificados por meio de ensaios de torção no laboratório do Departamento de Estruturas da EESC. Os ensaios foram realizados pelo Prof. Maximiliano Malite e acompanhados pela autora desta tese.

Foram realizados ensaios nos quatro tubos distintos:

- Tubo de aço com diâmetro externo igual a $73 \mathrm{~mm}$ e espessura igual a 5,16 mm (sem emenda); 
- Tubo de aço com diâmetro externo igual a $73 \mathrm{~mm}$ e espessura igual a 5,16 mm (com emenda);

- Tubo de aço com diâmetro externo igual a $73 \mathrm{~mm}$ e espessura igual a 7,1 mm (sem emenda);

- Tubo de aço com diâmetro externo igual a $73 \mathrm{~mm}$ e espessura igual a 7,1 mm (com emenda).

As emendas dos tubos ensaiados de estacas helicoidais são idênticas a apresentada na Figura 2.10 da revisão bibliográfica desta tese. A base alargada de um tubo é presa a outro tubo por meio de três parafusos de $19 \mathrm{~mm}$ x $165 \mathrm{~mm}$ em aço $1045 \mathrm{SAE}$.

Para a realização destes ensaios foi montado um sistema provido de uma de viga de aço que trabalhou como braço de alavanca para aplicação da força. Nesta viga foi fixada uma seção do do tubo ensaiado, o qual estava preso em outra parte a um pedestal engastado no solo (Figura 4.40). As forças eram aplicadas gradativamente à extremidade da viga oposta ao tubo e o deslocamento vertical de um ponto da viga (a $25 \mathrm{~cm}$ do centro do tubo) era medido simultaneamente à aplicação da força por um transdutor de deslocamento. Por meio destas medidas foi possível traçar os gráficos de momento torçor x rotação. O momento torçor foi calculado multiplicando a força pelo braço de alavanca igual a $45 \mathrm{~cm}$ (Figura 4.40) e os valores de rotação $\alpha$ foram calculados pela seguinte equação:

$$
\alpha=\operatorname{arctg} \frac{d}{l}
$$

onde: 
$d=$ medida do deslocamento vertical (em centímetros)

$l=$ distancia entre o eixo do tubo e o ponto da viga de aço onde está instalado o transdutor de deslocamento (igual a $25 \mathrm{~cm}$ )

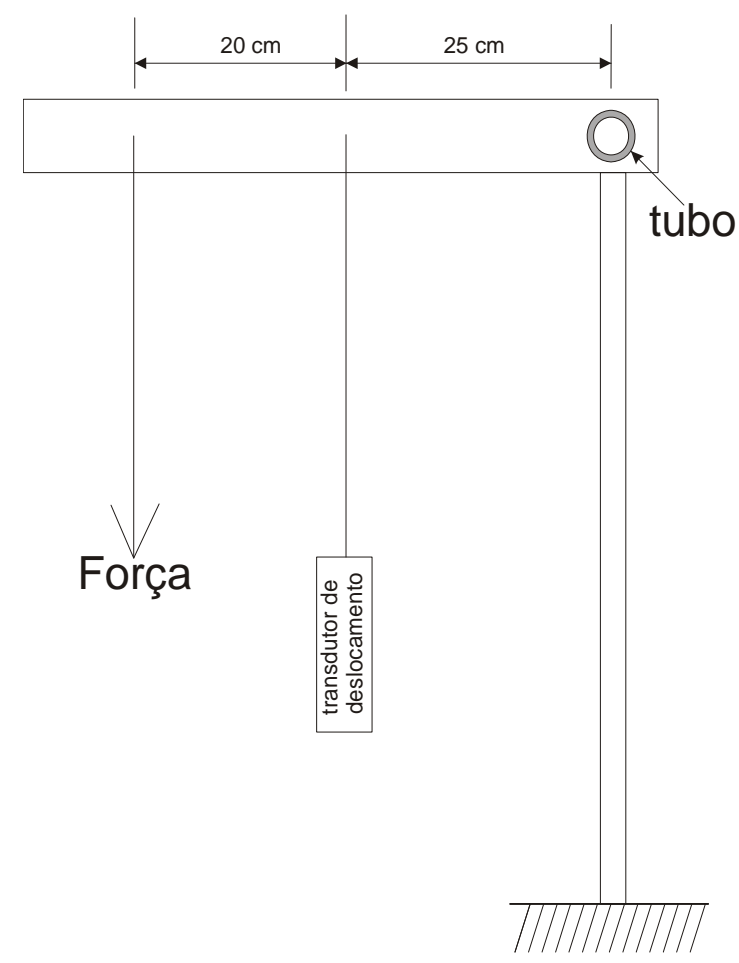

Figura 4.40 - Esquema do ensaio de torção no tubo 


\section{$5 \quad$ RESULTADOS}

Neste capítulo são apresentados os resultados obtidos nas provas de carga e nos ensaios de laboratório realizados nesta tese.

\subsection{Provas de carga realizadas em campo}

\subsubsection{Contagem}

Os resultados de torque de instalação das quatro estacas metálicas helicoidais ensaiadas em Contagem, medidos a cada metro penetrado, são exibidos na Tabela 5.1. As dimensões das estacas contidas nesta tabela são indicadas na Tabela 4.1 do capítulo anterior.

Tabela 5.1 - Profundidade da ponta da estaca x torque de instalação (Contagem)

\begin{tabular}{cc|cc|cc|cc}
\hline \multicolumn{2}{c}{ Estaca $1 \mathrm{C}$} & \multicolumn{2}{c}{ Estaca 2C } & \multicolumn{2}{c}{ Estaca 3C } & \multicolumn{2}{c}{ Estaca 4C } \\
\hline $\begin{array}{c}\text { Profund. } \\
(\mathrm{m})\end{array}$ & $\begin{array}{c}\text { Torque } \\
(\mathrm{kN} . \mathrm{m})\end{array}$ & $\begin{array}{c}\text { Profund. } \\
(\mathrm{m})\end{array}$ & $\begin{array}{c}\text { Torque } \\
(\mathrm{kN} . \mathrm{m})\end{array}$ & $\begin{array}{c}\text { Profund. } \\
(\mathrm{m})\end{array}$ & $\begin{array}{c}\text { Torque } \\
(\mathrm{kN} . \mathrm{m})\end{array}$ & $\begin{array}{c}\text { Profund. } \\
(\mathrm{m})\end{array}$ & $\begin{array}{c}\text { Torque } \\
(\mathrm{kN} . \mathrm{m})\end{array}$ \\
1,0 & 4,1 & 1,0 & 2,7 & 1,0 & 2.7 & 1,0 & 4,1 \\
2,0 & 5,4 & 2,0 & 2,7 & 2,0 & 4,1 & 2,0 & 5,4 \\
3,0 & 4,1 & 3,0 & 4,1 & 3,0 & 8,1 & 3,0 & 6,8 \\
4,0 & 4,1 & 4,0 & 4,1 & 4,0 & 9,5 & 4,0 & 8,1 \\
5,0 & 5,4 & 5,0 & 5,4 & 5,0 & 9,5 & 5,0 & 6,8 \\
5,7 & 6,8 & 5,3 & 5,4 & 5,9 & 10,9 & 6,0 & 9,5 \\
& & & & & & 6,3 & 10,9 \\
\hline
\end{tabular}


Na Figuras 5.1 podem ser observadas as curvas torque de instalação x profundidade da ponta das estacas instaladas em Contagem.

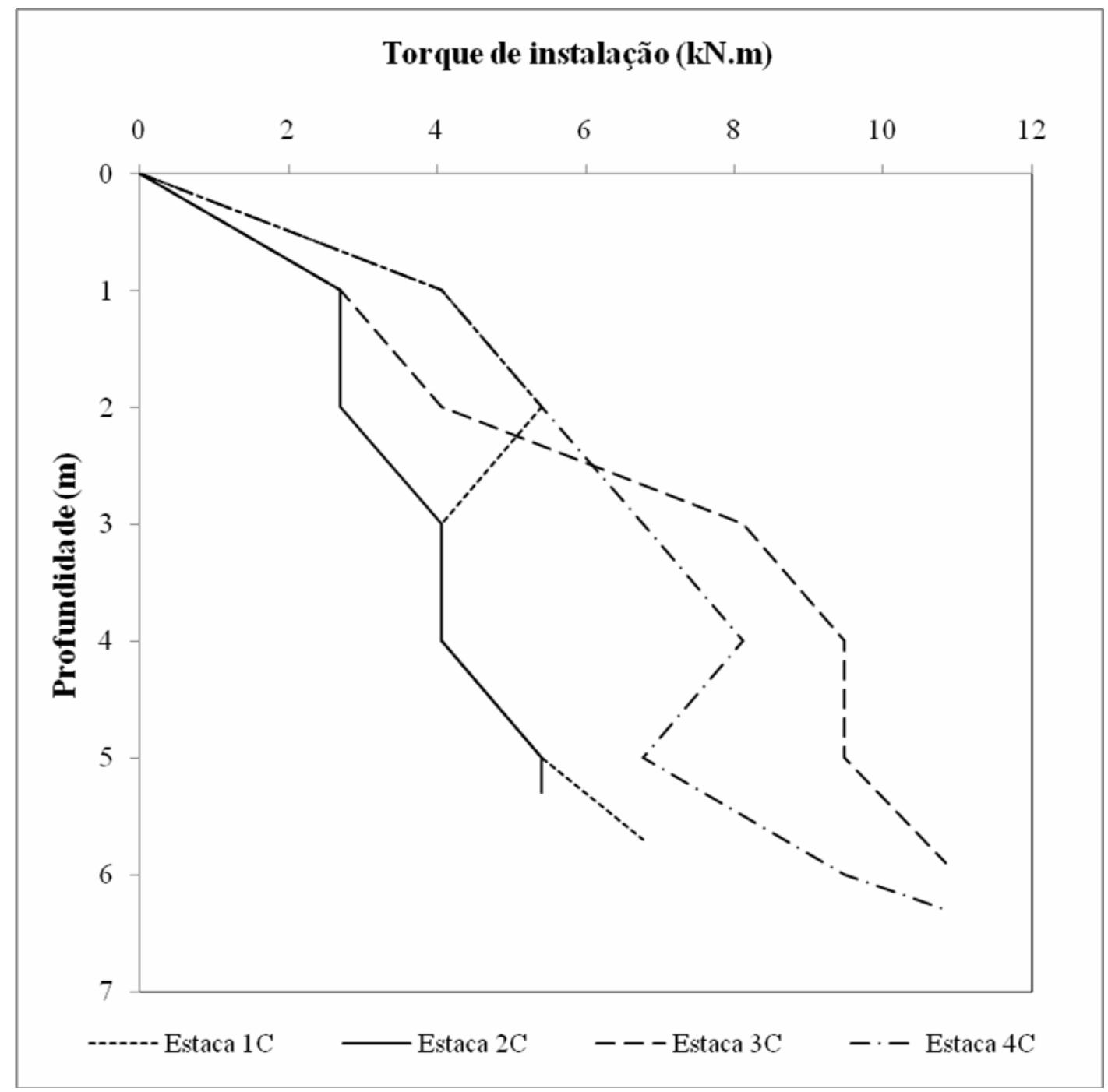

Figura 5.1 - Curva torque de instalação x profundidade da ponta das estacas 1C, 2C, 3C e 4C

As Figuras 5.2 a 5.5 apresentam as curvas de carga de tração x deslocamento obtidas por meio das provas de carga à tração realizadas nas estacas metálicas helicoidais instaladas em Contagem. 


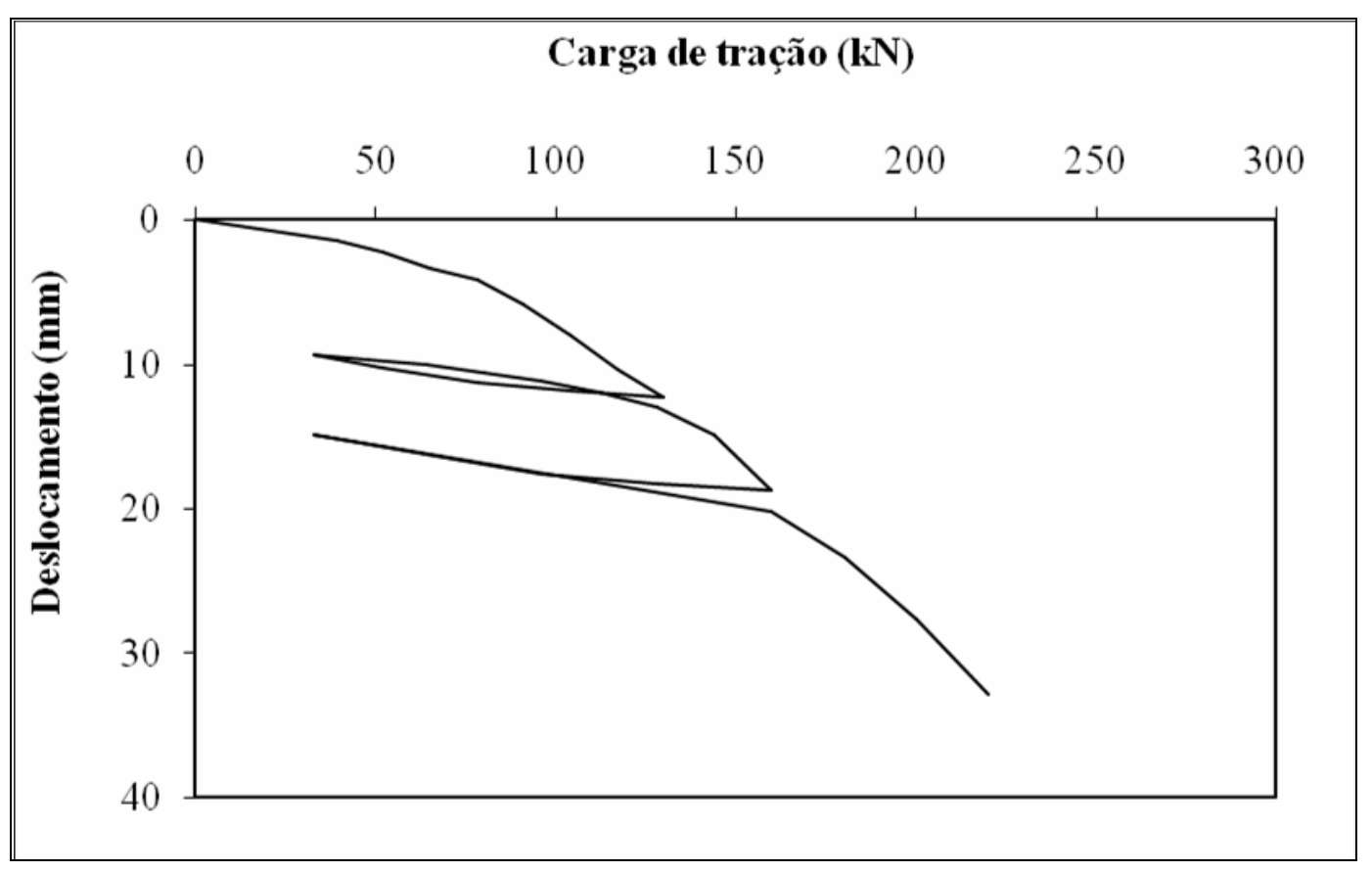

Figura 5.2 - Curva carga de tração x deslocamento da estaca 1C

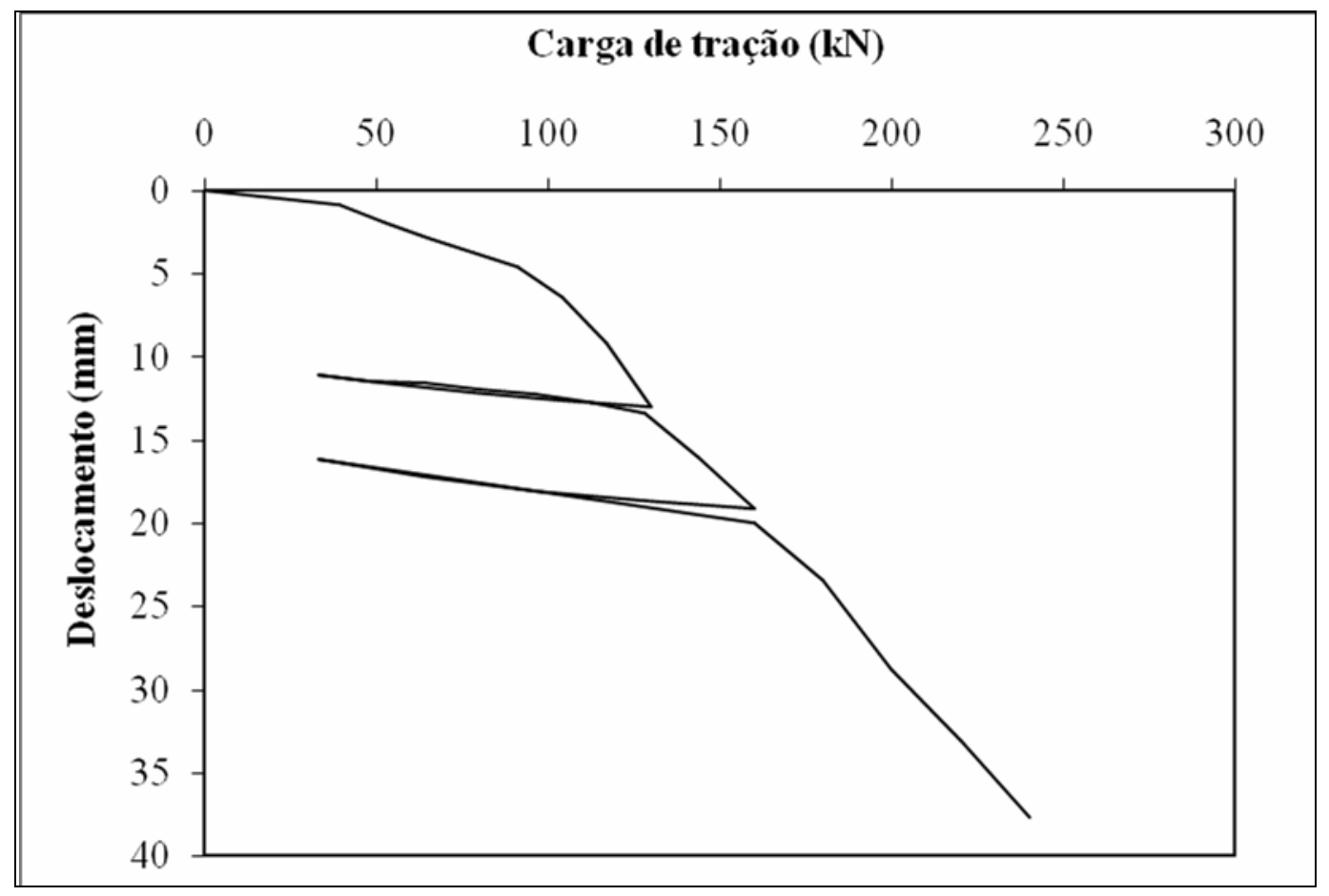

Figura 5.3 - Curva carga de tração x deslocamento da estaca 2C 


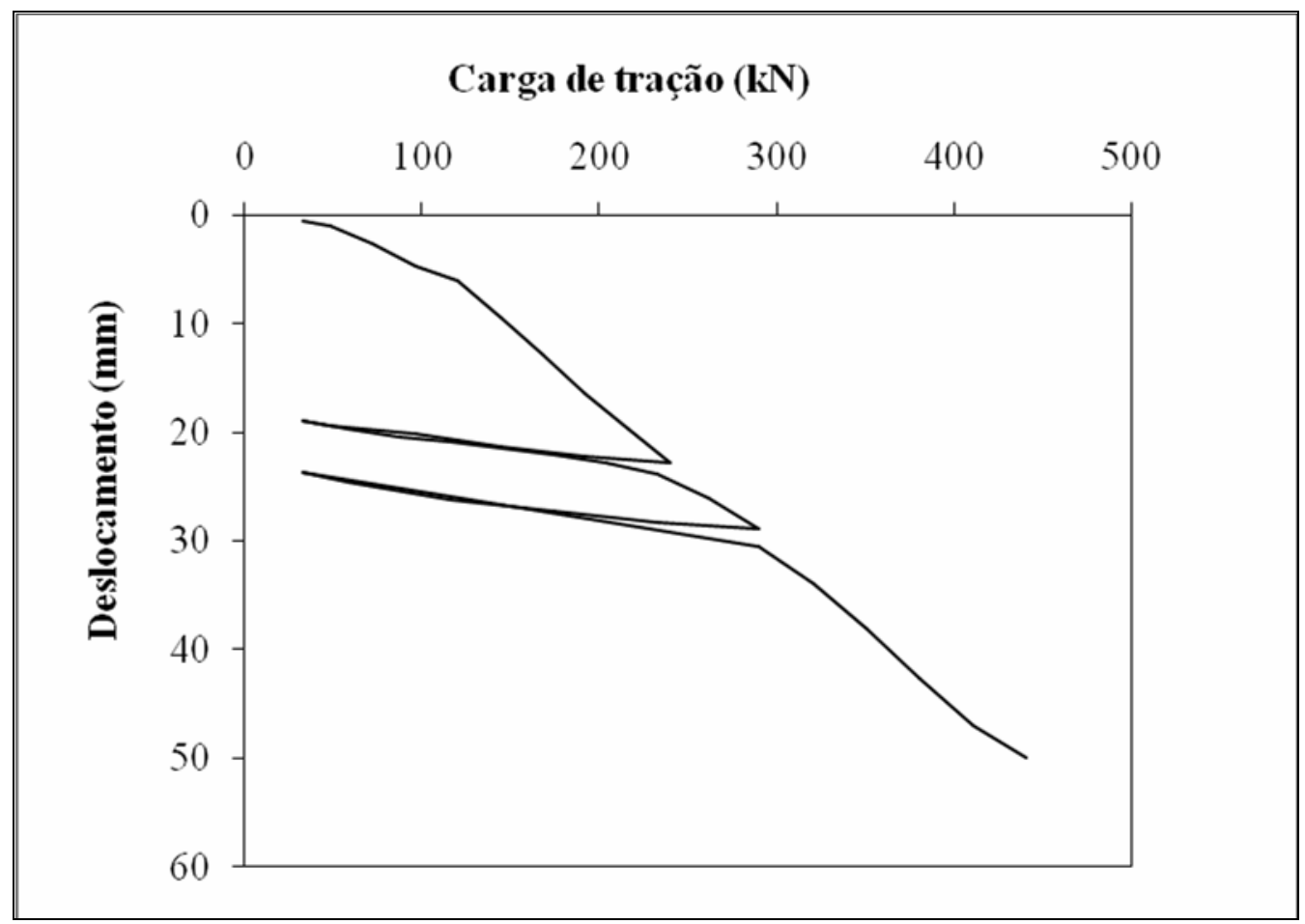

Figura 5.4 - Curva carga de tração x deslocamento da estaca 3C

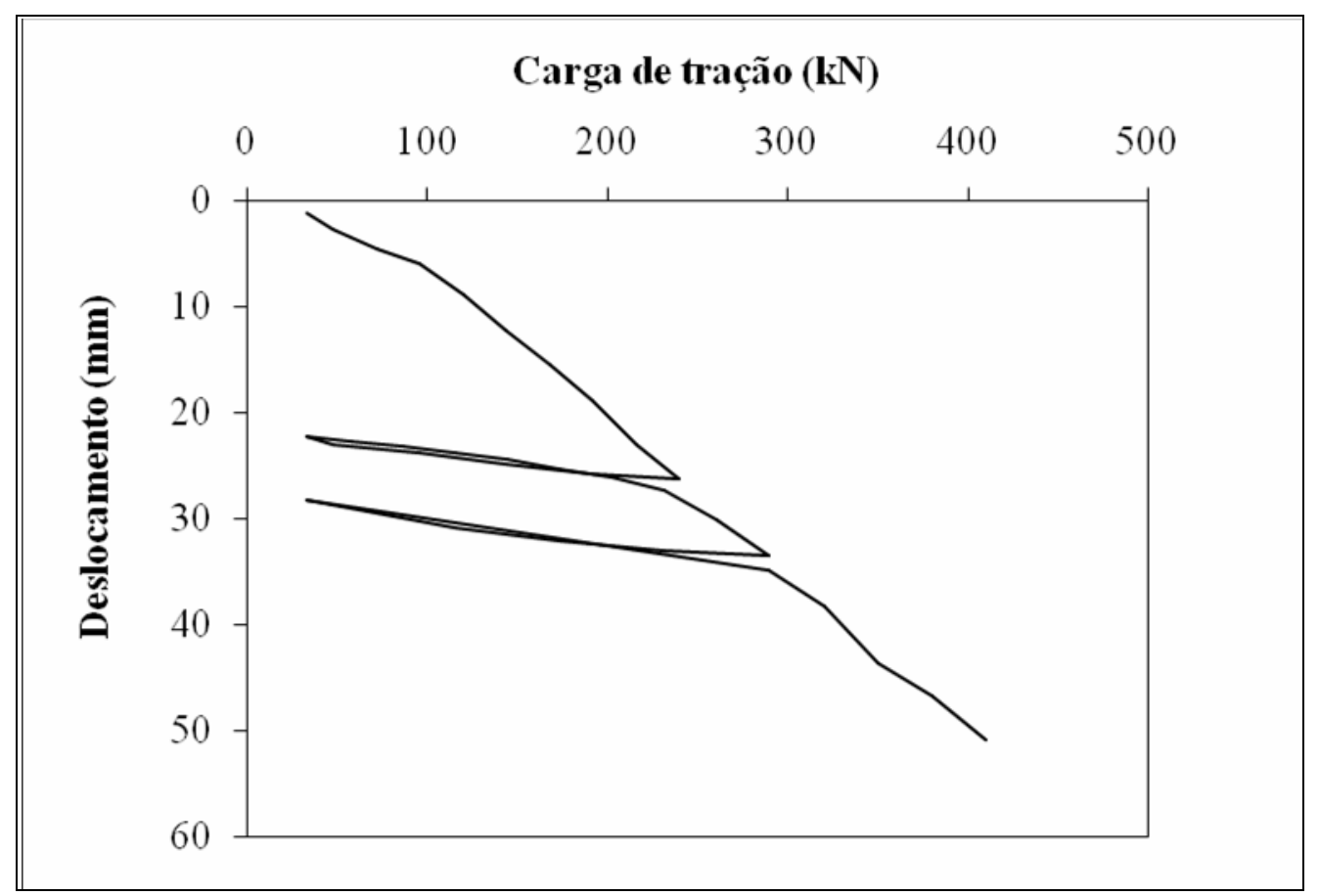

Figura 5.5 - Curva carga de tração x deslocamento da estaca 4C 


\subsubsection{Campo Experimental EESC}

Os resultados de torque de instalação das duas estacas metálicas helicoidais ensaiadas no Campo Experimental da Escola de Engenharia de São Carlos (USP), medidos a cada metro penetrado, são mostrados na Tabela 5.2. As dimensões das estacas contidas nesta tabela são indicadas na Tabela 4.2 do capítulo anterior. A Figura 5.6 apresenta as curvas torque de instalação x profundidade da ponta das estacas citadas.

Tabela 5.2 - Profundidade da ponta das estacas x torque de instalação (EESC)

\begin{tabular}{cc|cc}
\hline \multicolumn{2}{c}{ Estaca 5C } & \multicolumn{2}{c}{ Estaca 6C } \\
\hline Profundidade (m) & Torque (kN.m) & Profundidade (m) & Torque (kN.m) \\
1,0 & 0,68 & 1,0 & 0,34 \\
2,0 & 0,95 & 2,0 & 0,27 \\
3,0 & 0,98 & 3,0 & 0,54 \\
4,0 & 1,49 & 4,0 & 0,81 \\
5,0 & 1,90 & 5,0 & 0,79 \\
6,0 & 2,03 & 6,0 & 0,92 \\
7,0 & 2,44 & 7,0 & 1,36 \\
8,0 & 3,09 & 8,0 & 1,83 \\
9,0 & 4,88 & 9,0 & 2,51 \\
10,0 & 4,88 & 10,0 & 2,54 \\
11,0 & 4,88 & 11,0 & 2,98 \\
12,0 & 5,83 & 12,0 & 3,39 \\
13,0 & 5,83 & 13,0 & 3,39 \\
14,0 & 6,10 & 14,0 & 3,86 \\
14,5 & 7,05 & 14,5 & 4,15 \\
\hline
\end{tabular}




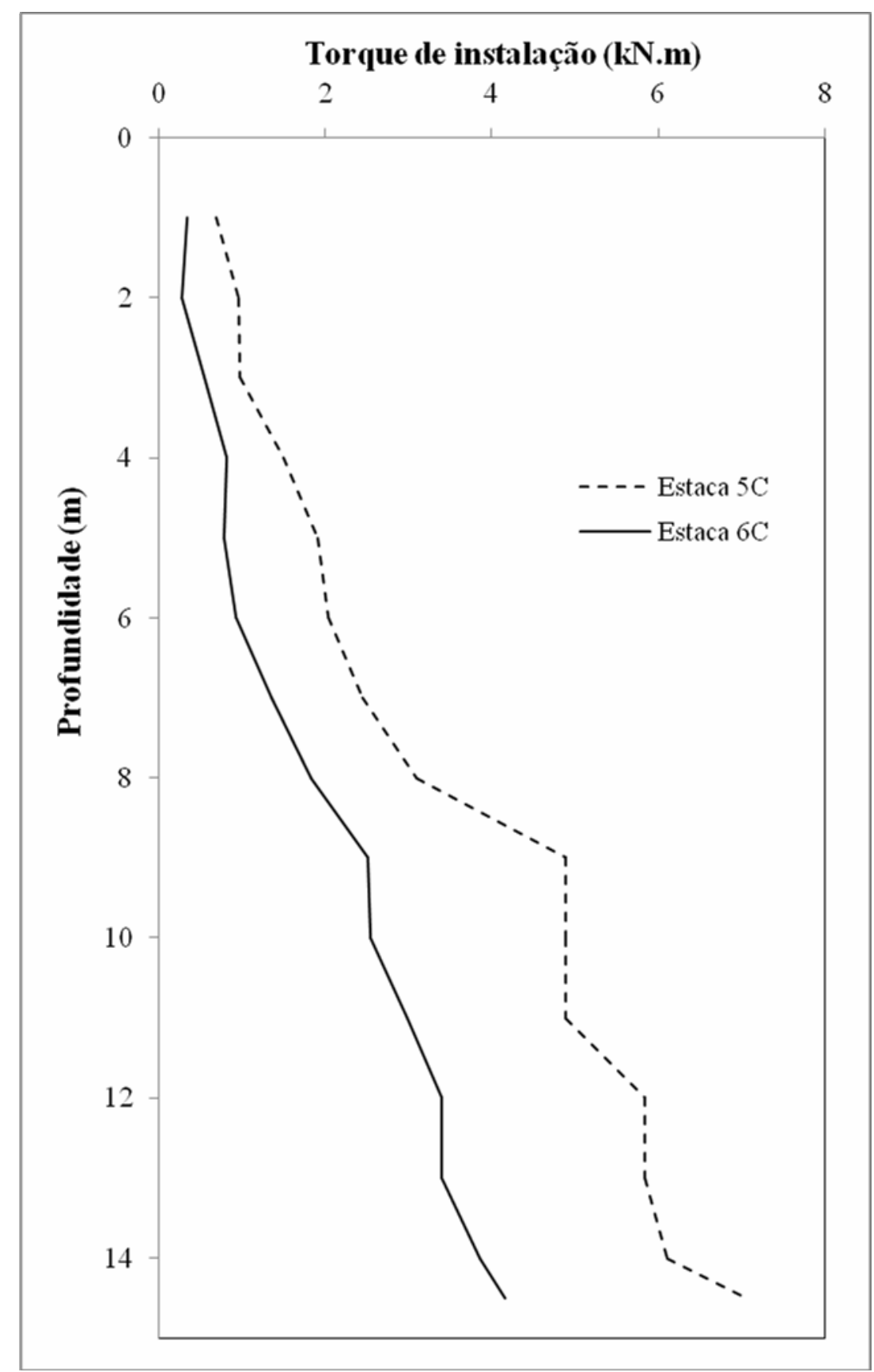

Figura 5.6 - Curva torque de instalação x profundidade da ponta das estacas $5 \mathrm{C}$ e $6 \mathrm{C}$

As curvas de carga de tração $\mathrm{x}$ deslocamento obtidas por meio das provas de carga realizadas nas estacas metálicas helicoidais instaladas no campo Experimental da EESC são exibidas nas Figuras 5.7 e 5.8. 




Figura 5.7 - Curva carga de tração x deslocamento da estaca 5C

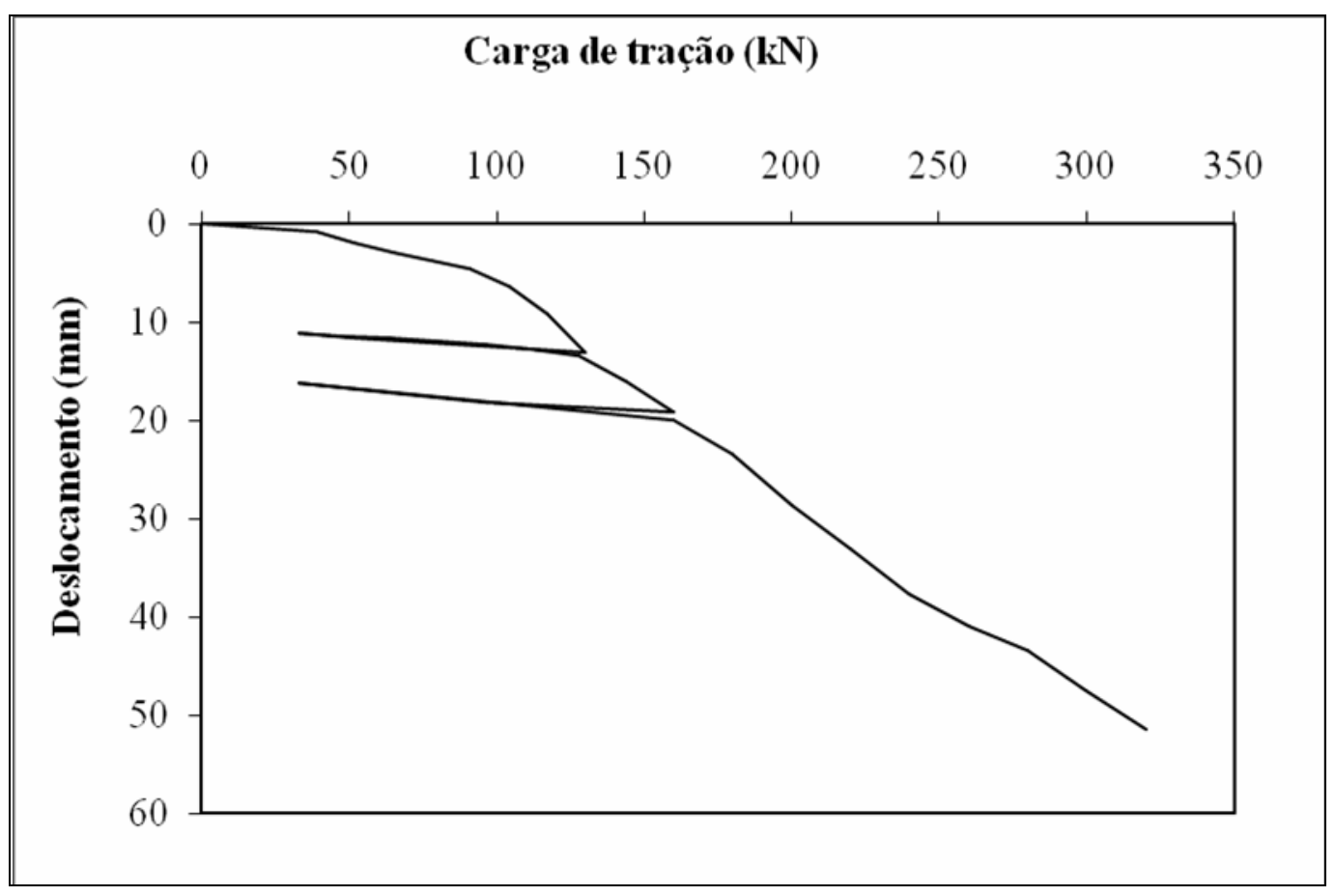

Figura 5.8 - Curva carga de tração x deslocamento da estaca $6 \mathrm{C}$ 


\subsubsection{Capacidade de carga}

Em virtude das formas das curvas carga de tração x deslocamento das provas de carga realizadas, foi notada a inexistência de ruptura física, o que invalida a utilização do critério de Van der Veen (1953).

Zhang (1999) ensaiou estacas helicoidais multi-hélices (hélices de mesmo diâmetro) à tração e à compressão, e adotou como carga de ruptura, em ambos os casos, a carga correspondente ao deslocamento do topo da estaca igual a 10\% do diâmetro da hélice.

Considerando-se o fato de não ocorrer ruptura física nas curvas obtidas por meio das provas de carga executadas, e de que na literatura geotécnica encontra-se o critério de ruptura convencional adotado por Zhang (1999) para ensaios à tração em estacas metálicas helicoidais, os valores de capacidade de carga à tração das estacas ensaiadas estimados nesta pesquisa correspondem ao deslocamento do topo da estaca igual a $10 \%$ do diâmetro médio das hélices. Este critério faz analogia ao critério de Terzaghi (1942), em que a capacidade de carga de uma placa submetida a um carregamento é a tensão correspondente a um recalque equivalente a $10 \%$ do seu diâmetro.

Os resultados de capacidade de carga à tração das estacas metálicas helicoidais ensaiadas nesta pesquisa são apresentados na Tabela 5.3.

Tabela 5.3 - Valores de capacidade de carga à tração $\left(\mathrm{Q}_{\mathrm{u}}\right)$ das estacas ensaiadas em campo

\begin{tabular}{cc}
\hline $\begin{array}{c}\text { Estaca } \\
\mathrm{N}^{\mathrm{o}}\end{array}$ & $\begin{array}{c}\text { Capacidade de carga à } \\
\text { tração } \mathrm{Q}_{\mathrm{u}}(\mathrm{kN})\end{array}$ \\
\hline $1 \mathrm{C}$ & 220 \\
$2 \mathrm{C}$ & 200 \\
$3 \mathrm{C}$ & 290 \\
$4 \mathrm{C}$ & 261 \\
$5 \mathrm{C}$ & 170 \\
$6 \mathrm{C}$ & 130 \\
\hline
\end{tabular}




\subsection{Modelagem física}

Para a modelagem física realizada nesta tese, foram necessários ensaios de caracterização da areia de Fontainebleau utilizada nos ensaios em centrífuga. Os resultados dos ensaios de granulometria (Figura 5.9), por serem realizados na França, foram executados de acordo com a norma francesa (NFP 94-056).

Os resultados dos ensaios para determinação dos índices de vazio máximo e mínimo e da massa específica dos sólidos são apresentados na Tabela 5.4. Nesta tabela, os resultados dos ângulos de atrito interno das areias utilizadas nos containeres 1 e 2 , com $\mathrm{D}_{\mathrm{r}}=56 \%$ e $\mathrm{D}_{\mathrm{r}}=85 \%$ respectivamente, foram obtidos por meio de ensaios de cisalhamento direto descritos no capítulo anterior.

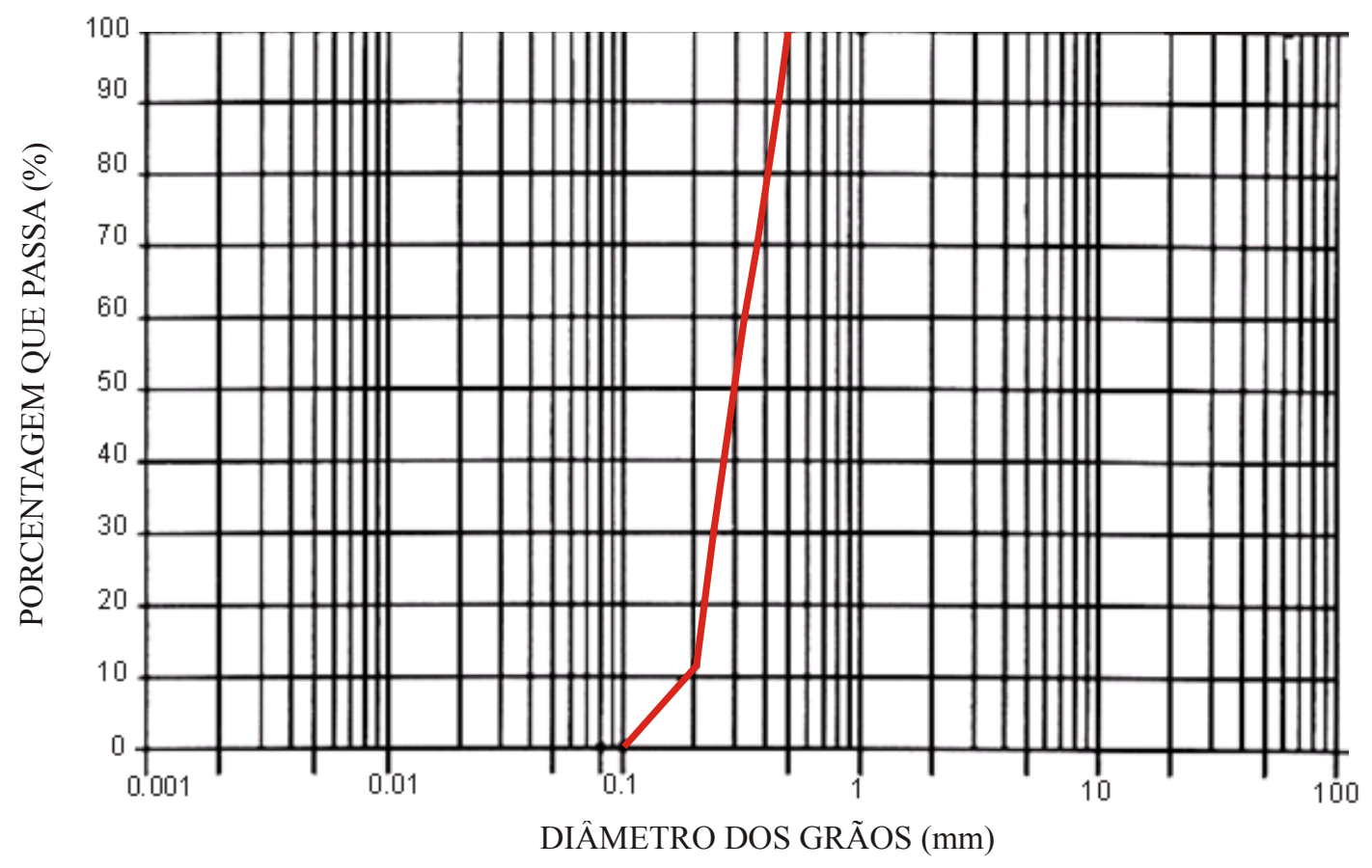

Figura 5.9 - Curva granulométrica da areia de Fontainebleau 
Tabela 5.4 - Propriedades da areia utilizada na modelagem física

\begin{tabular}{|c|c|}
\hline Propriedade & Valor \\
\hline Peso específico dos sólidos $\left(\mathrm{kN} / \mathrm{m}^{3}\right)$ & 25,90 \\
\hline Máximo peso específico seco $\left(\mathrm{kN} / \mathrm{m}^{3}\right)$ & 16,68 \\
\hline Mínimo peso específico seco $\left(\mathrm{kN} / \mathrm{m}^{3}\right)$ & 14,13 \\
\hline Índice de vazios máximo & 0,834 \\
\hline Índice de vazios mínimo & 0,550 \\
\hline Porosidade máxima & 0,455 \\
\hline Porosidade mínima & 0,355 \\
\hline \multicolumn{2}{|l|}{ Container 1} \\
\hline Peso específico $\left(\mathrm{kN} / \mathrm{m}^{3}\right)^{a}$ & 15,46 \\
\hline Densidade relativa $(\%)^{a}$ & 56 \\
\hline Ângulo de atrito $\left({ }^{\mathbf{o}}\right)^{\mathbf{b}}$ & 31 \\
\hline \multicolumn{2}{|l|}{ Container 2} \\
\hline Peso específico $\left(\mathrm{kN} / \mathrm{m}^{3}\right)^{a}$ & 16,30 \\
\hline Densidade relativa $(\%)^{a}$ & 85 \\
\hline Ângulo de atrito $\left({ }^{\mathbf{o}}\right)^{\mathbf{b}}$ & 41 \\
\hline
\end{tabular}

As curvas resultantes dos ensaios de cisalhamento direto são apresentadas nas Figuras 5.10 e 5.11. Nestas figuras observa-se que os valores das forças cisalhantes residuais são os mesmos para o mesmo nível de tensão normal aplicada, independentemente do índice de vazios inicial da amostra, ou seja, o ângulo de atrito a volume constante é o mesmo.

Foram realizados ensaios de caracterização dos maciços na centrífuga (a 22 g) por meio de ensaios penetroméricos nos contêineres 1 e 2. Durante os ensaios no container 1, ocorreu um problema no penetrômetro e foi feito somente um perfil penetromérico. No container 2 foram executados três ensaios, locados de acordo com a Figura 4.27 do capítulo anterior. Os perfis penetrométricos, em valores de protótipo (do maciço em grandeza real), são apresentados nas 
Figuras 5.12 e 5.13. A semelhança das curvas da Figura 5.13 mostra boa uniformidade do maciço.



Figura 5.10 - Curvas força cisalhante $\mathrm{x}$ deslocamento relativo (amostra $\gamma=15,46 \mathrm{kN} / \mathrm{m}^{3}$ )



Figura 5.11 - Curvas força cisalhante $\mathrm{x}$ deslocamento relativo (amostra $\gamma=16,30 \mathrm{kN} / \mathrm{m}^{3}$ ) 
Resistência de ponta $\mathrm{q}_{\mathrm{c}}$ (MPa)

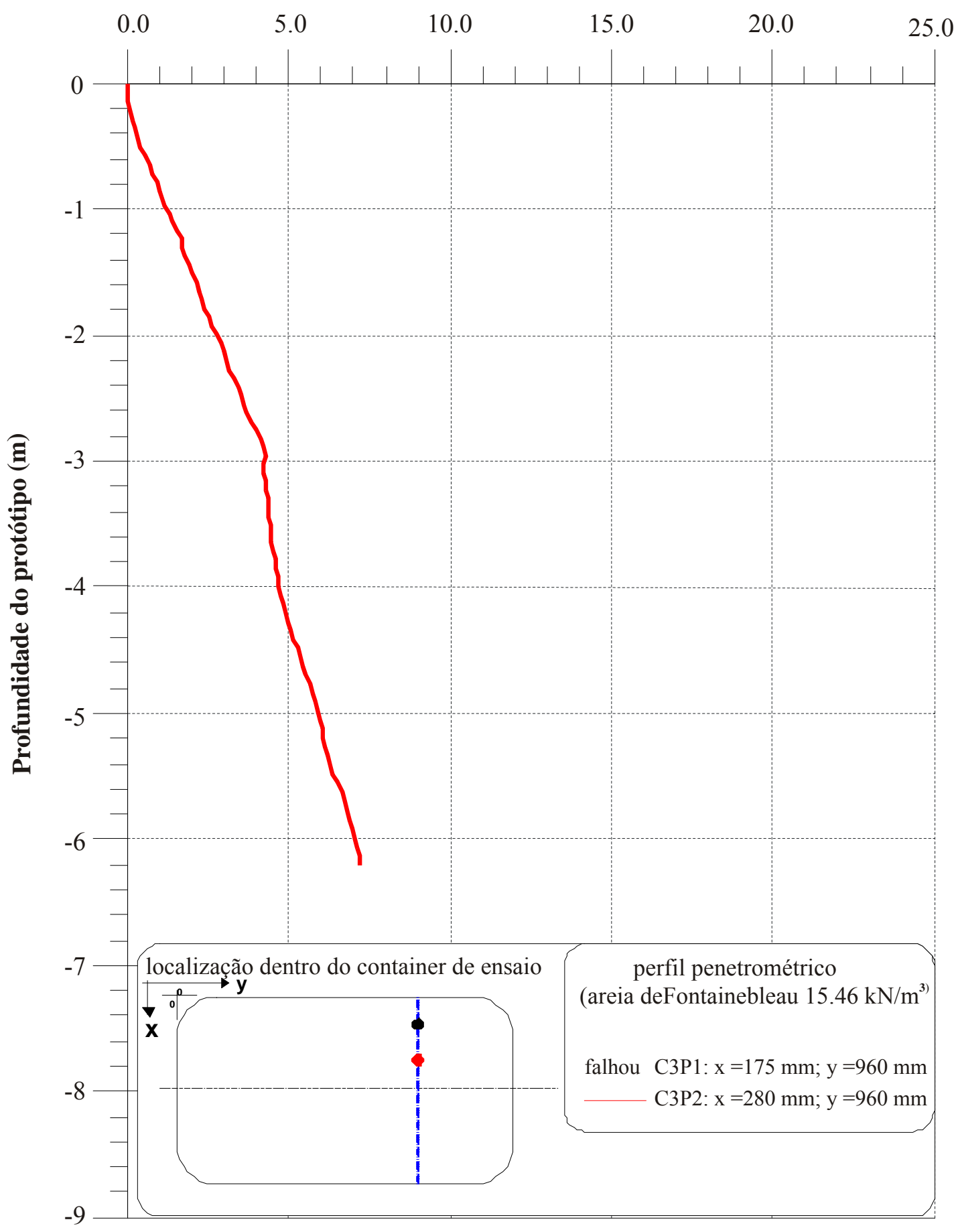

Figura 5.12 - Perfil penetrométrico realizado dentro do container $1\left(\gamma=15,46 \mathrm{kN} / \mathrm{m}^{3}\right)$ 


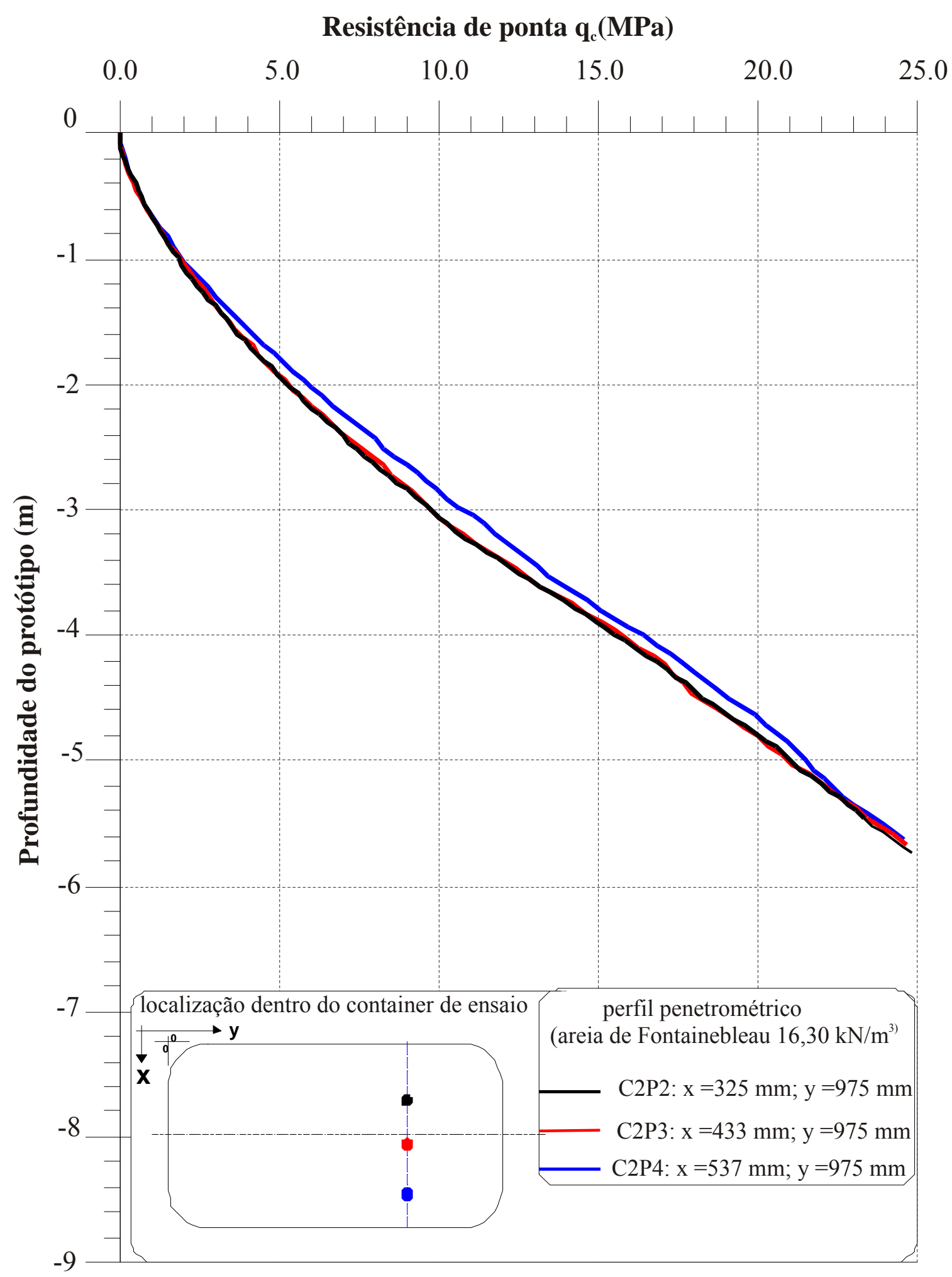

Figura 5.13 - Perfis penetrométricos realizados dentro do container $2\left(\gamma=16,30 \mathrm{kN} / \mathrm{m}^{3}\right)$ 


\subsubsection{Ensaios na centrífuga}

$\mathrm{Na}$ centrífuga foram realizados 24 testes. Doze tipos diferentes de estacas foram instaladas em dois maciços de areia com diferentes densidades relativas (containeres 1 e 2). Os ensaios executados no container 2 foram repetidos (areia com $\mathrm{D}_{\mathrm{r}}=85 \%$ ) e os resultados de capacidade de carga à tração obtidos foram semelhantes. Este fato mostra boa repetibilidade dos resultados. Nesses ensaios repetidos os valores de torque não foram medidos pelo torquímetro.

Durante toda a fase de instalação e carregamento das estacas foram feitas medidas (na cabeça das estacas) de deslocamento vertical, força e torque. Os ensaios foram realizados em 5 fases (Figura 5.14):

1. Instalação da estaca a $1 \mathrm{~g}$

2. Aumento da gravidade de $1 \mathrm{~g}$ para $22 \mathrm{~g}$

3. Instalação da estaca a $22 \mathrm{~g}$ (últimos $60 \mathrm{~mm}$ )

4. Tempo de espera entre a instalação e o ensaio de arrancamento da estaca

5. Ensaio de arrancamento

A Figura 5.14 mostra o resultado das medidas (escala do modelo) de um ensaio típico. Nesta figura, os valores das medidas de força englobam o peso próprio das estacas modelo e do sistema de transmissão de rotação e de tração (varia de acordo com o modelo de estaca de $13,5 \mathrm{~N}$ a $14,8 \mathrm{~N}$ à $22 \mathrm{~g}$ ). Para o cálculo da capacidade de carga à tração das estacas esse valor de peso próprio foi subtraído do valor total. 

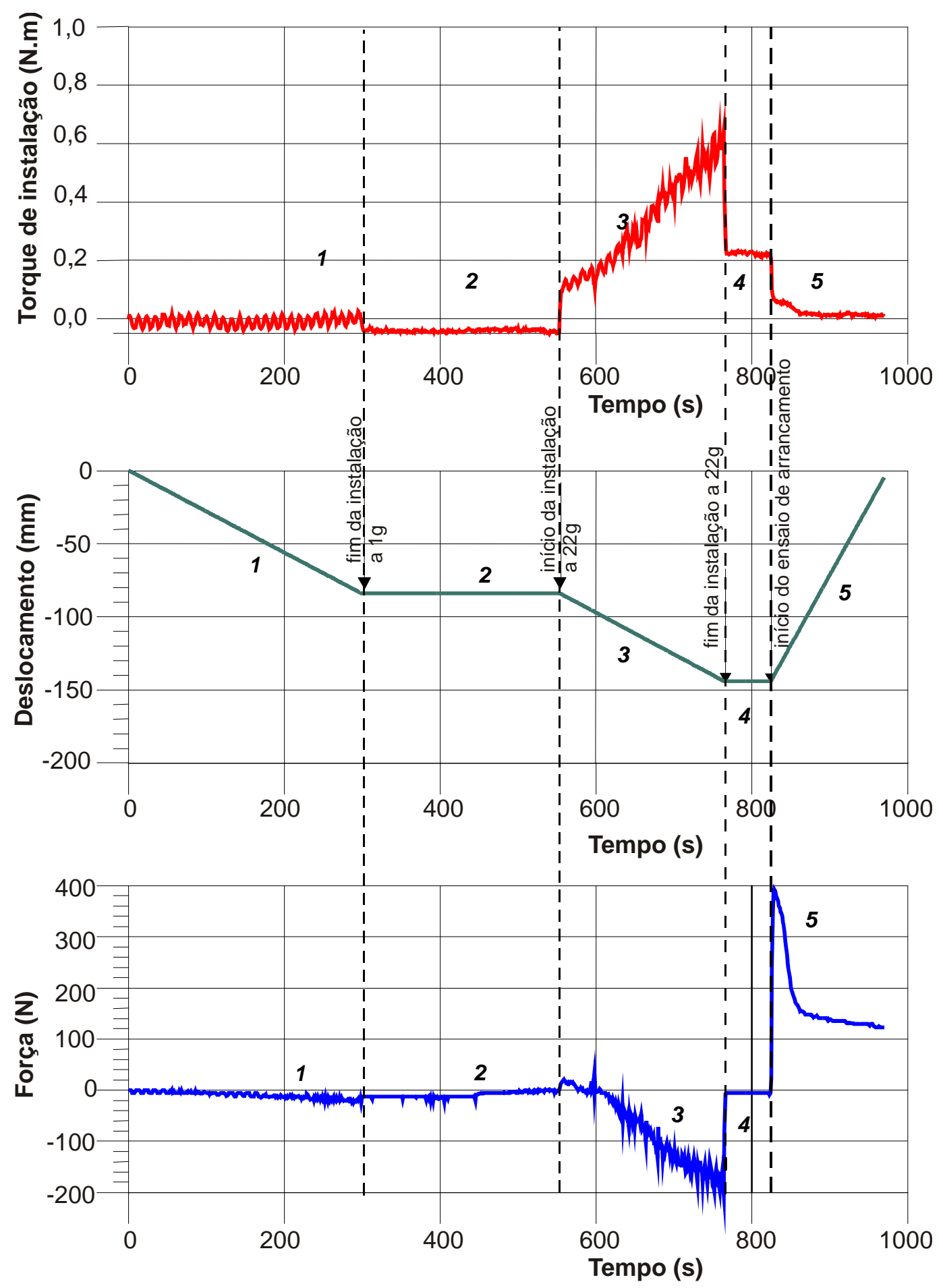

1 - Instalação da estaca a $1 \mathrm{~g}$

2 - Aumento da gravidade de $1 \mathrm{~g}$ para $22 \mathrm{~g}$

3 - Instalação da estaca a $22 \mathrm{~g}$

4 - Tempo de espera entre instalação e ensaio da estaca

5 - Ensaio de arrancamento

ESCALA DO MODELO

Figura 5.14 - Instalação e ensaio de arrancamento da estaca modelo $\mathrm{N}^{\mathrm{o}} 3 \mathrm{~L}$ no container 2 (areia de $\mathrm{D}_{\mathrm{r}}=85 \%$ ) 
Com exceção da Figura 5.14, todas as curvas e tabelas deste item mostram os resultados da instalação e dos ensaios dos modelos convertidos para o protótipo (estacas em grandeza real). Para transformar os resultados de deslocamento vertical, torque e força medidos nos ensaios para valores de estacas em grandeza real foram utilizados os fatores de escala para modelagem física em centrífuga exibidos na Tabela 4.3 do capítulo anterior. Esta conversão foi feita conforme as equações 5.1 a 5.3 descritas abaixo:

$$
z_{p}=N . z_{m}
$$

onde:

$\mathrm{z}_{\mathrm{p}}=$ deslocamento vertical da ponta da estaca na escala do protótipo

$\mathrm{N}=$ números de $g$ utilizado nos ensaios em centrífuga

$\mathrm{z}_{\mathrm{m}}=$ deslocamento vertical da ponta da estaca na escala do modelo

$$
T_{p}=N^{3} \cdot T_{m}
$$

onde:

$\mathrm{T}_{\mathrm{p}}=$ torque de instalação da estaca na escala do protótipo

$\mathrm{T}_{\mathrm{m}}=$ torque de instalação estaca medido do modelo

$$
Q_{p}=N^{2} \cdot Q_{m}
$$

onde:

$\mathrm{Q}_{\mathrm{p}}=$ resistência à tração da estaca na escala do protótipo

$\mathrm{Q}_{\mathrm{m}}=$ resistência à tração da estaca medida do modelo 
Nesta investigação, os modelos das estacas foram instalados em diferentes profundidades. Conseqüentemente, para extrapolação dos resultados medidos nos modelos para os valores de protótipos equivalentes, foram adotados os seguintes níveis de gravidade:

- 21,44 g para as estacas $\mathrm{N}^{\circ} 1 \mathrm{~L}, 2 \mathrm{~L}, 3 \mathrm{~L}$ e $10 \mathrm{~L}$

- 21,71 g para as estacas $\mathrm{N}^{0} 4 \mathrm{~L}, 5 \mathrm{~L}, 6 \mathrm{~L}$ e $11 \mathrm{~L}$

- 22,00 g para as estacas $\mathrm{N}^{\circ} 7 \mathrm{~L}, 8 \mathrm{~L}, 9 \mathrm{~L}$ e $12 \mathrm{~L}$

As curvas de torque de instalação $\mathrm{x}$ profundidade da ponta dos modelos de estacas ensaiados no container $1\left(\mathrm{D}_{\mathrm{r}}=56 \%\right)$ são vistas nas Figuras 5.15, 5.16 e 5.17. Essas curvas, que representam a instalação dos modelos de estacas em grandeza real, descrevem a fase final (fase 3 da Figura 5.14) da instalação da estaca realizada a 22g.

As Figuras 5.18, 5.19 e 5.20 mostram as curvas de torque de instalação x profundidade da ponta dos modelos de estacas instaladas no container $2\left(D_{r}=85 \%\right)$. Estas curvas, convertidas para o protótipo, descrevem a fase final da instalação da estaca no maciço.

Nas Figuras 5.15 a 5.20 as curvas das estacas $N^{\circ} 10 \mathrm{~L}, \mathrm{~N}^{\circ} 11 \mathrm{~L}$ e $\mathrm{N}^{\mathrm{0}} 12 \mathrm{~L}$ correspondem a parcela de torque referente ao atrito na haste das estacas com hélices $\left(\mathrm{T}_{\mathrm{s}}\right)$. Deste modo, é possível isolar das curvas das estacas com hélice ( $\mathrm{N}^{\circ} 1 \mathrm{~L}$ a $\left.\mathrm{N}^{\circ} 9 \mathrm{~L}\right)$ a parcela de torque relativa às hélices $\left(T_{h}\right)$.

O referencial "zero" do eixo correspondente ao torque de instalação das curvas das Figuras 5.15 a 5.20 equivale ao início da fase 5 (Figura 5.14), após a instalação da estaca a 22 g. Não foi adotado como referencial zero o valor de início da instalação, pelo fato de que para iniciar o motor para rotacionar a estaca no maciço de areia ocorre um pico de torque. Quando é terminada a rotação (início da fase 4), foi observado que aparece um torque residual que decresce regularmente, de acordo com a redução do atrito da areia sobre as hélices. Nos 
ensaios em que esta fase 4 foi prolongada, o valor do torque atinge o valor de início da fase 5, quando a estaca é submetida à tração. Quando a estaca é submetida à tração a parcela de torque residual se libera.



Figura 5.15 - Curva torque de instalação x profundidade da ponta dos modelos de estacas com haste de diâmetro igual $3.0 \mathrm{~mm}$ instaladas no container 1

Na Figura 5.20, nota-se que a curva da estaca $\mathrm{N}^{\circ}$ 9L não atinge a profundidade de $-6,16 \mathrm{~m}$ como as outras. As leituras de torque nesta estaca apresentaram problemas e irregularidades após a profundidade de $-5,70 \mathrm{~m}$. Devido a este fato, e pela observação desta curva, o torque final de instalação foi estimado como sendo o valor encontrado para a estaca $\mathrm{N}^{\circ} 8 \mathrm{~L}$. 


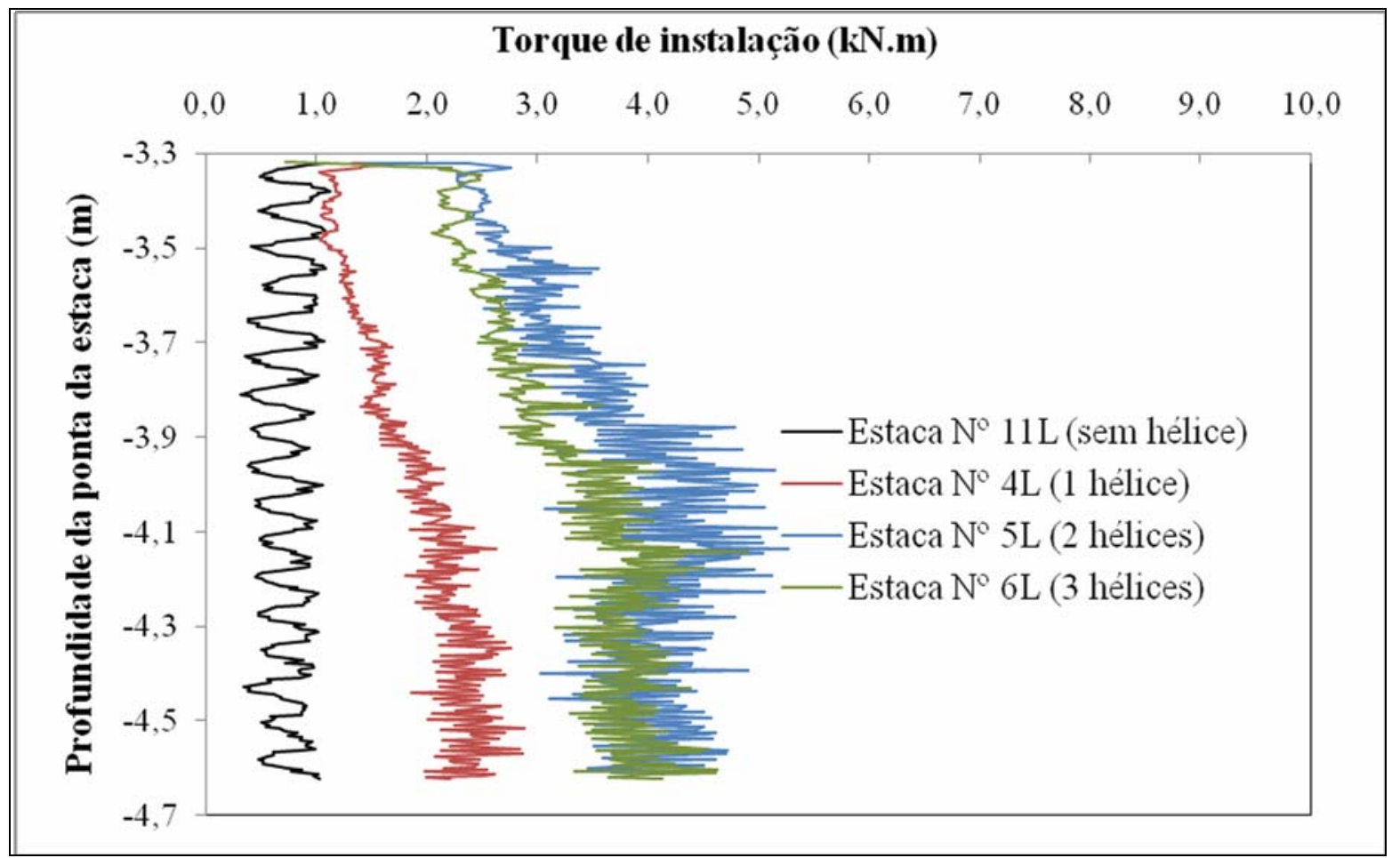

Figura 5.16 - Curva torque de instalação x profundidade da ponta dos modelos de estacas com haste de diâmetro igual $4.5 \mathrm{~mm}$ instaladas no container 1

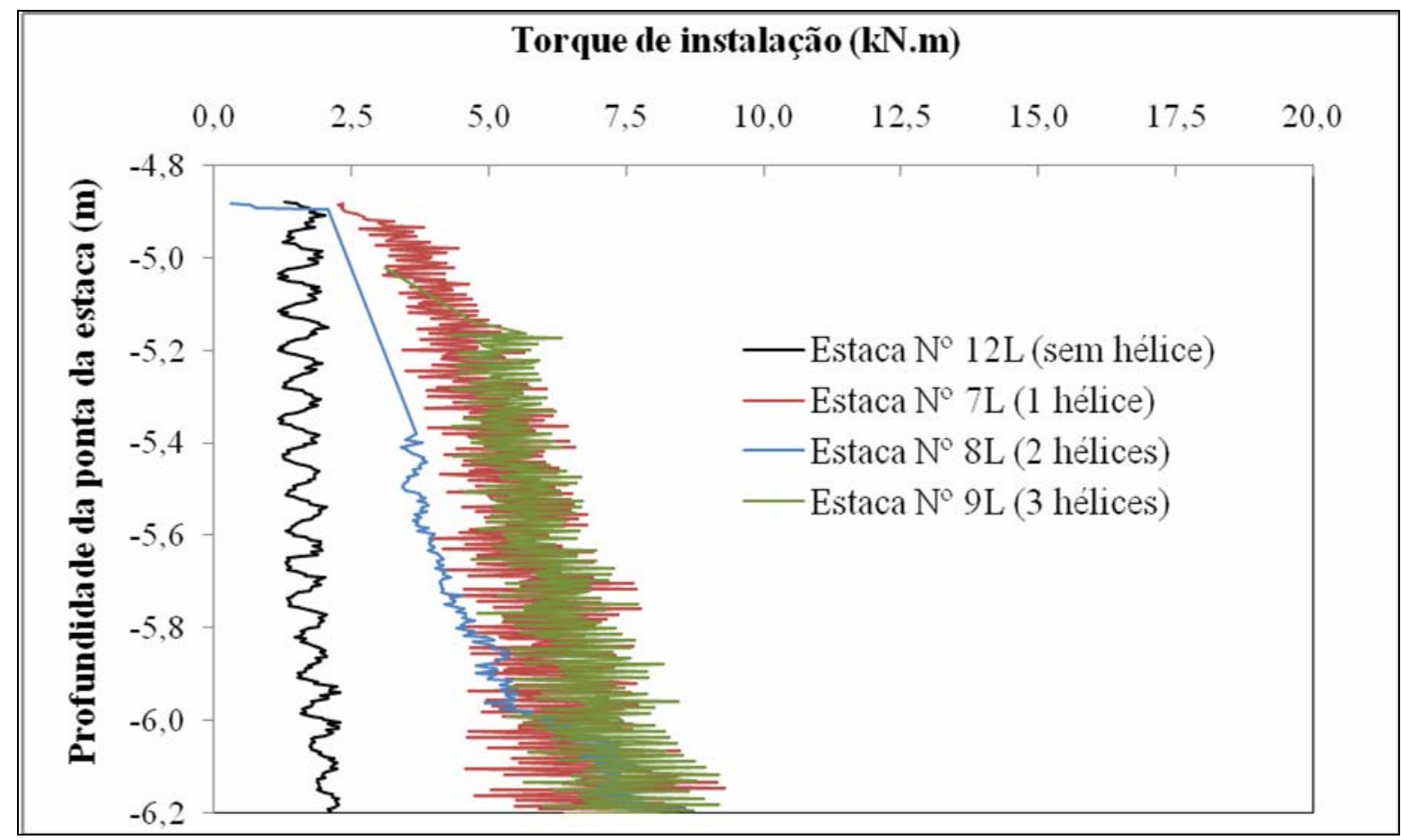

Figura 5.17 - Curva torque de instalação x profundidade da ponta dos modelos de estacas com haste de diâmetro igual $6.0 \mathrm{~mm}$ instaladas no container 1 


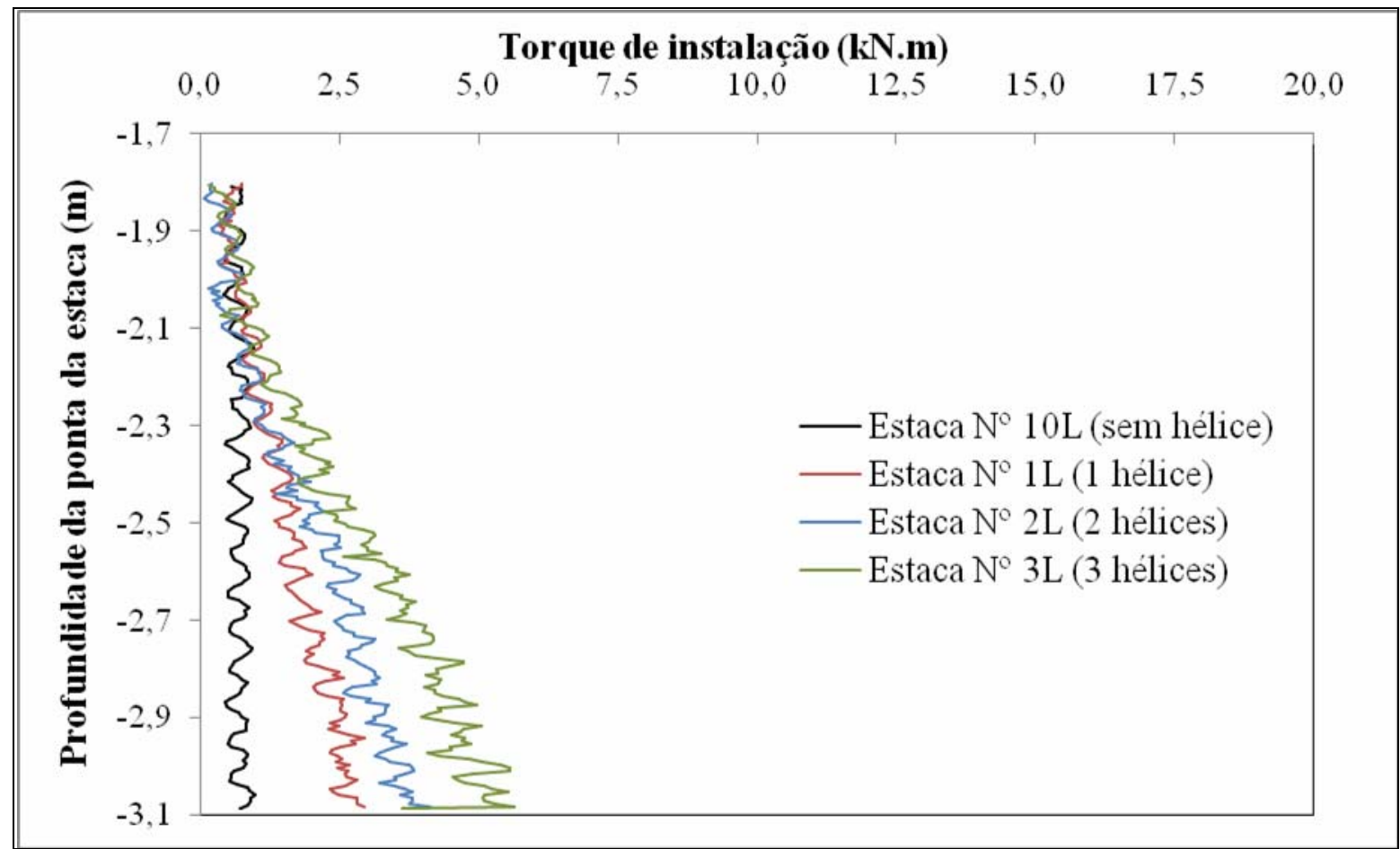

Figura 5.18 - Curva torque de instalação x profundidade da ponta dos modelos de estacas com haste de diâmetro igual $3.0 \mathrm{~mm}$ instaladas no container 2

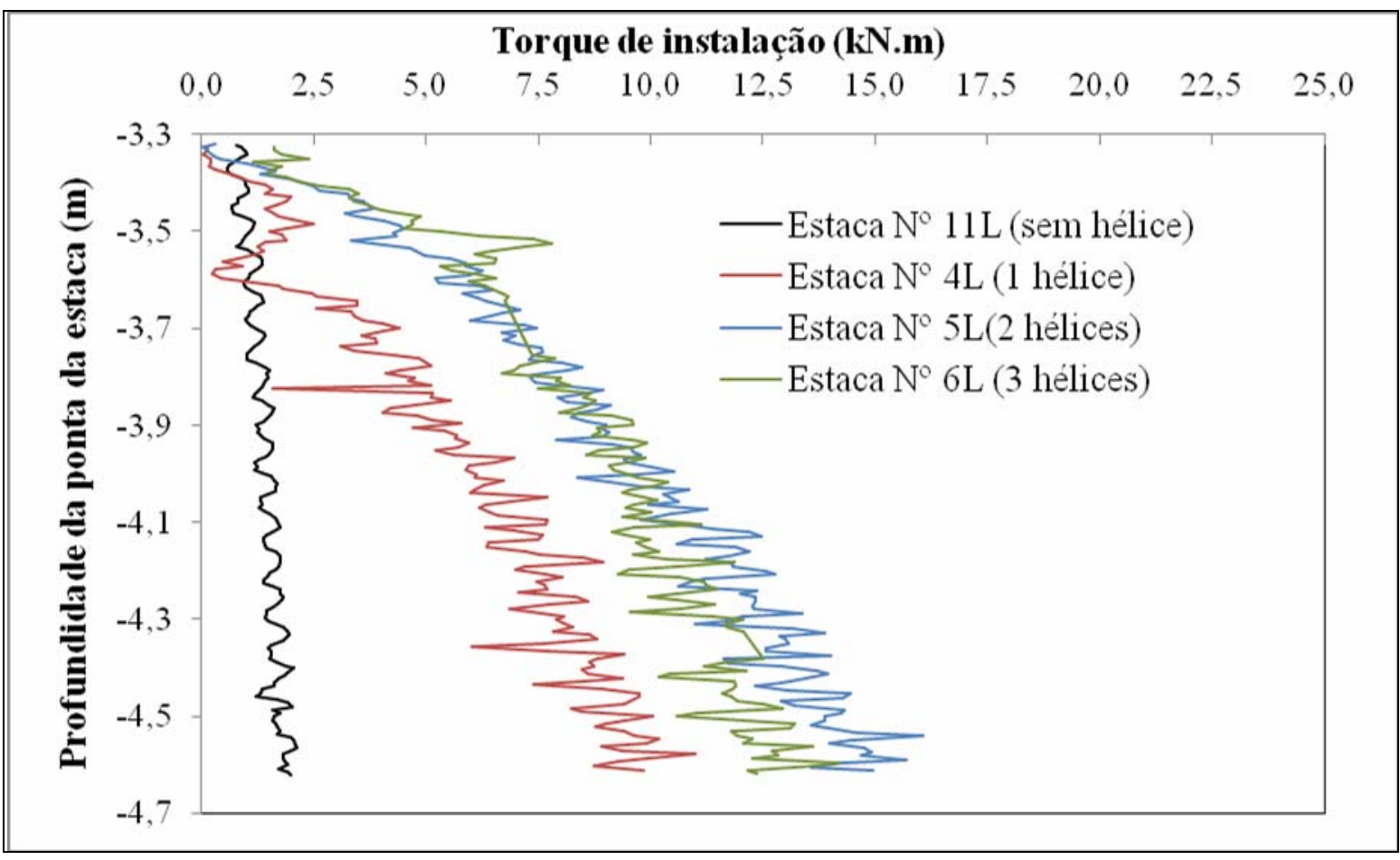

Figura 5.19 - Curva torque de instalação x profundidade da ponta dos modelos de estacas com haste de diâmetro igual $4.5 \mathrm{~mm}$ instaladas no container 2 


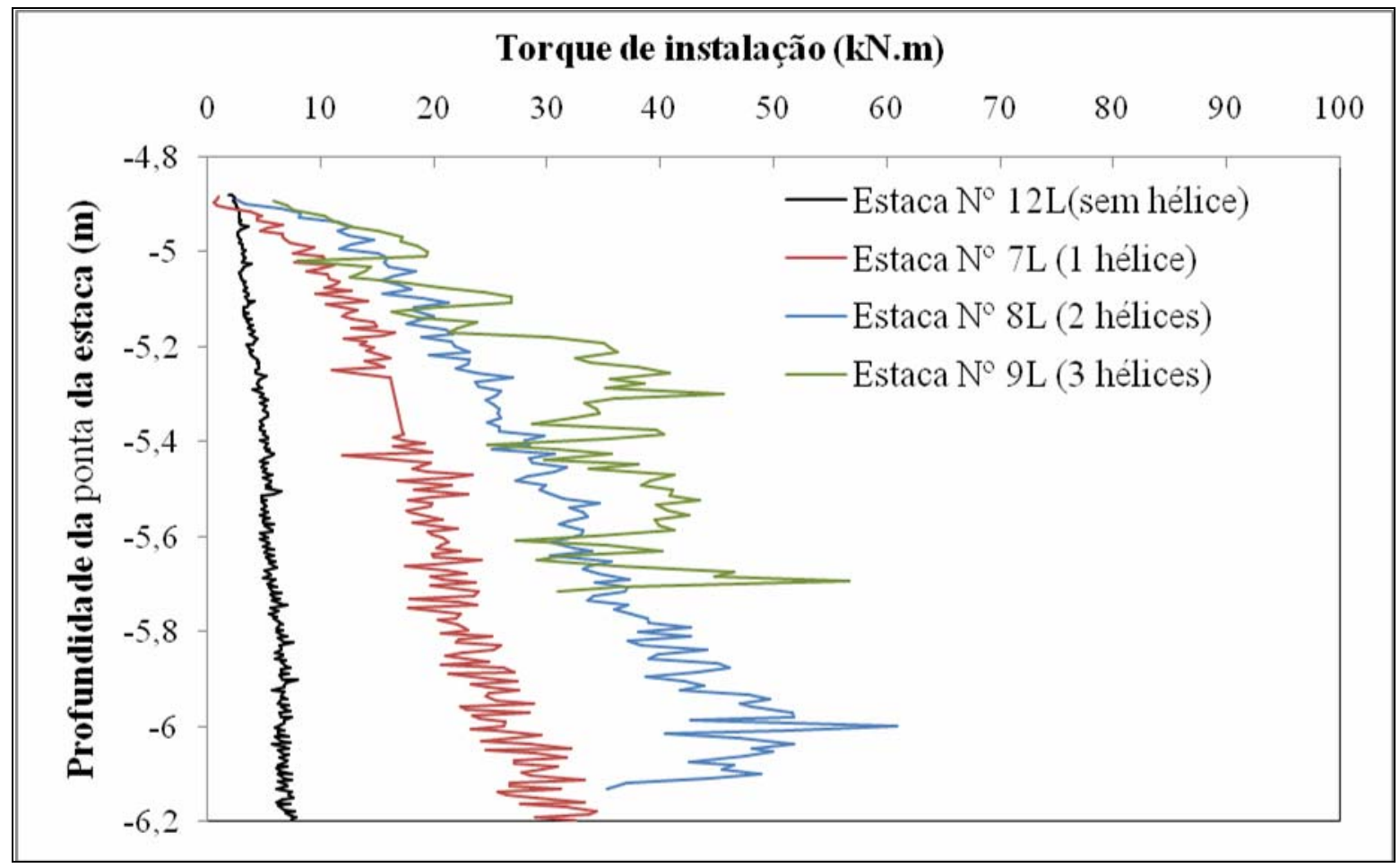

Figura 5.20 - Curva torque de instalação x profundidade da ponta dos modelos de estacas com haste de diâmetro igual $6.0 \mathrm{~mm}$ instaladas no container 2

As curvas de carga de tração x deslocamento vertical dos ensaios realizados nos modelos de estacas com hélices (grupo I), instalados nos containeres 1 e 2 (densidade relativa de 56\% e $85 \%$ respectivamente), são apresentadas nas Figuras 5.21 a 5.38. Estas curvas representam os ensaios das estacas em grandeza real.

As curvas das estacas sem hélices (grupo II) são mostradas juntamente às curvas das estacas com hélices (Figuras 5.27 a 5.38) de mesma profundidade e diâmetro de haste. Deste modo, é possível observar nos gráficos a parcela de resistência à tração da estaca relativa ao atrito na haste $\left(\mathrm{Q}_{\mathrm{s}}\right)$. As parcelas da capacidade de carga à tração relativa às hélices $\left(\mathrm{Q}_{\mathrm{h}}\right)$ das estacas $\mathrm{N}^{\circ} 1 \mathrm{~L}$ a $\mathrm{N}^{\circ}$ 9L são obtidas descontando-se a parcela relativa ao atrito na haste obtida por meio dos ensaios de tração realizados nas estacas sem hélices (estacas No $10 \mathrm{~L}, \mathrm{~N}^{\circ} 11 \mathrm{~L}$ e $\mathrm{N}^{\mathrm{o}}$ 12L). 
A curva de carga de tração $x$ deslocamento vertical do ensaio realizado na estaca $\mathrm{N}^{\circ} 10 \mathrm{~L}$ (sem hélice) instalada no container 1 não é apresentada nas Figuras 5.21 a 5.26, devido ao fato de que o valor medido de resistência à tração por atrito lateral na haste desta estaca neste maciço foi igual a zero. Contudo, nas Figuras 5.24 a 5.26 as parcelas de carga de tração relativa ao peso próprio das estacas modelo e do sistema de transmissão de rotação e de tração são indicadas. Para o cálculo da capacidade de carga esta parcela é descontada. Nas curvas das Figuras 5.21 a 5.23, os valores da carga de tração relativos a esta parcela não estão inclusos. Nestas curvas os valores de resistência à tração das estacas são muito baixos, e para melhor visualização da curva os valores dos pesos próprios do sistema de ensaio mais estaca foram excluídos.

Em todas as curvas das Figuras 5.24 a 5.38 os valores de carga de tração medidos pelo transdutor de força utilizado englobam o peso próprio das estacas modelo e do sistema de transmissão de rotação e de tração.

Os valores dos pesos próprios do sistema de ensaio e das estacas modelos são apresentados na Tabela 5.5. Nesta tabela os valores mostrados são das estacas em grandeza real.

Tabela 5.5 - Valores do peso próprio do sistema de ensaio + estaca (protótipo)

\begin{tabular}{cc}
\hline $\begin{array}{c}\text { Modelo de } \\
\text { estaca }\left(\mathrm{N}^{\circ}\right)\end{array}$ & $\begin{array}{c}\text { Peso próprio do sistema de } \\
\text { ensaio + estaca }(\mathrm{kN})\end{array}$ \\
\hline $1 \mathrm{~L}$ & 61,9 \\
2L & 62,0 \\
3L & 61,8 \\
$4 \mathrm{~L}$ & 65,6 \\
$5 \mathrm{~L}$ & 65,8 \\
$6 \mathrm{~L}$ & 65,8 \\
$7 \mathrm{~L}$ & 71,1 \\
$8 \mathrm{~L}$ & 71,0 \\
$9 \mathrm{~L}$ & 71,6 \\
$10 \mathrm{~L}$ & 61,9 \\
$11 \mathrm{~L}$ & 65,6 \\
$12 \mathrm{~L}$ & 70,3 \\
\hline
\end{tabular}




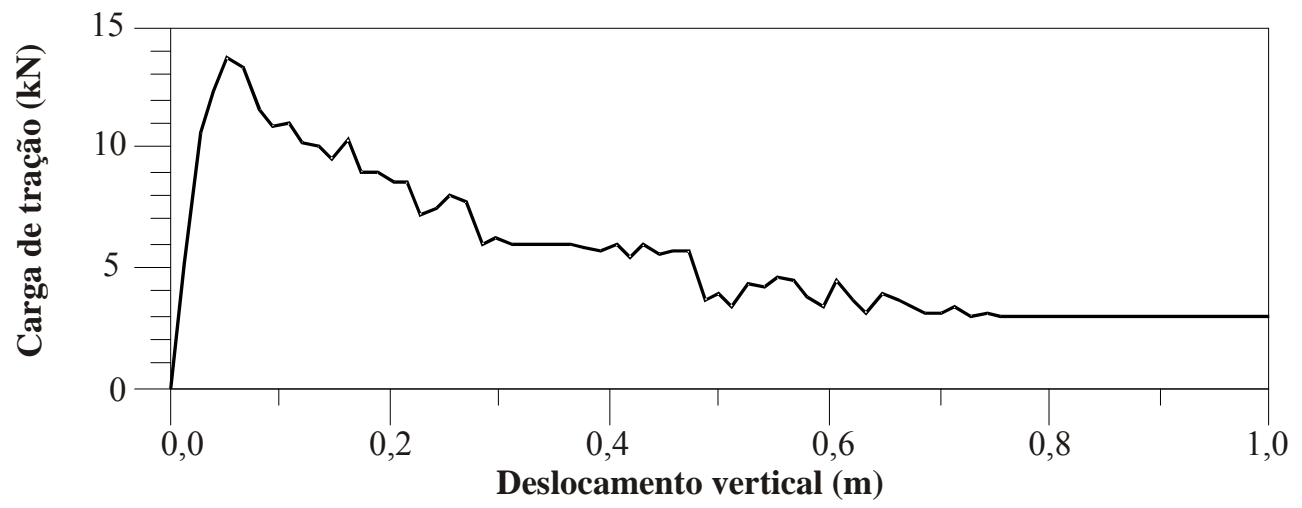

Figura 5.21 - Curva carga de tração x deslocamento vertical da estaca $\mathrm{N}^{\mathrm{o}} 1 \mathrm{~L}$ no container 1 (convertida para o protótipo)



Figura 5.22 - Curva carga de tração x deslocamento vertical da estaca $\mathrm{N}^{\mathrm{o}} 2 \mathrm{~L}$ no container 1 (convertida para o protótipo)

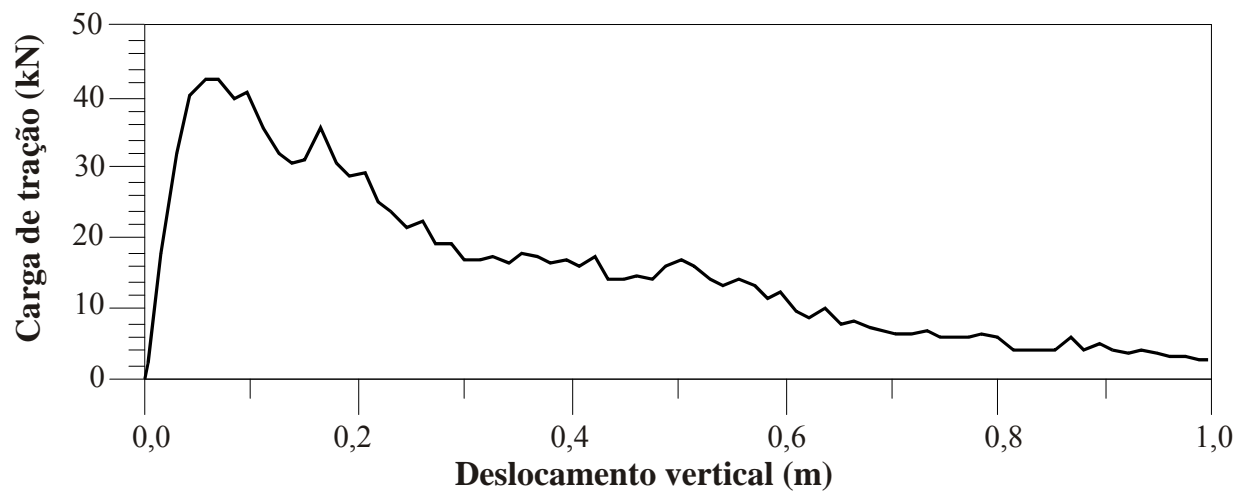

Figura 5.23 - Curva carga de tração x deslocamento vertical da estaca $\mathrm{N}^{\mathrm{o}} 3 \mathrm{~L}$ no container 1 (convertida para o protótipo) 


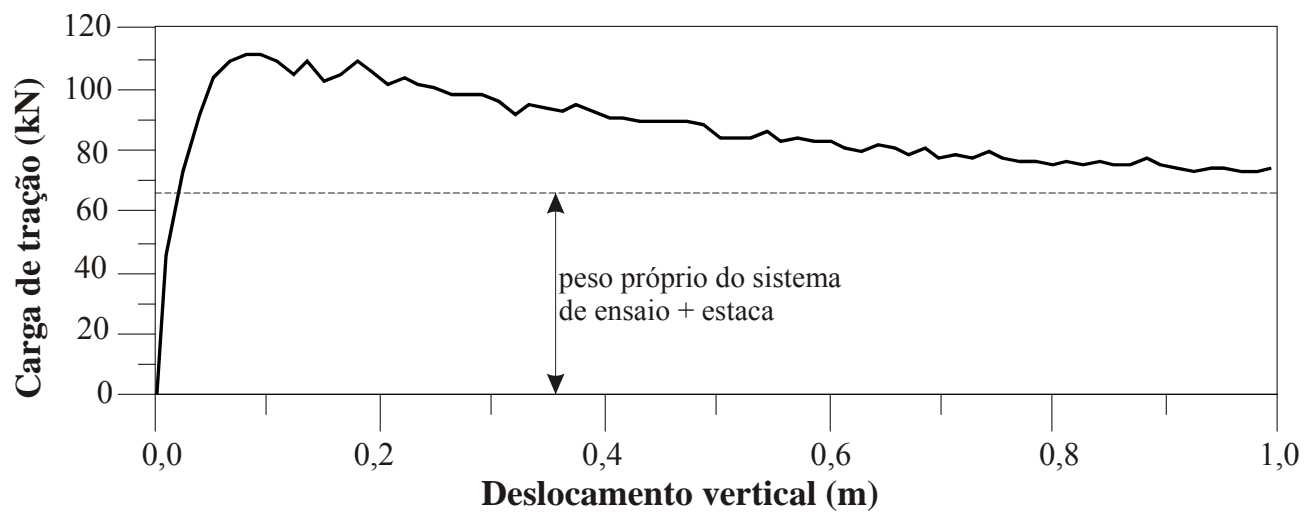

Figura 5.24 - Curva carga de tração x deslocamento vertical da estaca $\mathrm{N}^{\circ} 4 \mathrm{~L}$ no container 1 (convertida para o protótipo)



Figura 5.25 - Curva carga de tração x deslocamento vertical da estaca $\mathrm{N}^{0} 5 \mathrm{~L}$ no container 1 (convertida para o protótipo)



Figura 5.26 - Curva carga de tração x deslocamento vertical da estaca $\mathrm{N}^{\circ} 6 \mathrm{~L}$ no container 1 (convertida para o protótipo) 


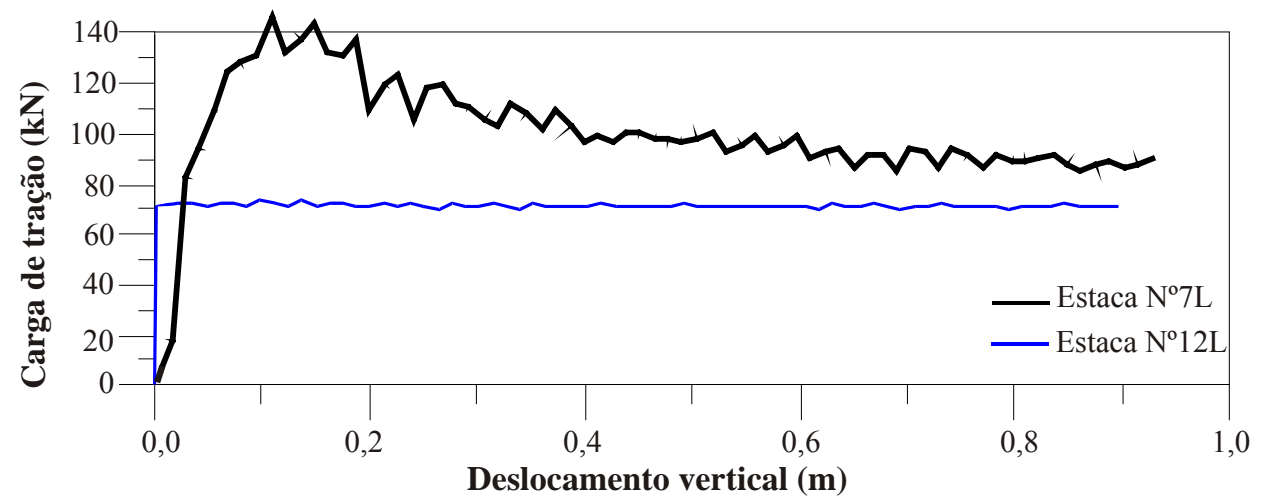

Figura 5.27 - Curva carga de tração x deslocamento vertical da estaca $N^{\circ} 7 \mathrm{~L}$ e No $12 \mathrm{~L}$ no container 1 (convertida para o protótipo)

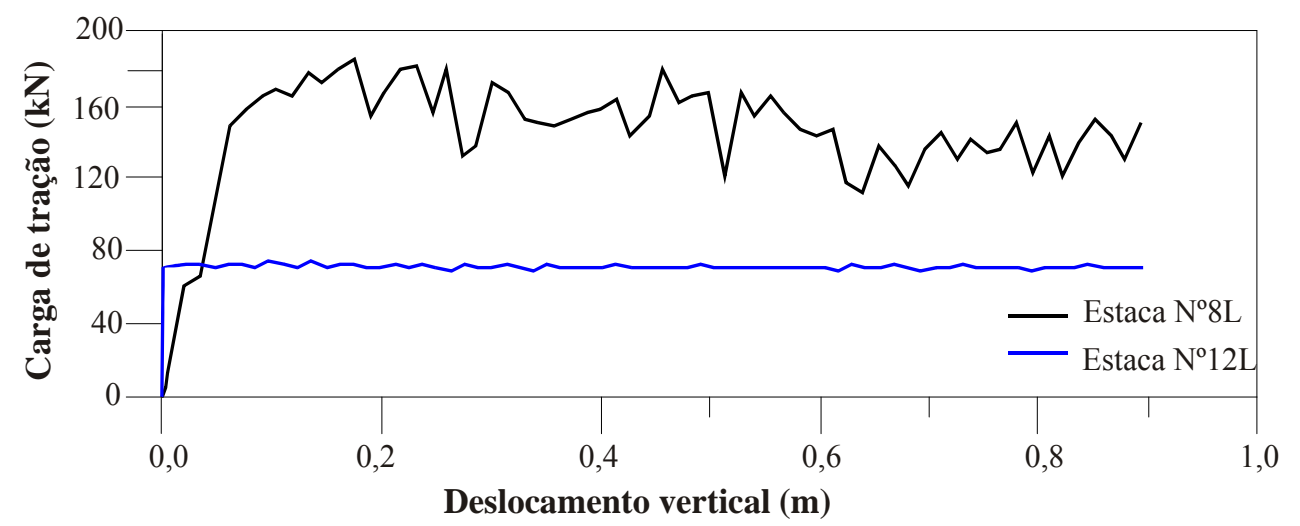

Figura 5.28 - Curva carga de tração x deslocamento vertical da estaca $\mathrm{N}^{\circ} 8 \mathrm{~L}$ e $\mathrm{N}^{\circ} 12 \mathrm{~L}$ no container 1 (convertida para o protótipo)

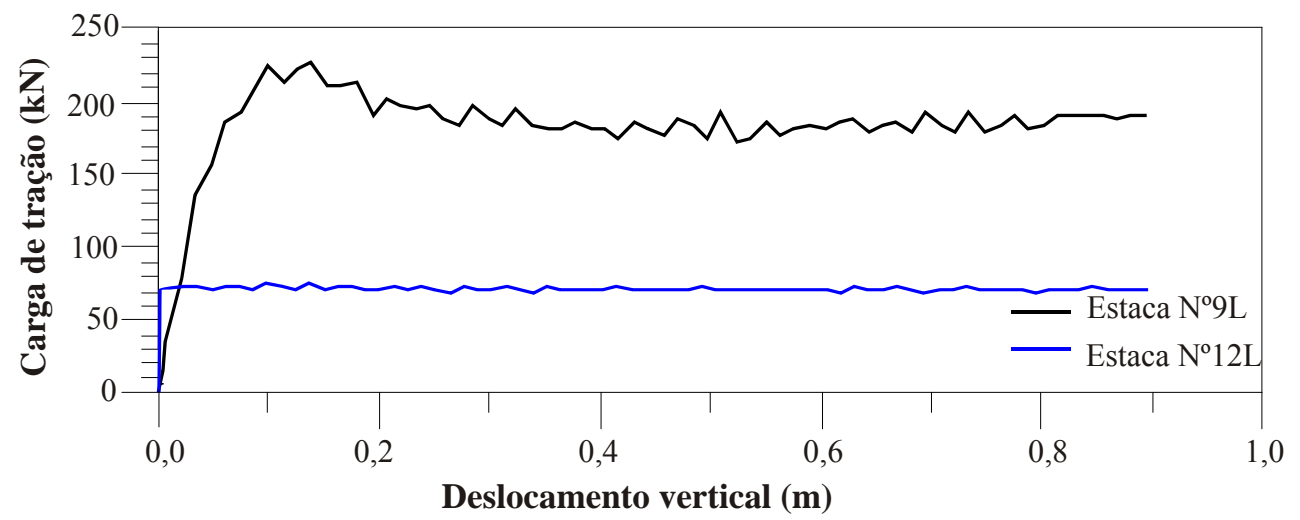

Figura 5.29 - Curva carga de tração x deslocamento vertical da estaca $\mathrm{N}^{\circ} 9 \mathrm{~L}$ e $\mathrm{N}^{\circ} 12 \mathrm{~L}$ no container 1 (convertida para o protótipo) 


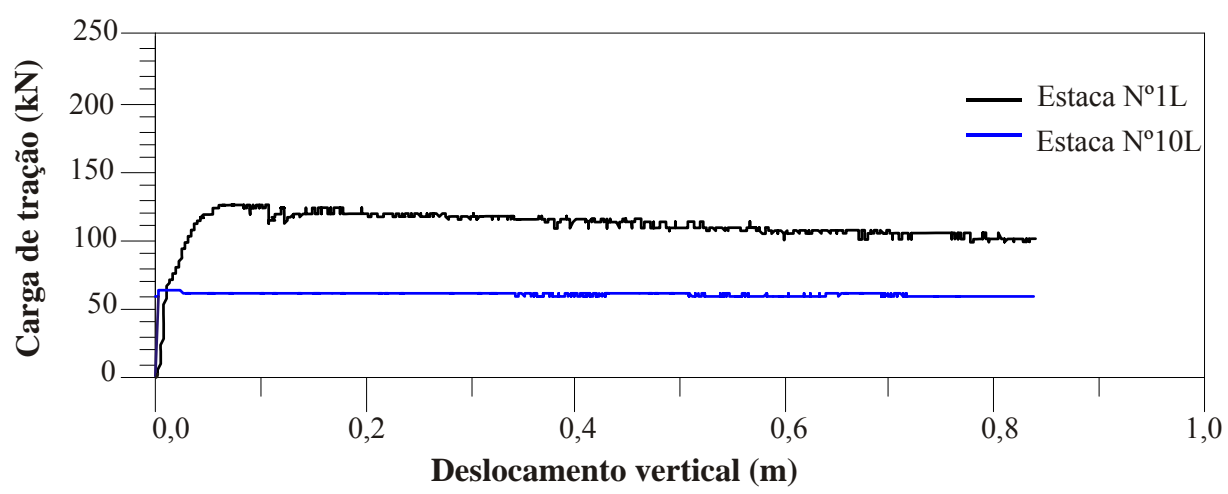

Figura 5.30 - Curva carga de tração x deslocamento vertical da estaca $\mathrm{N}^{\circ} 1 \mathrm{~L}$ e $\mathrm{N}^{\circ} 10 \mathrm{~L}$ no container 2 (convertida para o protótipo)

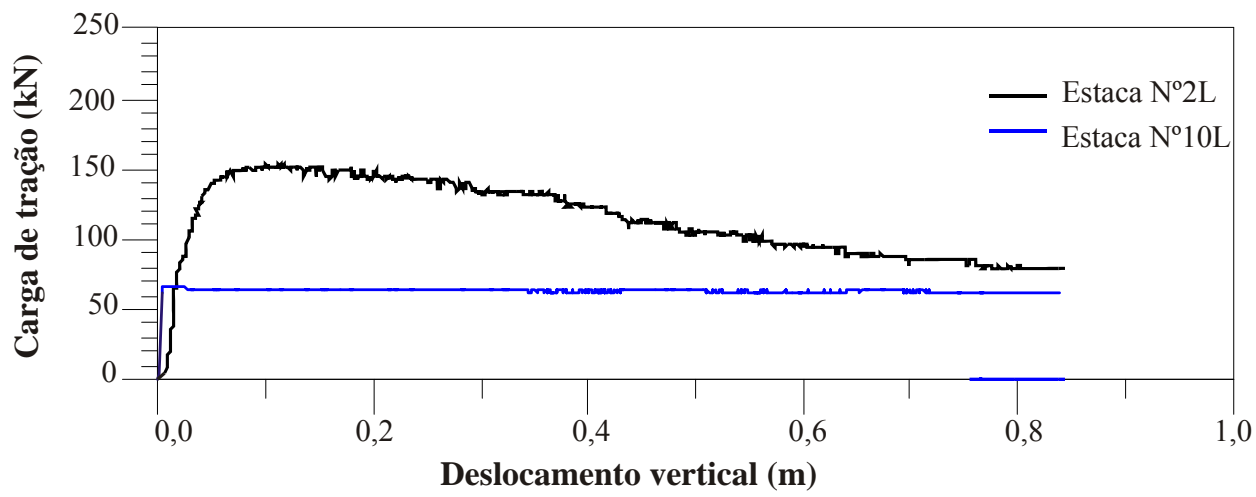

Figura 5.31 - Curva carga de tração x deslocamento vertical da estaca $\mathrm{N}^{\circ} 2 \mathrm{~L}$ e $\mathrm{N}^{\circ} 10 \mathrm{~L}$ no container 2 (convertida para o protótipo)



Figura 5.32 - Curva carga de tração x deslocamento vertical da estaca $\mathrm{N}^{\circ} 3 \mathrm{~L}$ e $\mathrm{N}^{\circ} 10 \mathrm{~L}$ no container 2 (convertida para o protótipo) 


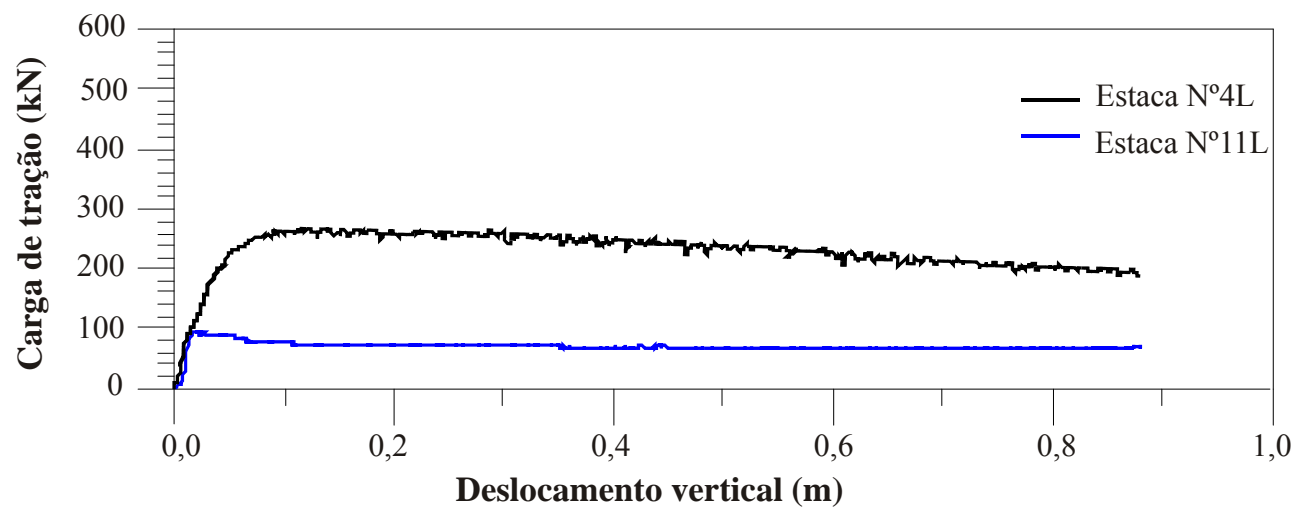

Figura 5.33 - Curva carga de tração x deslocamento vertical da estaca $\mathrm{N}^{\circ} 4 \mathrm{~L}$ e $\mathrm{N}^{\circ} 11 \mathrm{~L}$ no container 2 (convertida para o protótipo)

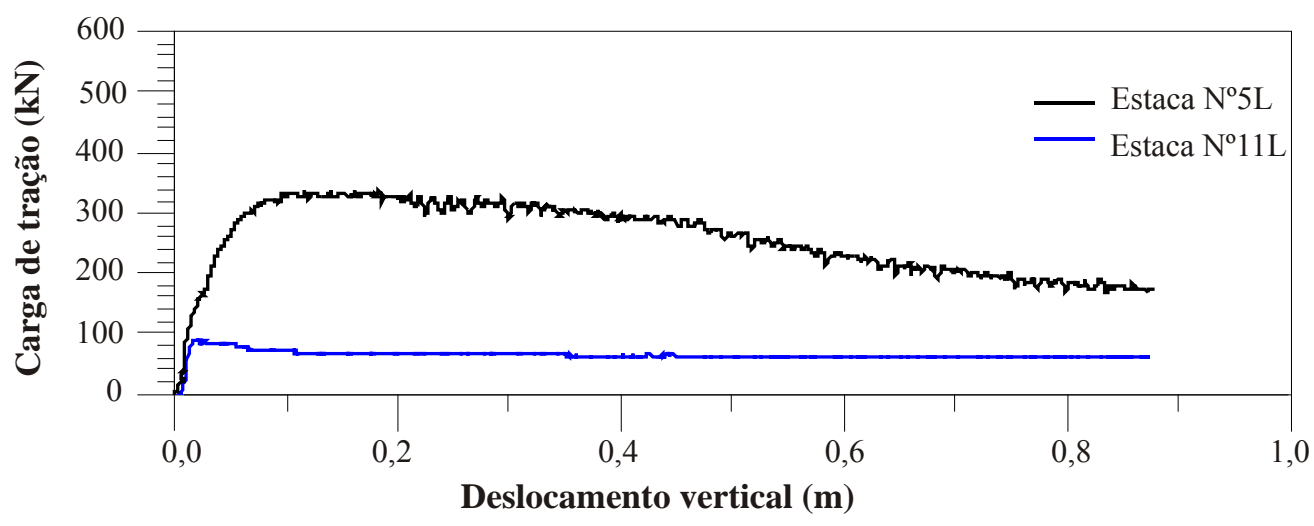

Figura 5.34 - Curva carga de tração x deslocamento vertical da estaca $\mathrm{N}^{\circ} 5 \mathrm{~L}$ e $\mathrm{N}^{\circ} 11 \mathrm{~L}$ no container 2 (convertida para o protótipo)



Figura 5.35 - Curva carga de tração x deslocamento vertical da estaca $\mathrm{N}^{\circ} 6 \mathrm{~L}$ e $\mathrm{N}^{\circ} 11 \mathrm{~L}$ no container 2 (convertida para o protótipo) 


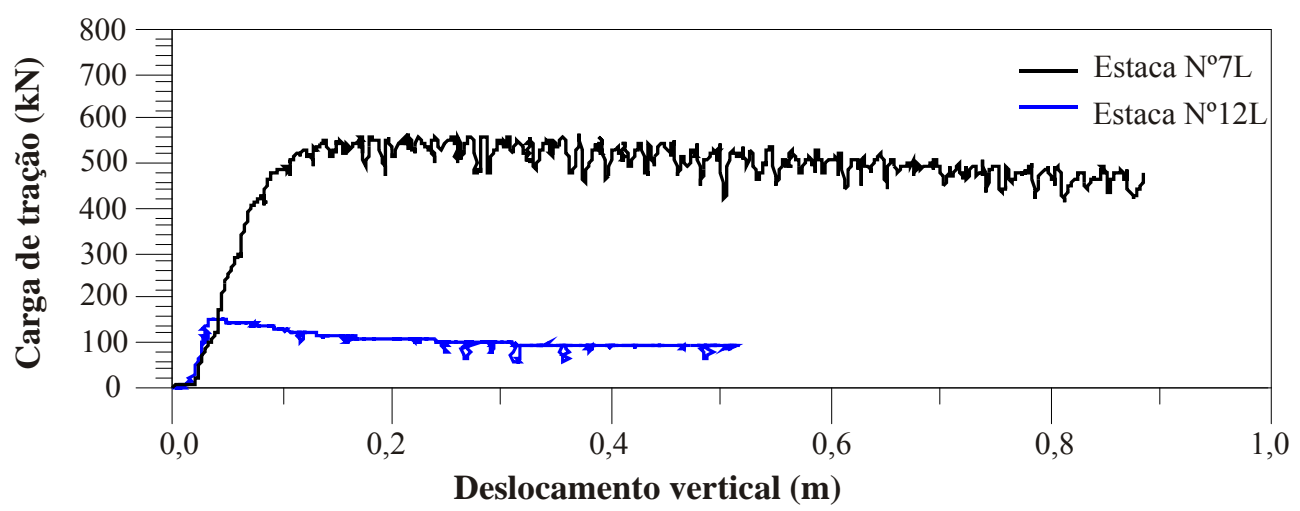

Figura 5.36 - Curva carga de tração x deslocamento vertical da estaca $\mathrm{N}^{\circ} 7 \mathrm{~L}$ e $\mathrm{N}^{\mathrm{o}} 12 \mathrm{~L}$ no container 2 (convertida para o protótipo)

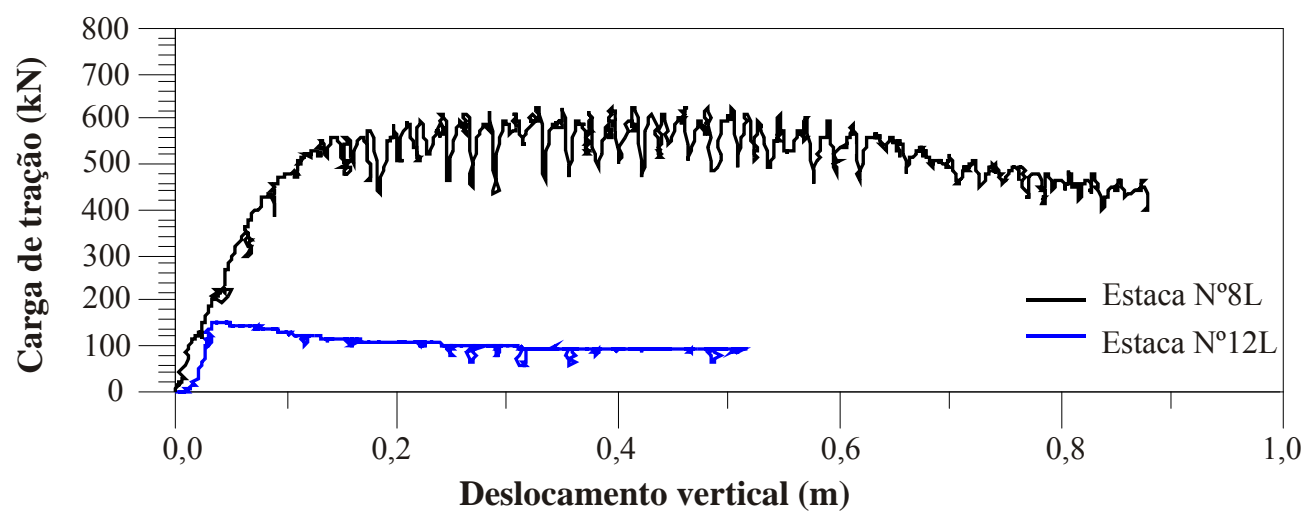

Figura 5.37 - Curva carga de tração x deslocamento vertical da estaca $N^{\circ} 8 \mathrm{~L}$ e $\mathrm{N}^{\circ} 12 \mathrm{~L}$ no container 2 (convertida para o protótipo)

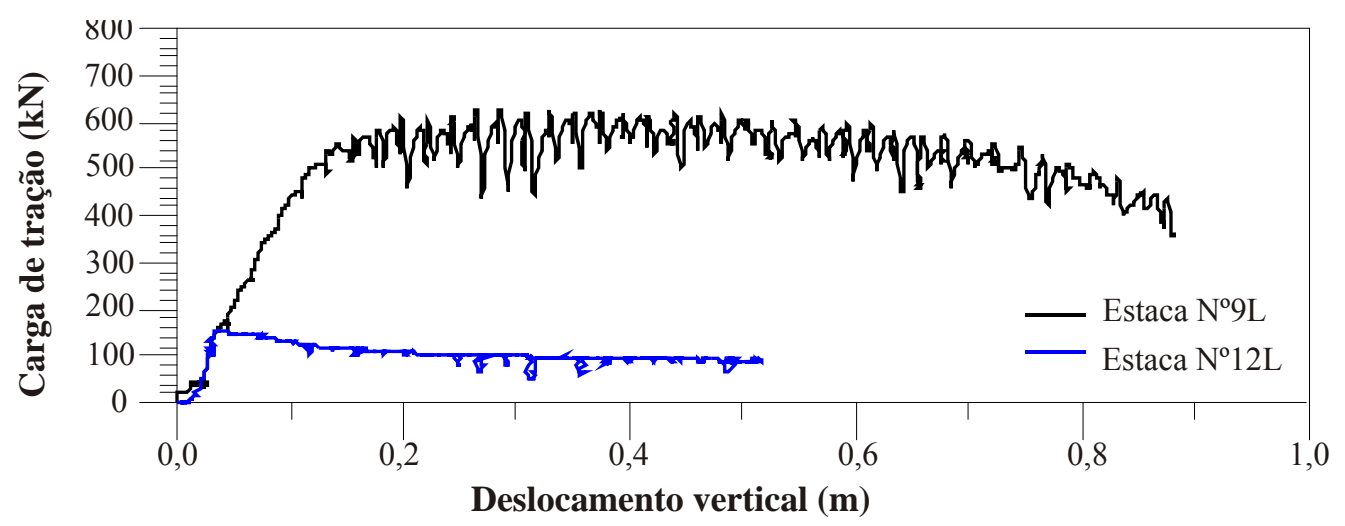

Figura 5.38 - Curva carga de tração x deslocamento vertical da estaca $\mathrm{N}^{\circ} 9 \mathrm{~L}$ e $\mathrm{N}^{\circ} 12 \mathrm{~L}$ no container 2 (convertida para o protótipo) 
Os resultados dos ensaios são apresentados na Tabela 5.6. Nos resultados de capacidade de carga à tração $\left(\mathrm{Q}_{\mathrm{u}}\right)$ desta tabela estão descontadas as parcelas de resistência à tração relativa ao peso próprio das estacas modelo e do sistema de transmissão de rotação e de tração (Tabela 5.5). Deste modo os resultados da capacidade de carga à tração $\left(Q_{u}\right)$ incluem somente a parcela relativa à resistência por atrito lateral do tubo $\left(\mathrm{Q}_{\mathrm{s}}\right)$ e a parcela relativa às hélices $\left(\mathrm{Q}_{\mathrm{h}}\right)$. Os valores da parcela da capacidade de carga à tração relativa às hélices $\left(\mathrm{Q}_{\mathrm{h}}\right)$ apresentados na tabela foram obtidos pela diferença entre os resultados dos ensaios das estacas com hélice (grupo I) e os resultados dos ensaios das estacas sem hélice (grupo II) de mesmo diâmetro de haste e mesma profundidade.

Os valores de capacidade de carga à tração $\left(\mathrm{Q}_{\mathrm{u}}\right)$ mostrados na Tabela 5.6 são correspondentes aos valores de pico das curvas mostradas nas Figuras 5.21 a 5.38. Os valores de torque de instalação apresentados nesta tabela correspondem ao valor médio medido entre os picos de máximo e de mínimo torque obtidos no final da penetração da estaca no solo.

Os resultados de resistência por atrito lateral da haste $\left(\mathrm{Q}_{\mathrm{s}}\right)$ e de momento resistente à instalação atuante na superfície da haste $\left(\mathrm{T}_{\mathrm{s}}\right)$ mostrados na Tabela 5.6 não são considerados verdadeiros devido à possibilidade da ocorrência de efeito de escala nos resultados da resistência por atrito lateral tanto na instalação da estaca como no ensaio de tração. Foray et al. (1998) citaram que o diâmetro do modelo de estaca deve ser maior que 200 vezes o $\mathrm{D}_{50}$ da areia para evitar qualquer efeito de escala na resistência por atrito lateral no fuste. Garnier e König (1998) notaram que para estacas com diâmetros bem inferiores a 100 vezes o $\mathrm{D}_{50}$ a resistência de cisalhamento mobilizada na haste varia de duas a três vezes os valores encontrados em estacas com diâmetros maiores. No presente programa experimental, a razão entre o diâmetro das estacas modelo e o $\mathrm{D}_{50}$ varia de 10 a 20, apresentando-se bem inferior aos limites citados anteriormente na literatura. Por esta razão os resultados $Q_{s}$ e $T_{s}$ não são considerados válidos. 
Tabela 5.6 - Resultados de capacidade de carga a tração e de torque final de instalação das estacas ensaiadas (convertidos para o protótipo)

\begin{tabular}{|c|c|c|c|c|c|c|c|}
\hline $\begin{array}{l}\frac{0}{0} \\
\text { in }\end{array}$ & 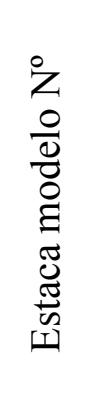 & 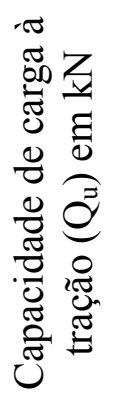 &  & 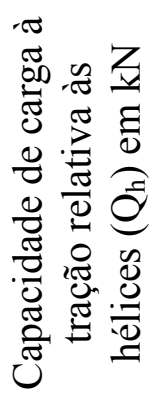 &  & 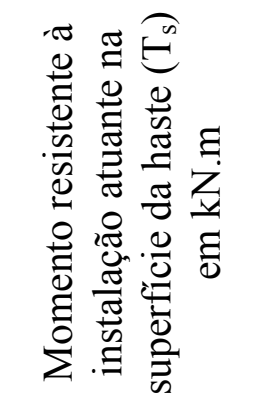 & 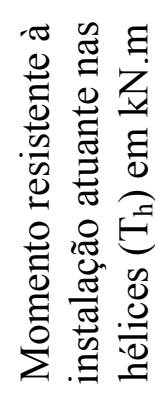 \\
\hline \multirow{12}{*}{ 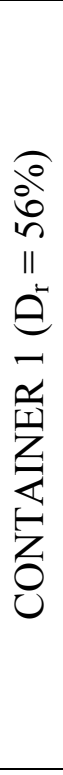 } & $1 \mathrm{~L}$ & 14 & $\mathrm{Q}_{\mathrm{u}}$ estaca $\mathrm{N}^{\mathrm{o}} 10$ & 14 & 0,9 & T estaca $\mathrm{N}^{\mathrm{o}} 10$ & 0,3 \\
\hline & $2 \mathrm{~L}$ & 19 & $\mathrm{Q}_{\mathrm{u}}$ estaca $\mathrm{N}^{\mathrm{o}} 10$ & 19 & 1,0 & $\mathrm{~T}$ estaca $\mathrm{N}^{\mathrm{o}} 10$ & 0,4 \\
\hline & $3 \mathrm{~L}$ & 43 & $\mathrm{Q}_{\mathrm{u}}$ estaca $\mathrm{N}^{\mathrm{o}} 10$ & 43 & 1,6 & $\mathrm{~T}$ estaca $\mathrm{N}^{\mathrm{o}} 10$ & 1,0 \\
\hline & $4 \mathrm{~L}$ & 46 & $\mathrm{Q}_{\mathrm{u}}$ estaca $\mathrm{N}^{\mathrm{o}} 11$ & 46 & 2,3 & $\mathrm{~T}$ estaca $\mathrm{N}^{\circ} 11$ & 1,6 \\
\hline & $5 \mathrm{~L}$ & 83 & $\mathrm{Q}_{\mathrm{u}}$ estaca $\mathrm{N}^{\mathrm{o}} 11$ & 83 & 3,9 & $\mathrm{~T}$ estaca $\mathrm{N}^{\mathrm{o}} 11$ & 3,2 \\
\hline & $6 \mathrm{~L}$ & 112 & $\mathrm{Q}_{\mathrm{u}}$ estaca $\mathrm{N}^{\mathrm{o}} 11$ & 112 & 4,0 & $\mathrm{~T}$ estaca $\mathrm{N}^{\circ} 11$ & 3,3 \\
\hline & $7 \mathrm{~L}$ & 74 & $\mathrm{Q}_{\mathrm{u}}$ estaca $\mathrm{N}^{\mathrm{o}} 12$ & 69 & 6,4 & $\mathrm{~T}$ estaca $\mathrm{N}^{\mathrm{o}} 12$ & 4,1 \\
\hline & $8 \mathrm{~L}$ & 113 & $\mathrm{Q}_{\mathrm{u}}$ estaca $\mathrm{N}^{\mathrm{o}} 12$ & 108 & 7,2 & $\mathrm{~T}$ estaca $\mathrm{N}^{\mathrm{o}} 12$ & 4,9 \\
\hline & $9 \mathrm{~L}$ & 155 & $\mathrm{Q}_{\mathrm{u}}$ estaca $\mathrm{N}^{\mathrm{o}} 12$ & 150 & 7,6 & $\mathrm{~T}$ estaca $\mathrm{N}^{\mathrm{o}} 12$ & 5,3 \\
\hline & $10 \mathrm{~L}$ & 0 & 0 & - & 0,6 & 0,6 & - \\
\hline & $11 \mathrm{~L}$ & 0 & 0 & - & 0,7 & 0,7 & - \\
\hline & $12 \mathrm{~L}$ & 5 & 5 & - & 2,3 & 2,3 & - \\
\hline \multirow{12}{*}{  } & $1 \mathrm{~L}$ & 66 & $\mathrm{Q}_{\mathrm{u}}$ estaca $\mathrm{N}^{\mathrm{o}} 10$ & 60 & 2,7 & $\mathrm{~T}$ estaca $\mathrm{N}^{\mathrm{o}} 10$ & 1,9 \\
\hline & $2 \mathrm{~L}$ & 94 & $\mathrm{Q}_{\mathrm{u}}$ estaca $\mathrm{N}^{\mathrm{o}} 10$ & 88 & 3,6 & $\mathrm{~T}$ estaca $\mathrm{N}^{\mathrm{o}} 10$ & 2,8 \\
\hline & $3 \mathrm{~L}$ & 122 & $\mathrm{Q}_{\mathrm{u}}$ estaca $\mathrm{N}^{\mathrm{o}} 10$ & 116 & 4,9 & $\mathrm{~T}$ estaca $\mathrm{N}^{\mathrm{o}} 10$ & 4,1 \\
\hline & $4 \mathrm{~L}$ & 204 & $\mathrm{Q}_{\mathrm{u}}$ estaca $\mathrm{N}^{\mathrm{o}} 11$ & 177 & 9,6 & $\mathrm{~T}$ estaca $\mathrm{N}^{\mathrm{o}} 11$ & 7,7 \\
\hline & $5 \mathrm{~L}$ & 261 & $\mathrm{Q}_{\mathrm{u}}$ estaca $\mathrm{N}^{\mathrm{o}} 11$ & 234 & 14,4 & $\mathrm{~T}$ estaca $\mathrm{N}^{\mathrm{o}} 11$ & 12,5 \\
\hline & $6 \mathrm{~L}$ & 302 & $\mathrm{Q}_{\mathrm{u}}$ estaca $\mathrm{N}^{\mathrm{o}} 11$ & 275 & 12,6 & $\mathrm{~T}$ estaca $\mathrm{N}^{\mathrm{o}} 11$ & 10,7 \\
\hline & $7 \mathrm{~L}$ & 494 & $\mathrm{Q}_{\mathrm{u}}$ estaca $\mathrm{N}^{\mathrm{o}} 12$ & 413 & 29,9 & $\mathrm{~T}$ estaca $\mathrm{N}^{\mathrm{o}} 12$ & 22,4 \\
\hline & $8 \mathrm{~L}$ & 556 & $\mathrm{Q}_{\mathrm{u}}$ estaca $\mathrm{N}^{\mathrm{o}} 12$ & 475 & 42,6 & $\mathrm{~T}$ estaca $\mathrm{N}^{\mathrm{o}} 12$ & 35,1 \\
\hline & $9 \mathrm{~L}$ & 556 & $\mathrm{Q}_{\mathrm{u}}$ estaca $\mathrm{N}^{\mathrm{o}} 12$ & 475 & 42,6 & $\mathrm{~T}$ estaca $\mathrm{N}^{\mathrm{o}} 12$ & 35,1 \\
\hline & $10 \mathrm{~L}$ & 6 & 6 & - & 0,8 & 0,8 & - \\
\hline & $11 \mathrm{~L}$ & 27 & 27 & - & 1,9 & 1,9 & - \\
\hline & $12 \mathrm{~L}$ & 81 & 81 & - & 7,5 & 7,5 & - \\
\hline
\end{tabular}

Contudo, os resultados de capacidade de carga à tração relativa às hélices $\left(Q_{h}\right)$ e momento resistente à instalação atuante nas hélices $\left(T_{h}\right)$ mostrados na Tabela 5.6 são 
considerados válidos. Para obtenção destes resultados, os modelos das estacas helicoidais foram fabricados com os diâmetros de hélice necessários para evitar o efeito de escala nos resultados relativos à $\mathrm{Q}_{\mathrm{h}} \mathrm{e} \mathrm{T}_{\mathrm{h}}$. Ovesen (1981) relatou que não foi observado efeito de escala em placas de ancoragem cuja razão entre o diâmetro da placa e o $\mathrm{D}_{50}$ fosse maior do que 25 . Esta conclusão confirma a citação feita por Ovesen (1979) de que não foi constatado efeito de escala em modelos de sapatas circulares com a razão entre o diâmetro da sapata e o $D_{50}$ maiores que 30. Como no presente programa experimental em centrífuga a razão entre o diâmetro da hélice e o $\mathrm{D}_{50}$ da areia utilizada variou de 33 a 67, conclui-se que, com base nas experiências reportadas anteriormente na literatura, não existe efeito de escala nos resultados de $Q_{h}$ e $T_{h}$.

Os resultados medidos dos deslocamentos verticais na ruptura são apresentados na escala do protótipo na Tabela 5.7. Nesta tabela nota-se que a razão u/D entre o deslocamento na ruptura e o diâmetro da hélice varia de 0,19 a 0,72 , e não é influenciada pelo número de hélices. Com a exceção das estacas $\mathrm{N}^{0} 1$ e $\mathrm{N}^{\mathrm{o}} 3$, a magnitude da razão u/D é menor nos ensaios realizados no container com menor densidade relativa.

Os valores da razão $\mathrm{u} / \mathrm{D}$ encontrados nos ensaios de tração das estacas metálicas helicoidais em centrífuga apresentam-se maiores do que os encontrados na estacas metálicas helicoidais reais. No entanto, a ruptura na centrífuga é facilmente caracterizada pelo pico da curva (valor máximo), enquanto que na prática este valor não é atingido e a ruptura é caracterizada por outros critérios.

Como já mencionado anteriormente na revisão bibliográfica desta tese, o controle de capacidade de carga à tração de fundações em estacas metálicas helicoidais é baseado em correlações empíricas entre o torque de instalação e a carga de ruptura à tração. 
Tabela 5.7 - Resultados de deslocamento vertical na ruptura (convertidos para o protótipo)

\begin{tabular}{|c|c|c|c|c|c|}
\hline Solo & $\begin{array}{c}\text { Estaca } \\
\text { modelo }\end{array}$ & $\begin{array}{l}\text { Diâmetro da } \\
\text { hélice (D) em }\end{array}$ & $\begin{array}{l}\text { Capacidade de carga } \\
\text { à tração }\left(Q_{u}\right) \text { em } k N\end{array}$ & $\begin{array}{l}\text { Desloc. vertical na } \\
\text { ruptura }(\mathrm{u}) \text { em } \mathrm{mm}\end{array}$ & $\mathrm{u} / \mathrm{D}$ \\
\hline \multirow{9}{*}{  } & $1 \mathrm{~L}$ & 214,4 & 14 & 53,9 & 0,25 \\
\hline & $2 \mathrm{~L}$ & 214,4 & 19 & 58,6 & 0,27 \\
\hline & $3 \mathrm{~L}$ & 214,4 & 43 & 70,8 & 0,33 \\
\hline & $4 \mathrm{~L}$ & 325,7 & 46 & 75,6 & 0,23 \\
\hline & $5 \mathrm{~L}$ & 325,7 & 83 & 86,4 & 0,27 \\
\hline & $6 \mathrm{~L}$ & 325,7 & 112 & 77,1 & 0,24 \\
\hline & $7 \mathrm{~L}$ & 440,0 & 74 & 85,1 & 0,19 \\
\hline & $8 \mathrm{~L}$ & 440,0 & 113 & 140,6 & 0,32 \\
\hline & $9 \mathrm{~L}$ & 440,0 & 155 & 120,6 & 0,27 \\
\hline \multirow{9}{*}{ 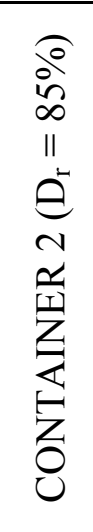 } & $1 \mathrm{~L}$ & 214,4 & 66 & 51,4 & 0,24 \\
\hline & $2 \mathrm{~L}$ & 214,4 & 94 & 82,4 & 0,38 \\
\hline & $3 \mathrm{~L}$ & 214,4 & 122 & 57,0 & 0,27 \\
\hline & $4 \mathrm{~L}$ & 325,7 & 204 & 101,5 & 0,31 \\
\hline & $5 \mathrm{~L}$ & 325,7 & 261 & 105,8 & 0,32 \\
\hline & $6 \mathrm{~L}$ & 325,7 & 302 & 101,3 & 0,31 \\
\hline & $7 \mathrm{~L}$ & 440,0 & 494 & 186,3 & 0,42 \\
\hline & $8 \mathrm{~L}$ & 440,0 & 556 & 316,8 & 0,72 \\
\hline & $9 \mathrm{~L}$ & 440,0 & 556 & 258,2 & 0,59 \\
\hline
\end{tabular}

Nota: Os resultados de deslocamento vertical na ruptura apresentados são correspondentes à capacidade de carga à tração medida, com o desconto do peso próprio do sistema de ensaio e das estacas modelos.

O presente programa experimental em centrífuga foi realizado para validar a relação física da Equação 3.14, do modelo teórico proposto nesta tese, entre a parcela de capacidade de carga à tração relativa às hélices $\left(\mathrm{Q}_{\mathrm{h}}\right)$ e momento resistente à instalação gerado nas hélices $\left(T_{h}\right)$. Para validar a verificação da Equação 3.14, os resultados da modelagem física em centrífuga devem reproduzir o comportamento deste tipo de fundação em grandeza real nas fases de instalação e de carregamento. Na prática de fundações de estacas metálicas helicoidais, o fator empírico de torque $\left(\mathrm{K}_{\mathrm{t}}\right)$ indica a magnitude da relação entre a capacidade de carga à tração e o torque final de instalação de uma estaca metálica helicoidal. Como neste estudo os valores de $Q_{u}$ e de $T$ apresentam erros em seus totais devido ao efeito de escala na resistência por atrito nas hastes dos modelos de estacas, não é possível comparar os valores de 
$\mathrm{K}_{\mathrm{t}}$ medido nos ensaios em centrífuga com os valores medidos em estacas metálicas helicoidais reais. No entanto, considerando-se a experiência de Garnier e König (1998), citada anteriormente neste texto, as magnitudes dos valores de $\mathrm{Q}_{\mathrm{s}}$ medidos nestes ensaios em centrífuga, mostrados na Tabela 5.6, são iguais a duas ou três vezes os valores que seriam encontrados em estacas reais correspondentes. Deste modo, nota-se na Tabela 5.6, que as parcelas de $Q_{\mathrm{s}}$ não apresentam proporção significante nesta investigação, comparando-se estas parcelas com as parcelas de $\mathrm{Q}_{\mathrm{h}}$. Com base nesta hipótese, foi determinado um fator de torque $\mathrm{K}_{\mathrm{t}}$, que é a razão entre $\mathrm{Q}_{\mathrm{h}}$ e $\mathrm{T}_{\mathrm{h}}$. Os valores de $\mathrm{K}_{\mathrm{t}}$ encontrados nestes ensaios são apresentados na Tabela 5.8.

Tabela 5.8 - Valores medidos de $\mathrm{K}_{\mathrm{t}}$

\begin{tabular}{|c|c|c|c|c|c|}
\hline Solo & $\begin{array}{c}\text { Estaca } \\
\text { modelo } \\
\mathrm{N}^{\mathbf{0}}\end{array}$ & $\begin{array}{c}\text { Diâmetro da } \\
\text { haste } \\
\text { convertido } \\
\text { para o } \\
\text { protótipo }(\mathrm{mm})\end{array}$ & $\begin{array}{c}\text { Capacidade } \\
\text { de carga à } \\
\text { tração } \\
\text { relativa às } \\
\text { hélices }\left(\mathrm{Q}_{\mathrm{h}}\right)\end{array}$ & $\begin{array}{c}\text { Momento } \\
\text { resistente à } \\
\text { instalação atuante } \\
\text { nas hélices }\left(\mathrm{T}_{\mathrm{h}}\right) \mathrm{em} \\
\mathrm{kN.m}\end{array}$ & $\begin{array}{c}\text { Fator } K_{t}^{\prime} \\
\left(\mathrm{Q}_{\mathrm{h}} / \mathrm{T}_{\mathrm{h}}\right) \mathrm{em} \\
\mathrm{m}^{-1}\end{array}$ \\
\hline \multirow{9}{*}{  } & $1 \mathrm{~L}$ & 64,3 & 14 & 0,3 & 47 \\
\hline & $2 \mathrm{~L}$ & 64,3 & 19 & 0,4 & 48 \\
\hline & $3 \mathrm{~L}$ & 64,3 & 43 & 1,0 & 43 \\
\hline & $4 \mathrm{~L}$ & 97,7 & 46 & 1,6 & 29 \\
\hline & $5 \mathrm{~L}$ & 97,7 & 83 & 3,2 & 26 \\
\hline & $6 \mathrm{~L}$ & 97,7 & 112 & 3,3 & 34 \\
\hline & $7 \mathrm{~L}$ & 132,0 & 69 & 4,1 & 17 \\
\hline & $8 \mathrm{~L}$ & 132,0 & 108 & 4,9 & 22 \\
\hline & 9L & 132,0 & 150 & 5,3 & 28 \\
\hline \multirow{9}{*}{ 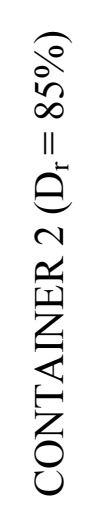 } & $1 \mathrm{~L}$ & 64,3 & 60 & 1,9 & 32 \\
\hline & $2 \mathrm{~L}$ & 64,3 & 88 & 2,8 & 31 \\
\hline & $3 \mathrm{~L}$ & 64,3 & 116 & 4,1 & 28 \\
\hline & $4 \mathrm{~L}$ & 97,7 & 177 & 7,7 & 23 \\
\hline & $5 \mathrm{~L}$ & 97,7 & 234 & 12,5 & 19 \\
\hline & $6 \mathrm{~L}$ & 97,7 & 275 & 10,7 & 26 \\
\hline & $7 \mathrm{~L}$ & 132,0 & 413 & 22,4 & 18 \\
\hline & $8 \mathrm{~L}$ & 132,0 & 475 & 35,1 & 14 \\
\hline & 9L & 132,0 & 475 & 35,1 & 14 \\
\hline
\end{tabular}


De acordo com a A. B. Chance Co. (1994), o fator empírico de torque $\left(\mathrm{K}_{\mathrm{t}}\right)$ deve variar de 10 to $66 \mathrm{~m}^{-1}$, conforme as condições do subsolo e das dimensões das estacas metálicas helicoidais. Os valores de $\mathrm{K}_{\mathrm{t}}$ encontrados na presente investigação variam de 14 a $48 \mathrm{~m}^{-1}$ (Tabela 5.9). Comparando-se os fatores $\mathrm{K}_{\mathrm{t}}$ e $\mathrm{K}_{\mathrm{t}}$, conclui-se que a magnitude da razão entre capacidade de carga à tração e o torque final de instalação medida neste experimento em centrífuga encontra-se dentro do intervalo verificado em estacas na grandeza real. Portanto, esta relação entre a capacidade de carga à tração e o torque final de instalação (ambos referentes às hélices) foi bem reproduzida na modelagem em centrífuga.

Observa-se na Tabela 5.8 que a grandeza de $\mathrm{K}_{\mathrm{t}}$ diminui com o aumento do diâmetro da haste da estaca. Este fato corrobora com os valores de fator empírico de torque $\left(\mathrm{K}_{\mathrm{t}}\right)$, recomendados na prática de fundações em estacas metálicas helicoidais, citados por Hoyt e Clemence (1989). De acordo com estes autores, quanto maior o diâmetro da haste, menor deverá ser o valor do fator empírico de torque $\left(\mathrm{K}_{\mathrm{t}}\right)$.

\subsubsection{Ensaios de arrancamento a 1 G}

Os resultados desses ensaios são qualitativos, obtidos por meio de fotos de cortes realizados no maciço após ensaio de arrancamento das estacas a 1g. Na Figura 5.39 observa-se o deslocamento das camadas coloridas sobre a hélice do modelo de estaca (o espaçamento entre as linhas azuis é igual ao diâmetro da hélice). Nesta figura e na Figura 5.40 observa-se que o deslocamento da terceira linha acima da hélice é imperceptível. Este fato confirma a afirmação de Adams and Klym (1972), que alegaram que durante o arrancamento de uma estaca metálica helicoidal multi-hélices, cada hélice se comporta independentemente da outra se o espaçamento vertical entre elas for no mínimo igual a duas vezes o diâmetro da hélice inferior. Além disso, apóia também a hipótese adotada (Figura 3.2) para o modelo proposto no 
capítulo 3 desta tese, em que a capacidade de carga à tração relativa às hélices é a somatória das capacidades individuais de cada hélice.

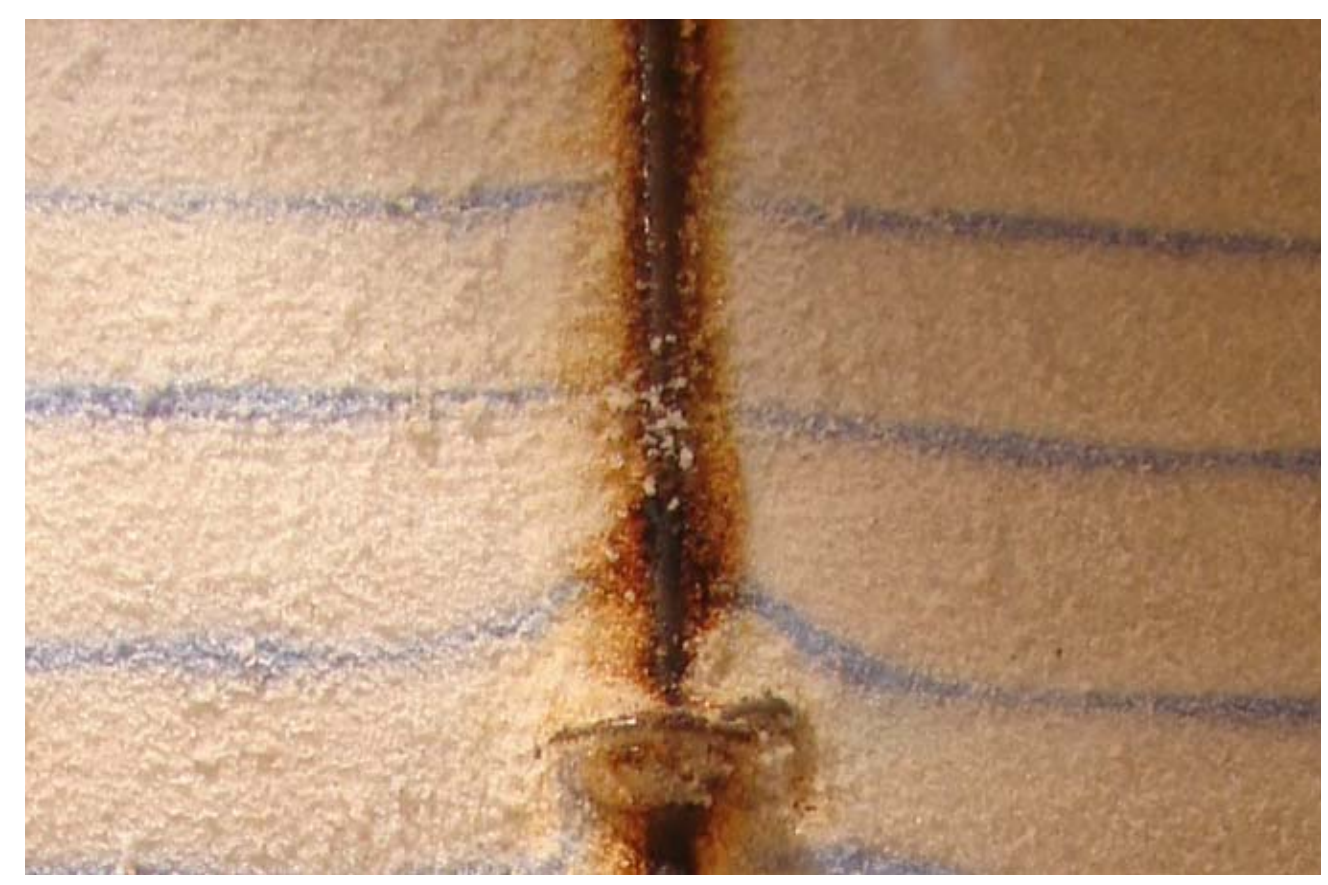

Figura 5.39 - Fotografia do corte do maciço sobre a hélice

Na Figura 5.40 nota-se abaixo das hélices a parcela de resistência ao arrancamento da estaca devida à coesão aparente. Esta coesão aparente ocorreu devido à sucção da areia úmida, pois como relatado anteriormente no capítulo anterior, o ensaio foi realizado num solo não saturado, porém com teor de umidade desconhecido na profundidade das hélices. Por esta fotografia conclui-se que em areias não saturadas as parcelas de capacidade de carga à tração da estaca sejam três:

- resistência por atrito lateral do tubo;

- capacidade de carga à tração relativa às hélices;

- resistência da ponta devido a sucção. 


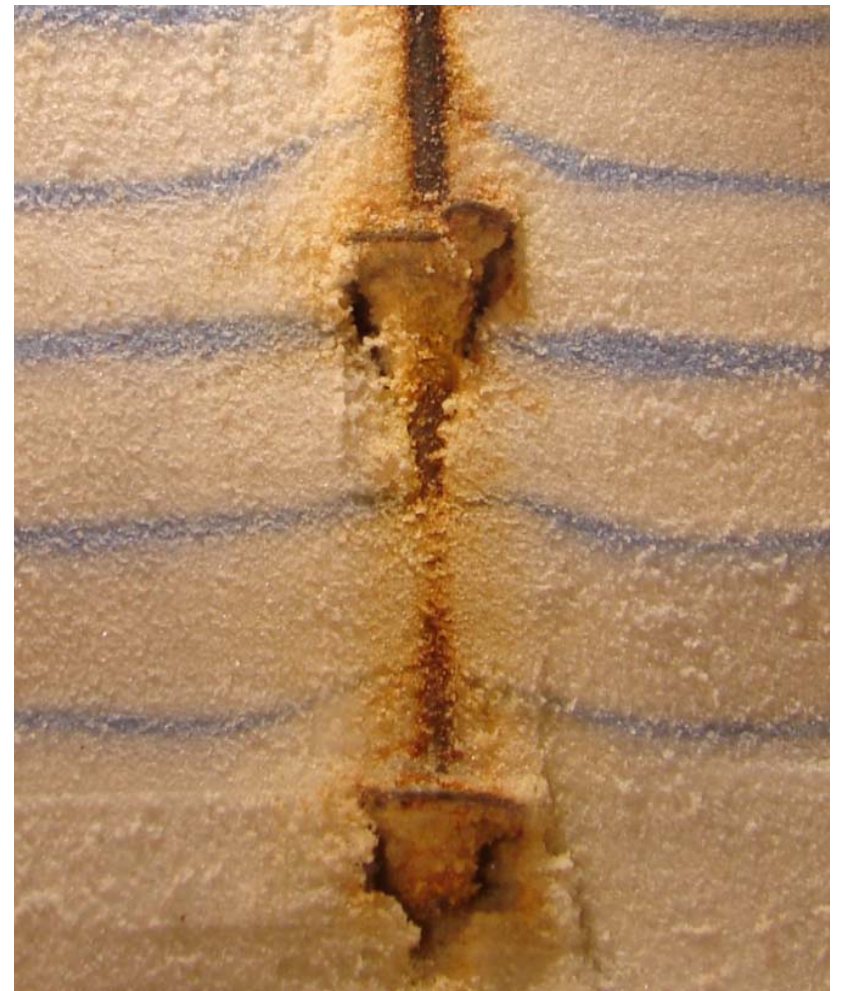

Figura 5.40 - Fotografia do corte do maciço entre as hélices da estaca modelo

\subsection{Ensaio de cisalhamento direto}

\subsubsection{Interface areia e aço da hélice do modelo ensaiado na centrífuga}

As curvas de força cisalhante $\mathrm{x}$ deslocamento relativo dos ensaios de cisalhamento direto de interface realizados no Laboratoire Central de Ponts et Chaussées são apresentadas nas Figuras 5.41 a 5.44. As Figuras 5.41 e 5.42 mostram os resultados dos ensaios realizados em interfaces da areia de $\gamma=15,46 \mathrm{kN} / \mathrm{m}^{3}$ com o aço da hélice e com o material de solda das hélices. 


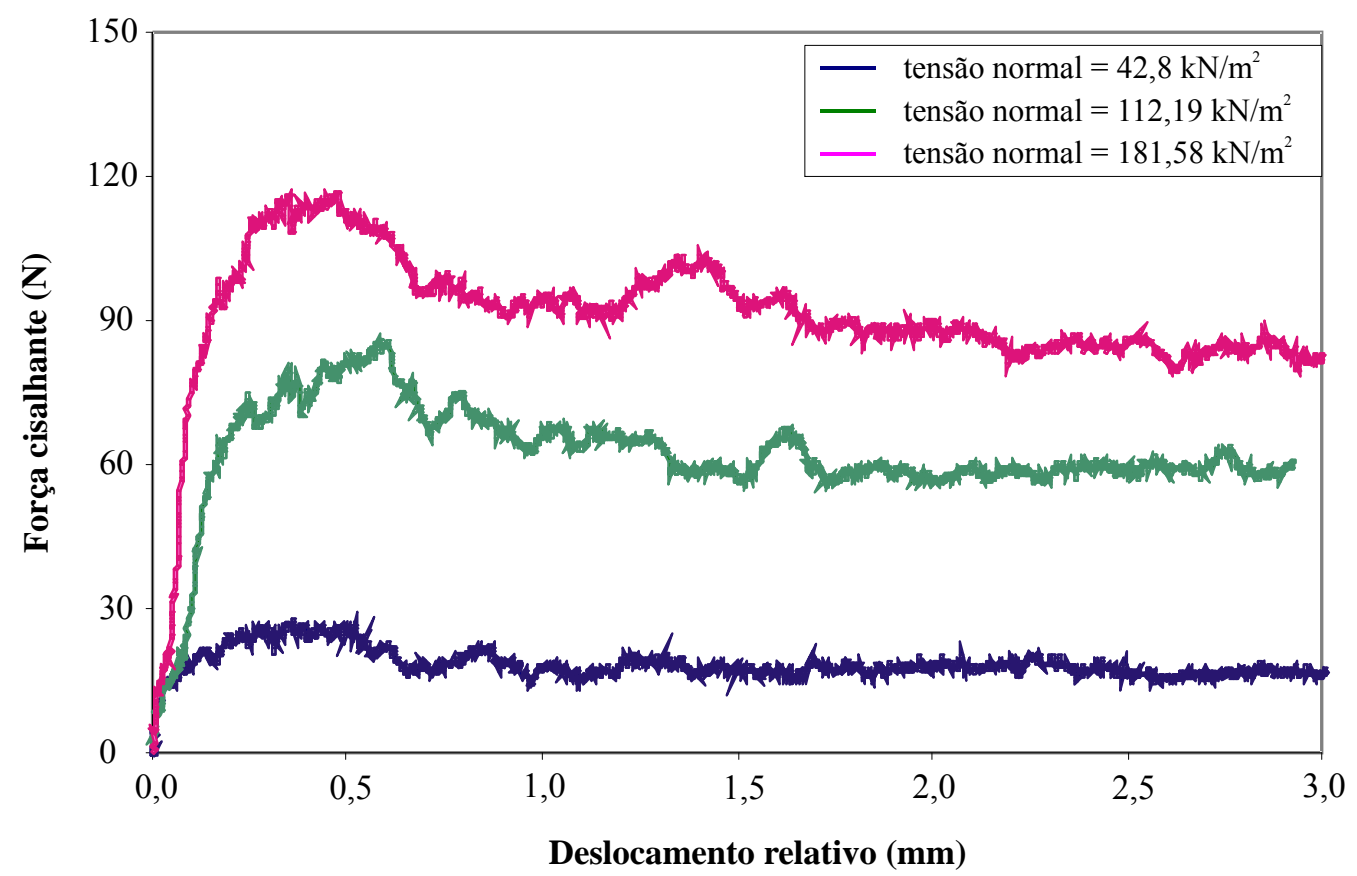

Figura 5.41 - Curvas força cisalhante $\mathrm{x}$ deslocamento relativo da interface entre aço e areia

$$
\left(\operatorname{amostra} \gamma=15,46 \mathrm{kN} / \mathrm{m}^{3}\right)
$$

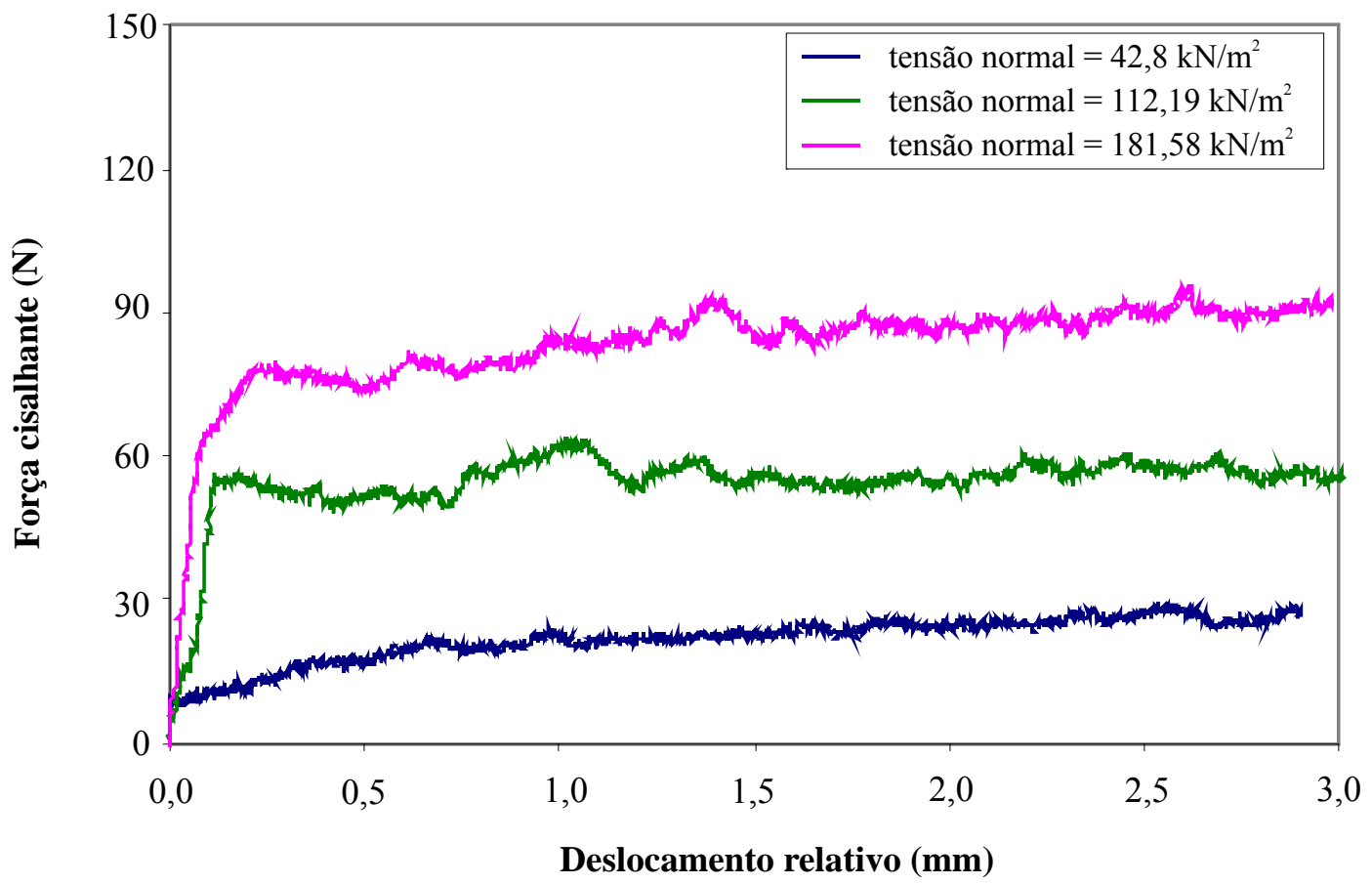

Figura 5.42 - Curvas força cisalhante x deslocamento relativo da interface entre chapa soldada e areia (amostra $\left.\gamma=15,46 \mathrm{kN} / \mathrm{m}^{3}\right)$ 
As Figuras 5.43 e 5.44 mostram os resultados dos ensaios realizados em interfaces da areia de $\gamma=16,30 \mathrm{kN} / \mathrm{m}^{3}$ com o aço da hélice e com o material de solda das hélices.

Os gráficos de tensão de cisalhante residual x tensão normal correspondentes às Figuras 5.41 a 5.44 são apresentadas nas Figuras 5.45 a 5.48. A partir destas figuras foram determinados os valores de ângulo de atrito residual entre o aço ou chapa soldada e a areia $\left(\delta_{\mathrm{r}}\right)$. A Tabela 5.9 mostra os valores de ângulo de atrito residual obtidos nas Figuras 5.45 a 5.48 .

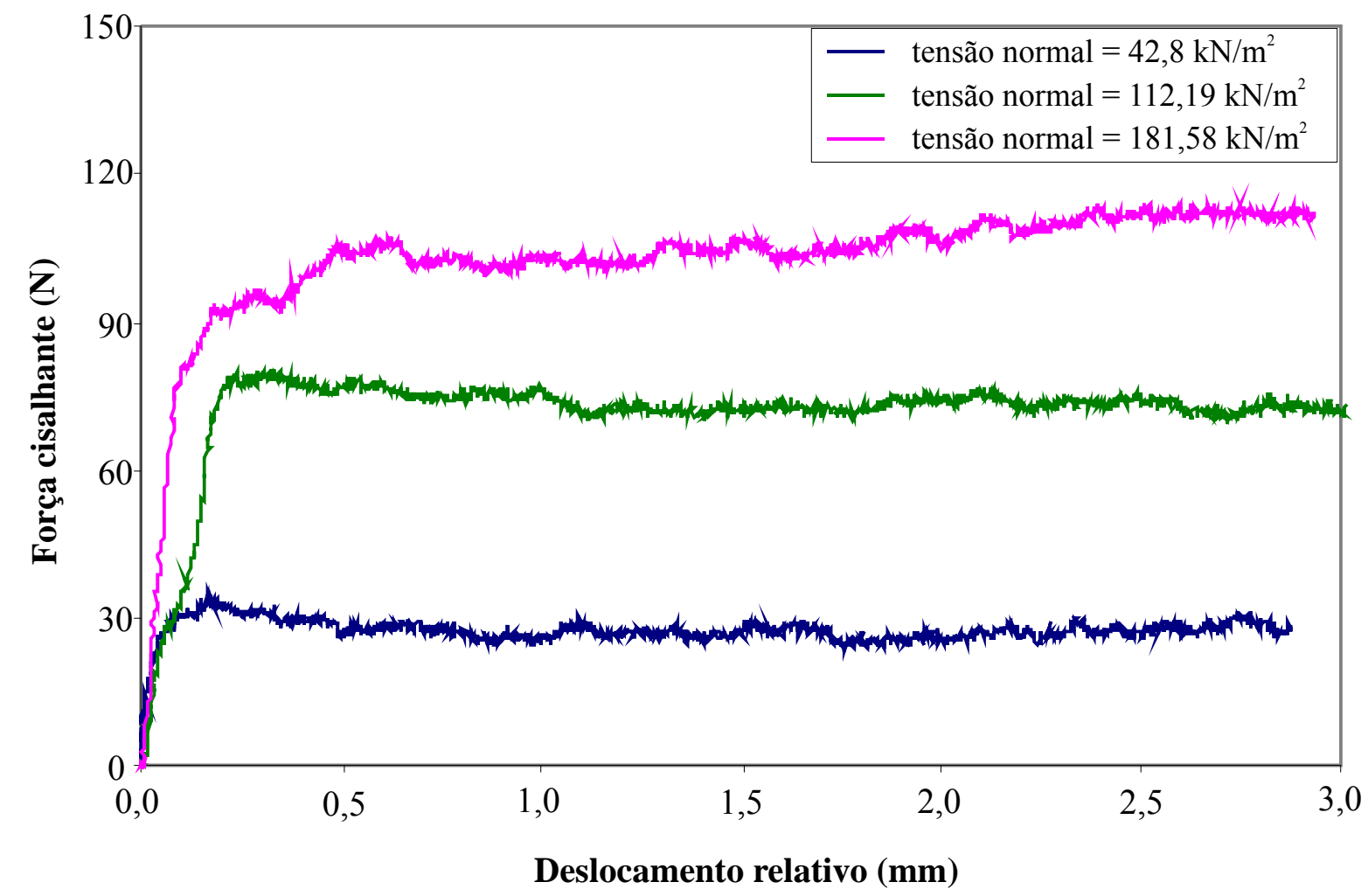

Figura 5.43 - Curvas força cisalhante $\mathrm{x}$ deslocamento relativo da interface entre aço e areia

$$
\left(\operatorname{amostra} \gamma=16,30 \mathrm{kN} / \mathrm{m}^{3}\right)
$$




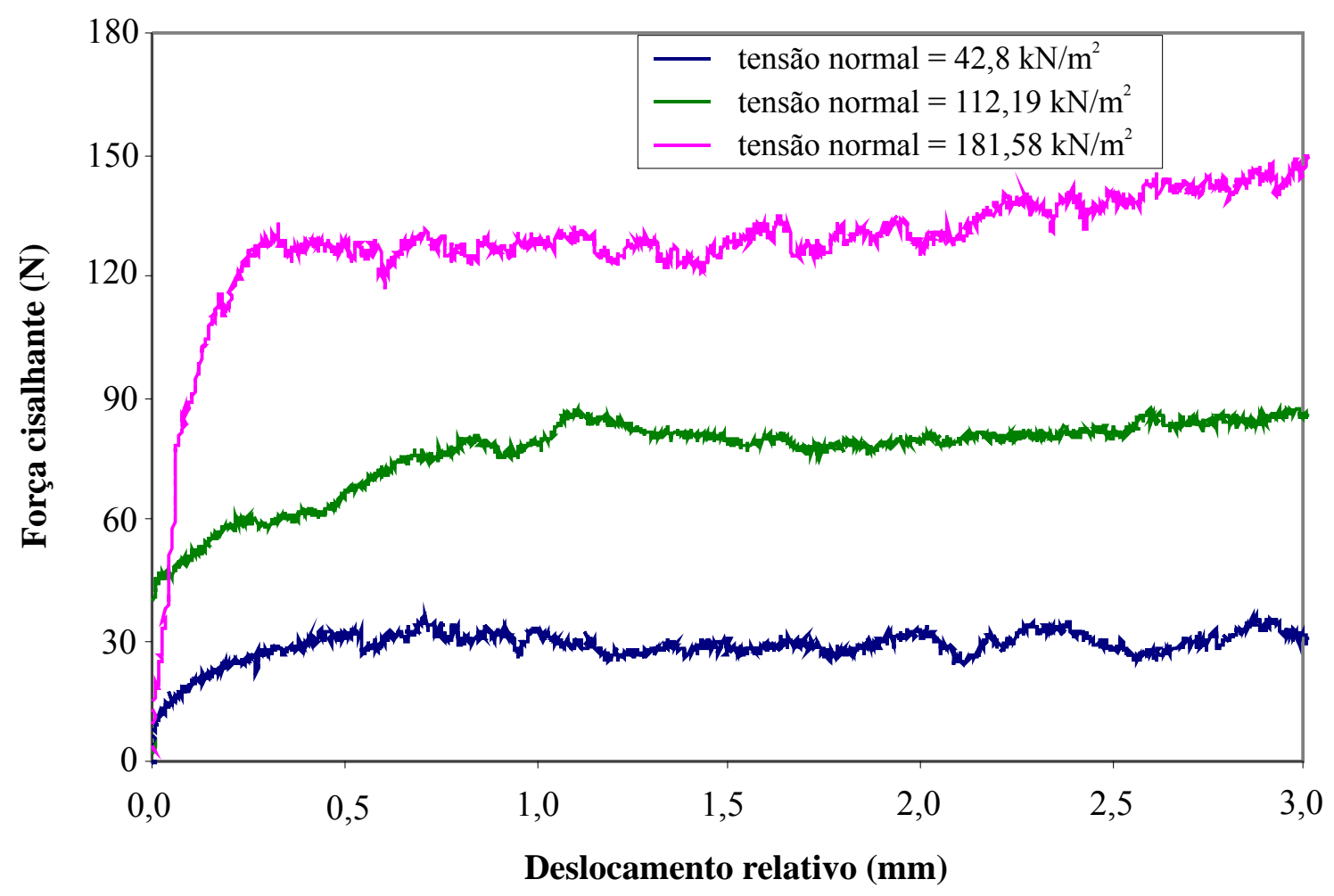

Figura 5.44 - Curvas força cisalhante x deslocamento relativo da interface entre chapa soldada e areia $\left(\operatorname{amostra} \gamma=16,30 \mathrm{kN} / \mathrm{m}^{3}\right)$

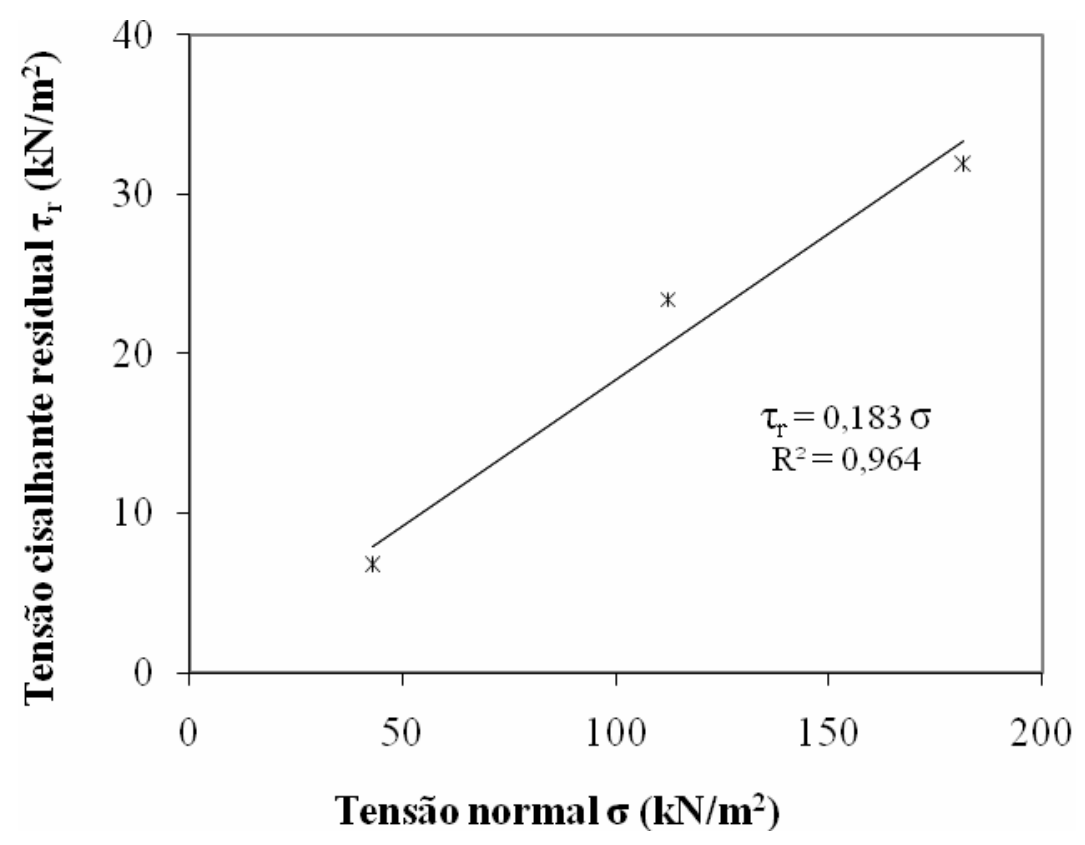

Figura 5.45 - Tensão cisalhante residual x tensão normal da interface entre aço e areia

$$
\left(\operatorname{amostra} \gamma=15,46 \mathrm{kN} / \mathrm{m}^{3}\right)
$$




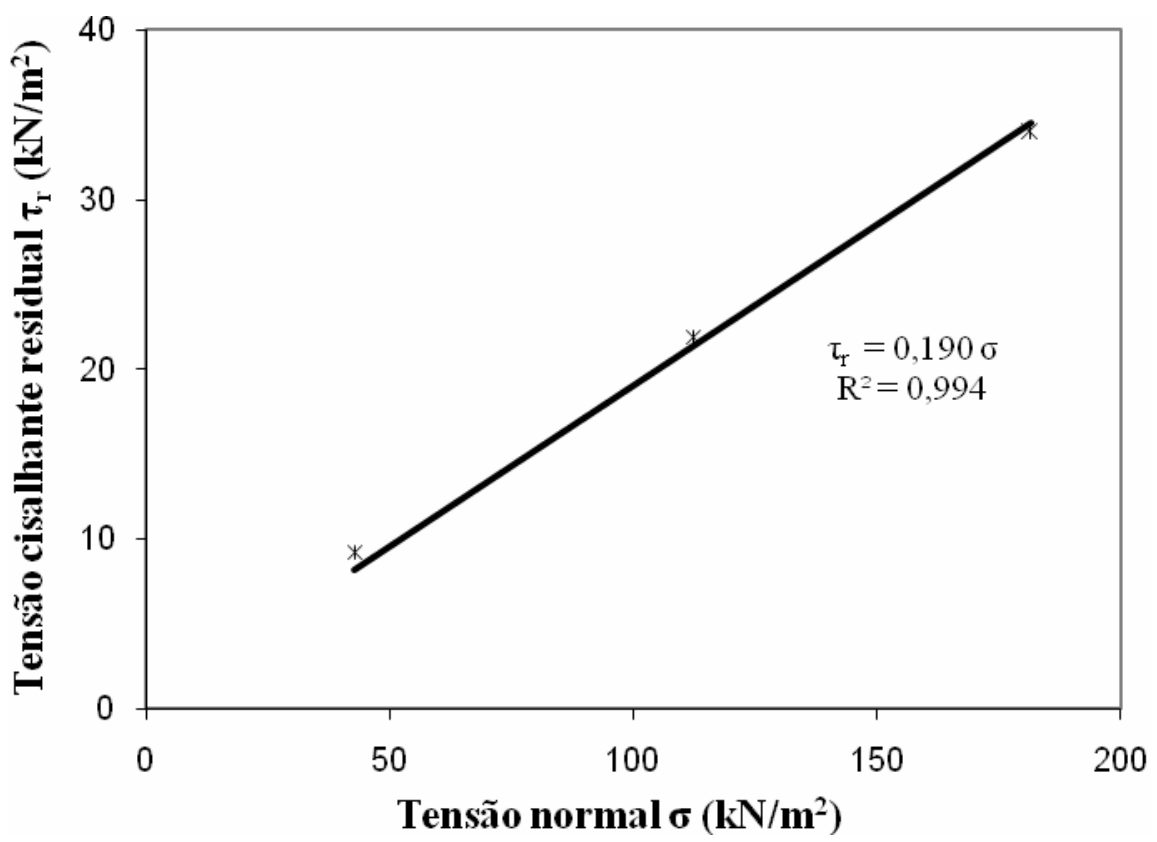

Figura 5.46 - Tensão cisalhante residual x tensão normal da interface entre chapa soldada e $\operatorname{areia}\left(\operatorname{amostra} \gamma=15,46 \mathrm{kN} / \mathrm{m}^{3}\right)$

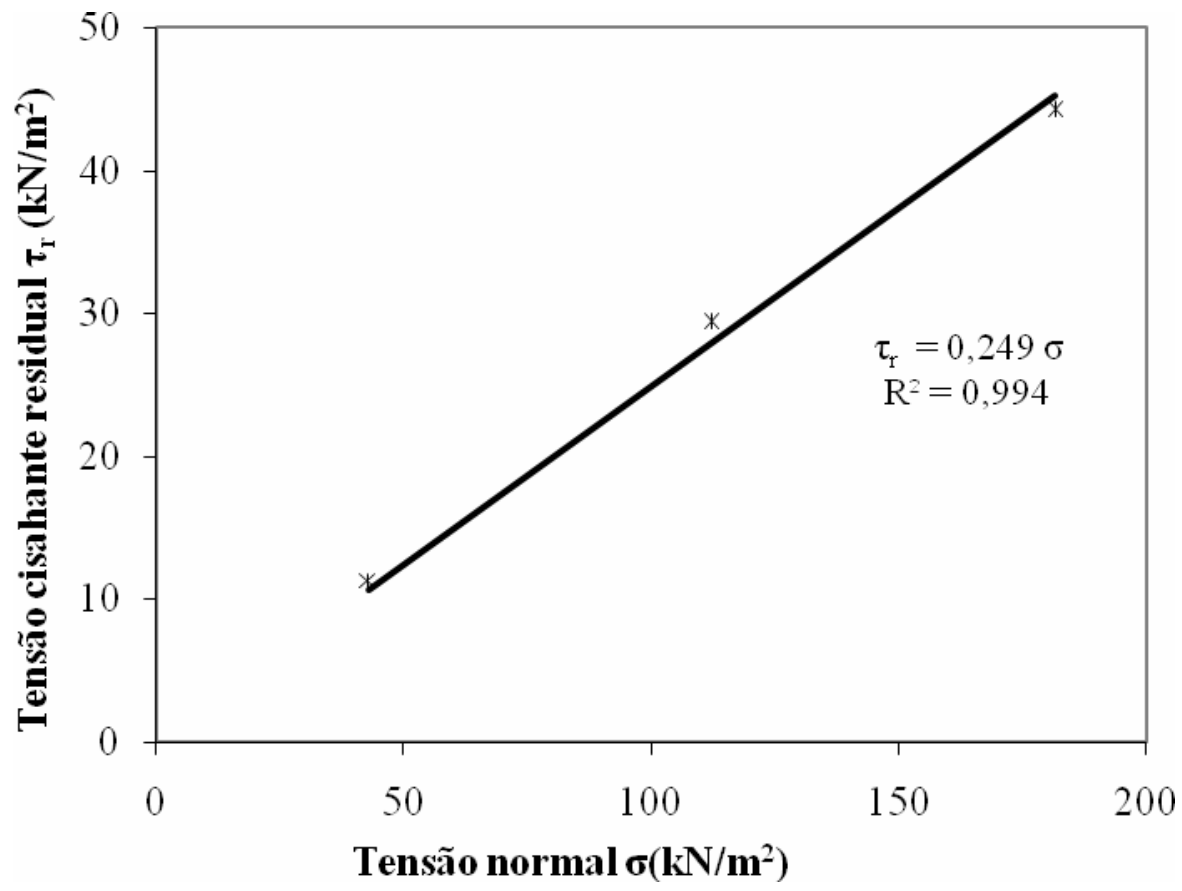

Figura 5.47 -Tensão cisalhante residual x tensão normal da interface entre aço e areia $\left(\operatorname{amostra} \gamma=16,30 \mathrm{kN} / \mathrm{m}^{3}\right)$ 


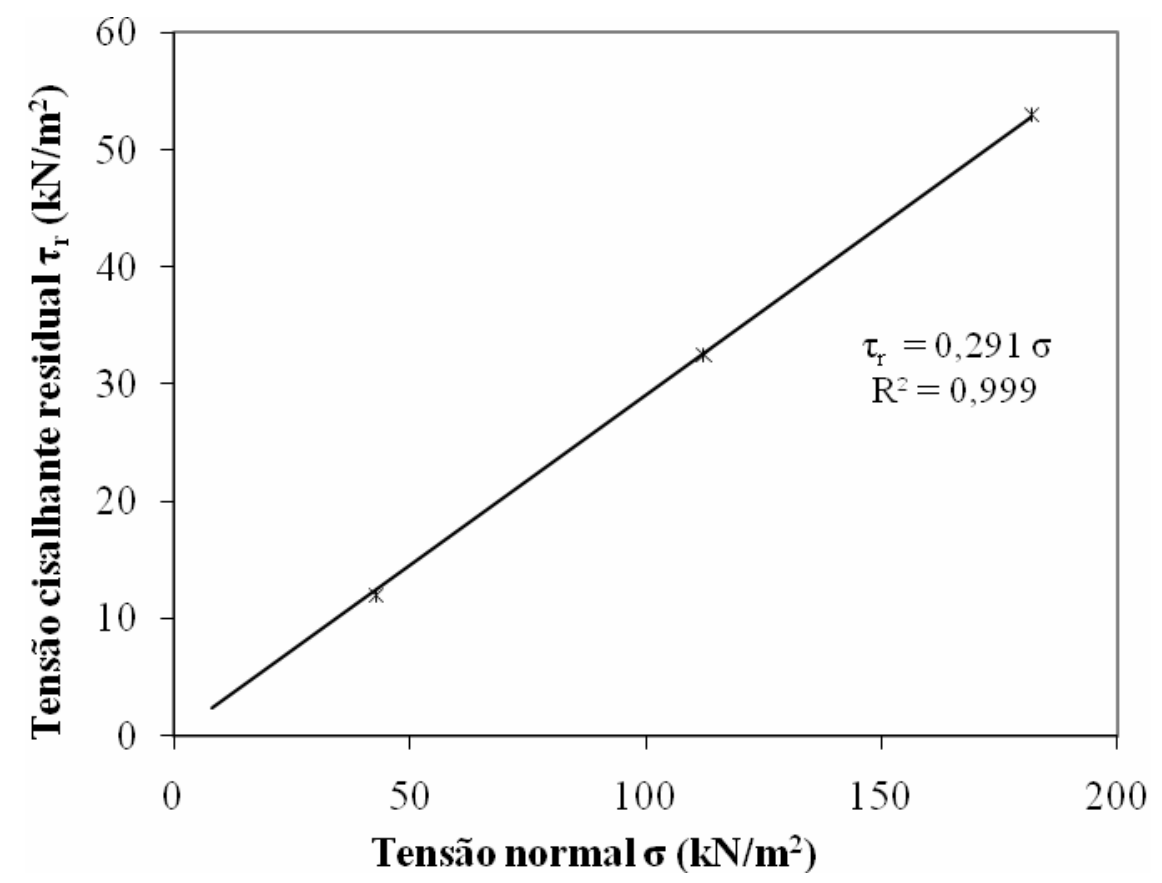

Figura 5.48 - Tensão cisalhante residual x tensão normal da interface entre chapa soldada e

$$
\operatorname{areia}\left(\operatorname{amostra} \gamma=16,30 \mathrm{kN} / \mathrm{m}^{3}\right)
$$

Tabela 5.9 - Ângulo de atrito residual nas interfaces entre o material das hélices e as amostras de $\operatorname{areia}\left(\delta_{\mathrm{r}}\right)$

\begin{tabular}{|c|c|c|}
\hline \multirow{2}{*}{$\begin{array}{l}\text { Tipo de } \\
\text { interface }\end{array}$} & \multicolumn{2}{|c|}{ Ângulo de atrito residual na interface $\left(\delta_{\mathrm{r}}\right)$} \\
\hline & $\begin{array}{l}\text { Areia do container } 1 \\
\left(\gamma=15,46 \mathrm{kN} / \mathrm{m}^{3}\right)\end{array}$ & $\begin{array}{l}\text { Areia do container } 2 \\
\left(\gamma=16,30 \mathrm{kN} / \mathrm{m}^{3}\right)\end{array}$ \\
\hline Aço & $10,4^{\circ}$ & $14,0^{\circ}$ \\
\hline Chapa soldada & $10,8^{\circ}$ & $16,2^{\circ}$ \\
\hline Valor médio & $10,6^{\mathrm{o}}$ & $15,1^{\mathrm{o}}$ \\
\hline
\end{tabular}

A Tabela 5.9 mostra que a densidade relativa inicial da areia afetou os resultados de ângulo de atrito residual nas interfaces estudadas.

De acordo com a pesquisa de Uesugi e Kishida (1986), já citada anteriormente nesta tese, as principais variáveis que influenciam o ângulo de atrito de pico entre uma superfície de aço e areia são: a rugosidade do aço, a forma de grão e a dimensão do grão $\left(\mathrm{D}_{50}\right)$. Após a 
realização destes ensaios, a rugosidade da chapa de aço e da chapa soldada foram medidas para verificar a influência nos resultados de ângulo de atrito residual na interface encontrados. A Tabela 5.10 mostra os valores de rugosidade máxima medido das interfaces estudadas. A rugosidade máxima $R_{\max }$ é calculada como valor médio dos valores de amplitude máxima encontrados para cada comprimento L padronizado (gauge lengh).

Tabela 5.10 - Rugosidade máxima das chapas ensaiadas

\begin{tabular}{c|c}
$\begin{array}{c}\text { Tipo de } \\
\text { interface }\end{array}$ & $\begin{array}{c}\text { Rugosidade máxima } \\
\mathrm{R}_{\max }(\mathrm{mm})\end{array}$ \\
\hline Aço & 8,7 \\
Chapa soldada & 4,7 \\
\hline
\end{tabular}

Nota-se na Tabela 5.9 que os resultados de $\delta_{\mathrm{r}}$ encontrados nas interfaces com solda são superiores ao encontrados nas interfaces com aço. Como a rugosidade da chapa de aço é maior que a da chapa soldada (Tabela 5.10), esperava-se que os resultados de $\delta_{\mathrm{r}}$ encontrados nas interfaces com solda fossem inferiores ao encontrados nas interfaces com aço. No entanto, isto não ocorreu porque a chapa soldada apresenta dureza inferior ao aço, o que facilitou a penetração da areia na solda, aumentando o atrito na interface. Esta conclusão foi baseada na observação das interfaces de aço e de solda após os ensaios. A chapa soldada apresentou-se superiormente riscada em relação à chapa de aço.

Como a forma do grão é considerada na literatura citada nesta revisão como fator que influencia o ângulo de atrito de pico entre uma superfície de aço e areia. Supõe-se que também influenciou os resultados de ângulo de atrito residual na interface encontrados. Para verificar a forma dos grãos da areia de Fointenebleau utilizada foi feita a fotografia microscópica dos grãos desta areia, exibida na Figura 5.49. Os grãos desta figura mostram-se arredondados (característica que diminui o atrito na interface). 




Figura 5.49 - Fotografia microscópica dos grãos da areia de Fontainebleau utilizada nos ensaios de cisalhamento direto de interface e em centrífuga

\subsubsection{Interface areia e aço da hélice da chapa da hélice comercialmente utilizada}

O objetivo desses ensaios foi de obter valores de ângulo de atrito residual entre o aço da hélice da estaca comercialmente utilizada e a areia $\left(\delta_{\mathrm{r}}\right)$ para a aplicação do método de cálculo proposto nesta tese (Equação 3.16), para controle da capacidade de carga à tração de estacas metálicas helicoidais por meio de medidas de torque de instalação, na prática de deste tipo de fundação instalada em solo arenoso.

A chapa de aço da hélice comercialmente utilizada foi testada em interfaces com três tipos de areia de diferentes $D_{50}$. Os resultados da caracterização dessas, por meio de ensaios de granulometria e de determinação dos índices de vazio máximo e mínimo, são apresentados na Tabela 5.11. As Figuras 5.50, 5.51 e 5.52 mostram os resultados dos ensaios de granulometria dessas areias.

Foram realizados 27 diferentes ensaios de cisalhamento em interface. Para cada tipo de areia foram ensaiadas três diferentes densidades relativas, e para cada densidade relativa foram testados três níveis de tensão normal (Tabela 5.12). 
Tabela 5.11 - Propriedades das areias utilizadas nos ensaios

\begin{tabular}{lc}
\hline \multicolumn{1}{c}{ Propriedade } & Valor \\
\hline Areia 1 & 15,88 \\
Máximo peso específico seco $\left(\mathrm{kN} / \mathrm{m}^{3}\right)$ & 13,68 \\
Mínimo peso específico seco $\left(\mathrm{kN} / \mathrm{m}^{3}\right)$ & 0,13 \\
$\mathrm{D}_{50}(\mathrm{~mm})$ & \\
Areia 2 & 15,32 \\
Máximo peso específico seco $\left(\mathrm{kN} / \mathrm{m}^{3}\right)$ & 13,62 \\
Mínimo peso específico seco $\left(\mathrm{kN} / \mathrm{m}^{3}\right)$ & 0,29 \\
$\mathrm{D}_{50}(\mathrm{~mm})$ & \\
Areia 3 & 16,54 \\
Máximo peso específico seco $\left(\mathrm{kN} / \mathrm{m}^{3}\right)$ & 14,42 \\
Mínimo peso específico seco $\left(\mathrm{kN} / \mathrm{m}^{3}\right)$ & 0,52 \\
$\mathrm{D}_{50}(\mathrm{~mm})$ & \\
\hline
\end{tabular}

PENEIRAS ABNT (NBR 5734/30)

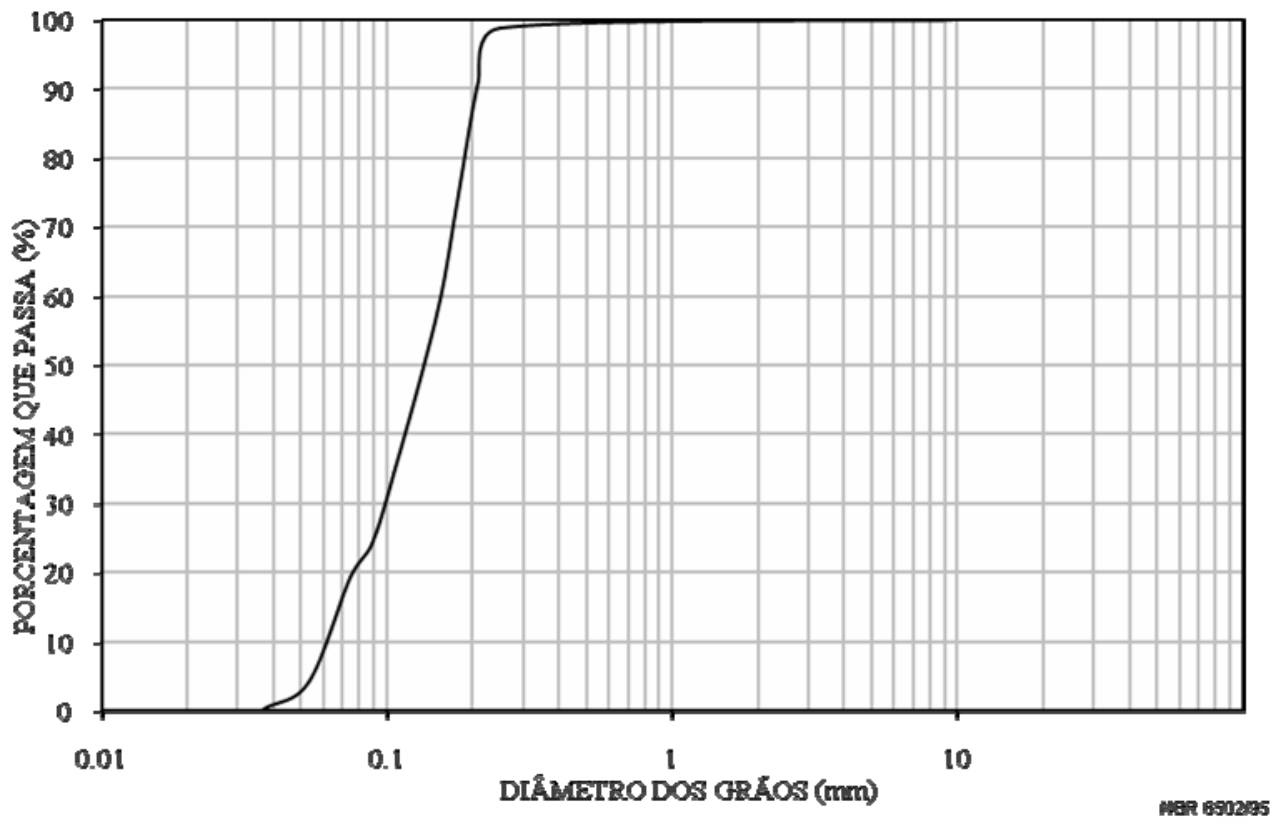

Figura 5.50 - Curva granulométrica da Areia 1 


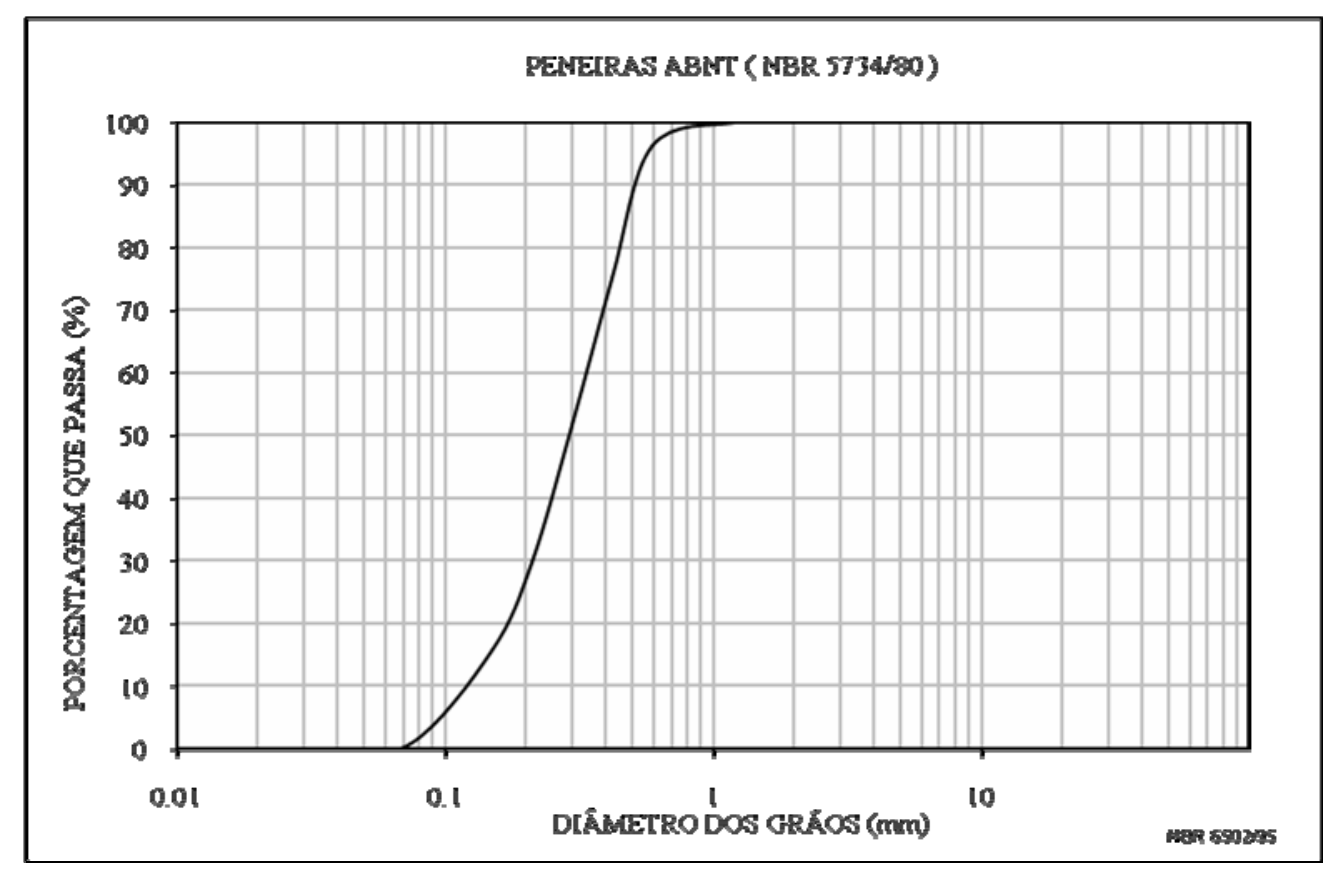

Figura 5.51 - Curva granulométrica da Areia 2

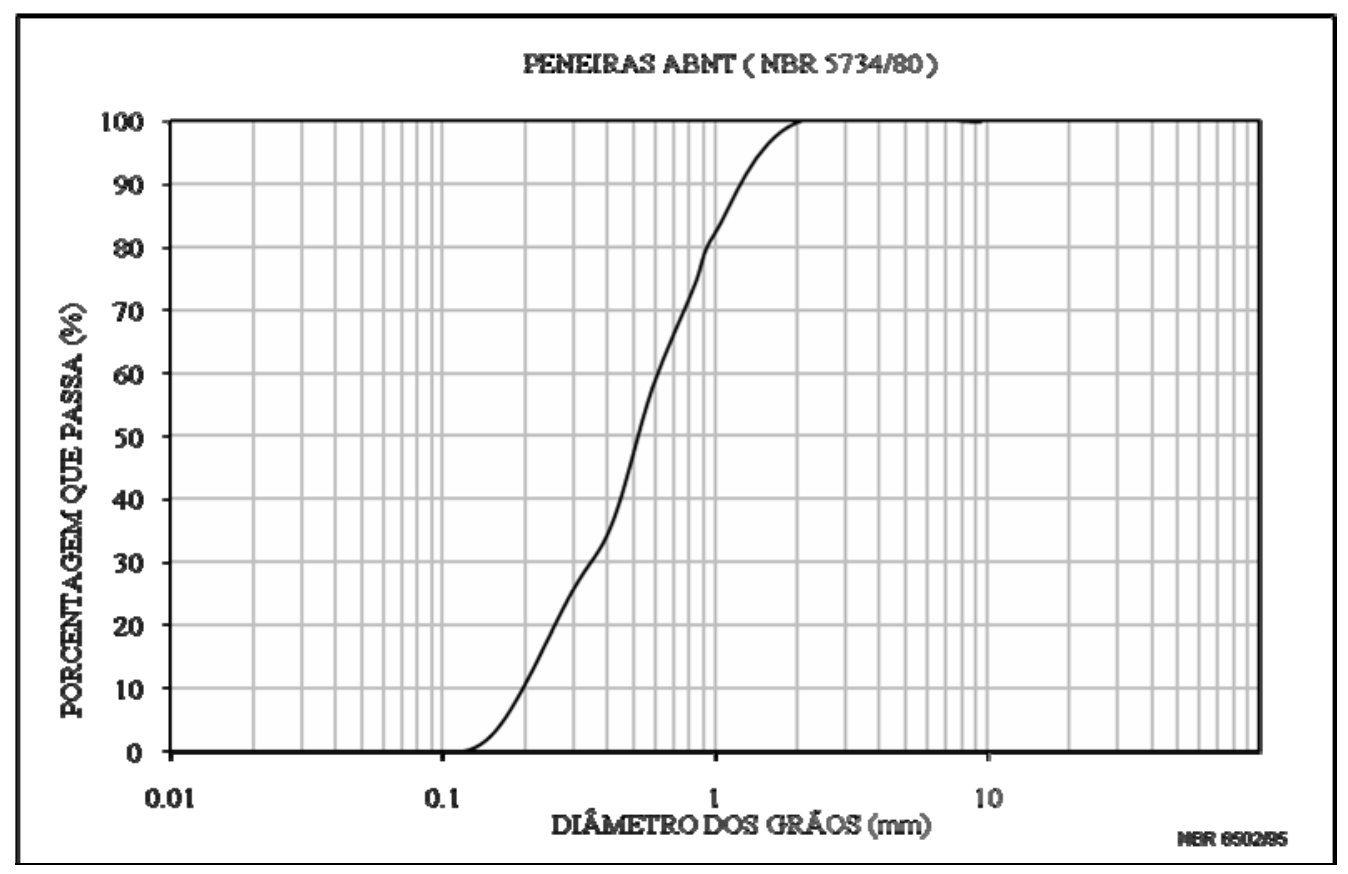

Figura 5.52 - Curva granulométrica da Areia 3

As Figuras 5.53 a 5.61 mostram as curvas de tensão cisalhante $\mathrm{x}$ deslocamento relativo da interface, resultantes dos ensaios (Tabela 5.12) realizados com amostras da Areia 1, da Areia 2 e da Areia 3. 
A partir das curvas exibidas nas Figuras 5.53 a 5.61, foram traçados os gráficos de tensão de cisalhante residual $x$ tensão normal, mostrados nas Figuras 5.62 a 5.70, para a determinação dos valores de ângulo de atrito residual entre o aço da hélice da estaca comercialmente utilizada e a areia $\left(\delta_{\mathrm{r}}\right)$. A Tabela 5.13 mostra os valores de ângulo de atrito residual obtidos por meio dos gráficos das Figuras 5.62 a 5.70.

Tabela 5.12 - Características dos ensaios de cisalhamento direto em interface aço/areia

\begin{tabular}{|c|c|c|c|}
\hline Tipo de areia & $\begin{array}{l}\mathrm{N}^{\mathrm{o}} \text { do } \\
\text { ensaio }\end{array}$ & $\begin{array}{c}\text { Densidade } \\
\text { relativa } D_{\mathrm{r}}(\%)\end{array}$ & $\begin{array}{c}\text { Tensão normal } \\
\sigma\left(\mathrm{KN} / \mathrm{m}^{2}\right)\end{array}$ \\
\hline \multirow{9}{*}{ Areia 1} & 1 & $25 \%$ & 9,9 \\
\hline & 2 & $25 \%$ & 48,9 \\
\hline & 3 & $25 \%$ & 98,6 \\
\hline & 4 & $55 \%$ & 9,9 \\
\hline & 5 & $55 \%$ & 48,9 \\
\hline & 6 & $55 \%$ & 98,6 \\
\hline & 7 & $85 \%$ & 9,9 \\
\hline & 8 & $85 \%$ & 48,9 \\
\hline & 9 & $85 \%$ & 98,6 \\
\hline \multirow{9}{*}{ Areia 2} & 10 & $25 \%$ & 9,9 \\
\hline & 11 & $25 \%$ & 48,9 \\
\hline & 12 & $25 \%$ & 98,6 \\
\hline & 13 & $55 \%$ & 9,9 \\
\hline & 14 & $55 \%$ & 48,9 \\
\hline & 15 & $55 \%$ & 98,6 \\
\hline & 16 & $85 \%$ & 9,9 \\
\hline & 17 & $85 \%$ & 48,9 \\
\hline & 18 & $85 \%$ & 98,6 \\
\hline \multirow{9}{*}{ Areia 3} & 19 & $25 \%$ & 9,9 \\
\hline & 20 & $25 \%$ & 48,9 \\
\hline & 21 & $25 \%$ & 98,6 \\
\hline & 22 & $55 \%$ & 9,9 \\
\hline & 23 & $55 \%$ & 48,9 \\
\hline & 24 & $55 \%$ & 98,6 \\
\hline & 25 & $85 \%$ & 9,9 \\
\hline & 26 & $85 \%$ & 48,9 \\
\hline & 27 & $85 \%$ & 98,6 \\
\hline
\end{tabular}




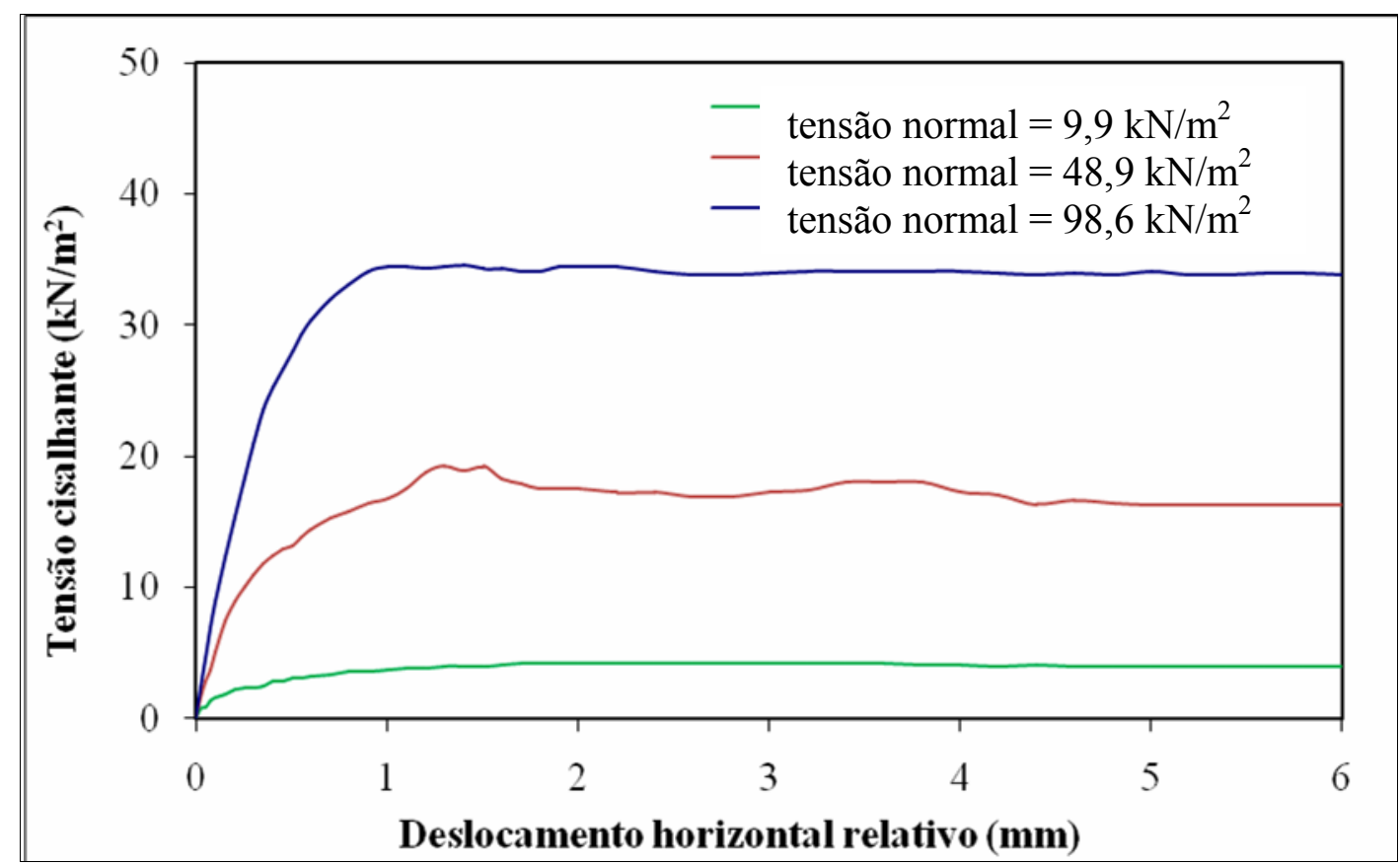

Figura 5.53 - Curvas tensão cisalhante x deslocamento horizontal relativo da interface entre o aço e a Areia $1\left(D_{r}=25 \%\right)$

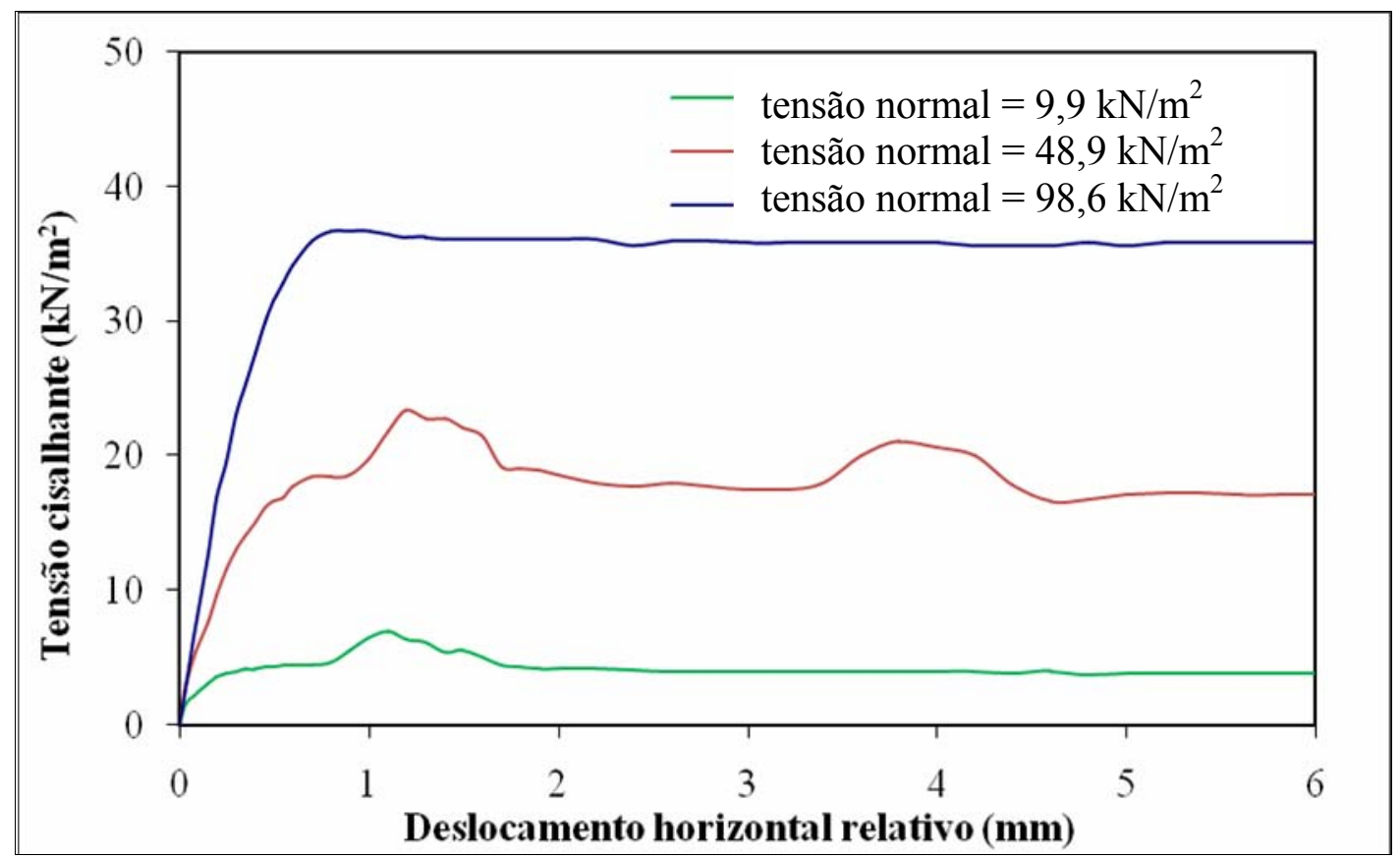

Figura 5.54 - Curvas tensão cisalhante x deslocamento horizontal relativo da interface entre o aço e a Areia $1\left(D_{\mathrm{r}}=55 \%\right)$ 


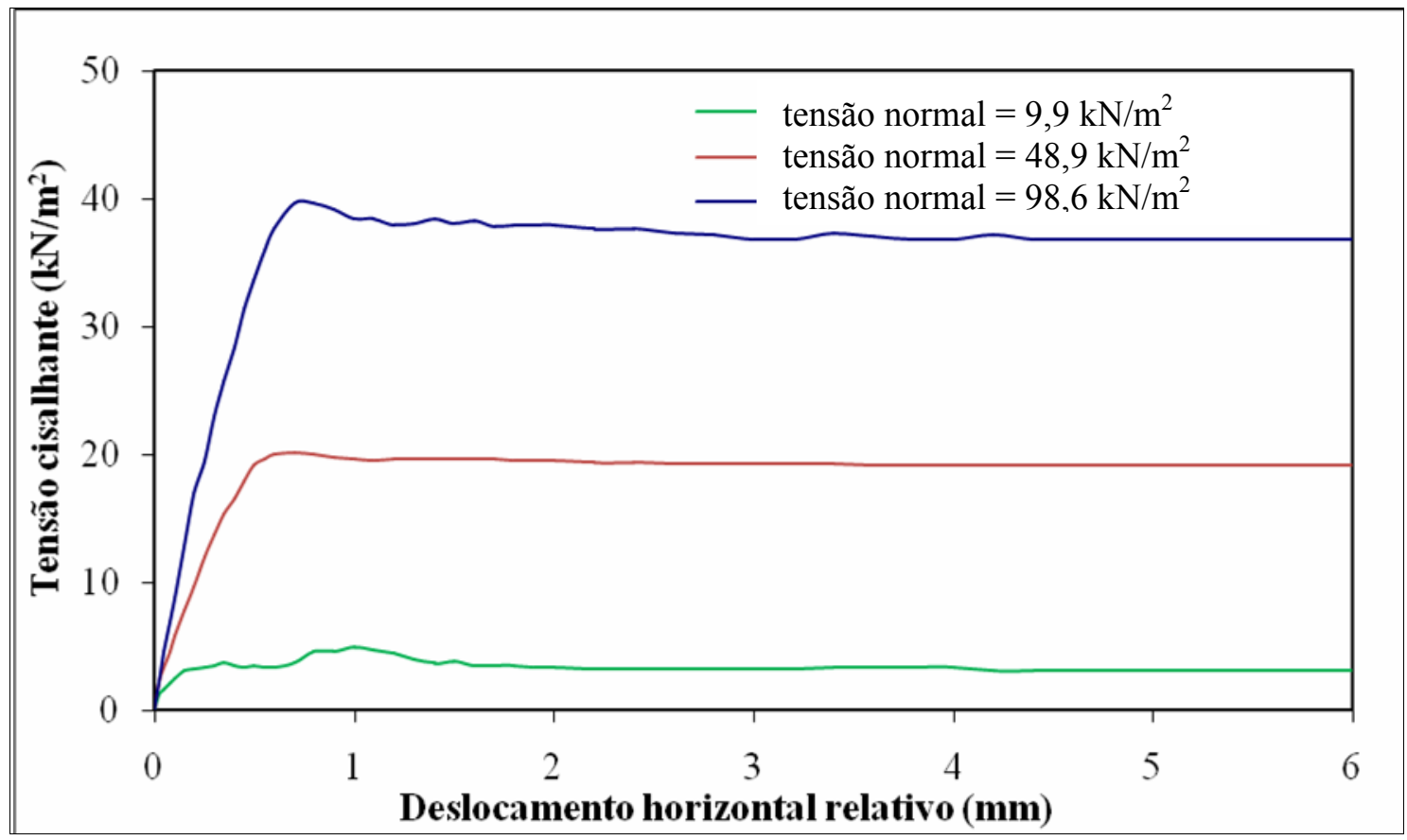

Figura 5.55 - Curvas tensão cisalhante $\mathrm{x}$ deslocamento horizontal relativo da interface entre o aço e a Areia $1\left(D_{\mathrm{r}}=85 \%\right)$

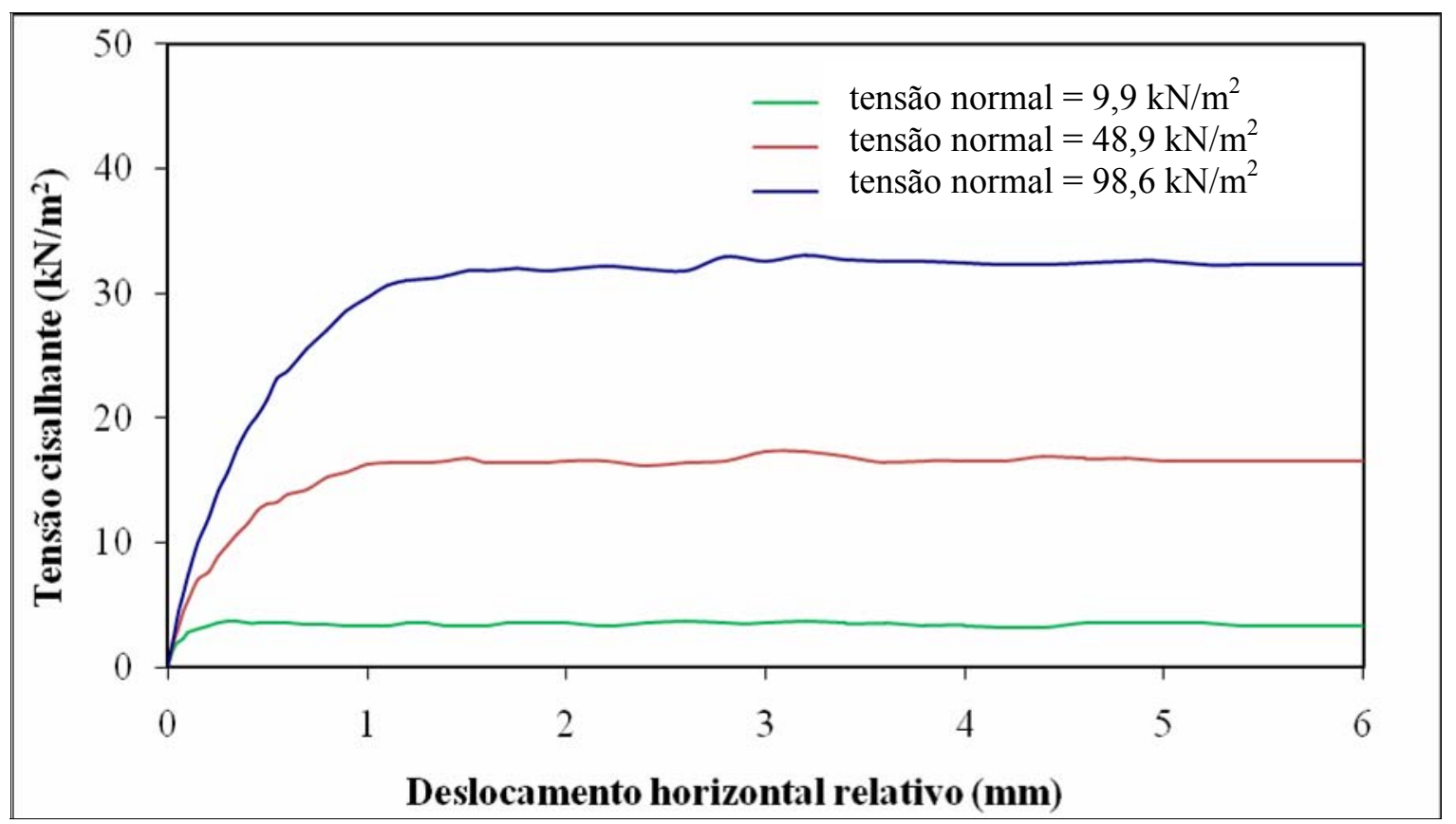

Figura 5.56 - Curvas tensão cisalhante $\mathrm{x}$ deslocamento horizontal relativo da interface entre o aço e a Areia $2\left(D_{r}=25 \%\right)$ 


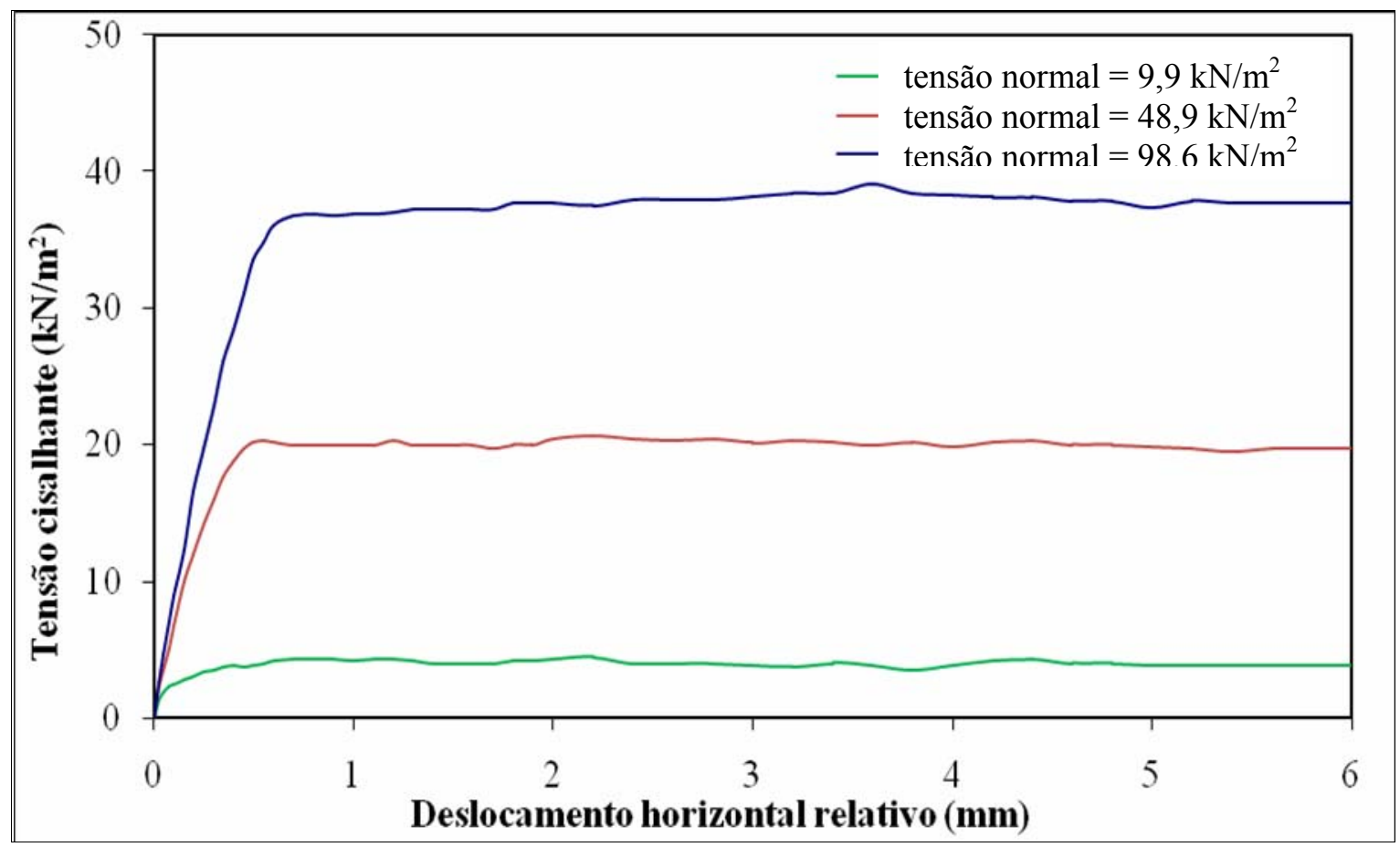

Figura 5.57 - Curvas tensão cisalhante $\mathrm{x}$ deslocamento horizontal relativo da interface entre o aço e a Areia $2\left(D_{\mathrm{r}}=55 \%\right)$

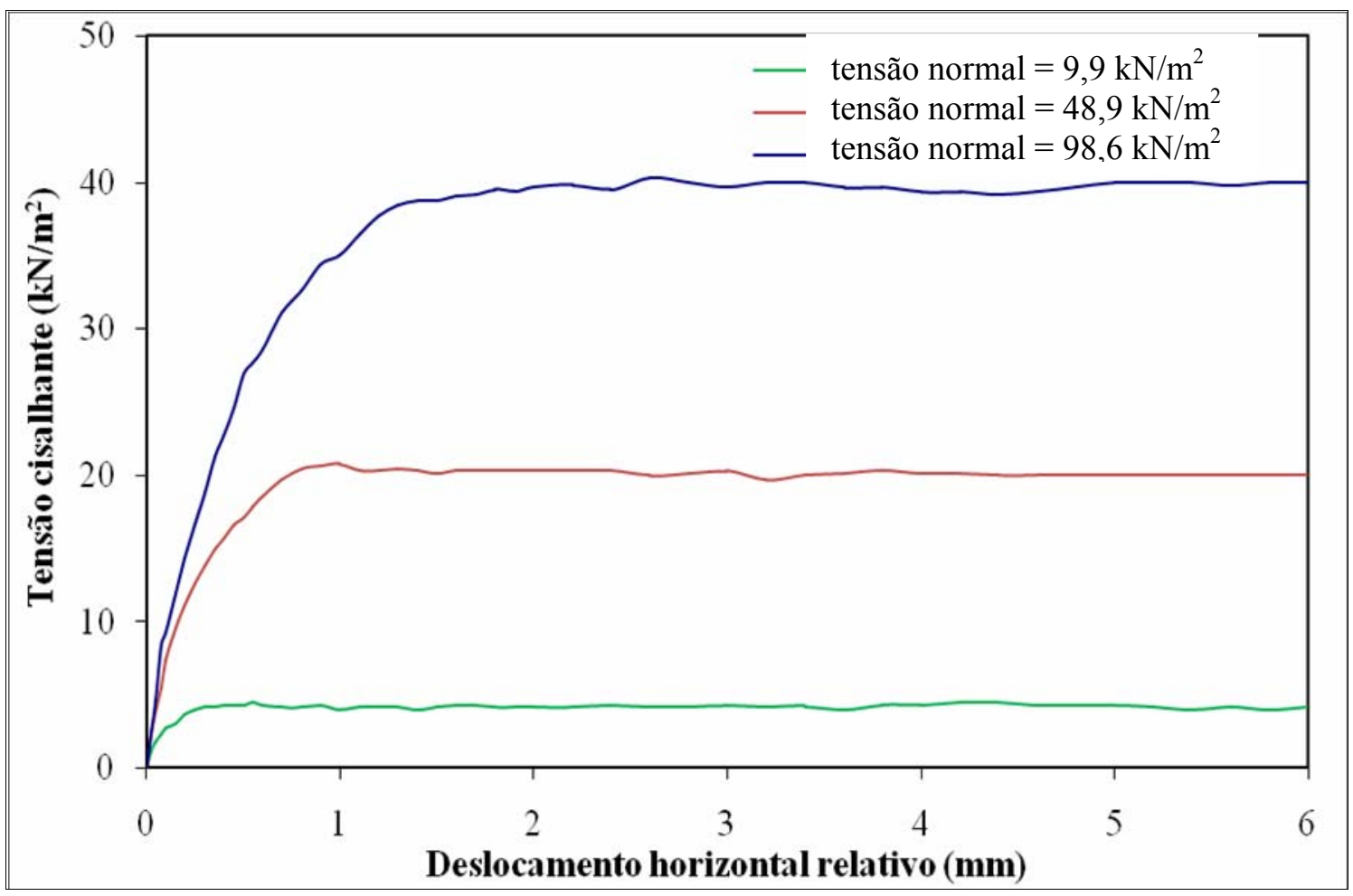

Figura 5.58 - Curvas tensão cisalhante $\mathrm{x}$ deslocamento horizontal relativo da interface entre o aço e a Areia $2\left(D_{r}=85 \%\right)$ 


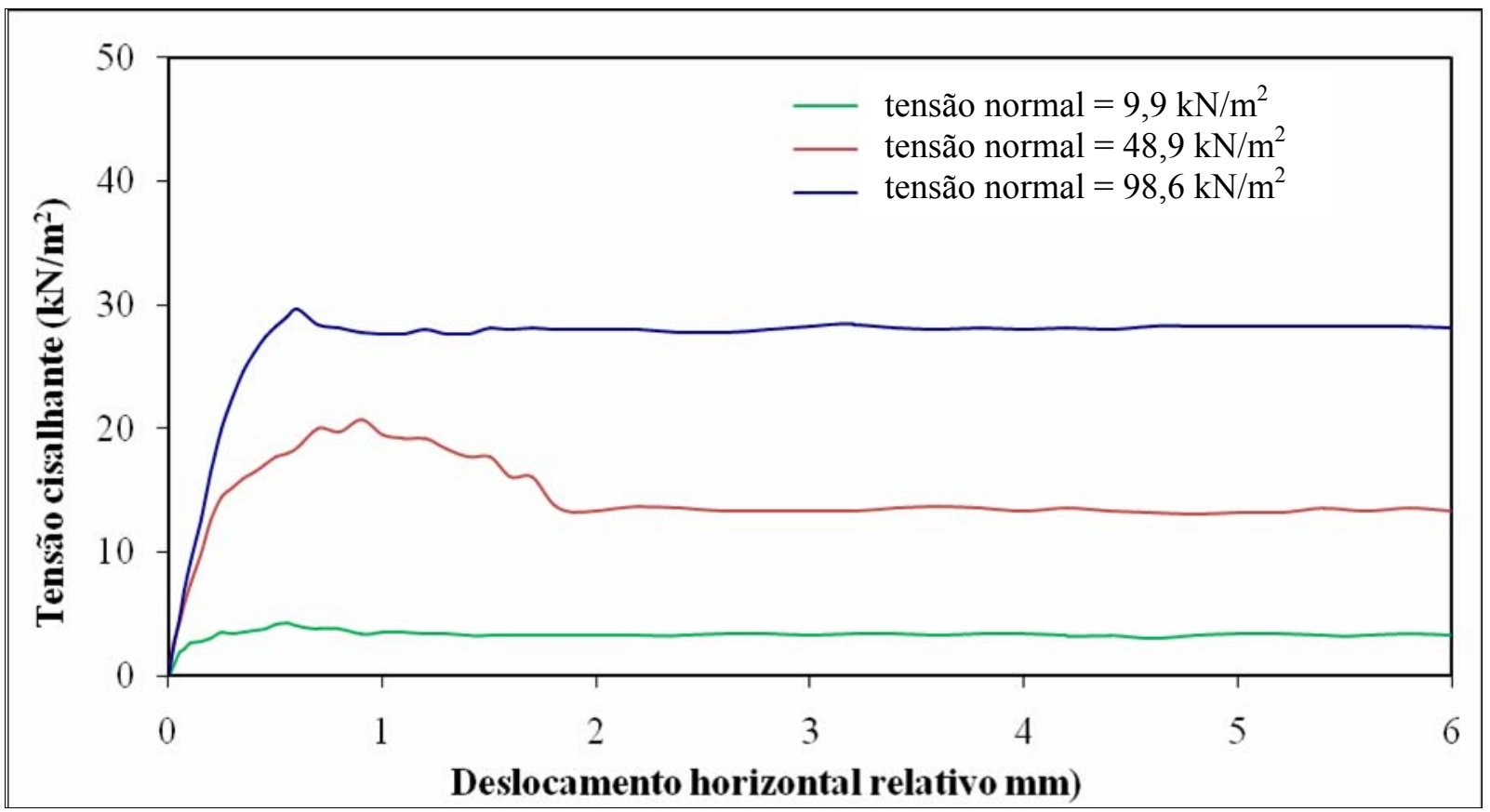

Figura 5.59 - Curvas tensão cisalhante x deslocamento horizontal relativo da interface entre o

$$
\text { aço e a Areia } 3\left(D_{r}=25 \%\right)
$$



Figura 5.60 - Curvas tensão cisalhante x deslocamento horizontal relativo da interface entre o aço e a Areia $3\left(D_{r}=55 \%\right)$ 


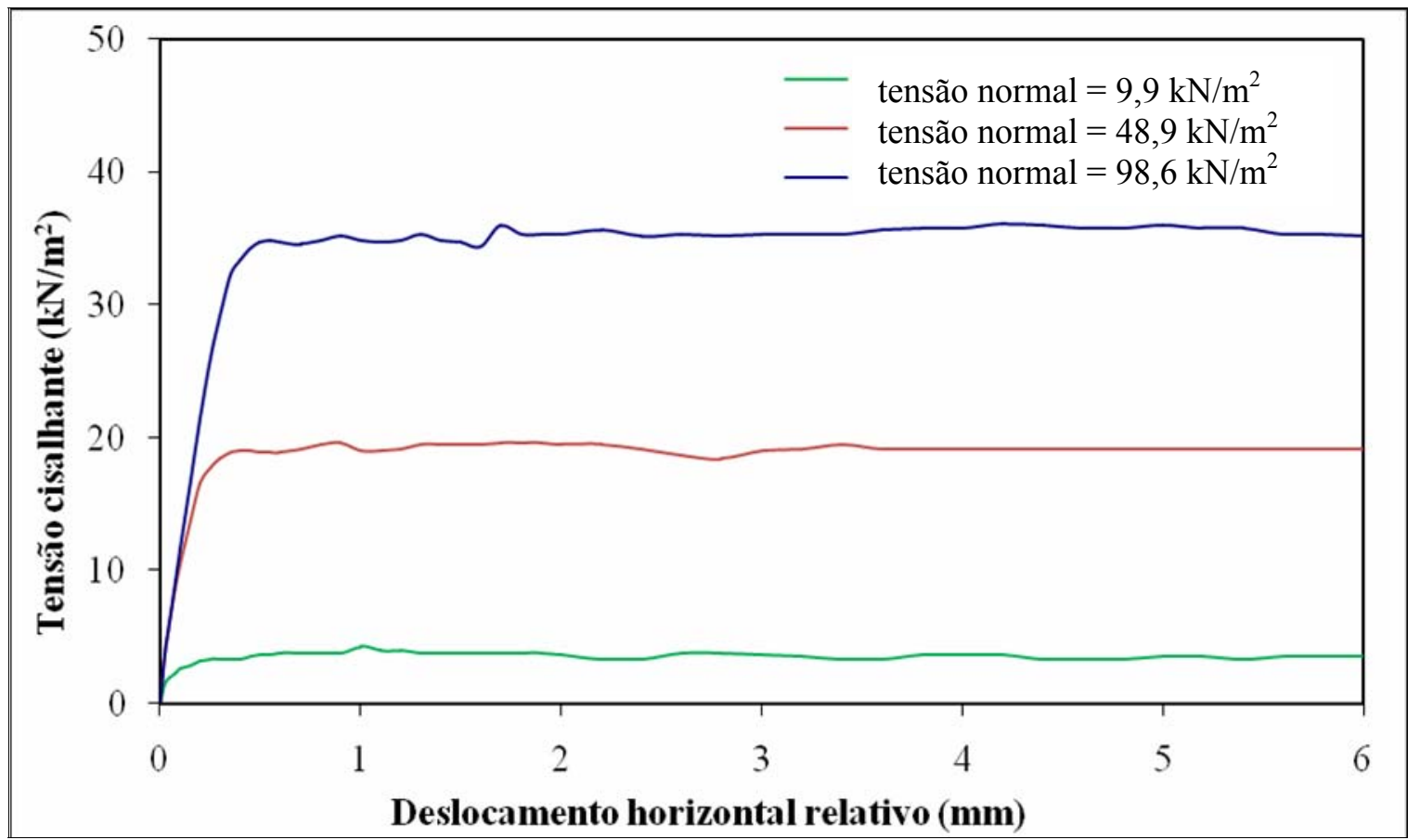

Figura 5.61 - Curvas tensão cisalhante $\mathrm{x}$ deslocamento horizontal relativo da interface entre o aço e a Areia $3\left(D_{r}=85 \%\right)$

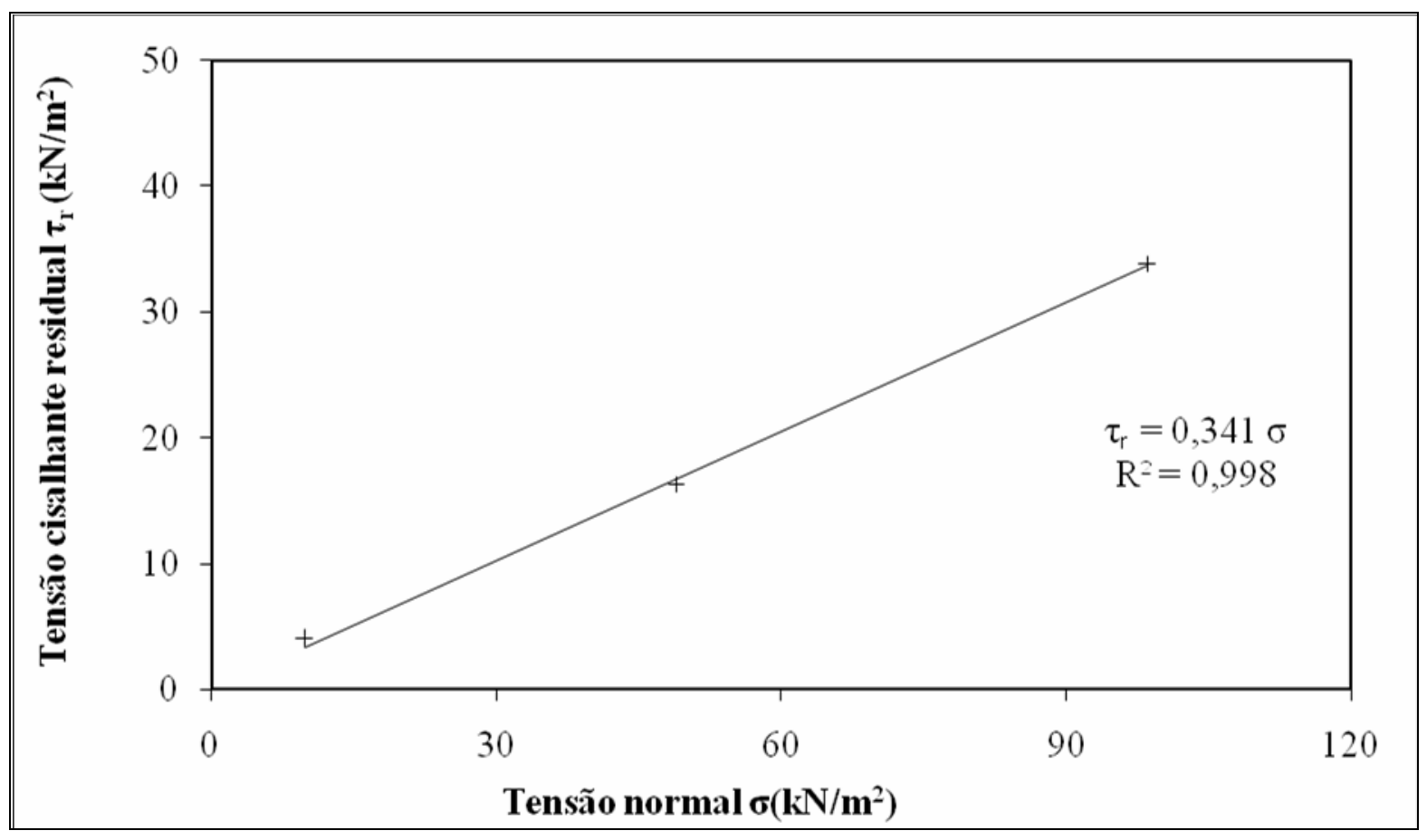

Figura 5.62 - Tensão cisalhante residual x tensão normal da interface entre o aço e a Areia $1\left(D_{r}=25 \%\right)$ 


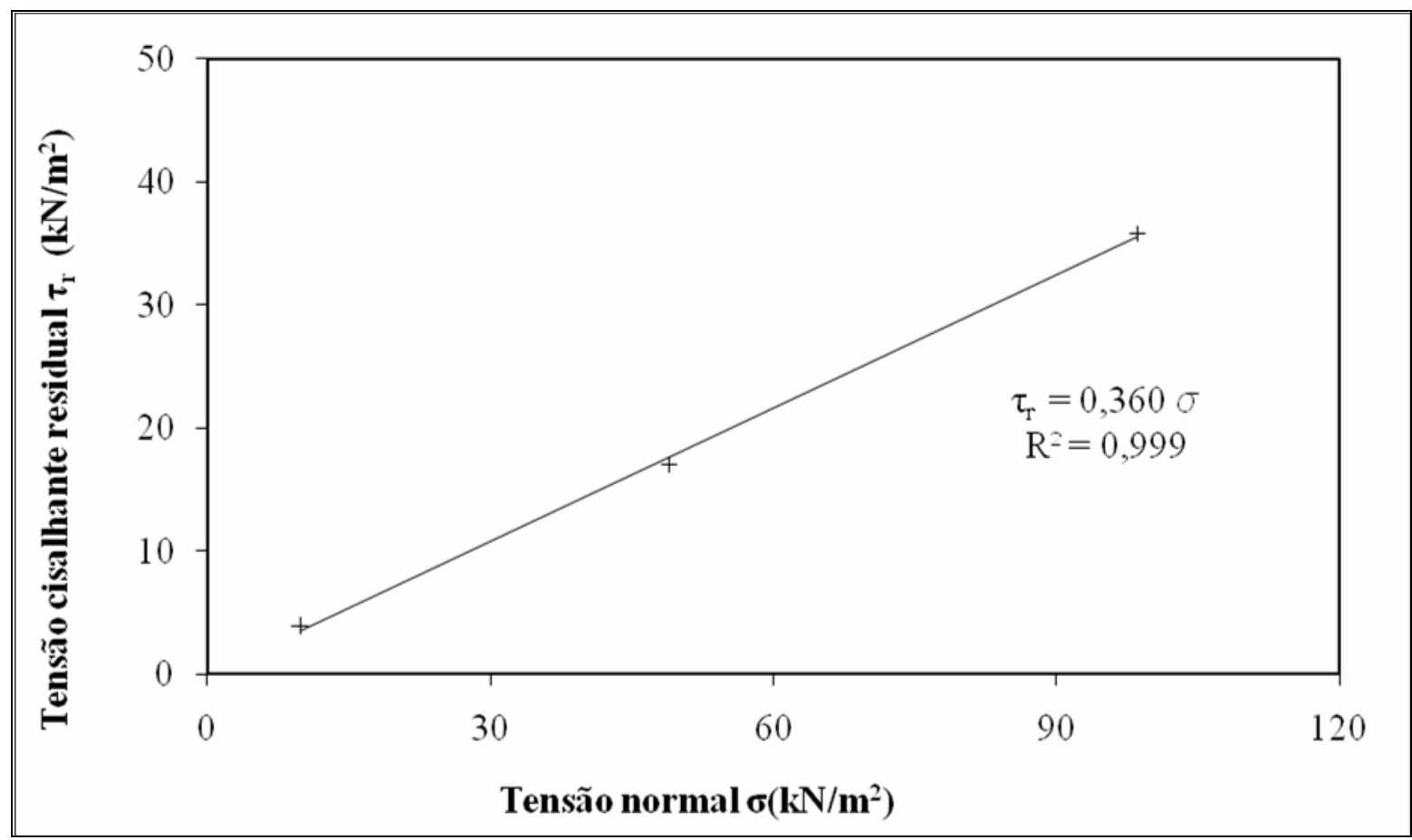

Figura 5.63 - Tensão cisalhante residual x tensão normal da interface entre o aço e a

Areia $1\left(D_{\mathrm{r}}=55 \%\right)$

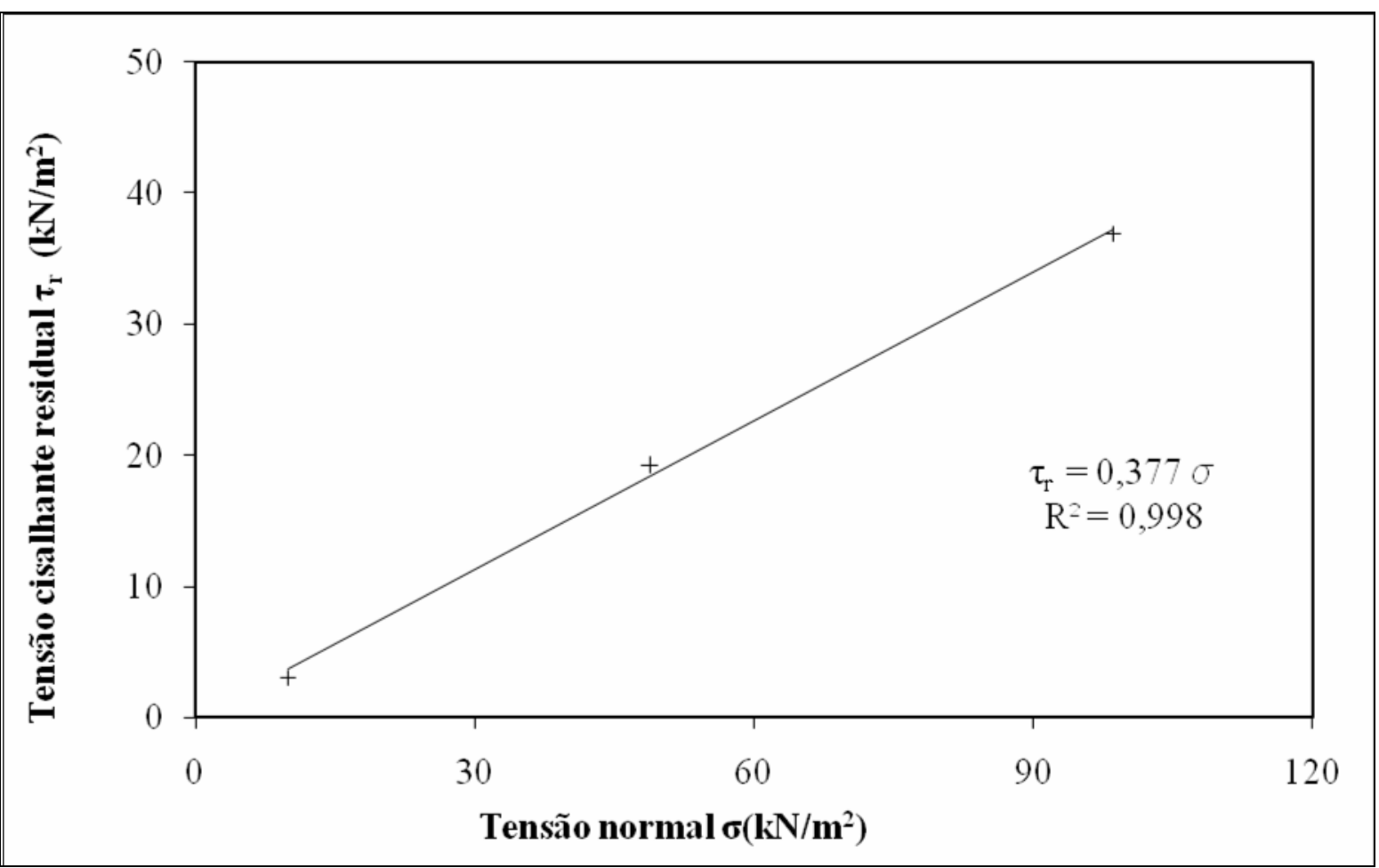

Figura 5.64 - Tensão cisalhante residual x tensão normal da interface entre o aço e a

$$
\text { Areia } 1\left(D_{r}=85 \%\right)
$$




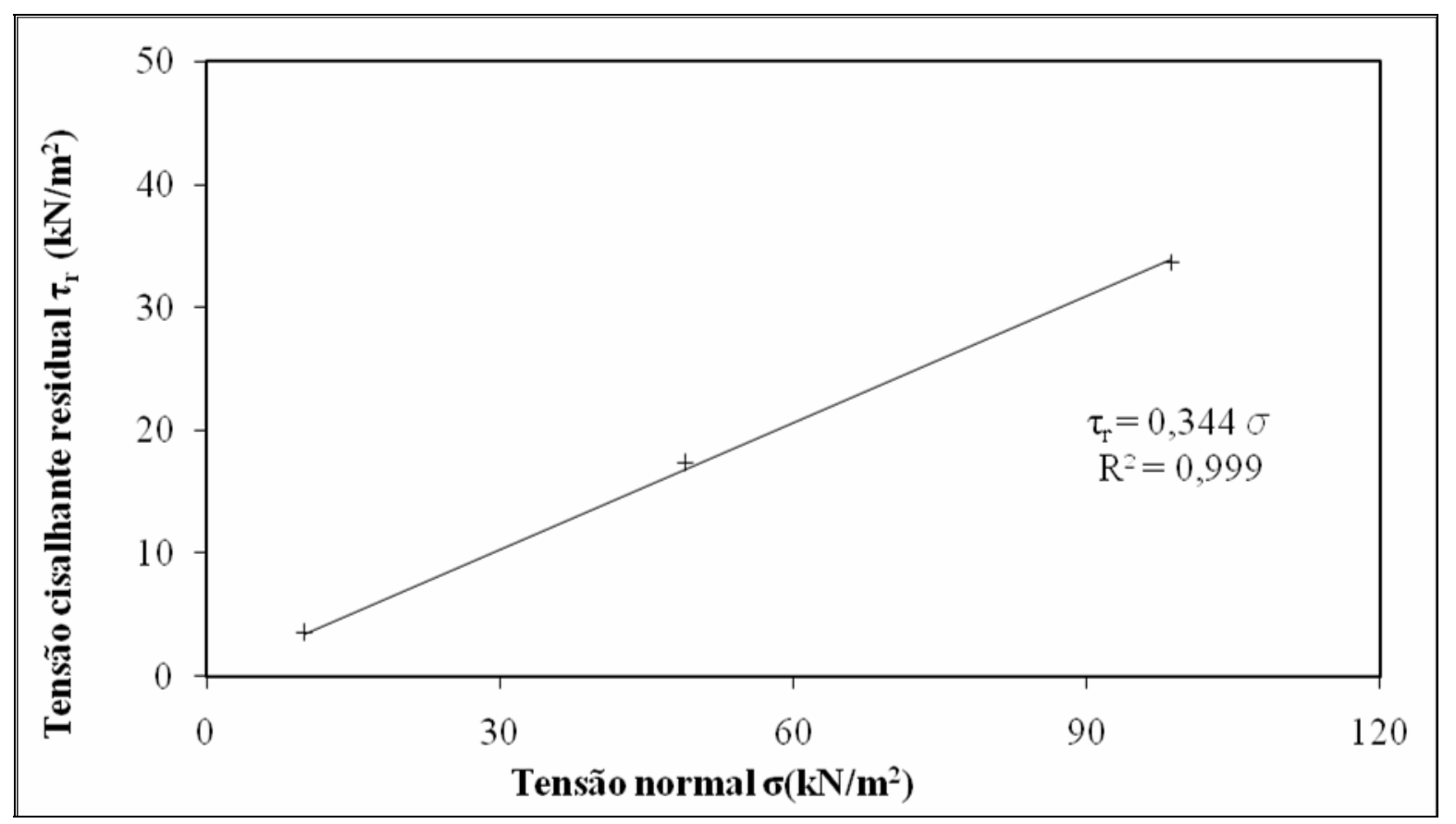

Figura 5.65 - Tensão cisalhante residual x tensão normal da interface entre o aço e a Areia $2\left(D_{r}=25 \%\right)$

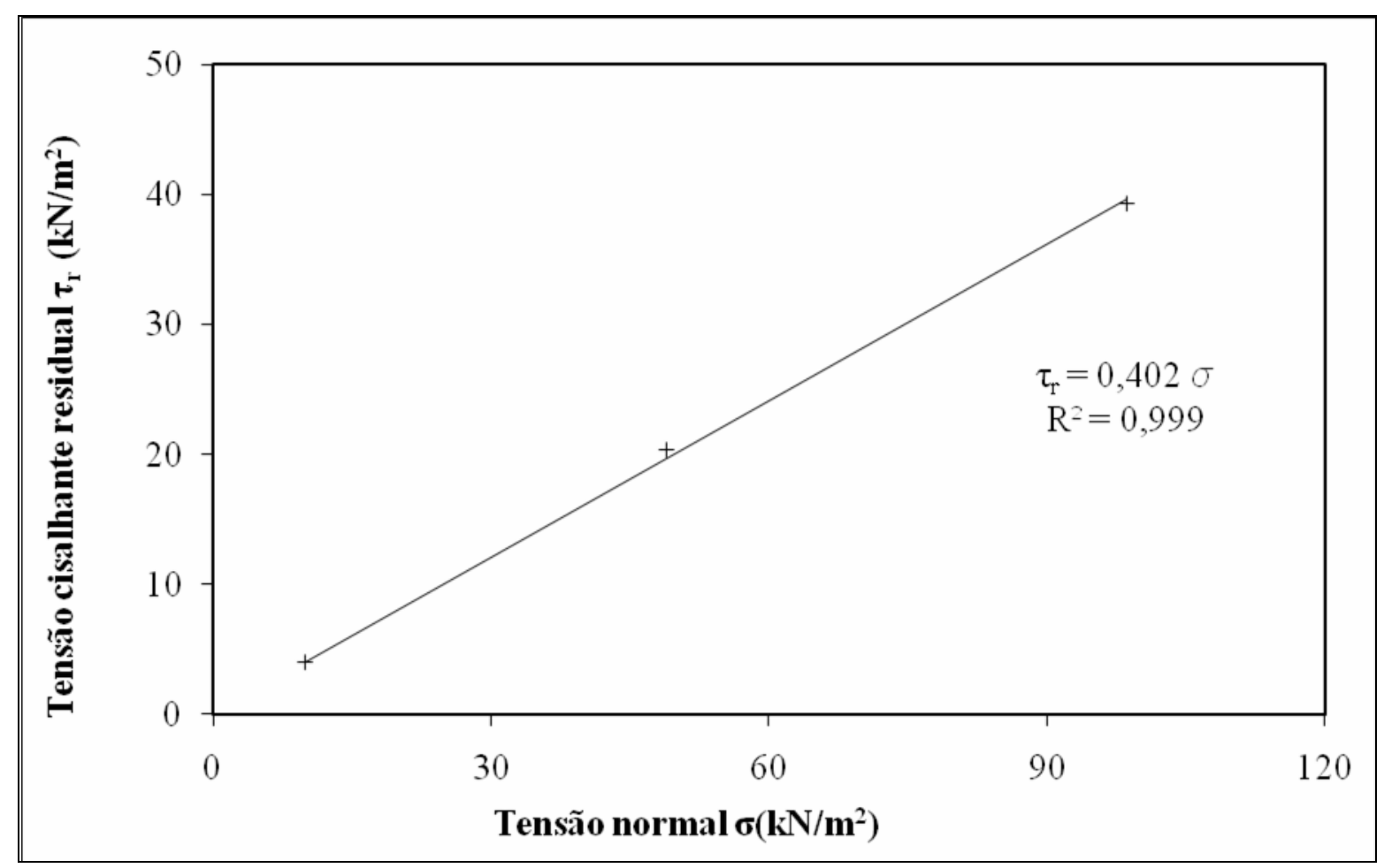

Figura 5.66 - Tensão cisalhante residual x tensão normal da interface entre o aço e a Areia $2\left(D_{r}=55 \%\right)$ 


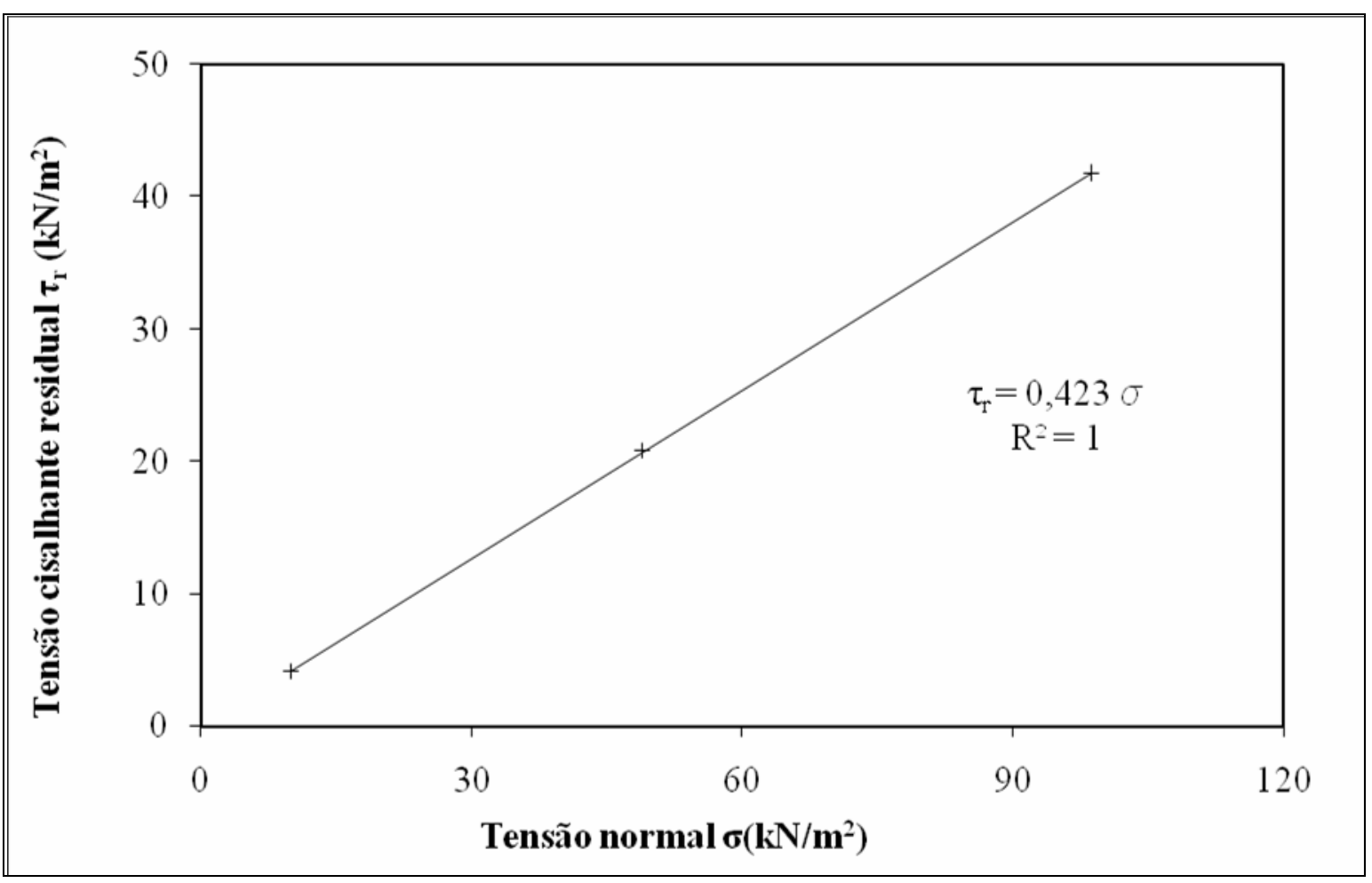

Figura 5.67 - Tensão cisalhante residual x tensão normal da interface entre o aço e a

Areia $2\left(D_{r}=85 \%\right)$

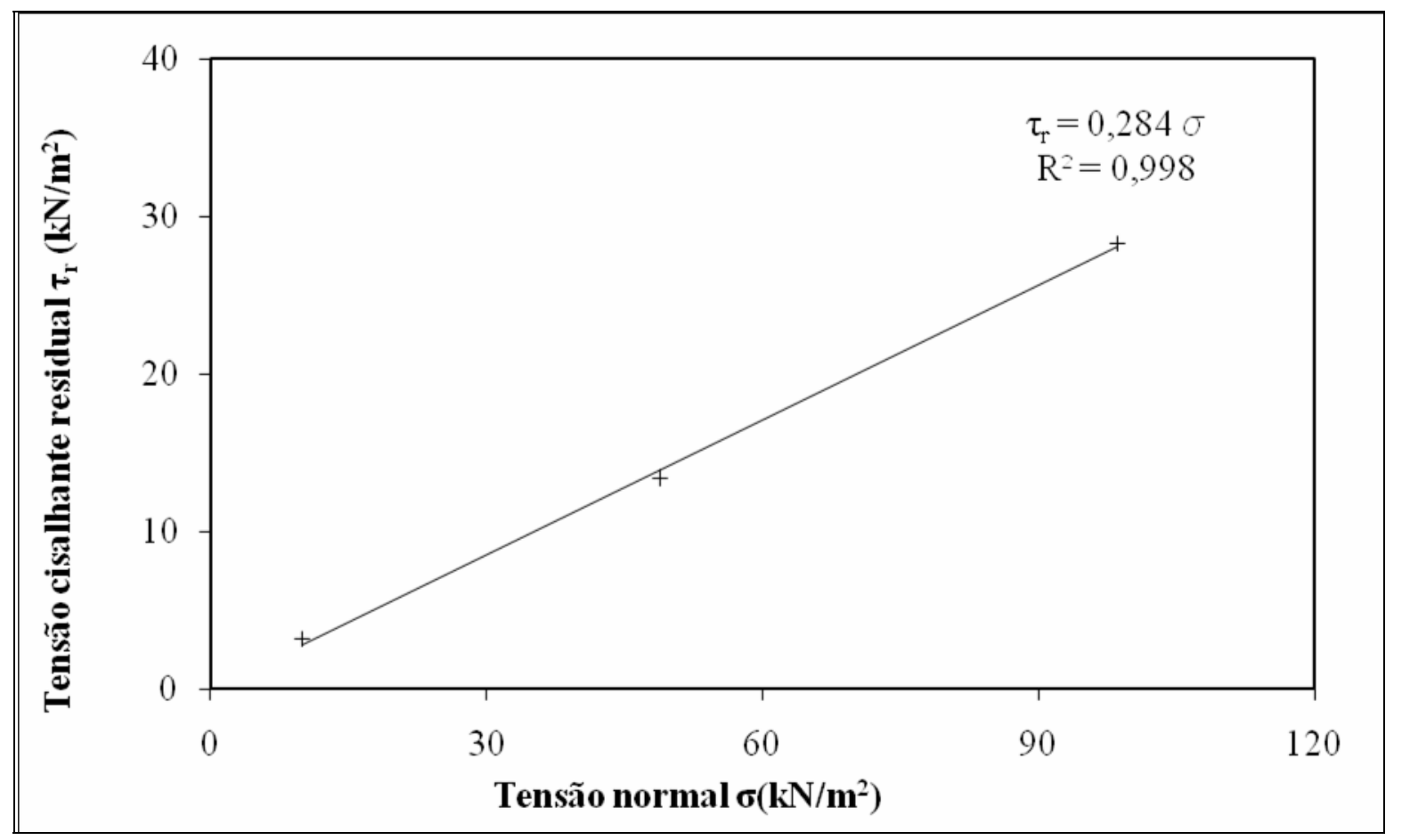

Figura 5.68 - Tensão cisalhante residual x tensão normal da interface entre o aço e a Areia $3\left(D_{r}=25 \%\right)$ 


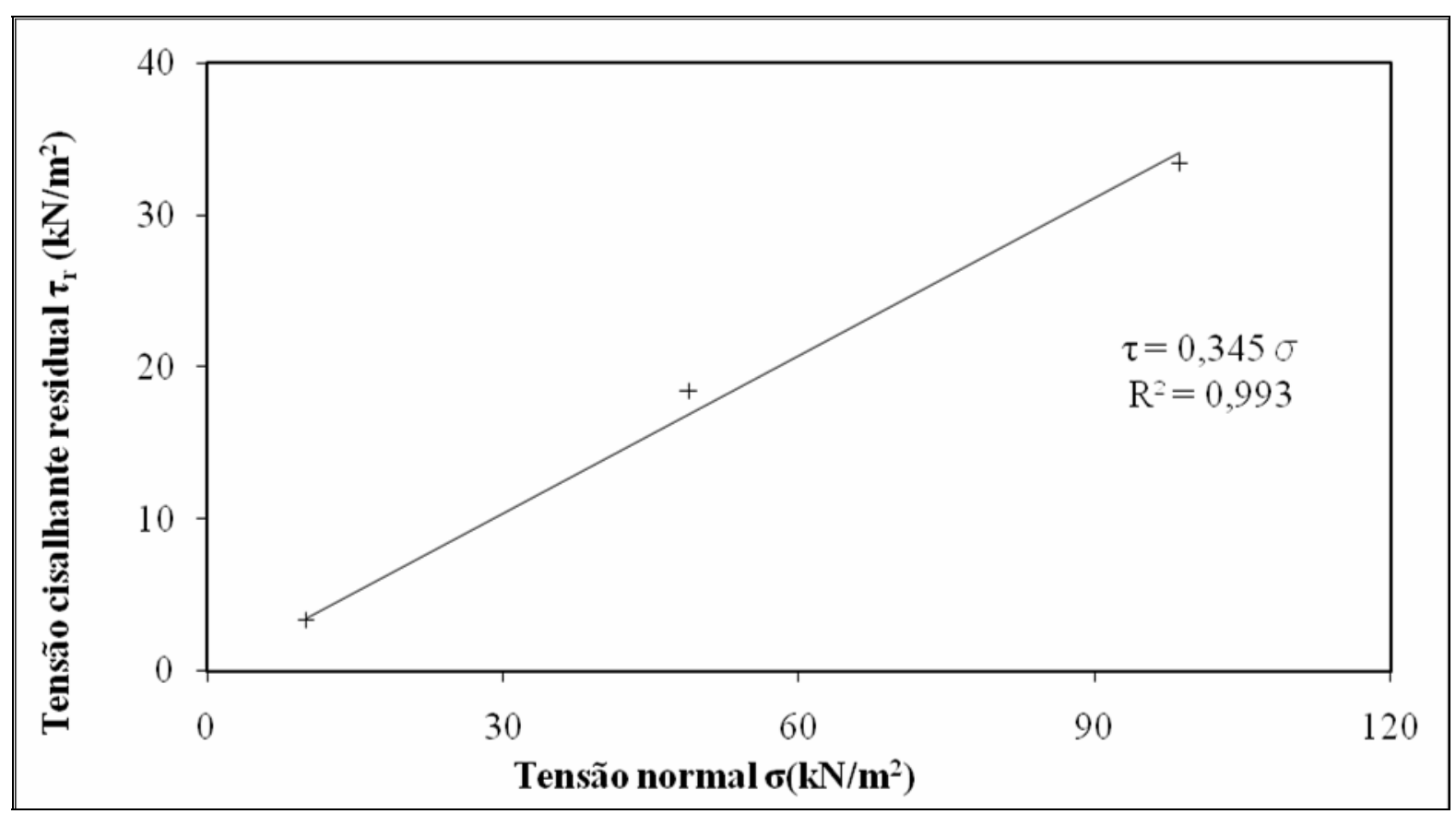

Figura 5.69 - Tensão cisalhante residual x tensão normal da interface entre o aço e a

$$
\text { Areia } 3\left(D_{r}=55 \%\right)
$$

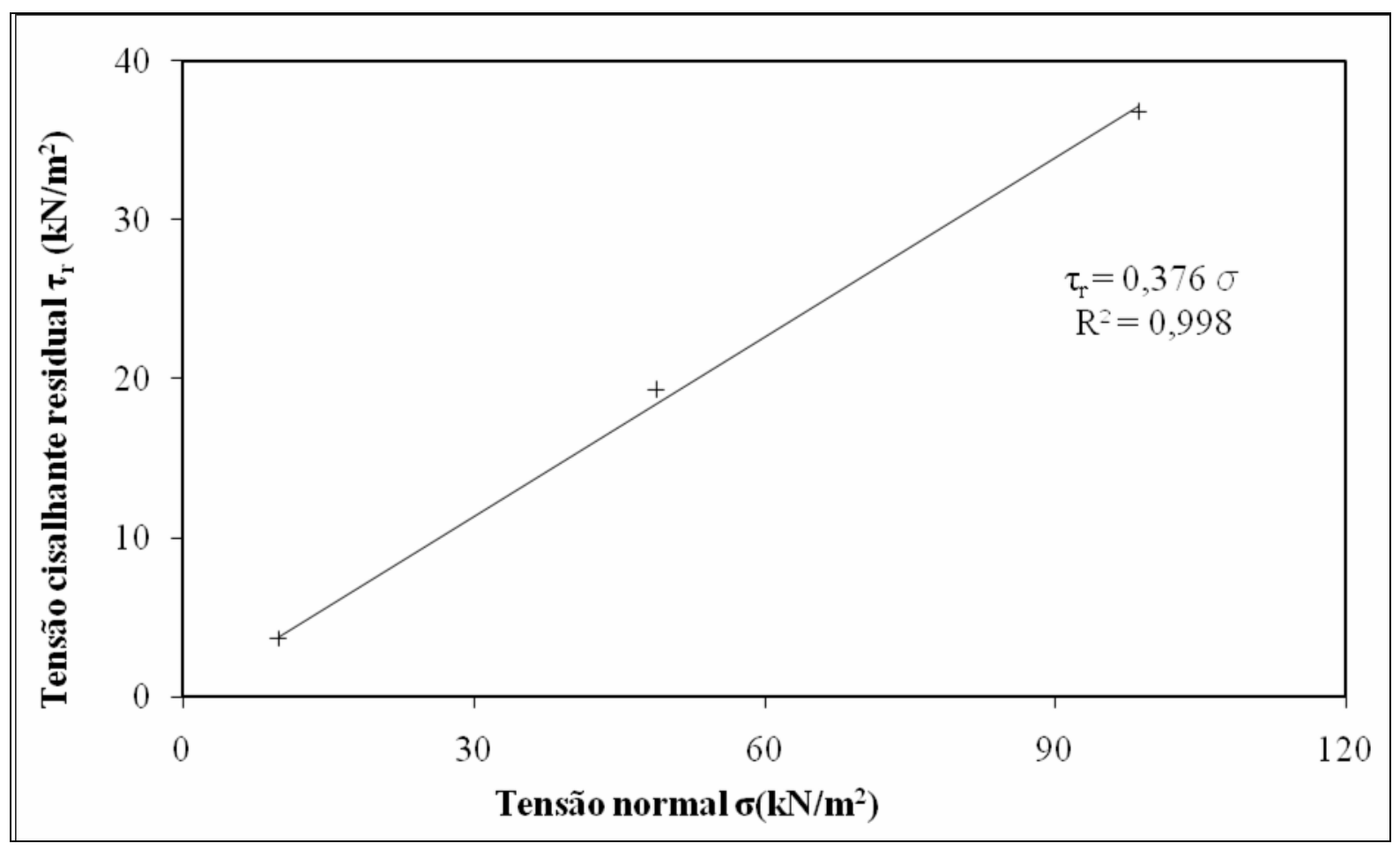

Figura 5.70 - Tensão cisalhante residual x tensão normal da interface entre o aço e a

$$
\text { Areia } 3\left(D_{r}=85 \%\right)
$$


Tabela 5.13 - Ângulo de atrito residual nas interfaces entre o material da hélice comercialmente utilizada e as amostras de areia de diferentes $\mathrm{D}_{50}$

\begin{tabular}{cccc}
\hline $\begin{array}{c}\text { Tipo } \\
\text { areia }\end{array}$ & $\begin{array}{c}\mathrm{D}_{50} \\
(\mathrm{~mm})\end{array}$ & Densidade relativa $\mathrm{D}_{\mathrm{r}}(\%)$ & $\begin{array}{c}\text { Angulo de atrito } \\
\text { residual na } \\
\text { interface }\left(\delta_{\mathrm{r}}\right)\end{array}$ \\
\hline Areia 1 & 0,13 & 25 & $18,8^{\circ}$ \\
& & 55 & $19,8^{\circ}$ \\
Areia 2 & 0,29 & 25 & $20,7^{\circ}$ \\
\hline \multirow{2}{*}{ Areia 3 } & 0,52 & 55 & $19,0^{\circ}$ \\
& & 85 & $21,9^{\circ}$ \\
& & 25 & $22,9^{\circ}$ \\
\hline & 55 & $15,9^{\circ}$ \\
& & 85 & $19,0^{\circ}$ \\
& & Valor médio de $\delta_{\mathrm{r}}$ & $19,8^{\circ}$ \\
& & Desvio padrão & $2,0^{\circ}$ \\
& & Coeficiente de variação & $10 \%$ \\
\hline
\end{tabular}

$\mathrm{Na}$ Tabela 5.13, nota-se que as variações de $\mathrm{D}_{50}$ e da densidade relativa da areia não influenciam significantemente no ângulo de atrito residual da interface entre o aço estudado e a areia $\left(\delta_{\mathrm{r}}\right)$. De acordo com a pesquisa de Uesugi e Kishida (1986), já citada anteriormente na revisão bibliográfica desta tese, as principais variáveis que influenciam o ângulo de atrito de pico entre uma superfície de aço e areia são: a rugosidade do aço, a forma de grão e a dimensão do grão $\left(\mathrm{D}_{50}\right)$. No caso em estudo, o ângulo de atrito analisado é o residual e não o de pico. Neste caso, o fator de maior influência foi a rugosidade do aço testado $\left(R_{\text {máx }}=22,3 \mathrm{~mm}\right)$, que foi a mesma em todos os ensaios. Para este nível de rugosidade o $D_{50}$ da areia não influenciou significativamente nos resultados. 
Jardine et al. (1992) apud Jardine et al. (1998) observaram que o ângulo de atrito residual na interface entre areia e uma superfície de aço com rugosidade de $10 \mathrm{~mm}$ diminuiu com o aumento do diâmetro das partículas da areia (Figura 5.71).

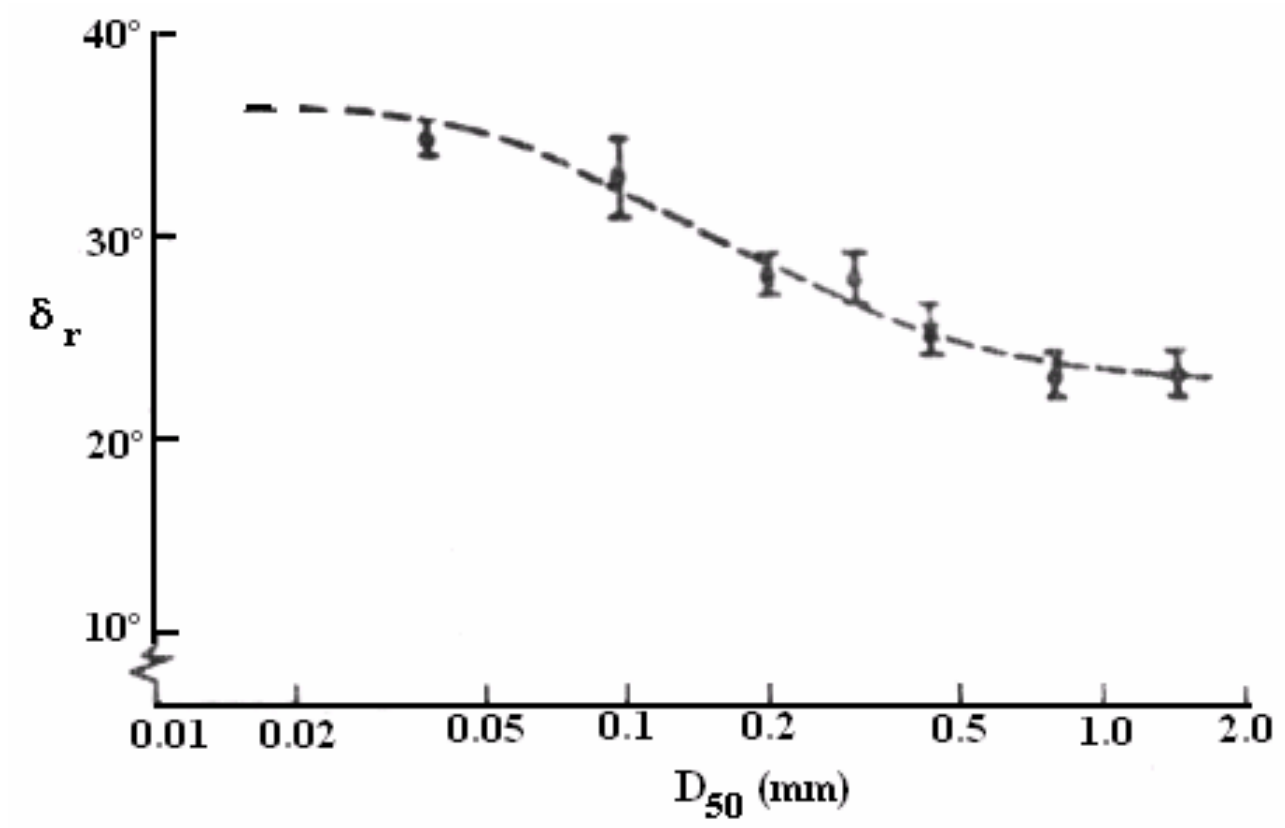

Figura 5.71 - Variação do ângulo de atrito residual na interface de uma superfície de aço com rugosidade de $10 \mu \mathrm{m}$ com o $\mathrm{D}_{50}$ da areia (Jardine et al., 1992 apud Jardine et al., 1998)

A Figura 5.72 mostra a variação do ângulo de atrito residual na interface com o $\mathrm{D}_{50}$ das areias utilizadas no presente programa de ensaios, e nota-se que não há uma variação significante do ângulo de atrito residual da interface $\delta_{\mathrm{r}}$ com o $\mathrm{D}_{50}$ das areias. Esta figura mostra que o valor de $\delta_{\mathrm{r}}$ tende a diminuir para a areia mais grossa (de $\mathrm{D}_{50}$ igual $\left.0,52 \mathrm{~mm}\right)$. No entanto, como a rugosidade do aço da interface ensaiada é diferente ao do aço utilizado na pesquisa referente à Figura 5.71, os resultados são desiguais. 


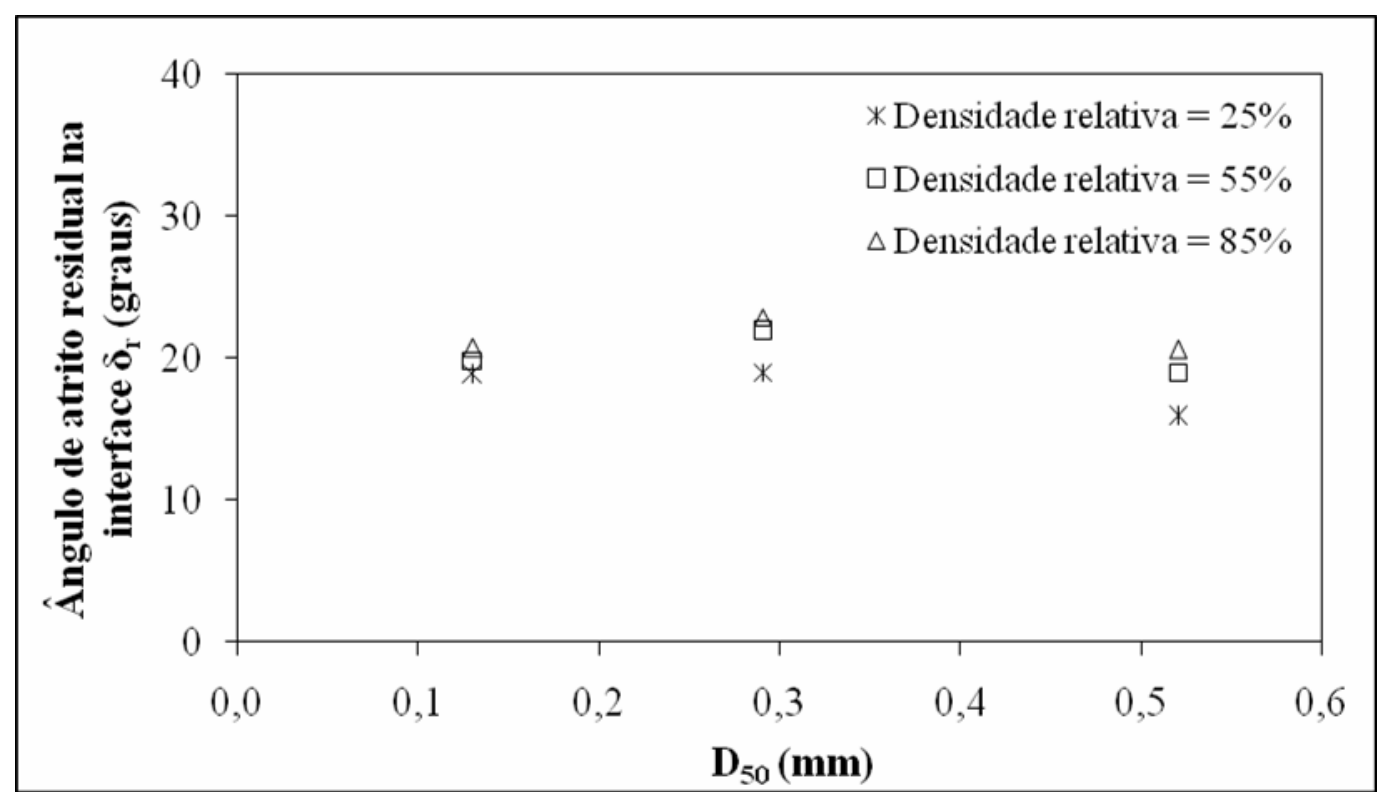

Figura 5.72 - Variação do ângulo de atrito residual na interface da superfície de aço estudada com o $\mathrm{D}_{50}$ da areia

Os resultados apresentados na Tabela 5.13 e exibidos na Figura 5.72 mostram que o ângulo de atrito residual obtido nos ensaios realizados com a Areia 2, de $\mathrm{D}_{50}$ igual a 0,30 mm, é superior ao ângulo de atrito residual dos ensaios realizados com a Areia 1, de $\mathrm{D}_{50}$ inferior, igual a $0,13 \mathrm{~mm}$. Apesar da diferença não ser significante, esperava-se que o valor de $\delta_{\mathrm{r}} \mathrm{da}$ Areia 2 fosse inferior ao da Areia 1, como ocorreu no trabalho ilustrado na Figura 5.71. Devido a este fato, foram tiradas fotos das areias para verificar a forma dos grãos, que, como já citado anteriormente nesta tese, segundo Uesugi e Kishida (1986) é uma variável que influencia o ângulo de atrito de pico da interface entre aço e areia. Supôs-se neste trabalho que esta variável tenha influenciado e contribuído para que o valor de $\delta_{\mathrm{r}}$ da Areia 2 fosse levemente superior ao da Areia 1. As Figuras 5.73, 5.74 e 5.75 mostram as fotografias em escala microscópica dos grãos das três areias utilizadas neste programa de ensaios. 


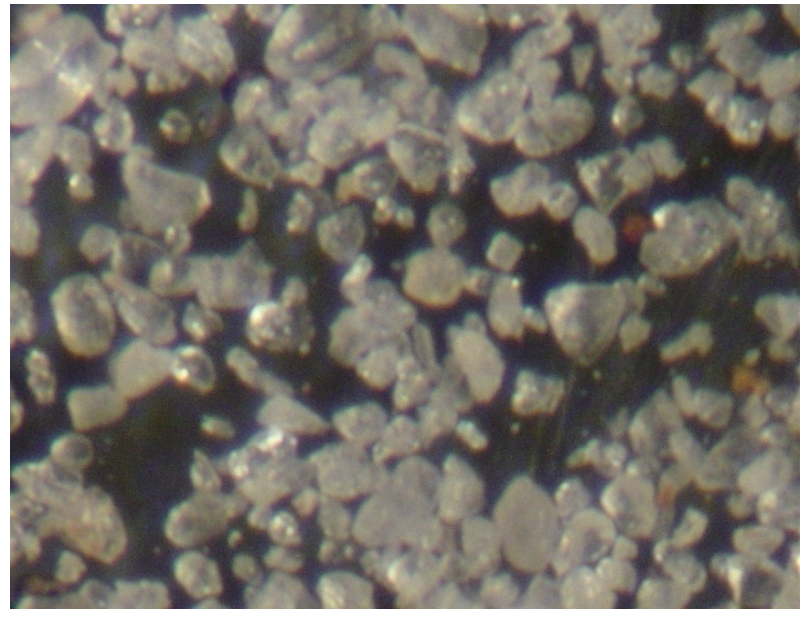

Figura 5.73 - Fotografia dos grãos da Areia $1\left(D_{50}=0,13 \mathrm{~mm}\right)$

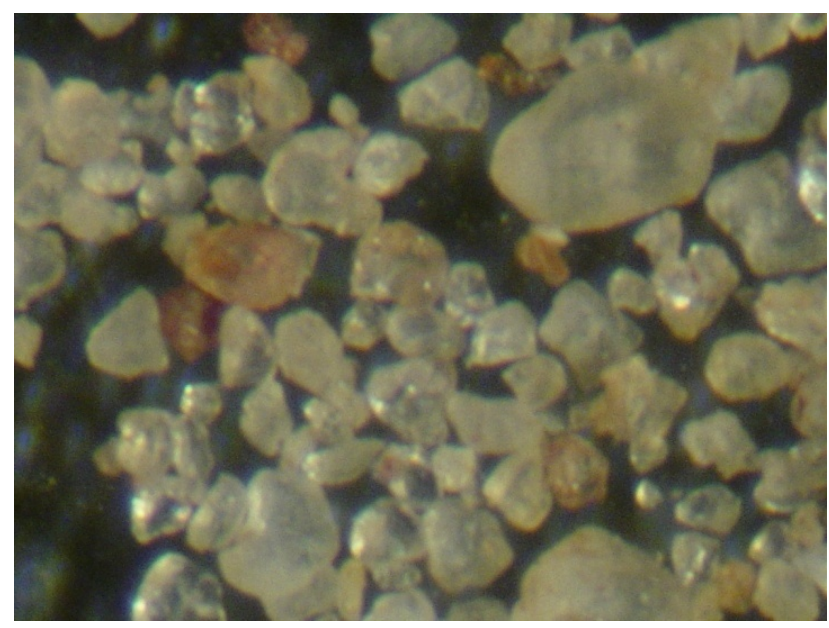

Figura 5.74 - Fotografia dos grãos da Areia $2\left(D_{50}=0,30 \mathrm{~mm}\right)$

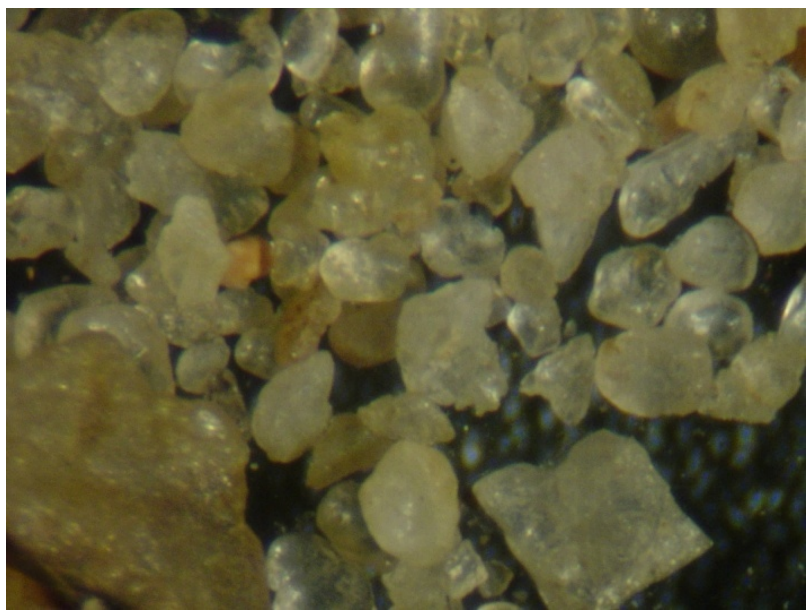

Figura 5.75 - Fotografia dos grãos da Areia $3\left(D_{50}=0,52 \mathrm{~mm}\right)$ 
Pelas fotografias das figuras 5.73 e 5.74 observa-se que a Areia 1 parece ter a forma dos grãos levemente mais arredondada do que do que a Areia 2. No entanto, a diferença é sutil e talvez somente a fotografia seja insuficiente para concluir que o valor de $\delta_{\mathrm{r}}$ da Areia 2 seja levemente maior do que o da Areia 1 devido à forma dos grãos. A Areia 3 fotografada na Figura 5.75 possui grãos arredondados e grãos angulosos.

A Tabela 5.14 mostra que a variação do ângulo residual nesta interface em estudo com a densidade relativa da areia foi maior nas areias de maior $\mathrm{D}_{50}$. Na areia mais fina a variação da densidade praticamente não afetou os valores de $\delta_{\mathrm{r}}$. A Figura 5.76 abaixo ilustra este fato.

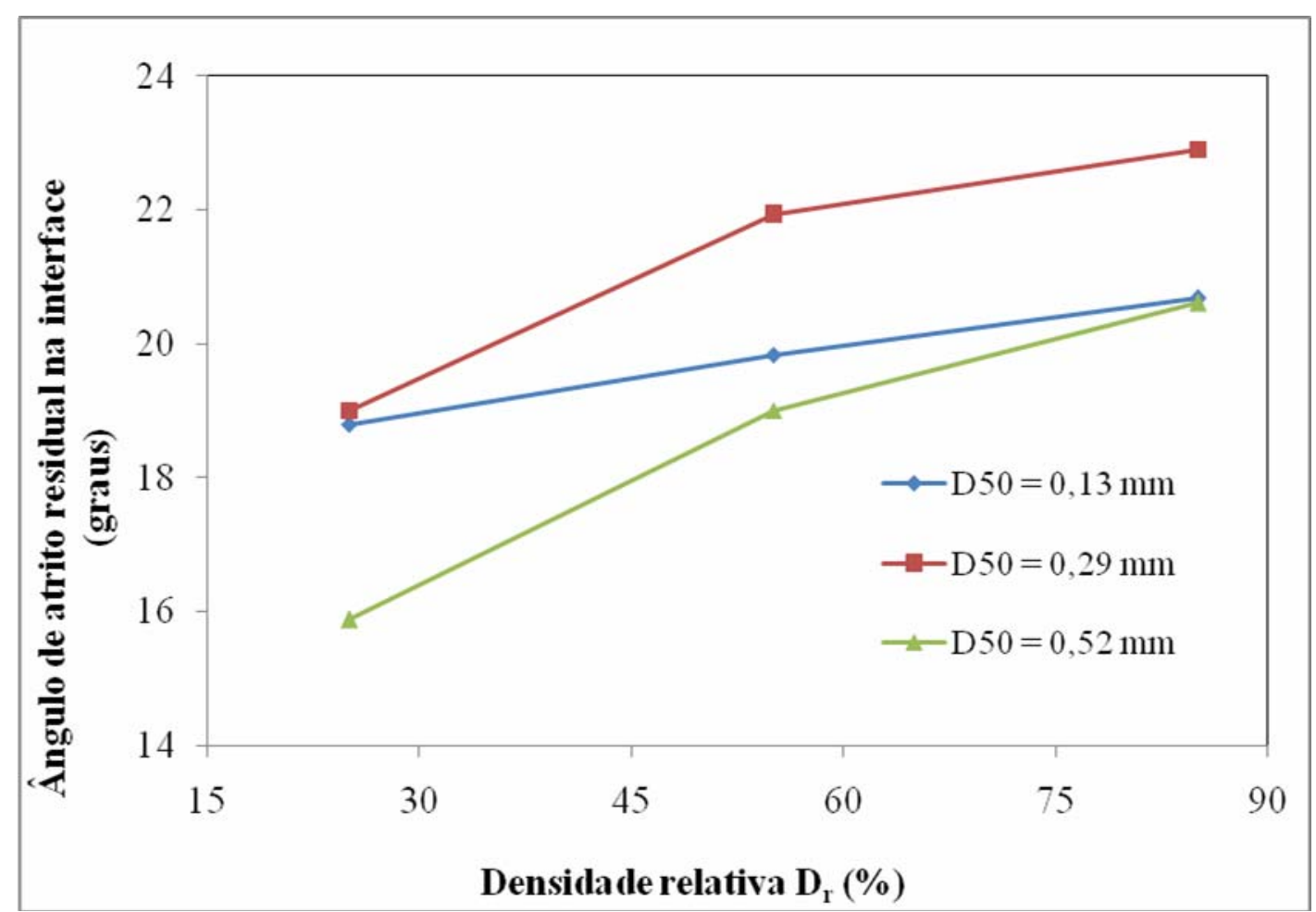

Figura 5.76 - Variação do ângulo de atrito residual de interface com a densidade relativa da areia 


\subsection{Ensaios de torção}

As curvas de momento torçor x rotação resultantes dos ensaios de torção realizados em tubos de aço de estacas metálicas helicoidais nesta pesquisa são apresentadas nas Figuras 5.77 a 5.80 .

Nas Figuras 5.77 e 5.79 nota-se que o formato da curva é diferente ao das Figuras 5.78 e 5.80. Isto ocorre porque os ensaios das Figuras 5.77 e 5.79 foram realizados em tubos sem emenda, e os ensaios das Figuras 5.78 e 5.80 foram realizados em tubos com emenda. Nos tubos sem emenda a ruptura ocorreu no tubo, e nos tubos com emenda a ruptura ocorreu nos furos da emenda, que foram alargados a partir de uma rotação específica aplicada.



Figura 5.77 - Curva de momento torçor x rotação do tubo de aço ensaiado com diâmetro externo igual a $73 \mathrm{~mm}$ e espessura igual a $5,16 \mathrm{~mm}$ (sem emenda) 


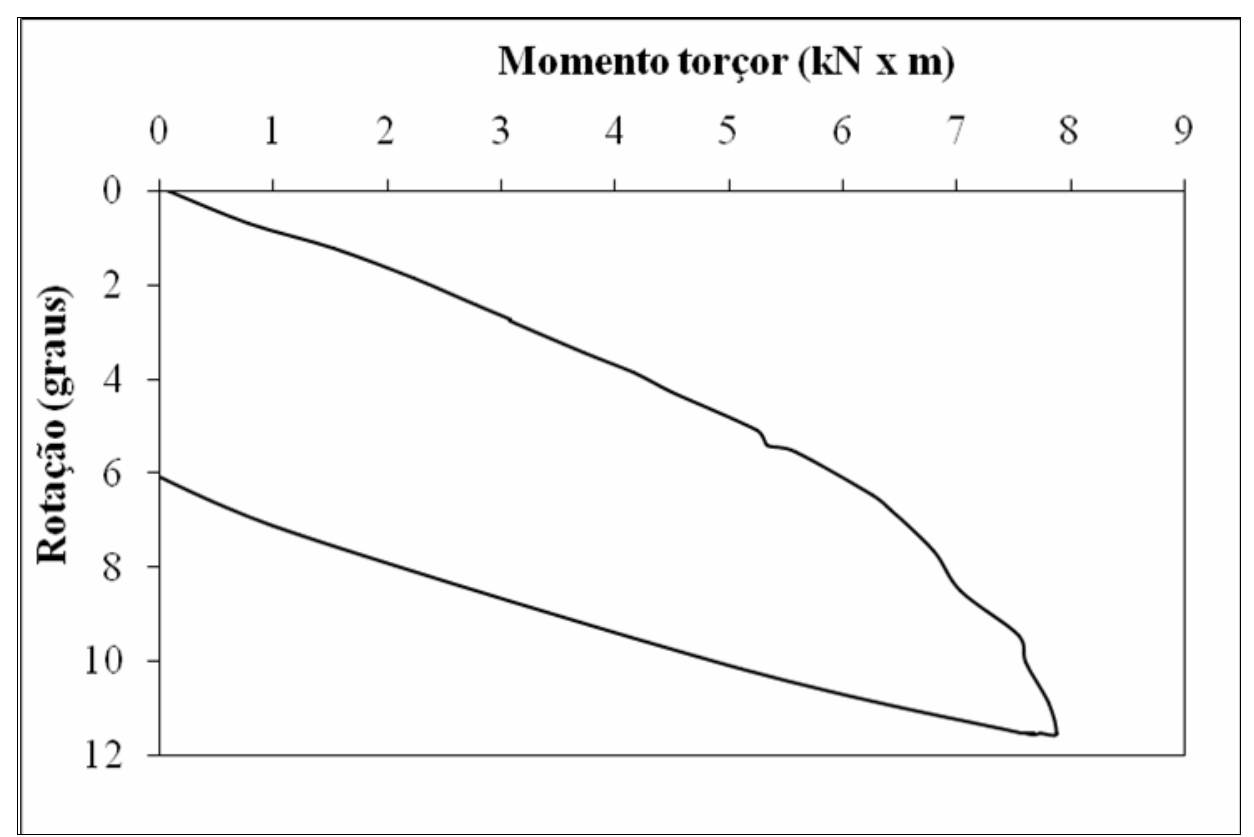

Figura 5.78 - Curva de momento torçor x rotação do tubo de aço ensaiado com diâmetro externo igual a $73 \mathrm{~mm}$ e espessura igual a 5,16 $\mathrm{mm}$ (com emenda)

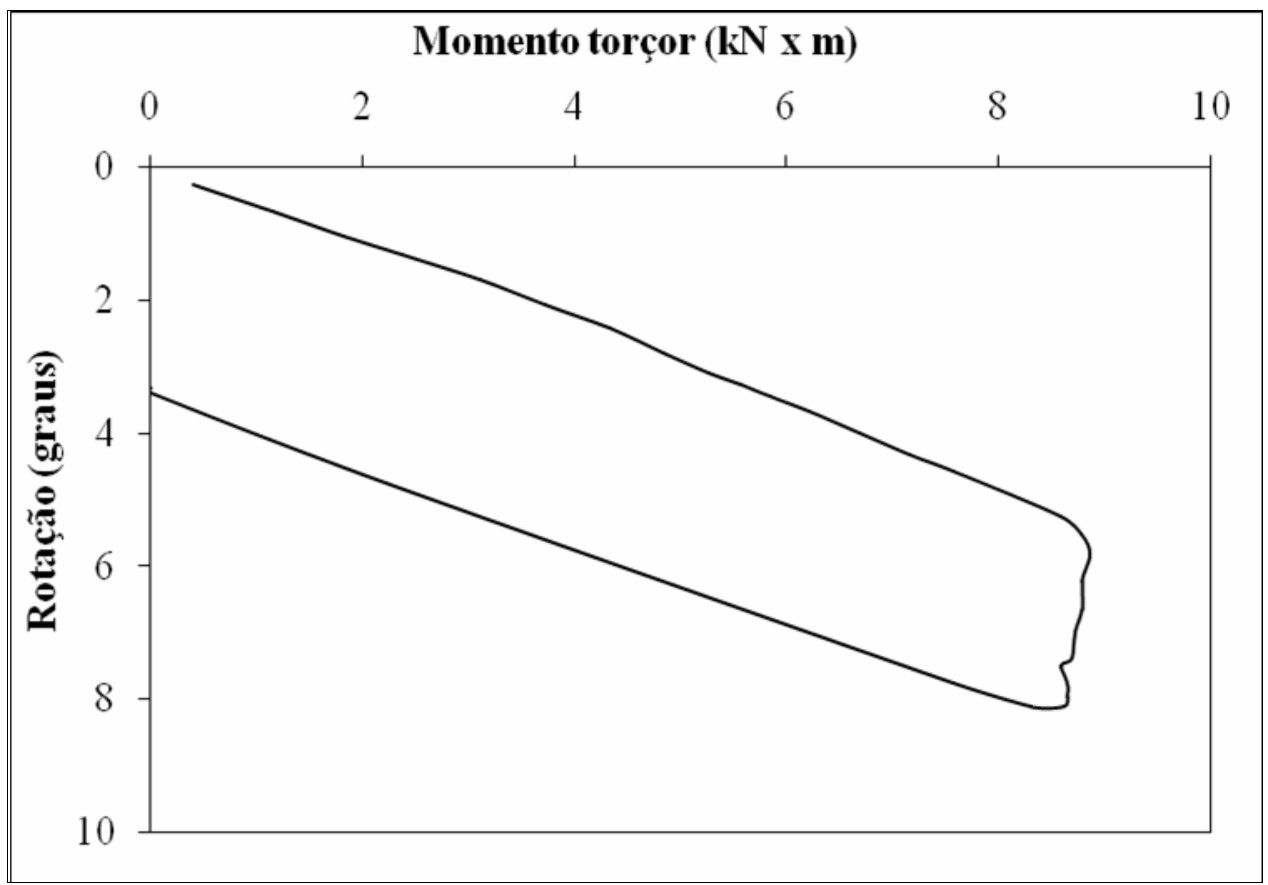

Figura 5.79 - Curva de momento torçor x rotação do tubo de aço ensaiado com diâmetro externo igual a $73 \mathrm{~mm}$ e espessura igual a $7,1 \mathrm{~mm}$ (sem emenda) 


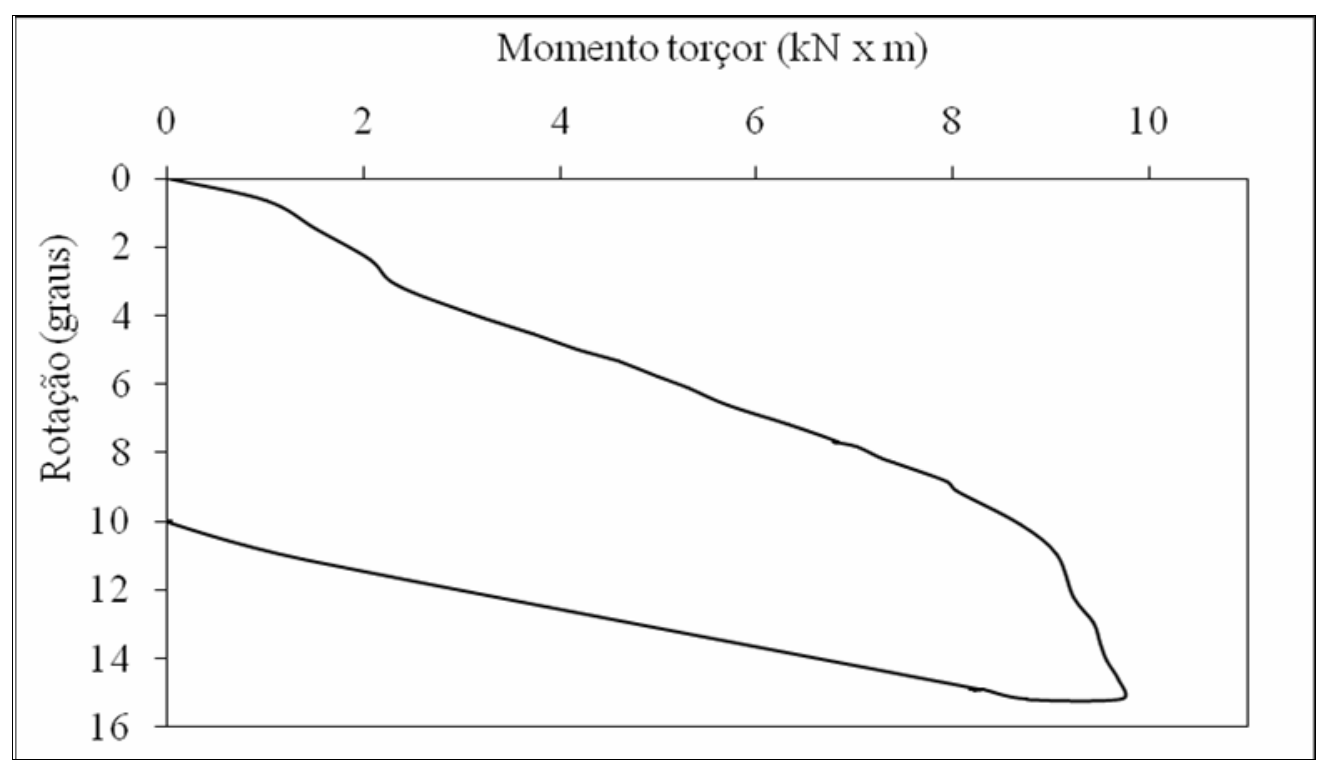

Figura 5.80 - Curva de momento torçor x rotação do tubo de aço ensaiado com diâmetro externo igual a $73 \mathrm{~mm}$ e espessura igual a $7,1 \mathrm{~mm}$ (com emenda)

Nas curvas das Figuras 5.77 e 5.78 a ruptura se inicia quando o momento torçor atinge o valor em torno de 7 kN.m. E nas Figuras 5.79 e 5.80 a ruptura se inicia quando o momento torçor atinge o valor em torno de 9 kN.m. Sendo assim, os tubos de mesmo diâmetro e espessura iniciam a ruptura a partir do mesmo valor de momento torçor aplicado, independentemente de ter ou não emenda. A única diferença entre o tubo com emenda e o tubo sem emenda é que para iniciar a ruptura no tubo com emenda a rotação mobilizada é maior (para alargar os furos da emenda a rotação mobilizada é maior) e o comportamento da curva momento torçor x rotação é diferente.

Segundo Queiroz (1988), a resistência nominal de uma barra sujeita à torção, para o estado limite de escoamento por tensão de cisalhamento, é igual a $0.6 \mathrm{f}_{\mathrm{y}}$ (onde $\mathrm{f}_{\mathrm{y}}$ é o limite de escoamento). $\mathrm{O}$ valor de $\mathrm{f}_{\mathrm{y}}$ dos tubos de aço ensaiado é de $3500 \mathrm{kgf} / \mathrm{cm}^{2}$. Para determinar-se a resistência de cálculo de barras sujeitas à torção, conforme a NBR8800, a resistência nominal deve ser multiplicada por um fator de redução igual a 0.9. Utilizando- 
se a resistência de cisalhamento de cálculo $\tau_{\max }=0,9 \times 0,6 \times \mathrm{f}_{\mathrm{y}}$, encontrou-se valores que foram substituídos na Equação 4.2 do capítulo anterior. Deste modo foram calculados os valores de momento torçor admissível para os ensaios de torção nos tubos sem emenda e comparados com os valores medidos na ruptura. Estes valores são apresentados na Tabela 5.14

Tabela 5.14 - Comparação entre valores de momento torçor medidos e calculados

\begin{tabular}{|c|c|c|}
\hline \multirow[b]{2}{*}{ Tipo de tubo } & \multicolumn{2}{|c|}{ Momento torçor (kN.m) } \\
\hline & $\begin{array}{l}\text { Medido } \\
\text { (ruptura) }\end{array}$ & $\begin{array}{c}\text { Calculado } \\
\text { (admissível) }\end{array}$ \\
\hline Tubo de espessura de $5,16 \mathrm{~mm}$ & 7,2 & 6,5 \\
\hline Tubo de espessura de $7,1 \mathrm{~mm}$ & 8,9 & 8,4 \\
\hline
\end{tabular}

A comparação da Tabela 5.14 mostra que os valores calculados de momento torçor admissível são levemente inferiores aos valores medidos na ruptura. Portanto, na fase de projeto de uma fundação em estaca metálica helicoidal deve-se fazer a verificação do momento torçor máximo a ser aplicado durante a execução da estaca pela Equação 4.2 para evitar a perda de estacas na fase de instalação. 


\section{6 \\ ANÁLISE DOS RESULTADOS}

Este capítulo é dividido em quatro partes. A primeira mostra o resultado da verificação do modelo teórico proposto nesta tese. A segunda apresenta um estudo da capacidade de carga dos modelos de estacas helicoidais ensaiados em centrífuga e em campo. A terceira parte é relativa ao efeito do número de hélices no torque de instalação e na capacidade de carga à tração das estacas instaladas em centrífuga. A quarta parte corresponde ao efeito da redução do diâmetro da hélice nos ensaios de campo da EESC.

\subsection{Verificação do modelo teórico proposto}

\subsubsection{Ensaios em centrífuga}

Neste item é verificada a Equação 3.14 apresentada no modelo teórico proposto no capítulo 3 desta tese. Esta equação relaciona parcela de capacidade de carga à tração relativa às hélices $\left(\mathrm{Q}_{\mathrm{h}}\right)$ e momento resistente à instalação gerado nas hélices $\left(\mathrm{T}_{\mathrm{h}}\right)$ medido no final da instalação da estaca. A Equação 3.15, que relaciona a capacidade de carga à tração $\left(\mathrm{Q}_{\mathrm{u}}\right)$ e o torque final de instalação $(T)$, por meio nas parcelas $T_{s}$ e $T_{h}$, não foi verificada pelos resultados medidos em centrífuga devido à possibilidade da ocorrência de efeito de escala nos resultados da resistência por atrito lateral tanto na fase de instalação da estaca como durante o ensaio de tração.

Para a verificação da Equação 3.14, foram utilizados os resultados de $Q_{h}$ e $T_{h}$ da Tabela 5.6, e os resultados dos valores médios entre os valores de $\delta_{r}$ encontrados para a chapa de aço e para a chapa soldada, exibidos na Tabela 5.9. Os outros parâmetros da Equação 3.14 são relativos às dimensões das hélices e foram obtidos diretamente por meio de um paquímetro. 
A Tabela 6.1 apresenta os resultados da parcela de capacidade de carga à tração relativa às hélices $\left(\mathrm{Q}_{\mathrm{h}}\right)$ calculados pela Equação 3.14 (parâmetros convertidos para o protótipo).

Tabela 6.1 - Parcela calculada de capacidade de carga à tração relativa às hélices $\left(\mathrm{Q}_{\mathrm{h}}\right)$

\begin{tabular}{|c|c|c|c|c|c|c|}
\hline Solo & $\begin{array}{c}\text { Estaca } \\
\mathrm{N}^{\mathrm{o}}\end{array}$ & $\begin{array}{c}\text { Diâmetro } \\
\mathrm{d}_{\mathrm{c}}, \text { em } \mathrm{m} \\
\text { (Eq. 3.12) }\end{array}$ & $\begin{array}{c}\text { Ângulo } \theta \text {, } \\
\text { em graus } \\
\text { (Eq. } 3.13 \text { ) }\end{array}$ & $\begin{array}{l}\text { Ângulo } \\
\delta_{r} \text {, em } \\
\text { graus }\end{array}$ & $\begin{array}{l}\text { Momento } \\
\text { resistente } \\
\text { atuante } \\
\text { nas hélices } \\
\left(\mathrm{T}_{\mathrm{h}}\right) \text {, em } \\
\text { kN.m }\end{array}$ & $\begin{array}{c}\text { Capacidade de } \\
\text { carga à tração } \\
\text { relativa às hélices } \\
\left(\mathrm{Q}_{\mathrm{h}}\right), \mathrm{em} \\
\mathrm{kN} \\
Q_{h}=\frac{2 T_{h}}{d_{c} \cdot \operatorname{tg}\left(\theta+\delta_{r}\right)}\end{array}$ \\
\hline \multirow{9}{*}{ 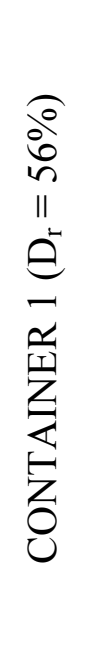 } & $1 \mathrm{~L}$ & 0,153 & 7,6 & 10,6 & 0,3 & 12 \\
\hline & $2 \mathrm{~L}$ & 0,153 & 7,6 & 10,6 & 0,4 & 16 \\
\hline & $3 \mathrm{~L}$ & 0,153 & 7,6 & 10,6 & 1,0 & 40 \\
\hline & $4 \mathrm{~L}$ & 0,232 & 5,4 & 10,6 & 1,6 & 48 \\
\hline & $5 \mathrm{~L}$ & 0,232 & 5,4 & 10,6 & 3,2 & 96 \\
\hline & $6 \mathrm{~L}$ & 0,232 & 5,4 & 10,6 & 3,3 & 99 \\
\hline & $7 \mathrm{~L}$ & 0,314 & 4,5 & 10,6 & 4,1 & 97 \\
\hline & $8 \mathrm{~L}$ & 0,314 & 4,5 & 10,6 & 4,9 & 116 \\
\hline & $9 \mathrm{~L}$ & 0,314 & 4,5 & 10,6 & 5,3 & 125 \\
\hline \multirow{9}{*}{ 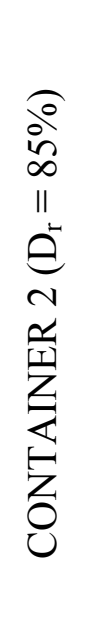 } & $1 \mathrm{~L}$ & 0,153 & 7,6 & 15,1 & 1,9 & 59 \\
\hline & $2 \mathrm{~L}$ & 0,153 & 7,6 & 15,1 & 2,8 & 87 \\
\hline & $3 \mathrm{~L}$ & 0,153 & 7,6 & 15,1 & 4,1 & 128 \\
\hline & $4 \mathrm{~L}$ & 0,232 & 5,4 & 15,1 & 7,7 & 178 \\
\hline & $5 \mathrm{~L}$ & 0,232 & 5,4 & 15,1 & 12,5 & 288 \\
\hline & $6 \mathrm{~L}$ & 0,232 & 5,4 & 15,1 & 10,7 & 247 \\
\hline & $7 \mathrm{~L}$ & 0,314 & 4,5 & 15,1 & 22,4 & 401 \\
\hline & $8 \mathrm{~L}$ & 0,314 & 4,5 & 15,1 & 35,1 & 628 \\
\hline & 9L & 0,314 & 4,5 & 15,1 & 35,1 & 628 \\
\hline
\end{tabular}

A Tabela 6.2 mostra a comparação entre os valores da parcela de capacidade de carga à tração relativa às hélices $\left(\mathrm{Q}_{\mathrm{h}}\right)$ calculados pela Equação 3.14 e medidos nos ensaios realizados em centrífuga (escala do protótipo). 
Tabela 6.2 - Comparação entre $\mathrm{Q}_{\mathrm{h}}$ calculada e $\mathrm{Q}_{\mathrm{h}}$ medida

\begin{tabular}{|c|c|c|c|c|}
\hline \multirow{2}{*}{ Solo } & \multirow{2}{*}{$\begin{array}{l}\text { Estaca } \\
\mathrm{N}^{\mathrm{o}}\end{array}$} & \multicolumn{2}{|c|}{$\begin{array}{c}\text { Capacidade de carga à tração relativa às } \\
\text { hélices }\left(\mathrm{O}_{\mathrm{h}}\right) \mathrm{em} \mathrm{kN}\end{array}$} & \multirow{2}{*}{$\begin{array}{l}\mathrm{Q}_{\mathrm{h}} \text { medida/ } \\
\mathrm{Q}_{\mathrm{h}} \text { calculada }\end{array}$} \\
\hline & & Medida & Calculada & \\
\hline \multirow{9}{*}{ 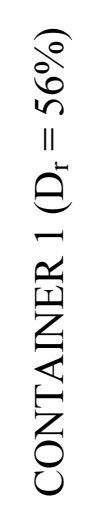 } & $1 \mathrm{~L}$ & 14 & 12 & 1,17 \\
\hline & $2 \mathrm{~L}$ & 19 & 16 & 1,19 \\
\hline & $3 \mathrm{~L}$ & 43 & 40 & 1,08 \\
\hline & $4 \mathrm{~L}$ & 46 & 48 & 0,96 \\
\hline & $5 \mathrm{~L}$ & 83 & 96 & 0,86 \\
\hline & $6 \mathrm{~L}$ & 112 & 99 & 1,13 \\
\hline & $7 \mathrm{~L}$ & 69 & 97 & 0,71 \\
\hline & $8 \mathrm{~L}$ & 108 & 116 & 0,93 \\
\hline & $9 \mathrm{~L}$ & 150 & 125 & 1,20 \\
\hline \multirow{9}{*}{  } & $1 \mathrm{~L}$ & 60 & 59 & 1,02 \\
\hline & $2 \mathrm{~L}$ & 88 & 87 & 1,01 \\
\hline & $3 \mathrm{~L}$ & 116 & 128 & 0,91 \\
\hline & $4 \mathrm{~L}$ & 177 & 178 & 0,99 \\
\hline & $5 \mathrm{~L}$ & 234 & 288 & 0,81 \\
\hline & $6 \mathrm{~L}$ & 275 & 247 & 1,11 \\
\hline & $7 \mathrm{~L}$ & 413 & 401 & 1,03 \\
\hline & $8 \mathrm{~L}$ & 475 & 628 & 0,76 \\
\hline & 9L & 475 & 628 & 0,76 \\
\hline \multicolumn{4}{|c|}{ Valor médio de $\mathrm{Q}_{\mathrm{h}}$ medida $/ \mathrm{Q}_{\mathrm{h}}$ calculada } & 0,98 \\
\hline & & & Desvio padrão & 0,15 \\
\hline & & & e de variação (\%) & 15,7 \\
\hline
\end{tabular}

Na tabela 6.2 observa-se que o valor médio da razão entre os valores da parcela de capacidade de carga à tração relativa às hélices medidos nos ensaios em centrífuga e calculados pela Equação $3.14\left(\mathrm{Q}_{\mathrm{h}}\right.$ medida/ $\mathrm{Q}_{\mathrm{h}}$ calculada) é igual a 0,98 , com um coeficiente de variação de $15,7 \%$. Este fato mostra que a Equação 3.14 do modelo teórico proposto nesta tese apresenta boa aproximação da realidade medida. Além disso, esta comparação mostra também que esta equação é válida para diferentes configurações de estacas (diâmetros e número de hélices variados). 
Nos ensaios realizados para modelagem física em centrífuga foi possível medir todos os parâmetros da Equação 3.14, por esta razão esta equação representa apropriadamente a relação física entre a parcela de capacidade de carga à tração relativa às hélices $\left(\mathrm{Q}_{\mathrm{h}}\right)$ e momento resistente à instalação gerado nas hélices $\left(T_{h}\right)$ medido no final da instalação da estaca.

A Figura 6.1 mostra a relação entre os valores medidos e calculados da parcela de capacidade de carga à tração relativa às hélices $\left(\mathrm{Q}_{\mathrm{h}}\right)$.

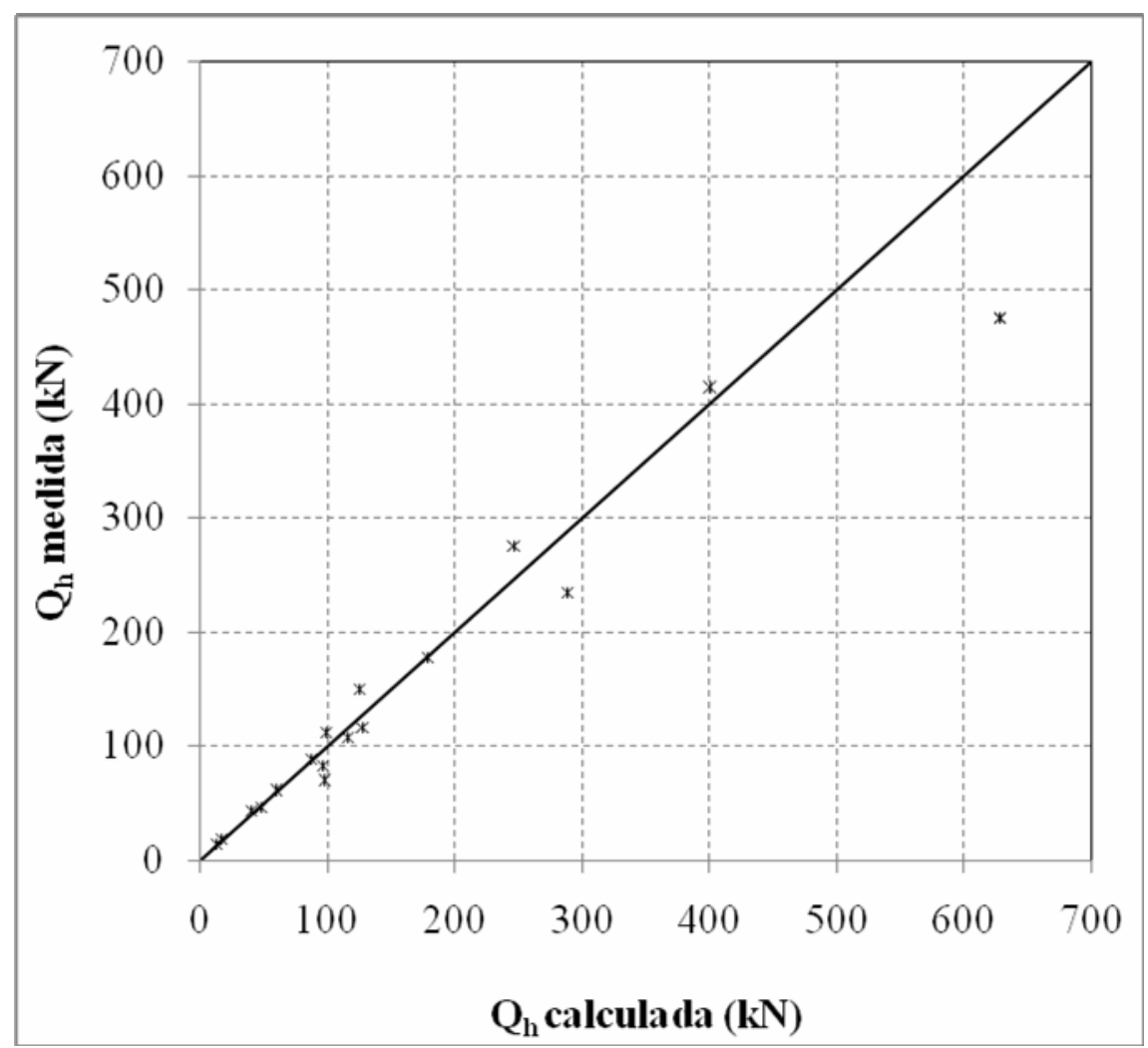

Figura 6.1 - Comparação entre os resultados medidos e calculados da capacidade de carga à tração relativa às hélices $\left(\mathrm{Q}_{\mathrm{h}}\right)$ em centrifuga

Entretanto, os resultados de $\mathrm{Q}_{\mathrm{h}}$ calculados pelo modelo proposto nesta tese pela Equação 3.14 se aproximariam ainda mais dos resultados medidos, se para a estimativa dos resultados experimentais de $\mathrm{Q}_{\mathrm{s}}$ (resistência à tração por atrito lateral da haste) exibidos na Tabela 5.6 não 
fosse considerado que a mobilização do atrito lateral na haste no momento do carregamento à tração ocorre ao longo de todo o comprimento da estaca embutida no maciço. No entanto, como não se sabe seguramente qual é a área lateral da estaca que resiste ao arrancamento da estaca por atrito na interface estaca/areia, adotou-se por simplificação a área equivalente ao comprimento total da haste.

\subsubsection{Ensaios de campo}

Neste item foi verificada a relação entre valor do torque final de instalação medido (T) e as parcelas $\mathrm{Q}_{\mathrm{s}}$ e $\mathrm{Q}_{\mathrm{h}}$ da capacidade de carga à tração $\left(\mathrm{Q}_{\mathrm{u}}\right)$ da estaca metálica helicoidal, dada pela Equação 3.16 abaixo, proposta nesta tese.

$$
T=\frac{Q_{s} d}{2}+\frac{Q_{h} d_{c} \tan \left(\theta+\delta_{r}\right)}{2}
$$

O modelo de cálculo proposto na Equação 3.16 foi elaborado para estacas com hélices de diâmetros iguais. Porém, a Equação 3.14, que corresponde à segunda parcela da Equação 3.16, foi validada pela modelagem física em centrífuga para estacas multi-hélices com hélices de diâmetros iguais. No entanto, para aplicar este modelo de cálculo nas estacas ensaiadas em campo, foi considerado para o cálculo de $d_{c}$ o valor médio do diâmetro das hélices para cada estaca.

Nos ensaios de campo realizados, não foi possível medir separadamente as componentes do torque de instalação e da capacidade de carga relativas às hélices e ao atrito nos fustes. Para isto seriam necessárias estacas sem hélices com mesmo diâmetro e instaladas em mesma profundidade do que as estacas com hélice. 
O objetivo fundamental desta tese é a utilização do método proposto na Equação 3.16 para controlar de modo simplificado a capacidade de carga da estaca à tração $\left(\mathrm{Q}_{\mathrm{u}}=\mathrm{Q}_{\mathrm{s}}+\mathrm{Q}_{\mathrm{h}}\right)$ por meio do torque medido no final da instalação (T). Para a aplicação desta equação na prática é preciso calcular separadamente as parcelas de $\mathrm{Q}_{\mathrm{s}}$ e de $\mathrm{Q}_{\mathrm{h}}$. A parcela $\mathrm{Q}_{\mathrm{s}}$, relativa ao atrito lateral na haste, pode ser estimada pela Equação 2.11, proposta por Mitsch e Clemence (1985), apresentada na revisão bibliográfica desta tese. A parcela de capacidade de carga à tração relativa às hélices $\left(\mathrm{Q}_{\mathrm{h}}\right)$ pode ser calculada pelos diferentes métodos apresentados na revisão bibliográfica desta tese para o cálculo de capacidade de carga de estacas metálicas helicoidais.

Na presente verificação, para o cálculo da parcela de capacidade de carga à tração relativa ao atrito lateral na haste $\left(\mathrm{Q}_{\mathrm{s}}\right)$, foi utilizada a Equação 2.11 do método de Mitsch e Clemence (1985). Para a estimativa dos parâmetros da areia desta equação utilizou-se os resultados das sondagens dos terrenos em que as estacas foram instaladas.

Na tese de Levesque (2002), sobre modelagem em centrífuga de estaca metálica helicoidal instalada em areia seca, foi verificado por meio de ensaio de cone em centrífuga, realizado em torno da estaca após a sua instalação, que o ângulo de atrito do maciço de areia fofa (neste trabalho citado não foi verificado este efeito em areia densa) diminuiu em torno de $10 \%$ em relação ao valor do ângulo de atrito de pico da areia medido em ensaios de cisalhamento direto. Devido a este fato, para a estimativa do valor de $\mathrm{Q}_{\mathrm{s}}$ (Tabela 6.3), foi considerada esta redução de $10 \%$ no ângulo de atrito estimado pelas sondagens, devido à modificação do solo sofrida após a instalação da estaca. Nesta estimativa da resistência por atrito lateral na haste $\left(Q_{s}\right)$ foi considerado todo o comprimento embutido da haste no solo, do nível do terreno à ponta da estaca.

Na comparação da Tabela 6.3, a parcela de capacidade de carga à tração relativa às hélices $\left(\mathrm{Q}_{\mathrm{h}}\right)$ foi determinada pela diferença entre os valores de carga de ruptura medidos nas provas 
de carga $\left(\mathrm{Q}_{\mathrm{u}}\right)$ e os valores de $\mathrm{Q}_{\mathrm{s}}$ estimados $\left(\mathrm{Q}_{\mathrm{h}}=\mathrm{Q}_{\mathrm{u}}-\mathrm{Q}_{\mathrm{s}}\right)$. Como as estacas $\mathrm{N}^{\circ} 1 \mathrm{C}$ a $\mathrm{N}^{\circ} 4 \mathrm{C}$ foram instaladas em silte arenoso, utilizou-se para o cálculo do torque no final da instalação (T) o valor médio de ângulo de atrito na interface $\left(\delta_{\mathrm{r}}\right)$ sugerido por Bowles (1988) para interfaces entre aço e silte arenoso $\left(12,5^{\circ}\right)$. Os valores de ângulo de atrito na interface $\left(\delta_{\mathrm{r}}\right)$ adotados para as estacas $\mathrm{N}^{\circ} 5 \mathrm{C}$ e $\mathrm{N}^{\circ} 6 \mathrm{C}$, instaladas em areia fina argilosa fofa a medianamente compacta, foi o mesmo que o obtido nos ensaios de cisalhamento de interface realizados nesta pesquisa (Tabela 5.13) para areia fina fofa $\left(18.8^{\circ}\right)$.

Os valores de $d_{c}$ e de $\theta$ da Tabela 6.3 foram calculados pelas Equações 3.12 e 3.13 substituindo-se as dimensões das estacas, adotando-se o valor de um diâmetro médio e de um passo médio das hélices para cada estaca multi-hélices. A Tabela 6.3 mostra os resultados estimados de torque final de instalação (T) obtidos pela Equação 3.16.

Observa-se na Tabela 6.3 que os resultados do torque medido em campo representam em média $87 \%$ dos valores de torque calculado pelo método proposto nesta tese, por meio da fórmula 3.16. Nas estacas $1 \mathrm{C}$ e $2 \mathrm{C}$, instaladas em silte arenoso, o valor de torque medido está em torno de $68 \%$ do valor calculado. No entanto, para estes casos, a utilização do método proposto para estimativa do torque final de instalação é conservadora, ou seja, adotando-se o torque calculado por este método como critério de parada da instalação da estaca, a fundação será executada para uma carga de ruptura superior a real.

Nota-se pela comparação da Tabela 6.3 que para as estacas $3 \mathrm{C}$ a $6 \mathrm{C}$ os valores de torque medidos e calculados são bem próximos. A partir deste fato, conclui-se que para estas estacas o método proposto nesta tese para o controle da capacidade de carga à tração de fundações em estacas metálicas helicoidais é apropriado. 
Tabela 6.3 - Comparação entre os valores de torque final de instalação medidos e calculados ensaios de campo

\begin{tabular}{|c|c|c|c|c|c|c|c|c|c|}
\hline Estaca & Solo & $\begin{array}{c}\mathrm{Q}_{\mathrm{s}} \\
(\mathrm{kN})\end{array}$ & $\begin{array}{c}\mathrm{Q}_{\mathrm{h}} \\
(\mathrm{kN})\end{array}$ & $\begin{array}{l}\mathrm{d}_{\mathrm{c}} \\
(\mathrm{m})\end{array}$ & $\begin{array}{c}\theta \\
\text { (graus) }\end{array}$ & $\begin{array}{c}\delta_{\mathrm{r}} \\
\text { (graus) }\end{array}$ & $\begin{array}{l}\text { Tcalc. } \\
\text { (kN.m) }\end{array}$ & $\begin{array}{l}\text { Tmed. } \\
\text { (kN.m) }\end{array}$ & $\begin{array}{l}\text { Tmed./ } \\
\text { Tcalc. }\end{array}$ \\
\hline 1 & \multirow{4}{*}{$\begin{array}{c}\text { Silte } \\
\text { arenoso }\end{array}$} & 40 & 180 & 0,236 & 7,5 & 12,5 & 9,7 & 6,8 & 0,70 \\
\hline 2 & & 32 & 168 & 0,210 & 8,4 & 12,5 & 8,3 & 5,4 & 0,65 \\
\hline 3 & & 30 & 260 & 0,202 & 8,7 & 12,5 & 11,3 & 10,9 & 0,96 \\
\hline 4 & & 34 & 227 & 0,213 & 8,3 & 12,5 & 10,4 & 10,9 & 1,04 \\
\hline 5 & \multirow{2}{*}{$\begin{array}{l}\text { Areia fina } \\
\text { argilosa }\end{array}$} & 90 & 80 & 0,196 & 8,9 & 18,8 & 7,4 & 7,1 & 0,95 \\
\hline 6 & & 90 & 40 & 0,110 & 9,4 & 18,8 & 4,5 & 4,2 & 0,93 \\
\hline \multicolumn{9}{|c|}{ Valor médio de Tmedido/Tcalculado } & 0,87 \\
\hline \multicolumn{9}{|c|}{ Desvio padrão } & 0,16 \\
\hline \multicolumn{9}{|c|}{ Coeficiente de variação (\%) } & 18,3 \\
\hline
\end{tabular}

\subsection{Estudo da capacidade de carga à tração}

\subsubsection{Previsão da capacidade de carga à tração}

Neste item são comparados os resultados de capacidade de carga à tração medidos nos ensaios desta tese com os resultados estimados pelos métodos tradicionalmente utilizados em projetos de fundações em estacas metálicas helicoidais.

Para a verificação dos valores de capacidade de carga à tração medidos nas estacas foram utilizados os seguintes métodos: "Método das capacidades de carga individuais" e "Método da ruptura cilíndrica". Estes dois métodos são descritos na revisão bibliográfica desta tese.

Nas verificações das fórmulas de capacidade da carga à tração de estacas metálicas helicoidais em areia e silte arenoso, os valores de ângulo de atrito utilizados foram ajustados 
para considerar o efeito da instalação da estaca no maciço, ou seja, diminuídos de $10 \%$ do valor total, de acordo com o trabalho de Levesque (2002), citado anteriormente nesta tese.

Na comparação com os resultados medidos em centrífuga foi excluída a parcela da capacidade de carga à tração devido à resistência por atrito lateral na haste $\left(\mathrm{Q}_{\mathrm{s}}\right)$, devido ao efeito de escala já explicado anteriormente no capítulo 5.

\subsubsection{Método das capacidades de carga individuais}

\section{Estacas protótipo da modelagem física em centrífuga}

O método das capacidades de carga individuais, proposto pela A. B. Chance Company, é descrito na revisão bibliográfica desta tese pela Equação 2.13. Este método de cálculo assume que a capacidade de carga à tração da estaca é a soma das capacidades individuais de cada hélice, e não considera a resistência por atrito na haste de estaca. No entanto, é recomendado pela A. B. Chance Co. (1994) que a resistência à tração por atrito lateral na haste deva ser considerada se o diâmetro da haste da estaca for redondo e superior a $89 \mathrm{~mm}$. Como o valor da parcela de capacidade de carga à tração relativa às hélices $\left(Q_{h}\right)$ medida em centrífuga também é a soma das capacidades individuais de cada hélice, é possível comparar os valores de capacidade de carga à tração $\left(\mathrm{Q}_{\mathrm{u}}\right)$ calculados por este método com os medidos em centrífuga.

A Tabela 6.4 mostra os resultados estimados pelo método das capacidades de carga individuais para as estacas protótipo utilizadas na modelagem física em centrífuga. A Tabela 6.5 mostra a comparação entre os valores da parcela de capacidade de carga à tração relativa às hélices $\left(\mathrm{Q}_{\mathrm{h}}\right)$ medidos em centrífuga e calculados pelo método das capacidades de carga individuais. 
Na comparação exibida na Tabela 6.5 , nos resultados do container $1\left(D_{r}=56 \%\right)$, nota-se que para as estacas de maior diâmetro de hélice (estacas 7L, 8L e 9L) a relação entre os valores medidos de calculados de $\mathrm{Q}_{\mathrm{h}}$, foi em torno de $51 \%$. Este fato mostra que para as estacas de hélice de maior diâmetro o valor do ângulo de atrito do maciço a ser considerado no cálculo por este método utilizado deve ser inferior ao adotado nesta verificação (com redução de 10 \% de acordo com Levesque (2002)). Supõe-se que o efeito da modificação do maciço de areia menos compacto provocado pela instalação das hélices maiores $(D=440$ $\mathrm{mm}$ ) seja maior do que o provocado pelas estacas de hélice menor (estacas 1L a 6L).

Para as estacas de menor hélice (estacas $1 \mathrm{~L}$ a $6 \mathrm{~L}$ ), instaladas no container 1, a relação entre $\mathrm{Q}_{\mathrm{h}}$ medida e $\mathrm{Q}_{\mathrm{h}}$ calculada, exibida na Tabela 6.5, apresenta o valor médio igual a 0.94 com o coeficiente de variação de $18 \%$. Deste modo, adotando-se a redução de $10 \%$ no ângulo de atrito, para considerar-se o efeito da instalação neste maciço de areia medianamente compacta, este método de cálculo superestima o valor de $Q_{\mathrm{h}}$. Este valor de $10 \%$ de redução do ângulo de atrito adotado para o cálculo foi medido para um maciço de areia fofa (Levesque, 2000) e adotado para estes ensaios em centrífuga no container 1 com areia com densidade relativa $\left(D_{r}\right)$ igual a 56\%. Portanto, para uma areia com esta densidade relativa, a redução do ângulo de atrito deve ser maior para que este método não superestime a capacidade de carga à tração.

Além disso, os resultados de $\mathrm{Q}_{\mathrm{h}}$ calculados pelo método das capacidades de carga individuais seriam mais próximos aos resultados medidos nos containeres 1 e 2 , se para a estimativa dos resultados experimentais de $\mathrm{Q}_{\mathrm{s}}$ (resistência à tração por atrito lateral da haste) exibidos na Tabela 5.6 não fosse considerado que a mobilização do atrito lateral na haste no momento do carregamento à tração ocorre ao longo de todo o comprimento da estaca embutida no maciço. Contudo, como não se sabe certamente qual é a área lateral da estaca 
que resiste ao arrancamento da estaca por atrito na interface estaca/areia, adotou-se por simplificação a área equivalente ao comprimento total da haste.

Tabela 6.4 - Valores de $\mathrm{Q}_{\mathrm{h}}$ calculados pelo método das capacidades de carga individuais para as estacas ensaiadas em centrífuga

\begin{tabular}{|c|c|c|c|c|c|c|}
\hline Solo & $\begin{array}{c}\text { Estaca } \\
\mathrm{N}^{\mathrm{o}}\end{array}$ & $\begin{array}{l}\mathrm{N}^{\mathrm{o}} \mathrm{de} \\
\text { hélices }\end{array}$ & $\begin{array}{c}\text { Cap. de carga } \\
\text { à tração } \\
\text { relativa a } \\
\text { hélice } 1 \\
\left(\mathrm{Q}_{\mathrm{h} 1}\right) \text {, em } \mathrm{kN} \\
\end{array}$ & $\begin{array}{l}\text { Cap. de carga } \\
\text { à tração } \\
\text { relativa a } \\
\text { hélice } 2 \\
\left(\mathrm{Q}_{\mathrm{h} 2}\right) \text {, em } \mathrm{kN} \\
\end{array}$ & $\begin{array}{c}\text { Cap. de carga } \\
\text { à tração } \\
\text { relativa a } \\
\text { hélice } 3 \\
\left(\mathrm{Q}_{\mathrm{h} 3}\right) \text {, em } \mathrm{kN} \\
\end{array}$ & $\begin{array}{c}\text { Cap. de carga } \\
\text { à tração } \\
\text { relativa as } \\
\text { hélices } \\
\left(\mathrm{Q}_{\mathrm{h}}\right) \text {, em } \mathrm{kN} \\
\end{array}$ \\
\hline \multirow{9}{*}{  } & $1 \mathrm{~L}$ & 1 & 15 & - & - & 15 \\
\hline & $2 \mathrm{~L}$ & 2 & 15 & 11 & - & 26 \\
\hline & $3 \mathrm{~L}$ & 3 & 15 & 11 & 8 & 34 \\
\hline & $4 \mathrm{~L}$ & 1 & 52 & - & - & 52 \\
\hline & $5 \mathrm{~L}$ & 2 & 52 & 40 & - & 92 \\
\hline & $6 \mathrm{~L}$ & 3 & 52 & 40 & 29 & 120 \\
\hline & $7 \mathrm{~L}$ & 1 & 127 & - & - & 127 \\
\hline & $8 \mathrm{~L}$ & 2 & 127 & 99 & - & 226 \\
\hline & $9 \mathrm{~L}$ & 3 & 127 & 99 & 71 & 296 \\
\hline \multirow{9}{*}{  } & $1 \mathrm{~L}$ & 1 & 50 & - & - & 50 \\
\hline & $2 \mathrm{~L}$ & 2 & 50 & 39 & - & 88 \\
\hline & $3 \mathrm{~L}$ & 3 & 50 & 39 & 28 & 116 \\
\hline & $4 \mathrm{~L}$ & 1 & 174 & - & - & 174 \\
\hline & $5 \mathrm{~L}$ & 2 & 174 & 135 & - & 309 \\
\hline & $6 \mathrm{~L}$ & 3 & 174 & 135 & 97 & 406 \\
\hline & $7 \mathrm{~L}$ & 1 & 429 & - & - & 429 \\
\hline & $8 \mathrm{~L}$ & 2 & 429 & 333 & - & 762 \\
\hline & 9L & 3 & 429 & 333 & 238 & 1000 \\
\hline
\end{tabular}


Tabela 6.5 - Comparação entre os valores de $\mathrm{Q}_{\mathrm{h}}$ calculados pelo método das capacidades de carga individuais e medidos nos ensaios em centrífuga

\begin{tabular}{|c|c|c|c|c|c|c|}
\hline \multirow[t]{2}{*}{ Solo } & \multirow[t]{2}{*}{$\begin{array}{c}\text { Estaca } \\
\mathrm{N}^{\mathrm{o}}\end{array}$} & \multirow[t]{2}{*}{$\begin{array}{l}\mathrm{N}^{\mathrm{o}} \text { de } \\
\text { hélices }\end{array}$} & \multirow[t]{2}{*}{$\begin{array}{l}\text { Diâmetro } \\
\text { da hélice } \\
\text { (D) em mm }\end{array}$} & \multicolumn{2}{|c|}{$\begin{array}{l}\text { Capacidade de carga à tração } \\
\text { relativa às hélices } \\
\left(\mathrm{Q}_{\mathrm{h}}\right) \text {, em kN }\end{array}$} & \multirow[t]{2}{*}{$\begin{array}{l}\text { Q } \mathrm{h} \text { medida/ } \\
\mathrm{Q}_{\mathrm{h}} \text { calculada }\end{array}$} \\
\hline & & & & calculada & medida & \\
\hline \multirow{9}{*}{ 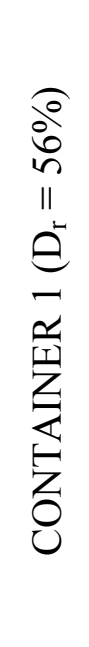 } & 1 & 1 & 214.4 & 15 & 14 & 0.95 \\
\hline & 2 & 2 & 214.4 & 26 & 19 & 0.73 \\
\hline & 3 & 3 & 214.4 & 34 & 43 & 1.25 \\
\hline & 4 & 1 & 325.7 & 52 & 46 & 0.89 \\
\hline & 5 & 2 & 325.7 & 92 & 83 & 0.91 \\
\hline & 6 & 3 & 325.7 & 120 & 112 & 0.93 \\
\hline & 7 & 1 & 440.0 & 127 & 69 & 0.54 \\
\hline & 8 & 2 & 440.0 & 226 & 108 & 0.48 \\
\hline & 9 & 3 & 440.0 & 296 & 150 & 0.51 \\
\hline \multirow{9}{*}{  } & 1 & 1 & 214.4 & 50 & 60 & 1.21 \\
\hline & 2 & 2 & 214.4 & 88 & 88 & 1.00 \\
\hline & 3 & 3 & 214.4 & 116 & 116 & 1.00 \\
\hline & 4 & 1 & 325.7 & 174 & 177 & 1.02 \\
\hline & 5 & 2 & 325.7 & 309 & 234 & 0.76 \\
\hline & 6 & 3 & 325.7 & 406 & 275 & 0.68 \\
\hline & 7 & 1 & 440.0 & 429 & 413 & 0.96 \\
\hline & 8 & 2 & 440.0 & 762 & 475 & 0.62 \\
\hline & 9 & 3 & 440.0 & 1000 & 475 & 0.47 \\
\hline
\end{tabular}

Observando-se a comparação mostrada nas estacas do container 2 da Tabela 6.5, nota-se que para as estacas de maior diâmetro de hélice $(D=325.7$ e $440.0 \mathrm{~mm})$ e com 2 e 3 hélices (estacas 5L, 6L, 8L e 9L) a razão $\left(\mathrm{Q}_{\mathrm{h}}\right.$ medida/ $\mathrm{Q}_{\mathrm{h}}$ calculada) é menor, principalmente nas estacas $8 \mathrm{~L}$ e 9L, em que as hélices possuem maior diâmetro. Este fato mostra que o efeito da instalação das estacas de maior diâmetro e com mais de 2 hélices no maciço de areia 
compacta $\left(\mathrm{D}_{\mathrm{r}}=85 \%\right)$ é maior do que o adotado no cálculo (redução de $10 \%$ do ângulo de atrito). Conclui-se que, pelo fato das do diâmetro das hélices das estacas com 2 e 3 hélices serem iguais, a modificação do maciço após a passagem de 2 ou 3 hélices é maior do que se as estacas tivessem hélices em tamanho decrescente do topo para a ponta. Geralmente as estacas metálicas helicoidais multi-hélices utilizadas na prática apresentam hélices em tamanho decrescente do topo para a ponta, para que o efeito da passagem da primeira hélice no maciço, na profundidade em que as outras hélices serão instaladas seja minimizado (Figuras 2.9 e 2.11 da revisão bibliográfica). Como o método de cálculo em questão foi desenvolvido pela A. B. Chance Company, que fabrica estacas com hélices em tamanho decrescente do topo para a ponta, supõe-se que o efeito da modificação do maciço pela passagem de estacas multi-hélices com hélices de igual diâmetro não tenha sido considerado.

Para as estacas $1 \mathrm{~L}, 2 \mathrm{~L}, 3 \mathrm{~L}, 4 \mathrm{~L}$ e $7 \mathrm{~L}$ a razão $\left(\mathrm{Q}_{\mathrm{h}}\right.$ medida/ $\mathrm{Q}_{\mathrm{h}}$ calculada) da Tabela 6.5 mostra que por este método de cálculo, adotando-se a redução de $10 \%$ do valor do ângulo de atrito de pico medido em ensaio de cisalhamento direto, obteve-se uma boa aproximação entre os valores e calculados e medidos em centrífuga.

\section{Estacas ensaiadas em campo}

A Tabela 6.6 apresenta os resultados estimados pelo método das capacidades de carga individuais para as estacas ensaiadas em campo nesta tese. Na Tabela 6.7 é mostrada a comparação entre os valores da parcela de capacidade de carga à tração relativa às hélices $\left(Q_{h}\right)$ medidos em campo e calculados pelo método citado.

Os valores de ângulo de atrito do solo de instalação das estacas $1 \mathrm{C}$ a $6 \mathrm{C}$ foram estimados por meio dos resultados das sondagens das Figuras 4.2 e 4.8 
Como em campo foram medidos os valores totais da capacidade de carga à tração das estacas helicoidais $\left(\mathrm{Q}_{\mathrm{u}}\right)$, para isolar o valor de $\mathrm{Q}_{\mathrm{h}}$ das estacas $1 \mathrm{C}$ a $6 \mathrm{C}$ para esta comparação, foi subtraído do valor medido de $\mathrm{Q}_{\mathrm{u}} \mathrm{o}$ valor da parcela de capacidade de carga à tração relativa ao atrito lateral na haste $\left(\mathrm{Q}_{\mathrm{s}}\right)$, estimada pela Equação 2.11 do método de Mitsch e Clemence (1985).

Tabela 6.6 - Valores de $\mathrm{Q}_{\mathrm{h}}$ calculados pelo Método de Capacidades de Carga Individuais para as estacas ensaiadas em campo

\begin{tabular}{|c|c|c|c|c|c|c|}
\hline Solo & $\begin{array}{c}\text { Estaca } \\
\mathrm{N}^{\mathrm{o}}\end{array}$ & $\begin{array}{l}\mathrm{N}^{\mathrm{o}} \mathrm{de} \\
\text { hélices }\end{array}$ & $\begin{array}{l}\text { Cap. de carga } \\
\text { à tração } \\
\text { relativa a } \\
\text { hélice } 1 \\
\left(\mathrm{Q}_{\mathrm{h} 1}\right), \text { em } \mathrm{kN} \\
\end{array}$ & $\begin{array}{l}\text { Cap. de carga } \\
\text { à tração } \\
\text { relativa a } \\
\text { hélice } 2 \\
\left(\mathrm{Q}_{\mathrm{h} 2}\right) \text {, em } \mathrm{kN}\end{array}$ & $\begin{array}{l}\text { Cap. de carga } \\
\text { à tração } \\
\text { relativa a } \\
\text { hélice } 3 \\
\left(\mathrm{Q}_{\mathrm{h} 3}\right) \text {, em } \mathrm{kN}\end{array}$ & $\begin{array}{l}\text { Cap. de carga } \\
\text { à tração } \\
\text { relativa as } \\
\text { hélices } \\
\left(\mathrm{Q}_{\mathrm{h}}\right), \text { em } \mathrm{kN} \\
\end{array}$ \\
\hline \multirow{4}{*}{$\begin{array}{c}\text { Silte } \\
\text { arenoso }\end{array}$} & $1 \mathrm{C}$ & 2 & 94 & 82 & - & 176 \\
\hline & $2 \mathrm{C}$ & 3 & 50 & 63 & 29 & 142 \\
\hline & $3 \mathrm{C}$ & 3 & 62 & 76 & 35 & 173 \\
\hline & $4 \mathrm{C}$ & 3 & 94 & 84 & 38 & 216 \\
\hline \multirow{2}{*}{$\begin{array}{c}\text { Areia } \\
\text { fina } \\
\text { argilosa }\end{array}$} & $5 \mathrm{C}$ & 2 & 85 & 61 & - & 146 \\
\hline & $6 \mathrm{C}$ & 2 & 17 & 11 & - & 28 \\
\hline
\end{tabular}

$\mathrm{Na}$ Tabela 6.7 observa-se que para as estacas $1 \mathrm{C}, 2 \mathrm{C}, 3 \mathrm{C}, 4 \mathrm{C}$ e $6 \mathrm{C}$, a relação entre $\mathrm{Q}_{\mathrm{h}}$ medida e $\mathrm{Q}_{\mathrm{h}}$ calculada mostra que os resultados do cálculo da capacidade de carga por este método são menores que os resultados medidos. Este fato mostra que este método de cálculo é conservador.

No entanto, na Tabela 6.7, para a estaca 5C instalada em areia fina argilosa, a razão $\left(\mathrm{Q}_{\mathrm{h}}\right.$ medida $/ \mathrm{Q}_{\mathrm{h}}$ calculada $)$ mostra que o método das capacidades de carga individuais superestimou o resultado. Este fato pode ser explicado pela elevada profundidade desta estaca (razão $\mathrm{H} / \mathrm{D}=45$ ) em relação às estacas padrão. Por esta razão, o valor da tensão efetiva acima 
da hélice da Equação 2.13, do método de cálculo utilizado, é elevado devido à grande profundidade da estaca, que foi penetrada em grande espessura de solo devido ao fato do subsolo ser composto por uma areia de baixa resistência à penetração (Figura 4.8). Com o valor de tensão efetiva elevado, o valor de $\mathrm{Q}_{\mathrm{h}}$ calculado é conseqüentemente majorado.

Tabela 6.7 - Comparação entre os valores de $\mathrm{Q}_{\mathrm{h}}$ calculados pelo Método de Capacidades de Carga Individuais e medidos nos ensaios de campo

\begin{tabular}{|c|c|c|c|c|}
\hline \multirow[t]{2}{*}{ Solo } & \multirow[t]{2}{*}{$\begin{array}{c}\text { Estaca } \\
\mathrm{N}^{\mathbf{0}}\end{array}$} & \multicolumn{2}{|c|}{$\begin{array}{c}\text { Capacidade de carga à tração relativa } \\
\text { às hélices } \\
\left(\mathrm{Q}_{\mathrm{h}}\right), \text { em kN }\end{array}$} & \multirow[t]{2}{*}{$\begin{array}{l}\mathrm{Q}_{\mathrm{h}} \text { medida/ } \\
\mathrm{Q}_{\mathrm{h}} \text { calculada }\end{array}$} \\
\hline & & calculada & medida & \\
\hline \multirow{4}{*}{$\begin{array}{c}\text { Silte } \\
\text { arenoso }\end{array}$} & $1 \mathrm{C}$ & 176 & 180 & 1,02 \\
\hline & $2 \mathrm{C}$ & 142 & 168 & 1,18 \\
\hline & $3 \mathrm{C}$ & 173 & 260 & 1,50 \\
\hline & $4 \mathrm{C}$ & 216 & 227 & 1,05 \\
\hline \multirow{2}{*}{$\begin{array}{l}\text { Areia } \\
\text { fina } \\
\text { argilosa }\end{array}$} & $5 \mathrm{C}$ & 146 & 80 & 0,55 \\
\hline & $6 C$ & 28 & 40 & 1,43 \\
\hline
\end{tabular}

\subsubsection{Método da ruptura cilíndrica}

Para as estacas instaladas em areia e em silte arenoso foi utilizado o método da ruptura cilíndrica, desenvolvido por Mitsch e Clemence (1985) para ancoragens profundas em areias, apresentado na revisão bibliográfica desta tese. Este método de cálculo assume que abaixo da hélice de topo da estaca a superfície de ruptura do solo é aproximadamente cilíndrica. Para a determinação do fator $\mathrm{N}_{\mathrm{qu}}$ utilizado na Equação 2.9 deste método para o cálculo da parcela de capacidade de carga devido à hélice de topo $\left(\mathrm{Q}_{\mathrm{p}}\right)$, foi utilizada a curva proposta pela A.B. Chance Co. (1994) na Figura 2.24 ao invés da relação apresentada por Mitsch e Clemence 
(1985) na Figura 2.23. A curva proposta pela A.B. Chance Co. (1994) entre o $\mathrm{N}_{\mathrm{q}}$ e o ângulo de atrito interno da areia $(\phi)$ foi escolhida pelo autor desta tese para a determinação do fator $\mathrm{N}_{\mathrm{qu}}$ nesta verificação pelo fato de ser uma curva baseada nos fatores de capacidade de carga modificados empiricamente com base na performance de fundações em ancoragens helicoidais.

\section{Estacas protótipo da modelagem física em centrífuga}

A Tabela 6.8 apresenta os resultados estimados pelo método da ruptura cilíndrica para as estacas protótipo utilizadas na modelagem física em centrífuga. A Tabela 6.9 mostra a comparação entre os valores da parcela de capacidade de carga à tração relativa às hélices $\left(Q_{h}\right)$ medidos em centrífuga e calculados pelo método em questão.

Nas Tabelas 6.8 e 6.9, a soma das parcelas $\mathrm{Q}_{\mathrm{p}}$ e $\mathrm{Q}_{\mathrm{f}}$ da Equação 2.8 corresponde à parcela da capacidade de carga à tração relativa às hélices $\left(\mathrm{Q}_{\mathrm{h}}\right)$ medida em centrífuga.

Observa-se na Tabela 6.9, nas estacas de maior diâmetro $(\mathrm{D}=440 \mathrm{~mm})$ do container 1 que os valores medidos de $\mathrm{Q}_{\mathrm{h}}$ são em torno $58 \%$ dos valores calculados. Porém, se o valor de ângulo de atrito da areia adotados no cálculo de $\mathrm{Q}_{\mathrm{h}}$ para estas estacas fosse menor do que o valor reduzido de $10 \%$ (utilizado para areia fofa por Levesque (2002)) os valores calculados se aproximariam dos medidos. Esta ocorrência mostra que para estacas com hélice de grande diâmetro em areia medianamente compacta $\left(D_{r}=56 \%\right)$ a modificação no solo durante a instalação é maior do que nas estacas de diâmetro menor. O mesmo fato ocorreu na comparação entre os valores de $\mathrm{Q}_{\mathrm{h}}$ medidos e calculados pelo método das capacidades de carga individuais.

A Tabela 6.9 mostra que estacas $1 \mathrm{~L}$ a $6 \mathrm{~L}$ instaladas no container 1 apresentam o valor médio da razão $\left(\mathrm{Q}_{\mathrm{h}}\right.$ medida $/ \mathrm{Q}_{\mathrm{h}}$ calculada $)$ igual a 1,08 com $24 \%$ de coeficiente de variação. 
Deste modo, este método proporcionou nestes casos valores calculados de $\mathrm{Q}_{\mathrm{h}}$ próximos aos valores medidos em centrífuga.

Tabela 6.8 - Valores de $\mathrm{Q}_{\mathrm{h}}$ calculados pelo método da ruptura cilíndrica para as estacas ensaiadas em centrífuga

\begin{tabular}{|c|c|c|c|c|c|}
\hline Solo & $\begin{array}{c}\text { Estaca } \\
\mathrm{N}^{\mathrm{o}}\end{array}$ & $\begin{array}{l}\mathrm{N}^{\mathrm{o}} \mathrm{de} \\
\text { hélices }\end{array}$ & $\begin{array}{l}\text { Cap. de carga } \\
\text { à tração } \\
\text { relativa a } \\
\text { hélice de topo } \\
\left(\mathrm{Q}_{\mathrm{p}}\right), \text { em } \mathrm{kN}\end{array}$ & $\begin{array}{c}\text { Cap. de carga } \\
\text { devido à resistência } \\
\text { por atrito na } \\
\text { superfície cilíndrica } \\
\left(\mathrm{Q}_{\mathrm{f}}\right) \text {, em } \mathrm{kN} \\
\end{array}$ & $\begin{array}{c}\text { Cap. de carga à } \\
\text { tração relativa as } \\
\text { hélices } \\
\left(\mathrm{Q}_{\mathrm{h}}=\mathrm{Q}_{\mathrm{P}}+\mathrm{Q}_{\mathrm{f}}\right), \\
\text { em kN }\end{array}$ \\
\hline \multirow{9}{*}{  } & $1 \mathrm{~L}$ & 1 & 15 & - & 15 \\
\hline & $2 \mathrm{~L}$ & 2 & 15 & 7 & 22 \\
\hline & $3 \mathrm{~L}$ & 3 & 15 & 13 & 28 \\
\hline & $4 \mathrm{~L}$ & 1 & 52 & - & 52 \\
\hline & $5 \mathrm{~L}$ & 2 & 52 & 26 & 77 \\
\hline & $6 \mathrm{~L}$ & 3 & 52 & 45 & 97 \\
\hline & $7 \mathrm{~L}$ & 1 & 127 & - & 127 \\
\hline & $8 \mathrm{~L}$ & 2 & 127 & 63 & 190 \\
\hline & $9 \mathrm{~L}$ & 3 & 127 & 111 & 238 \\
\hline \multirow{9}{*}{  } & $1 \mathrm{~L}$ & 1 & 50 & - & 50 \\
\hline & $2 \mathrm{~L}$ & 2 & 50 & 26 & 76 \\
\hline & $3 \mathrm{~L}$ & 3 & 50 & 45 & 95 \\
\hline & $4 \mathrm{~L}$ & 1 & 174 & - & 174 \\
\hline & $5 \mathrm{~L}$ & 2 & 174 & 91 & 265 \\
\hline & $6 \mathrm{~L}$ & 3 & 174 & 159 & 333 \\
\hline & $7 \mathrm{~L}$ & 1 & 429 & - & 429 \\
\hline & $8 \mathrm{~L}$ & 2 & 429 & 224 & 652 \\
\hline & 9L & 3 & 429 & 392 & 820 \\
\hline
\end{tabular}

Na comparação mostrada nas estacas do container 2 da Tabela 6.9, nota-se que para as estacas de maior diâmetro de hélice ( $D=325,7$ e 440,0 mm) e com 2 e 3 hélices (estacas 5L, $6 \mathrm{~L}, 8 \mathrm{~L}$ e $9 \mathrm{~L})$ a razão $\left(\mathrm{Q}_{\mathrm{h}}\right.$ medida/ $\mathrm{Q}_{\mathrm{h}}$ calculada) é menor, principalmente nas estacas $8 \mathrm{~L}$ e $9 \mathrm{~L}$, em que as hélices possuem maior diâmetro. Este fato ocorreu também na comparação feita anteriormente entre os valores de $\mathrm{Q}_{\mathrm{h}}$ calculados pelo método das capacidades de carga individuais e medidos em centrífuga, pela mesma razão explicada anteriormente no item 
6.2.1.1. No entanto, para as estacas 1L, 2L e 3L instaladas no container 2, os valores da razão $\left(\mathrm{Q}_{\mathrm{h}}\right.$ medida/ $\mathrm{Q}_{\mathrm{h}}$ calculada) indicam que os resultados das estimativas por este método de cálculo é conservadora, ou seja, os valores calculados em torno de $20 \%$ superiores aos medidos. Para as estacas $4 \mathrm{~L}$ e $7 \mathrm{~L}$ os valores calculados e medidos mostraram-se bem próximos.

Na tese de Levesque (2002), onde foram realizados ensaios de modelagem em centrífuga de ancoragens helicoidais rasas instaladas em areia, a verificação dos resultados de capacidade de carga à tração $\left(\mathrm{Q}_{\mathrm{u}}\right)$ medidos em centrífuga pelo método da ruptura cilíndrica para estacas instaladas em areia fofa, mostrou a razão $\left(Q_{h}\right.$ medida/ $Q_{h}$ calculada entre) 0,45 e 0,82 , ou seja, os valores calculados foram superestimados. Por outro lado, para estacas instaladas em areia densa neste trabalho citado, esta razão variou de 1,08 a 1,74. No entanto, deve-se frisar que o método da ruptura cilíndrica utilizado na pesquisa mencionada foi apropriado para ancoragens rasas, e para o cálculo da parcela da capacidade de carga relativa à hélice de topo $\left(\mathrm{Q}_{\mathrm{p}}\right)$ a fórmula utilizada para ancoragens rasas é diferente da utilizada nesta tese, já que as estacas ensaiadas no presente trabalho são qualificadas como profundas $(\mathrm{H} / \mathrm{D}>5)$.

A Tabela 6.10 mostra a comparação entre os valores medidos em centrífuga de parcela da capacidade de carga à tração relativa às hélices $\left(\mathrm{Q}_{\mathrm{h}}\right)$ e os resultados das estimativas feitas pelos dois métodos de cálculo utilizados.

Nota-se nesta tabela, que independentemente do método de cálculo, os valores de ângulo de atrito adotados para estacas de maior diâmetro e número de hélices devem ser diminuídos, principalmente nas estacas de 2 e 3 hélices (de diâmetros iguais) instaladas na areia mais compacta, para que os valores estimados de capacidade de carga aproximem-se dos medidos. Esta redução deve ser feita para considerar-se o efeito da modificação do maciço após a passagem das hélices e não superestimar-se os valores de $\mathrm{Q}_{\mathrm{h}}$. Além do efeito da redução do ângulo de atrito, os resultados de $\mathrm{Q}_{\mathrm{h}}$ medidos em centrífuga (para estacas de maior diâmetro) 
são inferiores aos estimados pelos dois métodos verificados, devido ao fato de se adotar para a medida de $\mathrm{Q}_{\mathrm{s}}$ a área lateral da haste correspondente ao comprimento total embutido nos containeres ensaiados.

Tabela 6.9 - Comparação entre os valores de $\mathrm{Q}_{\mathrm{h}}$ calculados pelo método da ruptura cilíndrica medidos nos ensaios em centrífuga

\begin{tabular}{|c|c|c|c|c|c|c|}
\hline \multirow[t]{2}{*}{ Solo } & \multirow[t]{2}{*}{$\begin{array}{l}\text { Estaca } \\
\mathrm{N}^{\mathrm{o}}\end{array}$} & \multirow[t]{2}{*}{$\begin{array}{l}\mathrm{N}^{\mathrm{o}} \mathrm{de} \\
\text { hélices }\end{array}$} & \multirow[t]{2}{*}{$\begin{array}{l}\text { Diâmetro } \\
\text { da hélice } \\
\text { (D) em mm }\end{array}$} & \multicolumn{2}{|c|}{$\begin{array}{l}\text { Capacidade de carga à tração } \\
\text { relativa às hélices } \\
\left(\mathrm{Q}_{\mathrm{h}}\right), \text { em kN }\end{array}$} & \multirow[t]{2}{*}{$\begin{array}{l}\mathrm{Q}_{\mathrm{h}} \text { medida/ } \\
\mathrm{Q}_{\mathrm{h}} \text { calculada }\end{array}$} \\
\hline & & & & calculada & medida & \\
\hline \multirow{9}{*}{ 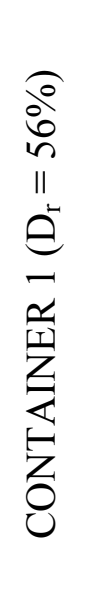 } & $1 \mathrm{~L}$ & 1 & 214,4 & 15 & 14 & 0,95 \\
\hline & $2 \mathrm{~L}$ & 2 & 214,4 & 22 & 19 & 0.86 \\
\hline & $3 \mathrm{~L}$ & 3 & 214,4 & 28 & 43 & 1,56 \\
\hline & $4 \mathrm{~L}$ & 1 & 325,7 & 52 & 46 & 0,89 \\
\hline & $5 \mathrm{~L}$ & 2 & 325,7 & 77 & 83 & 1,07 \\
\hline & $6 \mathrm{~L}$ & 3 & 325,7 & 97 & 112 & 1,16 \\
\hline & $7 \mathrm{~L}$ & 1 & 440,0 & 127 & 69 & 0,54 \\
\hline & $8 \mathrm{~L}$ & 2 & 440,0 & 190 & 108 & 0,57 \\
\hline & $9 \mathrm{~L}$ & 3 & 440,0 & 238 & 150 & 0,63 \\
\hline \multirow{9}{*}{  } & $1 \mathrm{~L}$ & 1 & 214,4 & 50 & 60 & 1,21 \\
\hline & $2 \mathrm{~L}$ & 2 & 214,4 & 76 & 88 & 1,17 \\
\hline & $3 \mathrm{~L}$ & 3 & 214,4 & 95 & 116 & 1,22 \\
\hline & $4 \mathrm{~L}$ & 1 & 325,7 & 174 & 177 & 1,02 \\
\hline & $5 \mathrm{~L}$ & 2 & 325,7 & 265 & 234 & 0,88 \\
\hline & $6 \mathrm{~L}$ & 3 & 325,7 & 333 & 275 & 0,83 \\
\hline & $7 \mathrm{~L}$ & 1 & 440,0 & 429 & 413 & 0,96 \\
\hline & $8 \mathrm{~L}$ & 2 & 440,0 & 652 & 475 & 0,73 \\
\hline & 9L & 3 & 440,0 & 820 & 475 & 0,58 \\
\hline
\end{tabular}

Tabela 6.10 - Comparação dos valores de $\mathrm{Q}_{\mathrm{h}}$ calculados pelo método da ruptura cilíndrica e pelo método das capacidades de carga individuais com os valores medidos nos ensaios em centrífuga 


\begin{tabular}{|c|c|c|c|c|c|c|}
\hline \multirow{2}{*}{ Solo } & \multirow{2}{*}{$\begin{array}{c}\text { Estaca } \\
\mathrm{N}^{\mathrm{o}}\end{array}$} & \multirow{2}{*}{$\begin{array}{l}\mathrm{N}^{\mathrm{o}} \text { de } \\
\text { hélices }\end{array}$} & \multirow{2}{*}{$\begin{array}{c}\text { Diâmetro da } \\
\text { hélice (D) } \\
\text { em mm }\end{array}$} & \multicolumn{3}{|c|}{$\begin{array}{l}\text { Capacidade de carga à tração relativa às hélices } \\
\qquad\left(\mathrm{Q}_{\mathrm{h}}\right), \mathrm{em} \mathrm{kN}\end{array}$} \\
\hline & & & & $\begin{array}{l}\text { Ruptura } \\
\text { cilíndrica }\end{array}$ & $\begin{array}{l}\text { Capacidades } \\
\text { individuais }\end{array}$ & $\begin{array}{c}\text { Medida em } \\
\text { centrífuga }\end{array}$ \\
\hline \multirow{9}{*}{ 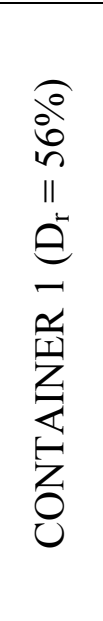 } & $1 \mathrm{~L}$ & 1 & 214,4 & 15 & 15 & 14 \\
\hline & $2 \mathrm{~L}$ & 2 & 214,4 & 22 & 26 & 19 \\
\hline & $3 \mathrm{~L}$ & 3 & 214,4 & 28 & 34 & 43 \\
\hline & $4 \mathrm{~L}$ & 1 & 325,7 & 52 & 52 & 46 \\
\hline & $5 \mathrm{~L}$ & 2 & 325,7 & 77 & 92 & 83 \\
\hline & $6 \mathrm{~L}$ & 3 & 325,7 & 97 & 120 & 112 \\
\hline & $7 \mathrm{~L}$ & 1 & 440,0 & 127 & 127 & 69 \\
\hline & $8 \mathrm{~L}$ & 2 & 440,0 & 190 & 226 & 108 \\
\hline & $9 \mathrm{~L}$ & 3 & 440,0 & 238 & 296 & 150 \\
\hline \multirow{9}{*}{ 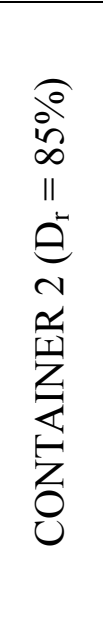 } & $1 \mathrm{~L}$ & 1 & 214,4 & 50 & 50 & 60 \\
\hline & $2 \mathrm{~L}$ & 2 & 214,4 & 76 & 88 & 88 \\
\hline & $3 \mathrm{~L}$ & 3 & 214,4 & 95 & 116 & 116 \\
\hline & $4 \mathrm{~L}$ & 1 & 325,7 & 174 & 174 & 177 \\
\hline & $5 \mathrm{~L}$ & 2 & 325,7 & 265 & 309 & 234 \\
\hline & $6 \mathrm{~L}$ & 3 & 325,7 & 333 & 406 & 275 \\
\hline & $7 \mathrm{~L}$ & 1 & 440,0 & 429 & 429 & 413 \\
\hline & $8 \mathrm{~L}$ & 2 & 440,0 & 652 & 762 & 475 \\
\hline & $9 \mathrm{~L}$ & 3 & 440,0 & 820 & 1000 & 475 \\
\hline
\end{tabular}

\section{Estacas ensaiadas em campo}

A Tabela 6.11 apresenta os resultados estimados de capacidade de carga à tração $\left(\mathrm{Q}_{\mathrm{u}}\right)$ pelo método da ruptura cilíndrica para as estacas ensaiadas em campo nesta tese. Na Tabela 6.12 mostra-se a comparação entre os valores de $\mathrm{Q}_{\mathrm{u}}$ medidos em campo e calculados pelo método da ruptura cilíndrica. 
Tabela 6.11 - Valores de $\mathrm{Q}_{\mathrm{u}}$ calculados pelo método da ruptura cilíndrica para as estacas ensaiadas em campo

\begin{tabular}{|c|c|c|c|c|c|c|}
\hline Solo & $\begin{array}{c}\text { Estaca } \\
\mathrm{N}^{\mathrm{o}}\end{array}$ & $\begin{array}{l}\mathrm{N}^{\mathrm{o}} \text { de } \\
\text { hélices }\end{array}$ & $\begin{array}{c}\text { Cap. de carga } \\
\text { à tração } \\
\text { relativa a } \\
\text { hélice de } \\
\text { topo }\left(\mathrm{Q}_{\mathrm{p}}\right), \text { em } \\
\mathrm{kN}\end{array}$ & $\begin{array}{l}\text { Cap. de carga } \\
\text { devido à } \\
\text { resistência por } \\
\text { atrito na } \\
\text { superfície } \\
\text { cilíndrica }\left(\mathrm{Q}_{\mathrm{f}}\right) \text {, } \\
\text { em kN } \\
\end{array}$ & $\begin{array}{l}\text { Cap. de carga } \\
\text { à tração } \\
\text { devido ao } \\
\text { atrito no tubo } \\
\left(\mathrm{Q}_{\mathrm{s}}\right), \text { em } \mathrm{kN}\end{array}$ & $\begin{array}{c}\text { Capacidade } \\
\text { de carga à } \\
\text { tração }\left(\mathrm{Q}_{\mathrm{u}}\right) \text {, } \\
\text { em } \mathrm{kN}\end{array}$ \\
\hline \multirow{4}{*}{$\begin{array}{c}\text { Silte } \\
\text { arenoso }\end{array}$} & $1 \mathrm{C}$ & 2 & 94 & 51 & 40 & 184 \\
\hline & $2 \mathrm{C}$ & 3 & 50 & 94 & 32 & 176 \\
\hline & $3 \mathrm{C}$ & 3 & 62 & 107 & 30 & 199 \\
\hline & $4 C$ & 3 & 94 & 135 & 34 & 263 \\
\hline $\begin{array}{l}\text { Areia } \\
\text { fina }\end{array}$ & $5 \mathrm{C}$ & 2 & 85 & 44 & 90 & 219 \\
\hline argilosa & $6 \mathrm{C}$ & 2 & 17 & 22 & 90 & 130 \\
\hline
\end{tabular}

Na Tabela 6.12 observa-se que para estacas 1C, 2C, 4C e 6C, o método da ruptura cilíndrica mostrou-se apropriado. Para a estaca 3C este método mostrou-se conservador. No entanto, para a estaca 5C, instalada em areia fina argilosa, este método superestimou os resultados da capacidade de carga. Como a estaca 5C apresenta elevada profundidade, ocorreu o mesmo que anteriormente na análise do método das capacidades de carga individuais, ou seja, o valor estimado da tensão efetiva acima da hélice é elevado, e o valor de $Q_{p}$ calculado (Tabela 6.11) é conseqüentemente majorado. 
Tabela 6.12 - Comparação entre os valores de $\mathrm{Q}_{\mathrm{u}}$ calculados pelo método da ruptura cilíndrica e medidos nos ensaios de campo

\begin{tabular}{|c|c|c|c|c|}
\hline \multirow[t]{2}{*}{ Solo } & \multirow[t]{2}{*}{$\begin{array}{l}\text { Estaca } \\
\mathrm{N}^{\mathrm{o}}\end{array}$} & \multicolumn{2}{|c|}{$\begin{array}{c}\text { Capacidade de carga à tração }\left(\mathrm{Q}_{u}\right), \\
\text { em } \mathrm{kN}\end{array}$} & \multirow[t]{2}{*}{$\begin{array}{l}\mathrm{Q}_{\mathrm{u}} \text { medida/ } \\
\mathrm{Q}_{\mathrm{u}} \text { calculada }\end{array}$} \\
\hline & & calculada & medida & \\
\hline \multirow{4}{*}{$\begin{array}{c}\text { Silte } \\
\text { arenoso }\end{array}$} & 1 & 184 & 220 & 1,19 \\
\hline & 2 & 176 & 200 & 1,14 \\
\hline & 3 & 199 & 290 & 1,46 \\
\hline & 4 & 263 & 261 & 0,99 \\
\hline $\begin{array}{c}\text { Areia } \\
\text { fina }\end{array}$ & 5 & 219 & 170 & 0,77 \\
\hline argilosa & 6 & 130 & 130 & 1,00 \\
\hline
\end{tabular}

\subsubsection{Fator de capacidade de carga à tração}

Segundo a literatura geotécnica (como, por exemplo, em Ovensen (1981) e em Rowe e Davis (1982)) para ancoragens em placa instaladas à mesma profundidade relativa (H/D, onde H é a profundidade da placa e D o diâmetro), e na mesma areia, os valores do fator de capacidade de carga à tração $\left(\mathrm{N}_{\mathrm{qu}}\right)$ deve ser o mesmo.

A Figura 2.23 da revisão bibliográfica mostra alguns valores da relação entre o fator de capacidade de carga à tração $\left(\mathrm{N}_{\mathrm{qu}}\right)$ versus a razão $\mathrm{H} / \mathrm{D}$ para estacas helicoidais em areia mostrada em Mitsch e Clemence (1985).

No programa experimental realizado em centrífuga nesta tese, foram ensaiadas estacas de uma hélice (estacas 1L, 4L e 7L) com diâmetros diferentes, instaladas à mesma profundidade relativa $\mathrm{H} / \mathrm{D}=13,5$ (Figura 4.26), em dois maciços distintos (areia com $\gamma=15,46 \mathrm{kN} / \mathrm{m}^{3}$ e com $\left.\gamma=16,30 \mathrm{kN} / \mathrm{m}^{3}\right)$. 
A Tabela 6.13 apresenta os valores de $\mathrm{N}_{\mathrm{qu}}$ encontrados experimentalmente nas estacas de uma hélice ensaiadas em centrífuga. Nesta tabela os valores são apresentados em escala do protótipo.

Tabela 6.13 - Valores do fator de capacidade de carga à tração $\left(\mathrm{N}_{\mathrm{qu}}\right)$ encontrados nos ensaios em centrífuga (estacas com a razão H/D igual a 13,5)

\begin{tabular}{|c|c|c|c|c|c|}
\hline Solo & $\begin{array}{c}\text { Estaca } \\
\mathrm{N}^{\mathrm{o}}\end{array}$ & $\begin{array}{c}\text { Área da } \\
\text { efetiva da } \\
\text { hélice (A), } \\
\text { em m }^{2}\end{array}$ & $\begin{array}{l}\text { Capacidade de } \\
\text { carga à tração } \\
\text { relativa à hélice } \\
\left(\mathrm{Q}_{\mathrm{h}}\right), \text { em } \mathrm{kN}\end{array}$ & $\begin{array}{c}\text { Profundidade } \\
\text { da hélice }(\mathrm{H}), \\
\text { em m }\end{array}$ & $\begin{array}{c}\text { Fator de } \\
\text { capacidade de } \\
\text { carga à tração } \\
\left(\mathrm{N}_{\mathrm{qu}}=\mathrm{Q}_{\mathrm{h}} / \gamma \mathrm{HA}\right)\end{array}$ \\
\hline$\stackrel{\widetilde{E}}{\xi}$ & $1 \mathrm{~L}$ & 0,033 & 14 & 2,89 & 10 \\
\hline  & $4 \mathrm{~L}$ & 0,076 & 46 & 4,40 & 9 \\
\hline$\succsim$ & $7 \mathrm{~L}$ & 0,138 & 69 & 5,94 & 5 \\
\hline 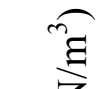 & $1 \mathrm{~L}$ & 0,033 & 60 & 2,89 & 39 \\
\hline 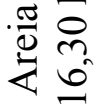 & $4 \mathrm{~L}$ & 0,076 & 177 & 4,40 & 33 \\
\hline 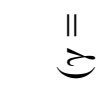 & $7 \mathrm{~L}$ & 0,138 & 413 & 5,94 & 31 \\
\hline
\end{tabular}

Na Tabela 6.13, observa-se que para a areia 1 o valor de $\mathrm{N}_{\mathrm{qu}}$ apresentou maior variação do que para a areia 2. Na areia 1 o valor médio encontrado de $\mathrm{N}_{\mathrm{qu}}$ é igual a 8 com coeficiente de variação de $27,8 \%$, e na areia 2 o valor médio de $\mathrm{N}_{\text {qu }}$ é igual a 34 com coeficiente de variação de $12,2 \%$.

Estes resultados mostram que apesar dos valores de $\mathrm{N}_{\mathrm{qu}}$ estarem na mesma ordem de grandeza para hélices instaladas na mesma profundidade relativa e no mesmo solo, existe um pequeno efeito da dimensão da hélice. Nota-se na Tabela 6.13 que para hélices maiores o valor de $\mathrm{N}_{\text {qu }}$ decresce em ambos os solos ensaiados. A Figura 6.2 mostra a relação entre o 
fator de capacidade de carga à tração $\left(\mathrm{N}_{\mathrm{qu}}\right)$ obtidos nos ensaios em centrífuga e o diâmetro da hélice (D).



Figura 6.2 - Fator de capacidade de carga à tração $\left(\mathrm{N}_{\mathrm{qu}}\right)$ obtidos nos ensaios em centrífuga versus diâmetro da hélice (D)

Comparando-se os valores de $\mathrm{N}_{\mathrm{qu}}$ obtidos com os exibidos na Figura 2.23 da revisão bibliográfica, nota-se que se utilizarmos os valores de ângulo de atrito de pico (medidos em ensaios de cisalhamento direto) para as duas areias ensaiadas $\left(\phi_{\mathrm{p}}=31^{\circ}\right.$ para a areia 1 e $\phi_{\mathrm{p}}=41^{\circ}$ para areia 2), os valores de $\mathrm{N}_{\mathrm{qu}}$ encontrados nos ensaios em centrífuga são inferiores aos mostrados nesta figura. Isto indica que o ângulo de atrito da areia acima da hélice tenha sido diminuído devido ao efeito da instalação da estaca nos maciços de areia e, conseqüentemente, os valores de $\mathrm{N}_{\mathrm{qu}}$ medidos nesta pesquisa correspondam a um valor de ângulo de atrito inferior ao valor de pico medido nos ensaios de cisalhamento direto. 
Este fato confirma o resultado encontrado na tese de Levesque (2002) sobre modelagem física em centrífuga de estacas helicoidais em areia. Neste trabalho citado foram executados ensaios de cone (em torno da estaca) em um container de areia fofa antes e após a instalação da estaca. Estes resultados mostraram que para a areia fofa utilizada o valor do ângulo de atrito diminuiu em torno de $10 \%$ em relação ao valor do ângulo de atrito de pico medido em ensaio de cisalhamento direto. No entanto supõe-se que o fator de redução do ângulo de atrito, conforme proposto por Levesque (2002), e adotado nesta tese, não deveria ser constante e sim variável em função das características do solo.

\subsection{Efeito do número de hélices}

$\mathrm{Na}$ maioria das vezes as estacas metálicas helicoidais multi-hélices utilizadas na prática apresentam hélices em tamanho decrescente do topo para a ponta, para que o efeito da passagem da primeira hélice no maciço, na profundidade em que as outras hélices serão instaladas seja minimizado.

Como podem existir diversas configurações de variação de diâmetro de uma estaca multihélice, optou-se por ensaiar em centrífuga um modelo padrão, com estacas multi-hélices de igual diâmetro.

Nos ensaios realizados em centrífuga, os modelos utilizados de estacas foram fabricados e instalados com a hélice da ponta na mesma profundidade, para verificar se o número de hélices influenciava a Equação 3.14 proposta nesta tese. Além deste fim, estes experimentos foram adequados para examinar o quanto o acréscimo de hélices de mesmo diâmetro contribui para a capacidade de carga à tração de uma estaca metálica helicoidal instalada em areia, para orientar o projetista deste tipo de fundação na fixação do número de hélices a ser adotado na produção desta estaca. 
Pelos resultados mostrados na comparação da Tabela 6.2 constatou-se que o número de hélices não afeta a relação sugerida nesta tese (Equação 3.14) entre parcela de capacidade de carga à tração relativa às hélices $\left(\mathrm{Q}_{\mathrm{h}}\right)$ e momento resistente à instalação gerado nas hélices $\left(\mathrm{T}_{\mathrm{h}}\right)$ medido no final da instalação da estaca.

Este fato ocorre porque o distúrbio causado pela passagem da primeira hélice de uma estaca multi-hélices na profundidade em que será instalada a segunda hélice afeta igualmente as parcelas de torque de instalação e da capacidade de carga relativa à segunda hélice. $\mathrm{O}$ mesmo ocorre com a estaca de três hélices, a passagem da primeira e da segunda hélice na profundidade em que será instalada a terceira hélice (hélice superior) afeta igualmente as parcelas de torque de instalação e da capacidade de carga relativa à terceira hélice.

A Tabela 6.14 mostra as parcelas de torque e de capacidade de carga relativas às hélices nas estacas com duas hélices ensaiadas em centrífuga. Para obter as parcelas de $T_{h}$ e de $Q_{h}$ relativa a cada hélice das estacas desta tabela, subtraiu-se do resultado de $T_{h}$ e de $Q_{h}$ das estacas de 2 hélices o resultado do $\mathrm{T}_{\mathrm{h}}$ e de $\mathrm{Q}_{\mathrm{h}}$ das estacas de uma hélice instalada na mesma profundidade (vide Figura 6.3). Deste modo, foram utilizadas as seguintes equações:

Parcela de torque da hélice 1 (inferior) da estaca $N^{o} 2 L=\frac{T_{h_{\text {estacaN }}^{\circ} 1 L}}{T_{h_{e s t a c a N^{\circ} 2 L}}}$

Parcela de torque da hélice 2 (superior) da estaca $N^{o} 2 L=\frac{T_{h_{e s t a c a N}{ }^{2} 2 L}-T_{\text {hestacaN }^{\circ} 1 L}}{T_{h_{\text {estacaN }} 2 L}}$

Parcela de torque da hélice 1 (inferior) da estaca $N^{\circ} 5 L=\frac{T_{h_{e s t a c a N^{\circ} 4 L}}}{T_{h_{\text {estacaN }} 5 L}}$

Parcela de torque da hélice 2 (superior) da estaca $N^{o} 5 L=\frac{T_{h_{\text {estacaN }}^{\circ} 5 L}-T_{h_{e s t a c a N^{\circ} 4 L}}}{T_{h_{e s t a c a N^{\circ} 5 L}}}$ 
Parcela de torque da hélice 1 (inferior) da estaca $N^{o} 8 L=\frac{T_{h_{e s t a c a N^{\circ} 7 L}}}{T_{h_{e s t a c a N^{\circ} 8 L}}}$

Parcela de torque da hélice 2 (superior) da estaca $N^{o} 8 L=\frac{T_{\text {estacaN }^{\circ} 8 L}-T_{h_{\text {estacaN }}^{\circ} 7 L}}{T_{\text {hestacaN }^{\circ} 8 L}}$

Parcela de $Q_{h}$ da hélice 1 (inferior) da estaca $N^{o} 2 L=\frac{Q_{\text {hestacaN }^{\circ} 1 L}}{Q_{\text {hestacaN }^{\circ} 2 L}}$

Parcela de $Q_{h}$ da hélice 2 (superior) da estaca $N^{o} 2 L=\frac{Q_{\text {hestacaN }^{\circ} 2 L}-Q_{\text {hestacaN }^{\circ} 1 L}}{Q_{h_{e s t a c a N^{\circ} 2 L}}}$

Parcela de $Q_{h}$ da hélice 1 (inferior) da estaca $N^{\circ} 5 L=\frac{Q_{h_{e s t a c a N^{\circ}} 4 L}}{Q_{\text {hestaca }^{\circ}{ }^{\circ} L}}$

Parcela de $Q_{h}$ da hélice 2 (superior) da estaca $N^{o} 5 L=\frac{Q_{h \text { estacaN }^{\circ} 5 L}-Q_{h_{\text {estacaN }}{ }^{\circ} 4 L}}{Q_{h_{\text {estacaN }}{ }^{\circ} 5 L}}$

Parcela de $Q_{h}$ da hélice 1 (inferior) da estaca $N^{o} 8 L=\frac{Q_{h_{\text {estaca }}{ }^{\circ} 7 L}}{Q_{h_{\text {estaca }}{ }^{\circ} 8 L}}$

Parcela de $Q_{h}$ da hélice 2 (superior) da estaca $N^{o} 8 L=\frac{Q_{h_{e s t a c a N^{\circ} 8 L}}-Q_{h_{\text {estaca }}{ }^{\circ} 7 L}}{Q_{h_{\text {estacaN }}{ }^{\circ} 8 L}}$ 




estaca estaca estaca estaca $\mathrm{N}^{0} 12 \mathrm{~L} \quad \mathrm{~N}^{\circ} 7 \mathrm{~L} \quad \mathrm{~N}^{\circ} 8 \mathrm{~L} \quad \mathrm{~N}^{\circ} 9 \mathrm{~L}$

Figura 6.3 - Modelos de estacas utilizados nos ensaios em centrífuga instalados na profundidade final

$\mathrm{Na}$ Tabela 6.15 são apresentadas as parcelas de torque e de capacidade de carga relativas às hélices nas estacas com três hélices ensaiadas em centrífuga. Para obter as parcelas de $T_{h} \mathrm{e}$ de $\mathrm{Q}_{\mathrm{h}}$ relativa a cada hélice, adotou-se o mesmo procedimento usado para estacas de duas hélices. As equações utilizadas foram as seguintes:

Parcela de torque da hélice 1 (inferior) da estaca $N^{o} 3 L=\frac{T_{h_{e s t a c a N^{\circ} 1 L}}}{T_{h_{\text {estaca }} 3 L}}$

Parcela de torque da hélice 2 (central) da estaca $N^{o} 3 L=\frac{T_{h_{e s t a c a N^{\circ} 2 L}}-T_{h_{e s t a c a N^{\circ} 1 L}}}{T_{h_{e s t a c a N^{\circ} 3 L}}}$ 
Parcela de torque da hélice 3 (superior) da estaca $N^{o} 3 L=\frac{T_{h_{\text {estacaN }}^{\circ} 3 L}-T_{h_{\text {estacaN }} 2 L}}{T_{h_{\text {estacaN }} 3 L}}$

Parcela de torque da hélice 1 (inferior) da estaca $N^{o} 6 L=\frac{T_{\text {hestaca }}{ }^{\circ} 4 L}{T_{\text {estacaN }^{\circ} 6 L}}$

Parcela de torque da hélice 2 (central) da estaca $N^{o} 6 L=\frac{T_{h_{e s t a c a N}{ }^{\circ} 5 L}-T_{h_{\text {estacaN }}^{\circ} 4 L}}{T_{\text {hestacaN }^{\circ} 6 L}}$

Parcela de torque da hélice 3 (superior) da estaca $N^{o} 6 L=\frac{T_{h_{e s t a c a N^{\circ} 6 L}}-T_{h_{e s t a c a N^{\circ} 5 L}}}{T_{h_{e s t a c a N^{\circ} 6 L}}}$

Parcela de torque da hélice 1 (inferior) da estaca $N^{o} 9 L=\frac{T_{h_{\text {estacaN }} 7 \mathrm{~L}}}{T_{\text {hestacaN }^{\circ} 9 \mathrm{~L}}}$

Parcela de torque da hélice 2 (central) da estaca $N^{o} 9 L=\frac{T_{\text {hestacaN }^{\circ} 8 L}-T_{h_{\text {estacaN }}^{\circ} 7 L}}{T_{h_{\text {estacaN }}{ }^{\circ} \mathrm{L}}}$

Parcela de torque da hélice 3 (superior) da estaca $N^{\circ} 9 L=\frac{T_{h_{e s t a c a N^{\circ} 9 L}}-T_{h_{\text {estacaN }}{ }^{\circ} \mathrm{L}}}{T_{h_{\text {estacaN }} 9 \mathrm{~L}}}$

Parcela de $Q_{h}$ da hélice 1 (inferior) da estaca $N^{o} 3 L=\frac{Q_{h_{\text {estaca }} N^{1} 1 L}}{Q_{h_{\text {estaca }} 3 L}}$

Parcela de $Q_{h}$ da hélice 2 (central) da estaca $N^{o} 3 L=\frac{Q_{\text {estacaN }^{\circ} 2 L}-Q_{\text {hestacaN }^{\circ} 1 L}}{Q_{h_{\text {estacaN }} 3 L}}$ 
Parcela de $Q_{h}$ da hélice 3 (superior) da estaca $N^{o} 3 L=\frac{Q_{h_{e s t a c a N}{ }^{\circ} 3 L}-Q_{h_{\text {estacaN }}^{\circ} 2 L}}{Q_{h_{\text {estacaN }} 3 L}}$

Parcela de $Q_{h}$ da hélice 1 (inferior) da estaca $N^{\circ} 6 L=\frac{Q_{\text {hestacaN }^{\circ} 4 L}}{Q_{\text {hestacaN }^{\circ} 6 L}}$

Parcela de $Q_{h}$ da hélice 2 (central) da estaca $N^{o} 6 L=\frac{Q_{\text {hestacaN }^{\circ} 5 L}-Q_{h_{e s t a c a N}{ }^{\circ} L}}{Q_{\text {estacaN }^{\circ} 6 L}}$

Parcela de $Q_{h}$ da hélice 3 (superior) da estaca $N^{o} 6 L=\frac{Q_{h_{e s t a c a N} 6 L}-Q_{h_{\text {estacaN }}{ }^{\circ} 5 L}}{Q_{h_{\text {estacaN }} 6 L}}$

Parcela de $Q_{h}$ da hélice 1 (inferior) da estaca $N^{\circ} 9 L=\frac{Q_{\text {estacaN }^{\circ} 7 L}}{Q_{h_{\text {estacaN }} 9 L}}$

Parcela de $Q_{h}$ da hélice 2 (central) da estaca $N^{o} 9 L=\frac{Q_{h_{e s t a c a N}^{\circ} 8 L}-Q_{h_{e s t a c a N^{\circ} 7 L}}}{Q_{h_{e s t a c a N}{ }^{\circ}{ }_{L}}}$

Parcela de $Q_{h}$ da hélice 3 (superior) da estaca $N^{o} 9 L=\frac{Q_{h_{e s t a c a N^{\circ} 9 L}}-Q_{h_{e s t a c a N^{\circ} 8 L}}}{Q_{h_{\text {estaca }}{ }^{\circ} 9 L}}$

Para o cálculo das parcelas de $\mathrm{T}_{\mathrm{h}}$ das estacas $\mathrm{N}^{\circ} 1 \mathrm{~L}$ a $\mathrm{N}^{\circ}$ 9L foram subtraídos do torque final medido $(\mathrm{T})$ os valores de momento resistente à tração atuante na superfície da haste $\left(\mathrm{T}_{\mathrm{s}}\right)$ medidos nas estacas sem hélice (estacas 10L, 11L e 12L) instaladas na mesma profundidade e com o mesmo diâmetro de haste. Para o cálculo de $\mathrm{Q}_{\mathrm{h}}$ das estacas $\mathrm{N}^{\circ} 1 \mathrm{~L}$ a $\mathrm{N}^{\mathrm{o}}$ 9L foram subtraídos da carga de ruptura medida $\left(\mathrm{Q}_{\mathrm{u}}\right)$ os valores de resistência por atrito lateral da haste 
$\left(\mathrm{Q}_{\mathrm{s}}\right)$ medidos nas estacas sem hélice (estacas 10L, 11L e 12L) instaladas na mesma profundidade e com o mesmo diâmetro de haste.

Tabela 6.14 - Parcelas de torque e de capacidade de carga relativas às hélices nas estacas com duas hélices ensaiadas em centrífuga

\begin{tabular}{|c|c|c|c|c|c|}
\hline Solo & $\begin{array}{c}\text { Estaca } \\
\mathrm{N}^{\mathrm{o}}\end{array}$ & $\begin{array}{l}\text { Diâmetro da } \\
\text { hélice em mm } \\
\text { (escala do } \\
\text { protótipo) }\end{array}$ & Hélice & $\begin{array}{c}\text { Parcela de } \\
\text { momento } \\
\text { resistente à } \\
\text { instalação atuante } \\
\text { nas hélices }\left(\mathrm{T}_{\mathrm{h}}\right)\end{array}$ & $\begin{array}{c}\text { Parcela da } \\
\text { capacidade de } \\
\text { carga à tração } \\
\text { relativa às hélices } \\
\left(\mathrm{Q}_{\mathrm{h}}\right)\end{array}$ \\
\hline \multirow{6}{*}{  } & \multirow[b]{2}{*}{$2 \mathrm{~L}$} & \multirow[b]{2}{*}{214,4} & $\mathrm{~h}_{1}$ (inferior) & $75 \%$ & $74 \%$ \\
\hline & & & $\mathrm{h}_{2}$ (superior) & $25 \%$ & $26 \%$ \\
\hline & \multirow[b]{2}{*}{$5 \mathrm{~L}$} & \multirow[b]{2}{*}{325,7} & $\mathrm{~h}_{1}($ inferior $)$ & $50 \%$ & $55 \%$ \\
\hline & & & $\mathrm{h}_{2}$ (superior) & $50 \%$ & $45 \%$ \\
\hline & \multirow[b]{2}{*}{$8 \mathrm{~L}$} & \multirow[b]{2}{*}{440,0} & $\mathrm{~h}_{1}$ (inferior) & $84 \%$ & $64 \%$ \\
\hline & & & $\mathrm{h}_{2}$ (superior) & $16 \%$ & $36 \%$ \\
\hline \multirow{6}{*}{ 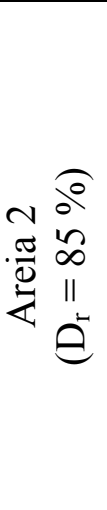 } & \multirow[b]{2}{*}{$2 \mathrm{~L}$} & \multirow{2}{*}{214,4} & $\mathrm{~h}_{1}$ (inferior) & $68 \%$ & $68 \%$ \\
\hline & & & $\mathrm{h}_{2}$ (superior) & $32 \%$ & $32 \%$ \\
\hline & \multirow{2}{*}{$5 \mathrm{~L}$} & \multirow{2}{*}{325,7} & $\mathrm{~h}_{1}$ (inferior) & $62 \%$ & $76 \%$ \\
\hline & & & $\mathrm{h}_{2}$ (superior) & $38 \%$ & $24 \%$ \\
\hline & \multirow{2}{*}{$8 \mathrm{~L}$} & \multirow{2}{*}{440,0} & $\mathrm{~h}_{1}$ (inferior) & $64 \%$ & $87 \%$ \\
\hline & & & $\mathrm{h}_{2}$ (superior) & $36 \%$ & $13 \%$ \\
\hline
\end{tabular}

Na Tabela 6.14 nota-se que com exceção da estaca №2 instalada na Areia 1, a parcela de capacidade de carga relativa à hélice inferior aumenta de acordo com o diâmetro da hélice e com a densidade da areia. Observa-se também nesta tabela que as parcelas de torque e de capacidade de carga à tração para cada hélice das estacas de duas hélices tendem a ser aproximadas. 
Na Tabela 6.15 observa-se que do mesmo modo que ocorre nas estacas de duas hélices (Tabela 6.14), as parcelas de capacidade de carga relativas à hélice inferior aumentam de acordo com o diâmetro da hélice e com a densidade da areia. Este fato mostra que o efeito da instalação das hélices na modificação das propriedades iniciais do maciço de areia é maior em estacas de hélices de maior diâmetro instaladas em areia de maior densidade. Supõe-se que a passagem da primeira hélice e da segunda hélice na região acima da posição final da segunda hélice, altera em maior proporção as propriedades da areia nesta profundidade em estacas de diâmetro maior e em areia mais densa. Do mesmo modo, a passagem da primeira, da segunda e da terceira hélice na região acima da posição final da terceira hélice (hélice superior) modifica em maior proporção as propriedades da areia nesta profundidade em estacas de maior diâmetro e em areia mais densa. Nota-se na estaca $N^{0}$ 9L que a terceira hélice praticamente não contribuiu com os valores de torque e de capacidade de carga relativa às hélices.

Estas parcelas apresentadas na Tabela 6.15 são válidas para estacas com três hélices de diâmetros iguais. Para estacas multi-hélices com hélices de diferentes diâmetros (crescentes da ponta ao topo), espera-se que o efeito da modificação das propriedades do solo na região acima da posição final das hélices superiores seja reduzido. Do mesmo modo que para as estacas de duas hélices, observa-se também nesta tabela que as parcelas de torque e de capacidade de carga à tração para cada hélice das estacas de três hélices tendem a ser aproximadas. 
Tabela 6.15 - Parcelas de torque e de capacidade de carga relativas às hélices nas estacas com três hélices ensaiadas em centrífuga

\begin{tabular}{|c|c|c|c|c|c|}
\hline Solo & $\begin{array}{c}\text { Estaca } \\
\mathrm{N}^{\mathrm{o}}\end{array}$ & $\begin{array}{l}\text { Diâmetro da } \\
\text { hélice em mm } \\
\text { (escala do } \\
\text { protótipo) }\end{array}$ & Hélice & $\begin{array}{l}\text { Parcela de momento } \\
\text { resistente à } \\
\text { instalação atuante } \\
\text { nas hélices }\left(\mathrm{T}_{\mathrm{h}}\right)\end{array}$ & $\begin{array}{c}\text { Parcela da } \\
\text { capacidade de } \\
\text { carga à tração } \\
\text { relativa às hélices } \\
\left(\mathrm{Q}_{\mathrm{h}}\right)\end{array}$ \\
\hline \multirow{9}{*}{ 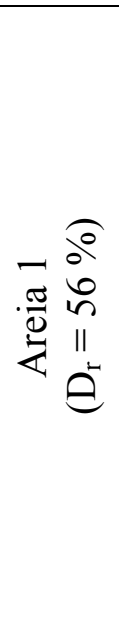 } & \multirow{3}{*}{3} & \multirow{3}{*}{214.4} & $\mathrm{~h}_{1}$ (inferior) & $30 \%$ & $33 \%$ \\
\hline & & & $\mathrm{h}_{2}($ central $)$ & $10 \%$ & $12 \%$ \\
\hline & & & $\mathrm{h}_{3}$ (superior) & $60 \%$ & $56 \%$ \\
\hline & \multirow{3}{*}{6} & \multirow{3}{*}{325.7} & $\mathrm{~h}_{1}$ (inferior) & $48 \%$ & $41 \%$ \\
\hline & & & $\mathrm{h}_{2}($ central $)$ & $48 \%$ & $33 \%$ \\
\hline & & & $\mathrm{h}_{3}$ (superior) & $4 \%$ & $26 \%$ \\
\hline & \multirow{3}{*}{9} & \multirow{3}{*}{440.0} & $\mathrm{~h}_{1}$ (inferior) & $77 \%$ & $46 \%$ \\
\hline & & & $\mathrm{h}_{2}($ central $)$ & $15 \%$ & $26 \%$ \\
\hline & & & $\mathrm{h}_{3}$ (superior) & $8 \%$ & $28 \%$ \\
\hline \multirow{9}{*}{ 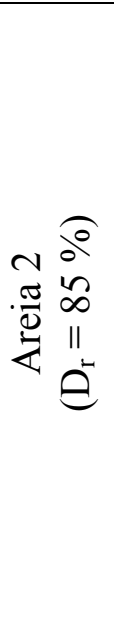 } & \multirow{3}{*}{3} & \multirow{3}{*}{214.4} & $\mathrm{~h}_{1}$ (inferior) & $46 \%$ & $52 \%$ \\
\hline & & & $\mathrm{h}_{2}($ central $)$ & $22 \%$ & $24 \%$ \\
\hline & & & $\mathrm{h}_{3}$ (superior) & $32 \%$ & $24 \%$ \\
\hline & \multirow{3}{*}{6} & \multirow{3}{*}{325.7} & $\mathrm{~h}_{1}$ (inferior) & $72 \%$ & $64 \%$ \\
\hline & & & $\mathrm{h}_{2}($ central $)$ & $28 \%$ & $21 \%$ \\
\hline & & & $\mathrm{h}_{3}$ (superior) & $0 \%$ & $15 \%$ \\
\hline & \multirow{3}{*}{9} & \multirow{3}{*}{440.0} & $\mathrm{~h}_{1}$ (inferior) & $64 \%$ & $87 \%$ \\
\hline & & & $\mathrm{h}_{2}($ central $)$ & $36 \%$ & $13 \%$ \\
\hline & & & $\mathrm{h}_{3}$ (superior) & $0 \%$ & $0 \%$ \\
\hline
\end{tabular}

\subsection{Efeito da dimensão da hélice no torque de instalação}

Nos ensaios de campo realizados em São Carlos na EESC, as estacas ensaiadas №5C e No6C tiveram as hélices instaladas na mesma profundidade final. No entanto, os diâmetros das hélices da estaca $\mathrm{N}^{\circ} 6 \mathrm{C}$ correspondem à metade dos diâmetros das hélices ํo5C (Figura 6.4, sem escala), e ambas as estacas foram fabricadas com a haste de mesmo diâmetro. 


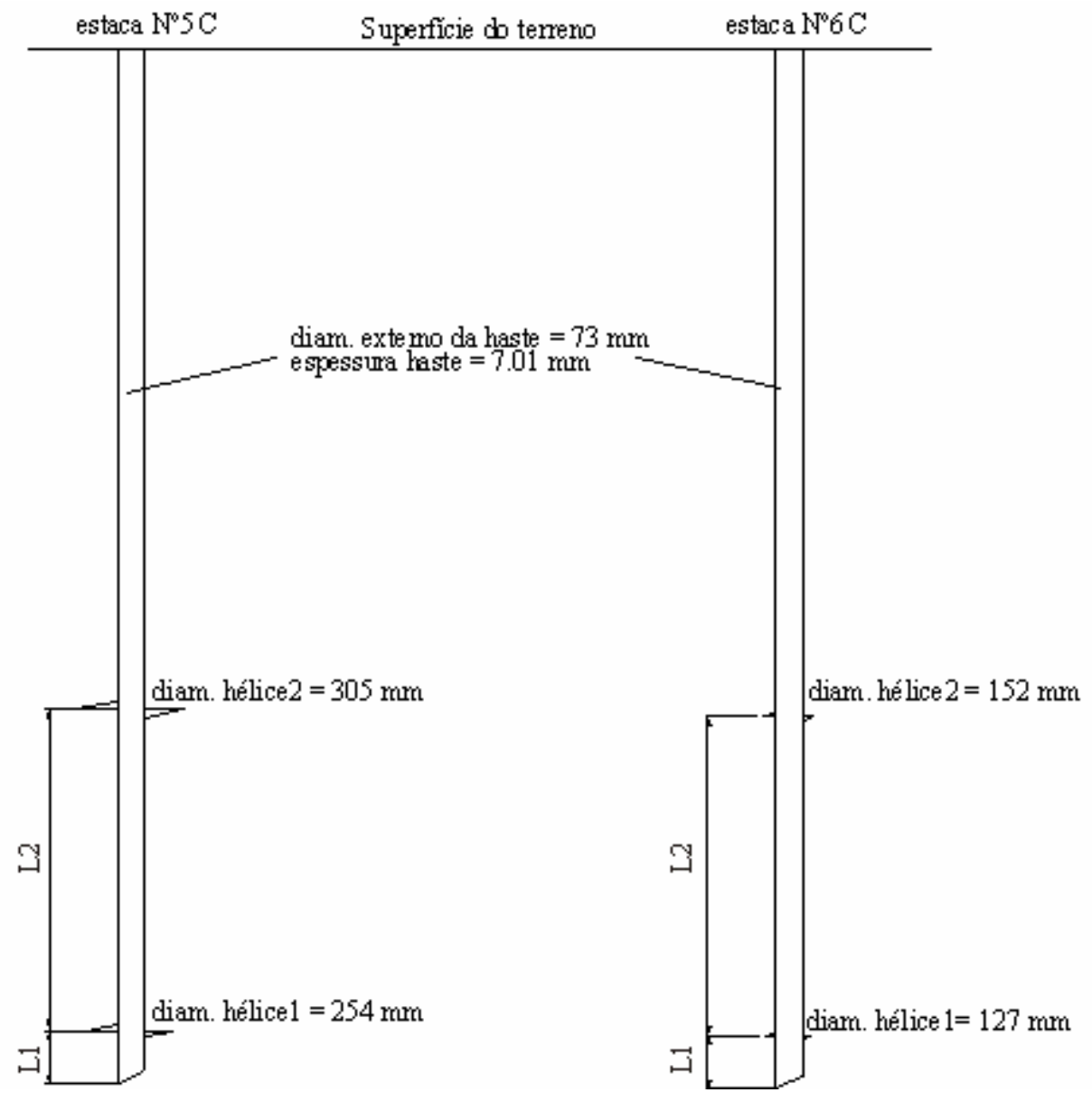

Figura 6.4 - Estacas $N^{\circ} 5 \mathrm{C}$ e No $6 \mathrm{C}$ ensaiadas na EESC em São Carlos

O objetivo de instalar e ensaiar as estacas com estas dimensões foi analisar se por meio do modelo proposto nesta tese (Equação 3.16), era possível prever o valor de torque medido em uma estaca metálica helicoidal padrão por meio de uma estaca de diâmetro reduzido de hélices (espaçadas entre si igualmente à estaca padrão). A finalidade era saber se esta estaca com hélices em dimensões reduzidas, para penetrar maiores profundidades, poderia ser utilizada na prática como método de investigação do subsolo na fase anterior ao projeto da fundação em estacas metálicas helicoidais em solos arenosos. Este instrumento seria utilizado juntamente com outro que reconhecesse as características do subsolo, para a determinação dos parâmetros $\mathrm{Q}_{\mathrm{s}}, \mathrm{Q}_{\mathrm{h}}$ e $\delta_{\mathrm{r}}$ da Equação 3.16. 
Para isso, foram calculados para as duas estacas os valores de torque na profundidade final de instalação, com base na sondagem (Figura 4.8), por meio da Equação 3.16 abaixo, proposta nesta tese:

$$
T=\frac{Q_{s} d}{2}+\frac{Q_{h} d_{c} \tan \left(\theta+\delta_{r}\right)}{2}
$$

As parcelas de $\mathrm{Q}_{\mathrm{s}}$, relativas ao atrito lateral na haste, foram estimadas pela Equação 2.11, proposta por Mitsch e Clemence (1985), apresentada na revisão bibliográfica desta tese. As parcelas de capacidade de carga à tração relativa às hélices $\left(\mathrm{Q}_{\mathrm{h}}\right)$ foram calculadas pela diferença entre as cargas de ruptura medidas nas provas de carga $\left(\mathrm{Q}_{\mathrm{u}}\right)$ e os valores de $\mathrm{Q}_{\mathrm{s}}$ estimados $\left(Q_{h}=Q_{u}-Q_{s}\right)$. Os valores de ângulo de atrito na interface $\left(\delta_{r}\right)$ utilizados foram estimados por meio dos resultados dos ensaios de cisalhamento de interface realizados nesta pesquisa com a chapa da hélice da estaca metálica helicoidal comercialmente utilizada (Tabela 5.13). Os valores de $\mathrm{d}, \mathrm{d}_{\mathrm{c}}$ e $\theta$ foram obtidos por meio de medidas com um paquímetro. Os resultados são apresentados na Tabela 6.16. Nesta tabela nota-se que a razão entre os valores de torque final de instalação das duas estacas $T_{\text {estaca6C }} / T_{\text {estaca5C }}$ é igual a 0,61.

Tabela 6.16 - Valores de torque final de instalação calculados pela Equação 3.16

\begin{tabular}{c|cccccc}
\hline Estaca & $\begin{array}{c}\mathrm{Q}_{\mathrm{s}} \\
(\mathrm{kN})\end{array}$ & $\begin{array}{c}\mathrm{Q}_{\mathrm{h}} \\
(\mathrm{kN})\end{array}$ & $\begin{array}{c}\mathrm{d}_{\mathrm{c}} \\
(\mathrm{m})\end{array}$ & $\begin{array}{c}\theta \\
(\text { graus })\end{array}$ & $\begin{array}{c}\delta_{\mathrm{r}} \\
(\text { graus })\end{array}$ & $\begin{array}{c}\mathrm{T}_{\text {calculado }} \\
(\mathrm{kN} . \mathrm{m})\end{array}$ \\
\hline $5 \mathrm{C}$ & 90 & 80 & 0,196 & 8,9 & 18,8 & 7,4 \\
$6 \mathrm{C}$ & 90 & 40 & 0,110 & 9,4 & 18,8 & 4,5 \\
\hline \multicolumn{5}{c}{} \\
\hline
\end{tabular}

A Tabela 5.2 do capítulo 5 mostra os valores medidos de torque de instalação das estacas N5C e N6C, ensaiadas na EESC em São Carlos, ao longo da profundidade. Com os dados 
desta tabela foi traçada a relação entre os valores de torque de instalação medidos na estaca №5C e na estaca $\mathrm{N}^{\circ} 6 \mathrm{C}$, para a mesma profundidade, exibida na Figura 6.5.

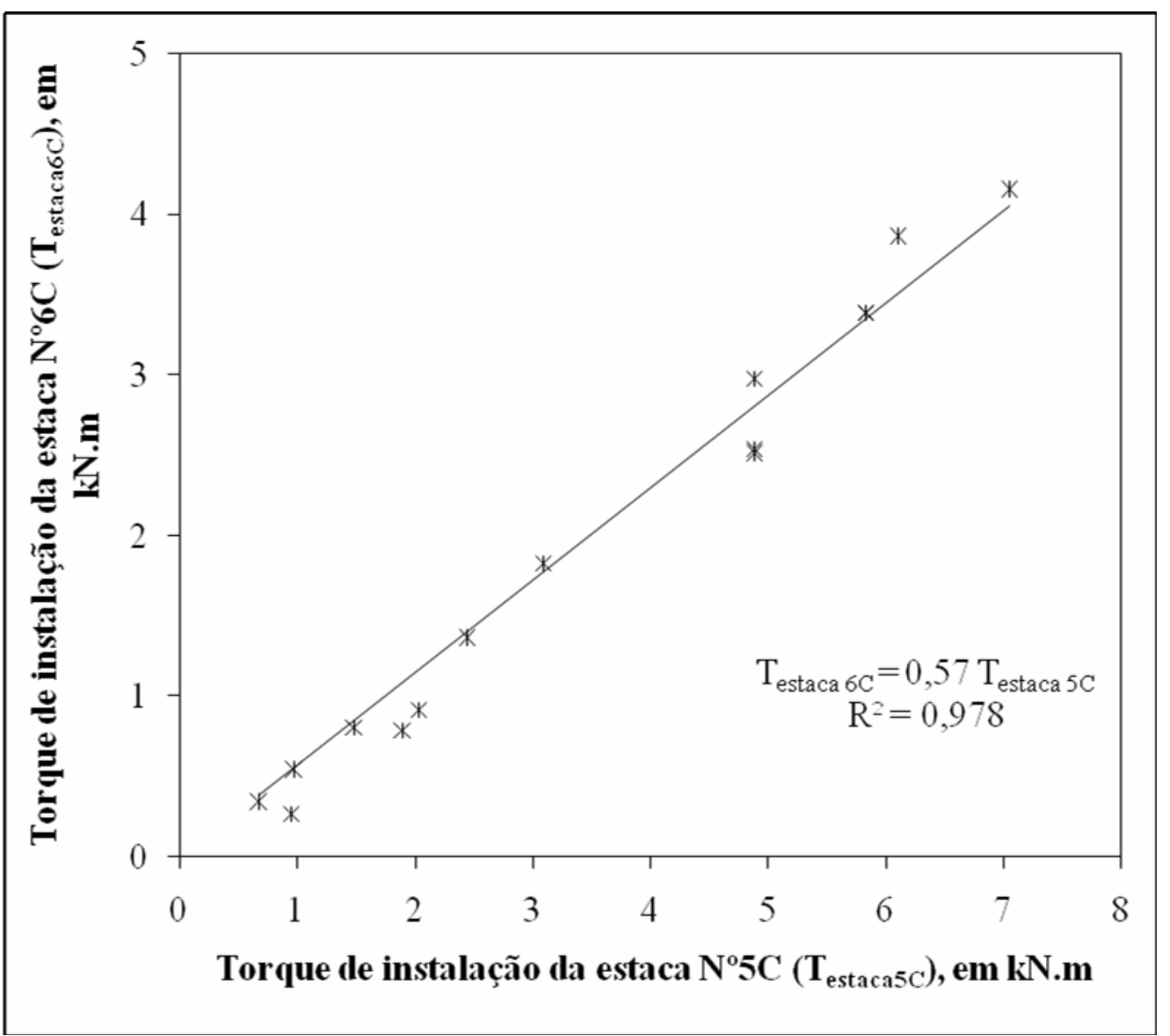

Figura 6.5 - Relação entre os valores medidos de torque de instalação das estacas $\mathrm{N}^{\mathrm{o}} 5 \mathrm{C}$ e $\mathrm{N}^{\mathrm{o}}$ 6C (para a mesma profundidade)

A Figura 6.5 mostra que a relação $\mathrm{T}_{\text {estaca6C }} / \mathrm{T}_{\text {estaca5c }}$ medida durante as instalações das estacas é em torno de 0,57 ao longo da profundidade. Na profundidade final da estaca $(14,5 \mathrm{~m})$ a razão $T_{\text {estaca6C }} / T_{\text {estaca5C }}$ calculada foi igual 0,61 . Os valores das razões são bem próximos.

Estes resultados mostram que é possível determinar a razão entre os valores de torque de instalação de duas estacas distintas, para uma mesma profundidade, por meio da Equação 3.16 proposta nesta tese, juntamente com um ensaio de investigação de subsolo para a estimativa dos parâmetros da areia para os cálculos de $\mathrm{Q}_{\mathrm{s}}$ e $\mathrm{Q}_{\mathrm{h}}$ (parâmetros de Equação 3.16). 


\section{$7 \quad$ CONCLUSÕES}

\subsection{Considerações iniciais}

A presente tese descreve um modelo teórico de cálculo para atuar como procedimento de controle de capacidade de carga durante a execução de fundações em estacas metálicas helicoidais instaladas em solos arenosos. Neste trabalho foi realizada uma investigação experimental, por meio de ensaios de campo e de laboratório, para a validação deste modelo e para a verificação dos métodos de cálculo de capacidade de carga à tração, correspondentes a este tipo de fundação, existentes na literatura. Para complementar este trabalho, foi analisado o efeito do número de hélices no torque de instalação e na capacidade de carga e a resistência ao cisalhamento do fuste durante a instalação da estaca.

\subsection{Modelo teórico proposto}

Nesta pesquisa foi desenvolvido um modelo teórico da relação física entre o torque final de instalação e a capacidade de carga à tração de uma estaca metálica helicoidal profunda instalada em areia.

Por meio dos resultados dos ensaios de modelagem física em centrífuga, foi verificada a relação teórica do modelo correspondente ao torque de instalação e a capacidade de carga relativa às hélices. Nesta averiguação foi constatado que o valor médio da razão entre os valores da parcela de capacidade de carga à tração relativa às hélices medidos e calculados pelo modelo de cálculo proposto $\left(\mathrm{Q}_{\mathrm{h}}\right.$ medida/ $\mathrm{Q}_{\mathrm{h}}$ calculada) é igual a 0,98 com um coeficiente de variação de $15,7 \%$. Este resultado mostra que a relação física apresentada é válida para estacas metálicas helicoidais profundas com diferentes dimensões e número de hélices 
instaladas em areia. No entanto, os resultados calculados pelo modelo proposto se aproximariam mais dos resultados medidos, se para a estimativa dos resultados experimentais de $\mathrm{Q}_{\mathrm{s}}$ (resistência à tração por atrito lateral da haste) não fosse considerado que a mobilização do atrito lateral na haste no momento do carregamento à tração ocorre ao longo de todo o comprimento da estaca embutida no maciço. Porém, como não se sabe seguramente qual é a área lateral da estaca que resiste ao arrancamento da estaca por atrito na interface estaca/areia, adotou-se por simplificação a área equivalente ao comprimento total da haste.

Utilizando-se os resultados dos ensaios de campo, foi verificada a relação entre o torque final de instalação e a capacidade de carga à tração deste tipo de estaca em silte arenoso e em areia fina argilosa. Esta relação teórica foi desenvolvida para estacas multi-hélices com hélices de diâmetros iguais, no entanto, como as estacas utilizadas em campo foram construídas com hélices em tamanho decrescente do topo para a ponta, para aplicar este modelo de cálculo foi considerado o valor do diâmetro médio das hélices para cada estaca.

Para as estacas $1 \mathrm{C}$ e $2 \mathrm{C}$ instaladas em silte arenoso o valor de torque medido está em torno de $68 \%$ do valor calculado. Nestes casos, adotando-se o torque calculado como critério de parada da instalação da estaca, a fundação será executada para uma carga de ruptura superior a real.

Nas outras estacas ensaiadas em campo, os valores de torque medidos e calculados são bem próximos. Para estas estacas, o método proposto nesta tese para o controle da capacidade de carga à tração de fundações em estacas metálicas helicoidais é apropriado.

As estacas instaladas em areia fina argilosa foram fabricadas em dimensões adequadas para verificar se por meio do modelo proposto nesta tese (Equação 3.16), era possível prever o valor de torque medido em uma estaca metálica helicoidal padrão por meio de uma estaca de diâmetro reduzido de hélices. O objetivo desta verificação era saber se esta estaca com hélices em dimensões reduzidas, para penetrar maiores profundidades, poderia ser utilizada na prática 
como método de investigação do subsolo na fase anterior ao projeto da fundação em estacas metálicas helicoidais em solos arenosos. Os resultados desta investigação mostraram que é possível determinar a razão entre os valores de torque de instalação de duas estacas distintas, para uma mesma profundidade, por meio da relação teórica desenvolvida nesta pesquisa, se houver também para o mesmo terreno um ensaio de investigação de subsolo para a estimativa dos parâmetros da areia.

\subsection{Métodos de cálculo de capacidade de carga à tração}

Foram comparados neste trabalho os resultados de capacidade de carga à tração medidos nos ensaios em centrífuga e nas provas de carga em campo com os resultados estimados pelos métodos tradicionalmente utilizados em projetos de fundações em estacas metálicas helicoidais. Nesta comparação foram utilizados os seguintes métodos: "Método das capacidades de carga individuais" e "Método da ruptura cilíndrica".

\section{Ensaios em centrífuga}

Para os ensaios realizados em centrífuga foi verificada somente a parcela de capacidade de carga relativa às hélices. Nesta verificação foi considerada a redução de $10 \%$ dos valores de ângulo de atrito inicial do maciço, devido ao procedimento de instalação da estaca, de acordo com a pesquisa de Levesque (2000).

Os resultados calculados pelos dois métodos de estimativa de capacidade de carga utilizada mostraram-se aproximados dos valores medidos, exceto para as estacas de hélice de maior diâmetro $(\mathrm{D}=440 \mathrm{~mm})$, com 2 e 3 hélices. 
Supõe-se que as hélices de maior diâmetro $(\mathrm{D}=440 \mathrm{~mm})$ modificam em maior proporção as propriedades do maciço de areia do que as hélices de menor diâmetro durante a instalação. Por este fato, deve-se utilizar na previsão de capacidade de carga para estacas com diâmetro desta grandeza testada um valor de ângulo de atrito do solo reduzido em relação ao adotado nos cálculos.

Além do efeito da dimensão da hélice no ângulo de atrito, nas estacas de maior diâmetro com 2 e 3 hélices iguais, a modificação do maciço após a passagem das hélices é maior do que se as hélices tivessem tamanho decrescente do topo para a ponta, como as estacas utilizadas na prática. Nestas estacas o efeito da passagem da primeira hélice no maciço na profundidade em que as outras hélices serão instaladas é minimizado.

A verificação realizada mostrou que se deve considerar nos dois métodos de cálculo o efeito da modificação do maciço após a passagem das hélices para não superestimar os valores de capacidade de carga relativa às hélices $\left(\mathrm{Q}_{\mathrm{h}}\right)$. No entanto, o fator de redução de ângulo de atrito do solo adotado nesta tese não deveria ser constante e sim variável em função das características do solo e da estaca.

Os resultados calculados pelos métodos de cálculo verificados seriam mais próximos aos resultados medidos em centrífuga, se na estimativa dos resultados experimentais de $\mathrm{Q}_{\mathrm{s}}$ (resistência à tração por atrito lateral da haste) não fosse considerada a mobilização do atrito lateral na haste ao longo de todo o comprimento da estaca embutida no maciço.

\section{Ensaios de campo}

Nesta verificação também foi considerada a redução de $10 \%$ dos valores de ângulo de atrito inicial da areia e do silte arenoso, devido ao procedimento de instalação da estaca, de acordo com o trabalho de Levesque (2000). 
Para $67 \%$ dos ensaios realizados, esta investigação mostrou que os resultados de capacidade de carga à tração das provas de carga realizadas em campo e os resultados calculados pelos dois métodos citados anteriormente mostraram-se aproximados. Na estaca 3C os valores calculados por ambos os métodos são em torno de $50 \%$ inferiores ao valor medido. Neste caso os métodos apresentam-se conservadores.

No entanto, para a estaca 5C instalada em areia fina argilosa, os dois métodos superestimaram a capacidade de carga à tração. Isto ocorreu devido à elevada profundidade desta estaca em relação às estacas padrão. Por este motivo, a tensão efetiva acima da hélice adotada nos métodos de cálculo utilizados é elevada devido à grande profundidade da estaca, que foi penetrada em grande espessura de solo devido ao fato do subsolo ser composto por uma areia de baixa resistência à penetração. Com o valor da tensão efetiva elevado, os valores de capacidade de carga relativa às hélices $\left(\mathrm{Q}_{\mathrm{h}}\right)$ calculados são conseqüentemente aumentados.

\subsection{Efeito do número de hélices}

As estacas utilizadas nos ensaios em centrífuga foram fabricadas de modo que se pudesse verificar o efeito do número de hélices no torque de instalação e na capacidade de carga a tração de estacas metálicas helicoidais de hélices de mesmo diâmetro. Dos ensaios realizados em centrífuga, em relação ao número de hélices, foram feitas as seguintes observações:

i. O número de hélices não afetou o modelo teórico proposto nesta tese da relação entre capacidade de carga à tração relativa às hélices $\left(\mathrm{Q}_{\mathrm{h}}\right)$ e momento resistente à instalação gerado nas hélices $\left(\mathrm{T}_{\mathrm{h}}\right)$ medido no final da instalação da estaca. 
ii. Na maioria das estacas com 2 e 3 hélices, as parcelas de porcentagem de torque e de capacidade de carga à tração para cada hélice das estacas tendem a ser aproximadas.

iii. A porcentagem de capacidade de carga relativa à hélice da ponta aumenta com o diâmetro da hélice e com a densidade da areia. Este fato mostra que o efeito da instalação das hélices na modificação das propriedades iniciais da areia é maior em estacas de hélices de maior diâmetro e em maciços mais compactos. Esta conclusão tem como fim orientar o projetista deste tipo de fundação em areia na definição do número de hélices a ser adotado na fabricação da estaca.

\subsection{Resistência estrutural do fuste da estaca durante a instalação ao cisalhamento}

Durante a execução de uma estaca metálica helicoidal no subsolo deve-se verificar se o torque de instalação não ultrapassa o valor do momento torçor máximo admissível para que a secção do tubo da estaca não sofra cisalhamento por torção e seja danificada.

Neste trabalho foram realizados ensaios em fustes de estacas com e sem emenda, para verificar o problema de torção de tubos ocorrido em uma obra. Destes ensaios foram feitas as seguintes observações:

- Os tubos de mesmo diâmetro e espessura iniciam a ruptura a partir do mesmo valor de momento torçor aplicado, independentemente de conter ou não emenda. A diferença entre o tubo com emenda e o tubo sem emenda é que no início da ruptura no tubo com emenda a rotação mobilizada é maior e o comportamento da curva momento torçor x rotação é diferente. 
- A verificação do momento torçor máximo a ser aplicado durante a instalação da estaca, por meio de equação tipicamente utilizada em Resistência dos Materiais para calcular a resistência ao cisalhamento por torção em tubos de aço, mostrou que os valores medidos e calculados são aproximados. 


\section{$8 \quad$ SUGESTÕES PARA FUTURAS PESQUISAS}

Para futuras pesquisas em fundações em estacas metálicas helicoidais recomenda-se:

- O desenvolvimento de um modelo teórico da relação entre torque de instalação e capacidade de carga à tração deste tipo de fundação instalada em solos argilosos para ser utilizado no controle de execução.

- A criação de uma modalidade de ensaio para obtenção de parâmetros de resistência do solo para ser utilizado na previsão da capacidade de carga à tração deste tipo de fundação, que tenha como ferramenta principal uma estaca metálica helicoidal com dimensões reduzidas.

- A quantificação do efeito do procedimento de instalação deste tipo de estaca nas propriedades do maciço de solo, para a correção dos métodos de cálculo de capacidade de carga.

- A análise do estado de tensão no maciço durante a instalação e solicitação deste tipo de fundação por meio da técnica de fotoelasticidade. 
A.B. Chance Co. (1994). "Helical pier foundation systems". Technical Manual, Centralia, Bulletin 01-9601.

A.B. Chance Co. (2003). “Model Specification”. Technical Manual, Centralia, Bulletin 010303.

A. B. Chance Co. (2004). Encyclopedia of anchoring. Centralia, USA.

A.B. Chance Co. (2006). "Civil construction installing tools for screw anchors and piles". Centralia, Bulletin 01-0203.

Adams, J. I.; Klym, T. W. (1972). “A study of anchors for transmission tower foundations”. Canadian Geotechnical Journal, v.9, n.1, p.89-104.

Bowles, J. E. (1988). “Foundation analysis and design”. McGraw-Hill, New York.

Clemence, S. P. (1985). "Uplift behavior of anchor foundations in soil". Proceedings of a session sponsored by the Geotechnical Engineering Division of the American Society of Civil Engineers in conjunction with the ASCE Convention in Detroit, Michigan, 126p.

Clemence, S. P.; Crouch, L. K.; Stephenson. R. W. (1994). "Prediction of uplift capacity for helical anchors in sand". Proceedings of $2^{\text {nd }}$ GeotechnicaL Engineering Conference, Cairo.

Conciani, W. (1989). "Desenvolvimento de uma placa helicoidal com capacidade de medida de poro-pressão, para o estudo do comportamento tensão-deformação dos solos”. Dissertação (Mestrado), Universidade Federal da Paraíba, 140p.

Corté J. F. (1989). "L'essor de la modélisation en centrifugeuse en géotechnique". Revue Française de Géotechnique, n.48, p.7-13. 
Das, B. M. (1990). “Earth Anchors”. Elsevier Science Publisher, New York, 241p.

Du-Plat-Taylor, F. M. (1949). "The design, construction and maintenance of docks, wharves \& piers”. 3.ed. Eyre \& Spottiswoode Publishers Ltd., London, 543p.

Faires, V. M. (1943). "Design of machine elements”. Revised Edition, Macmillan Company, New York, 490 p.

Flores, C. A. S.; Marcolino, F. G. L.; Duarte, R. D. A.; Gomes, J. I. (2001). "Estacas metálicas helicoidais como elementos de fundação para torres de linha de transmissão". In: XVI Seminário Nacional de Produção e Transmissão de Energia Elétrica, Campinas.

Foray, P.; Balachowski, L.; Rault, G. (1998). "Scale effects in shaft friction due the localization of deformations". Proceedings of the International Conference Centrifuge 98, Kimura et al. (eds), Balkema, v.1, p. 211-216.

Frick, P. (1905). “Fouilles et fondations". Ed. Dunod, Paris, 496p.

Fuglsang, L. D.; Ovesen, N. K. (1988). "The Application of the Theory of Modelling to Centrifuge Studies”. Centrifuge in Soil Mechanics, Ed. Balkema, Rotterdam, p. 119-138.

Garnier J., (2001). "Physical models in geotechnics: state of the art recent advances". 1st Coulomb Lecture, Caquot Conférence, Paris, p. 1-59.

Garnier, J.; König, D. (1998). "Scale effects in piles and nails loading tests in sand". Proceedings of the International Conference Centrifuge 98, Kimura et al. (eds), Balkema, v.1, p. 205-210.

Ghaly, A. M. (1995). "Drivability and pullout resistance of helical units in saturated sands". Soil and Foundations, v.35, n.2, p. 61-66.

Ghaly, A.; Hanna, A. (1991). "Experimental and theoretical studies on installation torque of screw anchors”. Canadian Geotechnical Journal, v.28, n.3, p.353-364. 
Ghaly, A.; Hanna, A.; Hanna, M. (1991a). "Uplift behavior of screw anchors in sand.

I: Dry sand”. Journal of Geotechnical Engineering, ASCE, v.117, n.5, p.773-793.

Ghaly, A.; Hanna, A.; Hanna, M. (1991b). "Installation torque of screw anchors in sand". Soils and Foundations, v.31, n.2, p. 77-92.

Higdon, A.; Stiles, W. B. (1968). "Engineering mechanics". Vol. 1, Third Edition, PrenticeHall, Englewood Cliffs, New Jersey, 395 p.

Hoyt R. M.; Clemence, S. P. (1989). "Uplift capacity of helical anchors in soil”. Proceedings of The Twelfth International Conference on Soil Mechanics and Foundation Engineering, v.2, p.1019-1022.

Jardine, R.J.; Overy, R.F.; Chow, F.C. (1998). “Axial capacity of offshore piles in dense north sea sands". Journal of Geotechnical and Geoenvironmental Engineering, ASCE, v.124, n.2, p.171-178.

Kelley, S. P.; Lutenegger, A. J. (2004). "Unit skin friction from the Standard Penetration Test supplemented with the measurement of torque". Journal of Geotechnical and Geoenvironmental Engineering, ASCE, v.130, n.5, p.540-543.

Kulhawy, F. H. (1985). "Uplift behavior of shallow soil anchors - An overview". Uplift behavior of anchor foundations in soil, Proceedings of a session sponsored by the Geotechnical Engineering Division of the American Society of Civil Engineers in conjunction with the ASCE Convention in Detroit, Michigan, p.1-25.

Levesque, C. (2002). "Centrifuge Modelling of Helical Anchors in Sand". M.Sc.E. Thesis. University of New Brunswick, 129p.

Litlle, A. L. (1961). "Foundations”. 1.ed. Edward Arnold Publishers Ltd., London, 364 p. 
Mitsch, M.P.; Clemence, S.P. (1985). "The uplift capacity of helix anchors in sand". Uplift behavior of anchor foundations in soil, Proceedings of a session sponsored by the Geotechnical Engineering Division of the American Society of Civil Engineers in conjunction with the ASCE Convention in Detroit, Michigan, p. 26-47.

Narasimha Rao, S.; Prasad, M.D.; Shetty, M.D.; Joshi, V.V. (1989). “Uplift capacity of screw pile anchors". Geotechnical Engineering, v.20, n.2, p. 139-159.

Narasimha Rao, S.; Prasad, Y. V. S. N.; Shetty, M. D. (1991). "The behavior of model screw piles in cohesive soils". Soil and Foundations, v.31, n.2, p.35-50.

Narasimha Rao, S.; Prasad, Y.V.S.N.; Veeresh, C. (1993). "Behaviour of embedded model screw anchors in soft clays". Géotechnique, v.43, n.4, p.605-614.

O’Brien R. (1964). “Machines”. Time Inc., New York, 200p.

Ovesen, N. K. (1979). "The scaling law relationship". Proceedings of the Seventh European Conference on Soil Mechanics and Foundation Engineering, Brighton, Vol. 4, pp. 319-323.

Ovesen, N. K. (1981). "Centrifuge tests of the uplift capacity of anchors". Proceedings of the Tenth International Conference on Soil Mechanics and Foundation Engineering, Stockholm, Sweden, v.1, p. 717-722.

Pack, J.S. (2003). "Helical Foundation and Tiebacks: Quality control, inspection and performance monitoring". Proceedings of $28^{\text {th }}$ Annual Conference on Deep Foundations, DFI, p. $269-284$.

Perko, H. A. (2000). "Energy method for predicting the installation torque of helical foundations and anchors". New Technological and Design Developments in Deep Foundation Technologies, ASCE, p.342-352.

Perko, H. A.; Stan, J.; Rupiper, P. E. (2000). "Helix pier engineering handbook 2000”. Ingal Precision Foundations, INC. Worldwide Helix Pier Distributors. 
Prasad, Y. V. S. N.; Narasimha Rao, S. (1994). "Pullout behavior of model pile and helical pile anchors subject to lateral cyclic loading”. Canadian Geotechnical Journal, v.31, n.1, p.110-119.

Prasad, Y. V. S. N. (1996). Discussion to paper on "Drivability and pullout resistance of helical units in saturated sands" by Ghaly, A. M. Soil and Foundations, v.36, n.2, p.139-140.

Queiroz, G. (1988). Elementos das estruturas de aço. $2^{\mathrm{a}}$ edição. Universidade Federal de Minas Gerais, Belo Horizonte, 455p.

Rankine, W. J. M. (1877). “A manual of civil engineering”. 20.ed. Charles Griffin and Company, London, 786p.

Rowe, R. K.; Davis, E. H. (1982). "Behaviour of anchor plates in sand". Geotechnique, v.32, p.25-41.

Saibaba Reddy, E.; Chapman, D.N.; Sastry, V.V.R.N. (2000). "Direct interface test for shaft capacity of piles in sand”. Geotechnical Testing Journal, v.23, n.2, p.199-205.

Stephenson, R. W. (2002). "Helical foundations and tie backs: state of the art". University of Missouri-Rolla.

Stoll, U.W. (1972). "Torque shear test of cylindrical friction piles”. Civil Engineering, ASCE, v.42, n.4, p.63-64.

Taylor, R. N. (1995). “Geotechnical centrifuge technology”. Routledge, USA, 297p.

Terzaghi, K. (1942). “Discussion on pile driving formulas”. Proc. ASCE, 68 (2), p. 311-323.

Trofimenkov, J. G.; Mariupolskii, L. G. (1965). "Screw piles used for mast and tower foundations". VI International Conference on Soil Mechanics and Foundation Engineering, Toronto, v.2, p.328-332. 
Uesugi, M.; Kishida, H. (1986). "Frictional resistance at yield between dry sand and mild steel". Soils and Foundations, v.26, n. 4, p.139-149.

Van der Veen, C. (1953). "The bearing capacity of a pile". Proceedings of the International Conference on Soil Mechanics and Foundation, III, v.1, p.125-151, Zurich.

Weech, C. N. (2002). "Installation and load testing of helical piles in a sensitive fine-grained soil”. M.A.Sc. Thesis, University of British Columbia, 335p.

WILSON, G. (1950). "The bearing capacity of screw piles and screwcrete cylinders". Journal of Institution of Civil Engineers, v.34, p.4-73.

Zhang, D. J. Y. (1999). "Predicting capacity of helical screw piles in Alberta soils". M.Sc.E. Thesis. University of Alberta, 273p.

Zhang, L. M.; Kong, L. G. (2006). "Centrifuge modeling of torsional response of piles in sand". Canadian Geotechnical Journal, v.43, n.5, p.500-515. 


\section{ANEXO A: Calibrações}

Calibração do torquímetro FGP CD1140-2 utilizado nos ensaios em centrífuga por medida direta de torque exercido na saída do motoredutor RDP

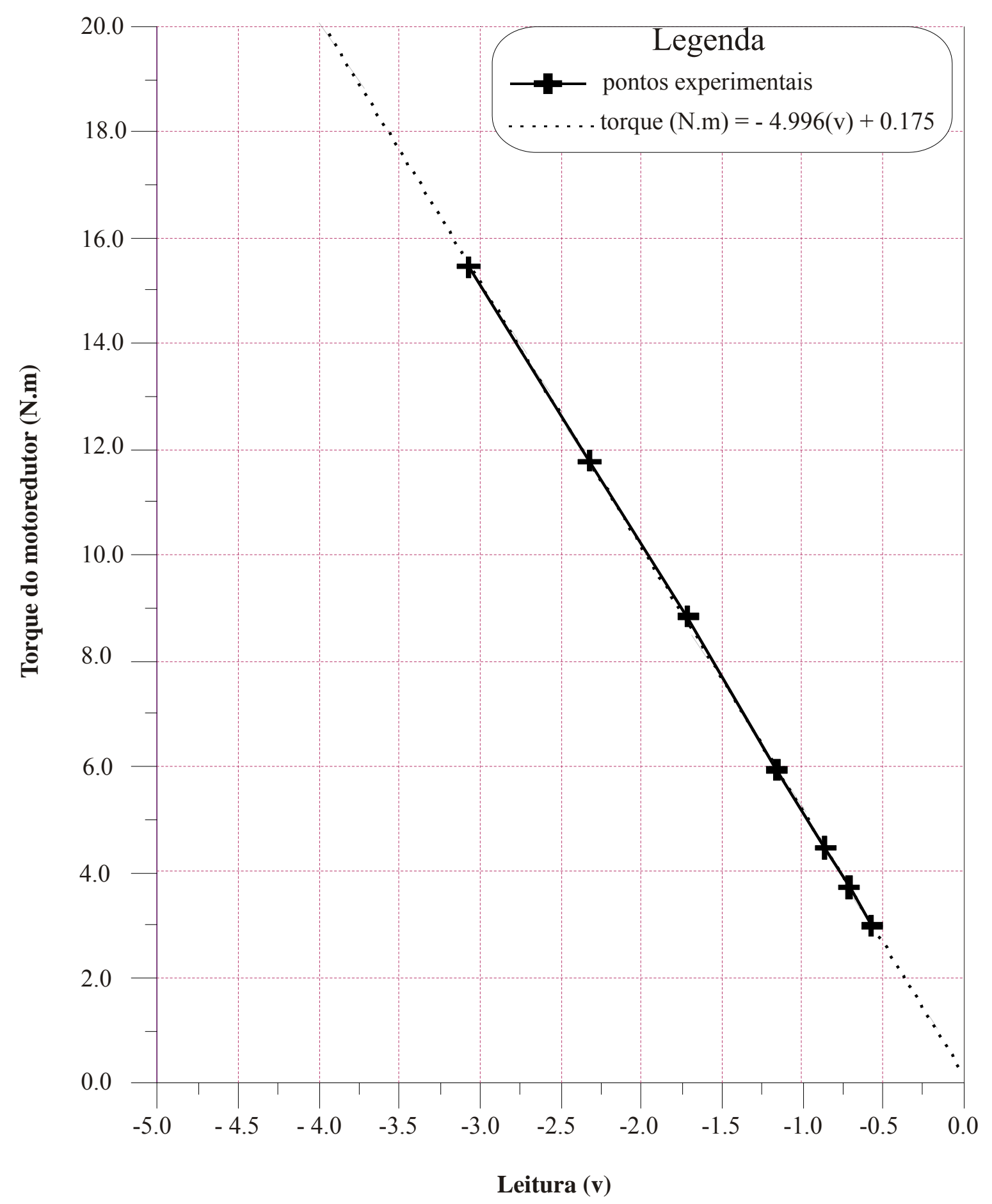


Calibração do transdutor de força TME $56(2500$ N) utilizado nos ensaios em centrífuga

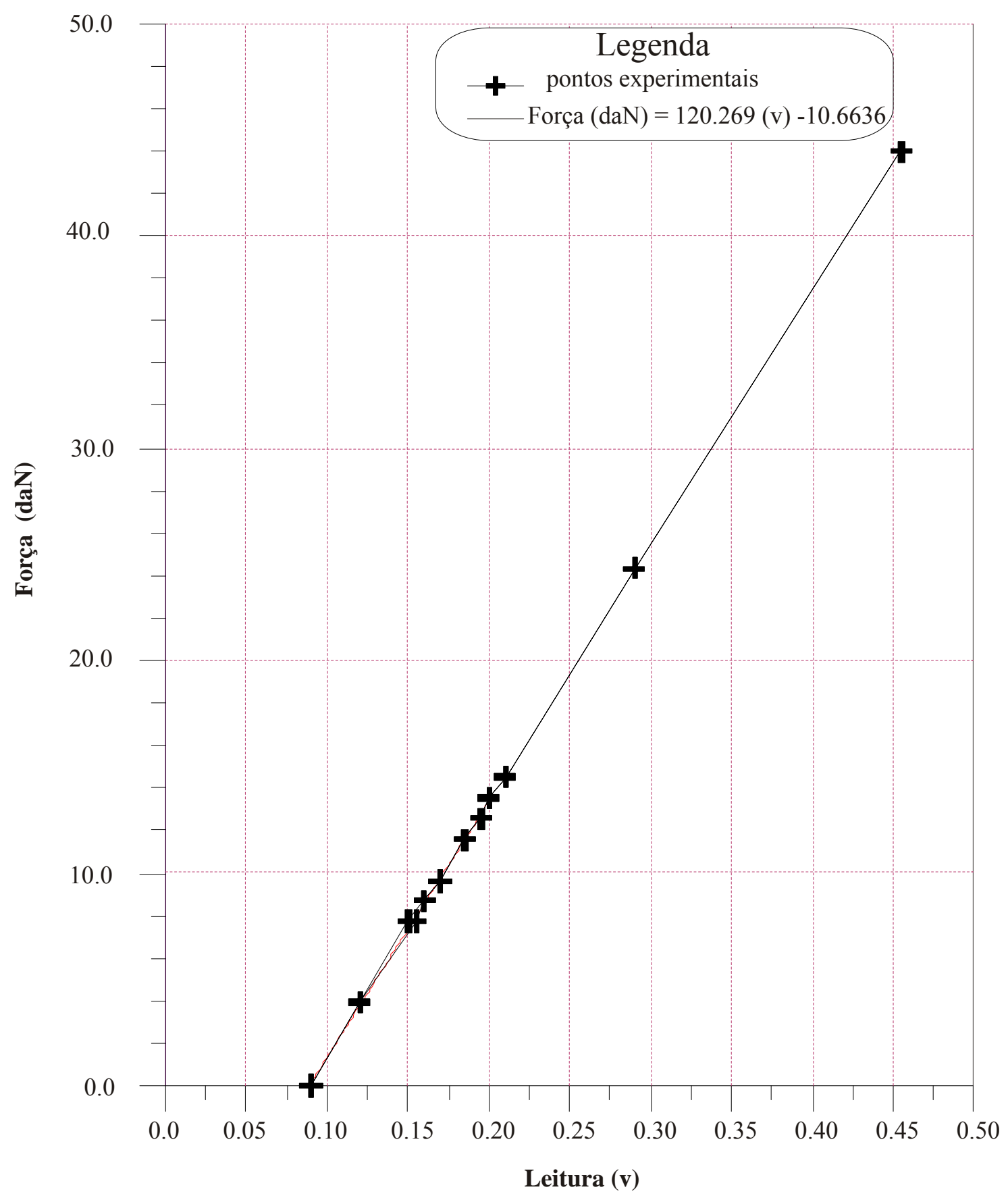


ANEXO B: Ensaios de campo - Provas de carga à tração

Prova de carga da estaca $\mathrm{N}^{\mathrm{o}} 1 \mathrm{C}$ (Contagem)

\begin{tabular}{|c|c|}
\hline $\begin{array}{c}\text { Carga de tração } \\
(\mathrm{kN})\end{array}$ & $\begin{array}{l}\text { Deslocamento } \\
(\mathrm{mm})\end{array}$ \\
\hline 0 & 0,00 \\
\hline 33 & 0,41 \\
\hline 48 & 2,11 \\
\hline 72 & 4,24 \\
\hline 96 & 6,96 \\
\hline 120 & 11,20 \\
\hline 144 & 16,71 \\
\hline 168 & 21,35 \\
\hline 192 & 26,61 \\
\hline 216 & 31,28 \\
\hline 240 & 36,37 \\
\hline 192 & 35,79 \\
\hline 144 & 33,41 \\
\hline 96 & 31,68 \\
\hline 48 & 29,24 \\
\hline 33 & 28,36 \\
\hline 58 & 28,95 \\
\hline 87 & 30,02 \\
\hline 116 & 31,08 \\
\hline 145 & 32,16 \\
\hline 174 & 33,51 \\
\hline 203 & 34,84 \\
\hline 232 & 36,71 \\
\hline 261 & 40,61 \\
\hline 290 & 44,99 \\
\hline 232 & 43,74 \\
\hline 174 & 41,80 \\
\hline 116 & 39,41 \\
\hline 58 & 36,50 \\
\hline 33 & 35,26 \\
\hline 290 & 46,83 \\
\hline 320 & 49,55 \\
\hline
\end{tabular}


Prova de carga da estaca $\mathrm{N}^{\mathrm{o}} 2 \mathrm{C}$ (Contagem)

\begin{tabular}{|c|c|}
\hline $\begin{array}{c}\text { Carga de tração } \\
(\mathrm{kN})\end{array}$ & $\begin{array}{l}\text { Deslocamento } \\
(\mathrm{mm})\end{array}$ \\
\hline 0 & 0,00 \\
\hline 33 & 2,00 \\
\hline 39 & 2,86 \\
\hline 52 & 3,87 \\
\hline 65 & 4,83 \\
\hline 78 & 5,72 \\
\hline 91 & 6,57 \\
\hline 104 & 8,38 \\
\hline 117 & 11,18 \\
\hline 130 & 15,04 \\
\hline 104 & 14,66 \\
\hline 78 & 14,15 \\
\hline 52 & 13,60 \\
\hline 33 & 13,13 \\
\hline 48 & 13,42 \\
\hline 64 & 13,58 \\
\hline 80 & 13,91 \\
\hline 96 & 14,21 \\
\hline 112 & 14,70 \\
\hline 128 & 15,38 \\
\hline 144 & 18,10 \\
\hline 160 & 21,07 \\
\hline 128 & 20,67 \\
\hline 96 & 20,10 \\
\hline 64 & 19,18 \\
\hline 33 & 18,17 \\
\hline 160 & 21,99 \\
\hline 180 & 25,41 \\
\hline 200 & 30,73 \\
\hline 220 & 35,04 \\
\hline 240 & 39,61 \\
\hline 260 & 42,92 \\
\hline 280 & 45,35 \\
\hline 300 & 49,44 \\
\hline 320 & 53,44 \\
\hline 340 & 58,47 \\
\hline
\end{tabular}


Prova de carga da estaca $\mathrm{N}^{\mathrm{o}} 3 \mathrm{C}$ (Contagem)

\begin{tabular}{|c|c|}
\hline $\begin{array}{c}\text { Carga de tração } \\
(\mathrm{kN})\end{array}$ & $\begin{array}{c}\text { Deslocamento } \\
(\mathrm{mm})\end{array}$ \\
\hline 0 & 0,00 \\
\hline 33 & 0,50 \\
\hline 48 & 1,03 \\
\hline 72 & 2,69 \\
\hline 96 & 4,73 \\
\hline 120 & 6,02 \\
\hline 144 & 9,53 \\
\hline 168 & 12,93 \\
\hline 192 & 16,44 \\
\hline 216 & 19,68 \\
\hline 240 & 22,86 \\
\hline 192 & 22,29 \\
\hline 144 & 21,33 \\
\hline 96 & 20,19 \\
\hline 48 & 19,40 \\
\hline 33 & 19,03 \\
\hline 58 & 19,75 \\
\hline 87 & 20,40 \\
\hline 116 & 20,90 \\
\hline 145 & 21,46 \\
\hline 174 & 22,03 \\
\hline 203 & 22,80 \\
\hline 232 & 23,82 \\
\hline 261 & 26,13 \\
\hline 290 & 28,86 \\
\hline 232 & 28,27 \\
\hline 174 & 27,28 \\
\hline 116 & 26,27 \\
\hline 58 & 24,64 \\
\hline 33 & 23,75 \\
\hline 290 & 30,60 \\
\hline 320 & 33,97 \\
\hline 350 & 38,09 \\
\hline 380 & 42,68 \\
\hline 410 & 46,93 \\
\hline 440 & 50,01 \\
\hline
\end{tabular}


Prova de carga da estaca $N^{\circ} 4 \mathrm{C}$ (Contagem)

\begin{tabular}{|c|c|}
\hline $\begin{array}{c}\text { Carga de tração } \\
(\mathrm{kN})\end{array}$ & $\begin{array}{c}\text { Deslocamento } \\
(\mathrm{mm})\end{array}$ \\
\hline 0 & 0,00 \\
\hline 33 & 1,27 \\
\hline 48 & 2,82 \\
\hline 72 & 4,58 \\
\hline 96 & 6,05 \\
\hline 120 & 8,97 \\
\hline 144 & 12,28 \\
\hline 168 & 15,58 \\
\hline 192 & 18,92 \\
\hline 216 & 23,12 \\
\hline 240 & 26,36 \\
\hline 192 & 25,90 \\
\hline 144 & 24,97 \\
\hline 96 & 23,90 \\
\hline 48 & 23,08 \\
\hline 33 & 22.38 \\
\hline 58 & 22,77 \\
\hline 87 & 23,22 \\
\hline 116 & 23,88 \\
\hline 145 & 24,53 \\
\hline 174 & 25,31 \\
\hline 203 & 26,22 \\
\hline 232 & 27,43 \\
\hline 261 & 30,16 \\
\hline 290 & 33,46 \\
\hline 232 & 33,08 \\
\hline 174 & 32,15 \\
\hline 116 & 30,90 \\
\hline 58 & 29,07 \\
\hline 33 & 28,32 \\
\hline 290 & 34,96 \\
\hline 320 & 38,31 \\
\hline 350 & 43,67 \\
\hline 380 & 46,69 \\
\hline 410 & 50,99 \\
\hline
\end{tabular}


Prova de carga da estaca $\mathrm{N}^{\circ}$ 5C (EESC)

\begin{tabular}{|c|c|}
\hline $\begin{array}{c}\text { Carga de tração } \\
(\mathrm{kN})\end{array}$ & $\begin{array}{c}\text { Deslocamento } \\
(\mathrm{mm})\end{array}$ \\
\hline 0 & 0,00 \\
\hline 12 & 4,61 \\
\hline 23 & 5,46 \\
\hline 50 & 9,49 \\
\hline 64 & 12,51 \\
\hline 23 & 10,91 \\
\hline 12 & 10,17 \\
\hline 50 & 11,70 \\
\hline 71 & 13,78 \\
\hline 99 & 18,01 \\
\hline 120 & 22,42 \\
\hline 57 & 19,41 \\
\hline 23 & 17,21 \\
\hline 12 & 16,27 \\
\hline 64 & 18,94 \\
\hline 120 & 23,69 \\
\hline 142 & 27,33 \\
\hline 170 & 32,93 \\
\hline 191 & 41,00 \\
\hline 219 & 49,28 \\
\hline 241 & 57,22 \\
\hline 177 & 56,03 \\
\hline 120 & 52,78 \\
\hline 64 & 47,61 \\
\hline 12 & 43,64 \\
\hline 0 & 18,03 \\
\hline
\end{tabular}


Prova de carga da estaca $\mathrm{N}^{\circ}$ 6C (EESC)

\begin{tabular}{|c|c|}
\hline $\begin{array}{c}\text { Carga de tração } \\
(\mathrm{kN})\end{array}$ & $\begin{array}{l}\text { Deslocamento } \\
(\mathrm{mm})\end{array}$ \\
\hline 0 & 0,00 \\
\hline 12 & 10,90 \\
\hline 23 & 10,98 \\
\hline 35 & 11,84 \\
\hline 12 & 10,51 \\
\hline 23 & 11,59 \\
\hline 35 & 12,03 \\
\hline 42 & 13,84 \\
\hline 50 & 16,34 \\
\hline 57 & 17,60 \\
\hline 64 & 18,89 \\
\hline 71 & 20,09 \\
\hline 78 & 21,01 \\
\hline 85 & 22,14 \\
\hline 92 & 23,36 \\
\hline 99 & 25,96 \\
\hline 106 & 31,83 \\
\hline 113 & 37,98 \\
\hline 120 & 43,45 \\
\hline 127 & 49,20 \\
\hline 135 & 60,82 \\
\hline 142 & 69,23 \\
\hline 149 & 91,56 \\
\hline 120 & 90,73 \\
\hline 92 & 89,57 \\
\hline 64 & 87,54 \\
\hline 35 & 84,87 \\
\hline 12 & 81,82 \\
\hline 0 & 61,81 \\
\hline
\end{tabular}

